

\section{DISCLAIMER}

This report was prepared as an account of work sponsored by an agency of the United States Government. Neither the United States Government nor any agency Thereof, nor any of their employees, makes any warranty, express or implied, or assumes any legal liability or responsibility for the accuracy, completeness, or usefulness of any information, apparatus, product, or process disclosed, or represents that its use would not infringe privately owned rights. Reference herein to any specific commercial product, process, or service by trade name, trademark, manufacturer, or otherwise does not necessarily constitute or imply its endorsement, recommendation, or favoring by the United States Government or any agency thereof. The views and opinions of authors expressed herein do not necessarily state or reflect those of the United States Government or any agency thereof. 


\section{DISCLAIMER}

Portions of this document may be illegible in electronic image products. Images are produced from the best available original document. 


\section{DO NOT MICROFILM}

\section{LEGAL NOTICE}

This book was prepared as an account of work sponsored by an agency of the United States Government. Neither the United States Government nor any agency thereof, nor any of their employees, makes any warranty, express or implied, or assumes any legal liability or responsibility for the accuracy, completeness, or usefulness of any information, apparatus, product, or process disclosed, or represents that its use would not infringe privately owned rights. Reference herein to any specific commercial product, process, or service by trade name, trademark, manufacturer, or otherwise, does not necessarily constitute or imply its endorsement, recommendation, or favoring by the United States Government or any agency thereof. The views and opinions of authors expressed herein do not necessarily state or reflect those of the United States Government or any agency thereof.

Printed in the United States of America

$$
\text { Available from }
$$

National Technical Information Service

U.S. Department of Commerce

5285 Port Royal Road

Springfield, VA 22161

Price Code: A09 


\title{
EARTH SCIENCES DIVISION ANNUAL REPORT 1981
}

\author{
LAWRENCE BERKELEY LABORATORY \\ UNIVERSITY OF CALIFORNIA \\ BERKELEY, CALIFORNIA 94720
}

\section{NOTICE}

PORTIONS OF THIS REPORT ARE ILLEGIBLE. It

has been reproduced from the best available copy to permit the broadest possible availability. 


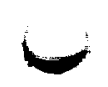




\section{CONTENTS}

Introduction $\quad 1$

NUCLEAR WASTE ISOLATION

3

\section{TOPICAL INVESTIGATIONS 5}

GEOLOGIC SYSTEMS AS ANALOGS FOR LONG-TERM RADIOACTIVE WASTE ISOLATION: INTRUSIVE-ROCK/COUNTRY-ROCK CONTACT ZONES ; 5

H. Wollenberg, D. Brookins, L. Cohen, S. Flexser, M. Abashian, and M. Shea

IRON-NICKEL ALLOYS AS CANISTER MATERIAL FOR RADIOACTIVE WASTE DISPOSAL IN UNDERGROUND REPOSITORIES 8

I. A. Apps

COUPLED HYDROLOGIC-THERMOMECHANICAL EXPERIMENTS FOR RADIOACTIVE WASTE ISOLATION 11.

G. Korbin, H. Wollenberg, B. Strisower, C. Wilson, and T. Chan

THERMAL IMPACT OF WASTE EMPLACEMENT AND SURFACE COOLING ASSOCIATED WITH GEOLOGIC DISPOSAL OF NUCLEAR WASTE 15

J. S. Y. Wang, D. C. Mangold, R. K. Spencer, and C. F. Tsang

BASIS FOR A TENTATIVE THERMOHYDROLOGIC CRITERION FOR EMPLACEMENT DENSITY IN A NUCLEAR WASTE REPOSITORY

18

J. S. Y. Wang, D. C. Mangold, and C. F. Tsang

THEORETICAL MODEL OF FLUID FLOW THROUGH A

DEFORMABLE ROCK FRACTURE

22

Y. W. Tsang and P. A. Witherspoon

POROUS MEDIA EQUIVALENT FOR A NETWORK OF DISCONTINUOUS

FRACTURES

24

J. C. S. Long

DETERMINING SIZE AND INTERCONNECTION OF FRACTURES FROM CONSTANTHEAD WELL TESTS

28

T. Doe and $\mathrm{H}$. Endo

DEVELOPMENT OF A COUPLED THERMAL-HYDRAULIC-MECHANICAL FINITEELEMENT MODEL FOR SATURATED FRACTURED POROUS MEDIA

J. Noorishad, J. S. Y. Wang, C. F. Tsang, and P. A. Witherspoon

ASSESSMENT AND EVALUATION OF ENGINEERING OPTIONS AT A LOW-LEVEL

RADIOACTIVE WASTE STORAGE SITE

B. Y. Kanehiro and V. Guvanasen 
VERIFICATION AND IMPROVEMENT OF A PREDICTIVE MODEL FOR RADIONUC்LIDE MIGRATION

38

C. W. Miller, L. V. Benson, and C. L. Carnahan

URANIUM DISEQUILIBRIUM MEASUREMENTS ON GROUNDWATERS

42

M. C. Michel and W. R. Keyes

URANIUM (VI) RETARDATION MECHANISMS

45

R. J. Silva and A. W. Yee

SORPTIVE DIFFUSION IN CLAY GELS

48

J. A. Apps and C. J. Radke

INVESTIGATION OF SILICATE SURFACE CHEMISTRY AND REACTION MECHANISMS ASSOCIATED WITH MASS TRANSPORT IN GEOLOGIC MEDIA 50

A. F. White and D. L. Perry

SWEDISH-AMERICAN COOPERATIVE PROGRAM

53

RESEARCH ON NUCLEAR WASTE ISOLATION AT STRIPA: AN OVERVIEW

53

P. A. Witherspoon, N. G. W. Cook, J. E. Gale, and C. R. Wilson

RADIOGEOLOGIC ASSESSMEN'T FOR NUCLEAR WASTE ISOLATION:

STUDIES OF THE STRIPA PLUTON 56

H. Wollenberg, S. Flexser, and L. Andersson

THERMOMECHANICAL PROPERTIES OF STRIPA GRANITE

58

L. Myer

ANALYSIS OF TEMPERATURE DATA FROM THE FULL-SCALE

HEATER EXPERIMENTS AT STRIPA

61

I. Javandel and P. A. Witherspoon

ROD-TYPE EXTENSOMETERS IN LONG-TERM ELEVATED TEMPERATURE SERVICE

A. O. DuBois, P. H. Nelson, M. Hood, and E. Binnall

DETERMINATION OF THE STATE OF STRESS AT THE STRIPA MINE, SWEDEN

T. Doe

GEOPHYSICAL BOREHOLE MEASUREMENTS IN LOW-PERMEABILITY ROCK

P. H. Nelson and R. Rachiele

DEVELOPMENT, VERIFICATION, AND APPLICATION OF MODELING TECHNIQUES FOR THERMOMECHANICAL ANALYSIS 75

T. Chan and E. L. Wilson

MEASUREMENT OF LOW RATES OF WATER INFLOW BY MONITORED EVAPORATION IN THE LARGE-SCALE PERMEABILITY EXPERIMENT AT STRIPA

M. J. McPherson 


\section{GEOPHYSICS AND RESERVOIR ENGINEERING}

EXPLORATION TECHNOLOGY 85

ELECTROMAGNETIC MODELING USING A FAST NUMERICAL

SOMMERFELD INTEGRAL

85

K. H. Lee and H. F. Morrison

AN INFERRED CONDUCTIVITY DISTRIBUTION IN THE VICINITY OF MOUNT HOOD, OREGON, BASED ON THE INTERPRETATION OF MAGNETOTELLURIC AND

TELLURIC DATA

86

E. C. Mozley and N. E. Goldstein

IN-FIELD PROCESSING AND MAGNETOTELLURICS WITH THE

EM-60 ELECTROMAGNETIC SYSTEM

88

M. Wilt, N. E. Goldstein, J. R. Haught, V. Labson, and H. F. Morrison

DEEP ELECTROMAGNETIC SOUNDING IN THE BASIN AND RANGE PROVINCE 90 M. Wilt, N. E. Goldstein, J. R. Haught, and H. F. Morrison

SIMPLE ONE-DIMENSIONAL INVERSIONS OF MAGNETOTELLURIC DATA W. M. Goubau

THE APPLICATION OF ASP: AN AUTOMATED SEISMIC PROCESSOR E. L. Majer and T. V. McEvilly

\section{RESERVOIR ENGINEERING}

ADVANCES IN TRANSIENT WELL-TESTING METHODOLOGY

C. W. Miller, S. M. Benson, and G. S. Bodvarsson

LOW- TO MODERATE-TEMPERATURE HYDROTHERMAL RESERVOIR ENGINEERING RESEARCH 102

S. M. Benson, R. Solbau, and G. S. Bodvarsson

EVALUATION OF THE HYDROTHERMAL POTENTIAL OF THE ASHDOD AREA, ISRAEL 105

S. M. Benson

THE BACA DEMONSTRATION PROJECT

108

G. S. Bodvarsson, M. Wilt, J. Delany, and C. F. Tsang

INJECTION OF COLD WATER INTO GEOTHERMAL RESERVOIRS

G. S. Bodvarsson, C. F. Tsang, K. Pruess, and M. J. O'Sullivan

MODELING OF FRACTURE RESERVOIRS

K. Pruess, T. N. Narasimhan, and G. S. Bodvarsson 
GENERIC STUDIES OF GEOTHERMAL RESERVOIR BEHAVIOR

K. Pruess, G. S. Bodvarsson, M. J. Lippmann, and A. H. Truesdell

SUBSIDENCE MODELING OF THE PLEASANT BAYOU GEOTHERMAL

GEOPRESSURED REGION 118

K. P. Goyal, T. N. Narasimhan, and S. P. Vonder Haar

FLUID SAMPLING AND ANALYSIS OF GEOPRESSURED BRINE

L. Hansen, R. M. Galbraith, O. Weres, M. Michel, and D. Sverjensky

SIMULATION OF THERMAL ENERGY STORAGE IN A DOUBLET WELL SYSTEM

T. A. Buscheck, C. Doughty, and C. F. Tsang

A DIMENSIONLESS PARAMETER APPROACH TO THE THERMAL BEHAVIOR OF AN AQUIFER THERMAL ENERGY STORAGE SYSTEM 126

C. Doughty, G. Hellstrom, C. F. Tșang, and J. Claesson

THE CHARACTERIZATION OF HEAT STORAGE IN CONFINED AQUIFERS WITH BUOYANCY FLOW 128

T. A. Buscheck and C. F. Tsang

A COMPARATIVE STUDY OF FOUR MAJOR APPROACHES TO PREDICTING ATES PERFORMANCE 129

C. Doughty, T. A. Buscheck, G. S. Bodvarsson, and C. F. Tsang

CERRO PRIETO PROGRAM

OVERVIEW OF THE MEXICAN-AMERICAN COOPERATIVE PROGRAM AT THE CERRO PRIETO GEOTHERMAL FIELD

M. J. Lippmann and R. Zelwer

133
GEOLOGIC MODEL OF THE CERRO PRIETO GEOTHERMAL FIELD

S. E. Halfman, J. H. Howard, and S. P. Vonder Haar

GEOPHYSICAL MONITORING AT THE CERRO PRIETO GEOTHERMAL FIELD M. Wilt, R. Zelwer, and E. L. Majer

RESERVOIR ENGINEERING STUDIES OF THE CERRO PRIETO GEOTHERMAL FIELD 144

K. P. Goyal, M. J. Lippmann, and C. F. Tsang
GEOSCIENCES

149

THE BEHAVIOR OF ROCK-FLUID SYSTEMS AT ELEVATED TEMPERATURES AND PRESSURES

W. H. Somerton 
THERMODYNAMICS OF HIGH-TEMPERATURE BRINES

K. S. Pitzer, P. S. Z. Rogers, and J. C. Peiper

PRELIMINARY DETERMINATION OF THE AI(OH) 4 - STABILITY CONSTANTS IN THE AQUEOUS PHASE AT ELEVATED TEMPERATURES 155

J. M. Neil and J. A. Apps

THERMODYNAMIC PROPERTIES OF SILICATE MATERIALS

157

I. S. E. Carmichael, L. K. Moret, M. L. Rivers, J. F. Stebbins, and X. Mo

NONEQUILIBRIUM, INTERPHASE MASS TRANSFER IN CHEMICAL TRANSPORT

BY GROUNDWATER 160

C. L. Carnahan and J. S. Remer

CHEMISTRY OF NUCLEAR WASTE SUBSTANCES IN AQUEOUS SOLUTIONS

S. L. Phillips and A. Igbene

ENHANCED RECOVERY OF HEAVY OILS WITH ALKALI 166

C. J. Radke and W. H. Somerton

THE PARTITIONING OF HYDROGEN SULFIDE IN THE CONDENSERS OF GEYSERS UNIT $15 \quad 168$

O. Weres

GEOANALYTICAL AND CHEMICAL BONDING STUDIES USING MODERN SURFACE TECHNIQUES 171

D. L. Perry

MINE VENTILATION PLANNING: A CASE STUDY

173

M. J. McPherson and M. Hood

THE MEASUREMENT OF IN SITU STRESS USING NQR/NMR

177

E. Schempp, J. B. Murdoch, and S. M. Klainer

UNIQUE DEVELOPMENTS IN LASER-INDUCED FLUORESCENCE FLUORIMETRY (LIFF) $\quad 180$

S. M. Klainer, H. R. Bowman, J. Conway, T. Hirschfeld, and F. Milanovich

\section{APPENDIXES}

APPENDIX A: PUBLICATIONS

183

APPENDIX B: EARTH SCIENCES DIVISION STAFF 


\section{INTRODUCTION}

The scientists and engineers of the Earth Sciences Division conduct research on a wide spectrum of geologic problems related to the nation's energy needs. The search for new geothermal and fossil fuel resources, the development of more intensive exploitation schemes, and the desire to develop large-scale underground methods for storage of energy and nuclear waste have all extended man's activities--and impacts--further into the earth. The lack of geologic knowledge and reliable technologies is hampering many of these national efforts and preventing the comprehensive assessment of important related environmental issues. The programs of the Earth Sciences Division are organized under three broad headings: Nuclear Waste Isolation, Geophysics and Reservoir Engineering, and Geosciences.

The Nuclear Waste Isolation program includes topical investigations--both basic and applied--and a significant field project, which was conducted in cooperation with Swedish scientists at the stripa mine. The topical studies address many factors affecting radionuclide migration, which is the critical issue to be resolved in the long-term isolation of nuclear waste from the biosphere. At the focus of several investigations is the problem of understanding the response of a rock mass to the coupled thermal, mechanical, and hydrological effects of waste emplacement. Identification of these significant topical problems was a major result of the stripa experiment, which started some four years ago and was phased out in 1981. The Swedish-American Cooperative Program was an early effort to gain field experience and knowledge of the geotechnical problems associated with the development and long-term monitoring of nuclear waste repositories. The work to date and some preliminary results are summarized within. Many of the field techniques and testing methodologies developed at stripa are now being utilized at other candidate repository sites.

The Geophysics and Reservoir Engineering projects are principally involved with geothermal energy development, but some address topics relevant to petroleum resources and subsurface storage of thermal energy. Our geophysicists are concerned with developing improved instruments and exploration techniques. Recent advances in the state of the art of electric, electromagnetic, and seismic technologies are reported. The development of the Automated Seismic Processor is especially noteworthy because of its importance to seismology and its broad engineering applications to real-time seismic monitoring in earth science research and natural hazards studies. The reservoir engineering reports summarize recent developments in reservoir modeling and testing, including a new downhole fluid sampler designed to operate under high temperatures and pressures. Finally, the results to date from the cerro Prieto geothermal case history studies are reported in four overview articles.

The Geosciences program is concerned with the fundamental chemistry and physics associated with geologic materials and processes. The research projects provide much needed data on geologic properties, rock-fiuid system dynamics, and basic scientific

problems associated with many geotechnical endeavors. Also reported upon is work on instrumentation developments to permit specialized measurements in the laboratory and in the field. 
U

( 


\section{NUCLEAR WASTE ISOLATION}

Although a number of different rock types continue to be considered as potential geologic repository environments for the emplacement of nuclear wastes, the majority of the Earth Sciences Division's efforts have emphasized hard rock geologies. Such phenomena as mechanical response to thermal loading, fluid flow through fractures, and chemical sorptivity must be investigated to understand their interactions and magnitudes. As this body of knowledge increases, the technical community will develop confidence in valid long-term predictions about the integrity of nuclear waste isolation in hard rock or other repository media. Within the Earth Sciences Division, research continues both on fundamental investigations of geologic aspects of fractured media and on experimental and field research projects of a more applied nature.

The Swedish-American Cooperative Program, begun in July 1977, was a first-of-itskind experiment for fractured rocks. The fundamental questions of how to characterize materials and geologic properties and how to measure them were approached both experimentally and theoretically. The major field-data-gathering portion of this effort was completed at the stripa mine in Sweden in August 1980. A comprehensive analysis of these field results was planned for 1981 and subsequent years. But a shift in the Department of Energy's overall program has forced the cancellation of these plans. However, the loss of this support to the Division's program in nuclear waste isolation has been replaced in part by one that is sponsored by the Nuclear Regulatory Commission (NRC) and which is concerned with the identification of technical issues that will need to be resolved during the site-characterization process prior to repository construction. These issues have been identified for the geologies currently under consideration as repository host environments, and, in some instances, methodologies have been proposed that might be utilized to resolve a particular technical issue. Some of these NRC efforts, selected stripa topics, and a wide range of theoretical analyses, laboratory studies, literature surveys, and computational simulations are discussed in this section.

This work was supported under $U$. S. Department of Energy Contract No. DE-AC03765500098 by (1) the Assistant secretary for Nuclear Energy, office of Nuclear Waste Management, Division of Waste Isolation; and (2) the Assistant Secretary for Nuclear Energy, Office of Nuclear Waste Management, Division of Surplus Facilities Management; and under Interagency Agreement DOE-50-80-97, FIN No. B 3109-0 by the High Level Waste Technology Branch, Division of Waste Management, Office of Nuclear Material Safety and Safeguards, U. S. Nuclear Regulatory Commission. 


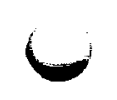

\footnotetext{
$\omega$
} 


\title{
TOPICAL INVESTIGATIONS
}

\section{GEOLOGIC SYSTEMS AS ANALOGS FOR LONG-TERM RADIOACTIVE WASTE ISOLATION: INTRUSIVE-ROCK/COUNTRY-ROCK CONTACT ZONES}

\author{
H. Wollenberg, D. Brookins, ${ }^{*}$ L. Cohen, ${ }^{+}$S. Flexser, M. Abashian, ${ }^{*}$ and M. Shea
}

Selected natural occurrences of minerals and rocks containing radioelements and fission-product elements can be considered as analogs of sites for geologic disposal of nuclear waste. They can be studied to ascertain how radionuclides and their daughter elements might migrate from sites of origin in response to long-term natural processes: heating due to an lgneous intrusion; circulation through hydrothermal systems; diffusion through the rock matrix, and weathering and erosion. The natural systems investigated are chosen to offer comparisons with models of radionuclide transport in fractured and unfractured rock and with models of the retention and migration of radionuclides in various forms of nuclear waste. Comparison of natural occurrences with conceptual models based on laboratory data will furnish a test of such models over time periods comparable to or longer than those expected for a waste repository.

Initial investigations have covered two quite different potential geologic analogs of nuclear waste isolation: (1) migration around the BryanEldora stock in colorado; and (2) migration away from the vein deposit of radioactive minerals at Marysvale, Utah. The Eldora and Marysvale studies test the concept of waste disposal in basement rocks under conditions more extreme than those proposed for nuclear waste disposal; both studies strongly suggest the feasibility of storage in basement rocks.

STUDIES AT ELDORA, COLORADO

The Bryan-Eldora stock, a composite body of quartz monzonite, syenodiorite, and granodiorite, intrudes crystalline metavolcanic and metasedimentary rocks of the Idaho Springs Formation (Fig. 1). The stock has been modeled by Hart et al. (1968) as a 26,000-ft by 10,000-ft "brick" intruded as magma at a temperature of approximately $780^{\circ} \mathrm{C}$ at $55_{\mathrm{MYBP}}$ (millions of years before the present). Previous mineralogic and chemical studies ind lcate that the intrusive rocks now exposed were originally at a depth of only $3000 \mathrm{ft}$ below the surface. The intruded rocks of the Idaho Springs Formation have been dated at 1600 to $1400 \mathrm{MYBP}$. A strong regional metamorphic event affected the Idaho Springs Formation at about 1350 to $1400 \mathrm{MYBP}$; the rocks then remained unaffected until the intrusion of the Bryan-Eldora stock. The classic work of Hart (see Hart et al.. 1968) has shown that variations in mineralogy, chemistry, and isotopic systematics of the Idaho Springs

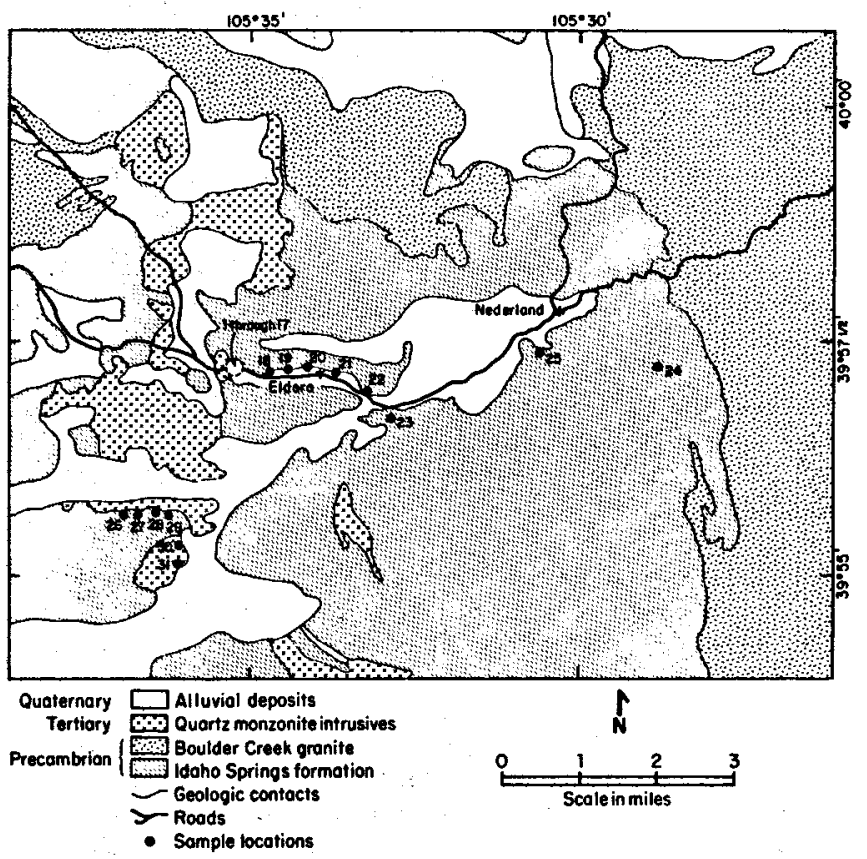

Figure 1. Simplifled geologic map (after Hart, 1968) showing sampling locations in the BryanEldora Stock/Idaho Springs Formation, Colorado.

[XBL 817-3377]

Formation can be explained by fairly simple heatflow models (Hart, 1964).

The current interest in the contact-metamorphosed zone of the Idaho Springs Formation is that the Bryan-Eldora stock was once a high-temperature magma rich in volatiles which could possibly have had the pronounced effect of producing hydrothermal fluids which, in turn, may have penetrated the contact zone. In short, the stock may be considered analogous to a gigantic waste canister emplaced in crystalline rocks. It should be readily apparent if abundant amounts of various elements have penetrated the Idaho Springs Formation from the stock. Alternatively, if fluids from the stock have not penetrated far, this, too, should be reflected in the rock chemistry. Since the estimated cooling time for the Bryan-Eldora stock $1 \mathrm{~s}$ between $10^{4}$ and $10^{6} \mathrm{yr}$ (Hart et al.. 1968), this analog is ideal in that this age interval covers the $2.5 \times 10^{5} \mathrm{yr}$ isolation for radioactive waste disposal (i.e.., 10 times the half-life of $239 \mathrm{Pu}$ ). 
Work Completed at Eldora

1. Samples obtained along well-defined traverses (Fig. 1) include some from approximate sites of Hart's (1961) original traverses as well as elsewhere along the contact between the stock and the Idaho Springs Formation. Collection sites were located by a compass-tape survey.

2. The reliability of correspondence between our collection sites and Hart's was checked by selected $K-A r$ mineral analyses; this was necessary to allow proper temperatures from various heatflow models to be used. Agreement between predicted and measured results was excellent.

3. Chemical analytical data for $\mathrm{Co}, \mathrm{Cr}, \mathrm{Sc}$, Cs, and other trace elements show that local equilibrium has probably been maintained since approximately 1200 MYBP for the Idaho Springs Formation except within a few feet of the contact.

4. The rare-earth element (REE) distribution patterns (Brookins et al., 1981) reveal the following:

(a) REE/chondrite vs. Ionic radius plots for the intrusive indicate that the magma behaved as an essentially closed system during crystallization.

(b) Low La values within $15 \mathrm{ft}$ of the contact indicate minor redistribution of light REE, but not gain or loss of the REE in the whole-rock samples.

(c) No whole-rock perturbations of the REE are noted at distances greater than $10 \mathrm{ft}$ from the contact except where local events (e.g., mineralization of prestock age) have affected the rocks.

5. The whole-rock oxygen isotopic data range from $+7.7 \%$ to $+9.6 \%$ from the contact. This implies closure of these rocks to hydrothermal fluids from the stock (i.e., such fluids would be preferentially enriched in 160 ). Mineral-to-mineral variation has not yet been analyzed but will presumably conform to redistribution as predicted on the basis of Hart's heat-flow models.

6. Rb-Sr data for samples collected at, near, and away from the contact indicate that our wholerock $R b-S R$ isochron age of the Idaho Springs Formation $(1.5 \neq 0.1$ billion $y r$; Brookins et al., $1981)$ is in agreement with that of Hart et al. (1968) . The earlier work (Hart, 1964; Hart et al.. 1968) showed that minerals nearer the contact had been reset more than those farther removed from the contact; our data, however, show that $\star 87 \mathrm{Sr}$ is redistributed within, and not removed from, the whole-rock samples. Further, there is no evidence in the Idaho Springs Formation for gain of $\mathrm{Rb}$ or $\mathrm{Sr}$ from the Bryan-Eldora stock, except possibly within 1 to $3 \mathrm{~m}$ of the contact, where some mixing of magmatic fluids with the metamorphic rocks occurred.

7. The relative abundance of uranium near and away from the contact was determined by fission- track radiography and gamma spectrometry (Flexser and Wollenberg, 1981). It was found that the occurrence of uranium is controlled predominantly by primary accessory minerals, both in the stock and in the Idaho Springs Formation. These accessories are zircon, sphene, monazite, allanite, opaques, and an unidentified highly uraniferous mineral present only in the Bryan-Eldora intrusive. Intrusion of the stock has caused secondary migration of uranium, but only on a small scale and only within a few meters of the contact. There is no indication of systematic enrichment or depletion in uranium, either in the country rock or in the stock, as a function of distance from the contact. Migration of uranium is probably due to local redistribution from the abovenamed accessory minerals by diffusion through the rock mass; again, there is no evidence to suggest that fracture transport of uranium by circulating hydrothermal solutions played a significant role.

Thus the entry of hydrothermal fiuids from the stock into the Idaho Springs Formation is contraindicated by the REE data; lack of $\mathrm{Rb}$ or $\mathrm{K}$ fixation (vs. diffusion as $f(T)$ ), 0 isotope data, and $\mathrm{Pb}, \mathrm{U}$, and $\mathrm{Th}$ data.

\section{Preliminary Conclusions}

1. Data for most elements show that the Idaho Springs Formation was not penetrated by hydrothermal fluids from the Bryan-Eldora stock within $10 \mathrm{ft}$ of the contact, although $\mathrm{Pb}$ migration to 20 ft is possible.

2. Some migration of $\mathrm{Pb}$ and light $\mathrm{REE}$ may have occurred in the first $10 \mathrm{ft}$ away from the stock contact.

3. The oxygen data indicate high resistance to isotopic exchange even in the immediate contact zone despite the high temperatures there.

4. The old and new data combined argue against anything but local migration (i.e., within $10 \mathrm{ft}$ of the contact) of $\mathrm{U}, \mathrm{Th}, \mathrm{Pb}, \mathrm{REE}, \mathrm{Co}$, etc. into the Idaho Springs Formation despite the high and prolonged thermal gradient.

5. Although the current hydrologic setting and the paleohydrology of the Idaho Springs formation are not known, these rocks appear to be well suited for retention of hydrothermal fluids which might be generated in the immediate vicinity of a breached radioactive waste canister. This is especially true when one considers that the size of proposed canisters is small in relation to the dimensions of the stock, that the heat content of a canister will be much lower than that of an invading magma, and that the Idaho Springs Formation was without benefit of canister or engineered backfill.

6. Crystalline rocks may be well-suited for radioactive waste storage.

STUDIES AT MARYSVALE, UTAB

A vein uranium deposit is being mined at Marysvale, Utah, about $260 \mathrm{~km}$ south of Salt Lake City. Samples of vein material and granitic host 
rock were collected for this study from exposures in the underground workings.

At the mine locale, some 10 million yr of active volcanism was followed by intrusion of a 3-km-dlameter quartz monzonite stock (Kerr, 1968, Steven et al., 1979). This stock, emplaced about 23 MYBP, established hydrothermal cells which altered the volcanic host rocks. A fine-grained granite in turn intruded the quartz monzonite about 20 MYBP. Both intrusives host uranium mineralization; there is also some mineralization in the youngest volcanics. The only workings that could be visited were at veins in the granite and the quartz monzonite. Because of the irregular nature of the veins, replicate samples along the strike of any one vein could not be collected.

The fission-track radiographic method was used to determine the location, distribution, and abundance of $U$ in the veins and adjacent country rock. Two fission-track cross sectlons show evidence for nuclide movement away from a vein and from veinlet (approximately 5 and $1 \mathrm{~cm}$ penetra$t$ ion into quartz monzonite and granite, respectively, Figs, 2 and 3), three cross sections show no evidence for uranium movement. The cross section showing movement into a granite had relatively low fission-track densities, about 30 per $\mathrm{mm}^{2}$ within a millimeter or so of the vein, which decreased in a manner is if controlled by a diffusion equation. The section showing movement Into the quartz monzonite had much higher track densitles: $10^{4}$ at $1 \mathrm{~mm}$ from the vein, with counts about 50 at $8 \mathrm{~mm}$ from the vein. The adjacent uranium veinlet was $1 \mathrm{~cm}$ wide, with an ore concentration of some $100,000 \mathrm{ppm}$. Fission tracks in both examples were usually around the grain boundaries of chlorite and biotite, along some cleavage planes of these two minerals, and along minerals crossing microfractures when within a few millimeters of the source vein.

Specimens showing no nuclide movement were from granite contalning a 1-mm-wide veinlet with a uranium concentration of approximately $100 \mathrm{ppm}$ from granite containing a 2-mm-wide veinlet with $20,000 \mathrm{ppm}$ and from an altered granite encompassing a small vein with 5000 ppra.

This study is still in progress; quantifica$t$ ion of the differences between degree of rock

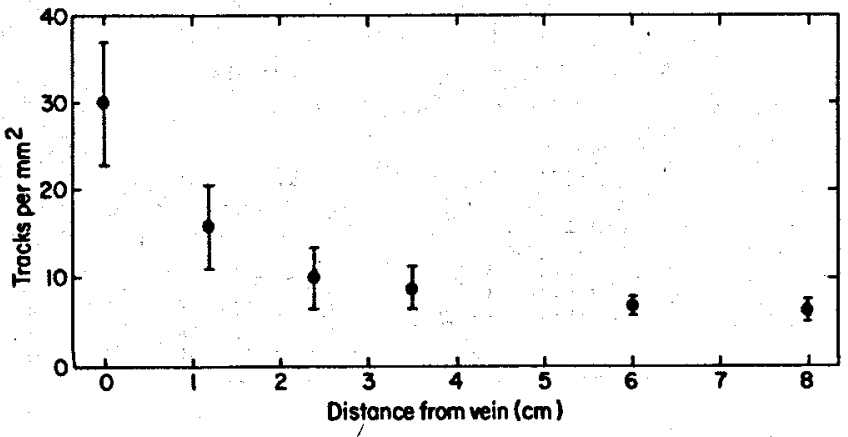

Figure 2. Fission-track densities due to uranium in quartz monzonite in contact $w$ ith a uranium vein at Marysvale, Utah.

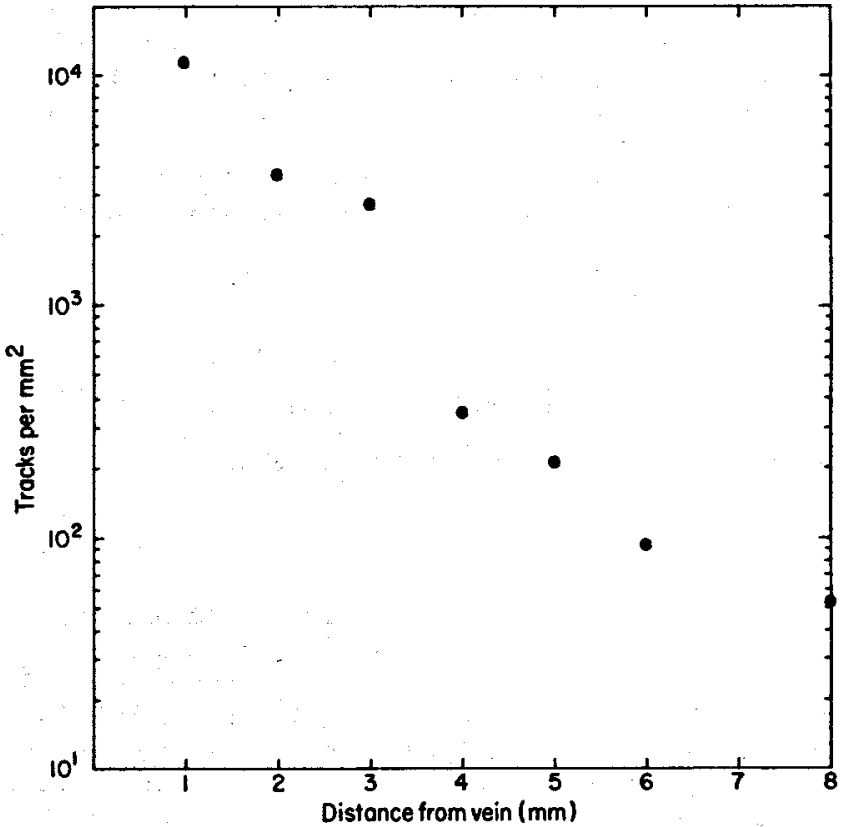

Figure 3. Fission-track densities associated with uranium in contact with a uranium vein at Marysvale, Utah.

[XBL 818-3379]

fracturing and uranium abundances remains to be done. Nevertheless, it is apparent that even in the fractured and sometimes altered rock at Marysvale, the hydrothermal fluids that emplaced the uranium did not circulate into the rock. Again, basement rocks appear to be good host rocks for waste isolation.

*Department of Geology, University of New Mexico, Albuquerque, IM 87131.

tDepartment of Geology, University of California, Riverside, CA 92521.

\section{REFERENCES CITED}

Brookins, D. G., Cohen, I. H., and Wollenberg, H. A., 1981. Geochemistry of a contact metamorphosed zone: Implications for radwaste disposal in crystalline rocks. In Proceedings, Symposium on Uncertainties Associated with the Regulations of the Geologic Disposal of High Level Radioactive Waste, Gatlinburg, Tennessee, 9-13 March, 1981.

Flexser, S., and Wollenberg, H. A., 1981. The distribution of uranium in and near the contact zone between the Tertiary Eldora stock and the Precambrian Idaho Springs Formation, Colorado, Lawrence Berkeley Laboratory Report, in preparation.

Hart, S. R., 1961. Mineral ages and metamorphism (Ph.D. dissertation). Mass. Inst. Technology.

Hart, S. R., 1964. The petrology and isotopic mineral age relations of a contact zone in the Front Range, Colorado, Journal of Geology, v. 72, p. 493-525.

Hart, S. R., Davis, G. L., stelger, R. H., and Tilton, G. R., 1968. A comparison of the 
isotopic mineral age variations and petrologic changes induced by contact metamorphism. In E. I. Hamilton and R. M. Farquhar (eds.), Radiometric Dating for Geologists. New York, Interscience Publications.

Kerr, P. F., 1968. The Marysvale, Utah uranium deposits. In J. D. Ridge (ed.), Ore Deposits of the United States 1933-1967, New York, A.I.M.E.

Steven, T. A., Cunningham, C. G., and Machette, M. N., 1980. Integrated uranium systems in the Marysvale volcanic Eleld, West-Central Utah, U. S. Geological Survey Open-File Report 80-524.

\title{
IRON-NICKEL ALLOYS AS CANISTER MATERIAL FOR RADIOACTIVE WASTE DISPOSAL IN UNDERGROUND REPOSITORIES
}

\author{
J. A. Apps
}

Canisters containing high-level radioactive waste must retain their integrity in an underground waste repository for at least one thousand years after burial (Nuclear Regulatory Commission, 1981). Since no direct means of verifying canister integrity is plausible over such a long period, indirect methods must be chosen. A persuasive approach is to examine the natural environment and find a suitable material which is thermodynamically compatible with the host rock under the environmental conditions expected in a waste repository. Several candidates have been proposed, among them being iron-nickel alloys that are known to occur naturally in altered ultramafic rocks (Fyfe, 1977, Apps and Cook, 1981). The following review of stability relations among iron-nickel alloys below $350^{\circ} \mathrm{C}$ is the initial phase of a more detailed evaluation of these alloys as suitable canister materials.

Before an iron-nickel alloy can be selected, several conditions must be met. The conditions expected to prevail in the repository environment must be determined to see how closely they match the natural conditions under which iron-nickel alloys are found. The phases occurring in the subsolidus region of the iron-nickel system below $350^{\circ} \mathrm{C}$ must be characterized and their corrosion resistance observed under repository conditions.

Different iron-nickel alloy compositions and structures are likely to have differing degrees of resistance to oxidation and sulfidation. Choice of an optimum composition is unimportant, not only in maximizing corrosive resistance but in minimizing the cost of raw materials.

All iron-nickel alloys except $\alpha \mathrm{Fe}$, kamacite, possess face-centered lattice structures. Ordering of the iron and nickel atoms within the facecentered lattice leads to the formation of a series of superlattice structures with discrete chemical compositions, as illustrated in Figure 1. These phases exsolve from the disordered face-centered cubic $\gamma$ phase, (Fe, Ni), Al, at temperatures below $500^{\circ} \mathrm{C}$. In this region, phase segregation is exceedingly slow, requiring annealing periods of up to millions of years to be detectable even under the very high magnifications obtainable with a transmission electron microscope (TEM). Fortunately, theoretical and experimental developments during the past five years now allow us to obtain a reasonable understanding of the thermodynamic properties and phase relations in the subsolidus region.

Huthmann (1977), using the lattice model approximation developed by Bragg and Williams (see Hill, 1960, p. 246f), was able to describe the properties of different mixed crystals in the iron-nickel system and compute the phase relations of face-centered lattice structures below $800 \mathrm{~K}$, as shown in Figure 2 . These relations are to a large extent compatible with recent observations of exsolution phenomena in iron-nickel meteorites and mineralogical studies of naturally occurring nickel-iron alloy assemblages in altered ultramafic rocks. The mineral awaruite, Ni3Fe, $\mathrm{Ll}_{2}, \mathrm{fm}$, has been observed many times in serpentinite (Ramdohr, 1952; Rrishnarao, 1964; Eckstrand, 1975; Botto and Morrison, 1976),

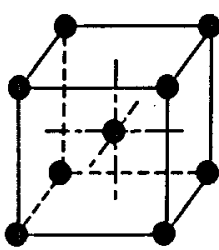

a Fe

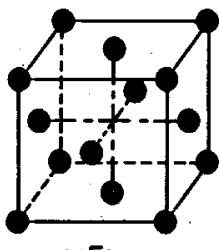

$\gamma \mathrm{Fe}$
A2, cubic, Im $3 m$
Al,cubic, Fm $3 m$

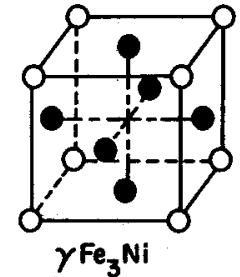

$\mathrm{LI}_{2}$, cubic, $\mathrm{Pm} 3 \mathrm{~m}$
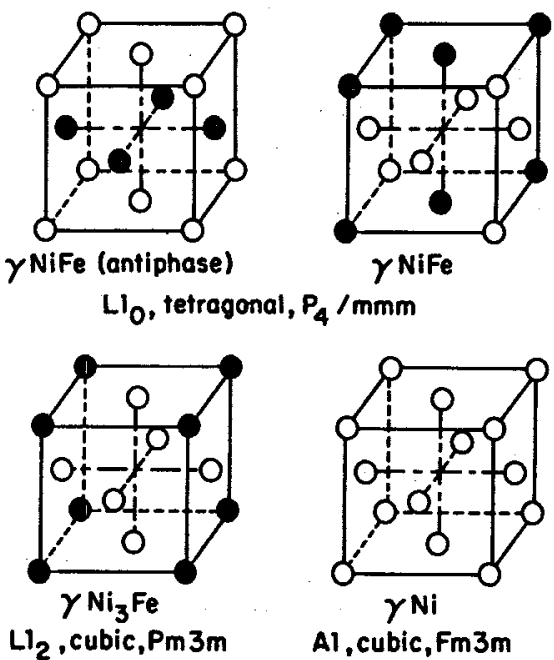

Al, cubic, Fm3m

Figure 1. Structures of iron-nickel alloys. [XBL 821-1601] 


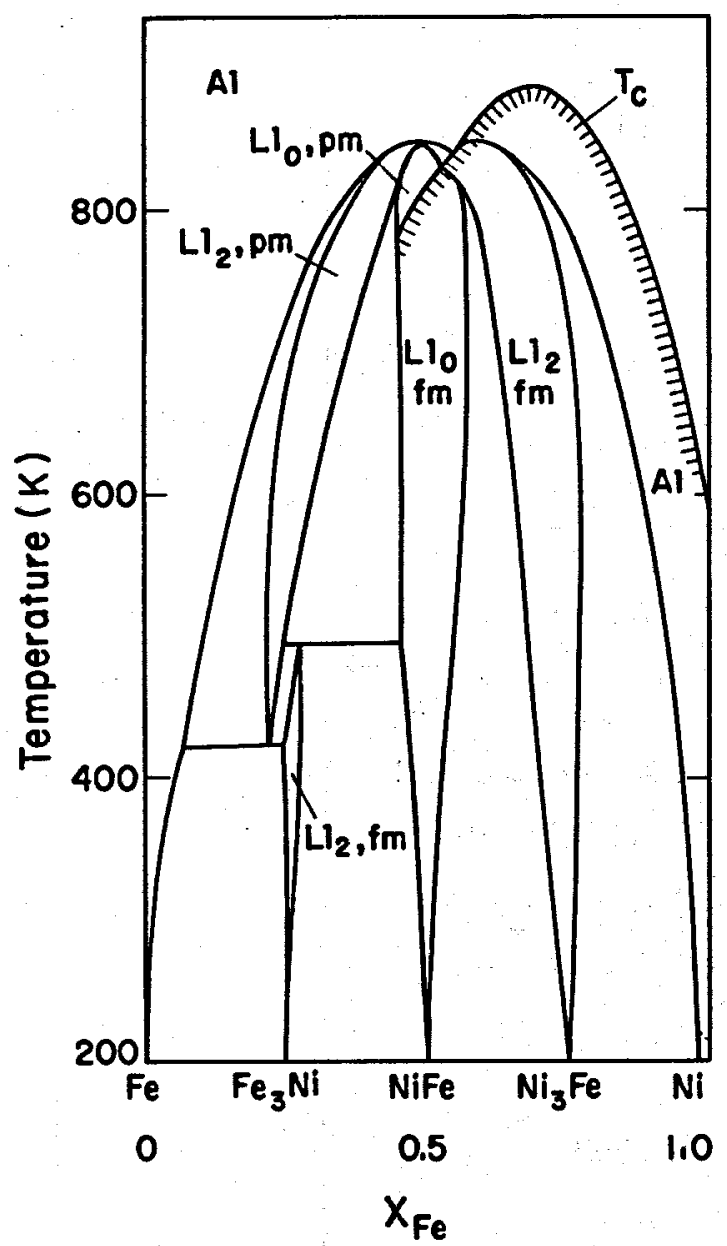

Figure 2. Calculated relations among face-centered lattice phases in the iron-nickel system below $900 \mathrm{~K}$ (after Huthmann, 1977). fm = ferromagnetic, $\mathrm{pm}=$ paramagnetic, $\mathbf{T}_{\mathrm{C}}=$ curie temperature.

[XBL 821-1617]

whereas NiFe, $\mathrm{Ll}_{0}, \mathrm{fm}$ is observed in many meteorites (Petersen et al., 1977; Albertsen et al., 1978, Danon et al., 1979a,b, 1980, Jago, 1979, 1980, scott and clarke, 1979) and may also exist in natural terrestrial material (Danon et al., 1979c). Mehta et al. (1980) even report the existence of FeNi antiphase domains in the Estherville meteorite. NiFe, $\mathrm{LI}_{0}$ can also be formed artificlally from $\gamma(\mathrm{Fe}, \mathrm{Ni}), \mathrm{A}_{2}$ by radiationinduced ordering through spinodal decomposition. This has been investigated using both electron radiation (Chamberod et al., 1979, Gruzin et al., 1980) and neutron radiation (Neel et al., 1964). Ordered $\mathrm{Fe}_{3} \mathrm{Ni}, \mathrm{Ll}_{2}$, fm has not been observed, presumably because its stability field may appear only below $223^{\circ} \mathrm{C}$ (Huthmann, 1977) and the kinetics of exsolution are unfavorable for its forma- tion, or it may be metastable with respect to kamacite and NiFe, $\mathrm{Ll}_{0}$.

Mössbauer spectroscopy, small-angle neutron scattering, and $x$-ray and electron-diffraction techniques have been used to examine the extent and nature of phase segregation both in artificial and naturally occurring samples. Observations resulting from these studies are also largely consistent with Huthmann's (1977) investigations, although between $\mathrm{Ni}=25$ and 50 at. 8 , only NiFe, $\mathrm{H}_{0}$, fm and a possibly disordered paramagnetic $\gamma$ phase with approximately 25 at. 8 nickel are observed (Petersen et al., 1977; Albertsen et al., 1978, Danon et al.., 1979a; Jago, 1979; Gruzin et al., 1980). The latter phase appears to decompose into $\mathrm{NiFe,} \mathrm{Ll}_{0}$, fm and kamacite upon annealing for one hour at $200^{\circ} \mathrm{C}$ (Jago, 1979).

Huthmann's (1977) analysis of phase relations among face-centered lattice structures in the iron-nickel system does not consider the presence of $\alpha \mathrm{Fe}$, kamacite, $A_{1}$, a body-centered cubic structure containing minor amounts of nickel, which according to Lin et al., (1977) can be as low as 3 wt8. Ramacite is commonly observed in meteorites and more rarely in altered mafic and ultramafic rocks (Deutsch et al., 1977). It appears to coexist both with the paramagnetic $\gamma$ phase containing approximately 25 at. 8 nickel and the NiFe, $\mathrm{LI}_{0}$, $\mathrm{fm}$ in meteorites (Jago, 1979). Kamacite is also found associated with awaruite in the Muskox intrusion in Canada (Chamberiain et al., 1965). This brlef review does not cover phase relations between kamacite and taenite above $450^{\circ} \mathrm{C}$ or the effect of metastabilities resulting from slow reaction kinetics. For a complete understanding of the iron-nickel system, these aspects ought to be taken into account.

The selection of iron-nickel canister materials should be based on physical properties and relative corrosion resistance of three alloys: (Fe,Ni) $\left(\approx 25\right.$ at.8 Ni), $\mathrm{Ll}_{2}, \mathrm{pm} ;(\mathrm{NiFe}), \mathrm{Ll} \mathbf{O}_{0}$ $f m$, and $\left(\mathrm{Ni}_{3} \mathrm{Fe}\right), \mathrm{Ll}_{2}, \mathrm{fm}$. The stoichiometric composition, $\mathrm{Fe}_{3} \mathrm{Ni}$, should also be considered in the event that prolonged exposure to radiation in a waste repository would stabilize the $\mathrm{Ll}_{2}$, fin structure.

Quantitative determinations of the corrosion resistance and stability in natural environments of selected alloys must await experimental verification after preparation of radiation-stabilized ordered forms. Nevertheless, approximate estimates of their stability can be made on the basis of observed phase relations. A preliminary Eh-pH diagram of the system Fe-Ni-S-O- ${ }_{2} \mathrm{O}$ at $25^{\circ} \mathrm{C}$ and 1 atmosphere pressure is given in Figure 3. This diagram shows that iron-nickel alloys are stable in the region between $\mathrm{pH}=8.5$ and 12 and between Eh $=-700$ and $-400 \mathrm{mV}$. Such conditions are within the realm of those that would prevail in waste repositories constructed in such mafic rocks as basalts. 


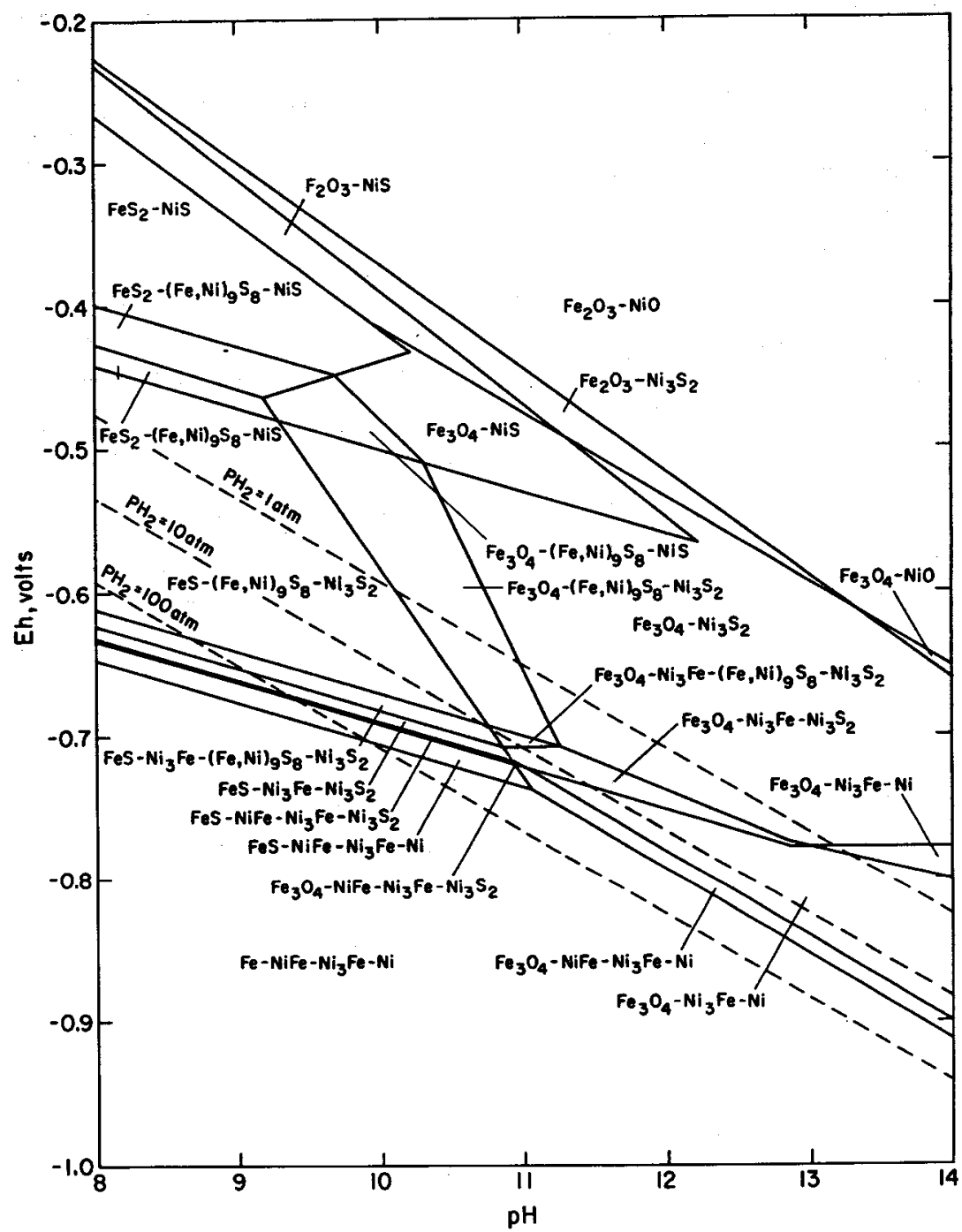

Figure 3. A preliminary Eh-pH diagram of part of the system $\mathrm{Fe}-\mathrm{Ni}-\mathrm{S}-\mathrm{O}-\mathrm{B}$ at $25^{\circ} \mathrm{C}$ and 1 atmosphere, including the provisional stability fields of NiFe and $\mathrm{Ni}_{3} \mathrm{Fe}$.

[XBL 8010-2868A]

\section{REFERENCES CITED}

Albertsen, J. F., Jensen, G. B., and Rnudsen, J. M., 1978. Structure of taenite in two iron meteorites. Nature, v. 273, p. 453-454. Apps, J. A.; and Cook, N. G. W., 1981. Backfill barriers: The use of engineered barriers based on geologic materials to assure isolation of radioactive wastes in a repository. In J. G. Moore (ed.), Scientific Basis for Nuclear Waste Management (Vol. 3). New York, Plenum Press.

Botto, R. I., and Morrison, G. H., 1976. Josephinite: A unique nickel-iron. American Journal of Science, v. 276, p. 241-274.

Chamberlain, J. A., McLeod, C. R., Traill, R. J., and Lachance, G. R., 1965. Native metals in the Muskox intrusion. Canadian Journal of Earth Sciences, v. 2, p. 188-215.

Chamberod, A., Laugier, J., and Penisson, J. M., 1979. Electron irradiation effects on ironnickel invar alloys. Journal of Magnetism and
Magnetic Materials, v. 10, p. 139-144. Danon, J., Scorzelli, R., Souza-Azevedo, I., Curvello, w., Albertsen, J. F., and Knudsen, J. M., 1979a. Iron-nickel 50-50 superstructure in the Santa Catharina meteorite. Nature, v. 277, p. 283-284.

Danon, J., Scorzelli, R. B., Souza-Azevedo, I. , and Christophe-Michel-Levy, M., 1979b. Iron-nickel superstructure in metal particles of chondrites." Nature, v. 281, p. 469-471. Danon, J., Scorzelli, R. B., Souza-Azevedo, I., Albertsen, J. F., Knudsen, J. M., Roy-Poulsen, N. O., Minai, Y., Wakita, H., and Tominaga, T., 1979c. Iron-nickel alloy superstructure in the mineral josephinite. Radiochemical and Radioanalytical Letters, v. 38, p. 339-342.

Danon, J., Scorzelli, R. B., Souza-Azevedo, I., Laugier J., and Chamberod, A., 1980. Santa Catharina meteorite and phase composition of irradiated Fe-Ni invar alloys. Nature, v. 284, p. 537-538. 
Deutsch, E. R., Rao, K. V., Laurent, R., and Sequin, M. K., 1977. New evidence and possible origin of native iron in ophiolltes of eastern Canada. Nature, v. 269, p. 684-685.

Eckstrand, O. R., 1975. The Dumont serpentinite: A model for control of nickeliferous opaque mineral assemblages by alteration reactions in ultramafic rocks. Economic Geology, v. 70, p. 183-201.

Fyfe, w. S., 1977. Container stability and permeability control. Abstracts with Programs, 1977 Annual Meetings, The Geological Soclety of America, v. 9, no. 7, p. 983.

Gruzin, P. L., Rodionov, Yu. L., and Pryakhin, v. A., 1980. Phase diagram of fcc ironnickel alloys. Soviet Physics Doklady, v. 25, no. 4, p. 306 .

Hill, T. H., 1960. An Introduction to Statistical Mechanics. Reading, Mass." Addison-Wesley Publishing Co., 508 p.

Huthmann, H., 1977. Gegenseitige Beeinflussung chemischer und magnetischer Ordnungsvorgange in kubisch flachenzentrierten Eisen-NickelLegierungen (Sci. D. dissertation) ReinischWestfälischen Technischen Hochschule, Aachen, 122 .

Jago, R. A., 1979. Santa Catharina and the origin of cloudy taenite in meteorites. Nature, v. 279, p. 413-415.

Jago, R. A., 1980. Metallography of Santa Catharina--The "invar" meteorite. Micron; v. 11, p. 323-324.

Krishnarao, J. S. R., 1964. Native nickel-iron alloy, its mode of occurrence, distribution and origin. Economic Geology, v. 59, p. $443-448$.

Lin, L. S., Goldstein, J. I., and Williams, D. B.. 1977. Analytical electron microscopy study of the plessite structure in the Cariton iron meteorite. Geochimica et cosmochimica Acta, v. 41, p. 1861-1874.

Mehta, S., Novotny, P. M., Williams, D. B., and Goldstein, J. I., 1980. Electron-optical observations of ordered FeNi in the Estherville meteorite. Nature, v. 284, p. 151-153.

Nee1, I., Pauleve, J.., Pauthenet, R., Laugier, J., and Dautreppe, D., 1964. Magnetic properties of an iron-nickel single crystal ordered by neutron bombardment. Journal of Applied Phystes, v. 35 , no. 3 (part 2), p. 873-876.

Nuclear Regulatory Commission, 1981. Proposed Rules, 10CFR Part 60, Disposal of high level radioactive wastes in geologic repositorles, Subpart E, Performance objectives, Par. 60.111(2), Performance of the engineered system, Federal Register, v. 46, no. 130, p. 352-389.

Petersen, J. F., Aydin, M., and Knudsen, J. M., 1977. Mossbauer spectroscopy of an ordered phase (superstructure) of FeNi in an iron meteorite. Physics Letters, v. 62A, p. 192-194.

Ramdohr, P. , 1952. Uber Josephinit, Awaruit, Souesit, ihre eigenschaften, entstehung und paragenesis. Mineralogical Magazine, v. 29, p. 375-393.

Scott, E. R. D., and Clarke, Jr., R. S., 1979 Identification of clear taenite in meteorites as ordered FeNi. Nature, v. 281, p. 360-362.

\title{
COUPLED HYDROLOGIC-THERMOMECHANICAL EXPERIMENTS FOR RADIOACTIVE
}

\section{WASTE ISOLATION}

\author{
G. Korbin, * H. Wollenberg, B. Strisower, C. Wilson, and T. Chan
}

Plans for an underground research facility have been formulated, incorporating techniques to assess the hydrologic and thermomechanical response of a rock mass to the introduction and long-term isolation of radioactive waste and to assess the effects of excavation on the hydrologic integrity of a repository and its subsequent backfill, plugging, and sealing.

In this report we sumarize the conceptual design of the hydrolog tc-thermomechanical exper 1ment to be conducted in the research facility. The schedule and cost estimate of the experiment, together with greater detail on 1 ts design, are the subjects of a report by rorbin et al. (1981). The identification of existing underground openings to accommodate such an experiment is the subject of a report by wollenberg et al. (1981).

In situ tests and experiments in underground penings have been conducted since the early $1960 \mathrm{~s}$ as part of the general worldwide program for geologic disposal of radioactive wastes. Initial efforts focused largely on salt as the disposal medium; more recent experiments have been conducted in other types of rock (e.g... granite, basalt, tuff, and shale). A detalled summary of this activity, including test description, objectives, and results presented by Gnirk (1980), has been updated by Rorbin et al. (1981) to include recent experiments. The in situ tests include a wide variety of heater experiments with single and multiple arrays at full and reduced scale, block tests, heated room-and-piliar tests, brine and water migration experiments, permeability tests, fracture hydrology and groundwater chemistry studies, instrumentation development and testing, and other investigations.

Conclusions and recommendations from the 1980 Workshop on Thermomechanical-Hydrochemical Mode1Ing for a Hardrock Waste Repository reconfirmed the importance of in situ testing. "In situ experiments and tests are required to understand the phenomena and mechanisms acting in rock masses under thermal loading, provide thermomechanical and hydrologic data for code verification, aid in repository design, and assist in instrumentation 
development and evaluation." Furthermore, the specific types of in situ tests needed for model validation and to aid in repository design were delineated. "Combined hydrologic-thermomechanical tests are the next logical sequence in the evolution of in situ testing. These need to be (of) a meaningful scale. The design of new and different tests of this type are a high priority task."

Combined or coupled hydro/thermomechanical field tests, of the type suggested above, representative of the repository environment, have not yet been carried out. Preliminary studies, however, have been made, exemplified by tests performed in granitic rock at the Climax stock (Ramspott, 1980) and in tuff in G-Tunnel on the Nevada Test Site (Lincoln, 1980). The experiments were located above the groundwater table in the partially saturated regime, influenced a relativeIy small volume of rock, and were affected by relatively complex boundary conditions. The complex boundary conditions, which limit the usefulness of the results for predictive model validation and development, were caused largely by the proximity of the underground openings to the test area.

Future in situ tests designed to investigate the hydro/thermomechanical response of a rock mass should:

1. be located near repository depth so that the stress field will be similar to that of the repository environment, table,

2. be located well below the groundwater

3. influence a relatively large volume of rock, including significant discontinuities and defects,

4. employ simple initial/boundary conditions,

5. be located within an undisturbed region away from extraneous openings or undesirable perturbations.

The objectives of the experiments should include:

1. model validation and development to confirm and improve predictive capabilities,

2. assessment of the physical properties of a rock mass on a large scale and comparison of those properties with laboratory results to aid in repository design,

3. investigation of the response of the rock to controlled excavation and thermally induced perturbations in order to improve understanding of the rock mass behavior and as an aid to confirmation of the rock mass integrity.

\section{CONCEPTUAL DESIGN FOR A HYDRO/THERMOMECHANICAL} EXPERIMENT

The hydro/thermomechanical experiment has been formulated to fulfill the above-stated objectives and design considerations. It is the purpose of the experiment to provide a comprehensive data base for predictive model verification and model development as well as to provide fundamental information on the physical properties of a rock mass and its response to excavation, heating, and cooling. The experiment is designed to consider the geologic environment--i.e., the hydrologic setting, geochemistry, and thermomechanical behavior of the rock as a coupled system. The ability to accurately model the measured response of the rock to experimentally produced perturbations would be a significant contribution to the ability to model an operational repository. The experiment provides for the necessary synthe$s$ is of rock mass physical property data, constitutive models, and numerical modes required for use in repository design.

\section{Approach}

The initial activities will consist of a detailed assessment of the geologic and hydrologic settings of the experimental site and its environs. Prior to the excavation of a $2-\mathrm{m}$-dianeter cylindrical test chamber, a large number of horizontal and inclined holes will be drilled in the rock surrounding the future excavation (Fig. 1). Instruments will be installed in the holes to monitor temperature, water pressure, changes in rock stress and strain, and to conduct tracer tests, fluid injection/withdrawal tests, and geophysical experiments. All drill holes will be sealed with packers to prevent drainage from the system.

The first stage of monitoring and testing will provide background data on the initial conditions of the rock mass for baseline information. These data are most important for the accurate interpretation of measured changes caused by excavation and heat-induced perturbations. After the baseline is established, the 100- to 150-ft (30- to 45-m) long cylindrical test chamber will be carefully excavated. The response of the surrounding rock mass to excavation will be recorded and the system allowed to equilibrate before beginning the experimental stage.

After a liner and a bulkhead are installed and monitoring devices placed in radial drill holes, the test chamber will be completely filled with formation water at ambient temperature and low pressure. Use of formation water--i.e., water with chemistry similar to that of the natural groundwater--eliminates the geochemical and hydrological complications associated with an air-water interface at the chamber wall. Monitoring the water flow from the test chamber at constant pressure and monitoring the pressure field within the surrounding rock will provide a measure of the rock mass permeability. (Because the water pressure within the test chamber is less than the hydrostatic pressure of the surrounding rock mass, groundwater will flow into the chamber.)

After establishing the permeability of the rock mass surrounding the test chamber, the effect of heating a relatively large volume of rock will be investigated by increasing the temperature 


\section{Hydro/Thermomechanical Experiment}

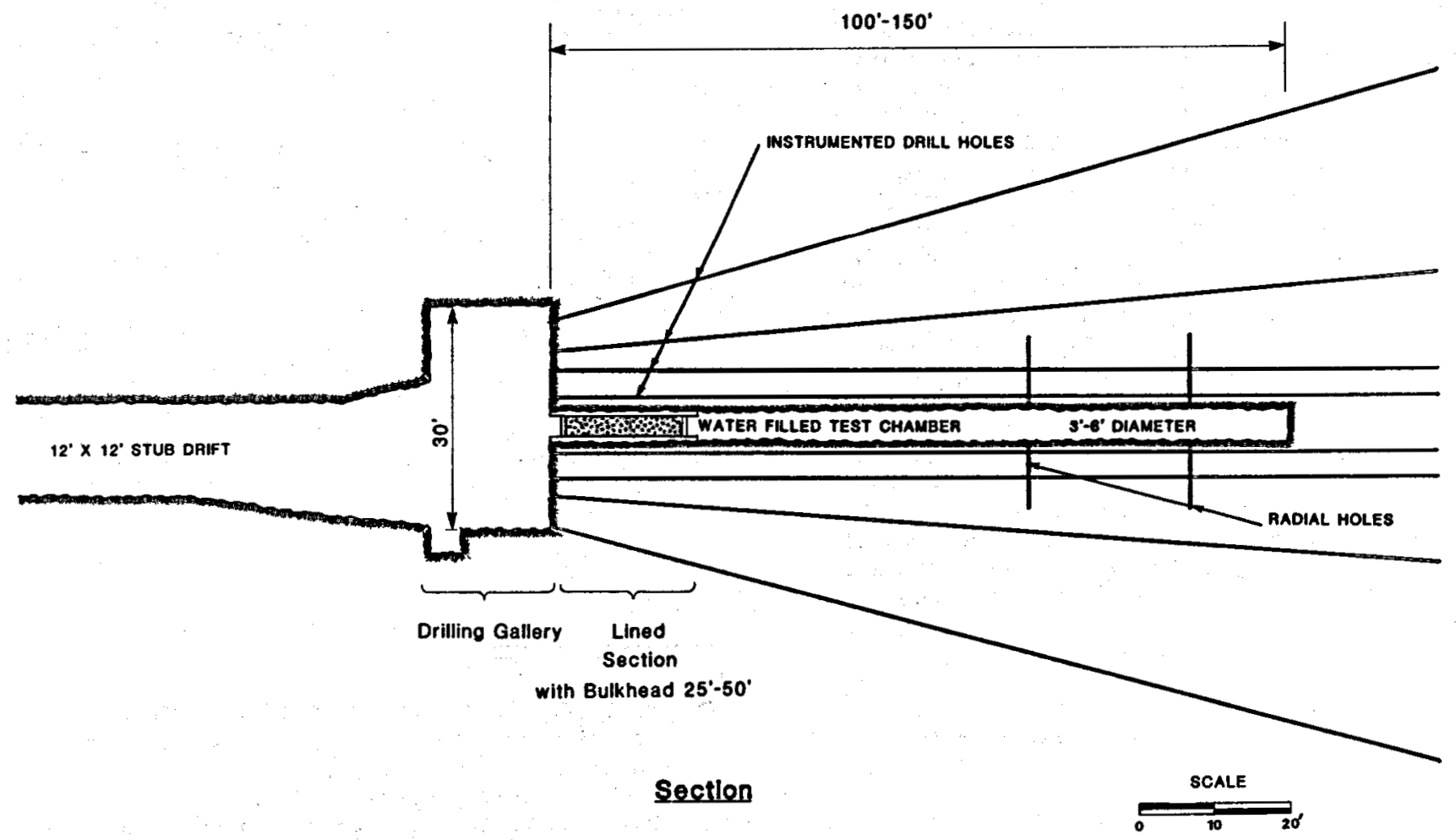

Figure 1. Longitudinal section of the excavation and drill holes for the hydro/thermomechanical experiment. [XBL 815-9966]

of the water within the chamber. Water is an excellent medium for transfering heat uniformly to the wall rock and provides a well-defined boundary condition. The maximum temperature will be less than $100^{\circ} \mathrm{C}$, sufficiently low to prevent flashing at ambient pressure. The changes in the rock mass permeability, the pressure fleld, the temperature field, as well as other mechanical and geochemical parameters will be monitored over a perlod of approximately one year. At the end of the period, the water flow from the test chamber will be shut of $f$ and the pressure allowed to increase. It will then be possible to study the re-estabIishment of pressure equilibrium within the hydrologic system of the rock mass and the possible development of convection currents in that hydrologic system.

The final phase of the experiment includes cooling the test chamber water to the initial ambient temperature and reducing the chamber pressure. Again, the permeability of the rock mass will be measured to determine if the cycle of heating and cooling has permanently altered the hydraulic properties of the surrounding rock. The influence on the geochemical and mechanical properties will also be examined.

'rogram and Test procedure

The various stages of the hydro/thermomechanical experimental program are itemized below:
1. Design and fabrication.

2. Baseline studies.

3. Chamber excavations.

4. Test chamber experiments (see Table 1 ).

5. Data analysis and modeling.

Energy Reguirements and Volume of Rock Affected

Preliminary thermal and thermomechanical calculations have been carried out by $x$. Chan and $D$.

Table 1. Phases of the experimental stage.

\begin{tabular}{cccc}
\hline Phase & P & T & Q \\
\hline A & several atm & ambient & measured \\
B & several atm & $100^{\circ} \mathrm{C}$ & measured \\
C & measured & $100^{\circ} \mathrm{C}$ & zero \\
D & reduced & ambient & measured \\
\hline
\end{tabular}

$P=$ test chamber pressure, $T=$ temperature, $Q=$ flow. 
Wedge using 1-D axisymetric finite-element models, for (1) a 1-m-diameter hot water test chamber and (2) a 2-m-diameter test chamber in a typical granitic rock. It was found that for the 2-m test chamber, which is the more likely size for operational convenience, a modest thermal power input of $2 \mathrm{~kW} / \mathrm{m}$ of chamber length suffices to heat the water from $10^{\circ} \mathrm{C}$ to $100^{\circ} \mathrm{C}$ in approx 1 mately 20 days. Thereafter, the thermal power would have to be reduced to maintain a $100^{\circ} \mathrm{C}$ water temperature (Fig. 2). At the end of a heating period of 500 days, approximately 2000 $\mathrm{m}^{3}$ of rock would be heated to $50^{\circ} \mathrm{C}(\mathrm{Fig}$. 3) and $40,000 \mathrm{~m}^{3}$ of rock would have a measurable ternperature rise in excess of $2^{\circ} \mathrm{C}$. A maximum compressive stress of about $60 \mathrm{MPa}$ and a radial displacement of about $2 \mathrm{~mm}$ are expected.

It is concluded that a large volume of rock (approximately fifty times that in the Stripa full-scale heater test) can be influenced within a reasonable time period in the proposed experiment, thereby bridging the gap between laboratory experiments and full-scale repository-sized experiments.

*Geotechnical Consultant, 46 California Avenue, Orinda, CA 94563

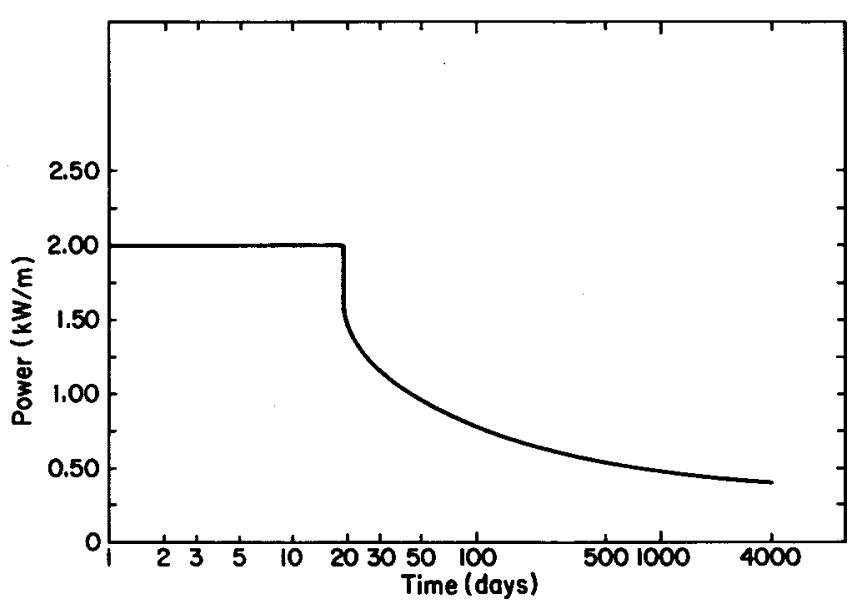

Figure 2. Thermal power consumed per meter of length along the test chamber as a function of time (2-m-diameter test chamber). [XBL 818-3420]

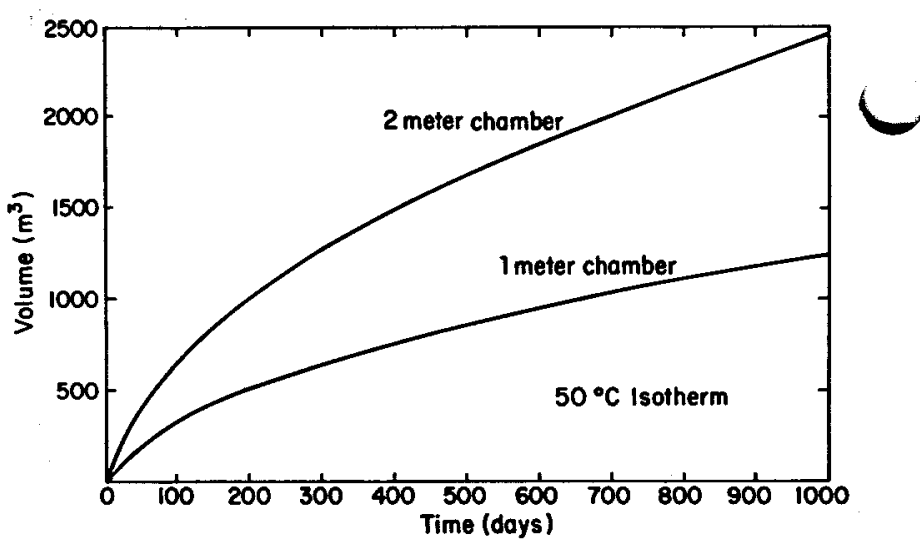

Figure 3. Volume of rock heated to at least $50^{\circ} \mathrm{C}$ for a 1-m-diameter chamber and a 2-m-diameter chamber.

[XBL 818-3428c]

\section{REFERENCES CITED}

Gnirk, P. F., 1980. Synopsis of in situ testing for mined geological disposal of radioactive wastes. In Proceedings, Workshop on Thermomechanical-Hydrochemical Modeling for a Hardrock Waste Repository. Lawrence Berkeley Laboratory Report LBL-11204, p. 22-24.

Korbin, G., Wollenberg, B., Wilson, C., Strisower, B., Chan, T., and Wedge, D., 1981. Experiments, conceptual design, preliminary cost estimates and schedules for an underground research facility, Lawrence Berkeley Laboratory Report LBL-13190.

Lincoln, R. C., 1980. Status of activities in the Nevada nuclear waste storage investigations. Presented at the 1980 National Waste Terminal Storage Program Information Meeting, office of Nuclear Waste Isolation Report ONWI-212.

Ramspott, L. D., 1980. Status of LLNL granite projects. In Proceedings, Workshop on Thermomechanical-fydrochemical Modeling for a Hardrock Waste Repository, Lawrence Berkeley Laboratory Report LBL-11204, p. 37-44.

Wollenberg, H. A., Korbin, G., Graf, A., and Strisower, B., 1981. Survey of existing underground openings for in-situ experimental facilities. Lawrence Berkeley Laboratory Report LBL-12600. 
THERMAL IMPACT OF WASTE EMPLACEMENT AND SURFACE COOLING ASSOCIATED WITH GEOLOGIC DISPOSAL OF NUCLEAR WASTE

\author{
J. S. Y. Wang, D. C. Mangold, R. K. Spencer, and C. F. Tsang
}

The age of nuclear waste--the length of time between its removal from the reactor cores and its emplacement in a repository--is a significant factor in determining the thermal loading of a repository. Although many studies in the past decade have demonstrated the importance of thermal effects on all components involved--the waste canisters, the repository structure, and the surrounding geologic setting--most of the studies have focused on the effects of $10-y r$-old wastes. Because no waste repositories have yet been constructed, a substantial part of the wastes eventually placed in a given repository could have been stored on the surface much more than $10 \mathrm{yr}$. The emplacement of older wastes may also be preferred if the thermal effects are of major concern. Several European countries (Great Britain, Sweden, Belgium) plan to allow their nuclear wastes to cool on the surface for longer periods, 25,40 , or $100 \mathrm{yr}$, before emplacing the material in a permanent site.

The surface cooling period as well as the density and sequence of waste emplacement affects both the near-field repository structure and the far-field geologic environment. In the nearfield, the thermomechanical stability of boreholes, shafts, and underground openings may be adversely changed if the heat power and density of waste are too high. The stability of the repository structure is the main concern for the safety of underground operations during the excavation, emplacement, and retrieval periods. On the regional scale, the thermal impacts persist for thousands of years. Thermal loading of the rock formation may induce surface uplift and may change the hydrologic properties of the rocks. The thermally induced buoyancy gradient may cause vertical movement of groundwater and thus accelerate the transport of radionuclides from the repository to the blosphere.

To investigate these issues, a comprehensive review was made of the available 1 iterature pertaining to thermal effects and thermal properties of mined geologic repositories. This included a careful evaluation of the effects of different surface cooling periods of the wastes, which is important for understanding the optimal thermal loading of a repository. This aspect of the thermal loading has received little quantitative examination in the literature. Therefore, additional calculations on surface cooling times were performed to supplement the data available in the literature. The results led to a clearer understanding of the importance of surface cooling in evaluating the overall thermal effects of a radioactive waste repository (Wang et al., 1981). The principal findings from these investigations are summarized below.

\section{FACTORS CONTROLLING THERMAL EFFECTS}

Thermally induced effects are determined by the waste characteristics, repository structure, and rock properties. Analyses in the literature show that:

1. For the same waste loading density, spent fuel releases more heat at long times than reprocessed wastes from which most of the long-lived plutonium and uranium isotopes have been removed. Thus the spent fuel will induce much larger longterm thermal impacts than reprocessed high-level wastes. Figure 1 illustrates the dependence of cumulative heat on waste types and surface cooling periods.

2. Waste inventory studies indicate that a significant fraction of the wastes received by the repositories will be more than 10 years old, especially with the expected delays in establishing fully operational repositories. Figure 2 shows the age of the spent fuel entering a repository for three assumed repository startup dates.

3. With many years of research on salt as a repository medium and several recent investigations on hard rocks, detalled designs of the configurations of the emplacement holes and the room-and-pillar structures are being developed; however, relatively simple repository geometries were used in most far-field models. Eventually. the depth, size, and shape of the repositories will be determined by the geologic setting as well as the enviromental impacts of waste emplacement.

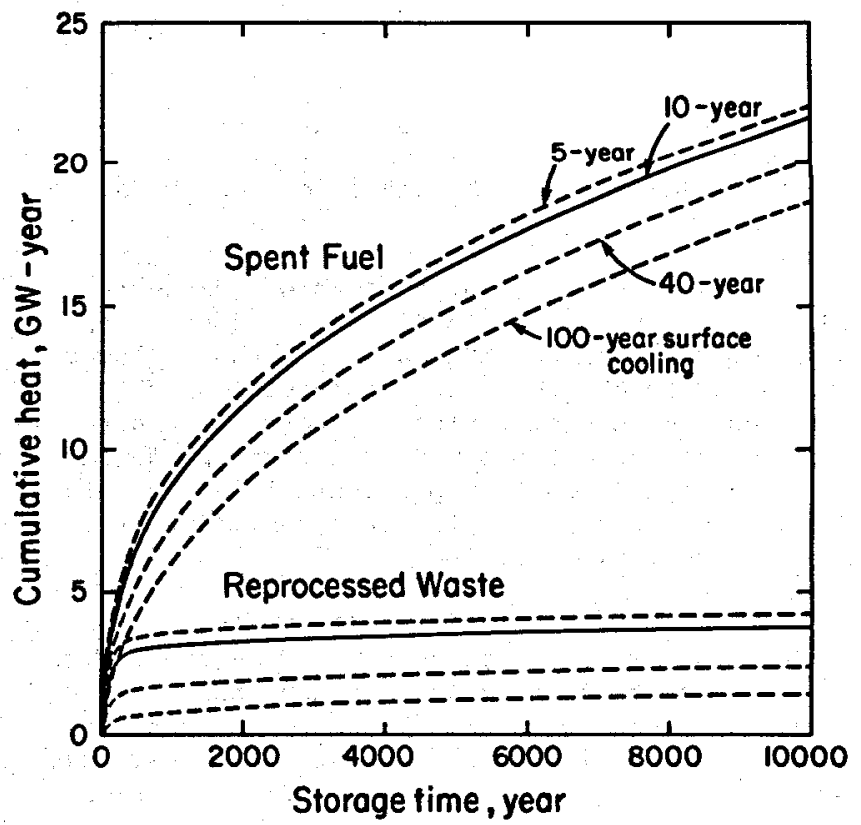

Figure 1. Cumulative heat released by emplaced wastes from 68,000 metric tons of heavy-metal fuel (MPHM) as a function of surface cooling pertod. 


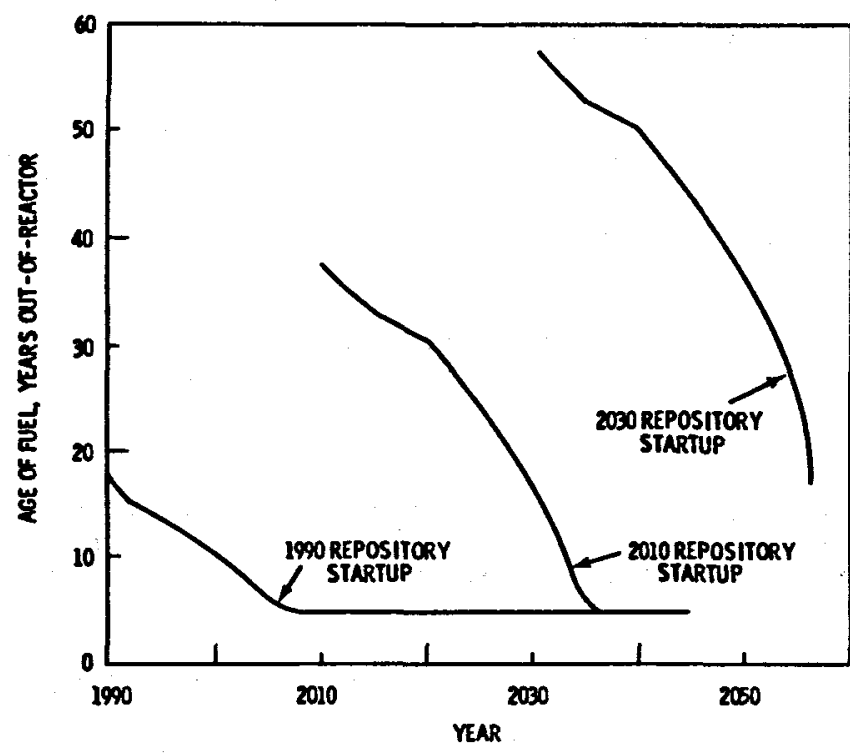

Figure 2. Age of spent fuel entering a repository for three assumed repository startup dates, based on the system of logistics considered in The Final Environmental Impact Statement for Management of Commercially Generated Radioactive Waste (Department of Energy, 1980).

[XBL 819-11586]

4. Thermal properties, including temperature dependence, can be measured fairly accurately in the laboratory and in the field. Mechanical properties of intact rock samples are not good representations of the properties of fractured rock masses. Hydrologic properties, especially permeability, have a wide range of uncertainty.

THERMAL EFFECTS BASED ON STUDIES OF 10-YEAR-OLD WASTES

The very-near-field, near-field, and far-field thermal effects have been extensively studied for 10-year-old wastes. The significant conclusions are:

1. The integrity of the waste package and the maximum temperatures of waste and canister are dependent on the heat power of the emplaced waste and on the thermal conductivities of the various components, including backfill or air gaps surrounding the canister. Borehole degradation has been studied experimentally and should be controlled to maintain retrievability for a prescribed period of time.

2. Thermomechanical stability of the roomand-pillar structure is determined by the stress changes due to both excavation and thermal loading. Controlling thermal loading and ventilation, and utilizing mining engineering techniques, such as roof bolting, will help to ensure mechanical stability.

3. Long-term, far-field thermal impacts depend mainly on the heat capacity of the rock. Heat capacity is the least site-specific and rock-specific property. This allows us to evaluate and predict long-term thermal effects with cautious optimism.

4. Surface uplift from thermal expansion of rock is largest for a spent fuel repository in salt. The surface uplift depends on the cumulative heat energy in the rock formation, which persists over thousands of years.

5. Buoyancy flow will persist for more than $1000 \mathrm{yr}$ : Distortion of the convection cells by a regional pressure gradient does not significantly change the amount of time for water to move from the repository to the surface.

\section{EMPLACEMENT WASTE DENSITY AND THERMAL LOADING OF} AGED WASTES

Different surface cooling periods can sensitively affect the emplacement density and thermal loadings of the radioactive wastes:

1. For the region in the vicinity of the waste package and the repository rooms and pillars, the lower thermal loadings associated with older wastes could reduce the short-term temperature rise and reduce the possibility of thermomechanical instability.

2. The thermal impacts of different surface cooling periods depend critically upon the method used to specify the emplacement density. With waste density specified in terms of the mass of material, surface cooling reduces thermal impact significantly for reprocessed waste, but only modestly for spent fuel. The main effect of surface cooling is to allow a significant portion of the fission products to decay. For spent fuel containing long-lived actinides, the thermal impacts over thousands of years are not significantly changed by the extension of surface cooling from 10 to $100 \mathrm{yr}$. The dependence of the repository temperature increase on surface cooling periods is shown in Figure 3.

3. If emplacement is specified as a constant power density, longer surface cooling increases the thermal impact significantly for spent fuel but only modestly for reprocessed waste. Thus opposite conclusions could be drawn for the effects of surface cooling periods if they were based on Figure 4 for the case of constant power density instead of Figure 3 with constant waste density. Since most of the design studies and economic analyses are expressed in terms of thermal power densities, conclusions based on 10-yearold waste should not be applied to older wastes unless careful re-evaluations are made.

4. If a higher waste density is considered in the repository design for older wastes, limitations of loading should be carefully determined by imposing both near-field and far-field thermal criteria that include consideration of buoyancy effects (wang et al.. 1981).

5. For spent fuel, the extension of surface cooling periods will allow only a very modest increase in waste density. The balance between a 


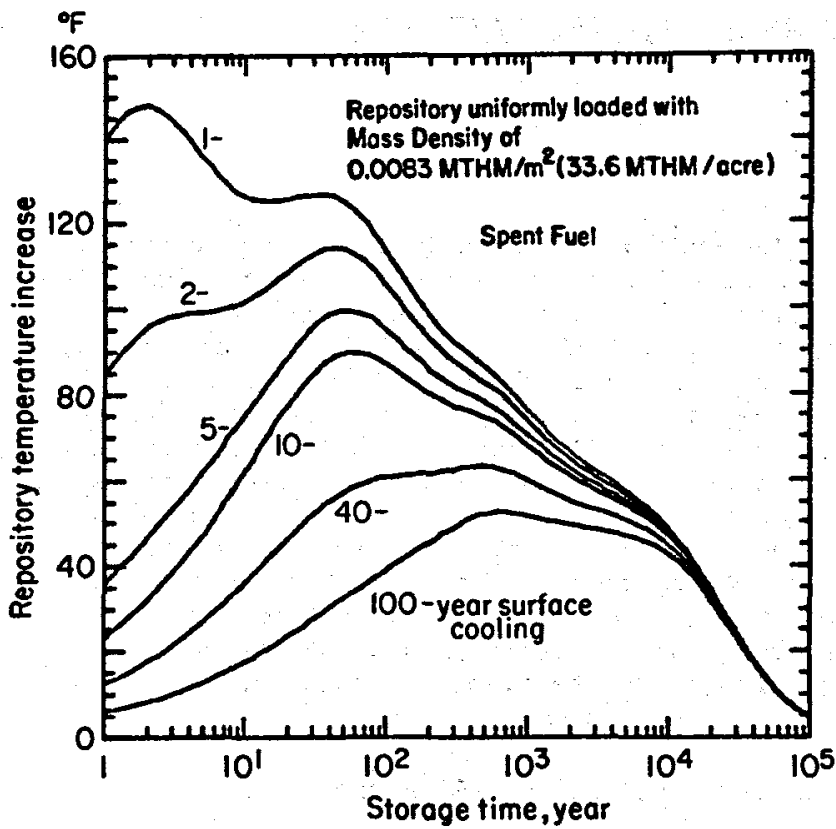

Figure 3. Temperature $r$ ise in spent fuel repository as a function of surface cooling period for the case of constant waste density loading.

[XBL 817-3274]

modest reduction in repository spatial requirements and the additional expense of the maintenance of surface storage facilities will be the determining factor in optimizing the duration of surface cooling.

6. For reprocessed waste, long surface cooling can significantly reduce the thermal impact. It may be advantageous to store reprocessed wastes above ground up to $100 \mathrm{yr}$ and allow a significant fraction of the fission products to decay.

7. If buoyancy effects are used to develop bounding criteria for determination of waste loadings, the preliminary analyses indicate that the waste loading densities considered in the current repository designs may be acceptable only for 100-year-old reprocessed wastes. For younger wastes and for other waste types, the allowable waste loading should be carefully re-evaluated.

\section{CONCLUSIONS}

The effects of thermal loading on a nuclear waste repository are sensitive to waste types,

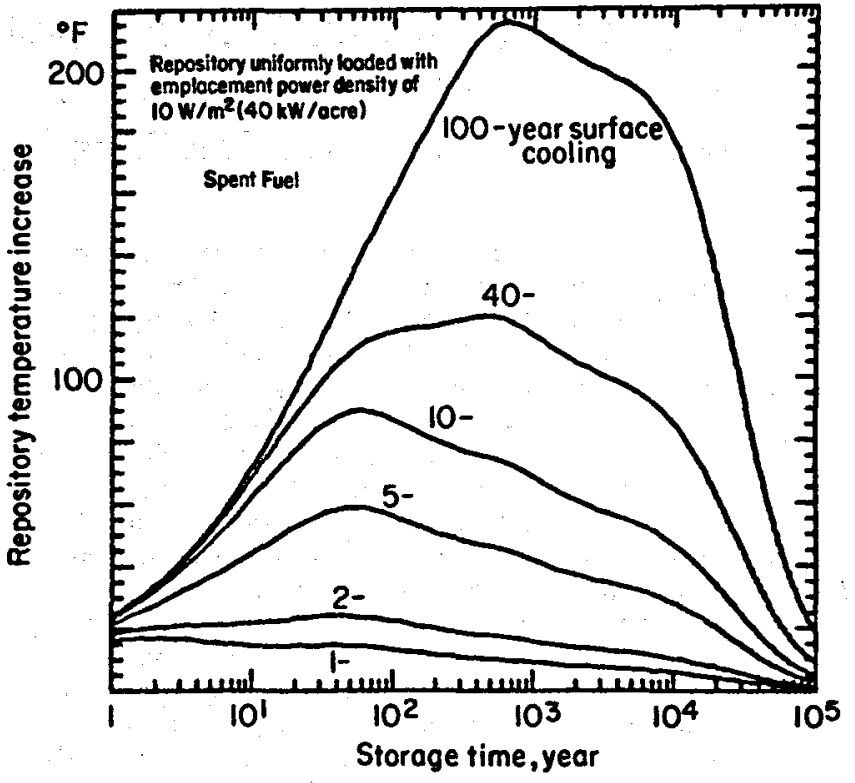

Figure 4. Temperature rise in a spent fuel repository as a function of surface cooling period for the case of constant emplacement power density loading.

[XBL 817-3277]

surface cooling, and waste loading. The shortterm near-field thermal impacts are determined by the heat power of the emplaced wastes. The longterm far-field thermal impacts are determined by the cumulative heat in the rock formations. The extension of the surface cooling period from 10 yr to longer periods can lower the near-field thermal Impact but has modest long-term effects, especially for spent fuel containing long-lived actinides. Current repository designs could be acceptable for 100-year-old reprocessed wastes, but more detailed studies should be made for other waste types and waste ages.

\section{REFERENCES CITED}

Department of Energy, 1980. Management of commercially generated radioactive waste. 0 . $\mathrm{s}$. Department of Energy, Washlngton, D. C., DOE/EIS-0046F.

Wang, J. S. Y., Mangold, D. C., Spencer, R. K.. and Tsang, C. F., 1981. Thermal 1mpact of waste emplacement and surface cooling associated with geological disposal of nuclear waste. Lawrence Berkeley Laboratory Report LBL-13341, in draft. 


\title{
BASIS FOR A TENTATIVE THERMOHYDROLOGIC CRITERION FOR EMPLACEMENT DENSITY IN A NUCLEAR WASTE REPOSITORY
}

\author{
J. S. Y. Wang, D. C. Mangold, and C. F. Tsang
}

Thermal loading is a principal consideration in the design and evaluation of a repository for geologic disposal of nuclear wastes. Existing criteria are based on thermomechanical stability considerations for the waste package and the repository structural components as well on the allowable surface uplift due to thermal expansion of the surrounding rock medium. The vertical buoyancy flow from the repository to the surface has not been considered as a boundary criterion in the determination of repository loading densities. In this synopsis we discuss a generic thermohydrologic criterion to directly address the issue of thermal impacts on groundwater movement and radionuclide transport. However, it should be stressed that the criterion is preliminary and that the problem of radionuclide transport is complex. The following summary of the factors that must be considered and the proposed criterion is based on a report by wang et al. (1981a).

\section{CONTROLLING FACTORS IN RADIONUCLIDE TRANSPORT}

The movement of each individual radionuclide depends on its release rate, the groundwater movement, its adsorption/desorption at the rock surfaces, its diffusion in the rock matrix, the radioactive decay chains, and the chemical processes of reaction, ion exchange, and complexing with other aqueous components. If the velocity field can be determined as a function of space and time, the path of a radionuclide can be traced and its contribution to the concentration and radiotoxicity of radionuclides in the biosphere can be evaluated.

Both the geochemical and hydrologic factors that must be considered in determining the radionuclide velocity in the groundwater are complex. However, lumped factors can be used to describe the velocity in terms of a conductance factor and a driving gradient: velocity $=$ conductance $x$ gradient.

\section{Conductance Factor}

The conductance factor can also be decomposed into the hydrologic and geochemical components:

conductance $=\frac{\text { hydraulic conductivity }}{\text { porosity }} \times \frac{1}{\text { retardation }}$.

The hydraulic conductivity, with units of velocity $(\mathrm{m} / \mathrm{s})$, is the volumetric flow rate per unit area normal to the flow ariven by unit gradient. To determine the water velocity within individual pores and fractures, the fluid flux is corrected by the porosity (the ratio of rock voids to total volume). The retardation factor is $\left(l+K_{d}\right)$, where $K_{d}$ is the equilibrium sorption coefficient, which accounts for the adsorption and other radionuclide-rock interactions in a lumped manner.
The hydraulic conductivity, or equivalently, the permeability, has a high degree of uncertainty with a very wide range in value even for a given rock type (Brace, 1980). The porosity may also contribute to the uncertainty, because not all the voids are necessarily flow paths for the fluid (Norton and Rnapp, 1977). The uncertainty in the radionuclide retardation factor depends not only on the rock properties but also on the geochemical conditions and radionuclide species in the groundwater. The overall conductance factor for radionuclides, then, will be difficult to determine with certainty, and must be carefully measured on a site-specific basis over the large scale of the rock mass.

\section{Pressure and Buoyancy Gradients}

In contrast to the conductance factor, the driving gradient for the fluid flow and radionuclide transport can be determined with a higher degree of certainty. There are two mechanisms for inducing a hydraulic gradient:

hydraulic gradient =

pressure gradient + buoyancy gradient.

The pressure gradient is determined by the natural hydrologic characteristics of the repository site, such as the distribution of recharge and discharge points and regional flow regime. The regional pressure variations can be measured with well-known hydrogeologic techniques. It is expected that the repository will be located in a region with a low regional pressure gradient: for example, $0.001 \mathrm{~m} / \mathrm{m}$ or $1 \mathrm{~m}$ of difference in water table elevation over $1 \mathrm{~km}$ distance, with a nearly horizontal flow path.

The mechanism of buoyancy flow is also well known. With increased temperature, the density of water decreases. The density contrast between the hot fluid near the repository and the cold fluid in the surrounding formation induces a buoyancy gradient in the vertical direction. The magnitude of the buoyancy gradient depends on the temperature rise in the rock formation and on the change of water density with temperature. The buoyancy gradient can be calculated for different rock formations. The temperature dependence of water density has been measured with a high degree of accuracy.

\section{THERMOHYDROLOGICAL CRITERION}

The proposed criterion is: The thermally induced buoyancy gradient should be less than the ambient pressure gradient. It is based on a single consideration: Thermal impact due to waste emplacement should not perturb the ambient hydrologic condition excessively.

When the hydrogeologic conditions around a suitable site have been evaluated and the rock 
formations have been shown to be tight enough to have slow groundwater flow, it is imperative that the waste emplacement not significantly reduce the effectiveness of the isolation provided by the geologic setting. If we want to maintain the hydrologic integrity of the rock formation in order to contain the radionuclides, the perturbation Induced by the waste should be as small as possible. If the waste emplacement changes the flow pattern drastically, the flow paths will no longer be the same. The long, favorable flow paths from the repository to the discharge zone will be short-circuited by the vertical flow paths. With drastic flow pattern changes, there is no longer a guarantee that the hydrologic conditions favorable for effective isolation can be preserved.

If the vertical buoyancy gradient is much less than the ambient pressure gradient, the distortion of the ambient flow pattern will be small. This will be ideal, but it may be to restrictive. The proposed criterion requires only that the buoyancy gradient be less than or equal to the ambient pressure gradient. For spent fuel repositories, the buoyancy gradient is at a maximum between 1000 and 10,000 years after waste emplacement, depending on the rock type and repository depth (Wang et al., 1981b). Prior to the maximum, when the release of fisston products is potentially dangerous, the distortion of the flow pattern will be small. During the period of maximum gradient, when the actinide release is the main concern, the distortion of the fluid flow should not render the original pattern unrecognizable.

The proposed criterion does not impose any assumptions on the ambient flow pattern. If the amblent groundwater flow is horizontal, the proposed criterion guarantees that the velocity vector through the repository will be oriented upward less than 45 degrees (Bourke and Robinson, 1981). If the ambient groundwater movement is downward, for a repository located below a recharge zone, the criterion ensures that the water will not reverse its direction during the thermal perlod. At the period of maximum buoyancy flow, the net gradient will be zero and the water will be at rest. For the highly unlikely situation of a repository in a discharge zone with ambient gradient pointing upward, the total discharge with both the buoyancy-driving gradient and the pressure-driving gradient will not be doubled with this hydrologic criterion.

Depending on one's viewpoint, this criterion may be regarded as elther not conservative enough or too restrictive. On the one hand, one may argue that reorientation of the velocity vector by 45 degrees is too large a distortion of the amb1ent groundwater flow pattern. According to this view, if the distance between the repository and the discharge zone is 10 times the depth of the repository, the allowable buoyancy gradient should be one-tenth of the regional pressure jradient. On the other hand, one may argue that the host formation has low enough permeability and high enough retardation that the buoyancy gradient can be much larger than the present amblent gradient. Therefore, the allowable magnitude of the buoyancy gradient is best left as an open question at present. We tentatively suggest that equality between the maximum buoyancy gradient and the ambient pressure gradient strikes a good balance between the different viewpoints.

A further requirement for a useful criterion is that it must allow meaningful quantitative evaluations with minimal assumptions and uncertainty. An essential feature of this thermohydrologic criterion is that it is expressed in terms of the magnitude of the gradient components. The determination of the velocity components is subject to enormous uncertainty. The buoyancy and pressure components of the hydraulic gradient, however, can be determined with reasonable precision by current hydrogeologic techniques and are free from the uncertainty associated with the hydrologic and geochemical parameters of the rocks.

Furthermore, compared to the existing thermomechanical criterion on surface uplift, this thermohydrologic criterion is more direct in addressing the long-term, far-field perturbation of water and radionuclide movement. Surface uplift was considered primarliy because of concer $n$ over potential fracturing in the rock formations. The opening of fractures will increase permeability, and this contributes additional uncertainty to the conductance factor for flow and radionuclide transport. The buoyancy driving force, however, is considered here because of specific concern over vertical upward movement of water and radionuclides from the repository to the blosphere.

It should be pointed out also that we have used the same thermohydrological criterion for both salt and nonsalt formations. The permeability of the formation is not a consideration of the thermohydrologic perturbation. For salt formations, the recirculation of fresh groundwater around the salt should be avolded, especially if the surrounding rock may be fractured by the thermal expansion of the salt. For nonsalt formations, with the repository below the water table, the thermohydrologic perturbation is of great concern.

\section{ALLOWABLE THERMAL LOADING FROM BUOYANCY CONSIDERATIONS}

In most studies reported in the literature, the repository thermal loading is determined by thermomechanical criteria. If the proposed thermohydrologic criterion is less restrictive than the existing criteria, it will be of limited interest as an additional check. The simple analysis presented below shows that the buoyancy criterion turns out to be more restrictive in many cases than the existing criteria in determining the allowable thermal loadings.

We base our analysis on the results of the Generic Environmental Impact statement (GEIS) study (Science Applications, Inc., 1978). In this study, surface uplift has been evaluated for spent fuel repositories and reprocessed high-level waste repositories in salt, granite, 
basalt, and shale. Since both the surface uplift and buoyancy flow are determined by the temperature rise from the repository to the surface, the buoyancy gradient can be deduced from the corresponding values of the surface uplift. The thermal expansion coefficient and the Poisson ratio factor are replaced by the thermal expansion coefficient of water in the conversion. The results are tabulated in Table 1.

For the 150-kW/acre repositorles in salt, the 190-kW/acre repositorles in granite and basalt, and the $120-\mathrm{kW} /$ acre repositories in shale considered in the GEIS study, the buoyancy gradients are in the range of 0.01 to $0.05 \mathrm{~m} / \mathrm{m}$. These values are 10 to 50 times larger than the typical ambient pressure gradient of $0.001 \mathrm{~m} / \mathrm{m}$. The $0.001 \mathrm{~m} / \mathrm{m}$ value has been used in most of the recent thermohydrologic studies in waste repositories (Dames and koore, 1978, Hardy and Hocking, 1978; Burgess et al., 1979; Hodgkinson, 1980, Wang and Tsang, 1980).

If we impose the thermohydrologic criterion by requiring that the buoyancy gradient induced by thermal loading be no larger than $0.001 \mathrm{~m} / \mathrm{m}$, then the GEIS thermal loading values based on the roon stability criterion must be reduced. The allowable thermal loadings are tabulated in Table 2.

\section{DISCUSSION}

If we adopt the proposed criterion based on buoyancy flow considerations, it is clear from Tables 1 and 2 that the allowable thermal loadings would have to be much smaller than those considered in the past $10 \mathrm{yr}$. The implication is obviously a dramatic one. To limit the long-term thermohydrologic perturbation and to preserve the integrity of the rock formation as a waste barrier, we either have to use 10 to 50 times more repositories to accommodate the same amount of wastes or extend the capacity (plan area) of each repository 10 - to 50-fold. These preliminary re- sults therefore indicate that the thermohydrologic considerations could be very restrictive and constitute a key area for further study.

The primary purpose of a waste repository is the long-term isolation of radionuclides. For the long-term prediction of radionuclide transport, we need to know the absolute magnitude of the movement of the water and radionuclides, which the gradient criterion does not include. In essence, the gradient criterion factors out the hydrologic and geochemical parameters, which are highly heterogeneous and difficult to measure. By comparing only the gradient components, most of the unknown or uncertain factors used in assessing the thermal impact are lumped together and thereby avoided when stating the criterion. The gradient criterion addresses only the change of the flow pattern, not the absolute magnitude of the velocity and travel time. This means that the proposed thermohydrologic criterion for repository design would complement the criteria for choosing a suitable geological setting.

Existing siting criteria emphasize the characterization of ambient hydrologic and geochemical conditions. Once a tight formation with long travel times to the biosphere has been found, it is important that the emplacement of waste not change the effectiveness of isolation. Determining the thermal loading by means of the proposed thermohydrologic criterion in repository design is intended only to ensure that the additional perturbation will not change the ambient conditions excessively. By imposing this thermohydrologic criterion, we preserve those features of a site which make it useful for the effective isolation of nuclear wastes. Thus the criterion complements the already-established criteria in the literature for choosing a suitable geologic setting for the repository. It seeks to ensure the effectiveness of the isolation of the wastes by placing limits on the changes permitted to occur in the groundwater flow pattern. This should preserve the capability of the entire multibarrier system to contain and isolate the radioactive wastes from the biosphere.

Table 1. Buoyancy gradient.

\begin{tabular}{|c|c|c|c|c|c|c|c|c|}
\hline \multirow{2}{*}{$\begin{array}{l}\text { Rock } \\
\text { Waste }\end{array}$} & \multicolumn{2}{|c|}{ Salt } & \multicolumn{2}{|c|}{ Granite } & \multicolumn{2}{|c|}{ Basalt } & \multicolumn{2}{|c|}{ Shale } \\
\hline & SF & HLW & SF & BLW & SF & HLW & $\mathbf{S F}$ & HLW \\
\hline $\begin{array}{l}\text { Buoyancy gradient, } \\
\mathrm{m} / \mathrm{m}\end{array}$ & 0.026 & 0,0097 & 0.051 & 0.018 & 0.040 & 0.013 & 0.046 & 0.019 \\
\hline $\begin{array}{l}\text { Time of occurrence } \\
\text { years }\end{array}$ & 1000 & 150 & 3000 & 1000 & 7000 & 3000 & 3800 & 1800 \\
\hline $\begin{array}{l}\text { Thermal loading; } \\
\text { kW/acre }\end{array}$ & 150 & & 190 & & 19 & & 12 & \\
\hline
\end{tabular}

Thermal expansion coefficient of water $=3.85 \times 10^{4}{ }^{\circ} \mathrm{C}-1$. Repository depth $=610 \mathrm{~m}(2000 \mathrm{ft})$.

$\mathrm{SF}=$ spent fuel; HLW = high-level waste. 
Table 2. Allowable thermal loading based on the buoyancy criterion.

\begin{tabular}{|c|c|c|c|c|c|c|c|c|}
\hline \multirow{2}{*}{$\begin{array}{l}\text { Rock } \\
\text { Waste }\end{array}$} & \multicolumn{2}{|c|}{ Salt } & \multicolumn{2}{|c|}{ Granite } & \multicolumn{2}{|c|}{ Basalt } & \multicolumn{2}{|c|}{ shale } \\
\hline & $\mathbf{S F}$ & HLW & $\mathbf{S E}$ & HIW & SF & HLN & SF & HLW \\
\hline $\begin{array}{l}\text { Allowable thermal } \\
\text { loading, kw/acre }\end{array}$ & 5.7 & 15.5 & 3.7 & 10.4 & 4.8 & 15.1 & 2.6 & 6.2 \\
\hline
\end{tabular}

\section{REFERENCES CITED}

Bourke, P. J., and Robinson, P. C., 1981. Comparison of thermally induced and naturally occurring waterborne leakages from hard rock depositories for radioactive waste. Radioactive Waste Management, v. 1, no. $1, p$. 365-380.

Brace, พ. F., 1980. Permeability of crystalline and argillaceous rocks. International Journal of Rock Mechanics and Mineral Sciences, v. 17, no. 5, p. 241-251.

Burgess, A. S., Charlwood, R. G., Skiba, E. L., Ratigan, J. L., Gnirk, P. F., Stille, H., and Lindblom, U. E., 1979. Analyses of groundwater flow around a high-level waste repository in crystalline rock. Presented at OECD Nuclear Energy Workshop on Low-flow, Low-permeability Measurements in Largely Impermeable Rocks, Paris, France, $10 \mathrm{p}$.

Dames and Moore, 1978. Technical support for GEIS: Radioactive waste isolation in geologic formations: Groundwater movement and nuclide transport. Dames and Moore, White plains, New York, Y/OWI/TM-36/21.

Hardy, M. P., and Hocking, G., 1978. Numerical modeling of rock stresses within a basaltic nuclear waste repository: Phase II - parametric design studies. Rockwell Hanford Operations, Richland, Washington, RHO-BWI-C-23, 303 p.
Hodgkinson, D. P., 1980. A mathematical model for hydrothermal convection around a radioactive waste depository in hard rock. Annals of Nuclear Energy, v. 7, p. 313-334.

Norton, D., and Knapp, R., 1977. Transport phenomena in hydrothermal systems: The nature of porosity. American Journal of Science, v. 277, p. 913-936.

Science Applications, Inc., 1978. Technical support for GEIS: Radioactive waste isolation in geologic formations: Thermal analysis. Office of Waste Isolation, Oak Ridge, Tennessee, Y/OWI/TM-36/19, 266 p.

Wang, J. S. Y., and Tsang, C. F., 1980. Buoyancy flow in fractures intersecting a nuclear waste repository. In Heat Transfer in Nuclear Waste Disposal, Proceedings of the Winter Meeting of the American Soclety of Mechanical Engineers, Chlcago, Illinols, v. 11, p. 105-112.

Wang, J. S. Y., Mangold, D. C., Spencer, R. K., and Tsang, C. F., 1981a. Thermal impact of waste emplacement and surface cooling associated with geological disposal of nuclear waste. Lawrence Berkeley Laboratory Report LBL-13341, in draft.

Wang, J. S. Y., Tsang, C. F., Cook, N. G. W., and Witherspoon, P. A., 1981b. A study of regional temperature and thermohydrologic effects of an underground repository for nuclear wastes in hard rock. Journal of Geophysical Research, v. 86 , no. B5, p. 3659-3770. 


\section{THEORETICAL MODEL OF FLUID FLOW THROUGH A DEFORMABLEROCK FRACTURE}

\section{Y. W. Tsang and P. A. Witherspoon}

We have developed a simple theoretical model to understand the effect of normal stress on flow through a single rough-walled fracture. In order to gain a fundamental understanding of the problem, we have made several simplifying physical assumptions and have excluded the use of arbitrary fitting parameters.

Steady laminar flow through two smooth parallel plates separated by a constant distance $b$ obeys the cubic law (Boussinesq, 1868; Bear, $1972)$; i.e., the flow rate is proportional to $b^{3}$. A rough-walled fracture does not have a constant $b$, but is better represented by an array of asperities with varying heights $h_{j}$, giving rise to a fracture with variable aperture $b_{j}$ (Fig. 1). Neuzil and Tracy (1981) and we (Tsang and Witherspoon, 1981) have demonstrated that flow through such a fracture is proportional to $\left\langle b^{3}\right\rangle$; i.e.. the cube of the aperture averaged over the aperture distribution. Therefore, an asperity height distribution function, which is a correct mathematical expression for the variability of the real physical fracture, is needed in the calculation of flow through a rough-walled fracture.

A fracture may also be considered to be conposed of a collection of voids (Fig. 2), and the closure of the fracture under stress may be considered to result from the deformation of these voids (Fig. 3). We have derived in a recent paper (Tsang and Witherspoon, 1981) the relation

$\frac{E_{\text {eff }}}{E} \approx 1-\frac{\pi<d>}{\Delta z}$,

where $E$ and $E_{e f f}$ are the Young's moduli for the intact and fractured rock, respectively, $\Delta z$ is the distance across the fracture plane over which $E_{\text {eff }}$ applies, and $\langle d>$ is the average void length in the fracture. Both $\mathrm{E}$ and $\mathrm{E}_{\text {eff may be obtained }}$ from axial stress-deformation measurements. As illustrated in Figure 3, increasing normal stress on the fracture reduces the average void length

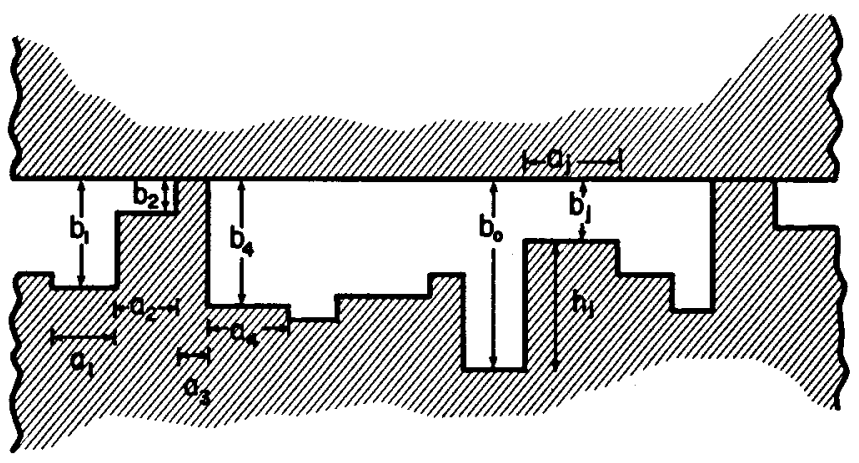

Figure 1. Schematic representation of a fracture by an asperity model.
[XBL 8011-2970]

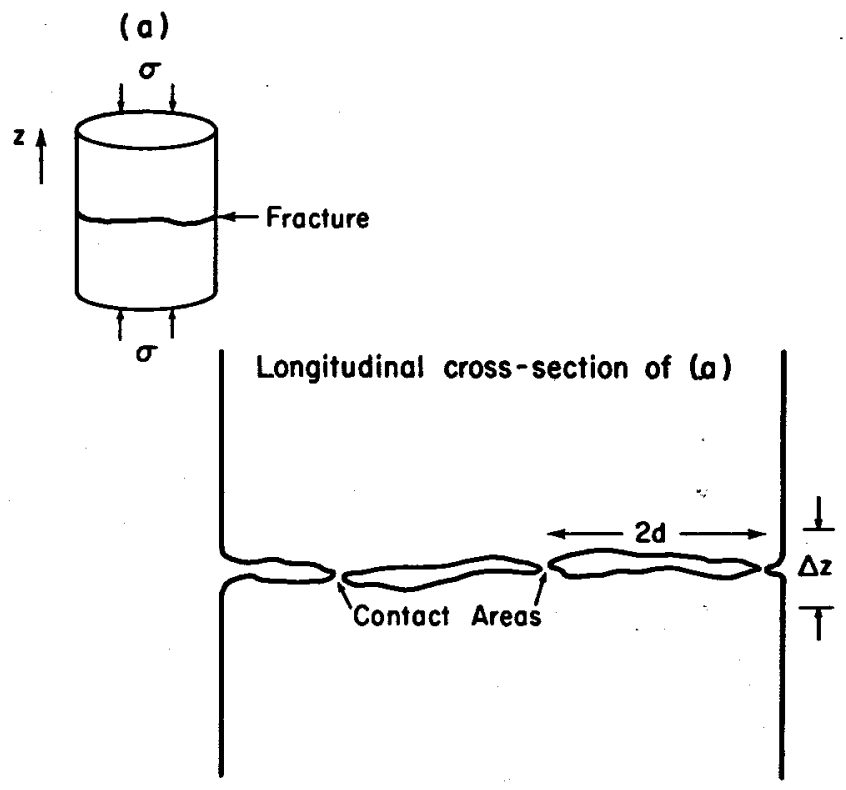

Figure 2. Representation of a single horizontal fracture by an array of voids.

[XBL 8011-2974]

(a) at normal stress $\sigma_{1}$

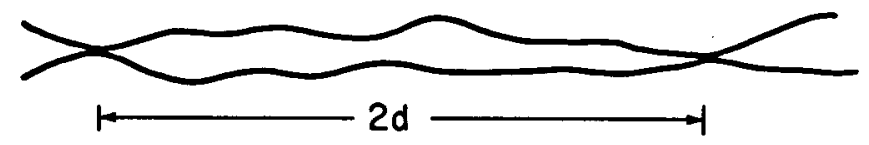

(b) at normal stress $\sigma_{2}>\sigma_{1}$

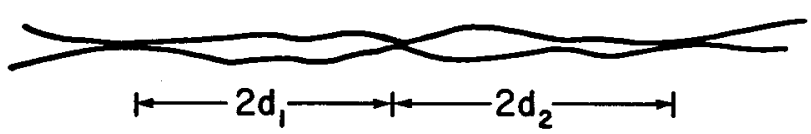

(c) at normal stress $\sigma_{3}>\sigma_{2}$

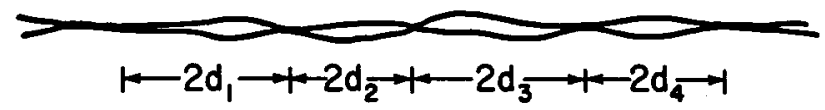

Figure 3. Deformation of voids in a sequence of increasing normal stresses. [XBL 8011-2975] 
$2<d>$ and increases the number of contact points, $\mathrm{N}_{C}$, where asperities bridge between the surfaces of the opening. This process results in the gradual stiffening of the jointed rock under compression, as predicted by (1). For a spatially random distribution of voids (or asperities). $\mathrm{N}_{C}$ is inversely proportional to $k d \lambda$. We have shown (Tsang and Witherspoon, 1981) that a fracture asperity height distribution function may be deduced if the stress-displacement data are avallable for the intact rock and for a specimen containing a

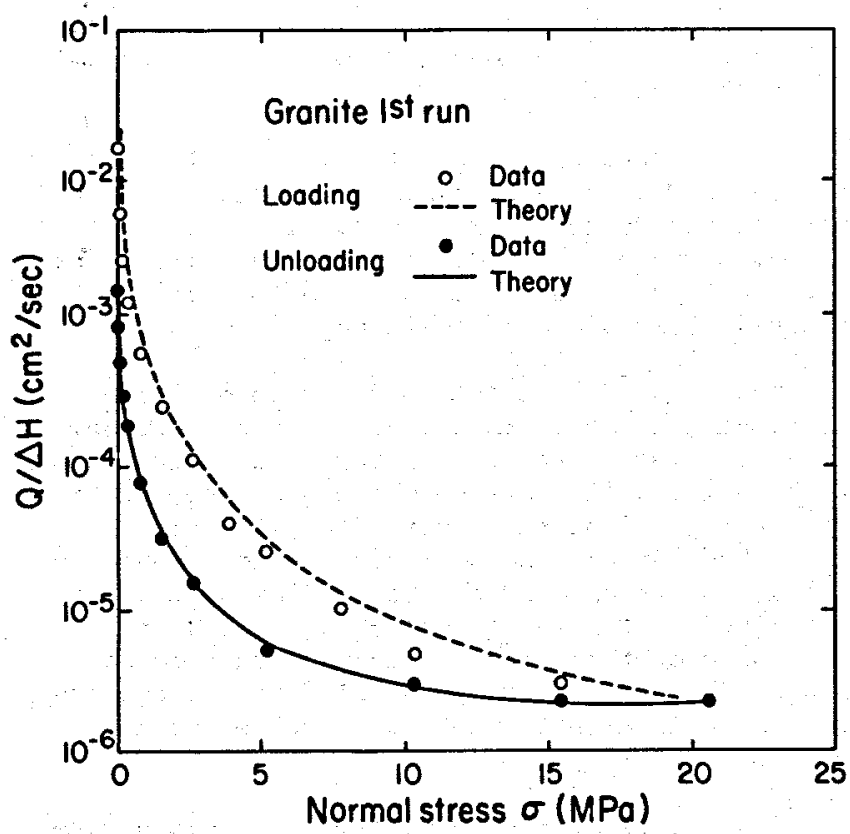

Figure 4. Experimental and theoretical flow as a function of normal stress in the first loading and unloading cycles in granite.

[XBL 8011-2989] fracture, and if an estimate of the contact area of the fracture can be made for any stress. From such a distribution function we were able to calculate the fluid flow through a fracture under normal stress.

Theoretically predicted flows were compared with Iwal's (1976) experimental data from radial flow tests on a normally loaded fracture in a granite specimen (Fig. 4). The stiffness properties and contact area of the fracture were obtained from the deformation measurement made on the same specimen. No curve fitting of the flow data was involved in making the flow predictions. The good agreement between the theoretical and experimental results suggests that we have gained a basic understanding of the factors which control the flow of fluids through a rough, deformable fracture.

\section{REFERENCE CITED}

Bear, J., 1972. Dynamics of Fluids in Porous Media. New York, American Elsevier Co.

Boussinesq, J., 1868. Mémolre sur l'influence des frottements dans les mouvements reguliers des fluides. Journal de Lionville, v. 13, p. $377-424$.

Iwal, K. . 1976. Fundamental studies of fluid flow through a single fracture (Ph.D. dissertation). Department of Civil Engineering, University of California, Berkeley.

Neuzil, C. E., and Tracy, I. V., 1981. Flow through fractures. Water Resources Research, v. 17, p. 191-199.

Tsang, Y. W., and witherspoon, P. A., 1981. Hydromechanical behavior of a deformable rock fracture subject to normal stress. Journal of Geophysical Research, v. 86, p. 9287-9297. 
POROUS MEDIA EQUIVALENT FOR A NETWORK OF DISCONTINUOUS FRACTURES

\author{
J. C. S. Long
}

One of the important questions that arises when considering the flow of fluids through a discontinuous rock mass is whether the fracture network behaves as a porous medium. That is, can one model the system by an equivalent permeability tensor and proceed to determine the movement of fluids under the application of known boundary and initial conditions?.

The work that has been done to determine the equivalent permeability of fractured rocks from information on fracture geometry (assuming an impermeable matrix) can be classified into two categories. Most of the work falls into the category in which fractures are assumed to be continuous, or of infinite extent (extensive fractures) (Snow, 1965). Very little work has been done in the category in which fractures are assumed to be discontinuous, or of finite extent (Parsons, 1966; Caldwel1, 1972; Rocha and Franciss, 1977).

It can be seen in the field that fractures are clearly of finite dimensions. The fact that fractures are finite means that each fracture can contribute to the permeability of the rock only insofar as it intersects other conducting fractures. In the extreme, an isolated fracture which does not intersect any other fracture effectively contributes nothing to the permeability of the total rock mass. This means that flow in any given fracture is not independent of flow in every other fracture.

\section{HOMOGENEOUS ANISOTROPIC PERMEABILITY}

In order to determine when a fractured medium behaves as a homogeneous, anistropic medium, one must determine if a symetric permeability tensor exists. The only way to show this is to actually measure the directional permeability.

For an ideal porous medium, when the permeability in the direction of the gradient, $K_{g}$, is measured and $1 / \sqrt{\mathrm{k}}_{\mathrm{g}}$ is plotted versus the orientation, $\alpha$, the plot will be an ellipsoid given by

$1=K_{\mathbf{i}} \mathbf{n}_{\mathbf{i}} \mathbf{n}_{\mathbf{j}}$

where $K_{i j}$ is the permeability tensor and $n_{i}, n_{j}$ is a unit vector in the direction of measurement.

Another basic problem is that of establishing equivalent homogeneity. In order to have a tractable analysis of flow, a scale of measurement (the macroscopic scale) must be found for which the porous medium is seen as a continuum (Hubbert. 1956). On this scale the medium is said to be homogeneous. The scale on which the parameter of interest--in this case, permeability--ceases to vary is defined as the representative elementary volume (REV). With respect to permeability, the REV of a medium can be sought by measuring the average permeability of increasing volumes of rock until the value does not change significantly with the addition or subtraction of a small volume of rock.

The difficulty in identifying equivalent permeability is that the permeability in one part of the field which has a higher gradient will have more effect on the total flux than the permeability in another part of the field which has a lower gradient. When the boundary conditions change, the emphasis changes.

If the gradient within the internally heterogeneous REV remains approximately constant, each part of the volume will have equal emphasis, and it may be possible to define a unique equivalent permeability tensor which will be correct for approximately linear flow in any direction.

The above discussion leads to several conclusions central to this investigation. First, it only makes sense to 100k for REVs in fractured rocks using a flow system which would produce a constant gradient and linear flow lines in a truly homogeneous, anisotropic medium. Boundary conditions which produce such a flow system are described in Long et al. (1981). Second, the following criteria must be met in order to replace a heterogeneous system of given dimensions with an equivalent homogeneous system for the purposes of analysis:

1. A small increase or decrease in the sample volume does not produce a significant change in the value of the equivalent permeability.

2. An equivalent symmetric permeability tensor exists which predicts the correct flux when the direction of gradient is changed.

Point (1) implies that the sample under consideration is a good statistical sample of the heterogeneities. point (2) implies that boundary conditions are applied to the sample which would produce a constant gradient throughout a truly homogeneous anisotropic sample. The actual detailed gradient within the heterogeneous sample does not have to be exactly constant for (2) to be satisfied.

\section{STATISTICS OF FRACTURE GEOMETRY}

Under a given set of boundary conditions, the hydraulic behavior of a fractured rock mass with an impermeable matrix is determined entirely by the geometry of the fracture system. Real fractures have complex surfaces and variable apertures, but for the purposes of this study and most other studies of fracture systems, the geometric description is simplified. The assumption is made that individual fractures lie in a single plane and have a constant hydraulic aperture. Characterization of a fracture system is considered complete when each fracture is described in terms of (1) hydraulic or effective aperture, (2) 
or lentation, (3) location, and (4) size. Baecher et al. (1978) have developed a conceptual joint geometry model. Joint trace lengths are assumed to be lognormally distributed, and spacings are assumed to be exponentially distributed. These authors infer that joints are circular disks randomly distributed in space. Joint radil are shown to be lognormally distributed.

NUMERICAL METHOD OF ANALYSIS

A numerical code has been developed to generate sample fracture systems in two dimensions using the geometric properties described above and to determine the permeability of such systems.

The two-dimensional mesh generator produces random realizations of a population of fractures. Input to the generator includes specification of the distributions that describe the fracture population. The mesh generator can randomly choose fractures for the sample according to these distributions. Details of the scheme for mesh generation are given in Long et al. (1981). A.finite-element analysis can then be used to calculate $Q_{g}$, the component of flow through the fractures in the direction of the gradient. The hydraulic conductivity in the direction of the gradient of the sample fracture pattern is calculated from Darcy's law:

$R_{g}=\frac{Q_{g}}{A \nabla \phi}$

where $A$ is the gross area perpendicular to flow and $\nabla \phi$ is the gradient. The analysis of permeability is independent of the type of fracture model generated. This generator produces models similar to Baecher's (1978), but another fracture model, such as that proposed by veneziano (1979), could fust as easily have been used.

The effect of sample size on conductivity measurement can be studied with this program. It can also be used to study the variation in conductivity between different realizations of a statistically described fracture system. This Monte Carlo type of analysis could also be used to analyze statistical data collected in the field. An expected value and a standard deviation of the equivalent conductivity of porous media would be obtained in this way.

In order to plot permeability ellipses, a method is used which obtains conductivity in the direction of the gradient. Flow through the fracture system is computed using a finiteelement program developed by wilson (1970) for fracture flow. Fractures are represented as line elements, with flux related to aperture by the cubic law. The rock matrix is assumed to be impermeable. Only the steady-state flow rate is calculated. Boundary conditions used to measure airectional permeability are described in Long et al. (1981).

In general, the fracture pattern results in an anisotropic medium for which $1 / \sqrt{\mathrm{K}_{\mathrm{g}}}$ may not plot as a smooth ellipse. In fact, a plot using measured values of $\mathbf{K}_{\mathbf{g}}$ for a $g$ iven volume of rock may be quite erratic in shape. Such a plot can be used to test whether the given volume can be approximated as a homogeneous porous medium. If $1 / \sqrt{\mathrm{K}_{\mathrm{g}}}$ does plot at least approximately as an ellipse, then no single symmetric conductivity tensor can be written to describe the medium. If there is no conductivity tensor, then flow through the medium cannot be analyzed by existing continuum techniques.

\section{USE OF THE NUMERICAL METHOD}

The following examples will lllustrate the use of this numerical method of analyzing flow in two-dimensional networks of fractures.

The first example (Fig. 1) is a random fracture system that was developed using the mesh-generation scheme described by Long et al. (1981). The system consists of two fracture sets for which aperture and orientation are allowed to vary. Figure 1A shows the fracture network of the original generation region, and Figures $1 B$, C, D illustrate how different flow regions were created simply by rotating the boundaries while the network remained fixed.

Figure 2 shows the values of $1 / \sqrt{K}_{g}$ plotted on polar coordinate paper, where $\mathrm{K}_{\mathrm{g}}$ is defined in terms of flux across side 2 . The results on Figure 2 clearly do not plot as an ellipse; nor are they symmetric. The plot shows that the sample chosen does not have a symetric conductivity tensor and cannot be represented by an equivalent
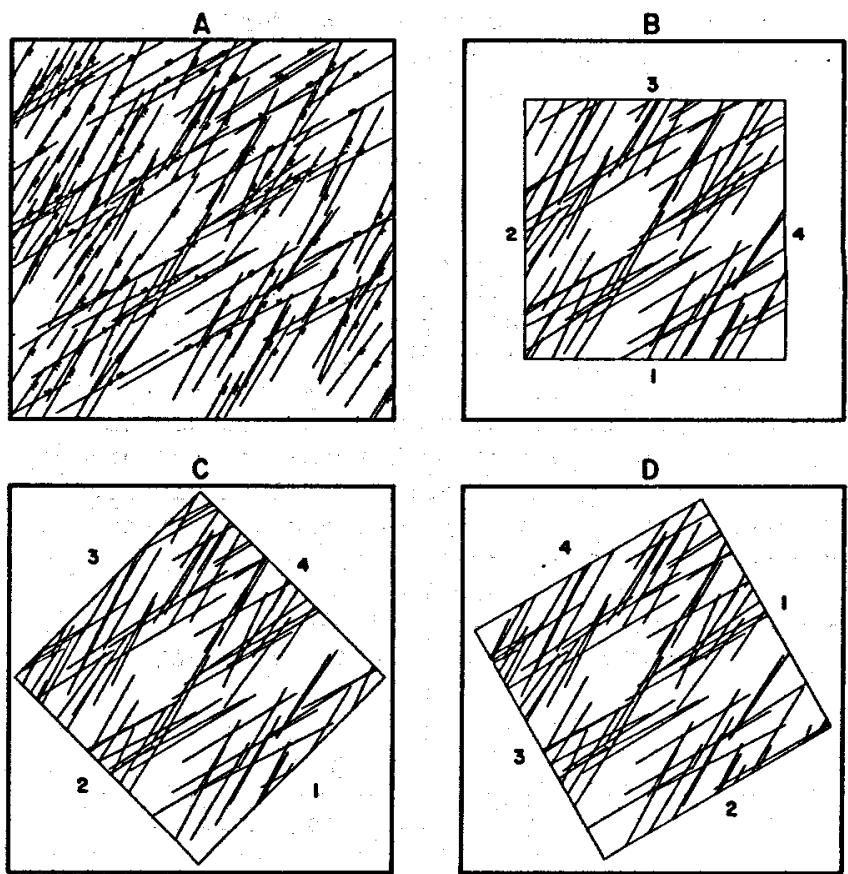

Figure 1. Nonextensive random fracture system showing original generation region (A) and flow regions investigated when $\alpha=0$ (B), $\alpha=45$

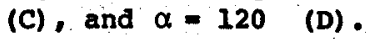

[XBL 814-8961] 


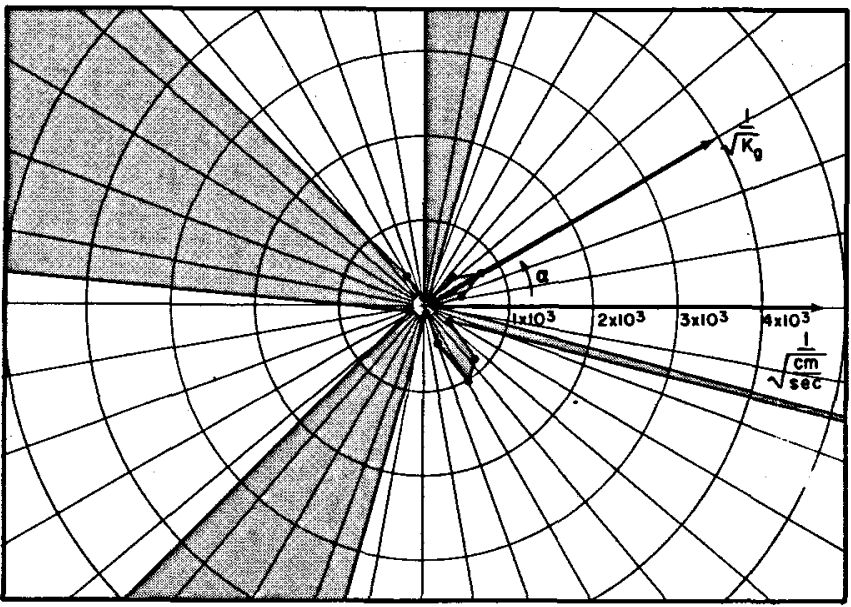

Figure 2. Polar plot of numerical results for $1 / \sqrt{k_{g}}$ for a nonextensive random fracture system.

[XBL 814-2818]

porous medium. As further proof of the nonhomogeneous nature of this network, flow regions of different sizes were extracted and tested. The particular orientation shown on Figure 1 for $\alpha=$ $0^{\circ}$ was selected, and the flow region was reduced, while remaining centrally located in the original generation region. The results reveal order-ofmagnitude changes in hydraulic conductivity from sample to sample and further illustrate the marked differences between the fluid-flow behavior of this random fracture network and that of homogeneous porous media.

\section{EFFECT OF ERACTURE DENSITY}

In order to determine how the density of fractures affects the hydraulic behavior, three examples were analyzed in which the same fractures were squeezed into successively smaller areas. Thus the number of fracture intersections and therefore the number of hydraulically active fractures increases. The least dense system had an irregular, nonsymetric "ellipse" which goes off to infinity for several directions of measurement. Where the plot goes off to infinity, the permeability in that direction is zero. When the fracture density has increased to the point where side 2 always intersects some conducting fractures, no zero permeability directions are found. The most dense system had a fairly regular but asymmetric ellipse. The size of the ellipses decreases with density as expected, since denser systems should be more permeable. The directions of minimum and maximum permeability are roughly the same in all three plots.

In summary, the hydraulic behavior of the fracture systems becomes more like that of a homogeneous, anisotropic material as fracture density increases. This is an expected result.

\section{EFFECT OF APERTURE AND ORIENTATION DISTRIBUTION}

The effect of distributing aperture or orientation is illustrated by comparing systems in which only aperture or only orientation had been distributed with systems in which all parameters are uniform. The permeability plot was less elliptical for the case in which only aperture was allowed to vary. This is because not all the conductors are of equal strength.

Varying the orientation of the fractures results in a more elliptical permeability plot. In this case the number of fracture intersections increases because fractures of the same set are no longer parallel and can now intersect each other. The degree of hydraulic connectivity is thus increased, and the permeability plot becomes moe symmetric and regular. Fracture systems with distributed orientations behave more like homogeneous porous media than do systems with uniform orientations. Fracture systems with distributed apertures behave less like homogeneous media than uniform aperture systems.

\section{Scale Effects}

In order to illustrate scale effect, a system of fractures was chosen with the following properties: The system consisted of two perpendicular sets of fractures, all with the same aperture and length. The orientation distribution for each set was the same. The fracture system generated is shown in Figure $3(A)$. Theoretically, two
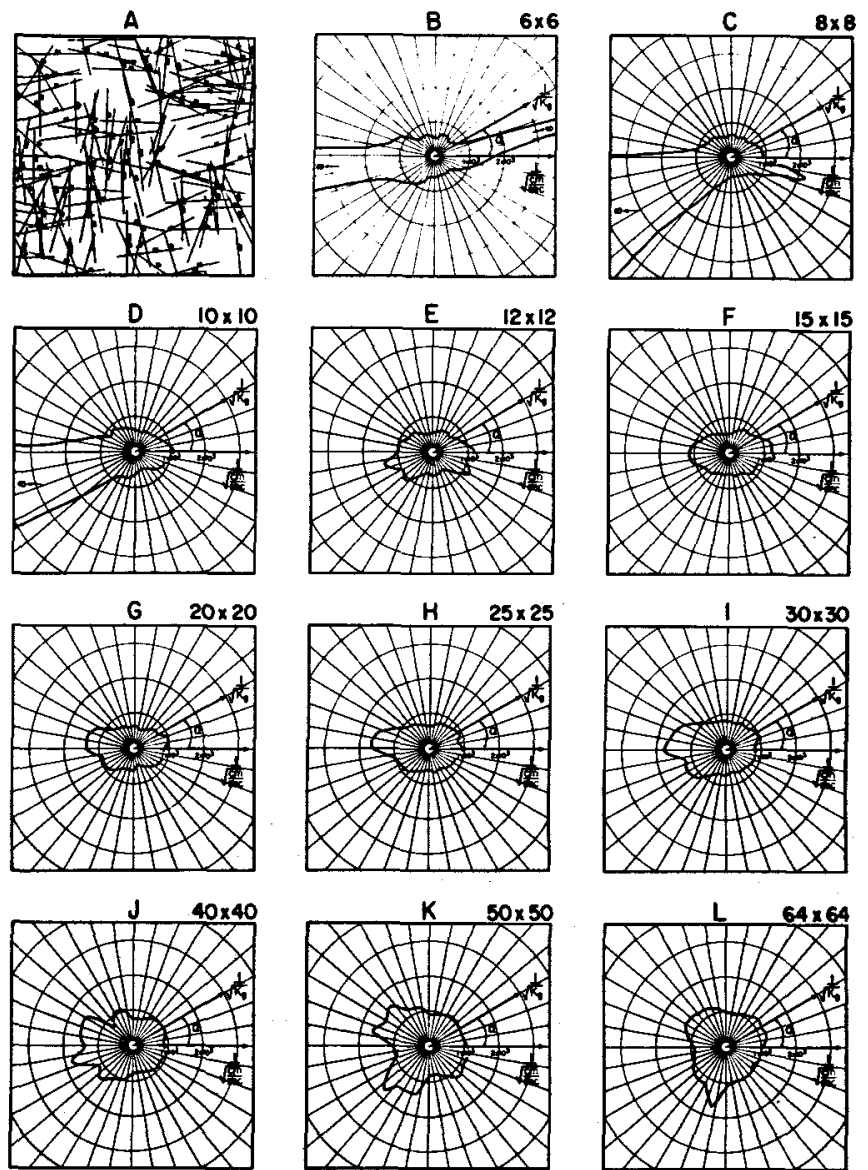

Figure 3. Fracture generation region (A) used to produce permeability plots B to L for flow regions of increasing size.

[XBL 813-2779] 
orthogonal sets with equal characteristics should have a roughly circular permeablitty plot. Random variations from the circle can be due only to insufficient density of fractures or insufficient sample size. Figure 3 (B to $L$ ) shows the permeability ellipses for the flow region of increasing size.

For Figure 3 (B) the results are erratic. Only a few fractures are included in the sample. Although in this figure most of the fractures transect the flow region, for certain values of the rotation angle no fractures intersect side 2 . Then the permeability is zero, and $1 / \sqrt{\mathrm{R}_{\mathrm{g}}}$ is infinite. In Figure $3(\mathrm{~F})$, for a $15 \times 15$ mesh, a fairly regular symmetric ellipse is obtained. For this flow region size, many of the fractures transect the entire flow region. However, the ellipse in Figure $3(F)$ is not circular, as expected. Further increase in sample size causes oscillation in the form of the permeability ellipse. As more fractures are gradually added to the sample, the effect of each fracture is to deform the ellipse in some way. However, the trend from $B$ to $L$ is toward the expected circular ellipse.

\section{CONCLUSION}

The techniques described here can be used to direct the emphasis of field testing programs designed to obtain fracture geometry data. Such field tests are currently under development (Doe and Remer, 1980). The numerical model can provide information on the sensitivity of permeabllity to the individual geometric parameters. In this way appropriate fleld tests can be identified. As these field tests are perfected, it will become attractive to extend this model to three dimensions. A three-dimensional model will allow geometric field data to be interpreted in terms of complete permeability tensors.

\section{REFERENCES CITED}

Baecher, C. B., and Lanney, N. A., 1978. Trace length biases in joint surveys. Proceedings, 19th U. S. Symposium on Rock Mechanics, p. 56-65.

Caldwell, J. A., 1972. The theoretical determination of the permeability tensor for jointed rock. Proceedings, Symposium on Percolation Through Fissured Rock, stuttgart, International Society for Rock Mechanics and International Association of Engineering Geology, T1-CIT1-C6.

Doe, T., and Remer, J., 1981. Analysis of constant head well tests in nonporous fractured rock. In T. Doe and $w$. Schwarz (eds.), 3rd Invitational Well-Testing Symposium, well Testing in Low Permeability Environment." Lawrence Berkeley Laboratory Report LBL-12076, p. 84-89.

Hubbert, M. K., 1956. Darcy's law and the field equations of the flow of underground fluids. Petroleum Transactions, AIME, v. 207, p. 222-239.

Long, J. C. S., Remer, J. S., Wilson, C. R., Witherspoon, P. A., 1981. Porous media equivalents for networks of discontinuous fractures. Water Resources Research, in press.

Parsons, R. W., 1966. Permeability of idealized fractured rock. Soclety of Petroleum Engineers Journal, v. 10, 126-136.

Rocha, M., and Franciss, F., 1977. Determination of permeability in anisotropic rock masses from integral samples. In W. J. Hall (ed.), Structural and Geotechnical Mechanics. New York, Prentice-Hall, p. 178-202.

Snow, D. T., 1965. A parallel plate model of fractured permeable media (Ph.D. dissertation). Dept. of civil Engineering, University of California, Berkeley, $331 \mathrm{p}$.

Veneziano, D., 1979. Probabilistic model of joints in rock, civil Engineering Dept., Mass. Inst. Technology, unpublished MS, 47 p.

wilson, C., 1970. An investigation of laminar flow in fractured porous rocks (Ph.D. dissertation). Dept. of Civil Engineering, University of California, Berkeley, $178 \mathrm{p}$. 


\title{
DETERMINING SIZE AND INTERCONNECTION OF FRACTURES FROM CONSTANT-HEAD WELL TESTS
}

\author{
T. Doe and $H$. Endo
}

The ability of low-permeability rock to transmit water is determined by the interconnection of the fractures in the rock. The degree of interconnection is related to the basic geometric parameters of the fracture system-orientation, aperture, density (number of fractures per unit volume), and fracture area. In borehole exploration the orientation, density, and, to some extent, the aperture can be obtained from the core or from well logs, such as television or televiewer logs. Fracture area, however, cannot be determined from any of these techniques. Even where underground openings are available, the areas of the fractures may be sufficiently large that the trace lengths exceed the dimensions of the tunnels.

The purpose of this program was to see if information on the areas, apertures, and interconnections of fractures could be obtained from well tests. Although the thrust of the work was toward single fracture tests, the results are applicable to test zones containing several fractures, as one should expect that the largest fracture in any given test zone will dominate the test behavior. A further objective was to see if conventional radial-flow well-test solutions could be applied to rock in which the flow conduits are finite fractures.

TRANSIENT FLOW-RATE ANALYSIS OF CONSTANT-BEAD WELL TESTS

The constant-head injection well test was chosen for detailed investigation for the following reasons:

1. It is the most extensively used test in nearly impermeable fractured rock.

2. There is no well bore storage (an advantage over standard pump tests).

3. There is no influence of elastic deformation of equipment (an advantage over pulse tests).

4. It can be conducted rapidly in low-permeability rock.

The constant-head injection test, known in civil and geological engineering as the Lugeon test, or packer test, is commonly analyzed by assuming that steady flow has been achieved (zeigler, 1976). This is equivalent to assuming the unrealistic condition that the fracture or aquifer has an open boundary at some radius from the well.

To avoid the limitations of steady-flow methods, we have developed transient flow-rate techniques analogous to the transient pressure techniques of standard constant-rate well tests for single fractures. Our first step has been to show that for the purposes of well-test analysis, a single fracture is like a confined porous aquifer except that the transmissivity, $T$, and the storativity, S, are defined as

$T=\rho g \frac{e^{3}}{12 \mu}$

where $\rho=$ fluid density, $g=$ gravitational acceleration, $\mu=$ kinematic viscosity, $e=$ fracture aperture, and

$s=\rho g\left(\frac{1}{k_{n}}+e \beta\right)$.

where $k_{\mathbf{n}}=$ fracture normal stiffness and $B=$ fluid compressibility. As in porous media, the first term in the parentheses of equation (2) represents the contribution of rock deformability, and the second reflects fluid compressibility. Because the values of fracture aperture are small, the fracture stiffness term should be predominant.

Type curves for analyzing constant-head tests have been developed for infinite features (Jacob and Lohman, 1952), for open or closed boundaries (Hantush, 1959; Ehlig-Economides, 1979; Uraiet, 1979), and for leaky aquifers (Hantush, 1956). The key to determining fracture area is to find deviations from the infinite type curve. Steady flow after a transient decline indicates either an intersection with an open boundary, such as a large fracture or shear zone, or leakage into the intact rock, if the rock is sufficiently permeable. A steep decline in flow along a closed boundary type curve may indicate that the fracture is finite. The size of the fracture can then be determined from the time elapsed before the flow deviates from the infinite type curve.

The standard open, closed, or infinite boundary conditions, however, may not be sufficiently accurate representations of actual fractures. The possible geometry of fractures intersecting a well is shown in Figure 1. Fracture "A" is a finite fracture with no intersection with other fractures, and should yield a flow-rate curve with closed boundary characteristics. Fracture " $B$ " has an intersection with another fracture "C." If the fracture intersected has a larger aperture than "B," then it may act as an open boundary, however, the resulting geometry of the boundary of " $B$ " is a mix of open and closed conditions. Transient flow-rate curves for fractures with these partially open boundaries have been studied numerically. Flow in fractures with a large portion of their boundaries open behave as fractures with completely open boundaries, whereas flow in fractures with small portions open show a slight decline from the infinite curve before becoming steady. Our results show 


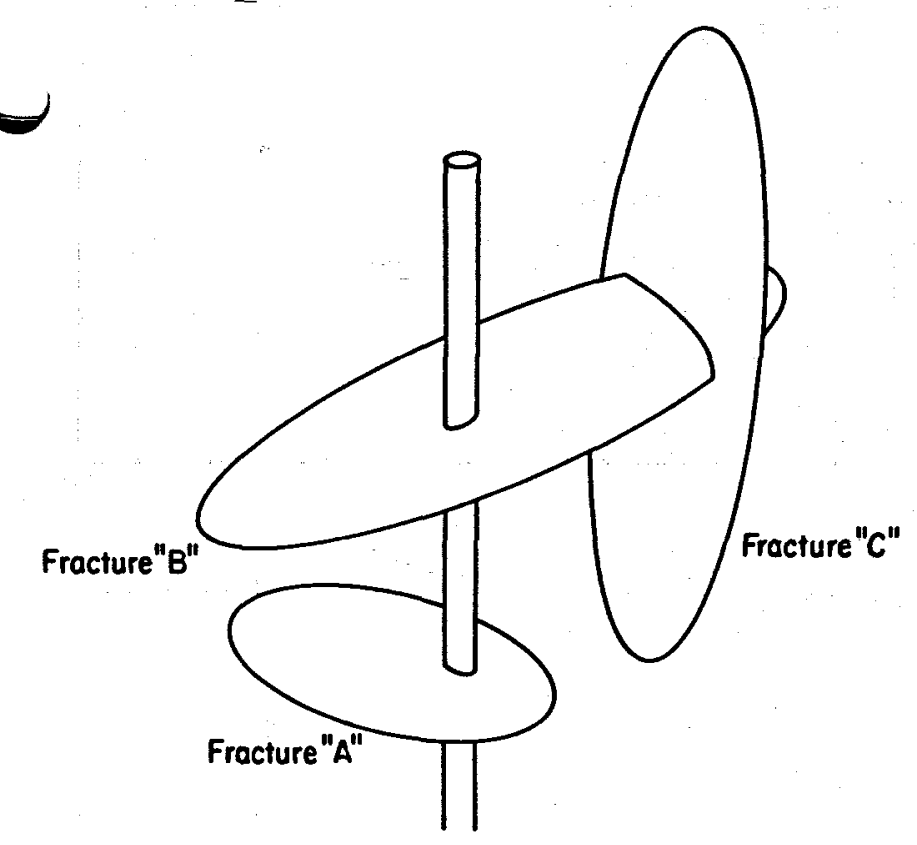

Figure 1. Hypothetical finite area fractures intersecting a well.

[XBL 819-7432]

that the steady flow from a fracture with 258 of its boundary open is reduced by only about 108 compared with a completely open fracture, whereas a 12.58 open boundary reduces flow by 508 (Fig. 2).

Additional work has been done using the numerical models of partially open fractures to investigate the effects on the flow-rate curve of aperture variabllity within single fractures. Initial results indicate that the presence of flow channels within the fracture do not alter the form of the flow-rate curve but do have a strong effect on the flow magnitude.

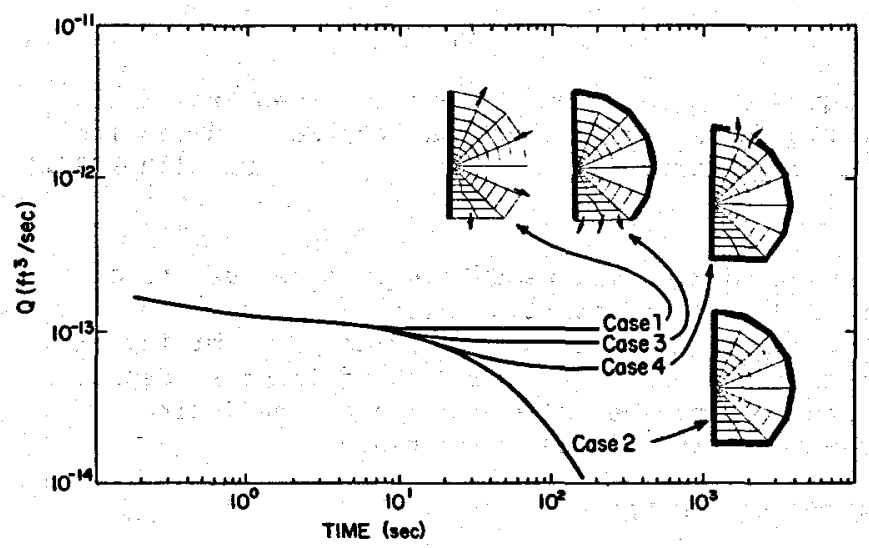

Figure 2. Transient flow-rate curves for partial1y open fractures: case 1 , open outer boundary; case 2, closed outer boundary; case 3, 258 open boundary; case $4,12.58$ open boundary.

[XBL 8112-12929]
On the basis of our theoretical studies, we have defined a three-part transient flow-rate curve which one might expect from injecting a single fracture. The first part we term the infinite stage (Fig. 3a), which Indicates the fiow that occurs before the pressure front intersects any fracture boundaries. The infinite curve match yields data on the transmissivity and storativity of the fracture, which can then be used to calculate aperture and fracture stiffness. The second stage of the curve shows the decline of flow that occurs when the pressure front reaches the boundary of the finite fracture. This portion of the curve, termed the depletion stage, is used to calculate the distance to the fracture boundary (Fig. 3b). In the final stage, leakage (Fig. $3 c)$, the flow becomes steady, either from intersection with another more permeable fracture or from leakage into the intact rock. This portion of the curve can be used to qualitatively assess the fracture interconnection or, if there is reason to suspect that the steady flow is caused by leakage into the rock, to calculate the intact rock permeability.

\section{FIELD TESTS}

A series of eleven constant-head injection tests were run in a 90-ft-deep borehole at the Raymond Granite Company quarry near Fresno to test the constant-head techniques described above. Much of the transient behavior associated with the fracture boundaries can occur within tens of seconds of the start of a test. We therefore designed and assembled a field system for capturing early transient flow-rate data. The system is shown schematically in Figure 4 and includes the following components:

1. Downhole pressure measurement system.

2. Pneumatic downhole shut-in valve for instantaneous application of constant head.

3. Mini-computer system for real-time data reduction and graphic display.

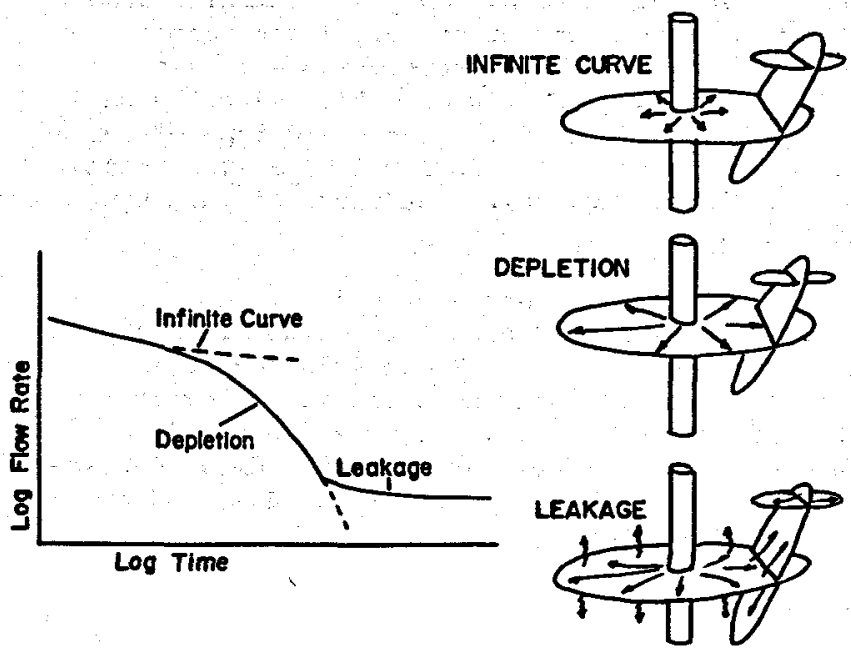

Figure 3. Three stages of transient flow-rate curve in finite fractures.

[XBL 8110-12126] 


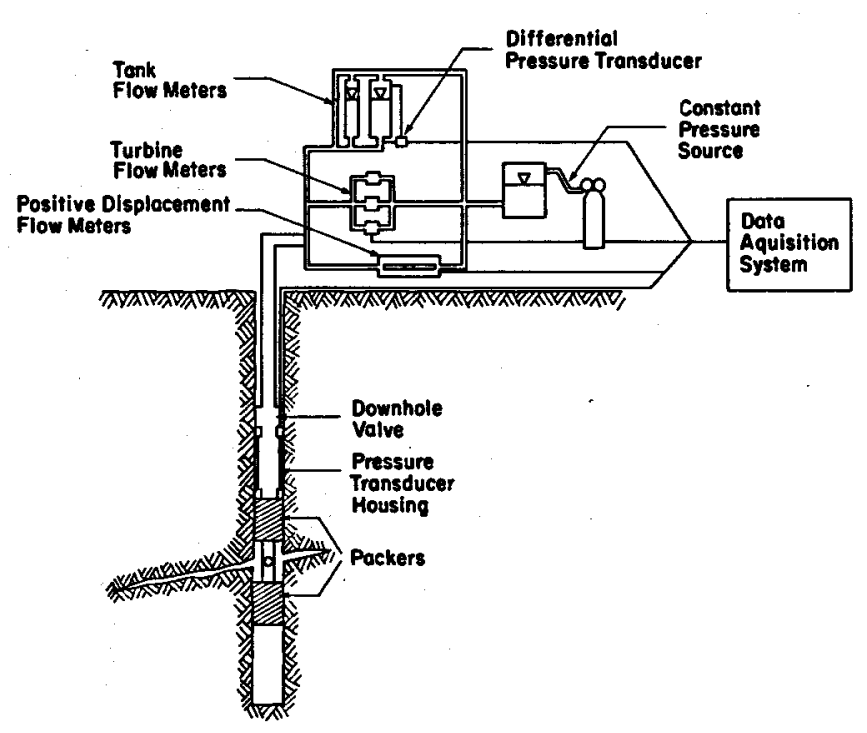

Figure 4. Schematic diagram of equipment for performing low-flow-rate, constant-head injection tests.

[XBL 8110-12129]

4. Turbine flow meter system for rates between 0.001 and $5 \mathrm{gpm}$.

5. Positive displacement flow meter for rates of $10^{-5}$ and $10^{-3} \mathrm{gpm}$ and lower.

Three types of transient flow-rate curves were found in the field tests. The first included all three parts of the curves shown in Figure 3. In some cases the magnitude of the drop in flow in the depletion portion of the curve suggested that the subsequent leakage might be due to flow into the intact rock. Calculations based on leakage coefficient values obtained from type curve matches gave reasonable values of intact rock permeability. For fractures with large surface areas, the flow into the fracture face can become comparable to the radial flow from the well into the fracture. An example of this first type of flow-rate curve is shown in Figure 5a. A second type of curve had only the infinite stage followed by the leakage stage. These results may have indicated either intersection with a more permeable fracture or intersection with the walls of the quarry (Fig. 5b). The third type of curve began with steady flow followed by a slow transient decline (Fig. 5c). The cause of this type of behavior is not clear.

Calculated fracture apertures ranged from 0.013 to $0.12 \mathrm{~mm}$. Storativity values lay between $4 \times 10^{-8}$ and $8 \times 10^{-6}$. These values correspond to fracture stiffness values of $10^{3}$ to $10^{5} \mathrm{MPa} / \mathrm{mm}$. Of the five tests which could be interpreted for area, three tests indicated fracture radii of $0.4 \mathrm{~m}$, one was about $4 \mathrm{~m}$, and one was about $400 \mathrm{~m}$.

\section{CONCLUSIONS}

Constant-head injection tests can be interpreted to yield information on fracture area, aperture, stiffness, and possibly permeability of
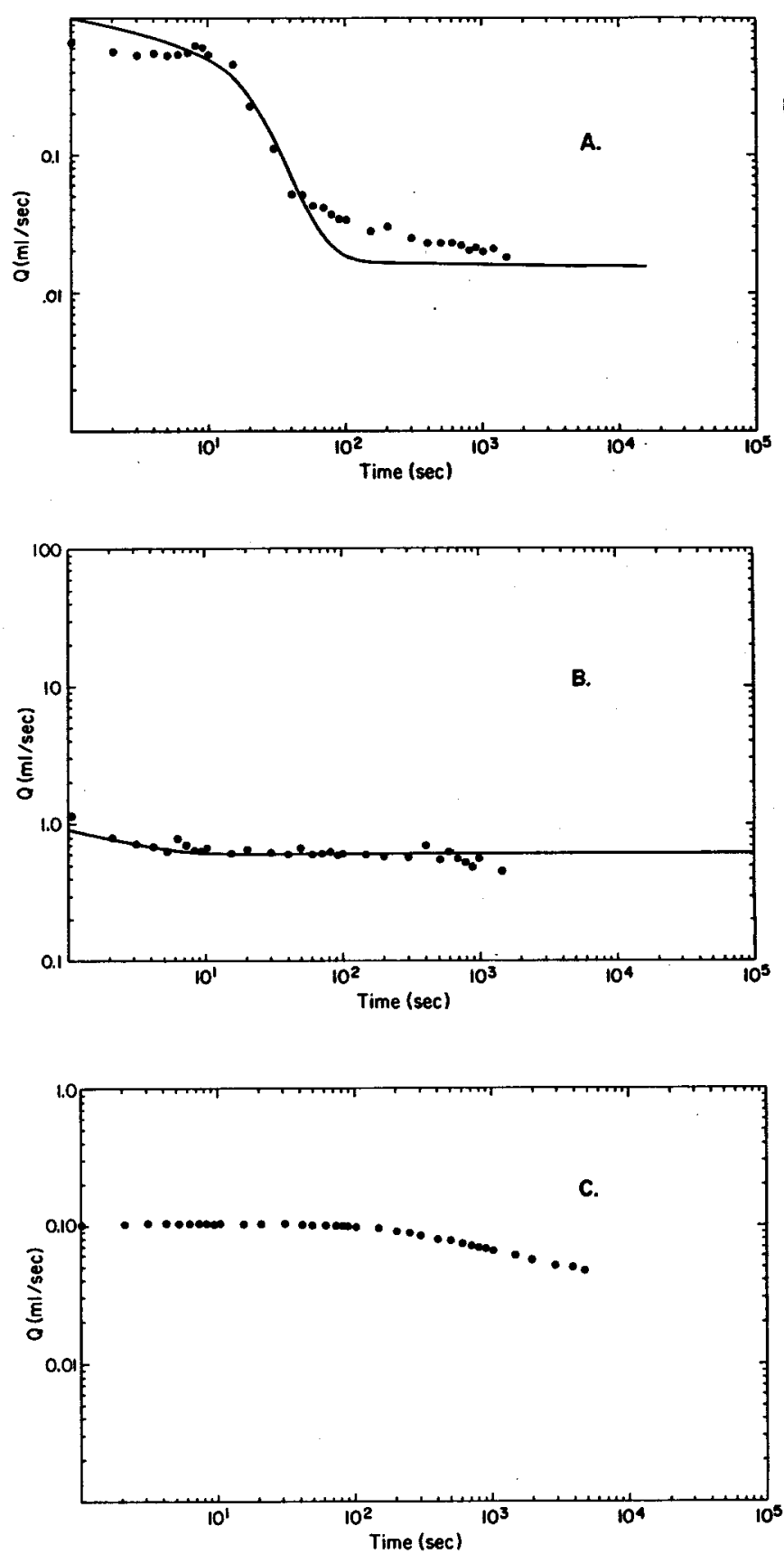

Figure 5. Transient flow-rate curves from field tests on single fractures at the Raymond Granite Company quarry.

[XBL 8112-12932]

intact rock. Well tests can thus be used to obtain data on fracture geometry away from the borehole. Attempts to determine permeability of rock masses from measurements of fracture density alone may not be valid because of the finite nature of individual fractures.

\section{REFERENCES CITED}

Ehlig-Economides, C., 1979. Well test analysis for wells produced at constant pressure (Ph.D. dissertation). Department of Petroleum Engineering, Stanford University, Stanford, California, $117 \mathrm{p}$. 
Hantush, M. S., 1956. Analysis of data from pumping tests in leaky aquifers. Transactions of the American Geophysical Union, v. 37, p. 702-714.

Hantush, M. S., 1959. Non-steady flow to flowing wells in leaky aquifers. Journal of Geophysical Research, v. 64, p. 1043-1052.

Jacob, C. S., and Lohman, S. W., 1952. Non-steady flow to a well of constant drawdown in an extensive aquifer. Transactions of the Aner 1- can Geophysical Union, v. 33, p. 559-569.

Uraiet, A., 1979. Transient pressure behavior in a cylindrical reservoir produced by a well at constant bottom hole pressure (Ph.D. dissertation) . Department of Petroleum Engineering, University of Tulsa, Oklahoma, $157 \mathrm{p}$.

zeigler, T., 1976. Determination of rock mass permeability. U. S. Army Eng ineer haterways Experiment Station Technical Report, 5-76-2, 85 p.

\title{
DEVELOPMENT OF A COUPLED THERMAL-HYDRAULIC-MECHANICAL FINITE- ELEMENT MODEL FOR SATURATED FRACTURED POROUS MEDIA
}

\author{
J. Noorishad, J. S. Y. Wang, C. F. Tsang, and P. A. Witherspoon
}

Investigations over the past decade at the University of California, Berkeley, and Lawrence Berkeley Laboratory have led to the development of numerical models capable of analyzing the coupled hydraulic-mechanical behavior of rock masses (Sandhu and Wilson, 1969; Ghaboussi and wilson, 1971; Noorishad et al., 1971, Ayatollah1, 1978; Noorishad et al., 1981). Employing the most recent results (Noorishad et al., 1981) it is now possible to investigate the coupled hydromechanical response of saturated fractured porous rocks subject to fluid-flow or structural-load boundary conditions.

Recent concerns about the safe disposal of radioactive wastes in geologic systems calls for simultaneous consideration of hydromechanical, hydrothermal, and thermomechanical effects in the designs of selected repositorles. In view of this fact, and as a natural outgrowth of earlier studies, work has been underway to develop an approach to the thermal-hydraulic-mechanical behavior of fractured rocks (Noor ishad and witherspoon, 1981; Witherspoon et al., 1981). The essential features of this coupled finite-element method are presented below.

\section{FUIDAMENTALS}

The fundamental laws governing static equilibrium, fluid flow, and heat flow are coupled through the dependent variables of the solid displacement vector, fluid pressure, and macroscopic medium temperature (Biot, 1940, witherspoon et al., 1981). These laws, in conjunction with constitutive equations, provide the complete mathematics of the coupled quasilinear, therma1-hydraulic-mechanical phenomena in saturated porous elastic media. These equations, with proper initial and boundary conditions, define the mixed-initialboundary-value problem for thermal-hydraulic-mechanical phenomena in unfractured porous media. Extension of the study of these phenomena to Dorous fractured rocks has been based on the same indamentals, and the nonlinearities brought about by the presence of fractures is handled by the stiffness perturbation technique.
METHOD OF SOLUTION

The complexity of the hydrothermoelasticity equations is such that an analytic (mathematical) solution for even simple initial- and boundaryvalue problems is not likely to be found. However, numerical solutions to the most general problems can easily be sought. Various numerical schemes using well-known numerical techniques, such as finite-element and finite-difference, can be utilized. In this work a finite-element technique was given strong preference because of prior success with this approach to linear and nonlinear problems of hydroelasticity (Ayatollahi, 1978; Noorishad et al., 1981). A mixed variational and Galerkin finite-element method forms the basis of this approach. As a result, a set of three matrix equations is obtained relative to each of the three phenomena involved.

To handle discretization in the time domain, two different schemes of time integration are used to integrate the matrix equations. A predictorcorrector scheme (Taylor, 1974) is used for the integration of the implicitly coupled hydromechanical equations (Ayatollahi et al., 1981), and the energy equation uses a Crank-Nicholson step-bystep procedure with the solution of each time step being sought in the midale of the interval.

The coupling of the flow equation to the energy equation is nonlinear and is implicitly expressed in the nonsymmetric convective thermal conductivity matrix. The large time constant for the energy equation as compared to that of the flow equation suggests that the above formulation is easily adapted to an interlacing scheme of solutions such as used by sorey (1975). This interlacing scheme uses the fluld velocities obtained from a direct solution of the hydromechanical equations and feeds back the temperature resulting from a solution of the energy equations. This approach of explicitly solving the coupled equations is enhanced by the low sensitivity of the dependent variables, pressure and displacement, within some ranges of temperature in different problems. Therefore, the energy equation in these ranges can march through time using 
large time steps compared to the small time steps required to solve the other two equations. A further advantage is gained in situations where the mass transfer contribution to temperature distribution is negligible. In these cases a single solution for the energy equation provides the needed temperature information for the stepwise solution of the other two equations.

Three types of elements are used in this coupled technique: (1) two-dimensional isoparametric elements for solid fluid mixtures, (2) one-dimensional elements representing fracture gegments from the flow point of view, and (3) one-dimensional joint elements to represent fracture segments for structural considerations. Natural coordinates are used for discretization of the displacement, pressure, and temperature fields within the quadrilateral element. This leads to a parametric formulation for the corresponding integrals in terms of coordinate parameters for the porous solid-fluid mixture elements. Numerical integration is performed using the Gauss quadrature formula. The isoparametric bilinear function used for discretization and the parametric details can be found in finite-element texts (zienkiewics, 1971). For the structural-joint element and the flow-line element, discretization of the displacement and pressure fields is written in terms of local coordinates. Where necessary, the results are transformed to the global coordinate system. The assumption of uniform aperture within each fracture was used throughout the derivation of the matrices involving fracture-volume integrals.

\section{VALIDATION OF NUMERICAL SCHEME}

The complexity of the coupled phenomena under consideration makes it possible to present only a partial verification of the method of analysis presented here. In the following discussion, we include results of the application of the method to hydromechanical, thermomechanical, and hydrothermal problems. These examples do not fully reveal the power of this approach.

\section{Hydromechanical Problem}

In choosing an example of a hydromechanical problem, we examined a fracture-flow problem for which an analytical solution exists (Raghaven et al., 1976). Since this problem does not require coupling between fluid flow and rock deformation, the coupling coefficient was set to zero. The problem is that of a single vertical fracture intersecting a well of zero radius in a rectangular porous medium. The fracture is assumed to be rigid and of very high conductivity. The material properties of the fluid and rock are given in Witherspoon et al. (1981). Figure 1 shows the finite-element mesh used, and Figure 2 shows how the numerical results compare with the analytical solution (Raghavan et al., 1976). For the case $x_{D}=1$, there is excellent agreement over the whole time span. In the case $X_{D}=3$, the differences noted in Figure 2 between numerical and analytical solutions is attributed to the coarseness of the finite-element mesh. The half-slope of the curve for $P_{D}$ versus $t_{D}$ at early time is often used as evidence in the petroleum literature

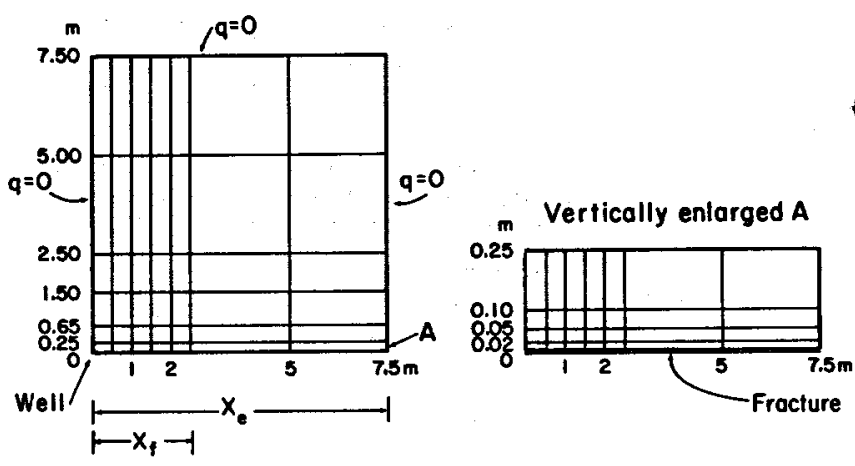

Figure 1. Two-dimensional finite-element mesh. [XBL 806-7222]

for the presence of a fractured system (Gringarten et al., 1975).

This problem was also solved in a coupled mode in which deformability was introduced for both fracture and matrix. The fracture was also given a specific aperture $\left(10^{-4} \mathrm{~m}\right)$ so that it had a finite permeability. The effect of treating the system in this fashion is to change the pressure drawdowns significantly. For example, Figure 3 shows how pressures decrease from the wellbore to the end of the vertical fracture. It will be noted that the pressure drop at the end of the fracture is about half that at the wellbore. For comparison, the problem was rerun in a decoupled mode, and the pressure differences proved to be far less (see curve labeled "fluid flow analysis" on Fig. 3).

\section{Thermomechanical Problem}

To demonstrate the ability of the code to handle nonlinearities, a simple thermomechanical problem was chosen that consists of a long column of rock intersected near its base by a fracture (see inset on Fig. 4). Initially, the column temperature is $0^{\circ} \mathrm{C}$; after a step increase of $50^{\circ} \mathrm{C}$ at

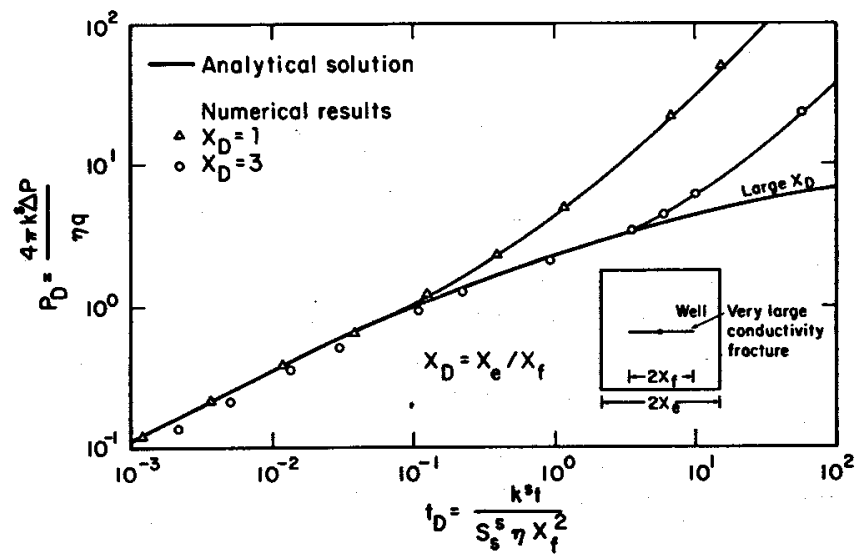

Figure 2. $P_{D}$ versus $t_{D}$ for single vertical fracture of very large conductivity in porous media. Analytical solution after Raghavan et al. (1976). 


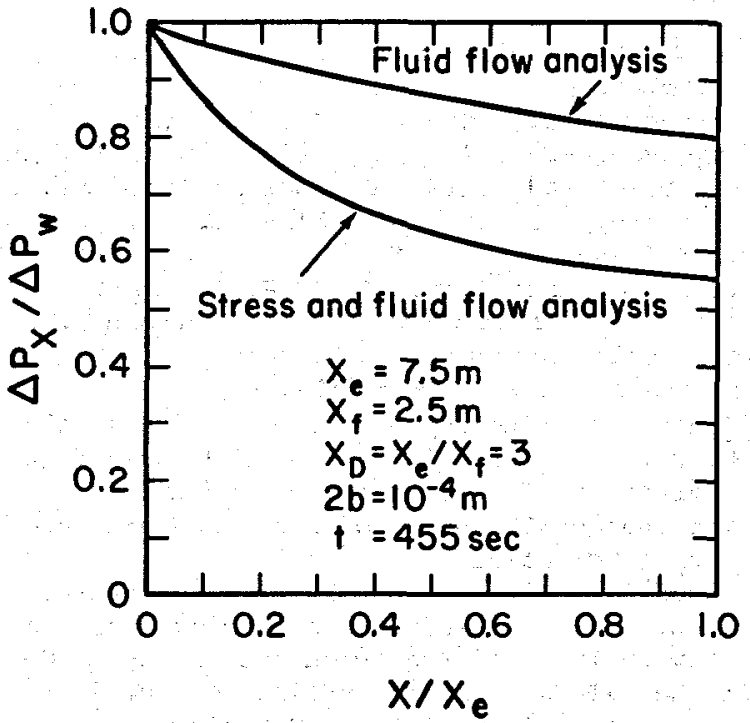

Figure 3. Pressure drops along vertical fracture of finite conductivity in porous media, showing differences between analyses based on fluid flow alone or on both coupled stress and fluid flow.

[XBL 813-2705]

the base, the problem is to determine the time variation of displacements above the fracture at a height of $10 \mathrm{~m}$. The material properties of the rock are given in witherspoon et al. (1981). $\therefore$ Figure 4 shows the highly nonlinear mechanical behavlor of the fractured column and illustrates the ability of this finite-element method to model discontinuous rock systems.

\section{Hydrothermal Problem}

An interesting problem that demonstrates only part of the hydrothermal capabilities of this code is the simulation of a saturated porous medium that is given a momentary thermal front. "The onset of convective motion due to buoyancy is to be determined. The physical system consists of two porous reservoirs that initially are kept at temperatures $T_{0}$ and $T_{1}$, as illustrated by the inset

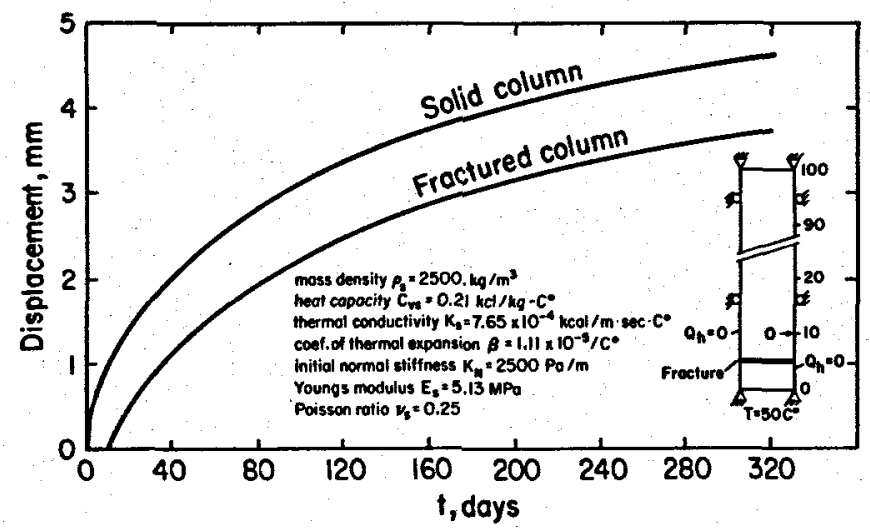

Figure 4. Displacement versus time at a point $10 \mathrm{~m}$ above base of rock column, showing effect of fracture in reducing movement.

[XBL 813-2700] in Figure 5. Initially, a thermal barrier separates the two reservoirs, both of which are horizontally semi-infinite and insulated top and bottom. At $t=0$, the barrier is removed, and the problem is to determine the instantaneous horizontal velocity profile along the thermal front. An analytical solution for this problem has been published by Cleasson (1979).

This particular problem is very sensitive to the finite-element mesh that is selected, and some effort was required to achieve the optimum grid for a specific number of nodal points. The problem was solved with a network of 252 elements requiring 286 nodal points. The material properties of the fluid and the porous medium are given in wither spoon et al. (1981).

Figure 5 shows a comparison of the numerical results for the instantaneous normal (horizontal) velocities compared with those of the analytical solution of cleasson (1979). Considering the fact that in the numerical approach the thermal front must be modeled by a zone of finite width, which In our case was $0.4 \mathrm{~m}$, the agreement is quite good. Further mesh refinement would undoubtedly lead to closer agreement with the analytical solution.

\section{SUMMARY}

An extension of Biot's (1940) theory of consolidation is proposed here to provide a new technique for a realistic method of investigating the thermal-hydraulic-mechanical behavior of fractured porous media. A direct-solution process has been developed that involves a variational formulation and a Galerkin integral to produce a set of three matrix equations. In this approach the equations of static equilibrium and fluid flow appear in an implicitly coupled form, and the energy equation is explicitly coupled to these equations. Finiteelement discretization, along with two schemes for time discretization, yield the final form of the matrix equations, which are then solved in a twostep procedure referred to as an interlacing scheme.

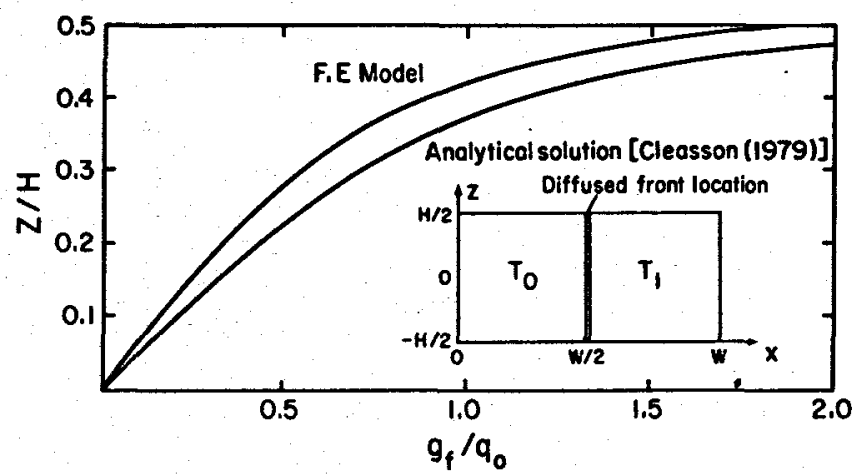

Figure 5. Profile of instantaneous horizontal velocities due to buoyancy effects at location of thermal front in saturated porous media. Analytical solution after Cleasson (1979).

[XBL 813-2701] 
A partial validation of this new technique is presented by considering applications to hydromechanical, thermomechanical, and hydrothermal problems. The hydromechanical problem involves the calculation of pressure drops in a vertical fracture that intersects a well and acts as a drain for the surrounding porous medium. The results reveal the errors that can occur when the interaction between hydraulic and mechanical stresses is ignored. The thermomechanical problem involves calculating the expansion of a rock column with a heat source placed at one end. When a fracture exists between the location of the heat source and a point where one is attempting to predict the magnitude of thermally induced displacements, a highly nonlinear behavior results that will not be predicted if one ignores the existence of the discontinuity. The hydrothermal problem involves a saturated porous medium that is given a momentary thermal front. The difficulty in predicting the onset of a natural convective motion can be handled by this new technique when the appropriate finite-element mesh is selected. Complete validation of this new thermal-hydraulic-mechanical finite-element model for saturated fractured porous media will require further study.

\section{REFERENCES CITED}

Ayatollahi, M. S., 1978. Stress and flow in fractured porous media (Ph.D. dissertation). Dept. of Materials Science and Mineral Engineering, University of California, Berkeley.

Ayatollahi, M. S., Noorishad, J., and Witherspoon, P. A., 1981. A finite-element method for stress and fluid flow analysis in fractured rock masses. Submitted to Journal of Engineering Mechanics Div., ASCE.

Biot, M. A., 1940. General theory of three-dimensional consolidation. Journal of Applied Physics, v. 12, p. 155-164.

Cleasson, J., 1979. Notes on ground water thermohydraulics. Report, Dept. of Mathematical Physics, Lund, Sweden.

Ghaboussi, J., and Wilson, E. L., 1971. Flow of compressible fluids in porous media, SESM
Report No. 72-12, University of California, Berkeley.

Gringarten, A. C., Ramey, B. J., Jr., and Raghavan, R.. 1975. Applied pressure analysis for fractured wells. Journal of Petroleum Technology, Transactions AIME, v. 259, p. 887-892.

Noor ishad, J., and witherspoon, P. A., 1981. Hydrothermoelasticity Part 1: Fundamentals and analysis approach. Lawrence Berkeley Laboratory Report LBL-12354.

Noorishad, J., Witherspoon, P. A., and Ayatollahi, M. S.. 1981. Coupled stress and fluid flow analysis of fractured rocks. Submitted to International Journal of Rock Mechanics and Mining Sciences.

Noorishad, J., Witherspoon, P. A., and Brekke, T. I. 1971. A method for coupled stress and flow analysis of fractured rock masses. Geotechnical Engineering Publication No. 71-6, University of California, Berkeley.

Raghavan, R., Uraiet, A., and Thomas, G. W., 1976. Vertical fracture height: Effect on transient flow behavior. Paper presented at 51st SPE-AIME meeting, New Orleans, October 3-6.

Sandhu, R. S., and Wilson, E. L., 1969. Finite-element analysis of seepage in elastic media. Journal of Engineering Mechanics, Division ASCE, v. 95, no. EM3, p. 641-652.

Sorey, M. L., 1975. Numerical modeling of liquid geothermal systems (Ph.D. dissertation). Dept. of Civil Engineering, University of California, Berkeley.

Taylor, R. L., 1974. Analysis of flow of compressible or incompressible fluids in porous elastic solids. Consulting report to the Naval Civil Engineering Laboratory, Port Hueneme, California.

Witherspoon, P. A., Tsang, Y. W., Long, J. C. S., and Noorishad, J.. 1981. New approaches to problems of fluid flow in fractured rock masses. Proceedings, 22nd U. S. Symposium on Rock Mechanics, Mass. Inst. Technology, July, 1981.

Zienkiewics, O. C., 1971. The Finite Element Method in Engineering Science. New York, MCGraw-Hill Book Company. 


\section{ASSESSMENT AND EVALUATION OF ENGINEERING OPTIONS AT A LOW-LEVEL}

\section{RADIOACTIVE WASTE STORAGE SITE}

\section{B. Y. Kanehiro and V. Guvanasen}

This report summarizes work done at the Weldon Spring radioactive waste storage site. The primary purpose of this work has been to seek solutions to hydrologic and geotechnical problems associated with existing disposal sites and to evaluate the efficiency of engineering options that have been proposed to improve the integrity of such sites. The Weldon Spring site is generally like other low-level nuclear waste sites, except that the wastes are primarily in the form of residues and contaminated rubble from the processing of uranium and thorium ores rather than industrial isotopes or mill tailings.

The Weldon Spring project involves two disposal sites, as shown in Figure 1. The larger site, originally a quarry, is located beside the Missour1 River about $20 \mathrm{mi}$ west of St. Louis. The second site is a group of four raffinate pits that were used for disposal purposes at the Weldon Springs Chemical Plant, located approx 1mately $4 \mathrm{mi}$ east of the quarry.

At the present time the quariy site presents more pressing problems than the raffinate pits because of its proximity to a municipal well field, as shown in Figure 2 (Ranehiro et al., 1981). This well field supplies water for the area extending from Weldon Spring up to and including parts of the city of St. Charles. The nearest pumping well is approximately $3500 \mathrm{ft}$ from the quarry and is located hydraulically down gradient. There are other wells in the field that are closer to the quarry and could be used for pumping in the future. Because of the relative urgency of the problem at the guarry, the major portion of the effort in this project was focused on work at that site. Thus the scope of this report $w 111$ be 1 imited to those facets of the project related to the Weldon Spring quarry.

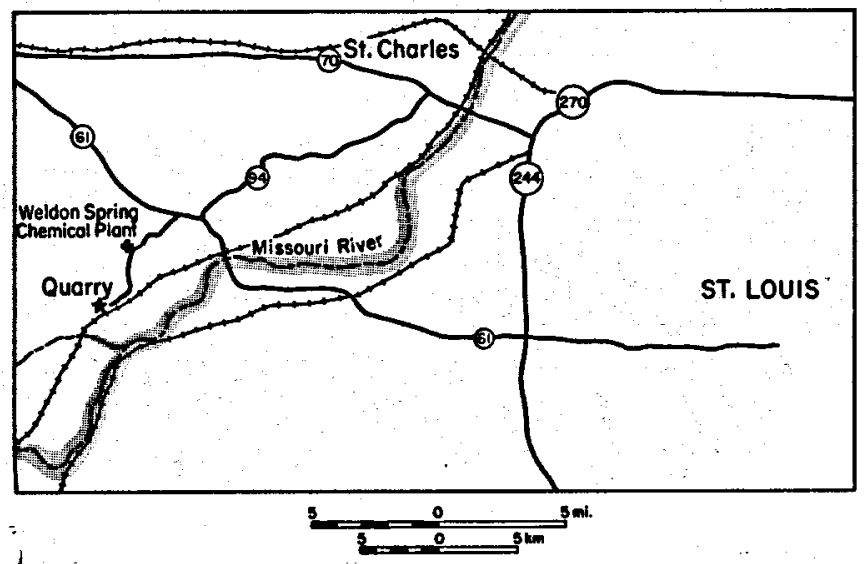

Figure 1. Iocation map of the Weldon Spring sites.

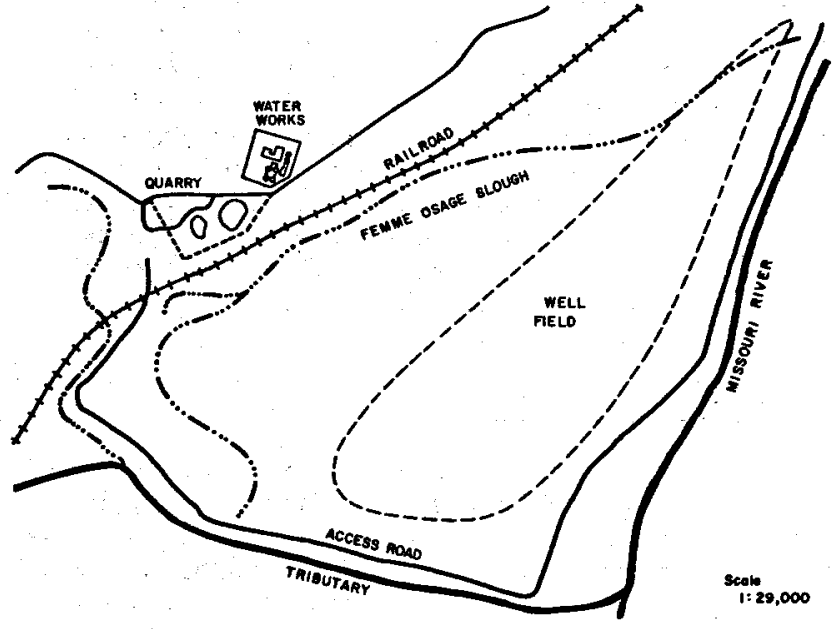

Figure 2. Location of the Weldon Spring Quarry with respect to the municipal well field and the Missouri River.

[XBL 813-2185]

The Weldon Spring Quarry site was acquired by the Atomic Energy Commission in 1958 and used for the disposal of radioactive waste during the 1960s. It had previously been used for the disposal of TNT-contaminated soils during the 1940s. The quarry site occuples 8.6 acres in an area between the Femme Osage Slough and the water works, as shown in Figure 2 .

\section{OBJECTIVES}

This project has three main objectives. The first is to characterize and assess the site. The second is to predict the future behavior of the site under existing conditions as well as under possibly differing conditions. The third is to evaluate the efficiency of the engineering options proposed for remedial action at the site.

\section{SITE CHARACTERIZATION AND PREDICTIVE ANALYSIS}

The realization of the first two objectives requires: (1) characterizing the geometry of the site with respect to topography, geology, and hydrologic boundaries; (2) characterizing the hydrologic and chemical properties of the geologic media found in and around the site--specifically, permeabilitles, storage coefficients, adsorptivities, dispersivities, and porosities; and (3) assessing the present conditions, Including an inventory of radioactive materials at the site and location of the present contaminant migration front. Since it is not practical to describe all of the work done at the site, an overview will be given under three headings: (1) site characterization, (2) forecasting related data, and (3) predictive analysis. 


\section{Site Characterization}

The characterization phase involves surface reconnaissance, drilling, collection and analysis of samples, and monitoring. The location and extent of geologic formations at the site were determined during surface reconnaissance and drilling. The shape of the piezometric surface and location of hydrologic boundaries were determined by monitoring wells drilled in and around the quarry. A radiological inventory of the waste materials was made from borehole samples taken within the quarry. The location of the migration front was determined from splitspoon samples taken at various depths during the drilling program and from water samples periodically taken from the wells.

\section{Forecasting Related Data}

Three types of data are required for predictive analysis: (1) boundary conditions, (2) initial conditions, and (3) material properties. As can be seen from the previous paragraph, the boundary conditions and the initial conditions are generally determined in the characterization phase of the project. The third category, material properties, includes permeability, storativity, porosities, diffusivities, and adsorption properties of the geologic media at the site. The determination of these properties required performing tests in both the fractured limestone (in which the quarry is located) and the alluvium between the quarry and the municlpal well field. Hyaraulic tracer and point dilution tests were run. The hydraulic tests included pumping one well and observing the response in other wells. This gave values of the permeability and storativity of the geologic media. The tracer tests consisted in injecting a tracer into the geologic formation through one well and observing its arrival in another well. In the case of fractured media, specific fractures were isolated in the injection well with the use of packers. The tracer tests were used to determine the porosity and diffusivity of the geologic media. Finally, point dilution tests were run by packing off a section in a well and injecting a fixed amount of tracer into this section. The natural flow of groundwater caused the tracer to move out of the isolated section of the well. The velocity of groundwater flowing through the geological formation was estimated by observing the decline in concentration of the tracer with time within the isolated section of the well.

\section{Predictive Analysis}

After the field data were collected, a model was used to organize the data and predict the future migration of contaminates from the site. The theoretical model consists of the standard convective dispersive equation (eq. 1) and the standard flow equation (eq. 2) for groundwater:

$\frac{\partial}{\partial x_{i}} D_{i j} \frac{\partial C}{\partial x_{i}}-\frac{\partial U_{i} C}{\partial x_{i}}=\frac{\partial C}{\partial t}-Q C_{i n^{\prime}}$

where $D_{i j}=$ the tensor of coefficients of hydrodynamic dispersion, $C=$ the solute concentra- tion, $v_{i}=$ the pore velocity in the $x_{i}$ direction, $Q=$ sources or sinks normalized with respect to the unit volume, $c_{i n}=$ the solute concentration of injected or abstracted fluid, $t=t i m e$, and $x_{i}=$ the Cartesian coordinates, and

$\frac{\partial}{\partial x_{i}} k_{i j} \frac{\partial h}{\partial x_{i}}=s_{s} \frac{\partial h}{\partial t}+Q$

where $K_{i j}=$ the hydraulic conductivity tensor, $h=$ the piezometric head, and $s_{s}=$ the specific storativity.

The velocity determined from the flow equation is coupled into the convective dispersive equation. The solution of the two equations of the theoretical model is accomplished through the use of computer codes. For this study two codes were used. The first is based on the generalized finite-difference schene (Kanehiro et al., 1980) and the second on the finite-element scheme (Guvanasen and Chan, 1980). Both codes can deal with anisotropic material properties. The generalized finite-difference code is three-dimensional and the finite-element code two-dimensional. Plan as well as cross-sectional models were developed for the Weldon Spring Quarry site. An example of one of the cross-sectional discretizations used is shown in Figure 3 , and examples of the results of cross-sectional and plan models are shown in Figures 4 and 5 .

\section{RESULTS}

The assessment phase of the project has shown that uranium is indeed migrating from the quarry in the direction of the well field. The location of the present uranium migration front corresponds roughly to the location of the Femne Osage slough (Fig. 2). The maximum concentration of uranium in the groundwater found outside the quarry is approximately $10 \mathrm{ppm}$. Analyses of water samples taken from the well field show no contamination at the present time.

Predictive analyses were run for two cases, a best case and a worst case. Each case was based

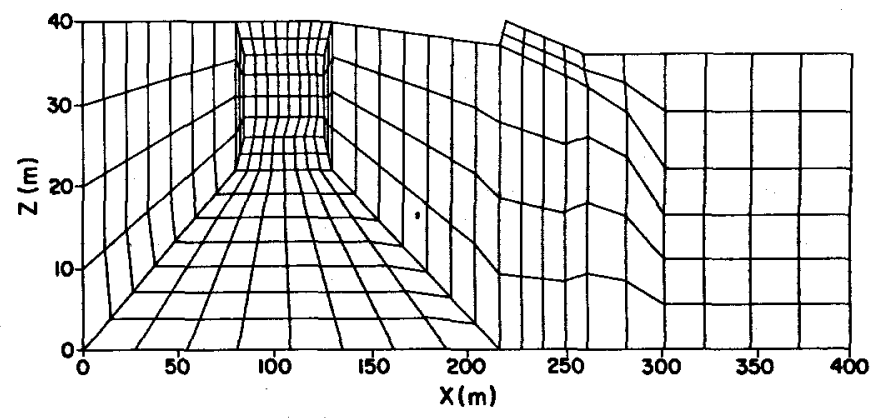

Figure 3. An example of a two-dimensional discretization used to model the Weldon Spring Quarry site. 
Concentration Contours (fraction of original concentration)

Time $=1.77 \times 10^{-8} \mathrm{sec}(5.6 \mathrm{yr})$

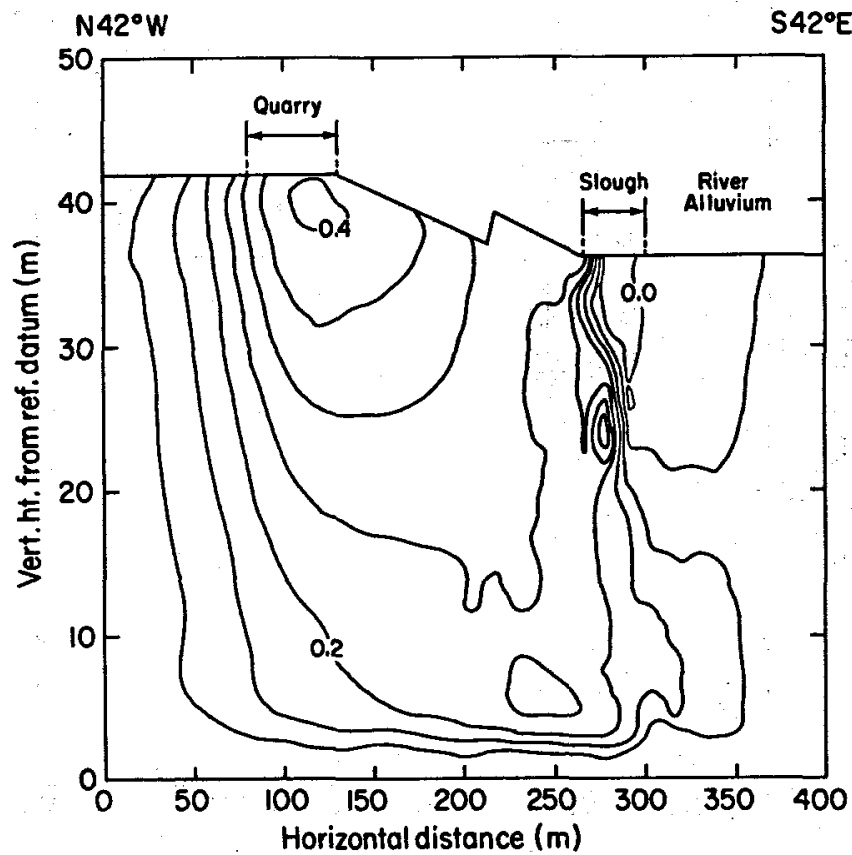

Figure 4. Results of cross-sectional modeling of the Weldon Spring Quarry site.

[XBL 821-1602]

Concentration Contours

(fraction of original concentration)

Time $=1.703 \times 10^{9} \sec (54.8 \mathrm{yr})$

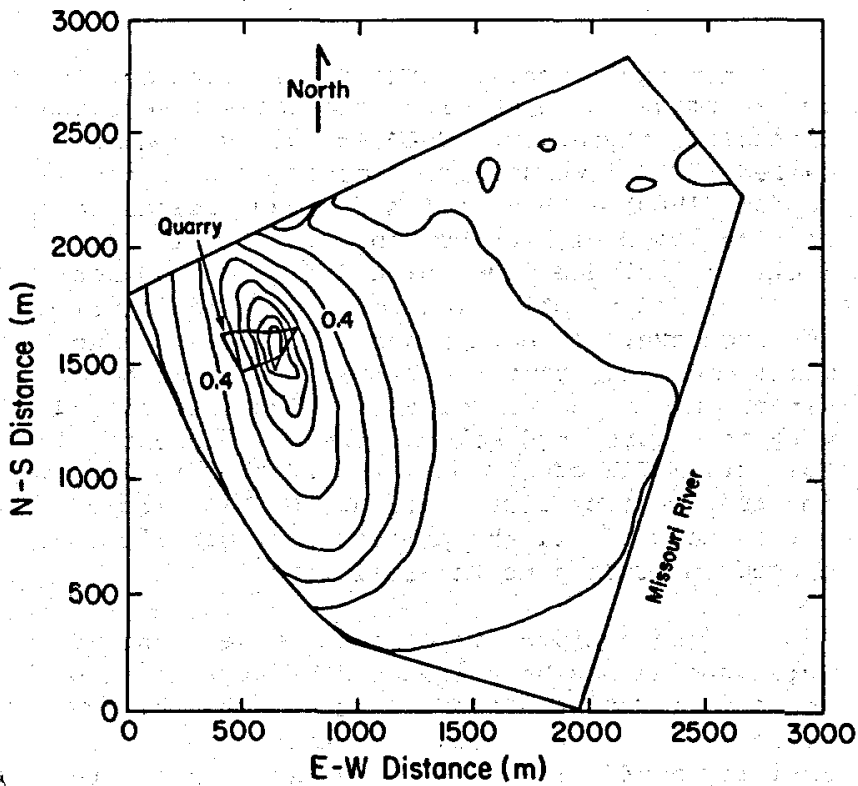

Figure 5. Results of plan model of the area around the Feldon Spring quarry site.

[XBL 821-1603] on the worst or best probable assumptions for areas where data on material properties are lacking. The worst case shows the uranium migration front approaching the well field in approximately three Years with a concentration of approximately $150 \mathrm{ppm}$. The best case shows the uranium migration front reaching the wells in approximately 300 years with a concentration of approximately $20 \mathrm{ppm}$. Additional field work would be required to narrow the range in these estimates.

\section{EVALUATION OF ENGINEERING OPTIONS}

The final phase of work at the Weldon spring Quarry site involved evaluation of engineering options proposed to Improve the integrity of the site (Ranehiro and Guvanasen, 1981). The options that have been considered include: (1) leaving the site as is: (2) removing as much of the original radioactive material as deemed practical by engineering considerations but leaving the site otherwise as is; (3) covering the radioactive materials in the quarry with a low-permeability material such as clay; and (4) entombing the materials. Option (4) may require an in situ fix of the material in addition to lining the quarry with a low-permeability material such as clay.

After a preliminary analysis of the above options, it became apparent that only option 4 would be suitable for the site. The primary reason for this is that the floor of the quarry is fractured limestone." Without some modification of the floor, it would be impossible to give any sort of assurance that the radioactive material would not find its way directly into an "undetected fracture" and migrate from the quarry at a relatively rapid rate.

A cross section of the entombment scheme used in the analysis of option 4 is shown in Figure 6.

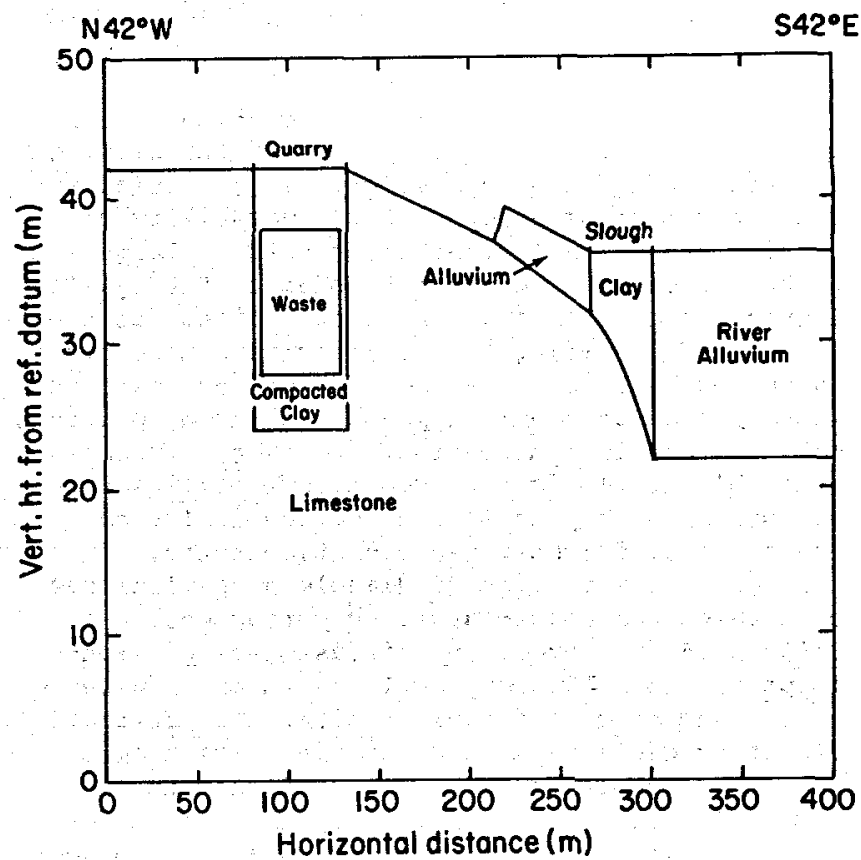

Figure 6. Cross section of the entombment engineering option for the Weldon Spring Quarry site. [XBL 821-1604] 
The results of the modeling of option 4 are shown in Figure 7. As can be seen, there is a noticeable improvement in the containment time that may be expected for the quarry. As would be expected, however, option 4 is the most costly of those studied.

\section{REFERENCES CITED}

Guvanasen, V., and Chan, T., 1980, Finiteelement solution of coupled heat and fluid flow, solute transport and thermomechanical deformation in fractured porous media. Presented at the American Geophysical Union Fall Meeting, San Francisco, Dec. 7-12.

Ranehiro, B. Y., and Guvanasen, V., 1981. Design and evaluation of engineered low level waste disposal sites. Lawrence Berkeley Laboratory Report, in preparation.

Kanehiro, B. Y., Guvanasen, V., sterrett, R., Smith, A., Moed, B., Doe, T., and Wollenberg, H., 1980. Preliminary characterization and assessment of the Weldon Spring low level radioactive waste disposal site, Weldon Spring, Missouri. Lawrence Berkeley Laboratory Report LBL-11481, in preparation.

Ranehiro, B. Y., Guvanasen, V., Smith, A., and Moed, B., 1981. Evaluation of the future of a low level radioactive waste disposal site, Weldon Spring, Missouri. Lawrence Berkeley Laboratory Report, in preparation.
Concentration Contours (fraction of original concentration)

Time $=2.95 \times 10^{9} \mathrm{sec}(93.5 \mathrm{yr})$

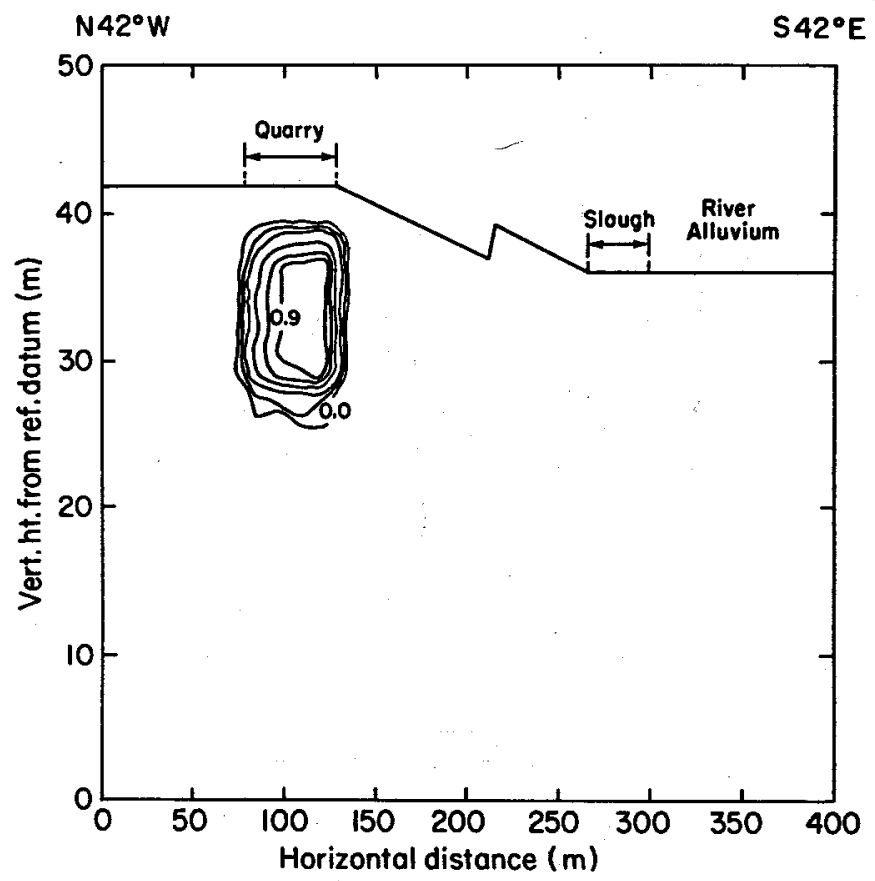

Figure 7. Results of modeling the entombment engineering option for the Weldon Spring Quarry site.

\title{
VERIFICATION AND IMPROVEMENT OF A PREDICTIVE MODEL FOR RADIONUCLIDE
}

\section{MIGRATION}

\author{
C. W. Miller, L. V. Benson, and C. L. Carnahan
}

Prediction of the rates of migration of contaminant chemical species in groundwater flowing through toxic waste repositories is essential to the assessment of a repository's capability of meeting standards for release rates. A large number of chemical transport models, of varying degrees of complexity, have been devised for the purpose of providing this predictive capability. These models have focused on one or more particular physical or chemical phenomena known to affect rates of chemical migration. However, currently available models do not incorporate complex descriptions of the entire set of chemical phenomena known to affect those migration rates. In general, the transport of dissolved chemical species through a water-saturated porous medium is influenced by convection, diffusion/dispersion, sorption, formation of complexes in the aqueous phase, and chemical precipitation. The reliability of predictions made with models which omit certain of these processes is difficult to assess. Therefore, there is an apparent need for a transport model capable of incorporating the above processes, which are necessary for understanding. and predicting migration rates.
A numerical model, CHEMTRN, has been developed to determine which chemical processes govern radionuclide migration. CHFMTRN builds on a model called MCСTM developed previously by Lichtner and Benson (1980). The model MCCTM was similar to one developed earlier by Rubin and James (1973); i.e., It included dispersion/diffusion and convection, and sorption was modeled by equilibrium ion exchange. In both cases, the lon-exchange model had a constant finite density of exchange sites, and the mass action relation was modeled with an uncorrected selectivity coefficient. However, MCCTM did go one step further by including treatment of complexation. CHENTRN includes a treatment of all the processes originally included in $\mathrm{MCCTM}$ plus the following:

1. The nonideality of both solvent and solute species has been included by approximating the activity of the species as an activity coefficient times the molar concentration. The activity coefficients in the aqueous phase are calculated by the Davies equations. An ideal mixing model has been applied to the sorbed cationic species; i.e.. the activity of a sorbed 
species has been set equal to its model fraction. Therefore, an equilibrium coefficient was approximated for the ion-exchange process instead of using an uncorrected selectivity coefficient.

2. The dissociation of water was included to allow treatment of $\mathrm{pH}$-dependent reactions for aqueous complexes and for the computation of the pH itself.

3. A solubility constraint was added as a boundary condition. At $X=0$, the solubility product of $\mathrm{SrCO}_{3}(\mathrm{~s})$ was imposed for the examples considered below.

MODEL

CHEMTRN solves for the transport of chemical species in groundwater. The species of interest are bare ions ( $\mathrm{Na}^{+}, \mathrm{Sr}^{2+}$, etc.) or complexes (NaOH, SrOH ${ }^{+}$, etc.) and can be convected, dispersed, or sorbed onto the supporting matrix. If equilibrium is assumed, then the concentration of the complex or the sorbed species can be determined as a function of the bare ion concentration. The sorption process has been modeled by an ionexchange mechanism. For species $A_{1}^{n_{1}}$ exchanging with species $A_{2}^{n_{2}}$ on the solid surface,

$n_{2}^{A_{1}^{n}}(a q)+n_{1} \bar{A}_{2}^{n_{2}}+n_{2} \bar{A}_{1}^{n_{1}}+n_{1} A_{2}^{n_{2}}$ (aq)

an equilibrium coefficient $k_{2}^{1}$ is defined to be

$\mathbf{k}_{2}^{1}=\frac{\left(\bar{m}_{1} / \bar{m}_{T}\right)^{n_{2}}\left(r_{2} m_{2}\right)^{n_{1}}}{\left(r_{1} m_{1}\right)^{n_{2}}\left(\bar{m}_{2} / \bar{m}_{T}\right)^{n_{1}}}$

where in is the molar concentration of the bare Ion, $\overline{\text { in }}$ is the sorbed concentration of the bare Ion, $\gamma$ is the activity coefficient in the aqueous phase, $n$ is the lonic charge, and $\mathrm{m}_{\mathrm{r}}$ is the total molar concentration of sorbed species. The total number of sites, $N_{s}$, available for sorption is a constant given by $\Sigma_{j} n_{j} m_{j}$ and is related to the cation exchange capacity, CEC, by $N_{s}=$ $\operatorname{CEC}\left[\rho_{\mathrm{g}}(1-\phi) / \phi\right]$, where $s$ is the solid density and $\phi$ is the porosity of the porous medium.

The formation of a complex $B_{1}$.

$a_{11} A_{1}^{n_{1}}+a_{12} A_{2}^{n_{2}}+\ldots+a_{i n_{n}^{A_{n}}}^{n_{n}}+B_{i}^{n c_{i}}$

can also be described by an equilibrium coefficient, $K_{i}$, where

$K_{1}=\frac{\gamma_{c_{i}} m_{c_{1}}}{\prod_{j}\left(\gamma_{j} m_{j}\right)^{a_{1 j}}}$

subscript $c$ denotes "complex," and $a_{i j}$ is the stoichiometric reaction coefficient.

The total concentration, $w_{j}$, of species

$A_{j}$ present in the aqueous phase is the sum of the bare ions and any complexes in which $A_{j}$ exists. Considering a mass balance of species $A_{j}$ on a volume element of a porous medium, the onedimensional transport of $A_{j}$ is

$\frac{\partial}{\partial t}-D \frac{\partial^{2}}{\partial x^{2}}+v \frac{\partial}{\partial x} w_{j}=-\frac{\partial \bar{m}_{j}}{\partial t}$.

where $D$ is the dispersion/diffusion coefficient and $v$ is the actual fluid velocity. Both $w_{j}$ and $\bar{m}_{j}$ have been expressed in units of moles/liter of solution. If the species $A_{j}$ does not sorb, $\bar{m}_{j}$ will be 0 .

CHEMTRN includes water dissociation. When the water dissociates, the activities of hydrogen and hydroxyl ions are related by the mass action relation:

$\left.\left[\mathrm{H}^{+}\right] \cdot \mathrm{OH}^{-}\right]=10^{-13.99}$,

where square brackets denote activities. To avoid having to solve for the concentration of water, a dummy variable $y$ is defined as

$\mathbf{Y}=\mathrm{m}_{\mathbf{H}}+\mathrm{OH}^{-}$

The program then solves for the transport of this dumny variable:

$$
\begin{aligned}
\left(\frac{\partial}{\partial t}-\right. & \left.D \frac{\partial^{2}}{\partial x^{2}}+v \frac{\partial}{\partial x}\right)\left[y+\sum_{1}\left(a_{1, H^{+}}-a_{1, \mathrm{OB}^{-}}\right) m_{c_{1}}\right] \\
& +\frac{\partial \mathrm{mH}^{+}}{\partial t}=0 .
\end{aligned}
$$

The hydroxyl ion is assumed not to sorb. Given $y$ and the mass action equation for water dissociation, $\mathrm{m}_{\mathrm{H}^{+}}$and $\mathrm{m} \mathrm{OH}^{-}$can be determined.

\section{APPLICATION TO CONTAMINANT TRANSPORT}

Model CHEMTRN has been used to investigate the effects of various chemical processes on the propagation of radionuclides through a porous medium. One-dimensional flow was assumed, A radionuclide source function (waste form) is located at $X=0$ and 15 open to flowing groundwater. The simulation of the propagation of strontium and its complexes was studied. In order to test the effects of composition on radionuclide propagation, the Initial groundwater composition was varied. The supporting electrolyte consisted of $\mathrm{NaCl}$ or mixtures of $\mathrm{NaCl}$ and $\mathrm{CaCl}_{2}$ dissolved in water. In all cases, a background level of $10^{-12} \mathrm{M} \mathrm{SrCO}_{3}$ was used.

The concentrations of $\mathrm{Sr}^{2+}$ and $\mathrm{CO}_{3}{ }^{2-}$ near the waste were determined by using the strontianite $\left(\mathrm{SrCO}_{3}\right)$ solubility constraint. For a variation in the initial groundwater composition, the amount of strontium in equilibrium with strontianite at the boundary will be different. 
Several different examples were run to illustrate the relative importance of the different chemical effects. The following values were used in all examples: a diffusion/dispersion coefficient of $0.0126 \mathrm{~m}^{2} / \mathrm{Yr}$, a fluid velocity of 0.04 $\mathrm{m} / \mathrm{Yr}$, a porosity of 408 , and a solid density of $2.0 \mathrm{~g} / \mathrm{cm}^{3}$. The cation exchange capacity was $0.033 \mathrm{meq} / \mathrm{g}$. The results of all the examples are given in Miller and Benson (1981). The results of three examples are given below.

The first example (Fig. 1) illustrates the general importance of the sorption process on radionuclide retardation. The figure shows the concentration of $\mathrm{Sr}^{2+}$ in the aqueous phase as a function of distance after a time period of $5 \mathrm{yr}$. Two cases were considered. In the first case, $\mathrm{Sr}^{2+}$ was not allowed to sorb; in the second case, $\mathrm{Sr}^{2+}$ was allowed to sorb via an ion-exchange model. The initial NaCl background concentration used for this calculation was 0.001 ․ The results of these calculations illustrate the fundamental importance of sorption (ion exchange) on $\mathrm{Sr}^{2+}$ mobility. Figure 1 shows that the sorption process of $\mathrm{Sr}^{2+}$ (as measured by the leading edge) decreases the mobility by approximately 908 .

Macroscopically, the tendency of an ion to be sorbed depends on its concentration in the aqueous phase relative to the concentration of other sorbate ions, the selectivity of the sorptive substrate for an ion relative to other ions, and the number of sites on the sorptive substrate. Given similar concentrations of sorbate ions in the aqueous phase, $\mathrm{Sr}^{2+}$ selectivity is found to be higher than the selectivity of $\mathrm{Na}^{+}$. However, as the concentration of $\mathrm{Na}^{+}$is increased, the enhanced selectivity for $\mathrm{Sr}^{2+}$ is outweighed by the $\mathrm{Na}^{+}$concentration effect.

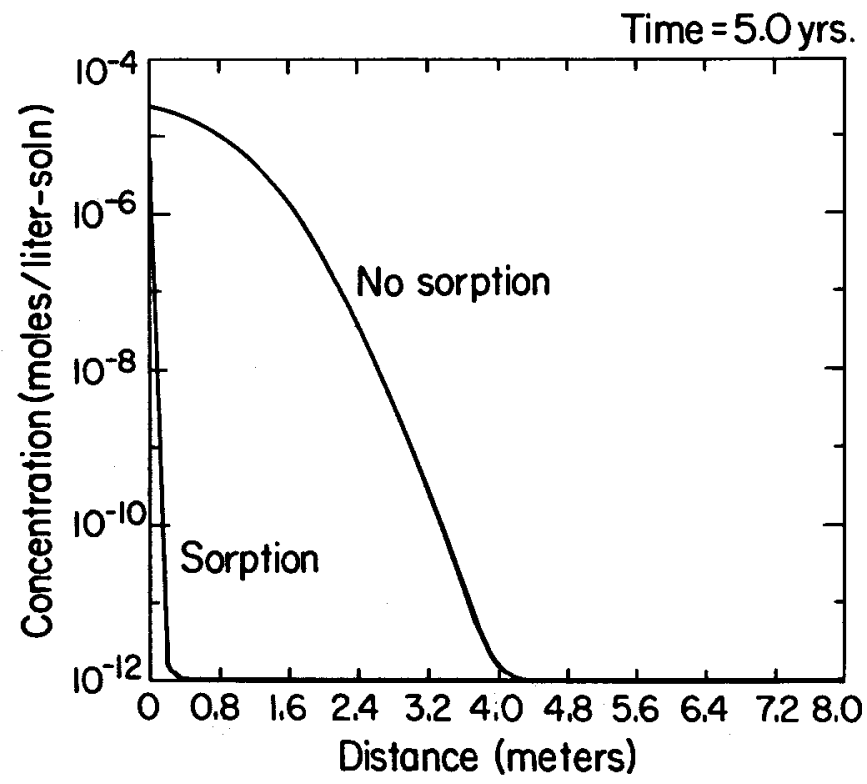

Figure 1. Transport of $\mathrm{Sr}^{2+}$ through a porous clay, illustrating the effect of adsorption on radionuclide mobility.

[XBL B110-1497]
As the concentration of $\mathrm{Na}^{+}$is decreased relative to that of $\mathrm{Sr}^{2+}$, a very interesting phenomena occurs, as shown in Figure 2. The amount of $\mathrm{Na}^{+}$displaced from the clay by $\mathrm{Sr}^{2+}$ increases the concentration of $\mathrm{Na}^{+}$in the aqueous phase significantly ( 2 to 3 times the initial concentration for this case). The enhanced $\mathrm{Na}^{+}$ concentration propagates downstream. The depleted $\mathrm{Sr}^{2+}$ ion competes with a higher concentration of $\mathrm{Na}^{+}$, resulting in low levels of $\mathrm{Sr}^{2+}$ being mobilized well beyond the region where it is expected to have been completely sorbed if the $\mathrm{Na}^{+}$ level had stayed constant.

Actual groundwaters generally contain several cations other than sodium which compete with strontium and with each other for exchange sites. In addition, the dissociation of water and the formation of nonsorbing complexes affect the transport of strontium. Figure 3 illustrates the effect of the third sorbing cation on the sorption of strontium and the effect of the formation of complexes on the $\mathrm{pH}$ of the water.

In Figure 3, the background level of $\mathrm{NaCl}$ and $\mathrm{CaCl}_{2}$ is $0.001 \underline{M}$ of each. This example can be compared to the first (Fig. 1), in which the only background electrolyte was $0.001 \mathrm{M} \mathrm{NaCl}$. When $\mathrm{Ca}^{2+}$ can also sorb, strontium is transported at significantly greater distances downstream; 1.e., after 5 yr the strontium propagates about $1 \mathrm{~m}$ in this example vs. only $0.2 \mathrm{~m}$ in the first.

Figure 3 also illustrates that a $\mathrm{pH}$ of approximately 10 is maintained near the waste form. Even when the initial $\mathrm{pH}$ was varied from 6 to 10 , the $\mathrm{pH}$ at the boundary was always calculated to be 10 because of the constraint on the

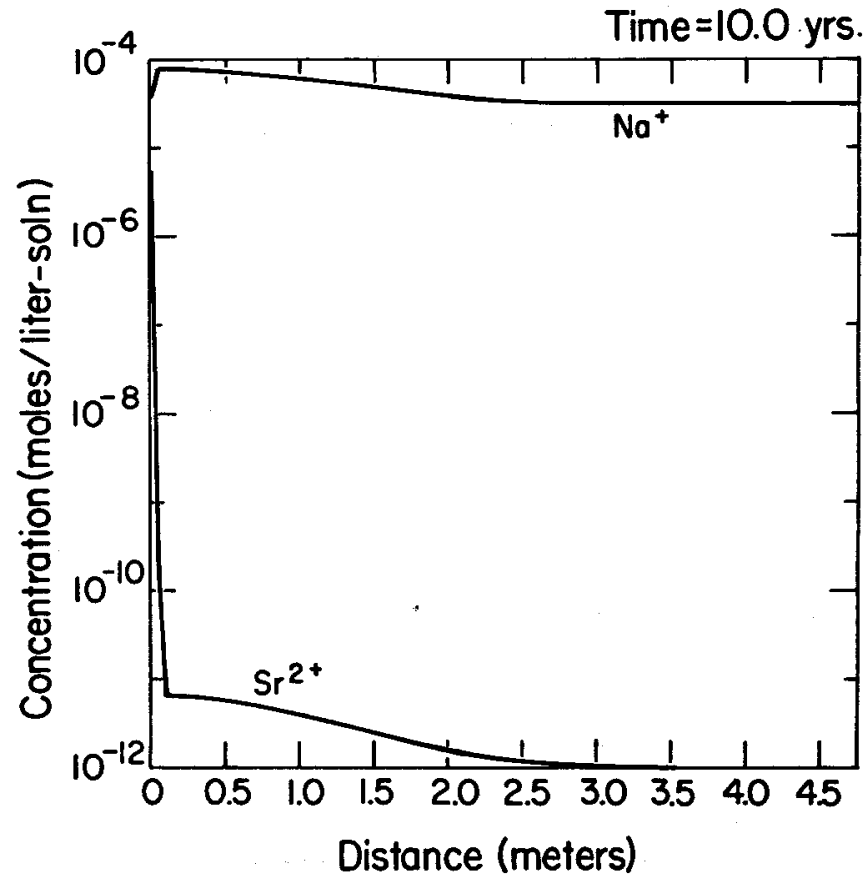

Figure 2. Transport of $\mathrm{Sr}^{2+}$ in background solution of $3 \times 10^{-5} \mathrm{M}$ NaCl, including adsorption on clay; concentration of $\mathrm{Na}^{+}$is also plotted.

[XBL 8110-7392] 
Time $=5.0$ yrs

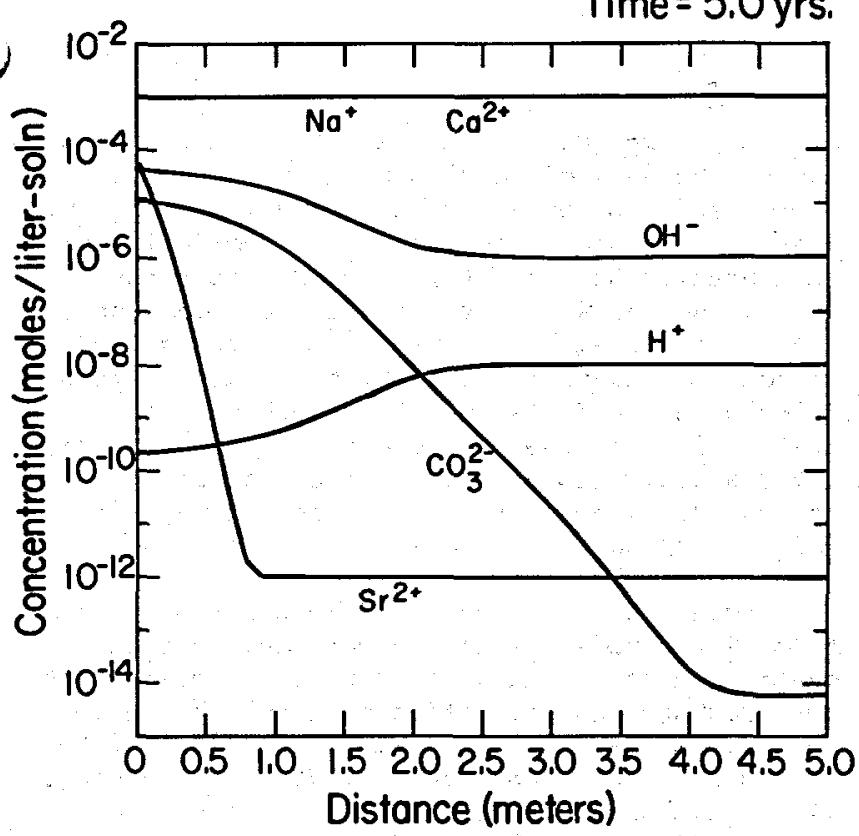

Figure 3. Transport of $\mathrm{sr}^{2+}$ in background solution of $10^{-3} \mathrm{M} \mathrm{NaCl}$ and $10^{-3} \mathrm{M} \mathrm{CaCl}_{2}$, Including complexation, water dissociation, and adsorption.

[XBL 8110-12142]

strontianite activity product. This suggests that the nuclear waste package can control certain facets of its surrounding chemical environment.

Figure 4 is a plot of the concentration of the corresponding complexes formed by the base ions in Figure 3. Strontium can be transported both as $\mathrm{SrOH}^{+}$and $\mathrm{SrCO}_{3}{ }^{\circ}$. Although the concentration of these complexes is small, other radionuclides exist principally in the complexed state. If these complexes do not sorb, they can be transported significant distances downstream from the canister.

\section{SUMMARY}

A transport model which accounts for most chemical processes common to hydrochemical systems has been developed and applied to the problem of contaminant transport. CHEMTRN provides for the formation of complexes in the aqueous

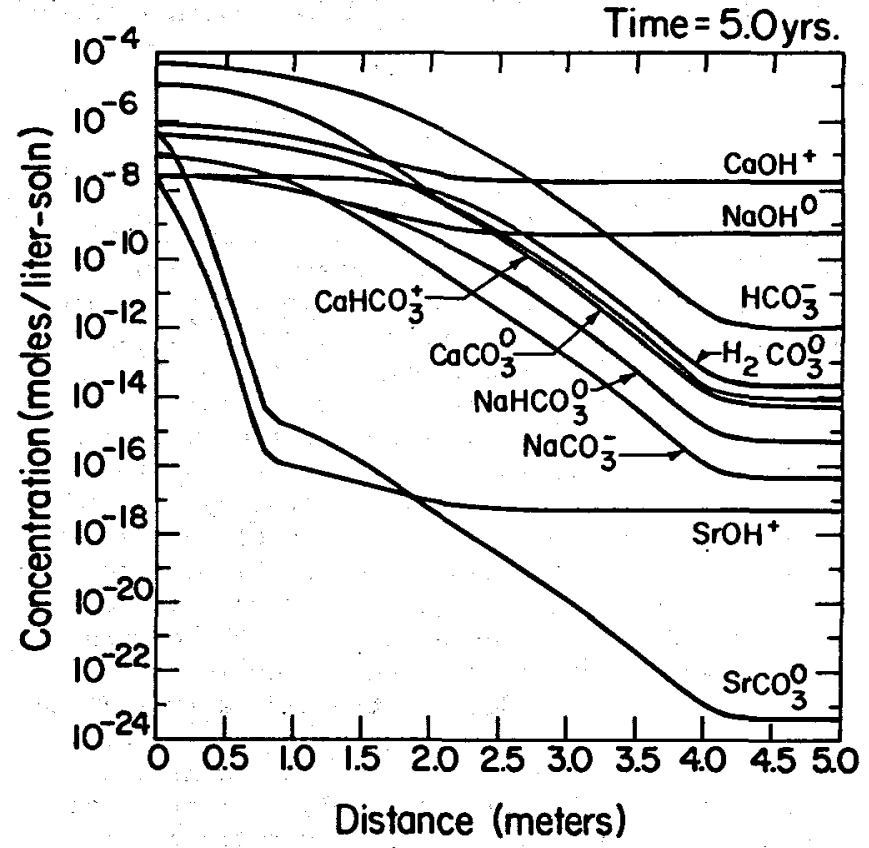

Figure 4. Transport of complexes corresponding to Figure 3. [XBL 8110-7389]

phase, treats sorption as an equilibrium ion exchange process, and includes water dissociation. It has been shown that because of competition for surface sites, low levels of strontium can propagate as far as in the no sorption case.

\section{REFERENCES CITED}

Lichtner, P., and Benson, L. V., 1980. Development of a multicomponent thermochemical transport model. Unpublished work.

Miller, C. W., and Bensen, L. V., 1981. simulation of solute transport in a chemically reactive heterogeneous system: Model development and application. Lawrence Berkeley Laboratory Report LBL-13828.

Rubin, J., and James, R. V., 1973. Dispersion-affected transport of reacting solutes in saturated porous media: Galerkin method applied to equilibrium-controlled exchange in unidirectional steady water flow. Water Resources Research, v. 9, no. 5 , p. 1332-1356. 


\section{C. Michel and W. R. Keyes}

Among its other uses, the naturally occurring disequilibrium between $234 \mathrm{v}$ and $238 \mathrm{v}$ in most groundwaters has been suggested as a method of determining the age of such waters (Cherdyntsev et al., 1955). This method is applicable to ages within the range of the half-life of $234 \mathrm{U}$ (about. $250,000 \mathrm{yr}$ ) and is therefore of interest in assessing sites for nuclear waste repositories. As with other suggested methods for groundwater dating, interpretation of the data raises issues that relate to the complexity of the system as well as to our imperfect knowledge of the mechanisms involved in the basic geochemical constraints on the system. It has been the purpose of our work to add to the understanding of the mechanisins by which $234 \mathrm{U}$ is enriched or depleted in groundwaters and to develop the necessary analytical techniques for studying these processes. Special emphasis has been given to techniques that will be applicable to likely nuclear waste repository sites--i.e., where water flows are low, rocks are impermeable, and recovery of samples is difficult.

As reported elsewhere (Michel, 1981), we have demonstrated the ability to analyze small water samples for the necessary parameters. This report deals with the application of our methods to real groundwater samples and with the changes that our data and the work of others suggests be made in the basic model of the enrichment process.

\section{BASIC DISEQUILIBRIUM MODEL}

The generally accepted model for the enrichment of $234 \mathrm{v}$ in groundwaters is well summarized by cowart and Osmond (1974) and Osmond and Cowart (1975). This model envisions an ideal aquifer where meteoric water enters the soil in the recharge area and picks up uranium from the soil and rocks by both dissolution and leaching processes. The uranium going into solution generally has an excess of ${ }^{234} \mathrm{v}$, presumably because it is left in a higher-energy lattice position by the nuclear recoil processes leading to its formation from $238 \mathrm{u}$. At lower depths the waters begin to lose uranium as they become anoxic and $\mathrm{v}^{\mathrm{IV}}$ is formed by reduction. This may cause a region of the aquifer to have very high surface concentrations of uranium, which, under the right circumstances, can lead to very high enrichments of ${ }^{234} \mathrm{U}$ by direct recoil injection of ${ }^{234}$ Th into the liquid phase. The direct recoil injection of $234 \mathrm{Th}$ has been shown to be effective in laboratory experiments (Kigoshi, 1971) and is belleved to be the only mechanism capable of producing the very high enrichments (activity ratios ${ }^{234} \mathrm{U} / 238 \mathrm{U}=$ 10 to 20) actually found in some groundwaters.

The use of uranium disequilibrium to determine water ages depends on using the return to equilibrium of $234 \mathrm{U}$ as a clock to measure the time elapsed. This ignores the possibility that the uranium may be strongly adsorbed or exchanged by certain surfaces; thus, in reality these ages are only a measure of the migration rate of uranium in the geologic environment and serve as an upper limit to the age of the water. Under many deep aquifer conditions, there is some evidence that uranium may be a fairly good tracer for water, and the ages may represent a good approximation to the age of the water. There is good reason to believe that, other than adsorption or ion-exchange effects, no other mechanism is known that would lead one to overestimate the age (or, alternatively, underestimate the flow rate) of the water, although there are several ways in which errors of the opposite sign can occur.

Recent developments are demonstrating that this simple model is almost certainly not adequate. In particular, it is becoming clear that ion-exchange and adsorption effects must be at least considered at each site. In addition, the work of Fleischer and Raabe (1978) and Fleischer (1980) has shown clearly that enrichment can occur in fracture-dominated flow systems by a process that is very similar to preferential leaching but has the possibility of very high levels of enrichment, and may occur periodically as new fractures are opened.

\section{GROUNDWATERS OF THE PASCO BASIN}

To test our analytical methods, we analyzed (both for uranium concentration and isotopic enrichment) samples of groundwaters and surface waters from the Pasco Basin (Washington). These samples had been collected as part of an earlier study of the geochemistry of the region, a possible candidate for a nuclear waste repository (Apps et al.. 1979). The methods are discussed in Michel (1981). As an indication of the sensitivity of these methods, the largest sample used was about $45 \mathrm{~g}$ of water.

Figure 1 shows the sampling locations and the major geologic features of the Pasco Basin. The sampling locations labeled 8 and 9 are holes drilled into and through the successive sheets of flow basalt that make up the subsurface features. Most of the groundwater flows in zones of higher hydraulic conductivity between sheets of basalt. Flow rates are not normally very high, although some areas (including location 9) are pressured slightly above the surface and are artesian after drilling. A detailed description of the geologic setting and sampling techniques is given in Apps et al. (1979) and will not be repeated here. The most interesting feature of these waters is the generally low uranium content of the water, with normal uranium concentrations in the surrounding rock. This makes the area ideal for the study of certain parts of the enrichment model which depend upon relative uranium concentration for their effect.

The analytical results presented in Table 1 show that the waters suspected of being fairly young do exhibit enrichments (activity ratio = 


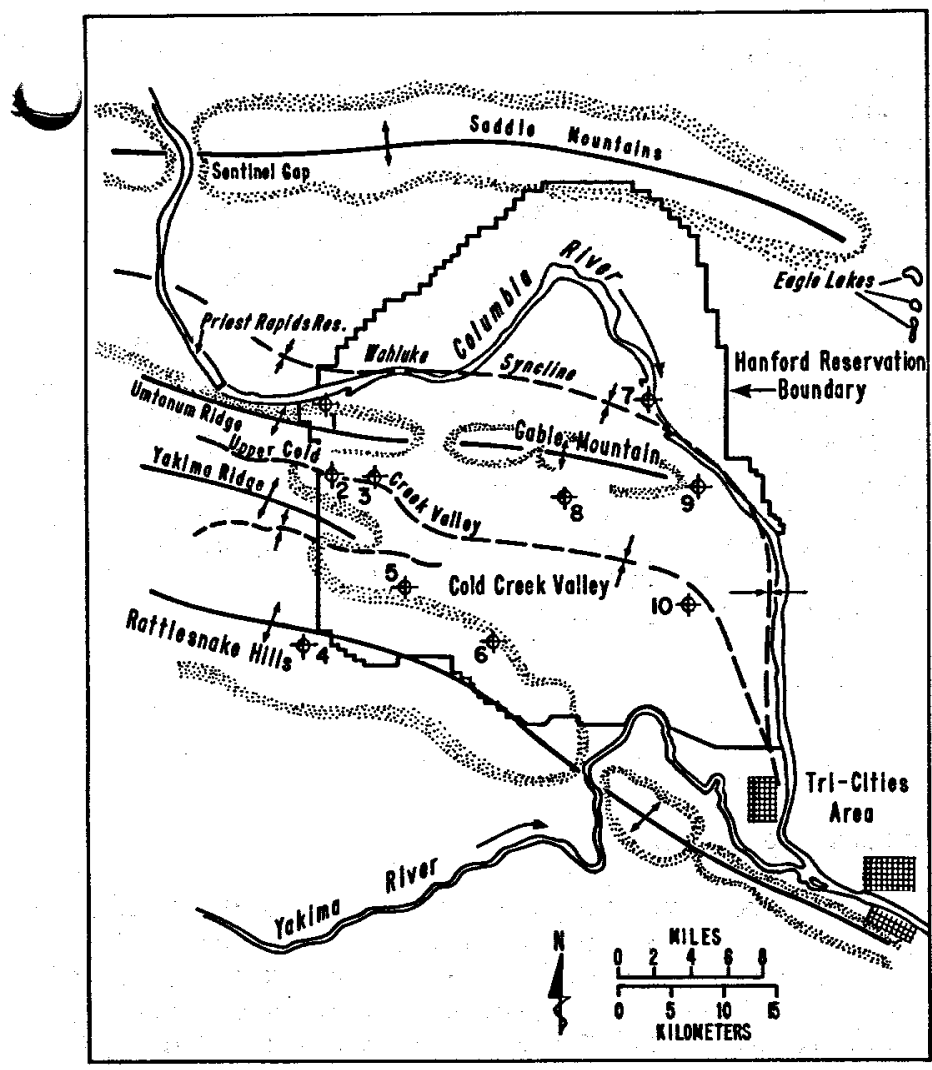

Figure 1. Location of sampling points in Pasco Basin, Washington, relative to major geologic features. The waters sampled are numbered as follows: 1 - Juniper Spring; 2 = Ford Well; 3 = MoGee Well, $4=$ Bennett Spring,

5 = Rattlesnake Spring; 6 = Benson Spring;

7 - Columbia River, $8=\mathrm{DC}-2 ; 9=\mathrm{DC}-6$.

[XBL 7810-2108C]
1.5 to 2.5) significantly higher than those of local surface streams (Columbia River; activity ratio $=1.3$ ). Of the two drilled holes that tap deeper waters ( 8 and 9 ), only the one at location 9 is believed to be properly sampled (see below). If one assumes that the waters in that hole originally had enrichment equal to the average for the springs sampled, these waters could be as old as $200,000 \mathrm{yr}$, although it is more likely that they are much younger. Further work is being done by Rockwell Hanford Operations (D. Graham, 1981, private communication). With better sampling and analysis, these new data will be much more useful in determining the characteristics of the deeper aquifers. However, the two artesian wells in Table 1 (Ford Well, McGee Well) are of extreme interest in testing the enrichment model. The two wells are only a few kilometers apart and are fed by an aquifer only about $1200 \mathrm{ft}$ below the surface, yet the uranium concentration drops by a factor of about 16 between the two and reaches what we believe to be the lowest value for groundwaters yet reported, 0.05 ppt. This offers the most sensitive possible test of the effect of continuous injection of ${ }^{234} \mathrm{Th}$ into the groundwater of a real aquifer. Assuming the average uranium concentration of about $1.5 \mathrm{ppm}$ in the rock, this water should exhibit a steadily increasing activity ratio with time, because the low total uranium concentration makes even a slight source of excess $234 \mathrm{U}$ very effective. In most aquifers continuous injection merely acts to reset the clock slightly, leading to relativeIy minor underestimation of the age. Since these waters are not significantly enriched in $234 \mathrm{U}$, such injection must not be occurring. Simple calculations based on work by Kigosh1 (1971) indicates that even if this water is only a few thousand years old, enrichments of over two in activity ratio should have occurred. We feel

Table 1. Analysis of Pasco Basin groundwaters.

\begin{tabular}{|c|c|c|c|}
\hline Iocation sampled & $\begin{array}{l}\text { Location number } \\
\text { on Figure } 1\end{array}$ & $\begin{array}{l}\text { Uranium } \\
\text { conc. } \\
\text { (ppt) }\end{array}$ & $\begin{array}{l}\text { Activity ratio } \\
\left(234 \mathrm{v} / 238_{\mathrm{V}}\right)\end{array}$ \\
\hline Juniper Spring & 1 & 21.6 & 2.41 \\
\hline Ford well & 2 & 0.787 & 1.2 \\
\hline McGee Well & 3 & 0.054 & 1.0 \\
\hline Bennett Spring & 4 & 337.8 & 1.99 \\
\hline Rattlesnake Spring & 5 & 572.7 & 2.51 \\
\hline Benson Spring & 6 & 159.7 & 1.55 \\
\hline Columbla River & 7 & 489.4 & 1.33 \\
\hline DC-2 & 8 & 1.17 & 1.0 \\
\hline DC-6 & 9 & 9.92 & 1.85 \\
\hline
\end{tabular}


that this may indicate that direct injection may not be very important in deep aquifers (in the absence of unusually high surface uranium concentrations) and therefore may be safely ignored in most cases. If this is true, one must look earlier in the aquifer's lifetime for the basic enrichment events, in general agreement with the model aquifer described above.

As to why direct injection is so ineffective in this case, we can think of only. two reasons. The most likely is that in many deep aquifers, where flow rates are low and waters quite old, the waters have already come close to equilibrium with the rocks, or at least with specific minerals, and are forming secondary mineral deposits slowly on the aquifer surfaces. If these coatings have lower uranium contents than the rocks-a quite likely situation--they will interfere completely with the direct injection of ${ }^{234} \mathrm{Th}$ when they reach a thickness of about 500 , the nominal range of the alpha recoil ${ }^{234} \mathrm{Th}$. Further study of the aquifer surfaces themselves should determine if this is the explanation in any particular aquifer.

There is another method of negating the effect of direct injection even if it is occurring. That is, if the average life of the ${ }^{234} \mathrm{Th}$ in solution is considerably shorter than its halfife (24 days) for nuclear decay through $234 \mathrm{~Pa}$ to $234 \mathrm{U}$. It has been shown that in some surface waters this lifetime can be as low as one day (Hussain and Krishnaswami, 1980). If this can occur under appropriate chemical conditions in an aquifer at depth, and if the two subsequent beta decays somehow lead to a chemical form of 234 that will not go back into solution, one can actually start with equilibrium uranium and obtain depletions below that (AR é 0.5) theoretically possible from dissolution of previously leached rocks (the primary mechanism by which surface waters are found to be slightly depleted).

Recent results at Rockwell Hanford Operations (D. Graham, 1981, private communication) have shown that extreme depletions of this nature do occur in one of the deeper aquifers in the Pasco Basin and in waters varying by at least one or two orders of magnitude in uranium content. This implies that the extreme depletions could not be from dissolution of depleted rock, since the concentration of uranium in rock does not vary as dramatically in the same aquifer as does the uranium content of the water. If this mechanism is operative there, and if the recharge waters were initially at equilibrium or modestly enriched, the observed depletions attributed to this mechanism cannot be attained except over long times, the calculation being identical with that for the normal return to equilibrium clock. Thus the ages of these waters would have to exceed 240,000 yr (uncorrected for the effects of adsorption of the uranium, if any).

\section{CONCLUSTON}

The present work, by investigating the behavior of waters usually low in uranium, raises ques- tions about the enrichment model that can be only partially answered by our data and the recent findings of others. The conclusion is that each area must be interpreted separately and that much additional information--particularly measurements of the surface concentrations of uranium, ${ }^{230} \mathrm{Th}$, and ${ }^{234} \mathrm{Th}$ (if possible) and the activity ratio ${ }^{234} \mathrm{U} /{ }^{238} \mathrm{U}$--are necessary to a clear interpretation of the migration rate of uranium in groundwaters, and that further information on the importance of ion exchange and adsorption is necessary for conversion of such data to actual groundwater ages or flow rates. In all this work a premium is placed on the ability to analyze very small samples of the elements of interest, since sample sizes are necessarily limited by sampling problems, particularly when investigating thin surface layers on aquifer rocks.

\section{REFERENCES}

Apps, J., Doe, T., Doty, B., Doty, S., Galbraith, R., Kearns, A., Dohrt, B., Long, J., Monroe, A., Narasimhan, T. N., Nelson, P., Wilson, C. R., and wither spoon, P. A., 1979. Geohydrological studies for nuclear waste isolation at the Hanford Reservation, Vol. II. Lawrence Berkeley laboratory Report LBL-8764.

Cherdyntsev, V. V., Chalov, P. I., and Khaidarov, G. Z., 1955. Transactions of the 3rd Session of the Committee for Determination of Absolute Ages of Geological Formations. Izvestiya Akademi $i$ Nauk SSSR, p. 175.

Cowart, J. F., and Osmond, J. K., 1974. $234_{\mathrm{U}}$ and $238 \mathrm{U}$ in the Carrizo sandstone aquifer of south Texas. In Isotope Techniques in Groundwater Bydrology. Proceedings, Symposiun International Atomic Energy Agency (IAEA), Vienna.

Fleischer, R. L., 1980. Isotopic disequilibrium of uranium: Alpha-recoil damage and preferential solution effects. Science, v. 207 , p. 979.

Fleischer, R. L., and Raabe, O. G., 1978. Recoiling alpha-emitting nuclei. Mechanisms for uranium-series disequilibrium. Geochimica et Cosmochimica Acta, v. 42, p. 973.

Hussain, N., and Krishnaswami, S., 1980. U-238 series radioactive disequilibrium in groundwaters: Implications to the origin of excess U-234 and fate of reactant pollutants. Geochimica et Cosmochimica Acta, v. 44, p. 1287.

Kigoshi, K., 1971. Alphe-recoil thorium-234: Dissolution into water and the uranium234/uranium-238 disequilibrium in nature. Science, v. 173, p. 47.

Michel, M. C., 1981. Mass spectrometric determination of $234 \mathrm{~g} / \mathbf{2 3 8} \mathrm{u}$ disequilibrium. In Earth Sciences Division Annual Report 1980. Lawrence Berkeley Laboratory Report LBL-12100, p. 199.

Osmond, J. R., and Cowart, J. F., 1976. The theory and uses of uranium isotopes in hydrology. Atomic Energy Review 14. 
URANIUM (VI) RETARDATION MECHANISMS

\author{
R. J. Silva and A. W. Yee
}

The solubility of hexavalent uranium, $\mathrm{UO}_{2}{ }^{2+}$, was measured as a function of $\mathrm{pH}(5$ to 10$)$, NaCl supporting electrolyte concentration $10.001 \mathrm{M}$ and $0.1 \mathrm{MaCl}$ ), and equilibration time in batch experiments. Dilute hydrochloric acid solutions of $\mathrm{UO}_{2}{ }^{2+}$ were titrated to the various $\mathrm{pH}$ values with NaOH. The solid which precipitated from the supersaturated solution was presumably uranyl hydroxide. The results of the determination of the uranium solution concentration for duplicate samples (labeled $\$ 1$ and $\$ 2$ ) for equilibration times of about 8.5 weeks and 10 weeks as a function of $\mathrm{pH}$ for a $0.001 \mathrm{M}$ NaCl supporting electrolyte are shown as points in Figure 2. Plots are of the

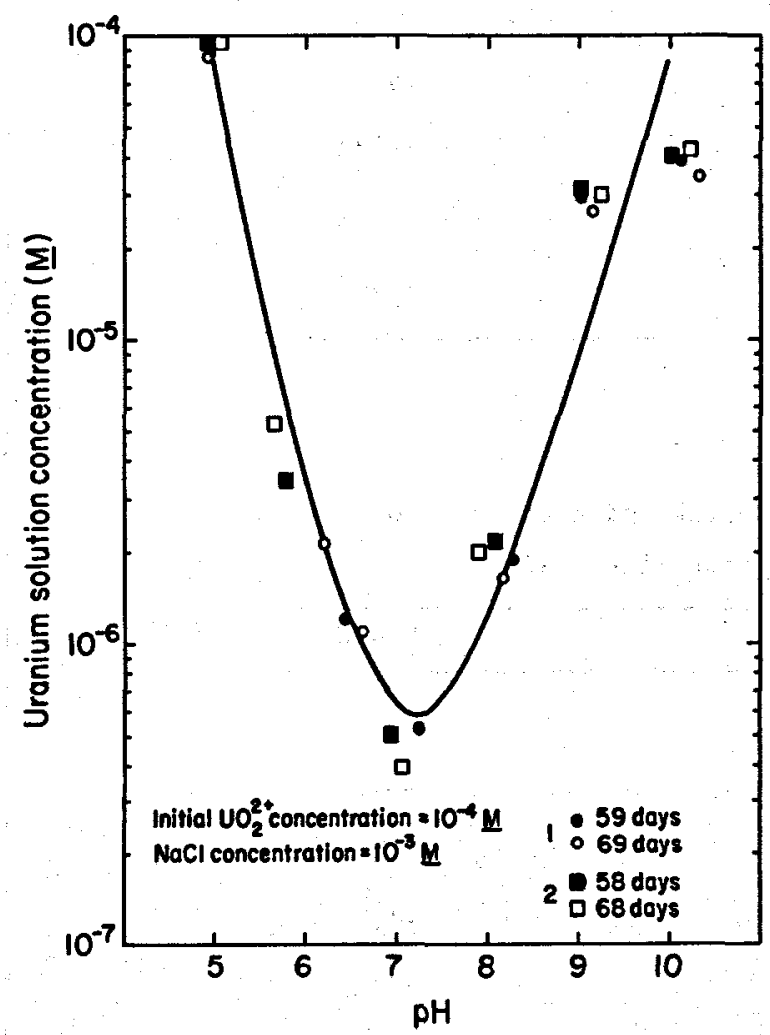

Figure 1. Uranium solution concentration as a function of $\mathrm{pH}$ at $23^{\circ} \mathrm{C}$. Points represent exper 1 mental results; solid curves result from MINEQL calculations using existing thermochemical data.

[XBL 821-1605] logarithm of the total measured $\mathrm{U}$ concentration (moles/liter) versus pH. With the computer code MINEQL, attempts were made to simulate the uran1um solubility using published thermochemical data on the hydrolysis of $\mathrm{vO}_{2}{ }^{2+}$ and the solubility of uranyl hydroxide (Smith and Martell, 1976, Langmuir, 1978; Sylva and Davidson, 1979; Allard et al., 1980, Lemire and Tremaine, 1980). The best fits to the experimental data were obtained by using a combination of the thermochemical data of Sylva and of Lemire for the formation of the hydrolysis products and the data of Langmuir for the formation of solid uranyl hydroxide. These constants are given in Table 1 , and the results of the calculation are presented in Figure 1 as the solid line.

The sorption of hexavalent uranium by Min-usil (a commercial silica) was measured as a function of $\mathrm{pH}(5$ to 10$)$, initial $\mathrm{UO}_{2}{ }^{2+}$ concentration $\left(10^{-6} \underline{M}\right.$ and $\left.10^{-7} \mathrm{M}\right)$, and $\mathrm{NaCl}$ supporting electrolyte concentration $(0.01 \mathrm{M}, 0.1 \mathrm{M}$, and $1 \mathrm{M})$ in batch experiments using finely divided silica samples $(2-1 \mathrm{~m}$-diameter particles). The results of the measurements for an initial $\mathrm{vO}_{2}{ }^{2+}$ concentration of $10^{-6} M$ are shown in Figure 2 . The plots are of the logarithm of the uranium distribution coefficient (uranium mass per gram of silica divided by the uranium mass per milliliter of solution) versus $\mathrm{pH}$ for the three NaCl concentrations. Using the solution thermochemical data in Table 1, the measured surface properties of the silica and proposed surface sorption reactions of the major uranium solution species with the surface hydroxyl groups of silica in Table 2, sorption isotherms for uranyl on silica were calculated with the computer code MINEQL (Silva et al., 1979). The results of the calculations are shown as the solid lines in Figure 2. Reasonably good fits to the experimental data could be obtained by assuming sorption of the major uranium species $\mathrm{UO}_{2}{ }^{2+}, \mathrm{UO}_{2}(\mathrm{OH})^{+}, \mathrm{UO}_{2}(\mathrm{OH})_{2}{ }^{\circ}, \mathrm{UO}_{2} \mathrm{Cl}^{+}$, and $\left(\mathrm{UO}_{2}\right)_{3}(\mathrm{OH})_{5}^{+}$. Suggested constants for the surface sorption reactions of these major uranium solution species with silica are given in Table 2 along with other surface reactions and parameter 8 used in the MINEQL calculations.

The results of this work demonstrate the utility of the proposed sorption reaction model and the computer code MINEQL to provide a basis for describing and quantifying the important surface and solution reactions that control solution concentrations and, thus, the aqueous transport of waste radionuclides in geologic settings. 
Table 1. Solution chemical thermodynamic data for $U$ used in MINEQL calculation of solubility.

\begin{tabular}{|c|c|}
\hline Reaction & $\log K$ \\
\hline \multicolumn{2}{|c|}{ Complexes } \\
\hline $\mathrm{UO}_{2}^{2+}+\mathrm{H}_{2} \mathrm{O}=\mathrm{UO}_{2}(\mathrm{OH})^{+}+\mathrm{H}^{+}$ & -5.50 \\
\hline $\mathrm{UO}_{2}{ }^{2+}+2 \mathrm{H}_{2} \mathrm{O}=\mathrm{UO}_{2}(\mathrm{OH})_{2}{ }^{\mathrm{O}}+2 \mathrm{H}^{+}$ & -11.93 \\
\hline $2 \mathrm{OO}_{2}{ }^{2+}+2 \mathrm{H}_{2} \mathrm{O}=\left(\mathrm{OO}_{2}\right)_{2}{ }^{(\mathrm{OH})_{2}}{ }^{2+}+2 \mathrm{H}^{+}$ & -5.89 \\
\hline $3 \mathrm{UO}_{2}^{2+}+4 \mathrm{H}_{2} \mathrm{O}=\left(\mathrm{OO}_{2}\right)_{3}{ }^{(\mathrm{OH})_{4}}{ }^{2+}+4 \mathrm{H}^{+}$ & -12.31 \\
\hline $3 \mathrm{UO}_{2}{ }^{2+}+5 \mathrm{H}_{2} \mathrm{O}=\left(\mathrm{UO}_{2}\right)_{3}(\mathrm{OH})_{5}^{+}+5 \mathrm{H}^{+}$ & -16.46 \\
\hline $30 \mathrm{O}_{2}{ }^{2+}+7 \mathrm{H}_{2} \mathrm{O}=\left(\mathrm{OO}_{2}\right)_{3}{ }^{(\mathrm{OH})_{7}}{ }^{-}+7 \mathrm{H}^{+}$ & -30.75 \\
\hline $4 \mathrm{UO}_{2}{ }^{2+}+7 \mathrm{H}_{2} \mathrm{O}=\left(\mathrm{OO}_{2}\right)_{4}{ }^{(\mathrm{OH})_{7}}{ }^{+}+7 \mathrm{~B}^{+}$ & -22.76 \\
\hline $\mathrm{UO}_{2}^{2+}+\mathrm{Cl}^{-}=\mathrm{UO}_{2} \mathrm{Cl}^{+}$ & 0.24 \\
\hline \multicolumn{2}{|c|}{ Precipitates } \\
\hline $\mathrm{UO}_{2}{ }^{2+}+\mathrm{H}_{2} \mathrm{O}=-\mathrm{UO}_{3}+2 \mathrm{H}^{+}$ & -7.69 \\
\hline $\mathrm{UO}_{2}{ }^{2+}+\mathrm{H}_{2} \mathrm{O}=\mathrm{UO}_{3}(\mathrm{amorph})+2 \mathrm{H}^{+}$ & -10.40 \\
\hline $\mathrm{vO}_{2}{ }^{2+}+2 \mathrm{H}_{2} \mathrm{O}=\mathrm{vO}_{2}(\mathrm{OH})_{2}+2 \mathrm{H}^{+}$ & -5.56 \\
\hline $\mathrm{UO}_{2}{ }^{2+}+3 \mathrm{H}_{2} \mathrm{O}=\mathrm{UO}_{2}(\mathrm{OH})_{2} \cdot \mathrm{H}_{2} \mathrm{O}+2 \mathrm{H}^{+}$ & -5.40 \\
\hline
\end{tabular}

Table 2. Surface reactions, constants, and other parameters used in the MINEQL calculations of $\mathrm{UO}_{2}{ }^{2+}$ plus Min-u-sil.

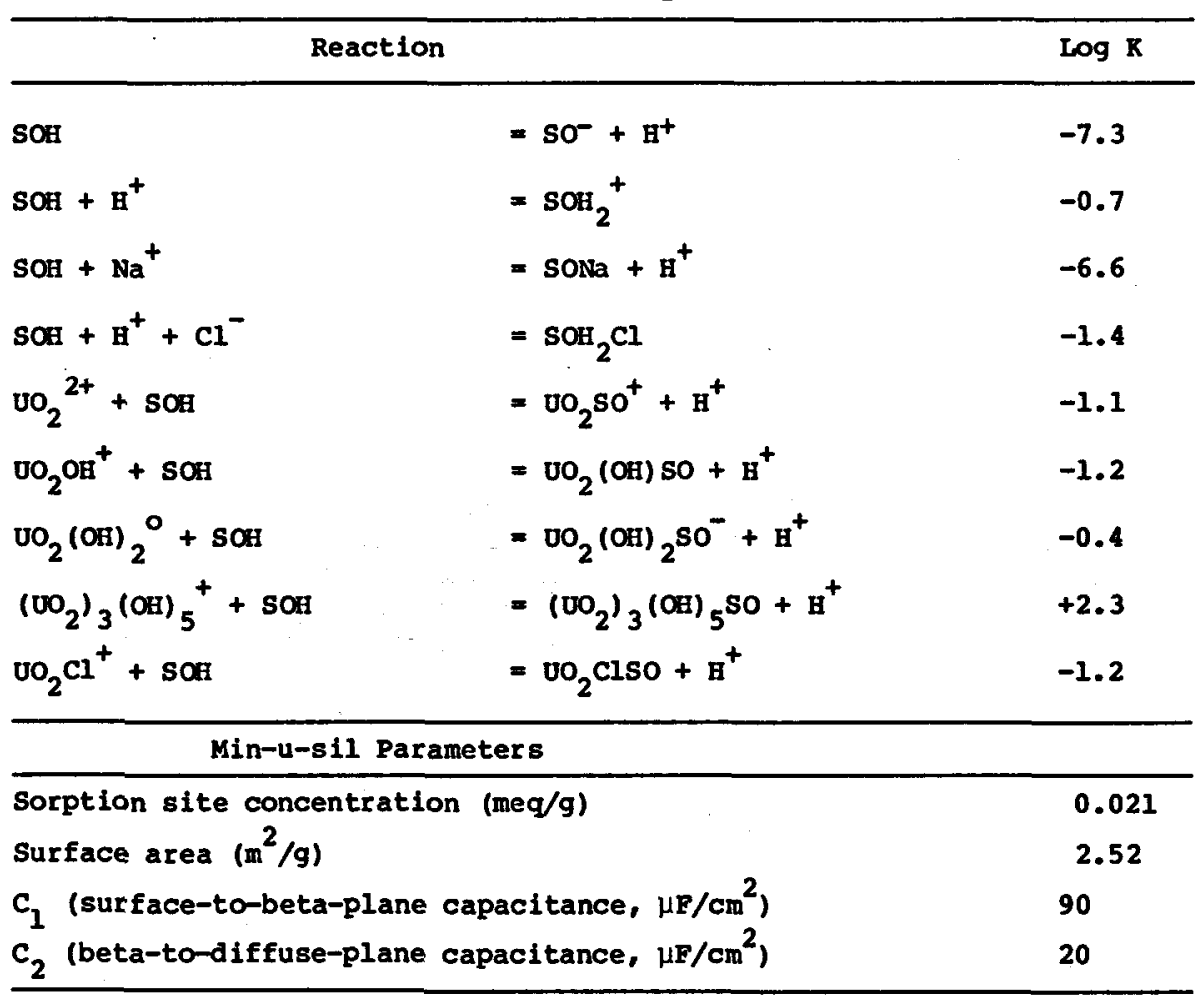




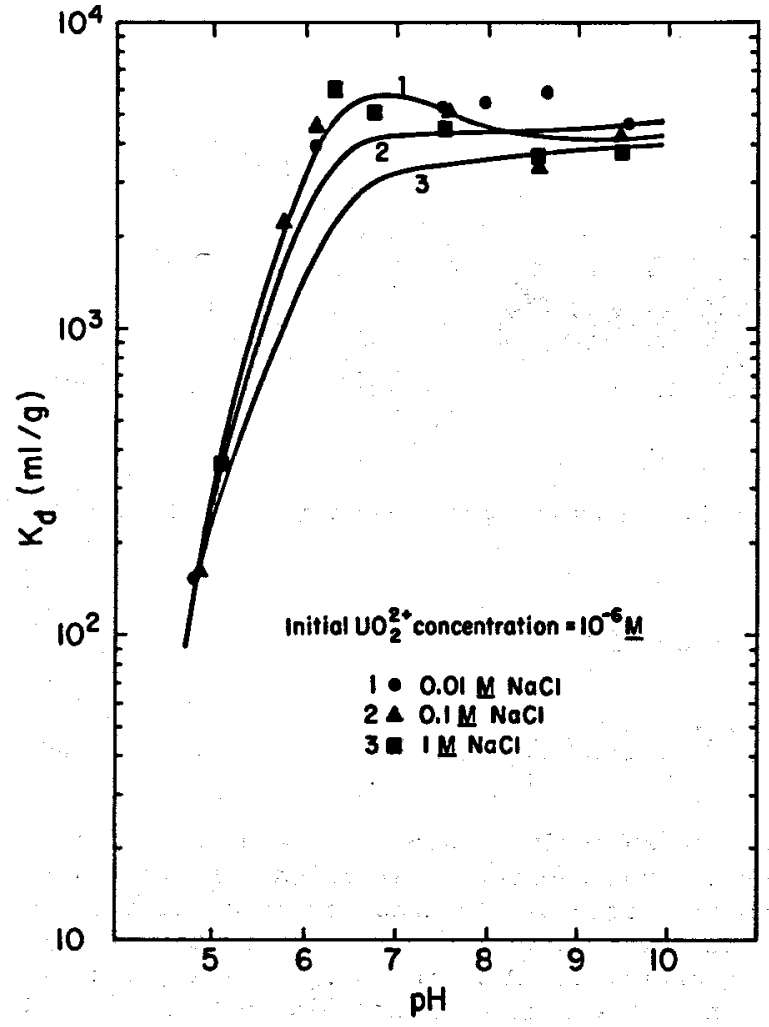

Figure 2. Urantum sorption isotherms for Min-usil at $25^{\circ} \mathrm{C}$ for different $\mathrm{NaCl}$ concentrations. Solid points represent experimental data. The solid curves were calculated with MINEQL using the reactions and data in Tables 1 and 2 . (1, 2, and 3 refer to calculations using $0.01 \mathrm{M}, 0.1 \mathrm{M}$, and $1 M$ NaCl as supporting electrolyte, respectively.)
REFERENCES CITED

Allard, B., Kipatsi, A. and Liljenzin, J. O., 1980. Expected species of uranium, neptunium and plutonium in neutral aqueous solutions. Journal of Inorganic and Nuclear Chemistry, v. 42, p. 1015-1027.

Langmuir, D., 1978. Uranium solution-mineral equilibria at low temperatures with application to sedimentary ore deposits. Geochimica et Cosmochimica Acta, v. 42, p. 547-569.

Lemire, R. J., and Tremaine, P. R., 1980. $U$ and $\mathrm{Pu}$ equilibria in aqueous solutions to $200 \mathrm{C}$. Journal of Chemical Engineering Data, v. 25, p. $361-370$.

Silva, R. J., Benson, L. V., Yee, A. W., and Parks, G. A., 1979. Theoretical and experimental evaluation of waste transport in selected rocks. 1979 Annual WISAP Report. Lawrence Berkeley Laboratory Report LBL-9945, $99 \mathrm{p}$.

Smith, R. M., and Martell, A. E., 1976. Critical stability constants (Vol. 4, Inorganic Conplexes). New York, Plenum Press, 257 p.

Sylva, R. N., and Davidson, M. R., 1979. The hydrolysis of metal ions. Part 2 Dioxouranium (VI). Journal of the Chemical society (Dalton), p. 465-471. 


\section{J. A. Apps and C. J. Radke}

Additional protection for the underground storage of high-level nuclear wastes can be provided by an engineered barrier or backfill material. If properly designed, such a barrier can significantly retard the migration of toxic ions even after failure of the waste canister. The backfill material should be inexpensive, relatively impermeable, thermally stable, highly sorptive to toxic ions, compatible with the host rock, easily applied, and, if possible, a fissure sealant. One material that apparently meets most of these qualifications is a swelling clay known as smectite or montmorillonite. The purpose of this research is to investigate experimentally the migration of representative nuclides in swollen clay gels and to formulate a quantitative transport model allowing reliable design of such an engineered barrier.

\section{BARRIER DESIGN}

Deciding how much clay is needed for adequate protection requires calculation of the rate at which typical toxic ions migrate through the backfill material. Because clay gels do not readily support flow, and because estimated convection rates in proposed geologic storage media are also low, diffusion controls the movement of ions in the gel. Ion migration rates are normally calculated from solution of the simplified diffusion equation, assuming instantaneous clay ion exchange, as defined by the retardation factor, $\mathbf{K}$.

Unfortunately, the simple diffusion equation cannot be relied upon to determine the requisite amount of clay backfill, even when the retardation factor of the clay backfill is accurately known. The reason is that no consideration is given to how the clay particles arrange themselves spatially to form the gel.

Montmorillonite clay particles are highly asymmetric platelets which aggregate to produce a gel structure. It is usually assumed that electrical double-layer and van der Walls forces cause the platelike montmorillonite particles to arrange themselves like a disheveled stack of cards (van Olphen, 1977). However, electrical conduction and low-temperature scanning electron microscopy studies in this laboratory suggest a much more open framework. A more realistic macro-microvoid geometry is therefore proposed (Fig. 1) which permits an open framework but retains the stack-of-cards arrangement.

Continuity equations must accordingly be written to account for diffusion in both the macrovolds and spherical microvoids. These have been derived for both micro- and macrovoids, assuming the geometry illustrated in Figure 1. Thus, for microvoids,

$$
\left[1+\frac{1-\varepsilon_{1}}{\varepsilon_{i}} \mathrm{k}\right] \frac{\partial c_{i}}{\partial t}=\frac{D_{i}}{r_{i}^{2}} \frac{\partial}{\partial r_{i}}\left[r_{i}^{2} \frac{\partial c_{i}}{\partial r_{i}}\right] ;
$$

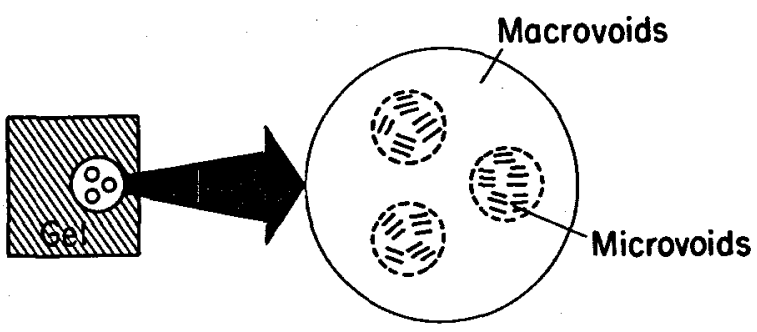

Figure 1. Proposed gel structure. [XBL 821-1618]

for macrovoids,

$\frac{\partial c}{\partial t}+\frac{4 \pi R^{2} \varepsilon_{i} D_{i} n}{\varepsilon}\left(\frac{\partial c}{\partial r}\right)_{R}=p \frac{\partial^{2} c}{\partial x^{2}}$,

where the subscript $i$ denotes the microvoid regions and unsubscripted variables refer to the macrovoid regions. In these expressions $c$ is the concentration, $\varepsilon$ is a porosity, $D$ is the diffusion coefficient, $R$ is the microsphere radius, and $n$ is the number of microvoid spheres per bed volume. The symbols $t, r$, and $x$ denote time, radial distance, and axial distance, respectively. Note that equations (1) and (2) are not equivalent to the simple diffusion equation, which does not recognize any gel structuring.

For a step release of ions from a canister at concentration $c_{0}$, Equations (1) and (2) can be solved by the method of Iaplace transforms with numerical inversion. Figure 2 reports ion-concentration profiles after a specified dimensionless release $t i m e, D t / R^{2}$, for both the simple diffusion model and the macro-microvoid model. This figure shows that toxic ions would travel farther into the barrier material for the micromacrovoid structure. For example, the 18 concentration level has traveled farther by a factor of three because of enhanced diffusion in the macrovoids as compared to uniformly dispersed clay

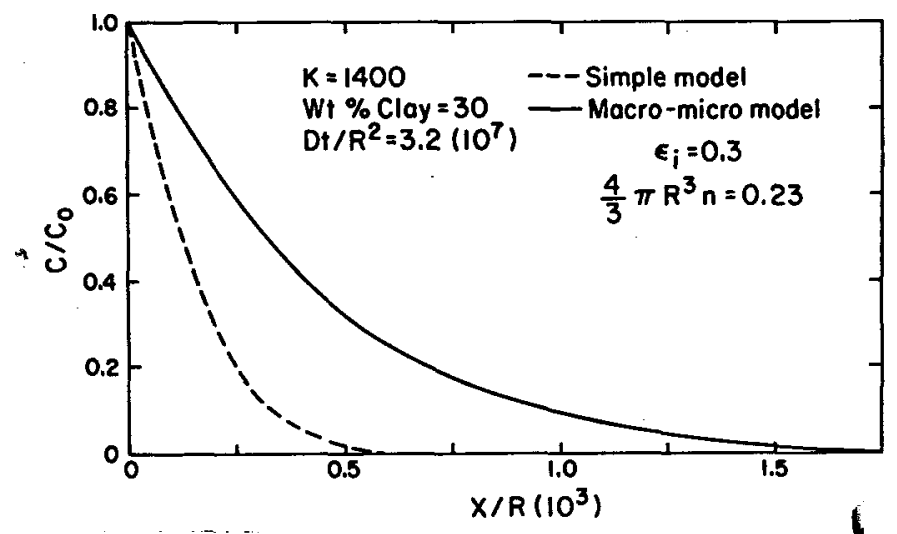

Figure 2. Ion-concentration profiles in a clay engineered barrier. [XBL 821-1620] 
particles. Consequently, nuclides could break through an engineered barrier sooner than simple model design calculations would indicate.

We conclude that it is very important to measure the actual ion-diffusion rates in montmorillonite gels and to obtain independent structure information. This will allow the formulation of a correct physical transport model, which in turn will permit reliable determination of backfill effectiveness as a nuclide-retarding medium.

\section{COLD-STAGE SCANNING ELECTRON MICROSCOPY}

(SEM)

The calculations presented in Figure 2 ind 1cate that it is essential to know the microstructure of the montmorillonite gel through which the radionuclides diffuse. Standard scanning or transmission electron microscopy (SEM or TEM) is not applicable because the high vacuum necessary to permit electron imaging sublimes the aqueous phase, destroying any gel structure. Likewise, freeze-drying will disrupt the clay gel. Only if the gel can be fast frozen and kept frozen during observation can microstructures remain intact. This is the goal of cold storage SEM or TEM. Fortunately, the University of California, at Berkeley, has one of the few cold-stage SEM units in the united states.

In the cold-stage SEM technique, the aqueous gel is placed upon a copper sample holder. The holder is then imuersed into cryogen to freeze the sample quickly. Fast freezing minimizes dendritic ice crystal formation and maintains the Ice density near that of 1iquid water. The sample is then placed into the cold-stage unit. Fracturing, etching, and coating are all performed within the cold stage at approximately $-180^{\circ} \mathrm{C}$. The sample holder is then transferred to the SEM proper, where the sample remains at $-180^{\circ} \mathrm{C}$ during examination.

Figure 3 shows an electron micrograph of the frozen, fractured, and carbon- and gold-coated montmorillonite gel. The light areas, labeled "C," are clay microregions or tactoids; the dark areas, labeled " $P$," consist of water-filled pores or macroregions, as confirmed by EDAX measurement of local silica content. The apparent roughness of the clay tactoids is a result of some instrument vibration.

Consideration of the size of an individual clay platelet (about $0.1 \mathrm{\mu m} \times 0.1 \mu \mathrm{m} \times 10 \AA$ ) leads to the conclusion that each clay tactoid region must be composed of a large number of individual platelets. This means that an ion must diffuse through the water-filled pores to the clay tactoid and then diffuse into the tactoid or card

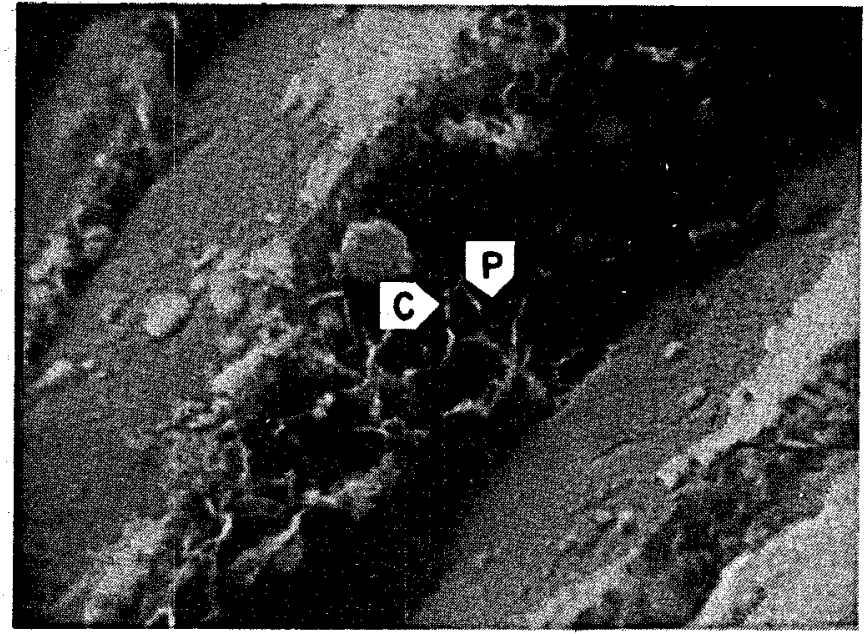

Figure 3. Freeze-fractured sample of 10 wt 8 montmorillonite clay.

[XBB 821-455]

house structure before it sorbs on the clay surfaces. Thus the cold-stage SEM micrograph in Figure 3 provides striking, yet preliminary, evidence for the existence of a micro-macrovoid structure. A more realistic description of ion transport in clay gels is provided by equations (1) and (2) rather than the simple, homogeneous diffusion equation.

\section{CONCLUSIONS}

Montmorillonite is an attractive backfill material for the underground storage of high-level radioactive waste. However, reliable design of engineered barriers using montmorillonite requires knowledge of the ion-transport phenomena in swelling clay gels. Th1s work suggests that montmorillonite gels comprise macro- and microvold regions and are most likely not a uniform, homogeneous dispersion of solid clay particles. If this assertion is correct, diffusion equations accounting for these structuring effects indicate that larger amounts of barrier material will be required than predicted from the simple diffusion equations. Preliminary cold-stage SEM studies provide striking evidence for the gel structure, thus supporting the macro-microvoid hypothesis.

\section{REFERENCE CITED}

van Olphen, J., 1977. An Introduction to Clay colloid Chemistry. New York, Wlley-Interscience. 
INVESTIGATION OF SILICATE SURFACE CHEMISTRY AND REACTION MECHANISMS ASSOCIATED WITH MASS TRANSPORT IN GEOLOGIC MEDIA

A. F. White and D. L. Perry

The concentration and rate of transport of radionuclides through geologic media can be strongly influenced by the extent of sorption on aquifer surfaces. Over time intervals relevant to such transport processes, rock and mineral surfaces cannot be considered as inert, unreactive substrates but rather as groundwater/solidphase interfaces which are commonly in a state of natural or artificially induced diseguilibrium.

The goal of the present research is to define experimentally the type of water/rock interactions that will influence surface chemistry and hence sorption characteristics and capacities of natural aquifers. As wide a range of silicate minerals as possible was selected for study to represent rock-forming minerals in basalt, tuff, and granite. The minerals include $\mathrm{K}$-feldspar, plagioclase feldspar, olivine, hornblende, biotite, and volcanic glass.

\section{CESIUM SORPTION EXPERIMENTS}

Previous workers (Relyea et al., 1978) have shown that laboratory-measured $\mathrm{R}_{D}$ 's describing cesium sorption change significantly with equilibrium time. Experiments in the current program were conducted under controlled experimental conditions of temperature, $\mathrm{pH}$, and partial pressures of dissolved $\mathrm{CO}_{2}$ and $\mathrm{O}_{2}$ in order to define surface reaction mechanisms responsible for such changes. Initial scoping tests were conducted to estimate ranges in surface area, cesium concentrations, and fluid volumes required to measure significant sorption. Figure 1 shows an example of cesiun loading for several mineral phases. As indicated, the $K_{D}$ is quite sensitive to the total amount of cesium present in solution, indicating that sorption sites are not saturated.

Long-term weathering experiments have been monitored for six months. Figures 2 and 3 show a comparison in rock-waste interaction rates of $\mathrm{R}$-feldspar and plagioclase feldspar in which the data are plotted for time in seconds versus aqueous concentrations in millimoles per 1iter. The broken lines indicate the initial cesium concentration in solution. As observed previously by Lagache and Sabatier (1973), K-feldspar dissolution is highly incongruent, since sodium is released more rapidly than potassium. In contrast, sodium and calcium releases from plagioclase are generally congruent. $\mathrm{K}$-feldspar shows an immediate initial uptake of cesium into the surface with time, which is probably due to substitution of cesium for potassium in the surface layer of the silicate structure, an effect observed in high-temperature solid solution studies of natural feldspar (Afonino, 1978). However, with longer times the cesium concentration increases in aqueous solution, indicating progressive desorption from the surface. Plagioclase feldspar shows a similar but less pronounced desorption of cesium with long-term reaction.

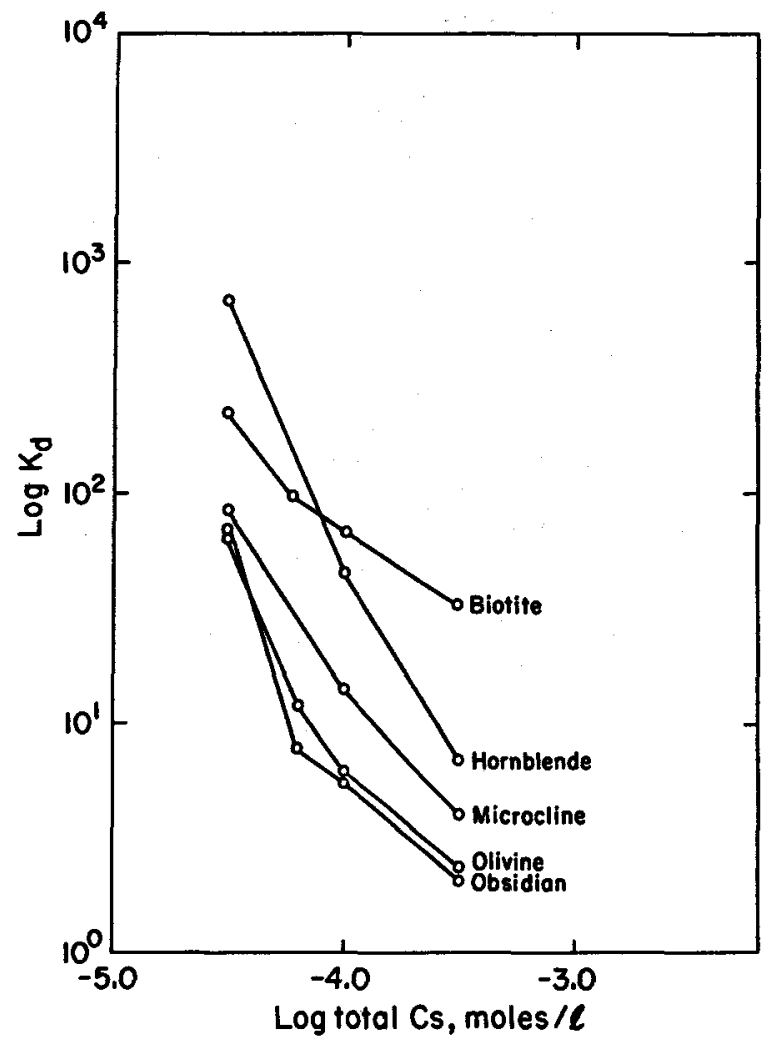

Figure 1. Changes in apparent cesium $K_{D}$ as a function of total cesium loading. [XBL 819-7229]

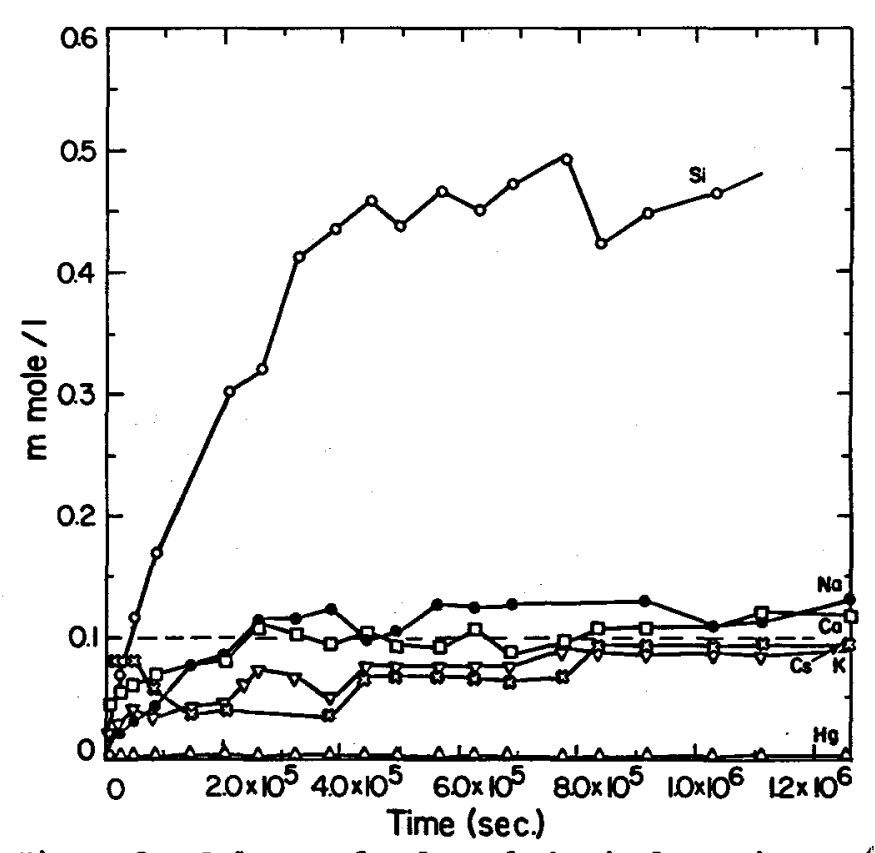

Figure 2. Release of selected chemical species and sorption of cesium during reaction of $\mathrm{K}-$ feldspar in water at pH 8 and a dissolved oxygen concentration of $0.1 \mathrm{ppm}$. [XBL 8110-1489] 


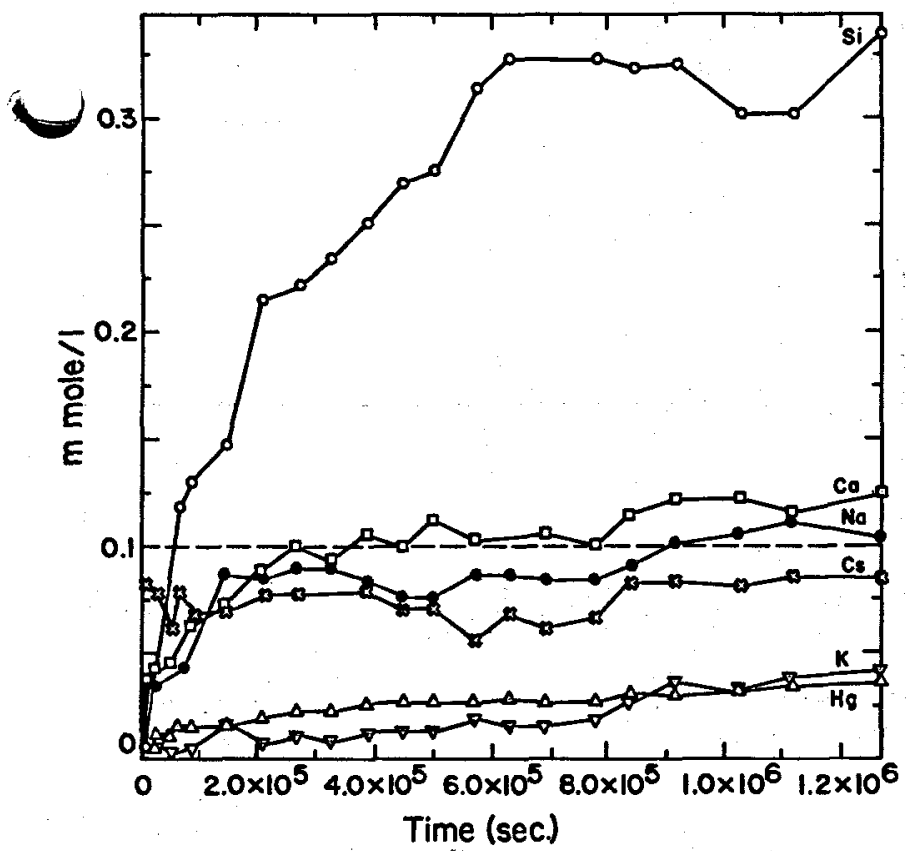

Figure 3. Release of selected chemical species and sorption of cesium during reaction of plagioclase feldspar in water at $\mathrm{pH} 8$ and a dissolved oxygen concentration of 0.1 ppm. [XBL 8110-1500]

\section{CLOSED SYSTEM EXPERIMENT}

A series of experiments was conducted to evaluate the rates at which dissolved oxygen is consumed by reaction with silicate minerals. such reactions may be instrumental in controlling the redox potential in groundwater. Interesting1y, many relatively old groundwater systems, such as Pleistocene groundwaters in tuff at the Nevada Test Site (I. Winograd, 1980 , personal communication) still possess significant dissolved oxygen, suggesting that oxygen-consuming reactions may be very slow. Initial experiments consisted of saturating detonized water with $80 \mathrm{ppm}$ dissolved oxygen in sealed bottles along with measured weights of mineral phases. Figure 4 shows an example of changes in dissolved oxygen with the square root of time for a number of minerals and a blank. As indicated, the overall change in oxygen content over a period of two months is generally very small. As would be expected, blotite and hornblende, two minerals with the largest concentrations of ferrous iron, show the greatest uptake of oxygen. Rates of reaction are generally slower than that observed by Siever and woodford (1979) for pyroxene and Iron-rich olivine.

\section{SURFACE ANALYTICAL TECHNIQUES}

In the last several years, a number of new instrumental surface techniques have been developed, such as $x$-ray photoelectron spectroscopy (XPS), Auger electron spectroscopy (AES), and condary ion mass spectrometry (SIMS), which may quite effective in detecting changes in the surfaces of minerals that have undergone rock-water interaction. Such techniques are sensitive to all metals in the periodic table; Several of

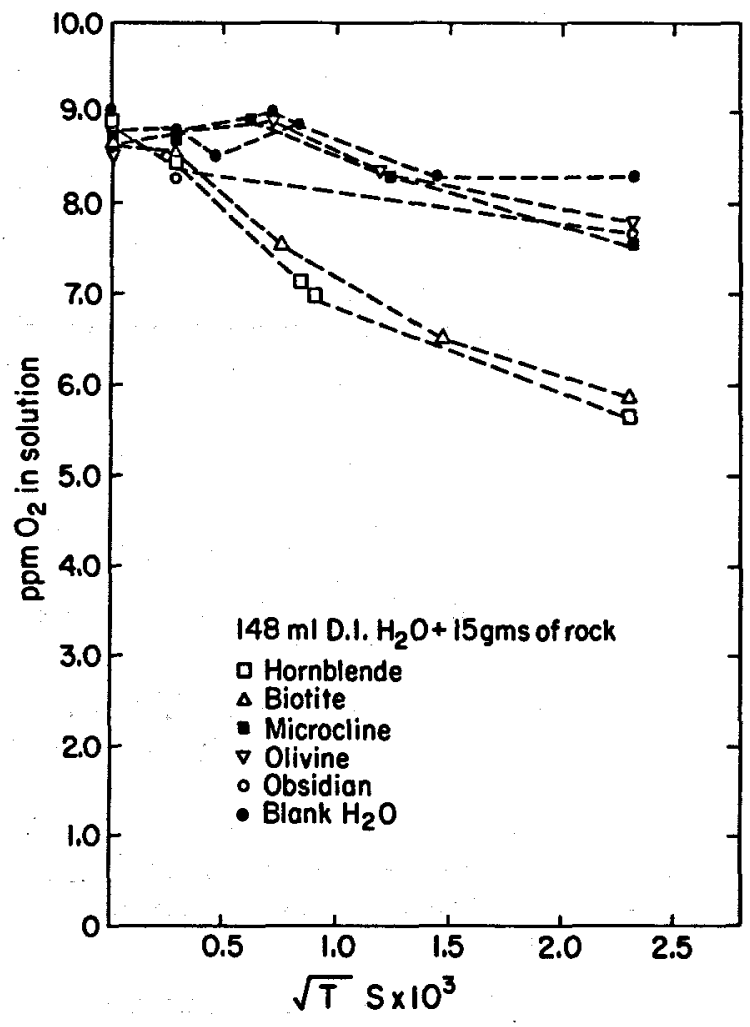

Figure 4. Dissolved oxygen uptake during rockwater interaction as a function of time.

[XBL 819-7232]

them give some information about the chemical bonding environment of the element being studied. Such surface studies involve only the first several layers of the mineral, the mineral volume most affected by the rock-water interaction process. Many of the instrumental surface approaches can be coupled with depth-profiling processes to actually measure changes in elemental concentrations as a function of depth within the surface layer.

Figure 5 shows an Auger survey. scan 10 to $1000 \mathrm{eV}$ ) of a hornblende sample that has not been surficlally modified by any type of chemical or rock-water interaction process. This particular spectrum reveals the major components of the mineral that would be expected, including a small amount of iron. The calcium line is slightly asymmetrically broadened because of overlap with a lower-energy carbon Auger line.

In order to check homogeneity of the hornblende surface with respect to the entire sample, the hornblende surface was sputtered so that the spectral features of the deeper material may be seen. The rate at which the layers are removed is about $30 \mathrm{~A} / \mathrm{s}$. This value is based on the sputtering rate of quartz, since precise individual sputtering rates for common minerals such as hornblende are not known. Figure 6 shows a survey scan of hornblende that has been sputtered for $1 \mathrm{~min}$, equal to the removal of $180 \AA$ of material. The spectrum is virtually identical to that of the untreated hornblende, except that all of the carbon originally present on the surface is 


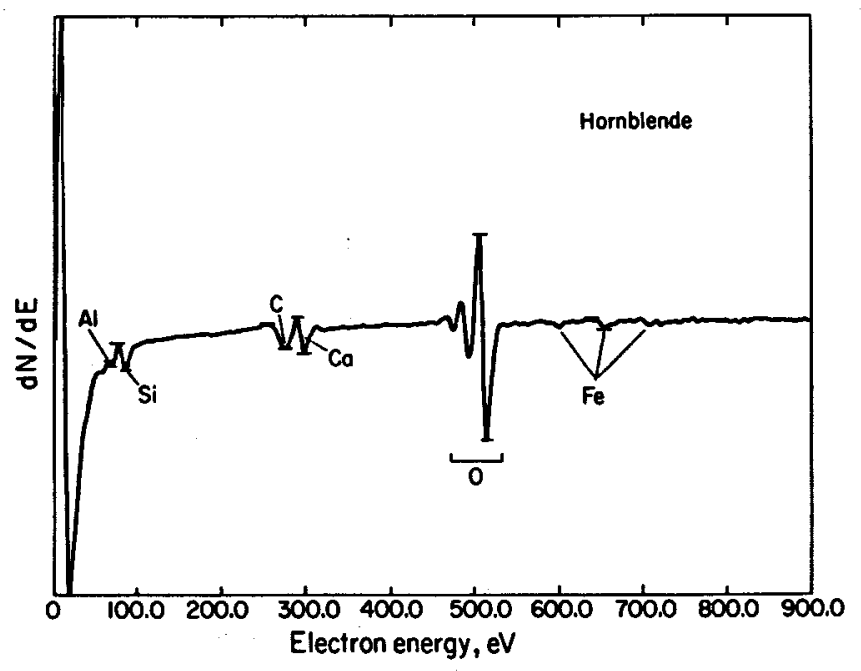

Figure 5. Hornblende Auger survey scan, "as received."

[XBL 813-2780]

absent. The calcium content is also diminished compared with that found on the initially untreated mineral surface.

Figure 7 shows the Auger spectrum of hornblende that has been leached in water at low oxygen pressure for one week. The qualitative,

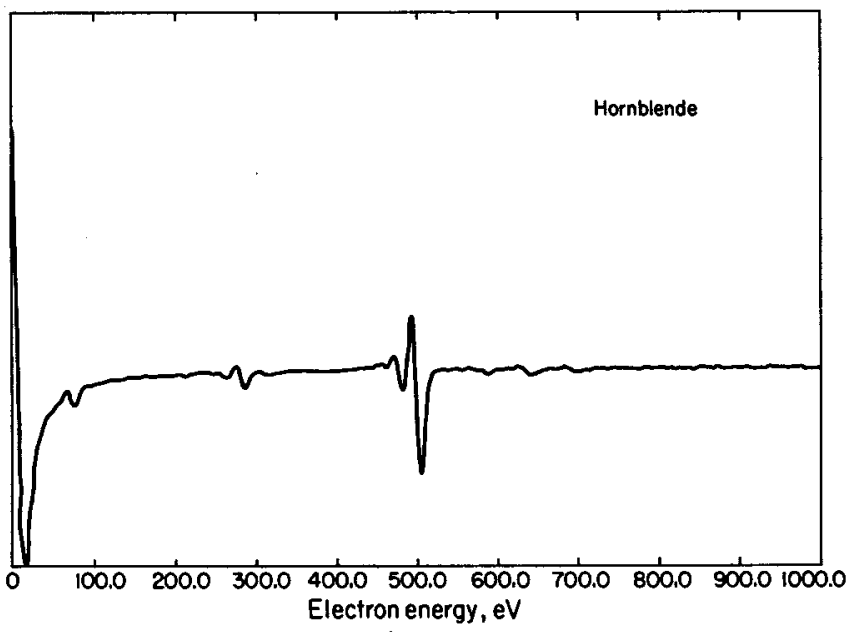

Figure 6. Hornblende Auger survey scan, "as received," 1-min sputter.

[XBL 819-7233]

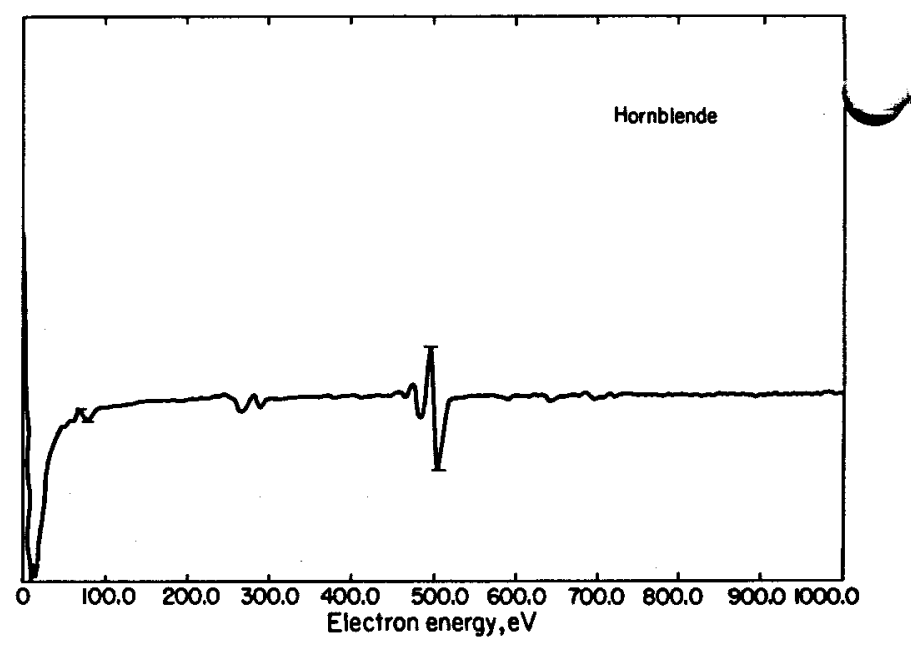

Figure 7. Hornblende survey scan, $\mathrm{H}_{2} \mathrm{O}$ leached for one week.

[XBL 819-7234]

elemental content of the surface is quite comparable to that in Figure 5, but there are some notable differences. For example, the gross spectral features of the calcium and potassium lines have shifted.

REFERENCES CITED

Afonino, G. C., 1978. Effect of rubidium and cesium on the structural states of potash feldspar from rare-metal pegmatites. International Geologic Review, v. 21, no. 5, p. 597-604.

Lagache, K., and Sabatier, G., 1973. Distribution des éléments $\mathrm{Na}, \mathrm{K}, \mathrm{Rb}$ et $\mathrm{Cs}$ á 1 'état de trace entre feldspaths alcalins et solutions hydrothermales a $650^{\circ} \mathrm{C}$ et 1 kbar: Données experimentales et interpretation thermodynamique. Geochimica et Cosmochimica Acta, v. 37, p. 2617-2640.

Relyea, J. F., Ames, L. L., and Serne, R. J., 1978. The kinetics and reversibility of radionuclide sorption reactions with rocks. Second Contractor Meeting, Waste Interaction Safety Assessment Program, Pacific Northwest Laboratories, Washington, p. 163-204.

Siever, J. F., and Woodford, N., 1979. Dissolution kinetics and the weathering of mafic minerals. Geochimica et Cosmochimica Acta, v. 43, p. 717-724. 


\title{
SWEDISH-AMERICAN COOPERATIVE PROGRAM
}

\section{RESEARCH ON NUCLEAR WASTE ISOLATION AT STRIPA: AN OVERVIEW}

\author{
P. A. Witherspoon, N. G. W. Cook, J. E. Gale, and C. R. Wilson
}

A principal attribute of deep geologic disposal of radioactive waste is the high degree of physical protection it provides against human intrusion and natural events. However, even in a geologically suitable area, transport to the biosphere may occur through groundwater. There are, therefore, a number of attributes that any site should have: low permeability, low interconnected porosity, low hydraulic gradient, and high sorptive capacity. Heat generated by the waste introduces the additional requirements of chemical and mechanical stability. To assess the ability of a rock mass to isolate waste, new experimental techniques and analytical procedures must be developed to Improve understanding of rock mass behavior and transport in slowly moving groundwaters (wither spoon et al., 1981).

Over the past several years, thermomechanical, hydrological, and geochemical investigations have been conducted by Lawrence Berkeley Laboratory in a fractured quartz monzonite rock (Olkiewicz et al., 1979) at a depth of some $340 \mathrm{~m}$ in a workedout iron ore mine at stripa in Sweden. This work is part of a Swedish-American cooperative program (Wither spoon and Degerman, 1978).

\section{THERMOMECHANICAL INVESTIGATIONS}

The thermomechanical investigations were designed to study in situ rock behavior under thermal loads comparable to those of a waste repository. There were two types of experiments: (1) full-scale heater tests to study the near-field response of the rock under simulated short-term and long-term conditions, and (2) a time-scaled experiment in which, by applying dimensional analysis to the laws of heat conduction, the linear proportions of the heater array were reduced to 0.32 of full-scale, making each year of data equivalent to 10 years of data from the full-scale system.

As shown in Figure 1, the full-scale heater experiments consisted of electric heaters housed in 3-m-1ong by $0.3-m-d i a m e t e r$ canisters that simulated the power output of the waste. Two canisters were placed in vertical holes penetrating $5.5 \mathrm{~m}$ into the floor of the entry. The 5-kW heater power of one canister was designed to model the heat produced by reprocessed waste 3 yr after removal from a light water reactor; the $3.6-\mathrm{kW}$ Dower of the other was to simulate 5-yr-old waste.

mperatures, stresses, and displacements in the bck surrounding the heaters were measured using an extensive array of thermocouples, borehole deformation stress gauges, vibrating wire stress

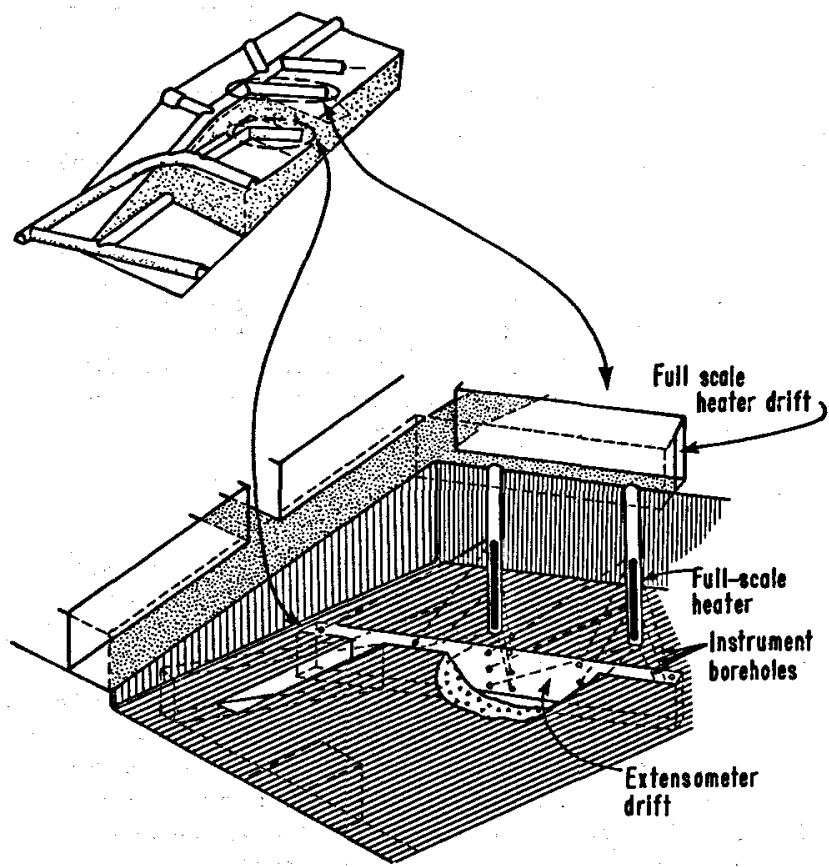

Figure 1. Arrangement of full-scale heater experiment. [XBL 785-970A]

gauges, and multiple-point extensometers (Schrauf et al.. 1979). Rock properties and rock mass characteristics were studied by an extensive program of laboratory tests, geologic investigations, geophysical techniques, and fracture mapping.

Comparison of the experimental data with the results of numerical methods of analysis showed excellent agreement between predicted and measured temperatures in the rock surrounding the heaters (Chan et al., 1980a). However, initial predictions of displacement and stresses were significantly greater than measured values. More advanced analytic procedures that included consideration of the temperature dependency of the coefficlent of thermal expansion, $\alpha$; Young $s$ Modulus, E; Poisson's ratio, $v$; and the thermal conductivity, $k$, for intact rock were applied later and showed much better agreement with the measured data. Figure 2 compares the initial predictions with the more advanced procedures for estimating rock displacement between anchor point $2.24 \mathrm{~m}$ vertically above and below the mid-plane of the 3.6-kw full-scale heater at a radial 


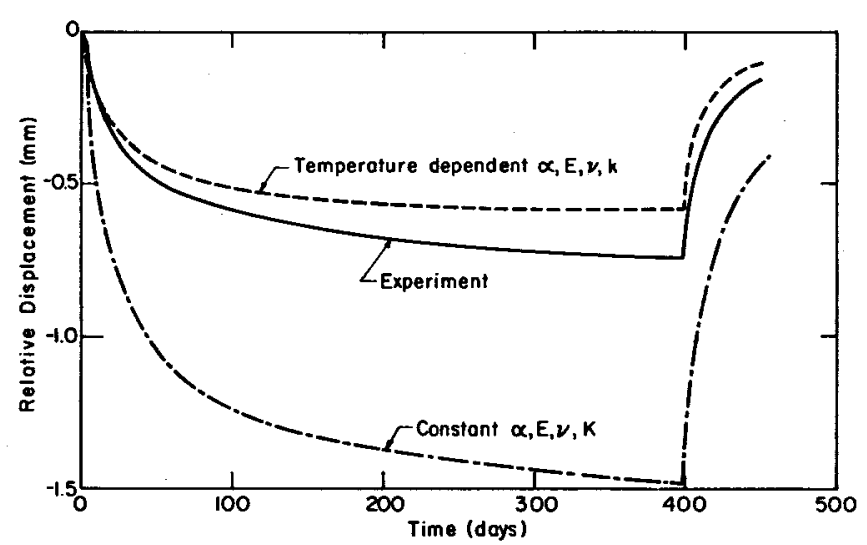

Figure 2. Measured and calculated vertical displacements at $1.0 \mathrm{~m}$ radius from the $3.6-\mathrm{kW}$ fullscale heater.

[XBL 801-4611]

distance of $1.0 \mathrm{~m}$. More study is required to resolve the remaining discrepancies, particularly with respect to the role of discontinuities in controlling the thermomechanical behavior of a rock mass (Chan et al.. 1980b).

\section{FRACTURE HYDROLOGY}

The hydrological properties of the rock mass - at Stripa are being studied by two approaches. The first involves gathering data by fracture mapping of outcrops, underground exposures, boreholes drilled from the surface to the experimental level, and boreholes drilled from the underground entries. Fracture orientations and frequency were reconstructed from oriented cores, and effective fracture apertures were computed from the results of a large number of injection tests (Gale et al., 1979). These data are being integrated in an attempt to define a permeability tensor for the rock mass.

The second approach is a new concept involving direct measurement of rock mass permeability through a large-scale test (Witherspoon et al., 1980). As shown in Figure 3, a 33-m long entry was sealed and equipped with a ventilation system to control the evaporation of water seeping into the room. The water seepage rate was measured as the difference in relative humidity between the inlet and exhaust air streams. Water pressure in the rock mass around the drift was measured at 90 points in boreholes radiating from the entry. This large-scale test measured the average permeability of $10^{5}$ to $10^{6} \mathrm{~m}^{3}$ of rock.

Figure 4 shows a distance-drawdown plot of pressure data from the radial boreholes. The weighted average of all data plots as a straight line with a correlation coefficient of 0.98 . Assuming that 808 of the $50-\mathrm{ml} / \mathrm{min}$ flow occurred radially into the drift, the average hydraulic conductivity of the rock mass is computed to be $1.0 \times 10^{-10} \mathrm{~m} / \mathrm{s}$. The break in the weighted average reflects a reduction in conductivity in the rock immediately surrounding the entry. This reduction could be attributed to perturbation of the rock mass during excavation of the opening. Results from the large-scale experiment will be

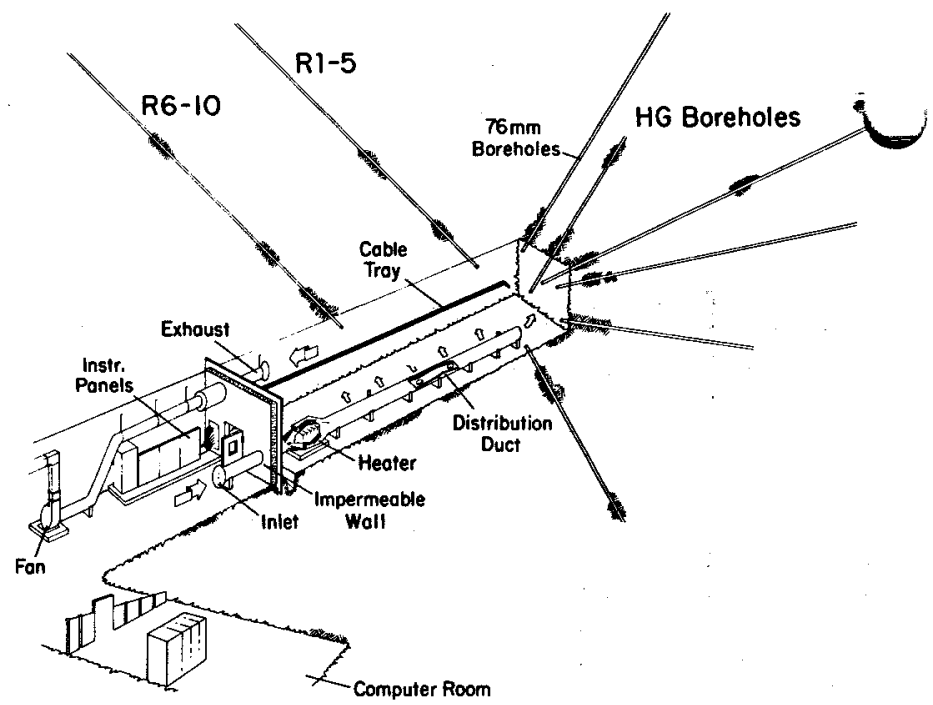

Figure 3. Large-scale permeability experiment.

[XBL 819-11583]

compared with estimates of rock mass permeability synthesized from the more conventional borehole methods to assess the accuracy of the integration techniques.

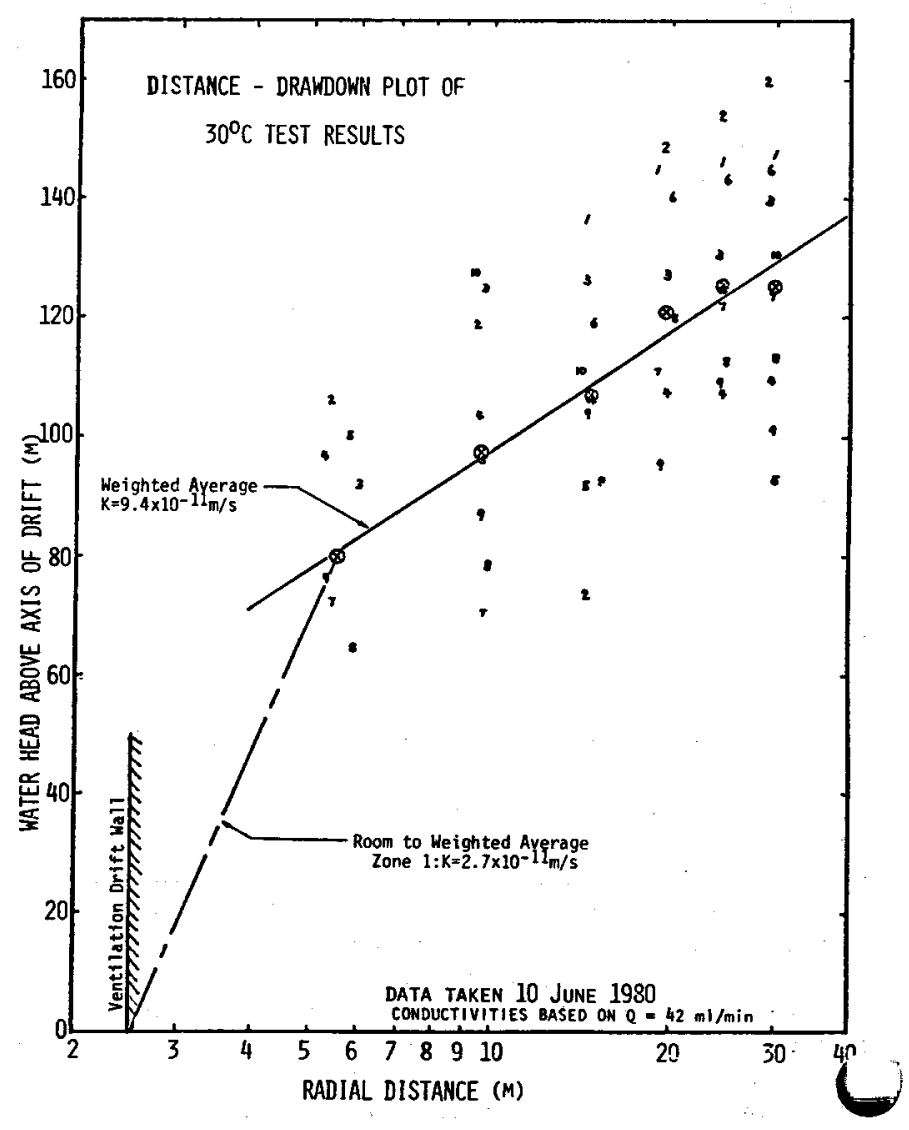

Figure 4. Distance-drawdown plot from large-scale permeability experiment.
[XBL 8011-12711] 
GEOCHEMISTRY AND ISOTOPE HYDROLOGY

Geochemistry and 1sotope hydrology provide an independent approach to evaluation of rock mass permeablilty. Comprehensive geochemical investigations of Stripa groundwaters have been carried out by Fritz et al. (1979). Water samples were collected from the surface, shallow wells, underground boreholes, and deep boreholes drilled from the surface. Analyses of the chlorine, deuterium, and 180 content of the samples indicate that the sources of deep mine waters are different from those of the near-surface waters and that the deep waters seeped into the rock mass at a time when the climatic conditions and the geochemical environment were much different from those that now prevail at Stripa.

Isotope dating using tritium and ${ }^{14} \mathrm{C}$ also indicates a sharp contrast between near-surface and deep groundwaters and suggests that the age of water at a depth of $330 \mathrm{~m}$ probably exceeds $20,000 \mathrm{yr}$. Dating methods based on the uranium decay series included uranium activity ratios, helium contents, and radium-radon relationships. Deep groundwater ages ranging from 10,000 to 35,000 yr were indicated by the radium-radon method. ${ }^{4} \mathrm{He}$ and $234 \mathrm{U} / 238 \mathrm{U}$ methods suggest ages exceeding 100,000 yr. Another method that relates ${ }^{4} \mathrm{He}$ to $i t s$ parent $238_{\mathrm{U}}$ yields ages ranging from tens of thousands to hundreds of thousands of years.

\section{CONCLUSIONS}

The work at stripa has demonstrated the importance of large-scale underground experiments to the evaluation of the thermomechanical and hydrologic evaluation of rock masses being considered as sites for the disposal of radioactive waste. Several innovative techniques have been developed that may be applied in repository site characterization and design studies. The experience gained at stripa indicates that extensive subsurface testing $w 111$ be required to reduce the uncertainties associated with the more conventional methods that rely on testing carried out on the surface or in boreholes arilled from the surface.

\section{REFERENCES CITED}

Chan, T., Hood, M., and Witherspoon, P. A. 1980a. Predicted and measured temperatures, displacements and stresses from the Stripa heater experiments. In Proceedings, Rockstore ' 80 , Stockholm, Sweden, June 23-27, 1980, p. 829-837.

Chan, T., Javandel, I., and witherspoon, P. A., $1980 \mathrm{~b}$. Heat transfer in underground heating experiments in granite, Stripa, Sweden. In F. A. Kulacki and R. W. Lyckkowski (eds.), American Society of Mechanical Engineers Monograph HTD-Vo1. II, p. 1-8.

Fritz, P., Barker, J. F., and Gale, J. E., 1979. Geochemistry and isotope hydrology of groundwaters in the Stripa granite. Results and preliminary interpretation. Lawrence Berkeley Laboratory Report LBL-8285 (SAC-12).

Gale, J. E., Quinn, O., Wilson, C., Foster, C., witherspoon, R. A., and Jacobson, L., 1979. Hydrologic characteristics of fractured rocks for waste isolation--The stripa experience. In Proceedings, Scientific Basis for Nuclear Waste Management, Vol. 2, Boston, Massachusetts, November 1979, p. 507-518.

Olkiewlcz, A., Gale, J. E.., Thorpe, R., and Paulsson, B.. 1979. Geology and fracture system at stripa. Lawrence Berkeley Laboratory Report LBL-8907 (SAC-21).

Schrauf, T., Pratt, H., Simonson, E., Hustrulid, W., Nelson, P., DuBois, A., Binnall, E., and Haught, R.., 1979. Instrument evaluation, callbration and installation for the heater experiments at Stripa. Lawrence Berkeley Laboratory Report LBL-8313 (SAC-25).

Wi therspoon, P. A., and Degerman, 0., 1978. Swedish-American cooperative program on radioactive waste storage in mined caverns. Lawrence Berkeley Laboratory Report LBL-7049 (SAC-01).

Witherspoon, P. A., Cook, N. G. W., and Gale, J. E., 1981. Geologic storage of radioactive waste: Field studies in sweden. Science, v. 211, p. 894-900.

Witherspoon, P. A., Wilson, C. R., Long, J. C. S., DuBols, A. O., Gale, J. E., and Galbraith, R. M.. 1980. Large-scale permeability measurements in fractured crystalline rock. In Proceedings, International Geologic Congress, Paris, France, July 1980. 


\title{
RADIOGEOLOGIC ASSESSMENT FOR NUCLEAR WASTE ISOLATION: STUDIES OF THE STRIPA PLUTON
}

\author{
$H$. Wollenberg, S. Flexser, and L. Andersson
}

To properly characterize candidate sites for radioactive waste isolation, it will be necessary to obtain a good understanding of their radiogeologic settings. The distribution and abundance of the naturally occurring radioelements--238 $\mathrm{J}$, ${ }^{232} \mathrm{Th}$, their daughters, and $40_{K}$, both in the rock mass encompassing the repository and in the neighboring rocks--constitute the baseline upon which the effects of the radioactive waste are super imposed. The distribution of these radioelements is also a good indicator of the geochemical homogeneity of the rock mass. At the Stripa experimental facility in an inactive iron mine in central Sweden, radiogeologic studies included gamma-spectrometric surveys, on the surface and underground, of the $U, T h$, and $K$ contents of the quartz monzonite pluton encompassing the experiments, the high-grade metamorphic rocks surrounding the pluton, and the neighboring larger granitic plutons (Wollenberg et al., 1981). The gamma-spectral surveys were calibrated by laboratory analyses of hand specimens and drill cores, permitting calculation of radioelement concentrations from field counting rates. It was found that the Stripa pluton has anomalously high $U$ and Th contents ( 25 to $35 \mathrm{ppm}$ ) and U/Th ratios $(\sim 1)$ compared to worldwide averages of granttic rocks and of neighboring plutons and metamorphic rocks (Table 1).

Fission-track radiography disclosed the distribution of $235_{\mathrm{U}}$ within the rock and indicated that at Stripa uranium is associated primarily with high-radioactivity (up to $258 \mathrm{U}$ ) - opaque

Table 1. Mean radioelement contents determined by field measurements.

Rock U (ppm) Th(ppm) $\quad K(8) \quad T h / U$

\section{Stripa Quartz Mon- zonite}

$\begin{array}{lllll}\text { Surface } & 27 & 33 & 4.6 & 1.1 \\ \text { Underground } & 37 & 29 & 3.9 & 0.8\end{array}$

Leptite

\begin{tabular}{lcccc} 
Surface & 3.3 & 12 & 3.1 & 3.6 \\
Underground & 5.4 & 18 & 2.8 & 3.9 \\
Regional Granitic & 18 & 27 & 5.2 & 2.4 \\
$\begin{array}{l}\text { Rocks } \\
\text { Regional Metamorphic }\end{array}$ & 6.1 & 15 & 2.5 & 2.6 \\
\hline
\end{tabular}

minerals, but is also disseminated in chlorite, the predominant fracture-filling mineral in the quartz monzonite (Fig. 1). This uranium-mineral association suggests that a significant component of the uranium has been mobile, and is in contrast to the association in most plutonic rocks, where $U$ is generally locked into accessory minerals, such as sphene, zircon, monazite, and apatite. The uranium concentrations associated with chlorite-filled fractures are the most likely sources of the radon-222 which Nelson et al. (1981) observed in water in some of the Stripa boreholes. This radon serves as a natural tracer to locate fractures in boreholes along which significant flow is occurring and to measure the groundwater flow rates in the fractures.

The concentrations and distributions of uranIum, thorium, and their daughters in the accompanying groundwater system also form an important baseline, and when combined with rock radioelement concentrations (Fig. 2), permit determination of
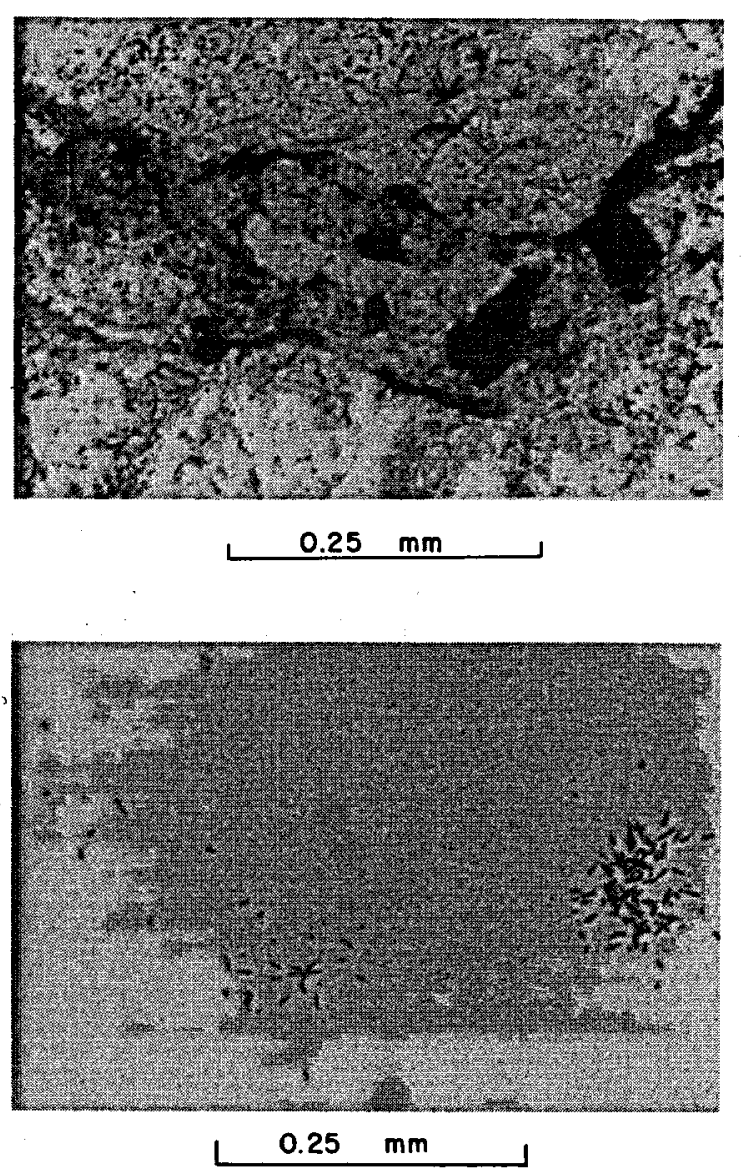

B

Figure 1. Fission tracks (B) from uranium in euhedral opaque grain (20 to $308 \mathrm{U})$ and along fine chlorite-filled fractures $(0.5$ to $18 \mathrm{U})$ in fractured quartz monzonite. 
Th and $\mathrm{U}$ in Quartz Monzonite

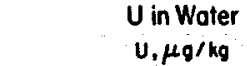

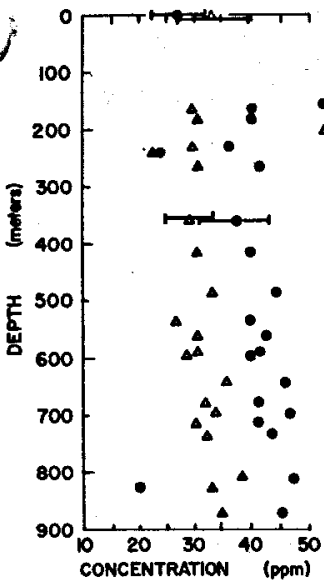

(a)

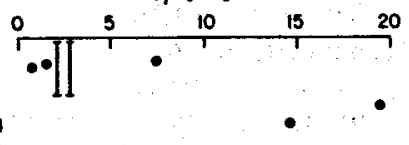

IX $\mathbf{F}^{1}$

I

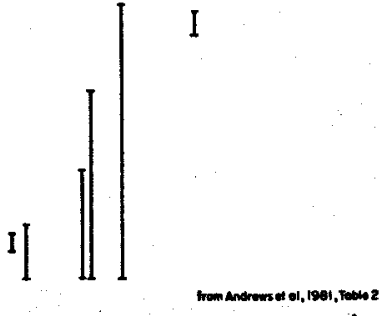

(b)

Figure 2. Variation of thorium and uranium with depth in quartz monzonite of the Stripa pluton (a) and of uranium with depth in Stripa groundwater (b). Vertical bars represent packed-off intervals in boreholes. (Data in part b after Andrews et al., 1981.)

[XBL 821-1607] those from $14 \mathrm{C}$ dating, which inalcated that water discharging in the deeper portions of the mine and in a deep borehole drilled below the 410-m level was recharged more than 20,000 years ago.

Besides defining the natural radioactivity baseline, radioactive decay of the $0, T h$, and $K$ in the rock $y$ ields the radiogenic heat production which, combined with measurement of the regional and local heat flow, permits calculation of the apparent size of the rock mass encompassing the repository. Heat flow and radiogenic heat productivity considerations show that even though the Stripa quartz monzonite contains high abundances of radioelements, it has little effect on the regional heat flow. If the stripa pluton occurs in a layered plutonic setting, it is probably not more than $\sim 1.5 \mathrm{~km}$ thick (Fig. 3), otherwise, it could be elther a stock or a dike that is relatively small compared to the large granitic plutons in the region. This method is especially useful in terranes like the one at stripa, where the size of the pluton is difficult to assess because its contacts with neighboring rock masses are concealed.

\section{REFERENCES CITED}

Andrews, J. N., Giles, I. S., Kay, R. L. F., Lee, D. J., Osmond, J. K., Cowart, J. B., Fritz, P. Barker, J. F., and Gale, J., 1981. Radioelements, radiogenic helium and age relationships for groundwaters from the granites at stripa. Sweden. In preparation.

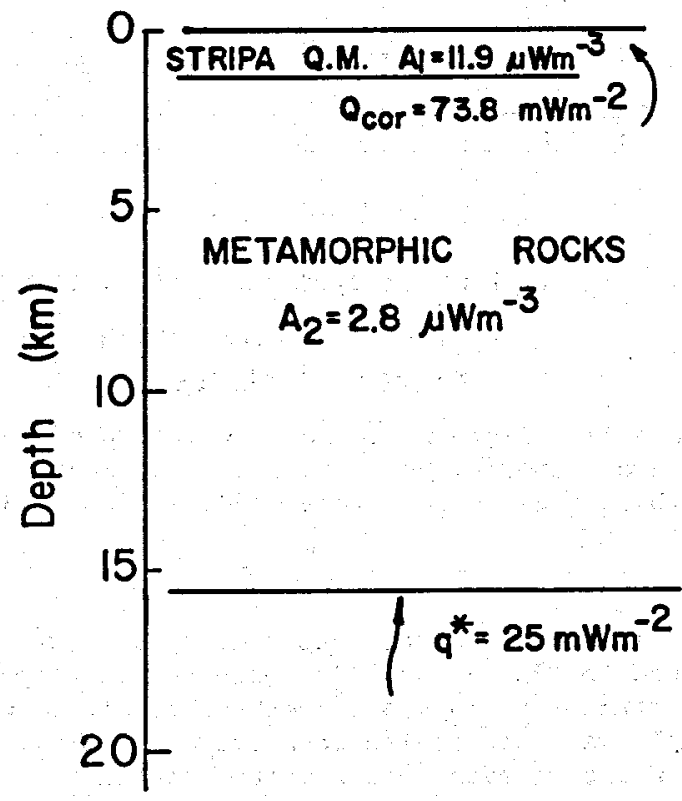

(a)

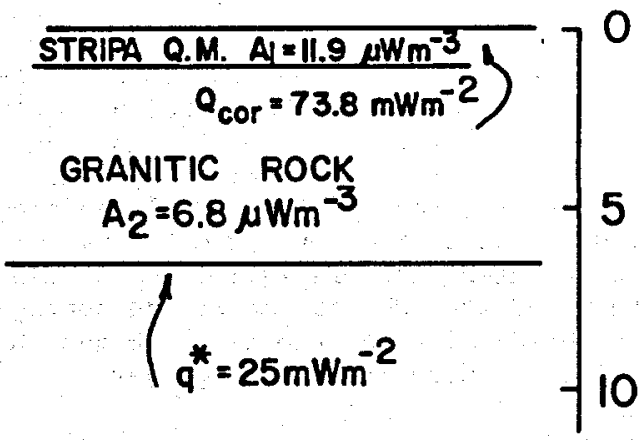

the apparent age of the groundwater. At Stripa
water ages in the range $5 \times 10^{4}$ to $2 \times 10^{5}$ yr were based on the 4 He content of the deep water and $v$ and Th contents of the rock and fracturefilling material (Fritz et al., 1979, Wollenberg et al.. 1981). These ages are in accord with 
Fritz, P., Barker, J. F., and Gale, J. E., 1979. Geochemistry and isotope hydrology of groundwaters in the Stripa granite. Results and preliminary interpretation. Lawrence Berkeley Laboratory Report LBL-8285 (SAC-12).

Nelson, P. H., Rachiele, R., and Smith, A., 1981. The effect of radon transport in groundwater upon gamma-ray borehole logs. Lawrence Berkeley Laboratory Report LBL-11180. Wollenberg, H. A., Flexser, S., and Anderson, L., 1981. Petrology and radiogeology of the Stripa pluton. Lawrence Berkeley Laboratory Report LBL-11654.

\section{THERMOMECHANICAL PROPERTIES OF STRIPA GRANITE}

L. Myer

The stripa material properties testing program was initiated to study, by laboratory testing, the thermomechanical behavior of the Stripa rock mass and to provide material properties for input into numerical programs for simulation of the in situ heater experiments at stripa. The portion of the program dealing with measurement of elastic moduli and coefficients of thermal expansion of dry, intact samples of stripa granite was completed in fiscal year 1980. A summary of the most significant findings resulting from tests on six samples are presented in this report.

\section{SAMPLE SELECTION AND PREPARATION}

Samples were selected from cores obtained from the various instrumentation holes in the experimental area. Although an effort was made to obtain samples from numerous locations in order to study spatial variability of parameters, sample selection was most heavily influenced by availability of intact lengths of core. As a result, most samples were actually from the time-scale experimental area.

The principal means of measuring sample deformations was by strain gauges attached directly to the sample. Four strain gauges 0.5 in. long were placed approximately at sample midplane. Two gauges were oriented axially and placed diametrically opposite each other. Similarly, two gauges were oriented circumferentially. Strain gauges were wired in a Wheatstone Bridge configuration, one bridge for the two axial gauges and one bridge for the circumferential gauges.

\section{TEST PROCEDURES}

In order to bracket temperature and stress conditions likely to have existed in the field experiment, tests were performed over a range of temperature (room to $\left.200^{\circ} \mathrm{C}\right)$, hydrostatic stress (2 to $55 \mathrm{MPa}$ ), and deviator stress. The manner in which testing proceeded through this matrix is illustrated by Figure 1. First of all, hydrostatic stress on the sample was increased to 55 Ma. While maintaining a constant hydrostatic stress, the temperature was increased to $50^{\circ} \mathrm{C}$ and allowed to stabilize. Thermal expansion measurements were taken and the temperature increased to $75^{\circ} \mathrm{C}$. At this temperature both thermal expansion measurements and stress-strain measurements for elastic modull determination were made. The sequence of thermal expansion measurements every

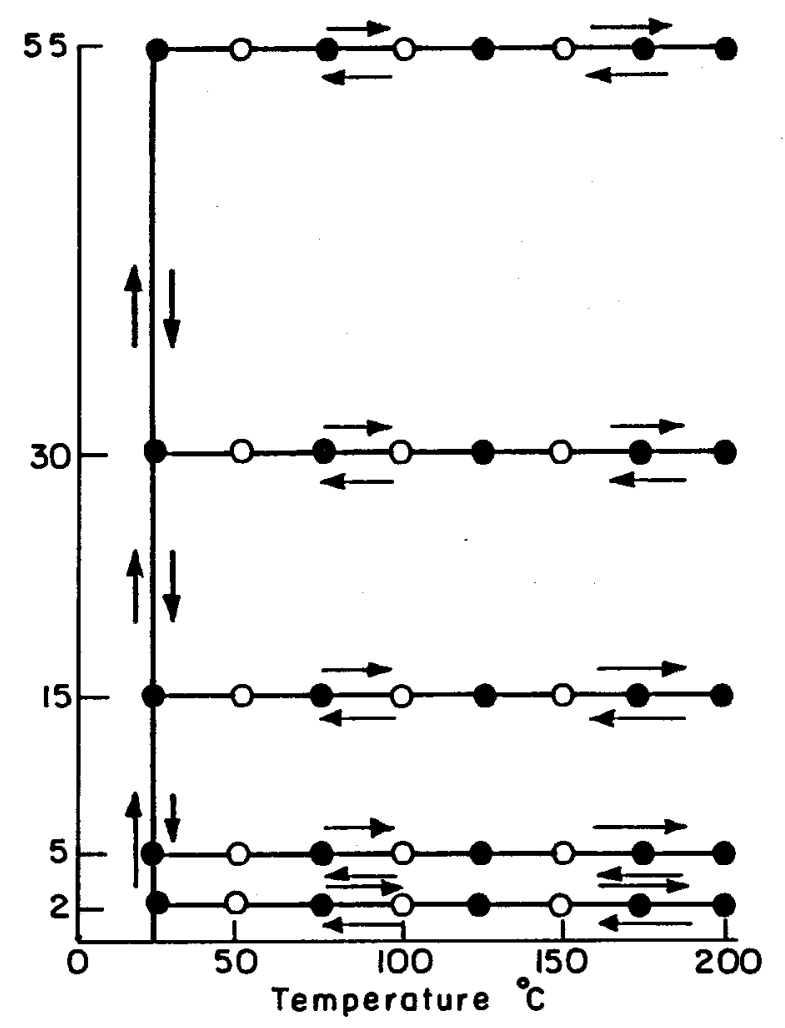

O Thermal exponsion measurements

- Thermal expansion measurement and stress-stroin test

Figure 1. Diagrammatic representation of test sequence, showing pressure and temperature states at which measurements were made.

[XBL 813-8385]

$25^{\circ} \mathrm{C}$ and stress-strain tests every $50^{\circ} \mathrm{C}$ was continued to $175^{\circ} \mathrm{C}$. At $200^{\circ} \mathrm{C}$ both thermal expansion and stress-strain measurements were made. The sample was then cooled in steps of $25^{\circ} \mathrm{C}$ with thermal expansion measurements made each $25^{\circ} \mathrm{C}$ and stress-strain tests made every $50^{\circ} \mathrm{C}$ from 175 to $25^{\circ} \mathrm{C}$. The confining pressure was then reduced to the next lower confining pressure in the test matrix and the above sequence of tests repeated. For two samples a shorter test procedure was followed in which thermal cycles at $30 \mathrm{MPa}$ and $2 \mathrm{MPa}$ confinement were eliminated. 
A potential disadvantage of a test sequence involving measurements at many P-T states is that the sample may be damaged at one $P-T$ state and this damage could affect properties at subsequent P-T states. Several steps were taken to minimize the amount of damage which might be accumulated during the testing sequence:

1. To prevent microfracturing due to thermal stresses induced during heating and cooling, sample heating and cooling rates were maintained at $1.5^{\circ} \mathrm{C} / \mathrm{min}$ or less.

2. As a precaution against damage due to thermal cycling, the first cycle was at the highest confining pressure and succeeding cycles at progressively, lower pressures. If crack growth due to differential thermal expansion did occur, it was felt that the high confining pressures would tend to limit crack growth more than low confining pressure.

3. Damage resulting from stress-strain tests was minimized by setting a deviator stress equal to 408 of the rock strength at a given P-T state at the maximum applied stress. This value was high enough to represent in situ stress conditions but low enough to prevent significant damage to the sample during the stress-strain tests. Data for the strength of intact stripa granite were obtained from Swan (1978).

4. One final check on the amount of damage sustained during the test sequence was provided by repeating thermal cycles at various times during the test procedure. The results of these repeated thermal cycles indicated that most sample damage occurred at confining pressures of 5 MPa and below. Thus it was concluded that trends in the data for confining pressures of $5 \mathrm{MPa}$ and above were not affected by previous thermal cycles.

\section{SUMMARY OF RESULTS}

The test procedure outlined above was designed so that the temperature and pressure dependence of the thermoelastic properties of the intact rock could be established. The particular properties measured at each P-T state were tangent Young's modulus, ETi Polsson's ratio, $v$; volumetric coefficient of thermal expansion, $\alpha_{v i}$ and linear coefficient of thermal expansion, $\alpha_{l}$... Determination of these parameters from the test data was assisted by curve-fitting computer routines utilizing polynomials of the form

$y=f_{0}+f_{1} x+f_{2} x^{2}+\ldots+f_{n} x^{n}$

Thus, for stress-strain data, polynomials expressing strain as a function of stress were determined, for thermal expansion data, polynomials expressed strain as a function of temperature. The best-fit polynomials were selected by visual inspection of the results as well as by calculation of the variance of the data about the best-fit line. Values of the parameters of interest were obtained by taking the derivative of the best-fit polynomials. For thermal expansion data, in addition to values of $\alpha_{v}$ and $\alpha_{l}$ determined from best-fit curves, incremental values were also calculated. By "incremental" it is meant that $\alpha_{v}$ or $\alpha_{\ell}$ was calcu- lated from the slope of the straight line joining each set of adjacent data points on a plot of strain versus temperature.

\section{Thermal Expansion Measurements}

Major trends in thermal expansion behavior of intact stripa granite are illustrated in Figure 2, which presents summary curves of average value of ov for the samples tested. The correlation between average values of $\alpha_{v}$ calculated using regression analysis and average values based on incremental slope values is illustrated by the discrete data points plotted for 5 MPa and 55 MPa confining pressure. The most significant trend shown by the average curves is an increase in the coefficlent of thermal expansion $\left(\alpha_{v}\right.$ or $\left.\alpha_{l}\right)$ for an isobaric temperature increase. Average values of $\alpha_{y}$ measured at $20^{\circ} \mathrm{C}$ range from 48 to 618 of those at $180^{\circ} \mathrm{C}$, whereas average values of $\alpha_{\ell}$ at $20^{\circ} \mathrm{C}$ range from 52 to 708 of those at $180^{\circ} \mathrm{C}$. The effect of isobaric temperature changes, though large, is somewhat less than observed by Heard and Page (1982) from tests on Stripa granite. The principal difference in results of these investigators is that they measured smaller values of the coefficient of thermal expansion at low temperature. Though reasons for differences in reported results are speculative, the discrepancies at low temperatures may be related to differences in experimental technique. Sample deformations were measured by Heard and Page (1982) using transducers external to the test cell, whereas measurements in the current work were made using strain gauges bonded to the rock. The greater sensitivity of the strain gauges may have resulted in greater resolution of the small deformations occurring at low temperatures.

Curves of average values of $\alpha_{v}$ shown in Figure 2 are nearly linear, indicating a constant rate of increase in volumetric thermal expansion with temperature up to $180^{\circ} \mathrm{C}$. Though on the average curves are nearly linear, it should be noted that curves for individual samples exhibit a variety of shapes, reflecting the polynomial function selected as the best fit of the data.

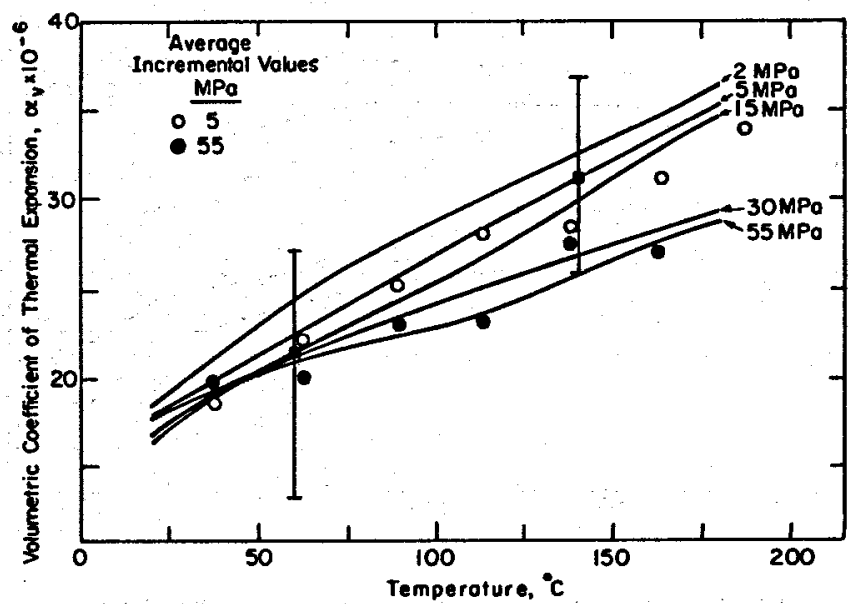

Figure 2. Average values of $\alpha_{v}$ for each confining pressure as a function of temperature. [XBL 818-6393] 
The pressure dependence of $\alpha_{v}$, as indicated by the difference between curves at one temperature in Figure 2, is much less than the temperature dependence. Increasing the confining pressure from 2 to $55 \mathrm{MPa}$ at any given termerature results in about a 10 to 208 decrease in $\alpha_{v}$ and only a 5 to 108 decrease in $\alpha_{\ell}$. The greater effects were noted at higher temperatures. These results are consistent with those of Heard and Page (1982), which showed, essentially, independence of $\alpha_{l}$ with pressure up to $130 \mathrm{C}$.

Error bars representing typical scatter in results are shown for selected data points in Figure 2. Each error bar shows the maximum variation in the data about the mean value, indicated by a filled square. Scatter in the magnitudes of the parameters was large, though it should be noted that data from each test reflected the same trends as seen in the average data. Aside from the natural variability of the rock, no satisfactory explanations could be found for the large scatter in the thermal expansion data.

\section{Elastic Noduli Measurements}

Major effects of temperature and confining pressure on $\mathrm{E}_{\mathrm{T}}$ are illustrated by Figures 3 and 4. Because the moduli not only varied as a function of confining pressure and temperature but also as a function of the deviator stress magnitude, all data were compared at a deviator stress of 60 MPa. Effects of isobaric temperature changes were limited at $30 \mathrm{MPa}$ and $55 \mathrm{MPa}$ confining pressure. In this range increasing temperature caused no more than a 58 difference between average maximum and minimum values of $E_{T}$. Interestingly, at these confining pressures, average values of $E_{T}$ increased slightly with increasing temperatures and then began to decrease. This behavior occurred in some, but not all, samples and as yet is unexplained. At confining pressures of $15 \mathrm{MPa}$ and less, increasing temperature over the test range resulted in a decrease in average $E_{T}$ values of

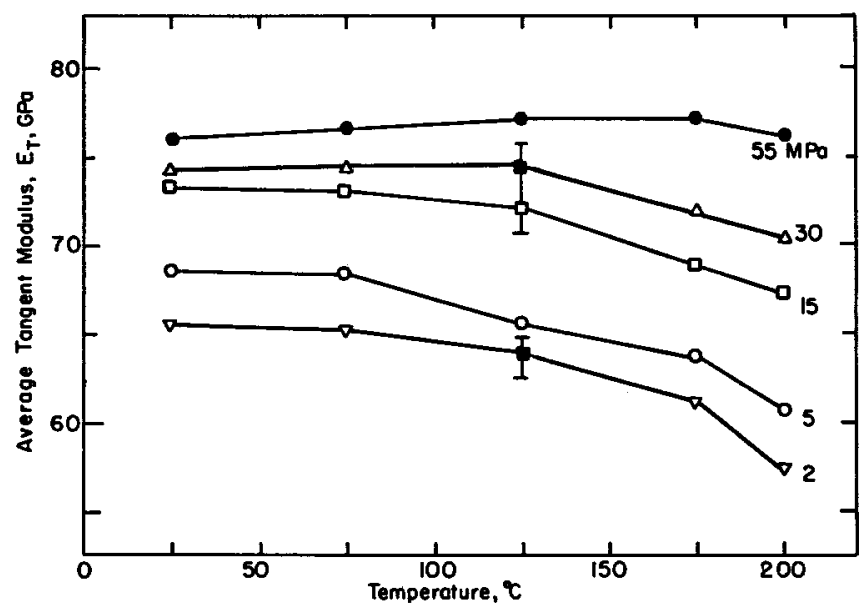

Figure 3. Average values of tangent Young's modulus for each confining pressure as a function of temperature. All values obtained at a deviator stress of $60 \mathrm{MPa}$.

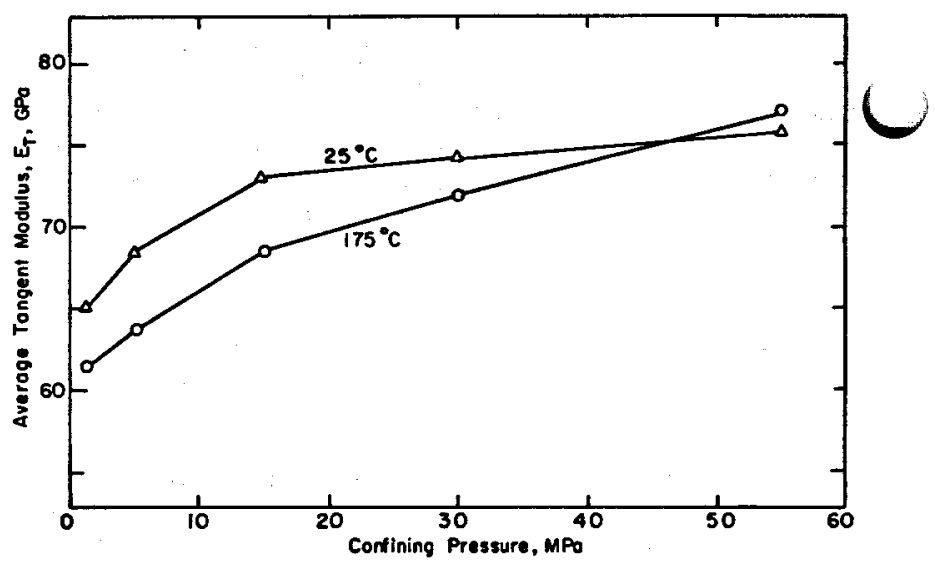

Figure 4. Average values of tangent Young's modulus for two temperatures as a function of confining pressure. All values obtained at a deviator stress of $60 \mathrm{MPa}$.

[XBL 818-6401]

about 128 , with the greatest effect noted at temperatures in excess of $125^{\circ} \mathrm{C}$. Data presented by other authors, including Birch (1966) and Beard and Page (1982), reinforce the observation of 1 imited dependence of Young ' $s$ modulus on temperatures up to $200^{\circ} \mathrm{C}$, particularly at high pressure.

The pressure dependence of $\mathrm{E}_{\mathrm{T}}$ was more pronounced than the temperature dependence. Some of the results of Figure 3 are replotted in Figure 4 to illustrate the effects of isothermal pressure changes. It can be seen that decreasing the confining pressure from $55 \mathrm{MPa}$ to $2 \mathrm{MPa}$ results in about a 13 to 258 decrease in $\mathrm{E}_{\mathrm{T}}$. This decrease is less than half as great as the decrease observed by Heard and Page (1982) for Stripa granite or Page and Heard (1981) for Climax quartz monzonite. Other authors (Hughes and Jones, 1950; Birch, 1966) have reported behavior more in line with the results of this study. Figure 4 also shows a decreasing rate of change in $\mathrm{E}_{R}$ for a given temperature as confining pressure increases, suggesting that at some higher confining pressure $E_{T}$ becomes independent of pressure.

Whereas pressure dependence of $\mathrm{E}_{\mathrm{T}}$ was the most significant trend in the $E_{T}$ data, the most significant trend in measurements of Poisson's ratio was the temperature dependence of $\nu$. The greatest temperature dependence was at low confining pressure. At $2 \mathrm{MPa}, v$ decreased by about $26 \%$ over the temperature range tested, whereas at 55 MPa the decrease was about 138. Results did not yield conclusive trends in the effects of isothermal confining pressure changes on $v$, though at low temperatures the data indicate that $\nu$ is independent of pressure change.

\section{IMPACT OF RESULTS ON MODEL PREDICTIONS}

Previous work (Chan and Cook, 1979) has shown that, assuming linear thermoelasticity, displacements and stresses in the vicinity of the heaters in the Stripa experiment are proportional to two factors, $D$ and $S$, where

$D=\frac{1+v}{1-v} \quad$ for displacements 
and

$$
\frac{\alpha_{\ell} E}{1-\nu} \quad \text { for stresses. }
$$

These factors were used to assess the effect on model predictions of assuming temperature-dependent properties as opposed to temperature-independent properties. Because $\alpha$ was found to be more strongly dependent upon temperature than the other parameters, it was expected that model prediction would be affected most by incorporation of the temperature dependence of $\alpha_{\ell}$. Moreover, since both $D$ and $s$ vary directly with $\alpha_{l}$. it was thought that changes in displacements and stresses would also be proportional to the difference between temperature-dependent values of $\alpha_{\ell}$ and temperature-Independent values of $\alpha_{l}$. For example, test results showed that $\alpha_{\ell}\left(200{ }^{\circ} \mathrm{C}\right)$ is about twice $\alpha_{\ell}\left(25^{\circ} \mathrm{C}\right)$. Therefore, ignoring the stress dependence of $\alpha_{\ell}$, if $\alpha_{\ell}\left(25^{\circ} \mathrm{C}\right)$ were used in computations for a problem at $200^{\circ} \mathrm{C}$, stresses and displacements would be off by a factor of two, assuming constant values for other material properties. Interestingly, the analysis showed that including the temperature dependence of $E$ and $\nu$ as well as $\alpha$ would result in smaller differences between predictions based on temperature-independent properties and those based on temperature-dependent properties. The reason is that the values of $\alpha$ and $E$ decrease with temperature whereas values of $\alpha$ increase with temperature. The factors $D$ and $S$ continue to increase with temperature because of the strong temperature dependence of $\alpha$, but the rate of increase is less because of the influence of changes in $E$ and $v$.

\section{REFERENCES CITED}

Birch, F., 1966. Compressibility; Elastic constants. In S. P. Clark, Jr. (ed.), Handbook of Physical Constants. Geological society of America Memoir 97, p. 97.

Chan, T.., and Cook, N. G. W., 1979. Calculated thermally Induced displacements and stresses for heater experiments at Stripa, Sweden. Lawrence Berkeley Laboratory Report LBL-7061 (SAC 22).

Heard, H. C., and Page, L., 1982. Elastic moduli, thermal expansion, and inferred permeability of two granites to $350^{\circ} \mathrm{C}$ and $55 \mathrm{MPa}$. Journal of Geophysical Research, in preparation.

Hughes, D. S., and Jones, H. J., 1950. Variation of elastic modull of igneous rocks with pressure and temperature. Bulletin of the Geological society of America, v, 61, p. 843-856.

Page, L., and Heard, H., 1981. Elastic moduli, thermal expansion, and inferred permeability of climax quartz monzonite and sudbury gabbro to $500{ }^{\circ} \mathrm{C}$ and $55 \mathrm{MPa}$. In Rock Mechanics from Research to Application. Proceedings, 22nd v. S. Symposium on Rock Mechanics, Mass. Inst. of Technology, p. 27-104.

Swan, G., 1978. The mechanical properties of Stripa granite. Lawrence Berkeley Laboratory Report LBL-7074 (SAC-03).

\title{
ANALYSIS OF TEMPERATURE DATA FROM THE FULL-SCALE HEATER EXPERIMENTS AT STRIPA
}

\author{
I. Javandel and P. A. Witherspoon
}

In order to examine the thermomechanical behavior of deeply fractured crystalline rock when it is used for the Isolation of high-level nuclear waste, a series of experiments was conducted in deep granitic rock at stripa, sweden, in a site adjacent to an abandoned iron mine (Witherspoon and Degerman, 1978, Witherspoon et al., 1981). Among these experiments were two "full-scale" heating experiments carried out at a depth of approximately $340 \mathrm{~m}$. These experiments were designed to study the near-field effects of heating the rock at two different thermal power levels, with electrical heaters substituting for nuclear waste canisters. Later, one of these experiments was supplemented by eight peripheral heaters to account for the Interaction of surrounding waste canisters.

The site of the experiments was excavated in granitic rock intruded by diabase and pegmatite dikes. Mapping of the drifts and core data from boreholes has shown that the rock is highly fractured (Olkiewicz et al., 1979). It is believed that all of the connected fractures were water saturated prior to the excavation.
Experiment 1 was energized by an electrical heater with a constant power of $3.6 \mathrm{kw}$. This heater, with a diameter of $0.324 \mathrm{~m}$ and a length of $2.60 \mathrm{~m}$, was placed in a vertical borehole (designated $\mathrm{H}-9$ ) with a dameter of $0.406 \mathrm{~m}$, leaving an annular gap of $41 \mathrm{~mm}$. This gap was intentionally designed to simulate the spacing between the nuclear waste canister and the rock. It is believed that such an air gap is unavoldable (Lowry et al.. 1980).

Experiment 2 was heated by another heater with the same dimensions as the $8-9$ heater but with a constant power of $5 \mathrm{~kW}$. This heater was placed in borehole $\mathrm{H}-10$, which has the same diameter as $\mathrm{E}-9$. The center-to-center distance between these two main heaters was $22 \mathrm{~m}$, which in effect thermally separated the two experiments for the duration of the tests.

Eight other heaters, each with a diameter of $0.027 \mathrm{~m}$ and a length of $4.3 \mathrm{~m}$, were placed in boreholes at a radius of $0.9 \mathrm{~m}$ around the $5-\mathrm{kW}$ heater. These peripheral heaters, each with a power of $1 \mathrm{~kW}$, were energized 204 days after the 
main heater turn on. After 40 days of operation, power in these heaters was reduced to $0.85 \mathrm{~kW}$ each.

In each of the above two experiments, several different kinds of measuring devices were located in vertical as well as horizontal holes in the vicinity of the heater boreholes. The main quantities measured were the temperatures in the rock and the displacements and stress changes due to the thermal loading. All of the above data have been organized and converted to engineering units and are available in the public domain (Chan et al., 1980a).

\section{EVALUATION AND INTERPRETATION OF EXPERIMENTAL DATA}

Previously, very good agreement was noted between measured temperatures and calculated temperatures based on closed-form solutions for the midplane of the heaters (Cook and Hood, 1978; Chan et al., 1980b). However, a detailed examination of the results revealed some discrepancies between measured and predicted temperatures, particularly for thermocouples at elevations of 1.5 $\mathrm{m}$ and $3.0 \mathrm{~m}$ above and below the midplane. The cause of these discrepancies has been investigated and the results are discussed below.

\section{Corrosion of the Stainless Steel Thermocouple Sheaths}

Investigation of the measured temperatures of the rock showed that shortly after the 5-kW heater was switched on, some of the stainless-steel sheathed thermocouples gradually started malfunctioning. After a few days, almost all of these thermocouples on or below an elevation of $z=1.5$ m were oscillating. Figure 1 shows oscillation of thermocouples around the 5-kW heater at an elevation of $z=0.0$.

At first it was believed that the oscillation of the thermocouples was an indication of corrosion due to the combined effects of moisture and

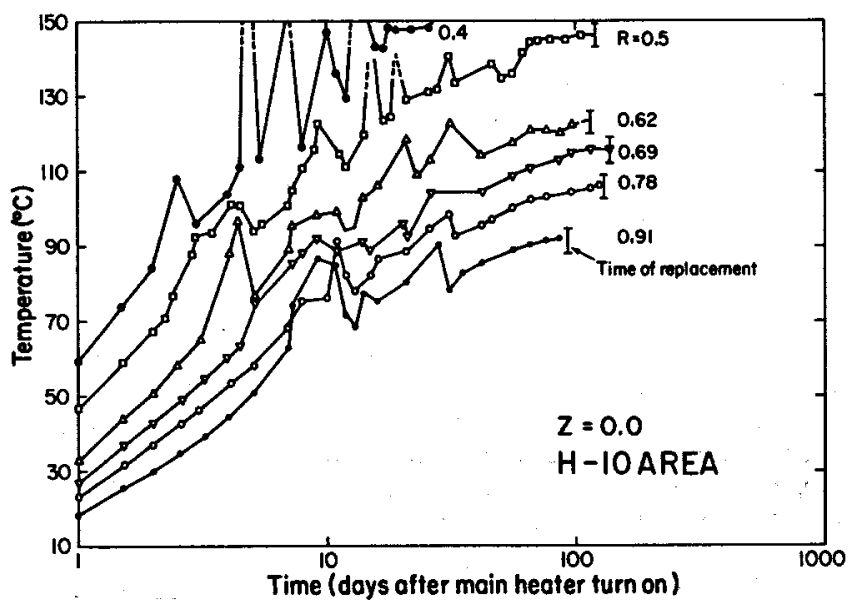

Figure 1. Semilog plot of measured temperatures versus time within $\mathrm{T}$-holes around $5-\mathrm{kW}$ heater at $z=0.0$ covering period from heater turn on until thermocouples were replaced. heat. Thus it was assumed that temperatures recorded by a thermocouple exhibiting an oscillating output were invalid and that these instruments required repair. However, the fact that after 40 days most of the thermocouple output ceased to oscillate and seemed to stabilize prompted us to look for another explanation. At present, we believe the heat treatment of the stainless steel sheath prior to installation made the thermocouples vulnerable to corrosion. Consequently, the sheaths which were exposed to modest moisture and heat were damaged, but the thermocouple wires themselves were unaffected at this stage. At a later stage, when significant moisture reached the wires through the damaged sheath, the thermocouples probably established a ground loop and generated random currents that affected the output signal. Still later, when the electrical ground was removed, most of the thermocouples in fact recorded stable temperatures (until the time of replacement) because the essential components of the instruments were undamaged.

In the 3.6-kW experiment, which started later, there was an opportunity to improve the design of the electrical ground, few data were lost because of corrosion even though the same type of thermocouple was used.

Deviations from Planned Locations of Thermocouples

Investigation of measured temperatures in the holes around the 5-kW heater revealed that (1) temperatures measured at certain positions before and after replacement of defective thermocouples differed by as much as $8^{\circ} \mathrm{C}$, and (2) initially, at any given elevation, temperatures measured at points closer to the heater were higher than those at points further away, but the reverse was true after thermocouple replacement. Figure 2 shows the measured temperatures versus time before and after replacement of the thermocouples at $\mathrm{z}=1.5 \mathrm{~m}$ around the $5-\mathrm{kW}$ heater. Evaluation of these observations and temperature records from other locations suggested the following hypothesis, which seems to explain these discrepancies.

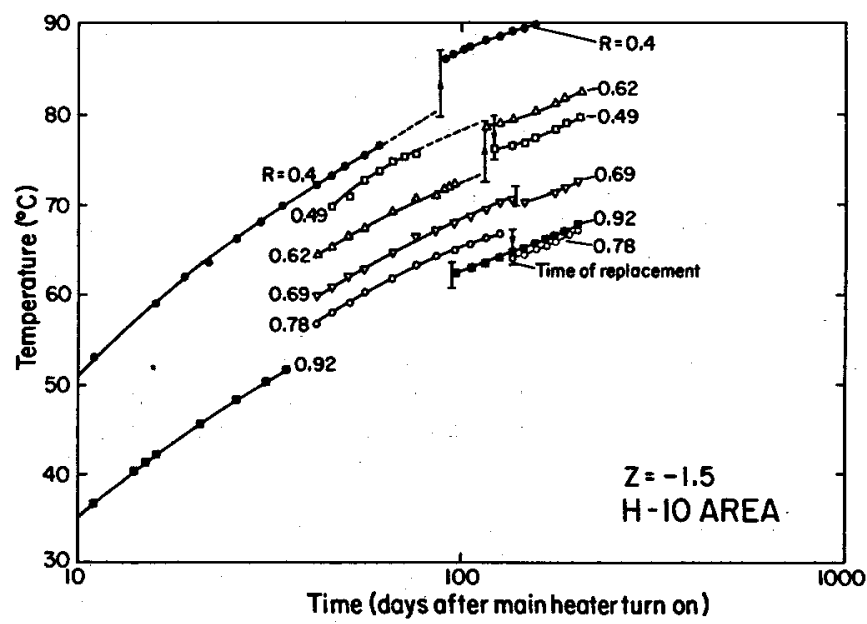

Figure 2. Semilog plot of measured temperatures versus time at $z=1.5$ around $5-k w$ heater; a comparison of data before and after the thermocouples were replaced. 
Leads of the five thermocouples in each hole were taped together before installation. Consepently a mislocation of the instrument string cring installation would cause all five thermocouples to deviate from their planned positions. If it is assumed that the string of thermocouples in a hole were located somewhat higher than the intended position, then the thermocouples assumed to be at $z=1.5 \mathrm{~m}$ would in fact be farther from the midplane of the heater and would measure cooler temperatures. Conversely, the thermocouple at elevation $\mathrm{z}=-1.5 \mathrm{~m}$ would be closer to the midplane and thus measure warmer temperatures.

On the basis of the above argument, thermocouples in two of the holes around the $5-\mathrm{kW}$ heater seemed to be slightly higher and two others slightly lower than their planned position. The magnitude of the mislocation of these thermocouples was estimated to be at most $7 \mathrm{~cm}$. Thermocouples at $z=0.0$ are not affected by this silght mislocation, because the vertical thermal gradient around the midplane is negligible. However, because of the large vertical gradient at elevations of $z= \pm 1.5 \mathrm{~m}, \mathrm{a}$ mislocation of the same magnitude at either position could account for the discrepancies between predicted and measured temperatures.

\section{Effects of Seepage on Recorded Temperatures}

Examination of temperature data in the holes around the 5-kW heater after peripheral heaters were turned on showed that the recorded temperatures at elevations of $\mathrm{z}=1.5 \mathrm{~m}$ and $\mathrm{z}=3.0 \mathrm{~m}$ exhibited considerable oscillation. Simultaneously, thermocouples at lower levels were recording smooth temperature variations. Figure 3 11lustrates the variation of temperatures with time at four different levels in one of the holes. Detailed investigations revealed that many of these oscillations were concurrent with some hydrological tests that were taking place in the ventilation drift more than 50 m away. Because of these activities, water injected into the rock temporarily saturated certain fractures in the vicinity of the heater experiments. Any fracture that happened to intersect a thermocouple hole provided a path for transferring water from the ventilation drift to the full-scale heater drift. water entering the borehole at some elevation about $z=1.5 \mathrm{~m}$ would seep down through the sand that filled the hole until it reached sand with a temperature above $100^{\circ} \mathrm{C}$. Under such circumstances the water would take heat from the sand and vaporize to steam. As a result, the temperature of any nearby thermocouple would be lowered. The ascending steam would then heat the thermocouples located above that point. In one case, water continued to enter the hole and kept generating steam, which caused the upper thermocouple to remain at a temperature of $101^{\circ} \mathrm{C}$ until shortly after the heater was turned off.

\section{COMPARISON OF CAICULATED AND MEASURED DATA}

Temperatures measured in the rock mass surrounding the heaters were compared with temperatures predicted using the DOT finite-element code developed by Polivka and wilson (1976). This code
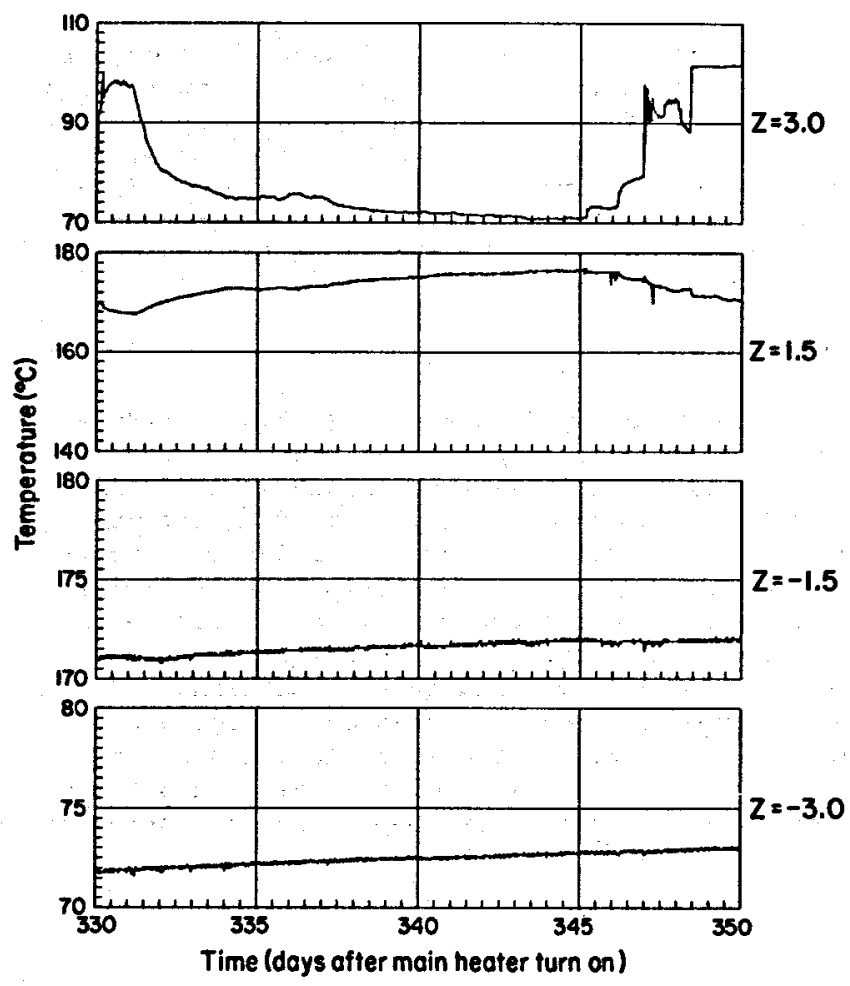

Figure 3. Variation of temperature with time at four different levels in a $\mathrm{T}$-hole around 5-kW heater after peripheral heaters were turned on. [XBL 821-1608]

is capable of handling a nonuniform initial temperature distribution, temperature-dependent rock properties, and all types of boundary conditions such as radiation, convection, and constant temperature.

In both experiments, rock temperatures measured above the midplane were higher than calculated, whereas those below the midplane were lower than calculated. The differences between measured and calculated temperatures were greater in the 3.6-kW heater test than in the 5-kW one. Considering that rock temperatures measured above the horlzontal nidplane are higher than those at equal aistances below the midplane, two possible causes could be suggested: (1) the positions of the heaters in the boreholes were slightly higher with respect to the positions of the thermocouples, (2) part of the heat transferred from the heater to the rock moved by convection. The generation of convection cells within the annular gap around the heaters would pump more heat to the upper part of the heater hole, causing temperatures to be warmer above the midplane.

The DOT finite-element code could not be used to investigate the possibility that experimental results were affected by convective heat transfer. However, assuming that heater misplacement was the only cause for the observed discrepancy, we have estimated that the vertical mislocation of the heaters around the $3.6-\mathrm{kW}$ and $5-\mathrm{kW}$ heaters was $13 \mathrm{~cm}$ and $8 \mathrm{~cm}$, respectively. Shifting the position of the heaters in the numerical model by the above amounts did improve the result for the 
5-kW heater test. Figure 4 illustrates a comparison between measured and calculated temperatures after the 5-kW heater was shifted $8 \mathrm{~cm}$ upward. A $13-\mathrm{cm}$ shift of the 3.6-kW heater also improved the results to some extent. However, some discrepancies still exist which may suggest that convection could also be the cause for the observed differences.

\section{CONCLUSIONS}

As reported by Chan et al. (1980b), prediction of rock mass temperatures around buried heat sources using finite-element procedures yields results which are generally in good agreement with measured values. However, a detalled analysis of the results of the stripa heater experiments showed that experimental errors can be introduced by relatively small deviations from planned thermocouple and heater locations and that convective heat transfer due to seepage of groundwater into the thermocouple holes can have important effects. Information gained about the performance of the thermocouples in the corrosive

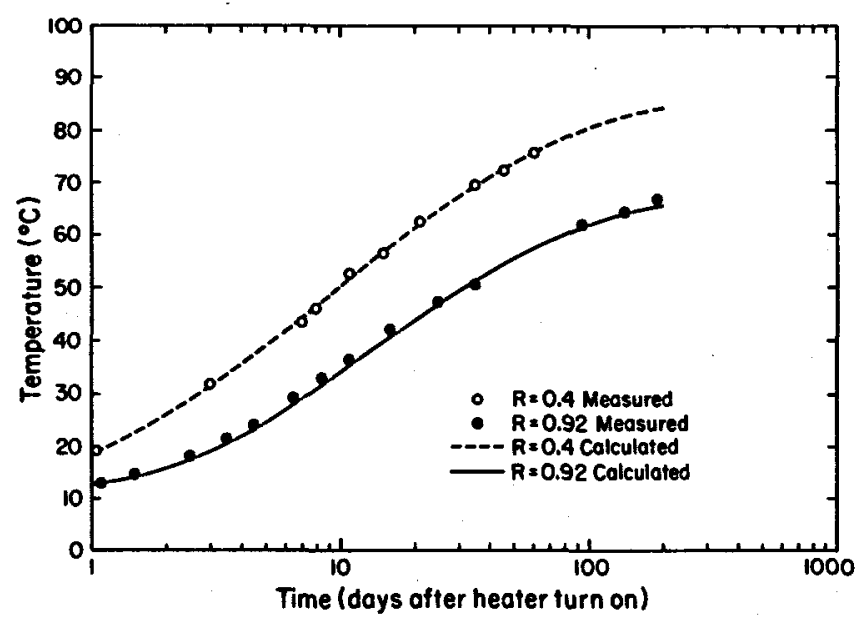

Figure 4. Comparison of calculated and measured temperatures at $\mathrm{z}=1.5$ around $5-\mathrm{kW}$ heater after adjusting the heater location.

[XBL 821-1609] environment of a heated rock mass will help in the design of temperature-measuring devices for future applications of this type. The results of this study provide valuable insights which can be used in the design and analysis of similar experiments which will be required in the development of prototype nuclear waste repositories.

\section{REFERENCES CITED}

Chan, T., Binnall, E. P., Nelson, P., Stolzman, R., Wan, O., Weaver, C., Ang, K., Braley, J., and MCEvoy, M., 1980a. Thermal and thermomechanical data from in situ heater experiments at Stripa, Sweden. Lawrence Berkeley Laboratory Report LBL-11477 (SAC-29).

Chan, T., Witherspoon, P. A., and Javandel, I., $1980 \mathrm{~b}$. Heat transfer in underground heating experiments in granite, Stripa, Sweden. In Heat Transfer in Nuclear Waste Disposal. American Society of Mechanical Engineers, HTD-Vol. 11, P. 1-8.

Cook, N. G. W., and Hood, M., 1978. Full-scale and time-scale heating experiments at stripa: Preliminary results. Lawrence Berkeley Laboratory Report LBL-7072 (SAC-11).

Lowry, w. E., Davis, B. W., and Cheung, H., 1980. The effects of annular air gaps surrounding an emplaced nuclear waste canister in deep geologic storage. In Heat Transfer in Nuclear Waste Disposal. American Society of Mechanical Engineer s, HTD-Vol. 11, p. 69-75.

Olkiewicz, A., Gale, J. E., Thorpe, R., and Paulsson, B., 1979. Geology and fracture system at Stripa. Lawrence Berkeley Laboratory Report LBL-8907 (SAC-21).

Polivka, R. M., and Wilson, E. L., 1976. Finite element analysis of nonlinear heat transfer problems. Department of Civil Engineering, University of California, Berkeley, Report UC SESM 76-2.

Witherspoon, P. A., and Degerman, 0., 1978. Swedish-American Cooperative program on radioactive waste storage in mined caverns. Lawrence Berkeley Laboratory Report LBL-7049 (SAC-01)

Witherspoon, P. A., Cook, N. G. W., and Gale, J. E., 1981. Geologic storage of radioactive waste: Field studies in Sweden. Science, v. 211, p. 894-900. 
ROD-TYPE EXTENSOMETERS IN LONG-TERM ELEVATED TEMPERATURE SERVICE

\author{
A. O. DuBois, P. H. Nelson, M. Hood, and E. Binnall
}

At Stripa, Sweden, 35 rod-type extensometers were used to measure displacements within the granite rock mass surrounding electrical heaters emplaced in the floor of an underground entry. One of the objectives of these thermomechanical tests was to evaluate the performance of currently available rock instrumentation when subjected to long-term service at elevated temperatures.

\section{DESCRIPTION}

The rod-type extensometers are of a commercially available design, Terrametrics Inc, (Golden, Colorado) model 4CSLT-R. Th1s instrument measures the axial displacement of each of four downhole anchor points with respect to the borehole collar over an operating range of $25 \mathrm{~mm}$. One spring-tensioned rod (at stripa these were up to 13-m long) connected each anchor point to one of the four linear variable differential transformer (LVDT) type sensors located at the borehole collar. The major elements of these extensometers (see Fig. 1) are: (1) the anchor system, (2) the anchor-to-collar rod connection mounted inside a waterproof flexible conduit, (3) a head assembly which includes a rod tensioning system and the displacement sensors, and (4) several thermocouples for sensing the temperature profile along the connecting rods.

The extensometer anchors were installed in 75-mm-diameter boreholes whose locations and or lentation are detalled in chan et al. (1980). After the extensometers were put in place, the boreholes were grouted, and hydraulically actuated anchors were inflated to secure them within the borehole. The construction of the extensometer $\mathrm{B}$, as well as their preliminary testing, installation, and fleld calibration, are described in greater detail by schrauf et al. (1979).
OPERATING HISTORY

General

Seventeen vertical and eighteen horizontal extensometers were installed and calibrated in the summer of 1978, prior to heater turn on. Each of three heater arrays was energized for approximately a year, and the rock instrumentation was monitored for an additional six months of cooldown. With one exception, all 140 of the LVDT sensors ( 4 anchors $X 35$ boreholes) remained in operation throughout the experiment.

The anchor-to-collar displacements recorded by these 140 sensors ranged from $0.6 \mathrm{~mm}$ of extension to $3.1 \mathrm{~mm}$ of contraction (Chan et al., 1980). Final recalibration and circuit verification were performed before shutdown of the data-acquisition system in June 1980 .

\section{Thermal Environment}

Four to seven thermocouples were taped to the longest superinvar rod in each borehole. All but one of these teflon-covered chromel-alumel thermocouples survived and provided an essentially continuous record of the rod temperature profiles in each borehole (Chan et al., 1980).

The warmest anchor (E31A) on any extensometer reached $159^{\circ} \mathrm{C}$ and was above $150^{\circ} \mathrm{C}$ for about ten weeks. Figure 2 shows the temperature profile along a horizontal extensometer (E29) wh1ch passed directly under a 5-kw heater. The temperature profile, when combined with the coefficient of thermal expansion data for superinvar, was used by the data processing system (McEvoy, 1979) to calculate a current total thermal expansion for each rod. Table 1 summarizes the dis-

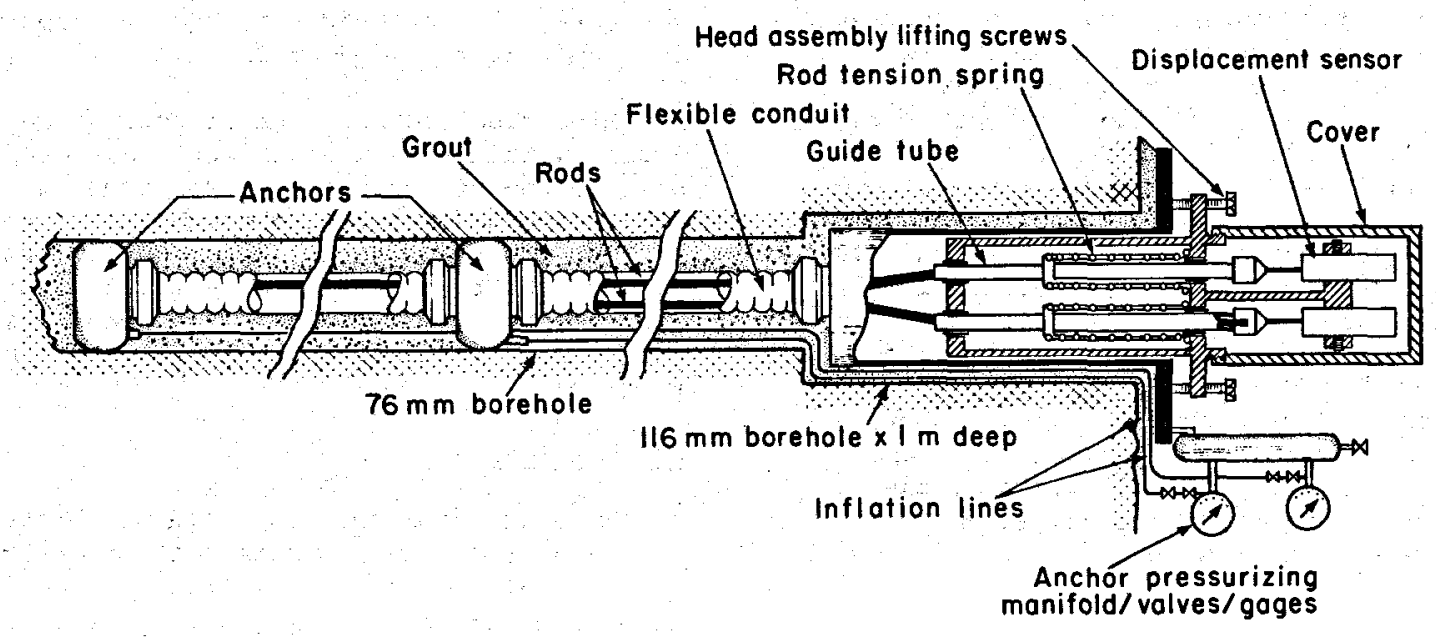

Figure 1. A foreshortened illustration of a two-anchor extensometer (after Binnall et al., 1979). [XBL 7910-4441] 


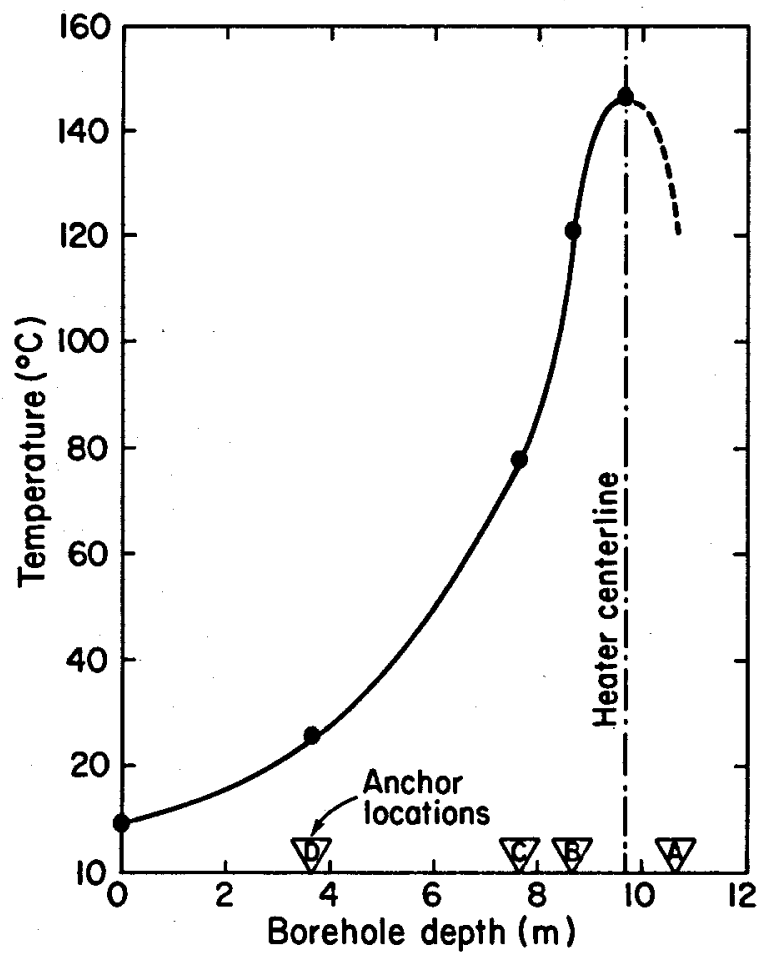

Figure 2. Temperature profile along horizontal extensometer E29 on experiment day 394. Tempera. ture profile is assumed to be symmetrical about heater center line.

[XBL 821-1610]

placement and thermal expansion data for E29 on experiment day 394--just before heater turn off. One can note there the very significant part played by the correction for thermal expansion.

\section{Anchors}

At the time of installation, each anchor was inflated to $1800 \mathrm{psi}$ and then isolated from the pressurizing manifold. Periodically during the experiment, each anchor was monitored and its pressure was adjusted to compensate for the thermal expansion of the hydraulic fluid. In the beginning of a heating cycle, some anchor pressures increased very rapidly--as much as 1000 psi in 24 hours. One anchor was inadvertently allowed to reach 3500 psi; however, it did not rupture and continued to perform well for the remainder of the experiment. Two anchors had shown evidence of leakage from the time of installation. By the conclusion of the experiment, eleven of the 140 anchors had completely lost pressurization. Temperature did not appear to be the critical factor causing this pressure loss, as the two hottest anchors (above $150^{\circ} \mathrm{C}$ ) did not fail. None of the sensors associated with unpressurized anchors showed any obvious change in output as a result of the pressure loss. Rod pull tests at the conclusion of the experiment also failed to show evidence of anchor slip.

\section{Rod Friction}

Within the first 100 experiment days, it became evident that many of the sensors were responding in a stepwise fashion (Hood, 1979). The source of this behavior became clear when rapping the head of a previously undisturbed extensometer stimulated it to respond with stepwise increases in indicated displacement. Repeated vibrations of the head resulted in smaller additional steps until finally no further response resulted. The total of the steps from each of the four sensors of that extensometer were roughly proportional to the depths of the four associated anchors. The largest of these responses was $81 \times 10^{-6} \mathrm{~m}$. We concluded that anchor displacement was being masked as a result of rod friction within the head and that the amount of displacement which was available to a step was determined by the axial spring constant of the rod as well as the length of time since it was last released. The release could result either from reaching the static friction capacity of the system or from an external stimulus. In most cases, if one sensor responded, all of the sensors on that extensometer would also step simultaneously.

On the basis of these tests, we instituted a periodic rapping of all extensometer heads so as to prevent accumulation of this frictional effect. Subsequent field and laboratory tests confirmed the existence of the frictional behavior and revealed some of the factors influencing its magnitude (DuBois et al., 1981).

\section{Electrical and Water Problems}

The drifts in which these experiments were conducted were relatively dry and well ventilated. Nevertheless, most of the rock instrumentation used at Stripa suffered from the effects of moisture. In spite of the protection of flexible metal conduit with a silicon rubber outer sleeve, which enclosed the extensometer rods and thermocouples, water accumulated in a few of the vertical extensometers and drained from the collar end of several of the horizontal extensometers. We believe that some of the leaks may have occurred as a result of abrasion damage to the rubber sleeve during installation and that other leakage occurred as a result of creep fallure of a plastic seal ring on the conduit-to-anchor adaptor when its temperature exceeded $120^{\circ} \mathrm{C}$.

Electrical connections at screw-type terminal strips within the extensometer heads caused trouble because of corrosion. Even some of the nominally dry heads condensed enough moisture from the atmosphere to cause corrosion of terminals. Many of the terminals were replaced with soldered and waterproofed junctions, and each horizontal extensometer head cover was drilled to provide a weep hole.

\section{Calibration}

Each extensometer was field calibrated prior to heater turn on and again just prior to the shutdown of the data-acquisition system. In this time, one sensor had changed its calibration factor by $128,51 x$ changed between 28 and 3.58, and the remainder changed by an average of 18 . The changes were of both polarities. 
Table 1. Thermal expansion and displacement data for each rod of extensometer E29 on experiment day 394, just before heater turn off.

Displacement of anchors with respect to borehole collar

\begin{tabular}{|c|c|c|c|c|c|}
\hline & & & Displacemer & & \\
\hline $\begin{array}{c}\text { Anchor } \\
\text { name } \\
\text { E29- }\end{array}$ & $\begin{array}{c}\text { Rod } \\
\text { length } \\
\text { (m) }\end{array}$ & $\begin{array}{c}\text { Gross }^{b} \\
\text { (mm) }\end{array}$ & $\begin{array}{c}\text { Expansion } \\
\text { (mn) }\end{array}$ & $\begin{array}{l}\operatorname{Net}^{d} \\
(\mathrm{~mm})\end{array}$ & $\begin{array}{c}\text { Ratio }^{e} \\
\text { (8) }\end{array}$ \\
\hline A & 10.64 & -1.040 & -0.363 & -1.403 & 26 \\
\hline B & 8.64 & -1.139 & -0.093 & -0.232 & 40 \\
\hline c & 7.63 & +0.017 & -0.029 & -0.012 & 242 \\
\hline D & 3.63 & -0.004 & -0.001 & -0.005 & 20 \\
\hline
\end{tabular}

Displacement between adjacent anchors

\begin{tabular}{cccccc} 
Span & Rod & \multicolumn{3}{c}{ Displacement } \\
between & $\begin{array}{c}\text { length } \\
\text { anchors }\end{array}$ & Gross & Expansion & Net & Rat1o \\
& & $(\mathrm{mm})$ & $(\mathrm{mm})$ & $(\mathrm{mm})$ & $(8)$ \\
\hline A-B & 2.00 & -0.901 & -0.270 & -1.171 & 23 \\
B-C & 1.01 & -0.156 & -0.064 & -0.220 & 29 \\
C-D & 4.00 & -0.021 & -0.014 & -0.007 & 200 \\
\end{tabular}

\footnotetext{
ay convention, contraction is considered positive in rock mechanics.

bisplacement indicated by sensor voltage output times calibration factor.

calculated thermal expansion of the applicable rod segment. atal of $b$ plus $c$.

$e(c \div d) \times 100$.
}

During the calibration procedure, the head was lifted and then lowered onto precision stepped blocks. The large motions used in this procedure obscured the stick-slip effect dezribed above. To overcome this limitation, a fear-driven microadjuster was constructed. This device allowed the head to be smoothly lifted or lowered with a least count of $2 \times 10^{-6} \mathrm{~m}$. The hysteresis revealed by manipulating the head with this device was quite reproducible. However, the hysteresis was always approximately $15 \times 10^{-6} \mathrm{~m}$ regardless of the anchor depth or the extensometer orientation. Laboratory test results have confirmed that the instrument response to movement of an anchor may result in a much larger amount of hysteresis than when lifting the head. Although these factors influence the amount of hysteresis, they do not change the calibration. 


\section{CONCLUSIONS}

The rod-type extensometers with their hermetically sealed LVDT sensors produced a great deal of useful data and demonstrated that they could function for up to two years with a borehole temperature which reached as high as $159^{\circ} \mathrm{C}$. However, additional development is necessary if this instrument is to function as a critical monitor in a hard rock nuclear waste repository. The rod fraction should be reduced by eliminating the change in alignment which the rods experience as they enter the head; the downhole friction should be reduced by providing a lubricant (or low-friction surface) where the rods pass through intervening anchors; the waterproof conduit sleeve should be protected against abrasion; a better grade of adapter fitting with a reliable hightemperature seal should be employed; the hydraulic anchors should be better protected against installation damage; the hydraulic manifold should be equipped with a large air-over-oil reservoir to eliminate the need to manually adjust the anchor pressure; and the electrical junctions and transducers should be isolated or made waterproof to protect against corrosion as a result of condensation.

\section{ACKNOWLEDGMENTS}

Hans Carlsson, Hakon Sellden, and Gunnar Ramqvist operated and maintained the extensometers. Bob Galbraith participated in the head vibration investigations and modified the heads for greater resistance to moisture. Lennart Andersson performed extensive laboratory tests and analysis.
Steve Lundgren designed much of the laboratory apparatus and assisted with laboratory tests.

\section{REFERENCES CITED}

Binnall, E. P., DuBois, A. O., and Lingle, R., 1979. Rock instrumentation problems experienced during in situ heater tests. Presented at the International symposium on the Scientific Basis for Nuclear Waste Management, Materials Research Society, Boston, Massachusetts, November 27-30, 1979. Lawrence Berkeley Laboratory Report LBL-9952.

Chan, T., Binnall, E., Nelson, P., Stolzman, R., Wan, O., Weaver, C., Ang, K., Braley, J., and McEvoy, M., 1980. Thermal and thermomechanical data from in situ heater experiments at Stripa, Sweden. Lawrence Berkeley Laboratory Report LBL-11477 (SAC-29).

DuBois, A. I., Bood, M., Binnall, E. P., and Andersson, L. N., 1981. Extensometer performance during experiments at Stripa. Lawrence Berkeley Laboratory Report, in preparation.

Hood, M., 1979. Some results from a field study of thermo-mechanical loading of a rock mass when heater canisters are emplaced in the rock. In Proceedings, 20th Symposium on Rock Mechanics, Austin, Texas, p. 429-438.

McEvoY, M. B., 1979. Data acquisition, handling, and display for the heater experiments at Stripa. Lawrence Berkeley Laboratory Report LBL-7062 (SAC-14).

Schrauf, T. A., Pratt, H., Simonson, E., Hustrulid, W., Nelson, P., DuBois, A., Binnall, E., Haught, R., 1979. Instrumentation evaluation, calibration, and installation for the heater experiments at stripa. Lawrence Berkeley Laboratory Report LBL-8313 (SAC-25). 


\section{DETERMINATION OF THE STATE OF STRESS AT THE STRIPA MINE, SWEDEN}

$\checkmark$ Doe

The goals of the Stripa stress measurement program are twofold: (1) to provide in situ stress data for the analysis of the thermomechanical and hydrologic measurements at the site and (2) to compare the results of hydraulic fracturing with a variety of overcoring techniques at a comnon site.

\section{FAR-FIELD MEASUREMENTS}

The first phase of the program was the measurement of in situ stress sufficiently far from the mine that the influence of the openings would be minimal. During the summer of 1980 , a series of overcoring measurements using the Swedish State Power Board's deep hole Leeman triaxial cell were made during the drilling of a 380-mdeep borehole, $5 B H-4$, about 400 m north of the underground test facility. The triaxial cell measurements, which obtain the complete stress field from a single hole (Hiltscher et al., 1979), were in groups of four each at $100 \mathrm{~m}, 200$ $\mathrm{m}, 300 \mathrm{~m}$, and $380 \mathrm{~m}$ depth. After the hole was completed, seventeen hydraullc fracturing measurements were made (Doe et al, , 1981). The results of both techniques agreed well in magnitude and in the direction of the maximum horizontal stress, which was found to be oriented in a westnorthwest to east-west direction. The overcoring results showed that although the maximum principal stress was hor izontal, the intermediate and minor principal stresses were skewed with respect to the vertical and horizontal; hence the ideal conditions for hydraulic fracturing of one principal stress co-axial with the borehole were not met.

After the measurements were made, Chan et al. (1981) performed a series of finite-element analyses to check on the effect of the mine on the stresses near SBH-4. Their results, which are approximate because of a necessary simplification of the mine geometry, indicated that the conditions measured by the overcoring, namely rotation of the minimum principal stress toward the mine and a vertical stress in excess of Iithostatic, were reasonable.

\section{NEAR-FIELD MEASUREMENTS}

The second phase of the Stripa stress program was to measure the in situ stress in the immed1ate vicinity of the full-scale experiment (Fig. 1). Hole BSP-1 was drilled vertically downward from the floor of the full-scale drift. It was $76 \mathrm{~mm}$ in diameter and $25 \mathrm{~m}$ in length. Six overcoring measurements were made between depths of 1.3 and $10 \mathrm{~m}$ by the Swedish State Power Board using the same deep hole Leeman cell technique that was used in SBH-4. Eight hydraulic fracturing tests were made in BSP-1. Three of the measrements were monitored acoustically to track the propagation of the fracture.

Hole BSP-2 was drilled at an angle of 3 degrees down from the horizontal from the wall of

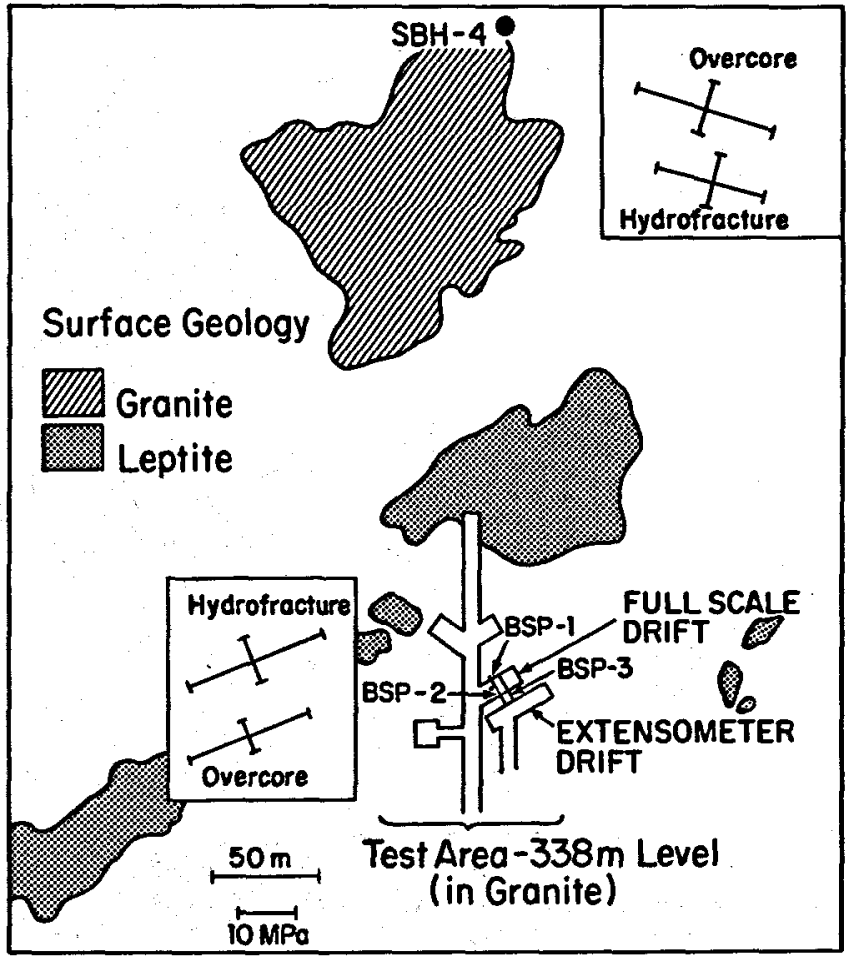

Figure 1. Location of holes for stress measurement at Stripa.

[XBL 811-4837]

the extensometer drift to the region under the full-scale drift. Eight hydraulic fractures were made over the $25 \mathrm{~m}$ length of BSP-2. The measurements in BSP-2 were made to check the influence of hole or lentation relative to the stress field on the behavior of the hydraulic fracture. It was hoped that the acoustic monitoring could be used to track any possible change in fracture orlentation into the plane of maximum and intermediate principal stresses.

Hole BSP-3 was drilled in essentially the same direction as BSP-2 but was inclined slightly upward to allow for water drainage. BSP-3 had a diameter of $150 \mathrm{~mm}$ and a length of $12 \mathrm{~m}$. This hole was used for twelve USBM gage, five CSIRo cell, and elght conventional Leeman triaxial cell stress measurements. The measurements were performed by william Hustrulid of the colorado School of Mines and Bengt reijon of the University of Lulea (Sweden). The purpose of the overcoring measurements was to serve as a check on both the hydraulic fracturing and the power Board's deep hole Leeman cell, which had not previously been compared with other overcoring methods. Figure 2 shows preliminary results for the conventional Leeman cell measurements from $B S P-3$ and the deep hole Ieeman cell measurements from BSP-1. The two methods give excellent agreement on the orientation of the maximum principal stress, which is in a 


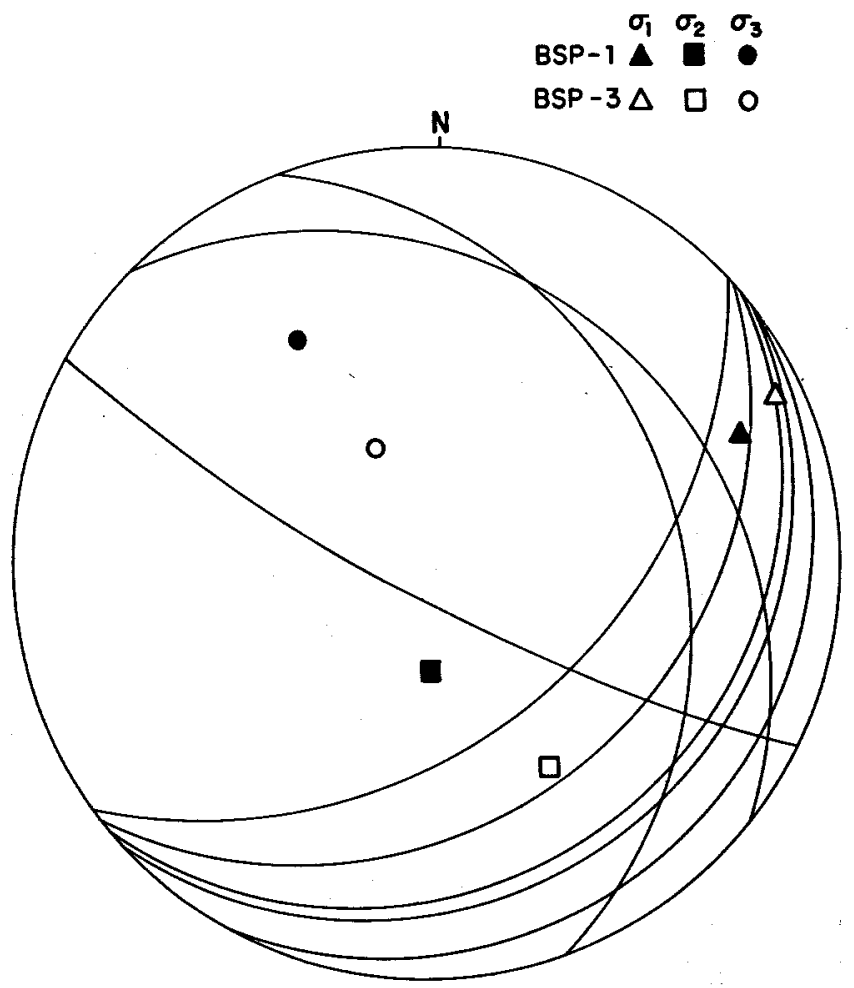

Figure 2. Stereographic projection of average - principal stress directions measured in BSP-1 and BSP-3 by overcoring and the planes of hydrofractures measured in BSP-2. northeast direction. This direction is parallel to the axes of the full-scale and extensometer drifts. It is also rotated 45 to 50 degrees from the orientation of the maximum stress measured in SBH-4. The USBM results, which measure stress components only normal to the hole, agree well in magnitude and orientation with the conventional Leeman cell results in the same hole (Table 1). Both sets of Leeman cell data show that the minor principal stresses are skewed with respect to the horizontal and vertical; however, the BSP-1 results show the intermediate stress closer to vertical, and the BSP-3 data show the minimum stress closest to vertical in the region directly below the fullscale drift, where the BSP-1 measurements were made.

The BSP-1 hydraulic fracturing measurements show excellent agreement with the overcoring methods in the orientation of the maximum principal stress. The fractures generated were vertical and oriented very closely to the axes of the drifts. A decrease in the shut-in pressure was observed as the fracture was extended, a phenomenon which has been interpreted as a rotation of the fracture into a horizontal orientation when the minimum stress is parallel to the hole (zoback and Pollard, 1978). This shut-in pressure behavior lends some support to the relatively steep dip of the minimum stress indicated by the conventional Leeman cell. Additional support to the steep dip of the minimum stress comes from the orientations of the hydraulic fractures in

Table 1. Summary of in situ stress results.

\begin{tabular}{|c|c|c|c|c|c|}
\hline $\begin{array}{l}\text { Hole } \\
\text { number }\end{array}$ & Technique & $\begin{array}{c}\text { Maximum horizontal } \\
\text { stress, } \sigma \text { Bmax } \\
\text { (MPa) }\end{array}$ & $\begin{array}{l}\text { Minimum horizontal } \\
\text { stress, } \sigma \text { Hmin } \\
\text { (MPa) }\end{array}$ & $\begin{array}{l}\text { Vertical } \\
\text { stress, } \sigma v \\
\text { (MPa) }\end{array}$ & $\begin{array}{c}\text { Bearing of } \\
\sigma \text { Hmax }\end{array}$ \\
\hline \multirow{3}{*}{ SBH-4 } & $\begin{array}{c}\text { Deep } \\
\text { overcoringa }\end{array}$ & 25.3 & 11.7 & 12.0 & WNW \\
\hline & Hydrofracture ${ }^{a}$ & 18.9 & 10.7 & (b) & WNW \\
\hline & $\begin{array}{c}\text { Deep } \\
\text { overcoring }\end{array}$ & 22.8 & 5.1 & 9.5 & NE \\
\hline \multirow[t]{3}{*}{ BSP-1 } & Hydrofracture & 24.1 & 7.7 & $5.1^{\mathrm{C}}$ & NE \\
\hline & USBM gage & 17.4 & (b) & 4.3 & (b) \\
\hline & $\begin{array}{c}\text { Conventional } \\
\text { overcoring }\end{array}$ & 19.9 & (b) & 4.5 & NE \\
\hline BSP-2, 3 & Hydrofracture & 24.1 & 7.7 & $4.8(3)$ & (b) \\
\hline
\end{tabular}

\footnotetext{
anterpolated to depth of test facility.

bIndeterminate from measurement.

Cossibly $\sigma_{3}$ based on lowest shut-in pressure value.
} 
the horizontal hole BSP-2. The fractures vere subhorizontal with a slight dip toward the extensometer drift. The planes of the BSP-2 hydraulic fractures are very close to being normal to the minimum stress measured in BSP-3 by the conventional Leeman cell method (Fig. 2).

\section{DISCUSSION AND CONCLUSIONS}

The preliminary values of the stresses calculated from the overcoring and hydraulic fracturing are given in Table 1 , and the or lentations are shown schematically in Figure 3 . The greatest stress runs in a northeast direction, which is parallel to the drifts. The least stress values based on the BSP-3 conventional Leeman cell measurements were supported by hydraulic fracturing results, but those of the deep hole Leeman cell were not. The least stress based on the conventional Leeman cell is about 30 degrees from the vertical and skewed toward the extensometer drift. This orientation for the minimum stress is also in general agreement with that predicted numerically for the near-field (T. Chan, personal communication) (Fig. 4).

The major questions yet unresolved are (1) the inconsistency of the minor stress orientations between the two Leeman cell techniques and (2) the cause of the rotation of the maximum stress from northwest in SBH-4 to northeast in the underground test area. Addressing the latter question, it appears that the northeast stress direction measured in the full-scale drift area is not due to a local stress concentration around the full-scale and extensometer drifts. This conclusion is based on a similar northeast trend measured by Carlsson (1978) several tens of meters away in the test area and by the Power Board in a 280-m-deep hole drilled from the 360-m-level of the mine. Although it is possible that the rotation is a gross effect of the large-scale mining of the Stripa ore deposit, any hypothesis will be difficult to confirm without a three-dimensional model of the site.

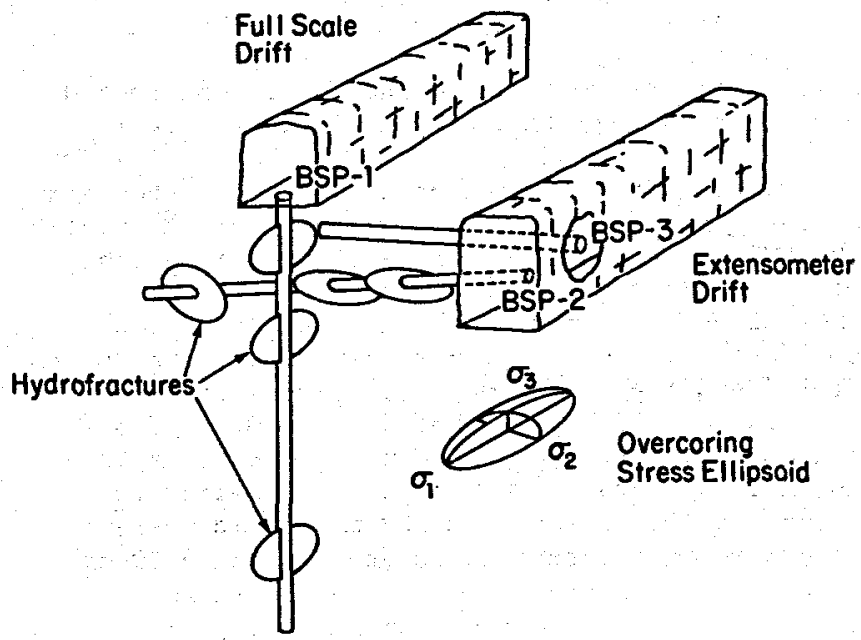

Figure 3. Sketch of the full-scale drift area, showing locations of holes, orientations of hydrofractures, and the average stress ellipsold from the overcoring.

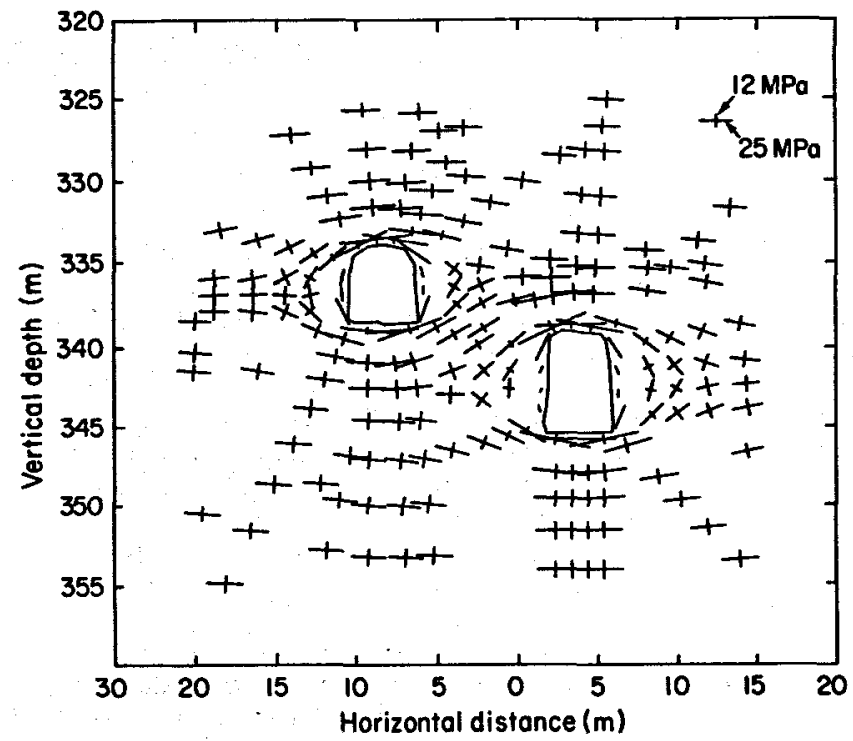

Figure 4. Principal stress distribution around full-scale and extensometer drifts as calculated from far-field stress measurements. [XBL 821-1612]

The additional work that has now been done underground at Stripa reinforces the conclusIons about comparability of overcoring and hydrofracturing that were made from the $S B H-4$ results. Despite controversy over both overcoring and hydraulic fracturing stress measurement methods, the similarity of results, especially with regard to magnitude and direction of the maximum stresses, does increase the level of confidence in the applications of these techniques to waste repository sites.

\section{REFERENCES CITED}

Carlsson, H., 1978. Stress measurements in the Stripa granite. Lawrence Berkeley Laboratory Report LBL-7078 (SAC-04), 13 p.

Chan, T., Guvanasen, D., and Littlestone, D.. 1981. Numerical modeling to assess possible influence of mine openings on far field stresses. Lawrence Berkeley Laboratory Report, in preparation.

Doe, r. W., Ingevald, K. , Strindell, L., Haimson, B. C., and Carlsson, H., 1981. Hydraulic fracturing and overcoring stress measurements in a deep borehole at the stripa test mine, Sweden. Proceedings, 22d U. S. Rock Mechanics Symposium, Mass. Inst. Technology, $p$. 373-378.

Hiltscher, F., Martha, J., and Strindell, L., 1979. The measurement of triaxial stresses in deep boreholes in the design and construction of underground openings. In proceedings, Fourth Congress International society of Rock Mechanics, Montreaux, Switzerland, v. 1, p. 227-234.

Zoback, M. D., and Pollard, D. D., 1978. Hydraulic fracture propagation and the interpretation of pressure time records for in situ determination. In Proceedings, 19th v. S. Symposium on Rock Mechanics, University of Nevada-Reno, p. 14-22. 
GEOPHYSICAL BOREHOLE MEASUREMENTS IN LOW-PERMEABILITY ROCK

\author{
P. H. Nelson and R. Rachiele
}

Many rock types offer low permeability to fluid flow. Examples are carbonates and dolomites, shales, high-grade metamorphics, and most intrusive igneous rocks. In such rocks the bulk permeability is controlled by fractures rather than by matrix permeability. Because fractures and faults are not distributed uniformly throughout a rock mass, permeability can vary tremendously among measurements made on a scale of meters or more. Detailed hydrologic testing is required if all permeable zones are to be identified and measured in a heterogeneous system.

Geophysical methods respond to the presence of discontinuities in rock, to the mineralogical properties, and to properties of fluids saturating the pore space. Permeability variations, which cannot presently be measured with geophysical techniques, are inferred from association with variations in these rock characteristics. In the following examples, permeability variations inferred from geophysical logs by simple inspection and correlation are compared with hydrologic permeability determinations. In addition, a new method of permeability profiling is illustrated by flow logs obtained with dissolved radon, a naturally occurring radioactive tracer.

All the records shown are from the field project at Stripa, Sweden. Boreholes SBH-1 and $\mathrm{SBH}-3$, inclined at 45 degrees, penetrated a metamorphic (leptite) sequence and a granitic (quartz monzonite) pluton. The 3-in.-diameter boreholes were logged with geophysical probes before permeability determinations were made with injection methods on intervals isolated with packers (Gale, 1981).

\title{
DELINEATION OF PERMEABLE ZONES
}

Partial results of the SBH-1 borehole measurements are shown in Figure 1, where permeability and fracturing increase to the right for all parameters. Permeability values range over more than five orders of magnitude, from less than $10^{-9}$ to almost $10^{-4} \mathrm{~cm} / \mathrm{s}$. Permeability values obtained with 7-m packer intervals agree fairly well with the values obtained at the same $10 \mathrm{ca}-$ tion with $2-m$ intervals. Fracture data are also presented in a bar chart format, averaged over 2-m intervals, to facilitate direct comparison with the permeability data. The sonic transit time and the resistivity logs shown have been selected from the suite of geophysical logs because they correlate best with the permeability data.

Before the start of hydrologic testing, the geophysical and core logs from SBH-1 were examined for selection of zones judged likely to be more permeable than others. A bar graph summary of the selected zones is reproduced in the right-hand column in Figure 1. All the geophysical data as well as the core logs were considered in selecting zones likely to be permeable.

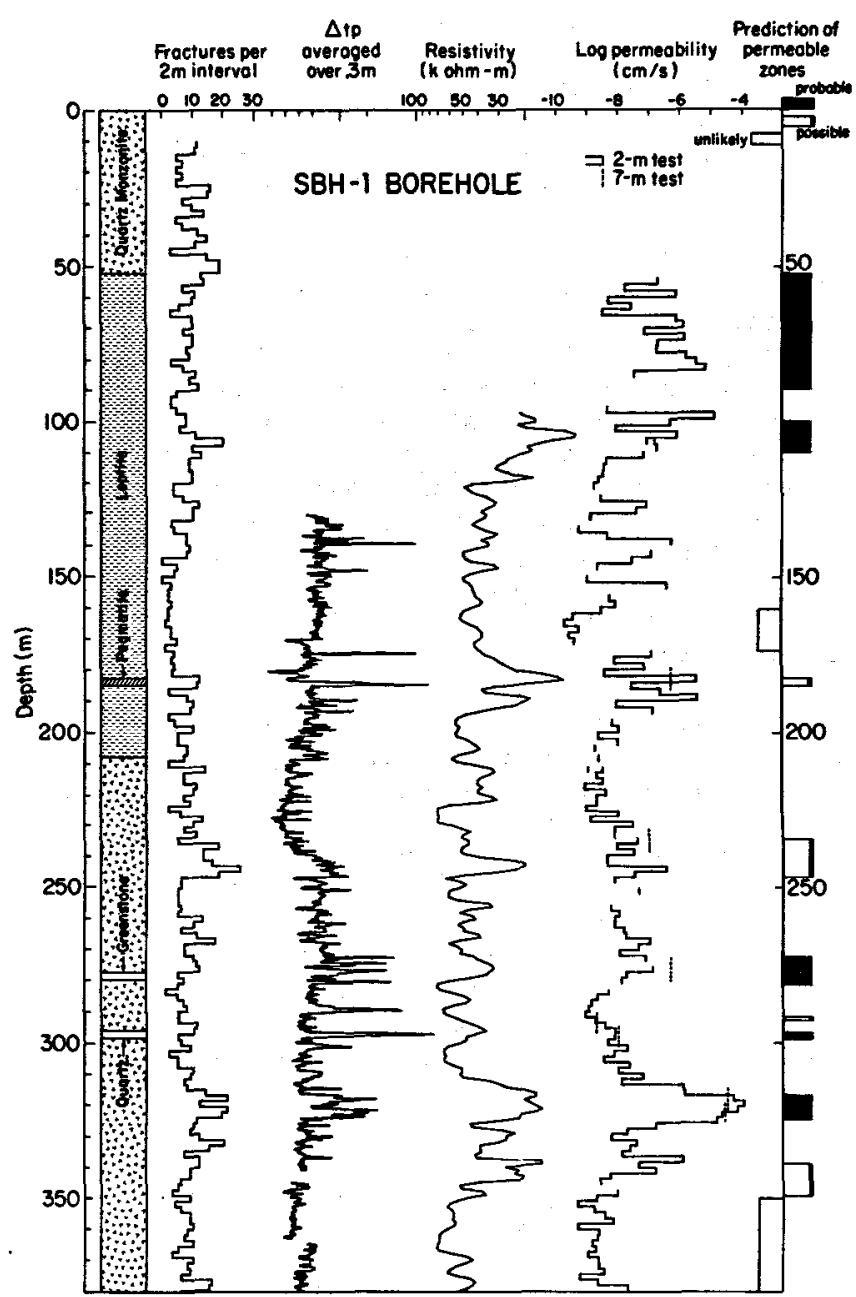

Figure 1. Measurements from borehole SBH-1 at Stripa, Sweden. Depth values indicate slant depth rather than vertical depth. [XBL 8110-12118]

so the bar graph summary cannot be reconstructed from the few logs accompanying it in Figure 1.

Overall, the comparison between predicted and measured permeable zones is quite good. Most of the 2-m intervals with permeabilities in excess of $10^{-6} \mathrm{~cm} / \mathrm{s}$ were selected as "probable" permeable zones, although of the two intervals centered at 183 and $189 \mathrm{~m}$, one was selected as "possible" and the other ignored, despite the reduction in resistivity at that depth. Other failures to predict permeable zones occurred at 139 and $153 \mathrm{~m}$, where the measured permeability is about $3 \times 10^{-6} \mathrm{~cm} / \mathrm{s}$. The 139-m zone is characterized by a marked sonic anomaly and a $30-\mathrm{cm}$ intercept of fractured core. The $139-\mathrm{m}$ zone is characterized by a marked sonic anomaly and a $30-\mathrm{cm}$ intercept of fractured core. The 153-m zone is without any accompanying distortions on the geophysical logs. Moreover, the core from this depth is nearly intact; the fracture frequency is about one per meter. This interval 
Tppears to be the only one devold of any regisfations on the accompanying logs.

The correlation between the resistivity log and the permeability data appears strikingly good, with most high-permeability zones associated with conductive troughs in the resistivity log. One would expect some correlation of this sort, since fluid flow paths should be continuous in order to conduct electrical current. Many authors have examined the relationship between permeability and electrical resistivity, which can usually be directly related to rock porosity. For purposes of this discussion, we simply point out that permeability, which varies by more than $10^{5}$ in Figure 1 , appears to be highly sensitive to variations in resistivity, which varies by less than a factor of 10.

Detalled records of the most permeable zone in SBH-1 are shown in Figure 2. The sonic waveform display is an abbreviated presentation of the time-varying sonic signal transmitted along the 1-ft distance separating transmitter and receiver in the borehole. Delays in the arrival at the receiver of any of the modes show as a distortion of the wavetrain and are attributed to fracturing in the rock. The delay of the first compressional arrival is also plotted in the fifth column of Figure 2. Permeability is recomputed and replotted as fracture aperture, which is proportional to the cube root of permeability. The computation assumes one fracture test interval ( $2 \mathrm{~m})$.

Distortions in the sonic waveform record over the interval 316 to $325 \mathrm{~m}$ are coincident with the high-permeability values measured in the same interval. Fractures observed in core are also considerably more numerous in this 9-m interval than in other intervals in the borehole. The permeability results also show higher-than-background values immediately above and below the 316- to 325-m interval. These permeable intervals are attributed to (1) isolated fractures revealed in the waveform record, and (2) over lap of the packer interval on the margins of the continuous fracture zones.

\section{FLOW PROFILES USING DISSOLVED RADON}

The total-count gamma-ray probe detects the summed gamma emissions of the radioactive elements occurring naturally in rock--potassium and the thorlum and uranium decay series. However, at Stripa an unusual circumstance prevails: the groundwater contains sufficlent amounts of radon to be observed on the total count $l \circ g$, over and above the gamma contribution from the rock itself

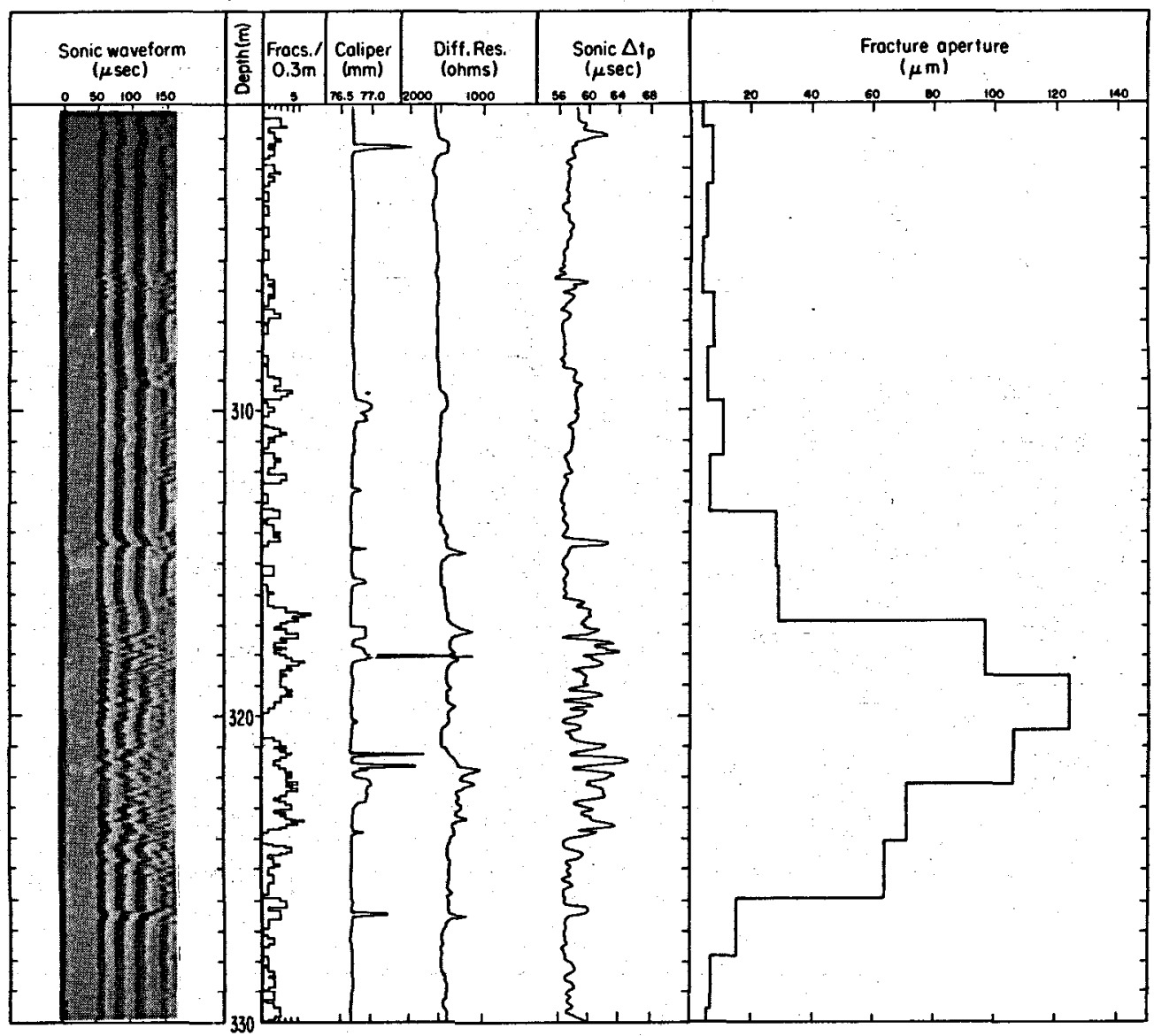

Figure 2. Measurements from 300- to 330-m interval in $5 B H-1$.

[XBL 811-2550] 
(Nelson et al., 1980). Such unusually high radon levels occur because: ( 1 ) the uranium content in the granitic rock is high, between 35 and $40 \mathrm{ppm}$ (2) the uranium seems to be localized along fractures, so that emanated radon escapes from the rock into pore water; and (3) groundwater flow is along fractures in low-porosity rock, so that dilution is minimal, and the flow rates are high enough to bring in sufficient radon to be detected.

A previous study (Neison et al. 1980) established that in cases where radon-charged groundwater enters (or exits) a borehole at one point and moves upward (or downward) within the borehole without diffusion or dispersion, then the concentration decays as $\exp (-\gamma t)$, where $\gamma$ is the decay constant of radon-222. The time of travel, $t$, from entry point to observation point is $A z / Q$, where $A$ is the cross-sectional area of the borehole, $z$ the distance between entry and observation points, and $Q$ the volumetric flow rate. Hence, if the logarithm of concentration, or equivalently the gamna-ray count rate, is plotted against depth, a straight-line fit to the decay provides an estimate of the flow rate $Q$.
This technique has been used to estimate flow rates in borehole SBH-3 under static open-hole conditions (Fig. 3). Radon-charged groundwater enters the borehole in the upper $100 \mathrm{~m}$ and flows downward under the prevailing hydraulic head, exiting the borehole at the deep permeable zones. For example, between 100 and $200 \mathrm{~m}$ slant depth in borehole SBH-3 the count rate decreases from 390 to $345 \mathrm{cps}$. Estimation of the flow rate by the method described above yields a value of 307 liters/day, which is posted in the right-hand column of Figure 3. A value of this magnitude, equivalent to a linear flow rate of $68 \mathrm{~m} /$ day, would not be measurable by most techniques of flow measurement, but is detectable by this method because the radon tracer is being continually added and because its 3.8 day half-life is appropriate to the flow rates occurring here.

Zones of fluid loss occur wherever the count rate decreases sharply before again decreasing at a uniform (exponential) decay rate. In SBH-3 the loss zones are as depicted in Figure 3: one at 210 to $220 \mathrm{~m}$ taking about 290 liters/day, and another, probably at $268 \mathrm{~m}$, taking about 17 1iters/day. Unfortunately, the hydrologic tests

Borehole SBH-3

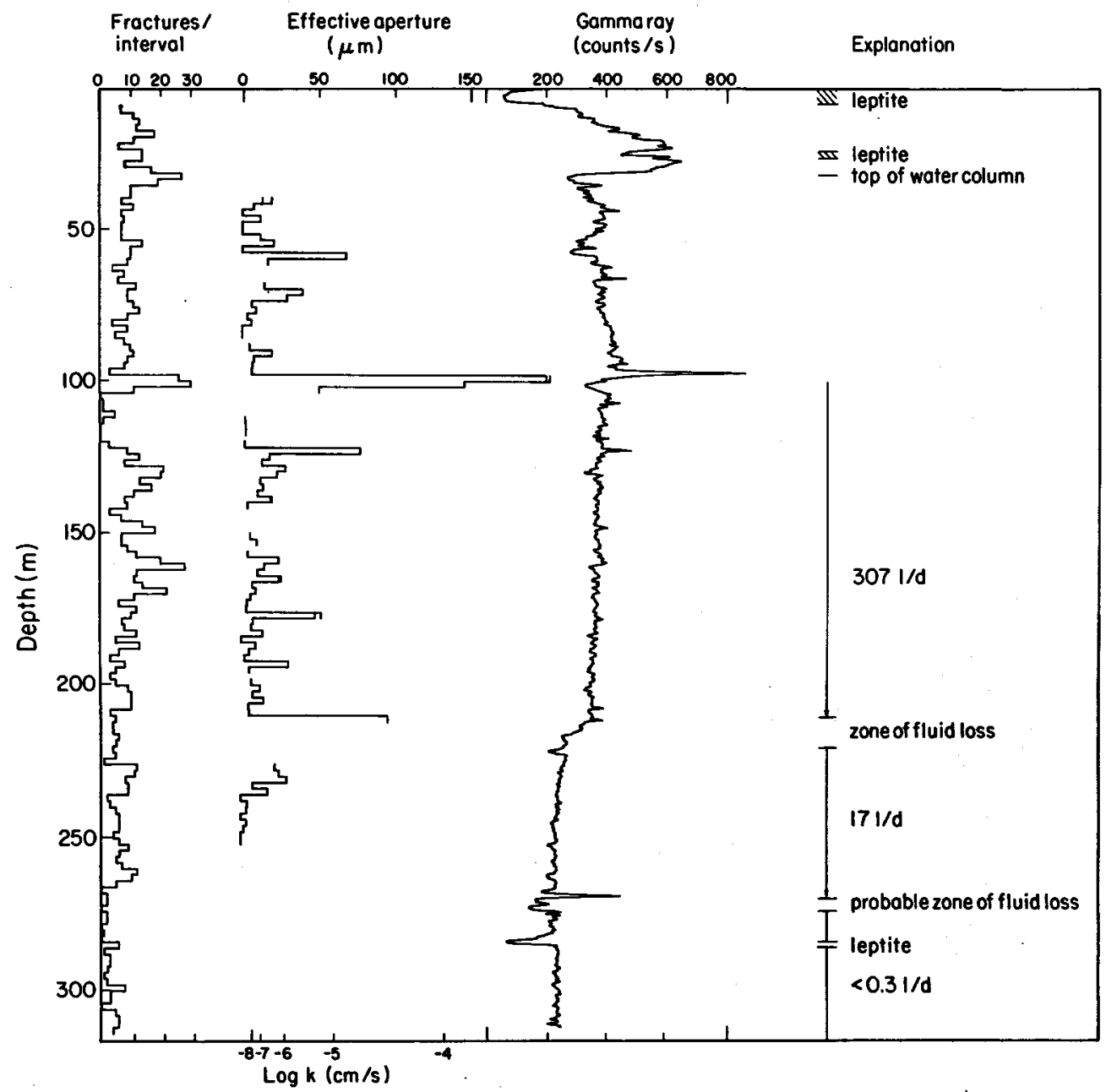

Figure 3. Gamma-ray $\log$ and interpreted flow profile from borehole SBR-3 at Stripa, Sweden. [XBL 8110-12131] 
were incomplete in this borehole, but the upper loss zone coincides with one $2-m$ test zone of high permeability.

SUMMARY

Correlation of a suite of geophysical logs with permeability test results $1 \mathrm{~s}$ encouraging in the sense that a high percentage of potentially permeable zones can be selected for detailed testing on the basis of logs. Alternatively, the logs can be used to confirm the results of hydrologic testing. For waste repository investigations, it is desirable to extract as much information as possible from exploratory boreholes, and hence a full suite of logs should be obtained. The sonic waveform especially merits more research attention to quantify the dependence of mode propagation on fractures.

Flow profiling can be effective in low-permeability rock if a tracer of suitable half-life is continuously injected into the borehole. Flow profiles delineate the dominant permeable zones under either static or steady-state injection conditions for the entire length of the borehole.

\section{ACKNOWLEDGMENTS}

J. E. Gale provided the permeability determinations shown in the figures. K. Magnusson of the Swedish Geological Survey acquired the electrical logs shown in Figures 1 and 2.

\section{REFERENCES CITED}

Gale, J. E., 1981. Fracture and hydrology data from fleld studies at Stripa, Sweden. Lawrence Berkeley Laboratory Report LBL-13101, in preparation.

Nelson, P. H., Rachiele, R., and Smith, A., 1980. The effect of radon transport in groundwater upon gamma-ray borehole logs. Lawrence Berkeley Laboratory Report LBL-11180 $(\mathrm{SAC}-30)$.

\title{
DEVELOPMENT, VERIFICATION, AND APPLICATION OF MODELING TECHNIQUES FOR THERMOMECHANICAL ANALYSIS
}

\author{
T. Chan and E. L. Wilson
}

The stripa heater tests (Witherspoon et al., 1981) have provided a comprehensive data base for the thermomechanical response of a granitic rock mass. Preliminary Ilnear thermoelastic calculations using constant rock properties measured from one or two small specimens did not accord well with field data (Chan and Cook, 1979). Following the completion of data based preparation (Chan et al., 1980), a project was established to develop improved analytical and numerical models to simulate thermally induced rock deformations and stresses. This paper summarizes the status of model development, verification, and application as of september $30,1981$.

For the purposes of this study, the following philosophy has been adopted. (1) Laboratory and field data will be used to gulde the development of models. (2) No single modeling technique will be employed exclusively. Instead, the optimum technique, to the best of the investigators' judgment, will be chosen according to the physical situation to be simulated.

EMPIRICAL DATA AND THEIR IMPLICATIONS ON MODELING

Close examination of rock deformation data from the Stripa heater experiments has led to the following conclusions: (1) the in situ thermal expansion coefficient of the granitic rock mass at Stripa is temperature-dependent, and (2) the presence of joints has some influence on rock fisplacement.

The first conclusion can be reached by comparing displacements in the two full-scale experiments, as illustrated by Figure 1. Here the history of the relative displacement of a pair of extensometer anchor points in the 3.6kW experiment is compared with the normalized (by a factor of $3.6 / 5$ ) relative displacement of a corresponding pair of anchor points in the 5-kw experiment. The normalization effectively removes the difference in the temperature fleld between the two experiments. If the thermal expansion coefficient were independent of temperature, the two curves would be nearly identical. The larger magnitude of the 5-kw curve clearly indicates that the in situ thermal expansion coefficlent increases with temperature.

In view of the poor signal-to-noise ratio in the displacement data and numerous instrumentation problems, the effect of the foints cannot be demonstrated unambiguously. However, by using nonparametric statistical analysis, we have shown that the amount of displacement is positively correlated to the total thickness of joints between two extensometer anchor points.

Laboratory testing on core specimens by several groups (Myer, 1981) has shown that both the mechanical and thermomechanical properties vary with temperature, confining pressure, and stress difference. Although the different laboratory investigators do not agree on the anisotropy of the rock properties, stress dependency means that there would be stress-induced anisotropy.

Taken together, the laboratory and fleld data imply that the numerical model for thermomechanical analysis in general should have the capabilities discussed in the next section. 


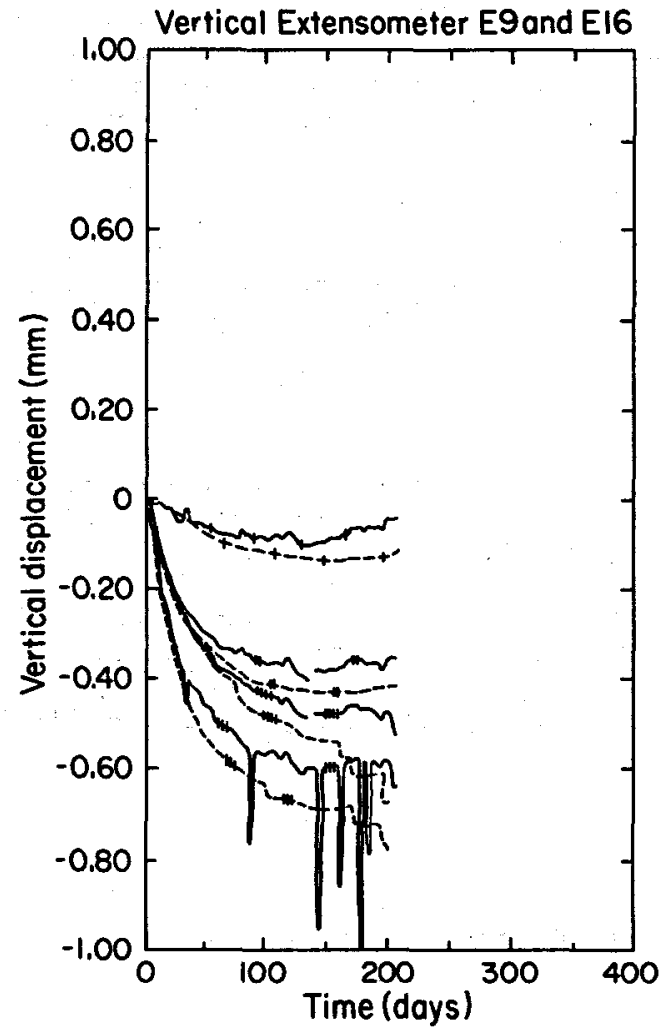

Relative Displacement of Anchor Points

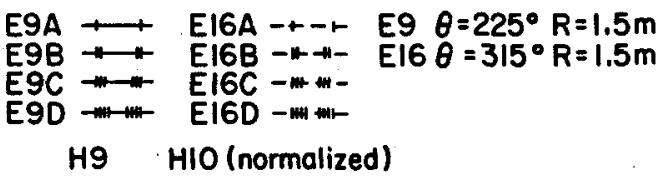

Figure 1. Comparison of relative displacements in the 3.6-kW experiment with normalized relative displacements in the 5-kW experiment for corresponding pairs of extensometer anchor points. The larger magnitudes of the broken curves indicate that the in situ thermal expansion coefficient increases with temperature. [XBL 819-11531]

\section{DEVELOPMENT AND VARIFICATION OF PROGRAM USAP}

From a brief review of existing computer programs, it was found that none could handle material properties varying simultaneously with temperature and stress. Accordingly, a small finiteelement program SAP-80 was modified into a special-purpose program USAP (Wilson et al., 1981) for thermomechanical data analysis.

Program USAP (underground structural analysis program) incorporates the following capabilities: in situ stress, thermal stress, and temperature and stress-dependent orthotropic materials with tension cutoff. The first version of this program, with a 3- to 9-node two-dimensional axisymmetric element, is now completely operational and has been verified by comparison with several benchmark problems, including: (1) a circular hole in an infinite isotropic medium subjected to a biaxial initial stress field under plane-strain conditions, (2) a circular hole in an infinite orthotropic medium subjected to internal pressure loading under plane-strain conditions, (3) a long cylindrical opening in an isotropic medium under gravity loading, and (4) a long, thick-walled circular cylinder subjected to temperature loading. Excellent agreement was found between USAP solutions and closed-form solutions, as illustrated in Figure 2. In the course of this work it was found that some of the published solutions for these "benchmark" problems--e.g. "Timoshenko and Goodier's (1970) solution for the thermal loading problem--were incorrect. In such cases we have provided the correct solutions.

No special joint element or interface element has been included, since Pande and Sharma (1979) have demonstrated numerically that even for an aspect ratio of $1,000,000$ the continuum element and the interface element give essentially identical results when a $C D C-7600$ computer, which has a 64-bit word length, is used.

\section{CLOSED-FORM SOLUTION}

In the time-scaled experiment the mean rock temperature in the volume bounded by the heater array was calculated to be $35^{\circ} \mathrm{C}$ or less, depending on time. Consequently, a linear thermoelastic solution with constant material properties may be a good first approximation. A closedform solution was obtained for the temperature, displacement, and stress fields caused by an array of line heaters in a semi-infinite medium. The results compare favorably with field data. Typical examples are illustrated in Figure 3 for the measured and calculated displacements between two anchor points in the rock in this experiment. The solld curve represents the closed-form solution obtained using a thermal expansion coefficient of $8 \times 10^{-6} / K$, the value calculated by Turner's formula from the thermal expansion of the individual minerals. Linear regression from a cross-correlation plot between calculated and measured displacements yields a best-fit value of $7.6 \times 10^{-6} / \mathrm{K}$ and an initial $\mathrm{lag}$ of $40 \mu \mathrm{m}$. The broken curve results from adjusting the calculation according to this regression analysis. In Figure $3 b$ the finite-element solution is also shown (lowest curve). In the finite-element solution (Chan and Cook, 1979), practical limitation of computational cost has restricted the model to a mesh of about 1000 solid elements, a rather coarse mesh for the geometry of this experiment. Consequently, the finite-element solution deviates more from the field data than does the closed-form solution. 

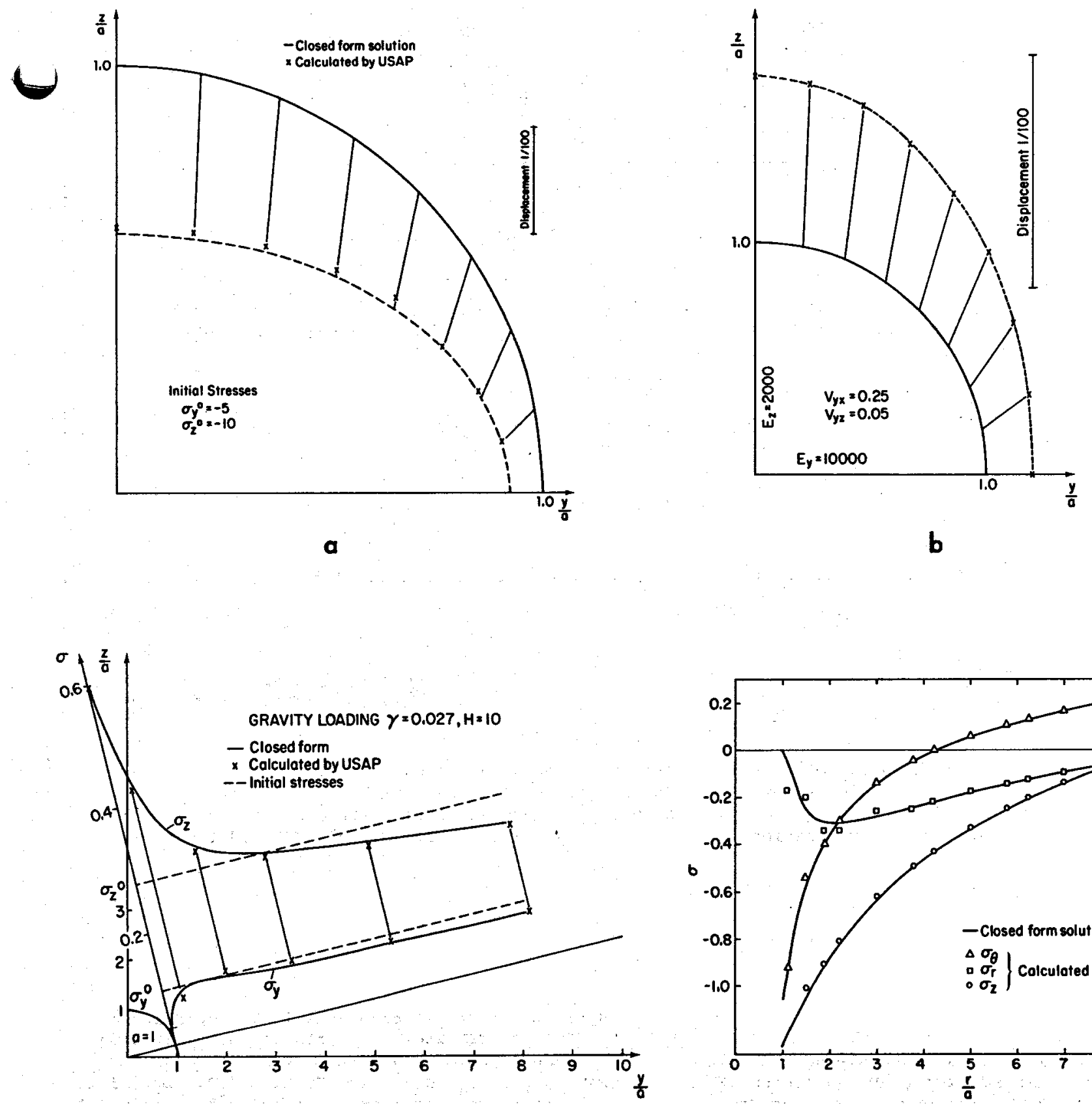

c

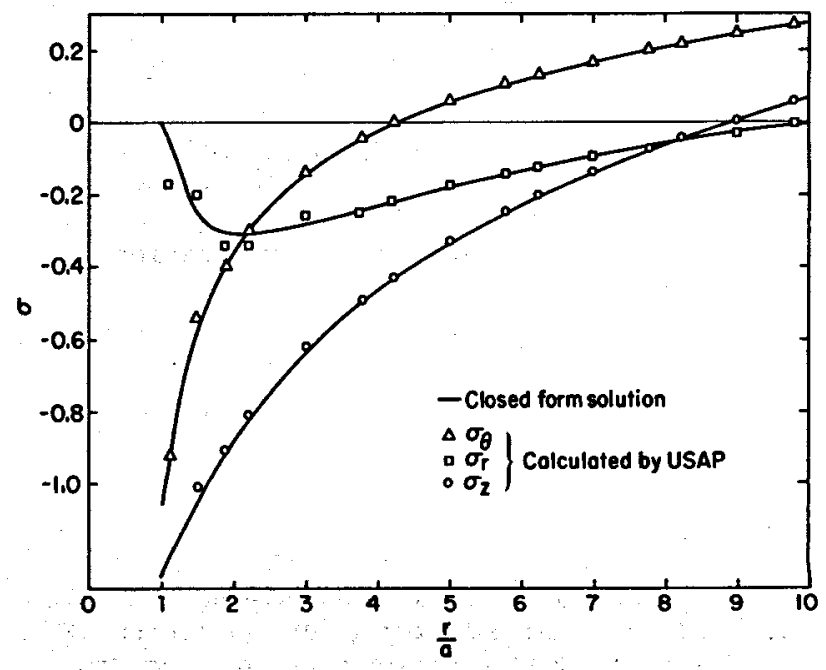

d

Figure 2. Comparison of USAP (finite-element) and closed-form solution for (a) deformation of a circular hole under biaxial in situ stress, (b) deformation of a circular hole under internal pressure in an anisotropic medium, (c) stress distribution around a circular hole under gravity loading, and (d) stress distribution in a thick-walled cylinder under thermal loading. [(a), XBL 819-11510; (b), XBL 819-11637; (c), XBL 819-11639; (d) XBL 819-11512] 
EXTENSOMETER DISPLACEMENTS

TIME SCALE EXP. 3

E2B-C

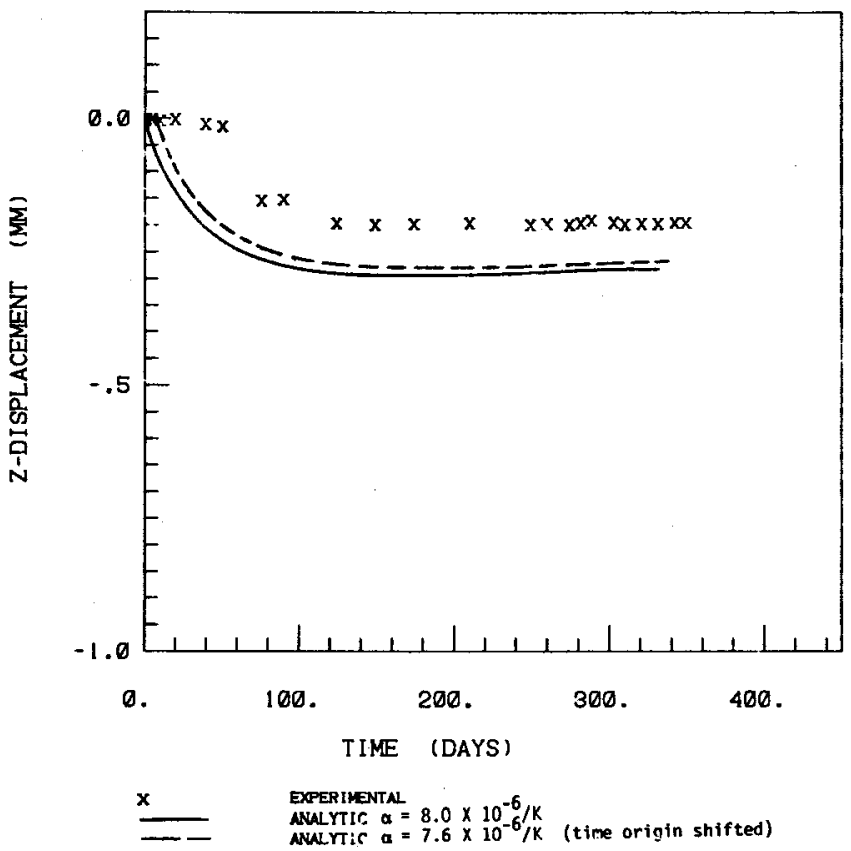

EXTENSOMETER DISPLACEMENTS

TIME SCALE EXP.3

$E 3 B-C$

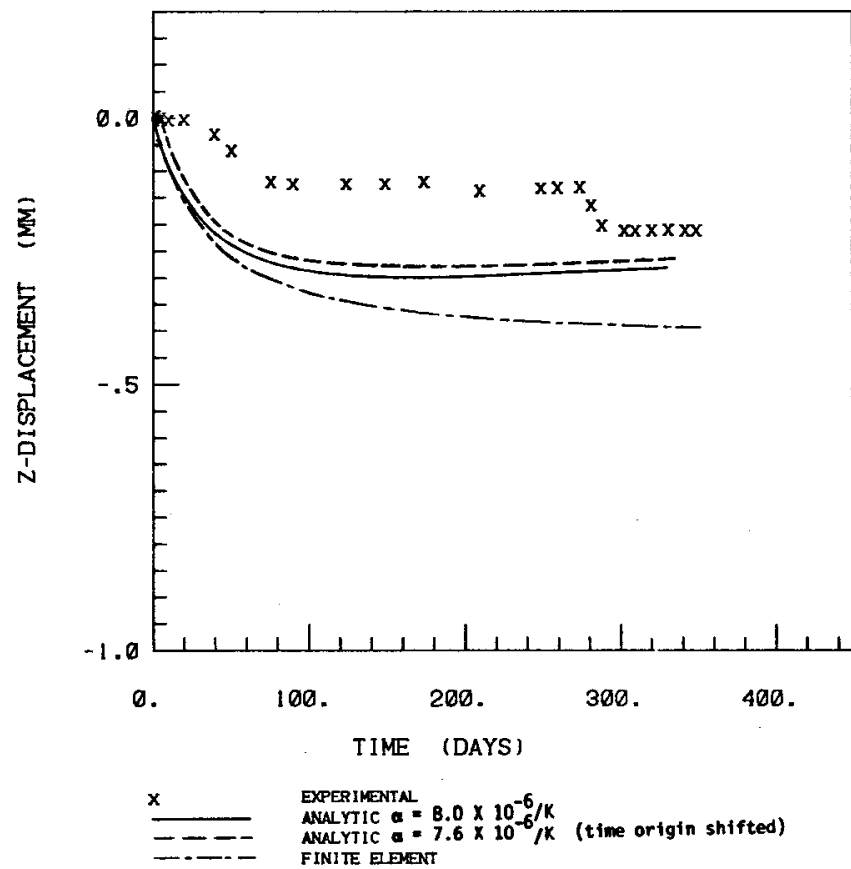

Figure 3. Typical plots of relative displacement between two extensometer anchor points in the time-scaled experiment: (a) comparing field data with closed-form solution, and (b) comparing field data with closed-form and finite-element solution. See text for further explanation.

[(a), XBL 819-11540; (b), XBL 819-11545]

\section{ACKNOWLEDGMENTS}

The authors gratefully acknowledge the able assistance of Marc Hoit for USAP development, Rari Saari for USAP verification, and Lap-Yan Chan for statistical data analysis.

\section{REFERENCES CITED}

Chan, T., and Cook, N. G. W., 1979. Calculated thermally induced displacements and stresses for heater experiments at Stripa. Lawrence Berkeley Laboratory Report LBL-7061 (SAC-22) .

Chan, T., Binnall, E., Nelson, P., Stolzman, R., Wan, O., Weaver, C., Ang, K., Braley, J., and McEvoy, M., 1980. Thermal and thermomechanical data from in situ heater experiments at Stripa, Sweden. Lawrence Berkeley Laboratory Report IBL-11477 (SAC-29).
Myer, L., 1981. Thermomechanical properties of Stripa granite. In Earth Sciences Division Annual Report 1981 (this volume).

Pande, G. N., and Sharma, K. C., 1979. On joint interface elements and associated problems of numerical Ill-conditioning. International Journal for Numerical and Analytical Methods in Geomechanics., v. 3, p. 239-300.

Timoshenko, S. P., and Goodier, J. N., 1970. Theory of Elasticity (3rd ed.). New York, MCGraw-Hill Book Company, 567 p.

Wilson, E. L., Boit, M., and Chan, T., 1981. USAP--An underground structural analysis program. Lawrence Berkeley Laboratory Report LBL-13289, in preparation.

witherspoon, P. A. Cook, N. G. W., and Gale, J. E.. 1981. Geological storage of radioactive waste: Field studies in Sweden. Science, v. 211, P. 894-900. 


\section{MEASUREMENT OF LOW RATES OF WATER INFLOW BY MONITORED EVAPORATION}

\section{$\checkmark$ THE LARGE-SCALE PERMEABILITY EXPERIMENT AT STRIPA}

M. J. McPherson

The low rates of water inflow to the heading used for the large-scale permeability experiment at Stripa were quantifled by monitoring the water-vapor content of the ventilation air. Coupled with measurements of water pressure in sealed sections of boreholes, the data could be utilized to evaluate the macropermeability of the fractured granite around the heading.

As indicated in a previous report (Wilson, 1981), the water inflow to the tunnel was measured as the difference between the water vapor in the heated air entering the test section and the water vapor leaving via the outlet air duct. The assumption was that all water entering the room was evaporated and exited as water vapor.

Transient effects on the apparent water inflow were noted after changes were made in the room temperature or airflow. These were shown to be caused by mixing processes within the room and self-correcting variations in the rate of evaporation from the rock walls. This report analyzes the results of moisture pickup and examines the time transients that occurred during the course of the experiment.
MOISTURE PICK-UP

\section{Selection of Time Periods for Analysis}

Observations of temperature, air pressures, and airflow made each day were used to compute the psychrometric conditions within the inlet and exhaust ducts (McPherson, 1979). In addition, a progressive plot was made of the most important parameters.

For the purposes of analysis, the data have been divided into three time periods. These are shown on Figure 1 together with the corresponding moisture plckups, airflows, and exhaust dry bulb (room) temperatures. In order to facilitate the analysis, this figure is based on "measurement days" from the start of each time period--i.e.. excluding weekends and other days when no observations were made.

\section{Interpretation of Results}

The results show considerable variation in the rate of molsture pickup on a day-to-day basis. There are three reasons for this:
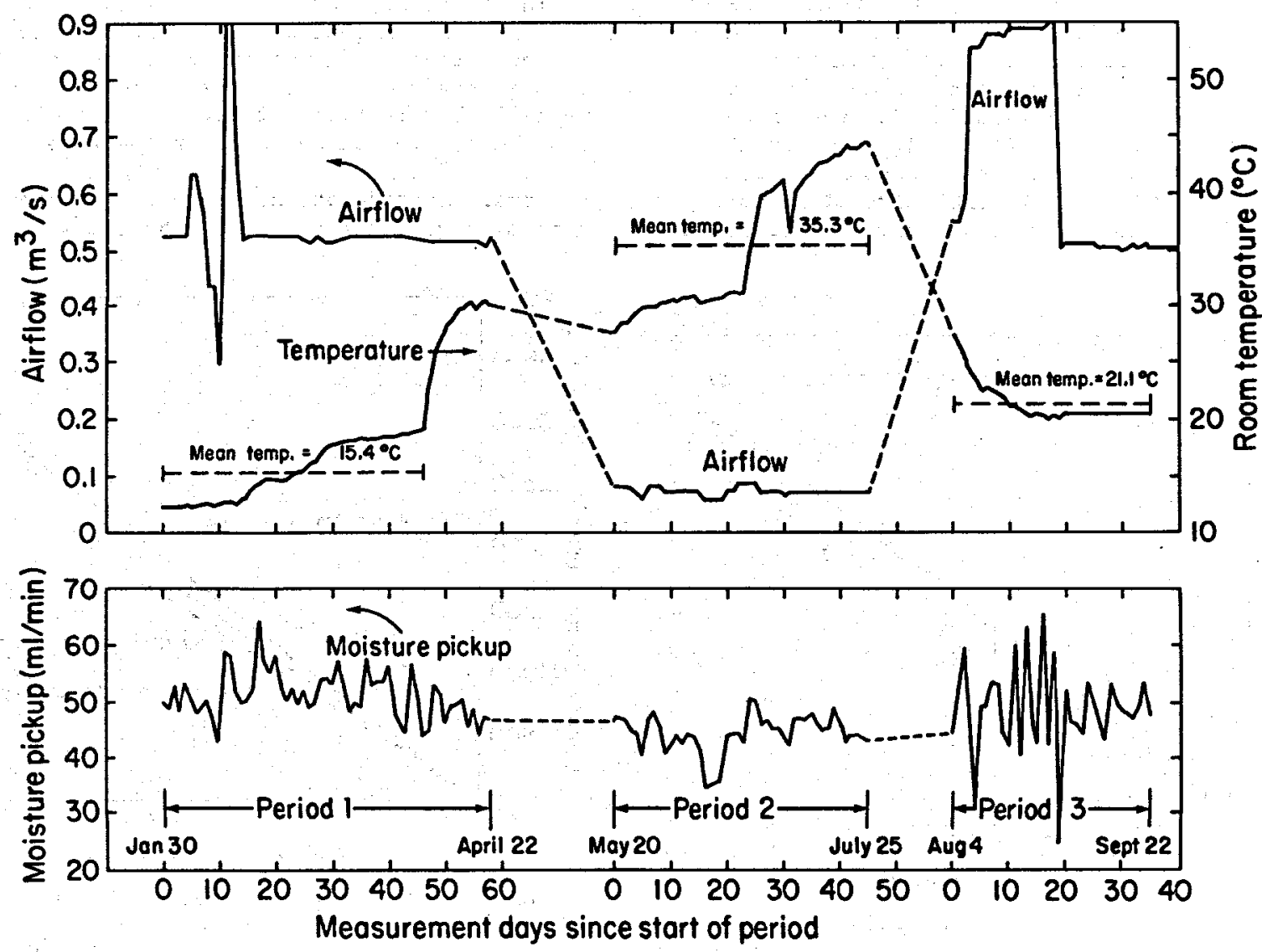

- Figure 1. Results obtained on measurement days. [XBL 821-1613] 
1. Changes in airflow.

2. Adjustments to the room air temperature.

3. Experimental accuracy limits.

The first two were caused by adjustments to the fan or outlet duct louvre and operation of the heaters. An increase in airflow causes a transient increase in molsture pickup. The effect is particularly sensitive at low airflows (period 2). Similarly, an increase in temperature causes a temporary increase in moisture pickup. These transients are examined in detail in the next section.

At completely steady state, the molsture pickup would equal the water inflow through the rock into the room, and would be sensibly constant for any given rock temperature. During each of the three time periods, all water entering the room was evaporated and would be sensed by the instrumentation. Hence the total volume of water evaporated over any time period must equal the total water inflow from the rock during the same period. The system is therefore selfbalancing. An increased evaporation rate caused by an adjustment to temperature or airflow would be compensated within the following few days by a corresponding decrease in evaporation rate. The pattern of compensating peaks and troughs can be seen in Figure 1. This suggested a method of analysis.

A cumulative plot of moisture pickup would be a straight line with relatively little scatter if the system is truly self-balancing. Figure 2 shows such a plot for time period 1 . An excellent linear relationship is obtained for the first 46 days, after which the curve shows a slight droop. The explanation for the change is clear from Figure 1. At day 46, additional heat was supplied to increase the room air temperature to $30^{\circ} \mathrm{C}$. Similar cumulative plots for time periods 2 and 3 also gave very good straight lines with little scatter.

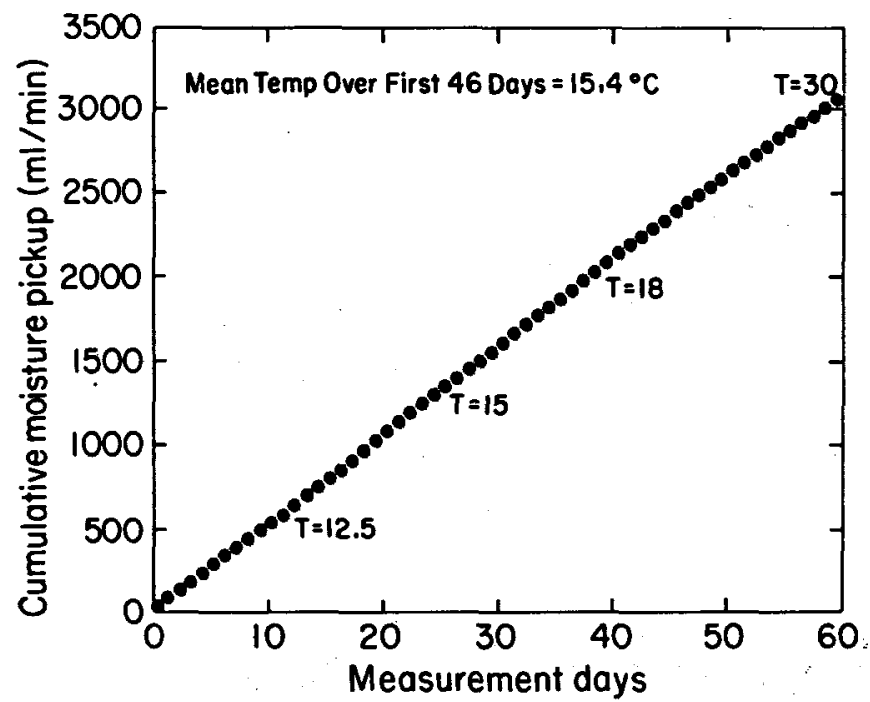

Figure 2. Cumulative moisture pickup rate for time period 1.

[XBL 821-1615]
The three cumulative plots are reproduced for comparison in Figure 3 . Each line has a clearly defined slope giving the corresponding integrated. value of molisture pickup rate. Each of the time periods is sufficiently long for the integrated moisture pickup to equal the water flow from the rock.

A linear regression carried out on the three sets of data gave the slopes (and hence water flowrates) shown in Table 1.

The results shown in the table are plotted in Figure 4 to show the variation of water flow from the rock with respect to room temperature. With only three points, the graph can hardly be said to be rigidly defined. However, the trend is clear, and it is significant that the middle point was from period 3 (the final cooldown phase of the experiment). Hence, within the range of temperatures encompassed, the effect would appear to be reversible.

An interpretation of the falling curve is that expansion of the heated envelope of rock around the room has caused closure, or partial closure, of flow paths, thus reducing the water inflow to the room. The curvature of the graph is indicative that the fractures of smallest aperture are affected first and to a greater relative degree by the expanding rock.

The curve appears to level out at 30 to $40^{\circ} \mathrm{C}$. This is confirmed by time period 2 , where there is no discernible distinction between water inflows during the $30^{\circ} \mathrm{C}$ and the $40^{\circ} \mathrm{C}$ tests. Bence an interpretation of Figure 4 is that the flow of $54 \mathrm{ml} / \mathrm{min}$ at ambient conditions took place mainly in the larger fractures and that the reduction in flow as the rock temperature increased was due to partial closure of all fractures, the effect being accelerated in the smaller apertures.

These considerations are based on the assumption of a constant pressure gradient within the

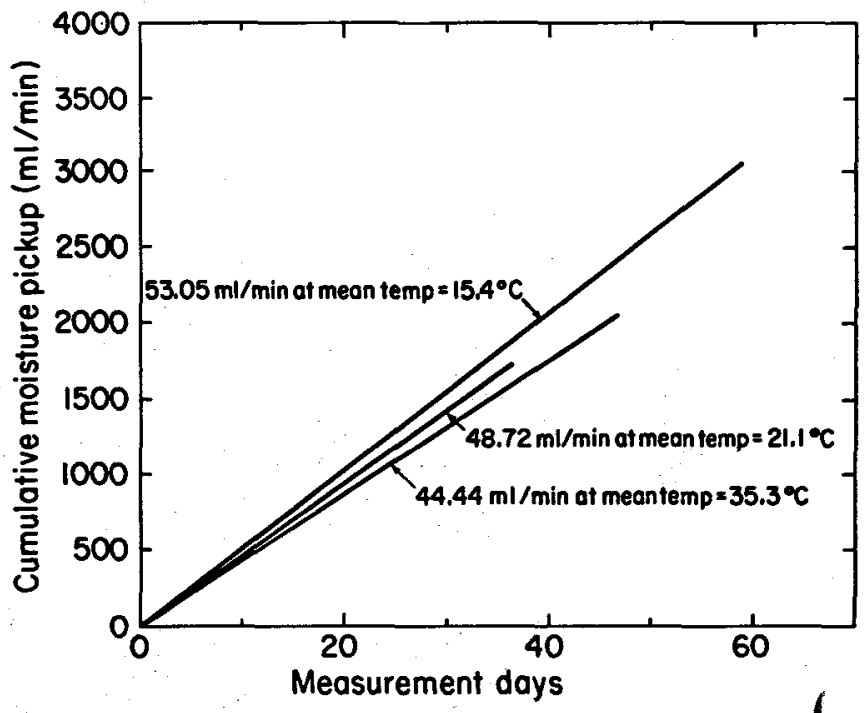

Figure 3. Comparison of cumulative moisture pickup rates for the three time periods.

[XBL 821-1614] 
strata. Any variations in the fluid pressures must, of course, be taken into account in the

final determination of macropermeability.

Table 1. Table of water inflow rates at three mean temperatures in the room.

Mean temperature Water inflow in room $\left({ }^{\circ} \mathrm{C}\right)$ rate $(\mathrm{ml} / \mathrm{min})$

$\begin{array}{lll}\text { Period } 1 \text { (1st } 46 \text { days) } & 15.4 & 53.05 \\ \text { Period } 2 & 35.3 & 44.44 \\ \text { Period } 3 & 21.1 & 48.72\end{array}$

TIME TRANSIENTS

Although an analysis of time transients is not necessary in the production of results, it does give a valuable insight into their cause and why they must balance out over a time period.

\section{The Temperature Effect}

In a completely steady state within the test room and the surrounding rock, the following conditions hold:

1. The rate of water inflow from the rock is constant.

2. The rate of water evaporation is constant and equal to the water inflow.

3. The vapor content of the room air is constant.

4. The rate of vapor removal from the room is constant and is equal to the evaporation rate less the vapor flow rate in the inlet air.

5. The room temperature is constant.

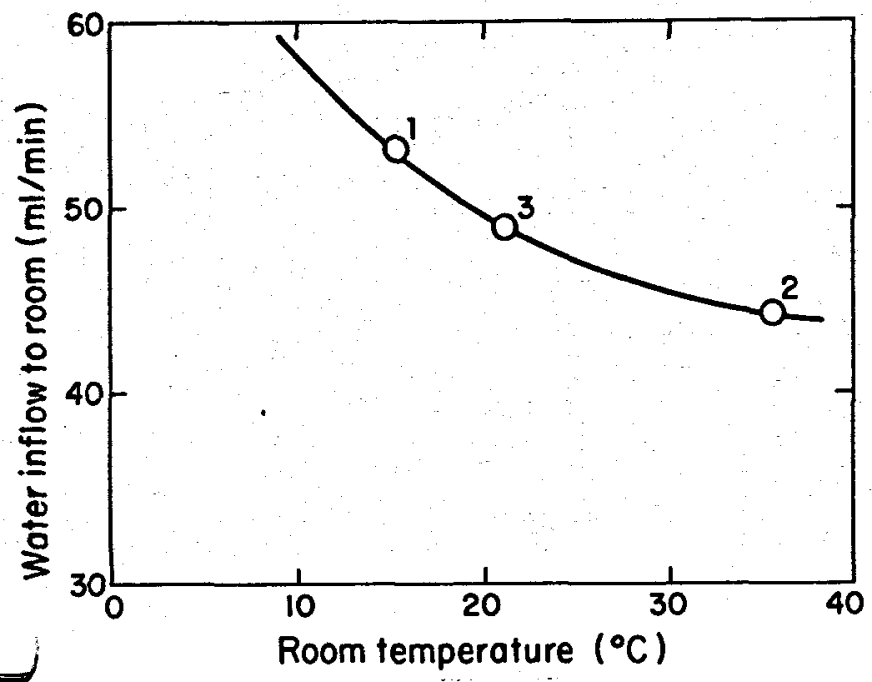

Figure 4. Variation of water inflow with room temperature.

[XBL 821-1616]
If any of these conditions does not hold, then the observations will indicate a transient in the plot of water pickup.

The rate of evaporation from a molst surface is given by

evaporation rate $(g / s)=$

$$
0.7 h_{c} A\left(e_{w}-e_{a c t}\right) / P \text {, }
$$

where $h_{c}=$ convective heat transfer coefficient, $\mathrm{W} / \mathrm{m}^{2}{ }^{\circ} \mathrm{C} ; \mathrm{A}=$ area of molst surface, $m^{2} ; e_{w}=$ saturated vapor pressure at the moist surface (wall), $\mathrm{kPa}$; eact = actual vapor pressure of the air, $k P a$; and $P$ = barometric pressure, $\mathrm{kPa}$. The heat transfer coefficient is a function of the air velocity, density, viscosity and thermal conductivity, and geometry of the wet surface. As all but the last were essentially constant within the room, the evaporation rate becomes a function of the geometry of the air/water interface on the rock surface and within fissures near the rock surface.

Following a step increase in room temperature and assuming constant rate of airflow, the following events occur:

1. The wall temperature rises, giving an increased $e_{w}$. From equation (1) the evaporation rate must also rise. This in turn causes two compensating reactions.

2. The increased humidity in the room raises eact, the vapor pressure within the air. Hence, from equation (1), the rate of evaporation is reduced.

3. The initial accelerated evaporation will result in some drying out of the peripheries of damp areas. The wet area, $A$, will decrease and again bring the evaporation rate back down until steady state is re-established.

The overall effect, then, of a sudden increase in room temperature is a rise in the monitored water pickup, followed within a day or two by a return to the original water pickup. If the rise in room temperature is maintained, then partial closure of the fracture will, of course, reduce the overall water flow into the room.

\section{The Airflow Effect}

There are two distinct consequences of a sudden alteration to the alrflow supplied to the room. One arises from the rate at which the air in the room is displaced by new inlet air. Secondly, there is the adjustment of psychrometric conditions within the room.

Air exchange and the mixing process. If the alrflow rate is suddenly changed, the exhaust duct at $t i m e t=0$ will still be drawing from the air previously contained within the room. Hence a $508 \mathrm{rIse}$ or fall will show up imnediately as a 508 rise or fall in the vapor removed. Thus even if the evaporation rate remains constant (which it does not), an adjustment to the airflow rate will cause a transient in the monitored moisture pickup. However, a 
time-dependent analysis showed that most of the transition is over within a few hours, whereas the actual observations indicated far longer transients after airflow changes--particularly during time period 2, when the airflow was low (Fig. 1). Hence the mixing process, by itself, is not sufficient to explain the slow recovery.

Reaction of psychrometric conditions within the room. Consider a sudden fall in the airflow rate, the room temperature remaining constant.

1. Inmediately after the reduction in airflow rate, the psychrometric condition (humidity) of the room air will be essentially the same as immediately before the fall in airflow. Hence the evaporation rate will be unchanged. However, the airflow is now smaller. The humidity of the room air must therefore increase.

2. As the room temperature has remained constant, the rock surface temperature and its saturation vapor pressure, $e_{w}$, will change by only a small amount. Bowever, the increased humidity raises the air vapor pressure, eact. quite substantially. Equation (1) indicates that the evaporation rate will exhibit a marked reduction. It is this effect, superimposed upon the mixing process, that delays the recovery to steady-state conditions.

3. The evaporation rate is now less than the water flow rate through the rock. The excess water will accumulate within fractures close to the rock surface. This may give rise to a dendritic pattern of fine dark lines on the rock walls, and was reported by the field engineer on occasions as "cobwebbing." If sufficient in quantity, the excess water will exude from the larger fractures and spread out over the wall surface or trickle downwards. The effect is to increase the area of water/air interface. Equation (1) shows that as A increases, the evaporation rate will also rise, opposing and eventually gaining ascendancy over the fall in evaporation rate caused by increased air humidity.
Because of these opposing mechanisms, the transient must be expected to be slow, particularly at low airflows. The effect is exhibited well during time period 2 .

\section{CONCLUSIONS}

The method of monitored evaporation to determine low rates of water flow into a mine airway has proved to be successful and capable of dealing with transient conditions. The results have been sufficiently precise to quantify the change in water flow rates at rock temperatures varying from 15 to $40^{\circ} \mathrm{C}$. The technique has shown itself of value in the determination of the macropermeability of the fractured rock at stripa.

In addition to the testing of potential sites for the underground storage of nuclear waste, the method may be employed in other situations where "in situ" permeability is required. Problems of mine drainage or the flow of fissure water adding to the heat and humidity of deep mine workings may be investigated.

Finally, the investigations into evaporation transients led to a consideration of water/air interfaces within the fractures. Further work may enable controlled transients to be used as a means of classifying the distribution of fracture dimensions.

\section{REFERENCES CITED}

McPherson, M. J., 1979. Psychrometry: The measurement and study of moisture in air. Mining Department Magazine, University of Nottingham, v. 31, p. 41-51.

wilson, C. R., 1981. Stripa macropermeability experiment. In Earth Sciences Division Annual Report 1980. Lawrence Berkeley Laboratory Report LBL-12100, p. 213-216. 


\section{GEOPHYSICS AND RESERVOIR ENGINEERING}

The Earth Sciences Division program in Geothermal Energy Development began in 1973 in response to the national goal of developing alternative energy sources for electrical and nonelectrical applications. The many varied projects in this program have continued in modified or expanded form, others have been added, and in recent years new projects have been undertaken in such areas as geopressured resources and underground storage of thermal energy. This section of the Annual Report summarizes our current activities in these programs.

Exploration technology projects deal with generic and site-specific research needed to improve our ability to locate and define reservoirs using surface geophysical techniques. Historically, our emphasis has been on electrical, electromagnetic, and seismic techniques because of the expertise available at the University of California, Berkeley, and because of the importance of these techniques.

During 1981 the electrical-electromagnetic research was directed toward improving data acquisition, survey procedures, and interpretation techniques. In magnetotellurics and controlled-source electromagnetics, we have been concerned mainly with developing better interpretation methods. In controlled source electromagnetics, we have developed an in-field processor for the EM-60 system that includes a magnetic reference for natural noise cancellation. The system is capable of making both magnetotelluric and controlled-source resistivity soundings. The Automated seismic Processor (ASP), under development since 1978, was operated at The Geysers, Cerro Prieto, and the Nevada Test site. This device was designed for rapid, cost-effective microearthquake monitoring and analysis in geothermal exploration.

In Reservoir Engineering studies, the greatest part of our effort has been on modeling heat and mass transfer of multicomponent, multiphase fluids through porous and fractured media. This work improves our capability of understanding the behavior of geothermal reservoirs under different production/reinjection conditions and should lead to better reservoir management. New numerical methods have been developed to model production from fractured reservoirs, to study the effects of cold water injection into fracture zones, and to understand the effects of two-phase well-bore flow on pressure transient techniques so that appropriate testing and analysis procedures can be designed. In 1981 a new program was established to develop reservoir engineering methodologies and assessment techniques specific to low- and moderate-temperature hydrothermal systems.

Research continued on the Cerro Prieto geothermal field, and the third symposium was hosted by LBL in San Francisco during March 1981. Significant advances were made on the subjects of hydrogeology, response of the system to large-scale fluid production, and indirect observation of field behavior using surface geophysical techniques.

In the area of geopressured geothermal resources, we continued developing a geologic model and the appropriate equations to calculate subsidence due to brine-methane production from geopressured reservoirs. A flow-through fluid sampler was designed and fabricated for the collection of brine samples from geopressured formations. Research also 
continued on the subject of hot water energy storage in aquifers.: Simple numerical techniques were developed to estimate energy recovery performance for any site under given operating conditions.

This work was supported under U. S. Department of Energy Contract No. DE-AC03$76 \mathrm{SF00098}$ by (1) the Assistant Secretary for Conservation and Renewable Energy, office of Renewable Technology, Division of Geothermal and Hydrothermal Technologies; and (2) the Assistant Secretary for Conservation and Solar Energy, Office of Advanced Conservation Technology, Division of Thermal and Mechanical Storage Systems. 


\title{
EXPLORATION TECHNOLOGY
}

\section{ELECTROMAGNETIC MODELING USING A FAST NUMERICAL SOMMERFELD INTEGRAL}

\author{
K. H. Lee and H. F. Morrison
}

The successful application of electromagnetic techniques in the search for anomalously conductive structures in the earth requires a means for rapid calculation of the response of three-dimenstonal bodies to dipole and plane wave fields. In the integral equation modeling technique, as in other useful techniques, a great number of Green's functions of the sommerfeld integral type must be numerically computed. Such integrals are evaluated primarily by means of a Gaussian quadrature integration technique, the convergence of which can be accelerated using Euler's transformation (Longman, 1956) . A recently developed numerical convolution or digital filter technique has become popular for calculating various Green's functions (Gosh, 1971; Anderson, 1979). The method avoids the evaluation of the Bessel function and appears to be about an order of magnitude faster than the Gaussian quadrature technique.

The fast algorithm that we are developing for the evaluation of the Green's functions for electromagnetic scattering makes use of a convolution integral operating in the spatial domain. The Green's function is a derivative of a combination of vector potentials. The potential function can be shown to be a convolution of a radially symmetric function, $f(\rho)$, and a three-dimensional outgoing wave function. Thus:

$\pi(R)=\int_{0}^{2 \pi} \int_{0}^{o} f(\rho) \frac{e^{-j k|\bar{R}-\bar{\rho}|}}{|\bar{R}-\bar{\rho}|} \rho d \rho d \phi^{\prime}$,

where $\pi$ is the potentlal at $(x, Y, z)$ aue to a point dipole source located at $\left(x^{\prime}, y^{\prime}, z^{\prime}\right)$, and $R=$ $R\left(x-x^{\prime}, y^{\prime}-y^{\prime}, z, z^{\prime}\right)$. The radially symmetric function $f(\rho)$ is properly. Interpolated in $\rho$ using a cubic spline algorithm. An example of $f(p)$ corresponding to the $x$-directed electric potential due to an $x$-oriented electric dipole source is shown in Figure 1. The source is in the lower half-space of a two-layer earth with a 20-m thick overburden of resistivity $10 \mathrm{ohm}-\mathrm{m}$. The lower half-space resistivity used is $100 \mathrm{ohm}-\mathrm{m}$, and the frequency is $100 \mathrm{H}_{2}$. The solid line in the figure shows the potential calculated by the Gaussian quadrature. The potential is interpolated using eighteen samples, and those interpolated potentials are shown as points on the solid iline.

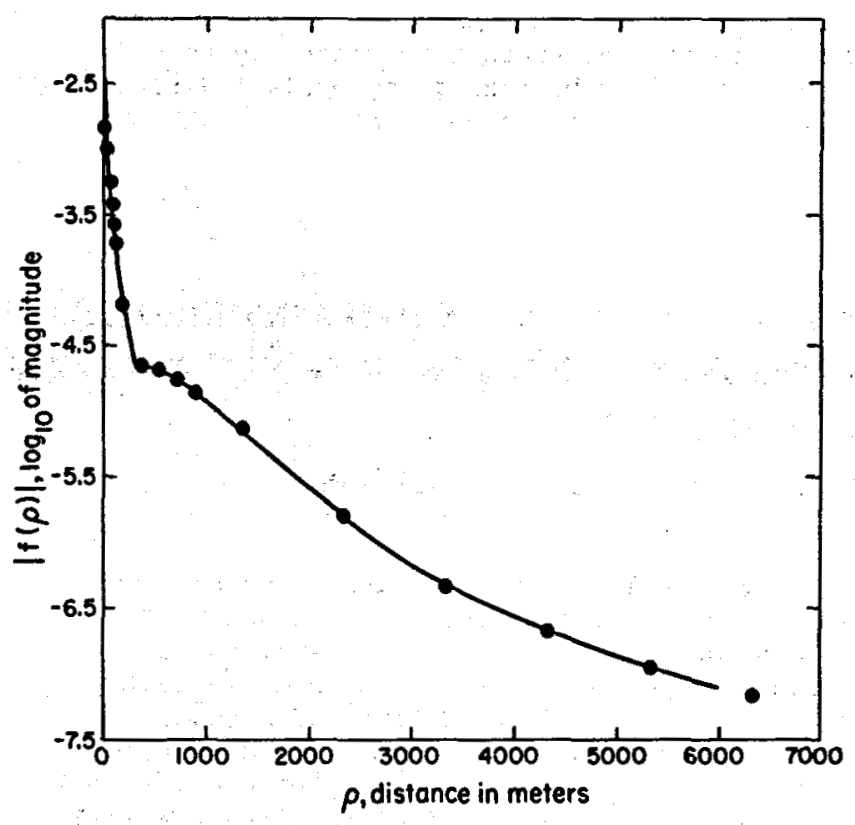

Figure 1. A sample plot of the radially symmetric function $f(\rho)$ for the $x$-directed electric potential due to an $x$-directed dipole located in the lower half-space of a two-layer earth.

[XBL 822-8061]

To evaluate equation (1), we expand the threedimensional wave function in terms of spherical harmonics:

$$
\begin{aligned}
& \frac{e^{-j k|\bar{R}-\bar{\rho}|}}{|\bar{R}-\bar{\rho}|}=\sum_{m=0}^{\infty} \varepsilon_{m} \frac{(m-m) !}{(n+m) !} \cos \{m(\phi-\phi)\} \\
& -j k \sum_{n=0}^{\infty}(2 n-1) \sum_{n}^{m}(\cos \theta) P_{n}^{m}\left(\cos \theta^{\prime}\right) \quad\left\{\begin{array}{l}
J_{n}(k \rho) n_{n}^{(2)}(k R), R>\rho \\
J_{n}(k R) h_{n}^{(2)}(k \rho), R>\rho
\end{array}\right.
\end{aligned}
$$


Substituting equation (2) into equation (1) and integrating over $\phi^{\prime}$, the potential becomes

$$
\begin{aligned}
\pi(R) & =\sum_{n=0}^{\infty} c_{n} P_{2 n}(\cos \theta) \\
& \cdot\left\{h_{2 n}^{(2)}(k R) \int_{0}^{R} f(\rho) j_{2 n}(k \rho) \rho d \rho\right. \\
& +j_{2 n}^{(k R)} \int_{R}^{\infty} f(\rho) h_{2 n}^{(2)}(k \rho) \rho d \rho \mid .
\end{aligned}
$$

where $C_{n}=-j k \pi(4 n-1) P_{2 n}(0)$. With these arrangements, the Green's function may then be readily obtained by taking appropriate derivatives of a combination of potentials.
Preliminary results show that the new technique should be approximately an order of magnitude faster than the digital filtering method, the fastest approach in general use.

REFERENCES CITED

Anderson, W. L., 1979. Numerical evaluation of related Hanke 1 transforms of orders 0 and 1 by adaptive digital filtering. Geophysics, v. 44, no. 7 , P. 1289-1305.

Gosh, D. P., 1971. The application of 1inear filter theory to the direct interpretation of geoelectric resistivity sounding measurements. Geophysical prospecting, v. 19, p. 192-217.

Longman, I. M.. 1956. Note on a method for computing infinite integrals of oscillatory functions. Cambridge Philosophical society Proceedings, v. 52, p. 764.

\title{
AN INFERRED CONDUCTIVITY DISTRIBUTION IN THE VICINITY OF MOUNT HOOD, OREGON, BASED ON THE INTERPRETATION OF MAGNETOTELLURIC AND TELLURIC DATA
}

\author{
E. C. Mozley and N. E. Goldstein
}

\begin{abstract}
Magnetotelluric and telluric measurements were acquired in the vicinity of Mount Hood, Orgeon, as part of a program to evaluate the geothermal potential of this stratovolcano 10cated in the High Cascade Range of northern Oregon (Goldstein and Mosley, 1978; Goldstein et al., 1981). The survey area is characterized by rugged topography ranging from deeply eroded valleys surrounding the volcano, with elevations as low as $2000 \mathrm{ft}$, to the volcanic peak itself, with an elevation of $11,235 \mathrm{ft}$. The most recent volcanism associated with Mt. Hood is recorded by three major sequences dated from 10,000 to 200 years before present. These Bolocene volcanics partially cover Miocene and Pliocene intrusives and flows which were built on Miocene Columbia River basalts.
\end{abstract}

The field procedure for data acquisition was to occupy four stations simultaneously and thus obtain a five-component magnetotelluric measurement supplemented by two remote telluric vector measurements and one remote two-component magnetic measurement (Goldstein and Mozley, 1978; Goldstein et al., 1981). The data were processed using the auto-power and cross-spectral estimates obtained via the fast Fourier transform algorithm. The remote magnetic data were used to estimate the signal and noise components of the measurements and thus calculate an unbiased impedance tensor and tipper vector (Gamble, 1978). Data used in the interpretation are from ten magnetotelluric and fourteen telluric sites distributed around the stratovolcano (Fig. 1). Quality of data ranges from fair to excellent over the band from 40 to $0.001 \mathrm{~Hz}$.

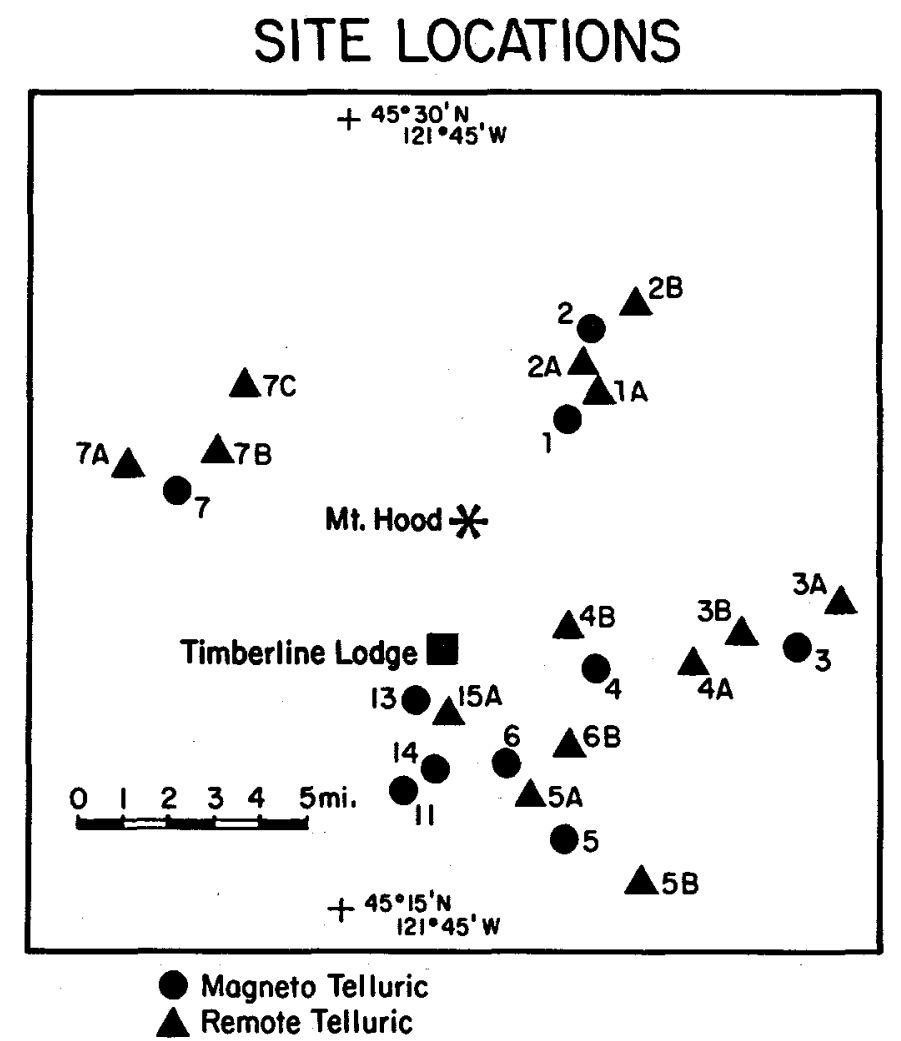

Figure 1. Locations of magnetotelluric and telluric stations in the vicinity of Mount Bood, Oregon.

[XBL 815-3000] 
The general character of the data is quite omplex. : The apparent resistivities vary by or ters of magnitude over distances as small as two kilometers. The principal directions of the tensor impedance estimates change as functions of frequency and site location. To obtain a coherent picture of these spatial variations, we generated polar diagrams from smoothed data. Figure 2 shows the band-averaged polar impedance estimates for the frequency range 0.01 to $0.001 \mathrm{~Hz}$. These dlagrams indicate that there are at least three regions in the survey area that manifest similar amplitude response characteristics. . The rapid changes in the magnitudes of the resistivities suggest that significant contrasts in conductivity occur near the surface in the vicinity of the two regions indicated by the stipple pattern in Figure 2.

The results of simple three-dimensional modeling (Lee et al.. 1981) indicate that the simulation of near-surface inhomogeneities (regions stippled in Fig. 2) would provide the observed characteristics in the apparent resistivities with only moderate contrasts in conductivity. In regions of the survey area where there appear to be no major distortions in the impedance parameters caused by near-surface bodies, we observed a strong, narrow-band phase response between 0.03 and $0.006 \mathrm{~Hz}$ on only one impedance mode. The polar phase diagrams for this band imply that this

AVERAGED FREQS. IN THE RANGE OF ,01-,001 HERTZ

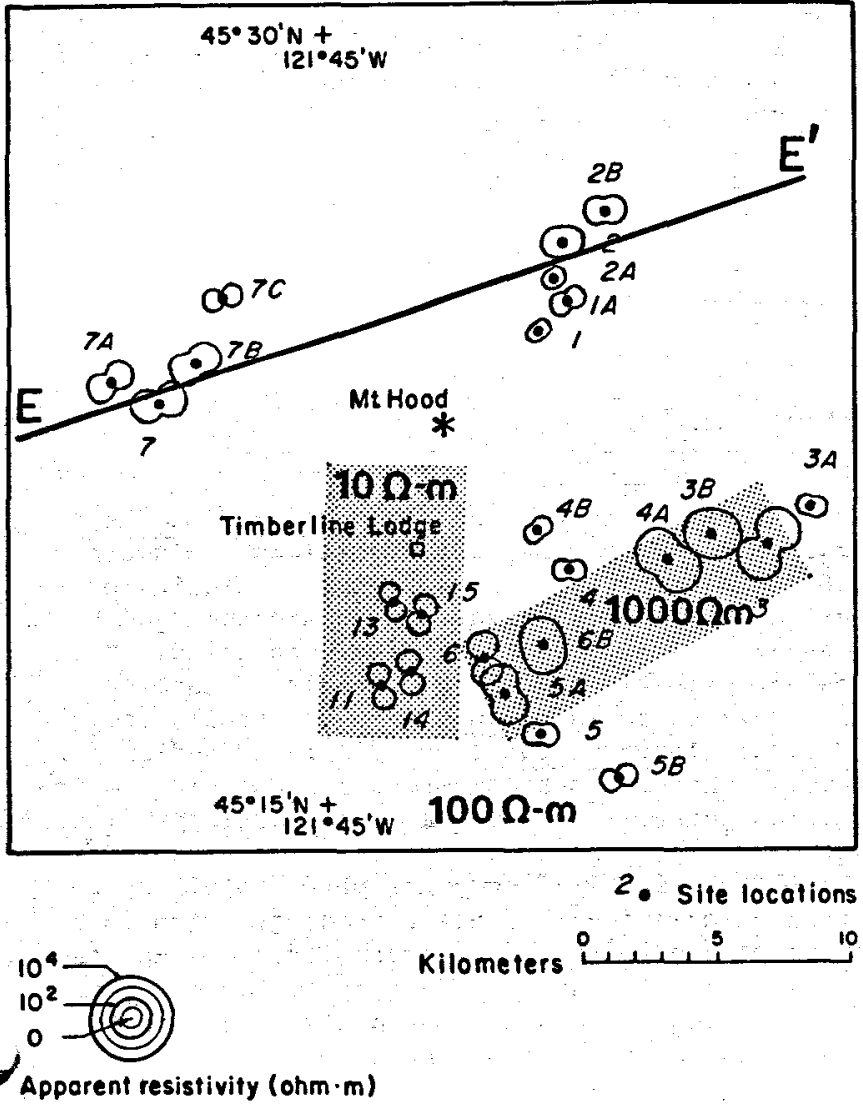

Figure 2. Polar diagram of apparent resistivity $x y$, band-averaged from 0.01 to $0.001 \mathrm{~Hz}$. [XBL 823-2001] component of the phase response is relatively uniform throughout the survey area. If the field measurements are assumed to be located near the center of an elongated causative body, the phase response indicates the existence of a large conductor at depth, striking $\mathrm{N}^{\circ} 0^{\circ} \mathrm{W}$. Profile E-E' was established perpendicular to the strike of the inferred conductor, as depicted by the solid line in Figure 2. Figure 3 shows the resulting two-dimensional conductivity distribution which best fits the data.

The conductivity structure inferred from a composite of two- and three-dimensional simulations is consistent with the frequency responses and spatial distribution of the observed data. This inferred distribution consists of three overlapping zones of anomalous conductivities (Fig. 4). The first zone extends from the surface to a depth of approximately $2 \mathrm{~km}$. This zone is extremely complex, with large lateral changes In conductivity ranging from 3 to 100 ohm-m. Within this zone, there are two regions of high conductivity and one area characterized by very low conductivities. The intermediate zone extends from 2 to $12 \mathrm{~km}$ and is dominated by a large thriee-dimensional resistive structure on the southwest flank of the volcano-perhaps a concealed Pliocene intrusive. The third zone is below $12 \mathrm{~km}$ depth and is characterized by an elongated conductor, with a resistivity of 1 to $3 \mathrm{ohm}-\mathrm{m}$, striking $\mathrm{N} 20 \mathrm{~W}$ and enclosed in a resistive medium.

The interpretation of the conductivity distribution in the intermediate zone was found to

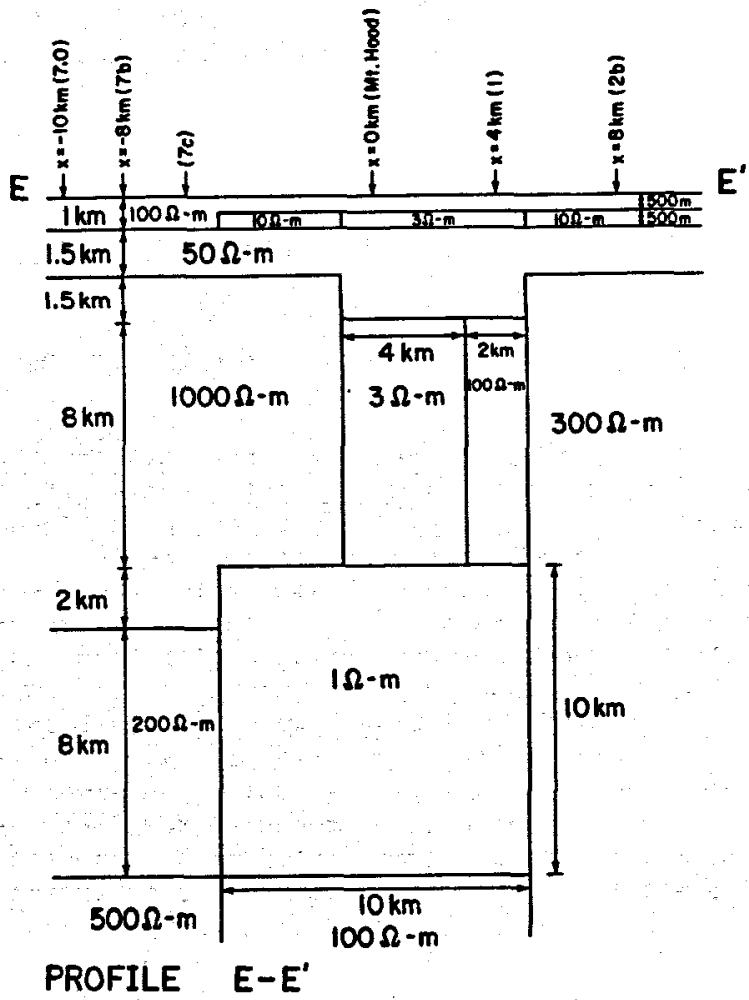

Figure 3. An inferred two-dimensional conductivity cross section along profile E-E'.

[XBL 819-11651] 
INFERRED CONDUCTIVITY DISTRIBUTION

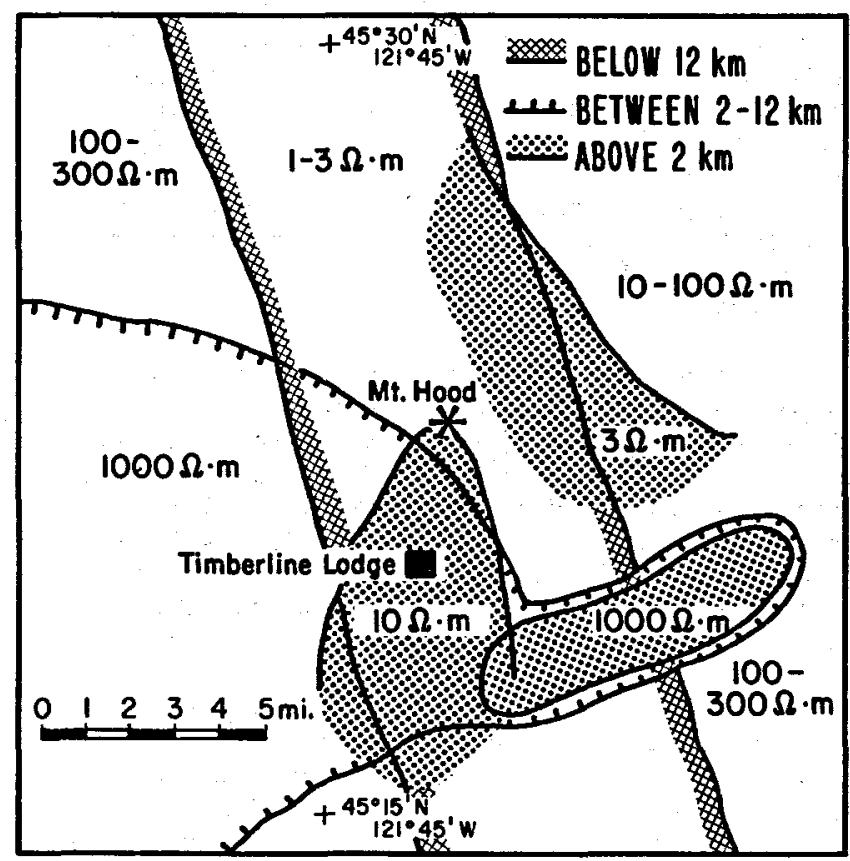

Figure 4. Inferred distribution of the main conductivity elements in the Mount Hood area.

[XBL 815-3001A]

be consistent with the teleseismic and seismic refraction data obtained by the U. $S$. Geological Survey (Craig Weaver, personal communication). The north-south-striking conductor below a depth of $12 \mathrm{~km}$ could be a zone of partial melt associ- ated with volcanism caused by subduction of the Juan de Fuca plate beneath the North American plate. This explanation for the conductor is confirmed by the presence of a north-south heat flow anomaly that follows the crest of the High Cascades (Blackwell et al., 1978). The conductor also coincides with a north-south regional gravity low (Couch and Gemperle, 1979), but much of the gravity anomaly might be explained by the pile of less dense Holocene volcanics at the surface.

\section{REFERENCES CITED}

Blackwell, D. D., Hull, D. A., Bowen, R. G. . and Steele, J. L., 1978. Heat flow of Oregon. State of Oregon, Department of Geology and Mineral Industries, Special Paper 4, $42 \mathrm{p}$.

Couch, R., and Gemperle, M., 1979. Gravity measurements in the area of Mt. Hood, Oregon. In Geothermal Resource Assessment of Mount Bood, Final Report, State of Oregon, Department of Geology and Mineral Industries, p. 137-187.

Camble, T. D., 1978. Remote reference magnetotellurics with SQUID (Ph.D. dissertation). Lawrence Berkeley Laboratory Report LBL-8062.

Goldstein, N. W., and Mozley, E. C., 1978. A telluric-magnetotelluric survey at $\mathrm{Mt}$. Hood, Oregon. Iawrence Berkeley Laboratory Report LBL-7050.

Goldstein, N. E., Mozley, E., and Wilt, M., 1981. Interpretation of shallow electrical features from electromagnetic and magnetotelluric surveys at Mount Bood, Oregon. Lawrence Berkeley Laboratory Report IBL-11212.

Lee, R. H., Pridmore, D. F., and Morrison, B. F., 1981. A hybrid three-dimensional electromagnetic modeling scheme. Geophysics, v. 46, no. 5, p. 796-805.

\title{
IN-FIELD PROCESSING AND MAGNETOTELLURICS WITH THE EM-60 ELECTROMAGNETIC SYSTEM
}

\author{
M. Wilt, N. E. Goldstein, J. R. Haught, V. Labson, and H. F. Morrison
}

In 1977, Lawrence Berkeley Laboratory and the Engineering Geosciences group at the University of California, Berkeley, designed and constructed the EM-60 electromagnetic system for use in intermediate-depth geothermal exploration (Morrison et al., 1978). This system has been used with excellent success for geothermal exploration and crustal studies and has proved to be effective even in areas of complex geology or rugged local terrain (Stark et al., 1980; wilt et al., 1980). Although the original system required an excessive amount of post-field-processing for data interpretation and was incapable of proper on-site data evaluation for quality control, significant improvements have been made during the past year. The EM-60 system now allows for in-field data processing and on-site calculation of apparent resistivity. The modified system also allows for the possibility of simultaneous measurements of controlled-source (dipole) electromagnetic and magnetotelluric (MT) soundings.
Figure 1 shows a schematic diagram of the modified systen. Hardware additions include a 16-channel multiplexer, a 2-channel digital oscilloscope for digitization and storage, and a desk-top minicomputer for data processing. The multiplexer mixes 8 or 16 channels of data on two data lines that connect to the oscilloscope. The oscilloscope digitizes, displays, and buffer stores the time series before transmission to the minicomputer. The scope also has a floppy disk for additional storage of time series. The Hewlett Packard AP9835 computer performs all spectral calculations. Fourier transformation is accomplished with a fast assembler code, and the remaining calculations are programmed in Basic. Calculation and printout of a 512-point time series requires about two minutes.

Figure 2 shows a sample printout for an EM sounding recently measured in Nevada. The printout includes calculated spectral values and stan- 

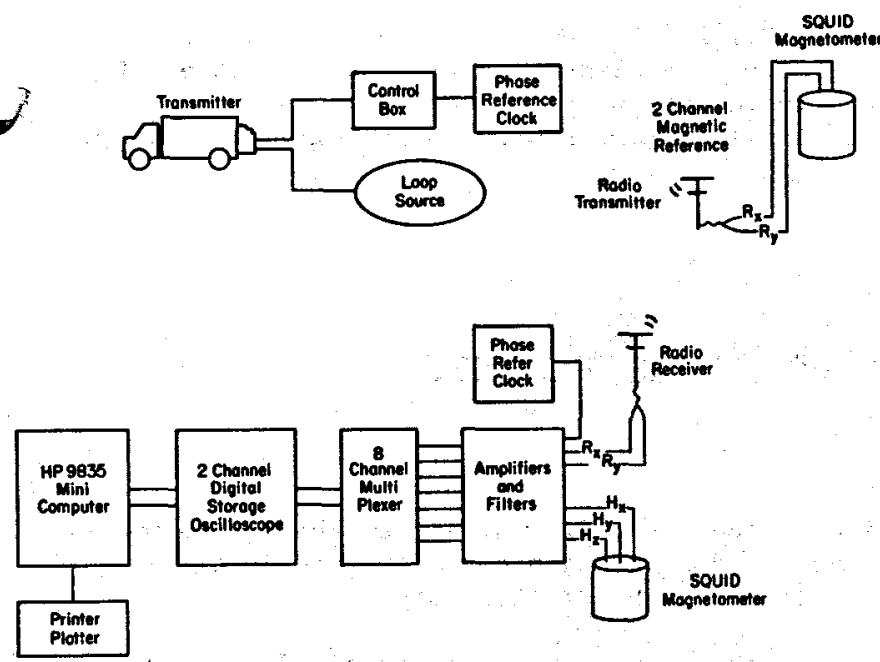

Figure 1. Schematic diagram of the EM-60 system with in-field processing.

[XBL 818-3383]

dard deviations for a transmitter frequency of 10 Hz; calculations can be accurately made up to the eleventh odd harmonic of the primary square wave signal. The program also calculates ellipticity, tilt angle, and wave tilt parameters. It will also calculate the spectral values for the $B_{\dot{y}}$ magnetic fleld.

One of the major advantages of the new system is that it makes possible simultaneous measurements of both dipole electromagnetic and natural (magnetotelluric) fields. Because the controlledsource signal is present only at the selected transmitter frequency in the range $10^{-3}$ to $10^{3} \mathrm{~Hz}$ plus a few higher odd harmonics, signals at all other frequencies are available for MT processing. As the system can manipulate up to 16 data channels, the two additional electric fleld channels

\begin{tabular}{|c|c|c|c|c|c|c|c|c|c|}
\hline $\begin{array}{l}\text { MEAN } \\
\text { SDEV }\end{array}$ & $\begin{array}{l}\text { FREQ } \\
10.00\end{array}$ & $\begin{array}{c}\text { AMF } \\
44.66 \\
.26\end{array}$ & $\begin{array}{r}\text { FHASE } \\
237.6 \\
.5\end{array}$ & $\begin{array}{r}\mathrm{Hz}^{\mathrm{AMF}} \\
185.8 \\
.36\end{array}$ & $\begin{array}{r}\text { PHASE } \\
172.7 \\
.2\end{array}$ & $\begin{array}{l}\text { ELLIPT } \\
\text { ICITY } \\
-.215 \\
.07\end{array}$ & $\begin{array}{r}\text { TILT } \\
\text { ANGLE } \\
\text { BJ. } 9 \\
.0\end{array}$ & $\begin{array}{l}\text { WAVE } \\
\text { AMP } \\
.240 \\
.17\end{array}$ & $\begin{array}{r}\text { TILT } \\
\text { PHASE } \\
64.9 \\
.0\end{array}$ \\
\hline MEAN & 30.00 & $\begin{array}{r}41.11 \\
.10\end{array}$ & $\begin{array}{r}195.7 \\
.5\end{array}$ & $\begin{array}{r}85.7 \\
.14\end{array}$ & $\begin{array}{r}140.8 \\
.4\end{array}$ & $\begin{array}{r}-.361 \\
.05\end{array}$ & $\begin{array}{r}72.2 \\
.1\end{array}$ & $\begin{array}{r}.480 \\
.12\end{array}$ & $\begin{array}{r}54.9 \\
.1\end{array}$ \\
\hline MEAN & 50.00 & $\begin{array}{r}27.96 \\
.16\end{array}$ & 165. & $\begin{array}{r}43.9 \\
.14\end{array}$ & $\begin{array}{r}113.1 \\
.3\end{array}$ & $\begin{array}{r}.419 \\
.14\end{array}$ & $\begin{array}{r}63.6 \\
.1\end{array}$ & $\begin{array}{r}.636 \\
.04\end{array}$ & $\begin{array}{r}51.9 \\
.1\end{array}$ \\
\hline MEAN & 70.00 & $\begin{array}{r}19.00 \\
.18\end{array}$ & 140 & $\begin{array}{r}24.8 \\
.14\end{array}$ & $\begin{array}{r}89.1 \\
.1\end{array}$ & $\begin{array}{r}-.454 \\
.09\end{array}$ & $\begin{array}{r}56.7 \\
.1\end{array}$ & $\begin{array}{r}.766 \\
.10\end{array}$ & $\begin{array}{r}51.2 \\
.0\end{array}$ \\
\hline MEAN & 90.00 & $\begin{array}{r}11.45 \\
.37\end{array}$ & $\begin{array}{r}119.5 \\
.2\end{array}$ & $\begin{array}{l}13.0 \\
.23\end{array}$ & $\begin{array}{r}69.2 \\
.0\end{array}$ & $\begin{array}{r}-.463 \\
.03\end{array}$ & $\begin{array}{r}50.7 \\
.0\end{array}$ & $\begin{array}{r}.879 \\
.03\end{array}$ & $\begin{array}{r}50.3 \\
.0\end{array}$ \\
\hline MEAN & 110.00 & $\begin{array}{r}5.44 \\
.49\end{array}$ & $\begin{array}{r}101.8 \\
.2\end{array}$ & $\begin{array}{r}5.5 \\
.47\end{array}$ & $\begin{array}{r}51.7 \\
.1\end{array}$ & $\begin{array}{r}-.467 \\
.13\end{array}$ & $\begin{array}{r}45.5 \\
.0\end{array}$ & $\begin{array}{r}.988 \\
.09\end{array}$ & $\begin{array}{r}50.0 \\
.1\end{array}$ \\
\hline
\end{tabular}

Figure 2. Sample on-site printout of an EM-60 dipole sounding taken in Nevada. Amplitude is in milligammas, phase is in degrees, and standard deviation is in percent.

necessary for MT are easily handled. Early fleld trials with the hybrid EM/MT method are encouraging, but there are still minor problems to be solved concerning system dynamic range and computer memory.

A remote reference magnetometer, shown in the upper-right corner of Figure 1, serves a dual purpose in the hybrid technique. Natural geomagnetic fields may be eliminated from dipole magnetic measurements by direct subtraction lour previous practice) or by calculation of a transfer tensor between the local and remote geomagnetic fields. If the tensor approach is used, then the remote magnetic fields are preserved and they may be used for both remote reference MT calculations and EM nolse reduction (Gamble et al., 1979).

The addition of computer processing has greatly enhanced the power and flexibility of the EM-60 system. In-field calculations greatly reduce post-field processing, can improve data quality, and give some on-site feedback so that the survey can be altered as data are evaluated. The 16-channel system also allows for multiple EM stations or EM/NT sounding, thereby increasing the utility and cost-effectiveness of the system.

REFERENCES CITED

Gamble, T. D., Goubau, W. M., and Clarke, J., 1979. Magnetotellurics with a remote magnetic reference. Geophysics, v. 44, no. 1 , p. 53-68.

Morrison, H. E., Goldstein, N. E., Boversten, M., Oppliger, G.. and Riveros, C., 1978. Description, fleld test and data analysis of a controlled-source EM system (EM-60). Lawrence Berkeley Laboratory Report IBL-7088, $150 \mathrm{p}$. 
Stark, M., Wilt, M., Haught, J. R., and Goldstein, N. E., 1980. Controlled-source electromagnetic survey at Soda Lakes geothermal area, Nevada. Lawrence Berkeley Laboratory Report IBL-11221, $93 \mathrm{p}$.
Wilt, M., Baught, J. R., and Goldstein, N. E., 1980. An electromagetic survey of the McCoy geothermal prospect, Nevada. Lawrence Berkeley Laboratory Report IBL-12012, 109 p.

\title{
DEEP ELECTROMAGNETIC SOUNDING IN THE BASIN AND RANGE PROVINCE
}

\author{
M. Wilt, N. E. Goldstein, J. R. Haught, and H. F. Morrison
}

During the spring of 1981, a deep electromagnetic (EM) sounding survey was undertaken in the northern Basin and Range Province by Lawrence Berkeley Laboratory (LBL). The purposes of the project were (1) to confirm the presence of deep conductive bodies first detected with magnetotelluric measurements, (2) to investigate the geometry of these bodies, and (3) to test the LBL controlled-source EM system (EM-60) as modified to perform deep sounding work. These deeply buried conductors may have important tectonic implications; if they consist of partially molten rock, they could be the heat source of the numerous hot springs and geothermal systems in northern Nevada.

Sixteen controlled-source electromagnetic soundings and one magnetotelluric sounding were made in Buena Vista Valley, Pershing County, Nevada (Fig. 1). The EM soundings were made relative to three loop sources with source-receiver separations from 0.5 to $30 \mathrm{~km}$. Two of the loops were small-moment sources $(100-\mathrm{m}$-diameter horizontal loops) intended for investigation to about $2 \mathrm{~km}$ in depth. The other was a $6.25-\mathrm{km}^{2}, \mathrm{sin}-$ gle-turn, large-moment source capable of provid-

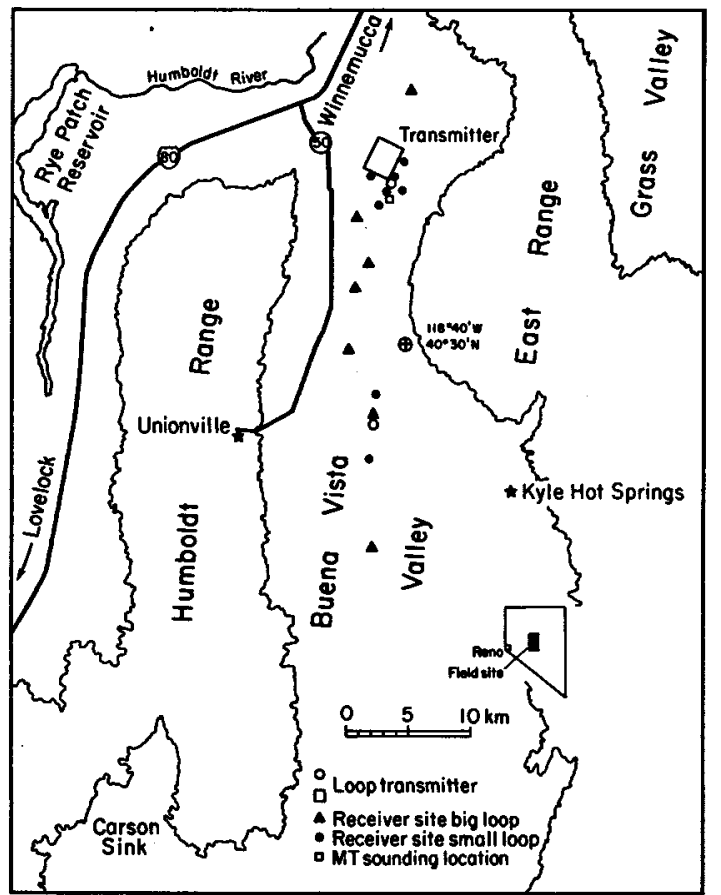

Figure 1. Project location map for deep-sounding experiment in Nevada. ing a signal for distant sites; this large-moment source had a strength approximately 50 times greater than the smaller loops.

In the $D M$ survey, magnetic field signals were detected by means of a three-component SQUID magnetometer oriented to receive the radial, vertical, and tangential magnetic fields. Received signals were amplified, filtered, and reduced on site, using a Hewlett Packard 9835 in-field computer. Field data were interpreted by means of a one-dimensional inversion (ridge regression method) of observed spectra. Two-dimensional modeling is possible, but the limitations of presently available software make it cumbersome and expensive. A new wave-efficient, two-dimensional computer code that is under development will, when ready, help us to perform the necessary two-dimensional model simulations.

Magnetotelluric data are provided by $w$. Goubau, who conducted a magnetic field noise study in the area.

\section{RESULIS}

We successfully obtained layered-model inversions on all 16 electromagnetic soundings and the one magnetotelluric sounding. Layered-earth fits to the data from a majority of stations were remarkably good, and the layered-model interpretations were reasonably consistent from sounding to sounding.

The low resistivity of the upper kilometer in Buena Vista Valley presented some problems for deep electromagnetic sounding. Although signals could be received at up to $30 \mathrm{~km}$ from the source, the high-frequency data at these large separations were severely attenuated by the conductive surface layer. It was therefore impossible for us to get reliable data above about $5 \mathrm{~Hz}$ when source-receiver separations exceeded $15 \mathrm{~km}$. The high-conductivity surface also limited penetration of electromagnetic waves, as governed by the skin-depth equation:

$\delta=0.5 \sqrt{\rho \mathrm{T}}(\mathrm{km})$,

where $\rho$ is a representative resistivity of the medium in ohm-meters and $T$ is the period of the wave in seconds. In Buena vista valley, for example, where the resistivity is $20 \mathrm{ohm}-\mathrm{m}$ or less for the upper several kilometers, we need a signal with a period in excess of $100 \mathrm{~s}$ to achieve a 
penetration depth of $20 \mathrm{~km}$. Although it is possible to measure such signals, the recording times jequired for proper sampling and averaging are very long, and telluric noise is of ten high at these frequencles.

\section{INTER PRETAT TON}

Figure 2 is a north-south section through Buena Vista Valley made up of layered resistivity interpretations. The section is a composite of sounding results for which we plot the layeredmodel interpretation at a point midway between the transmitter and the receiver.

The resistivity cross section reveals that the shallow crust beneath Buena vista valley can be approximated by four or five layers. The first (top) layer has a resistivity of $20 \mathrm{ohm}-\mathrm{m}$ and a thickness of between 50 and $200 \mathrm{~m}$. These parameters seem to be fairly consistent at most locations in the valley. This layer most likely consists of partially saturated Quaternary alluvium. The second layer is some 200 to $500 \mathrm{~m}$ thick and has a resistivity of approximately $10 \mathrm{ohm}-\mathrm{m}$. This layer is thickest in the northern and southern parts of the valley and may be absent in the center of the valiey. Magnetotelluric studies in adjacent Grass valley have identified Tertiary sediments of similar resistivity at about the same depth (Morrison et al., 1979). Deeper parts of this horizon have resistivities of 2 to $5 \mathrm{ohm}-\mathrm{m}$, which may indicate saline pore water or possibly the presence of the graphitic Valmy Formation.

A high-resistivity basement has been detected beneath Buena Vista Valley at depths between 0.5 and $2.5 \mathrm{~km}$. Basement is shallowest in the narrowest portion of the valley, which implies that the valley may be divided Into two basins, a northern one 1 to $1.5 \mathrm{~km}$ deep and a southern one 2 to $2.5 \mathrm{~km}$ deep. The resistivity of the basement is poorly resolved with electromagnetic and MT soundings because it carries relatively little current and therefore does not impart much information to the received signals. The northernmost sounding indicated an abrupt lateral increase in resistivity to a considerable depth. This area is associated with some low hills that separate Buena Vista Valley from the adjacent Humboldt River Valley, it probably marks the northern boundary to Buena vista Valley.

The presence of a deep conductor was ind 1 cated by three electromagnetic soundings as well as the Mr sounding. For the EM soundings, a good electrical conductor ( 3 to $7 \mathrm{ohm}-\mathrm{m}$ ) was indicated 4 to $7 \mathrm{~km}$ beneath the central portion of the valley. The MT sounding indicated a good conductor (approximately $25 \mathrm{ohm}-\mathrm{m}$ ) at a depth of $11 \mathrm{~km}$ beneath the northern end of the valley. If the

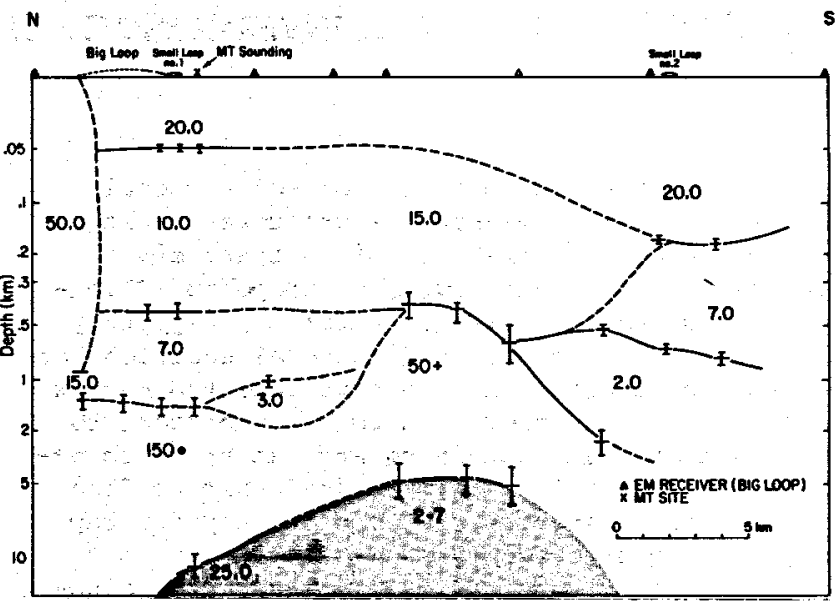

Figure 2. Two-dimensional north-south resistivity cross section obtained from $E M$ and MT sounding measurements.

[XBL 818-3384]

resistivity section is accurate, the conductive body is present at shallower depths in the southern parts of the valley. Further to the south in the Carson Sink, experiments by the Colorado School of Mines have indicated conductors at about $5 \mathrm{~km}$ in depth (Reller et al., 1981). It is tempting, therefore, to conclude that this deep conductor is an extension of the Carson Sink conductor and may be a regional feature. For two reasons, caution is urged against drawing this conclusion. First, the irregular basement surface in the valley makes it possible that the deep conductor may instead be related to a feature outside the plane of the section. Two-dimensional modeling would be necesssary to confirm this. Second, EM field measurement beyond 15-km separations show abnormally small radial field components, although vertical field data seem normal. Radial field data are distorted to the point where quantitative interpretation is $1 \mathrm{~m}-$ possible, but vertical fields fit calculated layered-model spectra with upper layer parameters that match nondistorted soundings. These models may be accurate, but some two-dimensional modeling may be necessary to simulate the measured fields.

\section{REFERENCES CITED}

Keller, G. V., Taylor, K., and Souto, J. M., 1981. Megasource $\mathrm{EM}$ method for detecting deeply buried conductive zones in geothermal exploration. Abstract, Society of Exploration Geophysicists Annual Meeting, los Angeles, Callfornia.

Morrison, H. F., Lee, K. H., Oppliger, G., and Dey, A., 1979, Magnetotelluric stuales in Grass Valley, Nevada. Lawrence Berkeley Laboratory Report LBL-8646. 


\title{
SIMPLE ONE-DIMENSIONAL INVERSIONS OF MAGNETOTELLURIC DATA
}

\author{
W. M. Goubau
}

The exact solution to the one-dimensional inverse problem in magnetotellurics was first derived by Weidelt (1972). Since then, several alternative solutions have been proposed (Oldenburg, 1979; Larsen, 1981). Unfortunately, they all require the solution of integral equations or interaction schemes that involve repeated matrix inversions. Thus they tend to be cumbersome to implement and $t$ ime-consuming and expensive to execute. Often it is much more desirable to find an approximate inverse that can be computed rapidly. The most commonly used "simple inverse" is one proposed by Bostick (1977). Bostick's algorithm is concise enough that it can be evaluated with a pocket calculator, and in many cases it yields an inverse that reflects all of the essential features of the true inverse. However, the Bostick method is founded on heuristic rather than rigorous mathematical arguments and therefore cannot be readily extended if greater accuracy is desired. This report presents alternative inversion schemes that are derived from Maxwell's equations and that can, in principle, be made more accurate.

FORMULATION OF THE ONE-DIMENSIONAL INVERSE PROBLEM

For a one-dimensional geology, the complex Fourier transform of the electric field, $E(x, w)$. satisfies the differential equation

$\frac{\partial^{2} E(x, \omega)}{\partial x^{2}}=j \omega \mu_{0} \sigma(x) E(x, \omega)$.

where $\omega$ is the angular frequency, $j=\sqrt{-1}$, time evolves as $e^{+j \omega t}, x$ is the depth measured positive downward, and $\sigma$ is the electrical conductivity. The boundary condition that determines a unique solution is $\partial E(\infty, \omega) / \partial x=(0,0)$. If one defines a complex response function

$\left(C(x, \omega) \equiv \frac{\partial E}{\partial x}(x, \omega) / E(x, \omega)\right.$,

then direct integration of equation (1) with respect to $x$ yields (using $\partial E(\infty, \omega) / \partial x=(0,0)$ )

$C(x, \omega)=j \omega \mu_{0} \int_{\infty}^{x} \sigma(y)\left[\frac{E(y, \omega)}{E(x, \omega)}\right] d y$,

where $C(x, w)$ satisfies the equation

$\frac{\partial C(x, \omega)}{\partial x}=j \omega \mu_{0} \sigma(x)-c^{2}(x, \omega)$

The goal is to find $\sigma(x)$ given the experimental data $c(0, \omega)$.

\section{SOLUTION OF THE PROBLEM}

To solve the problem, it was found that the unknown electric field $E(x, \omega)$ could be eliminated by introducing two sounding depths $a(x, \omega)$ and $d(x, \omega)$, which are defined by the equation

$$
\begin{aligned}
c(x, \omega)= & j \omega \mu_{0}\left[\int_{a(x, \omega)}^{x} \sigma(y) d y-c(x, \omega)\right. \\
& \left.\cdot \int_{a(x, \omega)}^{x} \int_{d(x, \omega)}^{y} \sigma(u) d u+I(x, \omega)\right],
\end{aligned}
$$

where

$I(x, \omega) \equiv \frac{1}{E(x, \omega)} \cdot \int_{\infty}^{x} \frac{\partial^{2} E(y, w)}{\partial y^{2}}\left[\int_{a(y, w)}^{y} d u \int_{d(v, w)}^{v} \sigma(v) d v\right] d y$.

This equation is obtained by integrating equation (2) by parts twice. The dependence on electric field is removed by choosing a $(x, \omega)$ and $d(x, \omega)$ so that $I(x, \omega)=(0,0)$ for all $x$ and $\omega$. Equating real and imaginary parts of equation (3) yields

$$
\begin{aligned}
& F(x, \omega)=\int_{x}^{d(x, \omega)} \sigma(y) d y, \\
& G(x, \omega)=\int_{x}^{a(x, \omega)} d y\left[\int_{y}^{d(y, \omega)} \sigma(u) d u\right],
\end{aligned}
$$

where

$F(x, \omega)=-\mid c\left(x,\left.\omega\right|^{2} / \omega \mu_{0} C_{I}(x, \omega)\right.$.

$G(x, \omega)=c_{R}(x, \omega) / \omega \mu_{0} c_{I}(x, \omega)$,

and the subscripts $R$ and $I$ denote real and imaginary parts, respectively. For a one-dimensional earth, $C_{R}(x, \omega)$ and $C_{I}(x, \omega)$ are always negative. Therefore, since $\sigma(x)$ is positive, there will always exist positive sounding depths $a(x, \omega)$ and $d(x, w)$ that satisfy equations $(4)$ and $(5)$. The inverse problem is solved once either $a(0, \omega)$ or $(0, \omega)$ is known.

Since equation (4) has a simpler form than equation (5), it is easier to solve for $d(x, w)$. Formally, this can be done by first differentiating equation (4) with respect to $w$ to get

$\frac{\partial F(x, w)}{\partial w}=\sigma(d) \frac{\partial d(x, \omega)}{\partial \omega^{2}}$

and then differentiating equation (4) with respect to $x$ (using equation 3 ) to get

$\sigma(x)\left[\frac{C_{R}(x, w)}{C_{I}(x, w)}\right]^{2}=\sigma(d) \frac{\partial d(x, w)}{\partial x}$.

From equations 7 and 8 , one finds that $d(x, \omega)$ must satisfy the partial differential equation 
$\frac{\partial d(x, w)}{\partial w}=g(x, w) \frac{\partial d(x, w)}{\partial x}$,

$g(x, \omega)=-\frac{\partial}{\partial \omega} \frac{|c(x, \omega)|^{2}}{\omega \mu_{0} C_{I}(x, \omega)}\left[\frac{C_{I}(x, \omega)}{C_{R}(x, \omega)}\right]^{2} / \sigma(x)$.

since the electromagnetic penetration depth goes to zero in the limit $\omega \rightarrow \infty$, the boundary condition is $\partial d(x, \infty) / \partial x=1$.

To find $d(0, \omega)$, one must know $\sigma(x)$ for all $x$ in a small but finite range $x<x_{0}$ near $x=0$. In principle, one could, without loss of generality, choose $\sigma(x)$ so that

$\sigma(x)=\left\{\begin{array}{l}\sigma_{0}, x<x_{0} \\ \partial(x), x>x_{0}, \sigma\left(x_{0}\right)=\sigma_{0}\end{array}\right.$

where $x_{0}$ is arbitrarily small. One would then have an analytic expression for $c(x, w)$ for $x<x_{0}$ that is given by

$$
\begin{aligned}
c(x, \omega)= & k\left[(1+A) e^{k x}-(1-A) e^{-k x}\right] \\
& {\left[(1+A) e^{k x}+(1-A) e^{-k x}\right]^{-1} }
\end{aligned}
$$

where

$$
A=c(0, \omega) / k \text { and } k=\sqrt{j \omega \mu_{0} \sigma_{0}} \text {. }
$$

The real and imaginary parts of equation (10) would then have to be substituted into equation (9). Because this is an extremely tedious procedure, it is more instructive not to pursue this formal solution, but rather to look for simpler approximate inverses that are based on equations (5) through (9).

The first 8 imple inverse that was found was derived using the Born approximation, which assumes weak scattering of the incident electromagnetic field. If one takes $E(x, w) / E(0, w) \approx$ $e^{C(0, \omega) x}$, then it can be shown that in equation (4) $I(0, w) \approx(0,0)$ when $a(0, w)=d(0, w)$. If one differentiates equations (5) and (6) with respect to $w$ and sets $x=0$ and $a(0, \omega)=d(0, \omega)$. One obtains

$$
\begin{aligned}
& \frac{\partial F(0, w)}{\partial \omega}=\sigma(d) \frac{\partial d(0, w)}{\partial \omega} \\
& \frac{\partial G(0, w)}{\partial \omega}=d(0, w) \sigma(d) \frac{\partial d(0, w)}{\partial \omega} .
\end{aligned}
$$

From the ratio of these equations, one obtains the depth $d(0, \omega)$ directly:

$d(0, \omega)=\frac{\partial G(0, \omega)}{\partial \omega} / \frac{\partial F(0, \omega)}{\partial \omega}$

Thus $\sigma(d)$ is given by equation $(1)$ and $d(0, w)$ by equation (13). The inverses obtained for the Born approximation for several model conductivitles are shown in Figure 1 and compared with the stick inverse.

In Figure $l(a)$ the model conductivity is analytic and has the form
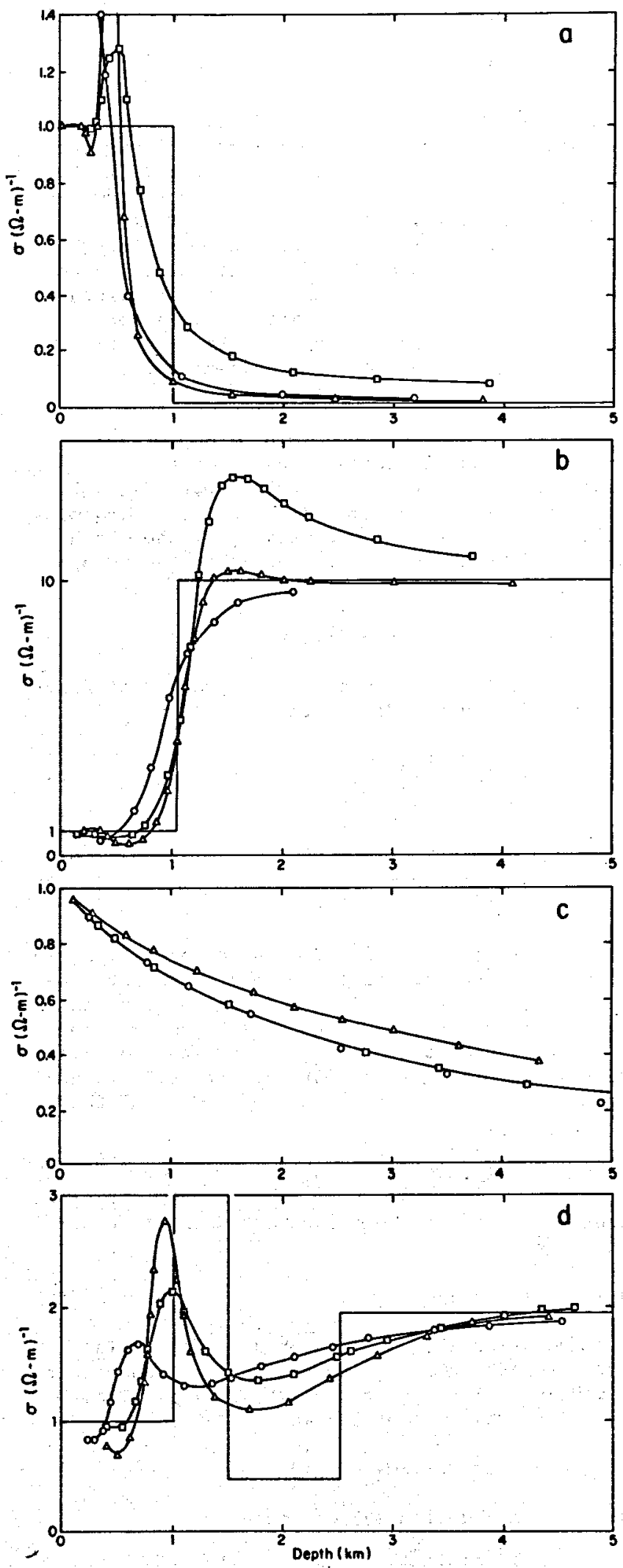

Figure 1. Comparison of simple one-dimensional inverses for several model conductivities. In (a) the model conductivity is given by equation (14). Circles indicate Bostick inverse; triangles indicate Born approximation; squares indicate method of apparent sounding depth with $d_{A}(0, \omega)=-1 / C_{R}(0, \omega)$. 
$\sigma(x)=\frac{\sigma_{0}}{(b x+1)^{2}}$,

with $\sigma_{0}=1 \mathrm{ohm}-\mathrm{m}^{-1}$ and $b=0.2 \mathrm{~km}^{-1}$. For this analytic function, the Born inverse follows the correct trend, but it gives values for $\sigma(x)$ that are systematically too high. The discrepancy is about 25 at $4 \mathrm{~km}$. In contrast, the Bostick inverse is almost exact for this model, although there are deviations of a few percent near $5 \mathrm{~km}$. For the other models, in which $\sigma(x)$ has discontinuities, the Born approximation gives consistently higher resolution than the Bostick inverse. This is particularly evident for the four-layer model of Figure $1(d)$.

A second scheme for obtaining approximate one-dimensional inverses is based on the determination of an apparent sounding depth $d_{A}(x, \omega)$. The derivation is motivated by the following considerations. If the conductivity of the earth has the form shown in equation $(14)$, then $c(0, \omega)$ is known to satisfy the quadratic equation

$0-b C(0, \omega)+j \omega \mu_{0} \sigma_{0}-c^{2}(0, \omega)$.

Thus the solution to the inverse problem of finding $b$ and $\sigma_{0}$ given $c(0, \omega)$ is

$\sigma_{0}=\frac{|C(0, \omega)|^{2}}{\omega \mu_{0}} \frac{C_{I}(0, \omega)}{C_{R}(0, \omega)}$

$b=\frac{c_{R}^{2}(0, \omega)-c_{0}^{2}(0, \omega)}{c_{R}(0, \omega)}$.

When the true conductivity does not satisfy equation (14), one can still define an apparent conductivity of the same form with $\sigma_{0}$ and $b$ given by equations (16) and (17), except that $\sigma_{0}$ and $b$ are now functions of $\omega$. By substituting equation (14) into equation (5) and integrating, one obtains an apparent sounding depth $d_{A}(0, w)$ that is simply given by

$d_{A}(0, \omega)=-1 / C_{R}(0, \omega)$.

When $x \neq 0$, it can be shown that $d_{A}(x, \omega)$ generalizes to

$d_{A}(x, \omega)=x-1 / C_{R}(x, \omega)$.

From equation (18) one can obtain two distinct estimates for the true conductivity by substituting $d_{A}(x, w)$ into equations (7) and (8). From equation ( 8$)$, one obtains at $x=0$ :

$\sigma\left(d_{A}\right)=\sigma_{0}\left[c_{R}(0, \omega) / C_{I}(0,(u)]^{4}\right.$,

while from equation (7) one obtains

$\sigma\left(d_{A}\right)=\frac{\partial F(0, \omega) / \partial \omega}{\partial d_{A} / \partial \omega}$.

Equation (20) leads to the result $\sigma\left(d_{A}\right) \rightarrow \sigma(0)$ rather than $\sigma\left(d_{A}\right) \rightarrow \sigma(\infty)$ as $\omega \rightarrow 0$. Therefore, it is not a generally acceptable inverse, a1though it does reproduce near-surface trends in conductivity. Equation (21), on the other hand, is well behaved for all models at all frequencies. The inverses derived from equations (18) and (21) are also shown in Figure 1. The inverse is exact for the analytic conductivity profile and also tends to have somewhat better resolution than the Bostick inverse for the more complex conductivities. In Figure $1(a)$ the inverse is not as good as the Born approximation, but in Figure $I$ (c) it is better.

It was pointed out above that the apparent sounding depth leads to two distinct inversions because $d_{A}(x, \omega)$ is not a simultaneous solution of equations $(20$ and (21). This suggests that improved inversions should be possible by modifying the functional form of $d_{A}(x, w)$ with adjustable parameters and then choosing the parameters so that equation (9) (and as many as possible of its derivatives) is satisfied. This approach has not yet been thoroughly explored. However, a function of the form

$d_{A}(x, w)=x-\frac{\lambda}{C_{R}(x, \omega)}$.

where $\lambda=$ constant, has been tried. If the parameter $\lambda$ is chosen at each frequency so that $d_{A}(x, \omega)$ satisfies equation (9), one obtains the inverse for a downward step in conductivity shown in Figure 2. It can be seen that the new inverse is capable of reproducing a vertical transition, although the position of the transition is not quite correct.

SUMMARY

It has been shown that simple one-dimensional inversions are possible when one expresses Maxwell's equations in terms of sounding depths

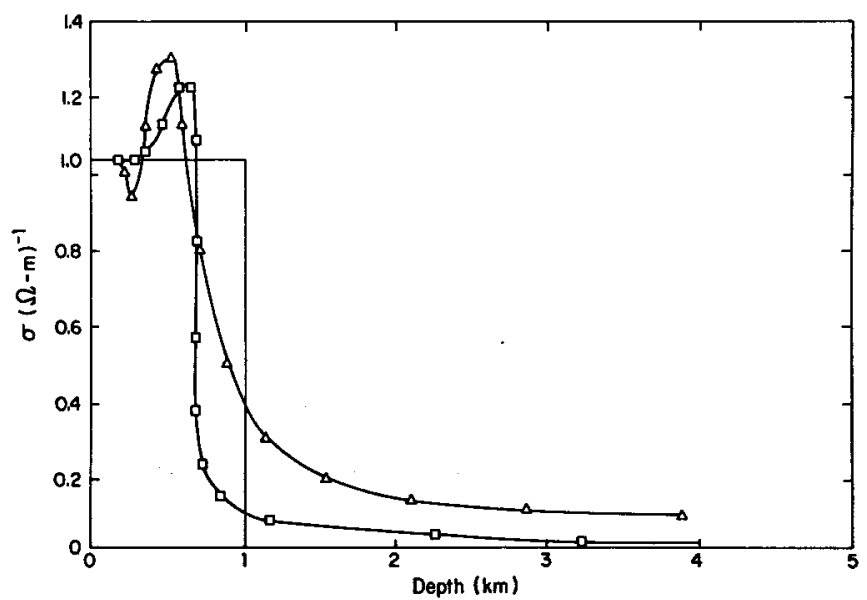

Figure 2. Examples of inverses from the method of apparent sounding depths. The depth $d_{A}$ is given by equation (22). Triangles are for $\lambda=1$; squares are for $\lambda$ adjusted so that $d_{A}$ satisfies equation (9). 
rather than electric fields. All of the inversions presented above were evaluated with an LSI-11 computer. To obtain an inverse at twenty jrequencies required at most one or two seconds of CPU time. In most cases, the simplest inversions are as good as the Bostick inverse, if not better. They have the advantage that they can, in principle, be systematically improved when higher accuracy is required.

\section{REFERENCES CITED}

Bostick, F. X., Jr., 1977. Workshop on electrical methods in geothermal exploration. U.S.G.S. contract no. 14-08-001-G-359.

Larsen, J. C., 1981. A new technique for layered earth magnetotelluric inversion. Geophysics, v. 46, p. 1247-1257.

Oldenburg, D. W., 1979. One-dimensional inversion of natural source magnetotelluric observations. Geophysics, v. 44, p. 1218-1244.

Weidelt, P., 1972. The inverse problem of geomagnetic induction. zeitschrift für Geophysik, v. 38, p. 257-289.

\title{
THE APPLICATION OF ASP: AN AUTOMATED SEISMIC PROCESSOR
}

\author{
E. L. Majer and T. V. McEvilly
}

For the past several years, the Seismographic Station of the University of California, Berkeley, and Lawrence Berkeley Laboratory have been developing an in-field, low-power, real-time processor for microearthquake data. The objective is to utilize CMOS microprocessor technology (RCA 1802) to automate the routine, labor-intensive processing of microearthquake survey data.

The Automated Seismic Processor (ASP) is presently set up to handle 15 channels of data, although the system is configured for up to 128 channels. - A WORRER computer on each channel automatically detects $\mathrm{P}$ - and $\mathrm{S}$-waves, measures their arrival times and amplitudes, and computes and fits FFT's for both waves on data sampled at $100 \mathrm{samples} / \mathrm{s}$. These data from each channel are then processed with a central microprocessor (the BOSS) for hypocenter location, running b-values, source parameters, event count, and $P$-wave polarities. The system is capable of processing a 15station detection in approximately $40 \mathrm{~s}$, excluding printout. The initial trials have demonstrated that in-field, real-time analysis of data maximizes the efficiency of microearthquake surveys, allowing flexibility in experimental procedures with a minimum of the traditional laborintensive postprocessing. Current efforts are directed toward improving efficiency of computation and data output and toward expanding software capabilities.

\section{THE GEYSERS}

The initial field test was carried out at The Geysers steam field in northern Callfornia during September and October of 1980. We use this experiment to illustrate the capabilities and peculiarities of the ASP.

Figure 1 shows the distribution of seismic stations and production and injection wells in relation to power plants $9,10,11$, and 15 at The ysers. During 23 days of monitoring, 562 events Ith magnitude between 0.5 and 2 were detected at 5 or more stations. Of these 562 events, 189 were judged to have good locations. Plotted in Figure

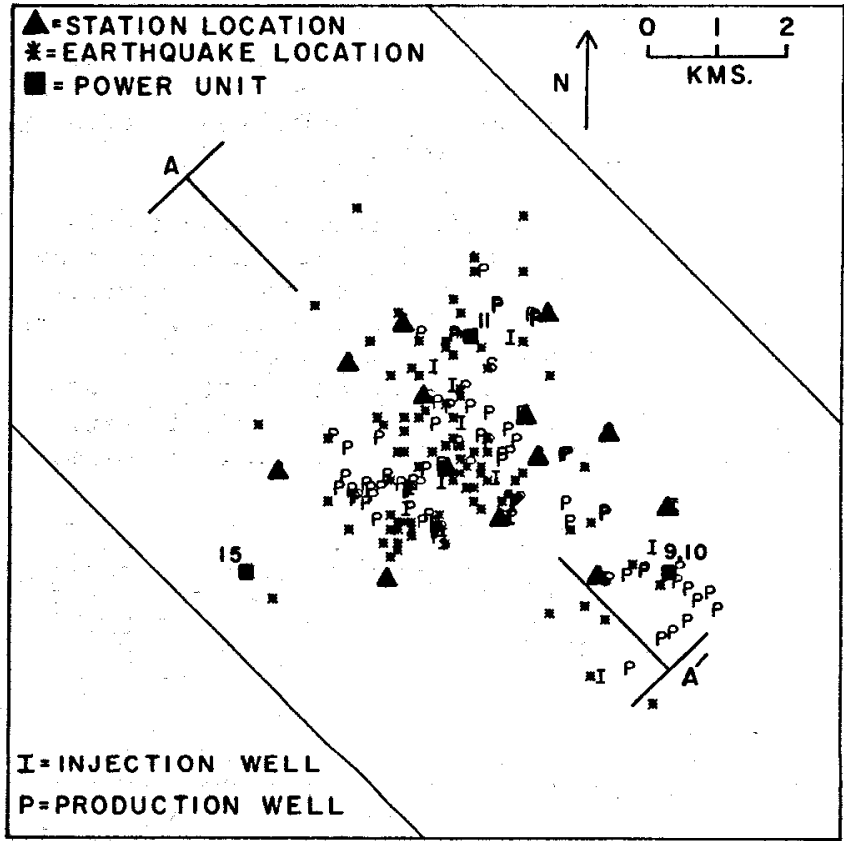

Figure 1. Map of the study area at The Geysers, California, showing the epicenters of events recorded during days 297 to 301,1980 .

[XBL 813-8568]

1 are 94 good events recorded during the last 5 days of operation, when the ASP was running unattended after having passed all field tests. To determine the valldity of these 94 locations, the data were compared with locations recorded by the U.S.G.S. Calnet and by an augmented calnet at. The Geysers operating on the automated U.S.G.S. 8ystem of Rex Allen (Allen and Ellis, 1980).

The 11 Calnet events located within this area and time period were also detected and 1ocated by ASP. Because the Calnet station distribution is less dense (although it is quite dense 
by normal microearthquake network standards), this is not a very good comparison. A better comparison can be made with events located by the augmented U.S.G.S. array, Figure 2 shows the principal stations of the augmented network. Al though more widely spaced than ASP stations, they are located more carefully at quieter sites, resulting in similar detection threshold sensitivities for the two nets. During the last 5 days of the recording period, 32 events were 10cated simultaneously by the two systems, and both locations are given in Figure 2. The two sets of locations show similar distributions both in plan view and in $\mathrm{NW}-\mathrm{SE}$ cross section.

The ASP located 94 good events during the 5-day period and the U.S.G.S. system only 32, as the latter system was inoperative for part of the 5-day period. In general, both systems seemed to detect and locate the same events during periods of simultaneous operation. The ASP, however, missed seven events that the U.S.G.S. system had located and assigned a quality of either $A$ or $B$. Four of these were missed because the ASP was busy with a prior event (this experiment was conducted before, and provided motivation for, the implementation of a fast arithmetic processor chip). The other three were missed apparently because of high noise levels at certain ASP sites.

Figure 3 shows the differences between epicenter locations for the 32 events as recorded by the two systems. True locations are, of course, unknown. In all the ASP locations shown, however, the epicenter is nearest to the station that had the first arrival. To be a good location by ASP standards, this "closest to first arrival station" criterion had to be satisfied in addition to small

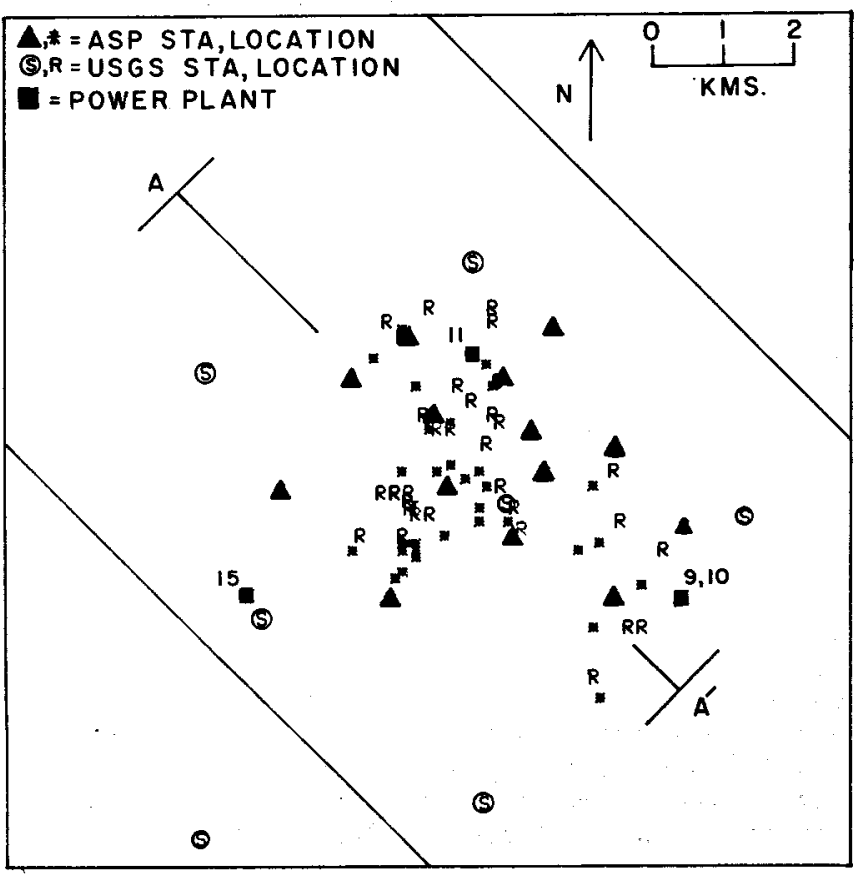

Figure 2. The Geysers geothermal field, showing ASP $(*)$ and augmented U.S.G.S. (R) stations and both epicenters for 32 commonly located events.

[XBL 813-8564]

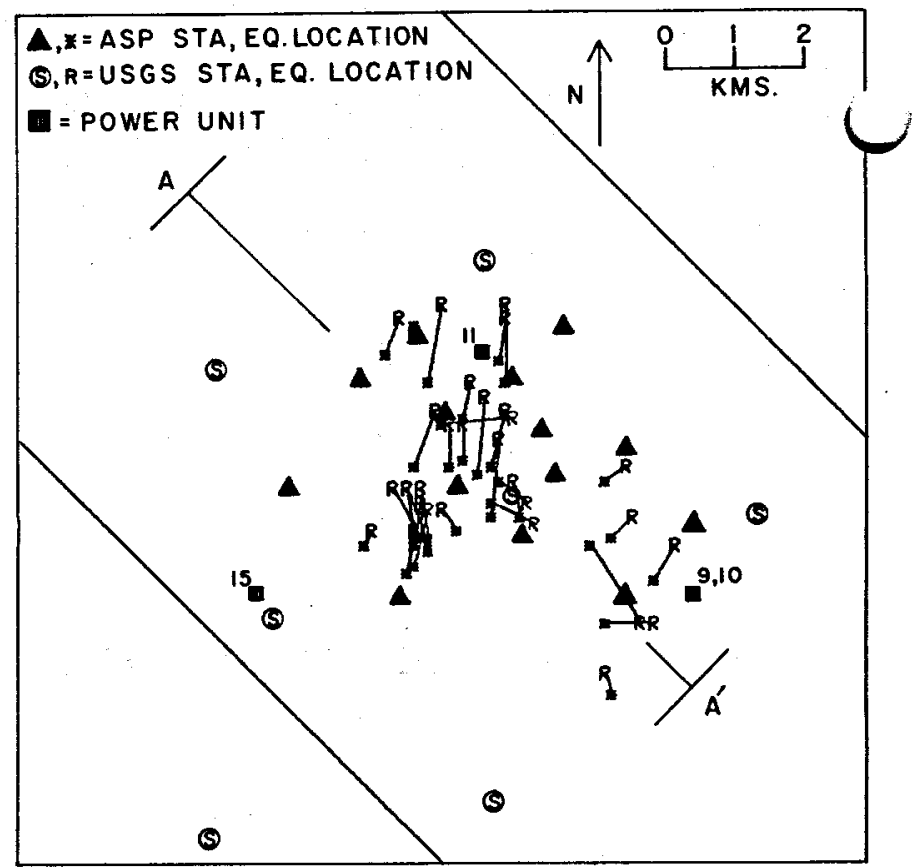

Figure 3. Differences in epicenters as determined by the ASP $(*)$ and U.S.G.S. (R) for $32 \mathrm{com}-$ monly located events, connected by line segments.

[XBL 813-8563]

RMS P-residuals. This "nearest station" criterion is violated by most of the epicenters located by the augmented U.S.G.S. system, whose locations are systematically displaced $\mathrm{N}$ or NE of the ASP epicenter. The RMS difference is $1.05 \mathrm{~km}$ in the $\mathrm{N}-\mathrm{S}$ direction and $0.24 \mathrm{~km}$ in the $\mathrm{E}-\mathrm{W}$ direction.

Focal depth differences are less systematic, reflecting the inherent difficulty in trying to locate an event in three dimensions with a twodimensional array. U.s.G.S. locations cluster at about $2 \mathrm{~km}$ in depth, with ASP locations clustering at 1 and at $3 \mathrm{~km}$. We observed this bimodal depth distribution in a previous study at The Geysers, using conventional processing and an equally dense array in the production zone (Majer and McEvilly, 1979), but it was not detected in the special Geysers study of Marks et al. (1980). The half-space velocity model is probably sufficient for small arrays, in which travel paths are largely vertical. It thus seems that, where an accuracy of $0.5 \mathrm{~km}$ or better is needed for hypocenters situated at depths of less than $5 \mathrm{~km}$, a station spacing of 0.5 to $1 \mathrm{~km}$ is required throughout the area of interest. For example, Figure 1 shows the earthquakes and the positions of the active production and injection wells at The Geysers. Even from these data, it would be difficult to conclude that earthquake activity was related to either production or injection, hence any such conclusions reached on the basis of networks of less dense coverage are no more than speculations.

\section{CERRO PRIETO}

The second use of the ASP was at the Cerro prieto geothermal field in northern Baja Cali- 
fornia, Mexico. Although array dimensions and objectives were similar to those of The Geysers study, the Cerro Prieto experiment differed in hat previous monitoring had indicated a higher level of microearthquake activity outside the production region than within. Despite this, the aim was to identify any earthquake activity within the production zone and to relate it to reservoir dynamics, including a search for evidence on regions of possible mass and heat transfer. Figure 4 shows the station distribution relative to known fault zones and production activity. At the time of the survey, the main production was coming from an area defined by wells $M 114, M 9$, $M 101$, and $M$ 109. In total, 26 wells were contributing to $150 \mathrm{MW}$ of power production. Well M 9 is the only injection well. The microearthquake situation was further complicated by the magnitude 6.7 event of June 1980, approximately 25 to $30 \mathrm{~km}$ southeast of the field on the Cerro Prieto fault system, and by aftershocks of the 1979 Imperial valley earthquake to the north.

During 17 days of monitoring, 119 events were recorded on 4 or more of the 11 stations deployed. of these 119 events, 40 were located within the array area. Iocations for 29 of the 40 locations were judged to be of good quality, and are shown in Figure 4. The ASP has two mechanisms for discriminating against events outside the array. In the first, an S-P input parameter, when exceeded, prevents location, and a message is printed out to that effect. The second mechanism is a time window in which a minimum number of P-readings must be received before an event is judged valid for further processing. For Cerro Prieto, this time window was $0.9 \mathrm{~s}$. That is, Boss had to receive at least four p-readings in a 1-6 time perlod ( $\mathrm{WW}+$ PIMIN), but the minimum time (PIMIN) between the first and last p-reading had to exceed 0.1 s. The maximum S-P time allowed was $3 \mathrm{~s}$. By adjusting these parameters--i.e., minimum number of stations (NMIN), time window (TW), and the minimum P-time difference (PMIN)-it is possible

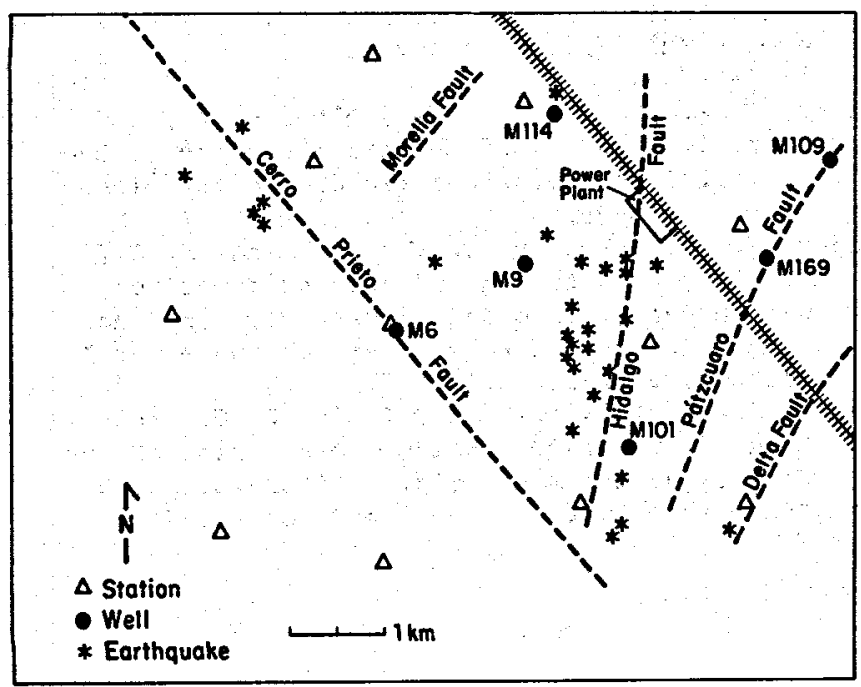

jgure 4. Map of Cerro Prieto geothermal field, Mexico, showing faults, temporary seismographic stations, wells, and epicenters of local microearthquakes determined by the ASP. to look at events within a specifled time and space window, while eliminating "glitches" in the system. Applying these methods, it was possible with a minimum amount of postprocessing to conclude after only 17 days of monitoring that there has been a clear increase in seismic activity in the production zone over previous levels (Majer et al. , 1980) and that there is excellent coincidence of hypocenters with the mapped fault zones.

\section{NEVADA TEST SITE}

At the Nevada Test Site, the ASP was used to monitor the sequence of afterevents associated with an underground nuclear explosion, before, during, and after cavity collapse. The 12-station net surrounding the explosion "BASEBALL" (15 January 1981) had station spacings of several hundred meters. The purpose of the experiment was to monitor the collapse process and the distribution of postcollapse events in time and space, and to determine the b-value for these events. It was obvious from the data that a shallow, strong lateral velocity gradient was confounding the half-space location method. Even though the explosion was located to within $5 \mathrm{~m}$ in depth and $20 \mathrm{~m}$ in the $x$ direction, the focus was biased $200 \mathrm{~m}$ in the $\mathrm{y}$ direction. Prior to collapse, the rate of events was so great that the ASP could not isolate discrete P-times associated with a single event for reliable processing. Examination of the simultaneously recorded analog tape, however, revealed that it is virtually impossible to do so even by conventional methods. Sixty-two postcollapse events over a 4-day period gave b-values of 1.0 to 1.1 , and 21 hypocenters were obtained, although noise and even interference conditions degraded location quality. This exercise also showed that a minimum size must be imposed on events for b-value computations in order to avoid effects of incomplete detection.

\section{LIVERMORE VALLEY}

The fourth ASP test was in the Livermore Valley of California, approximately 15 months after the occurrence of a relatively strong ( $M_{\mathrm{L}}=5.5$ ) earthquake (Bolt et al. , 1981). The array dimensions were approximately 25 by $30 \mathrm{~km}$ with 5 to 10 $\mathrm{km}$ between stations. This network is operated by Lawrence Livermore National Laboratory (LLNL) and monitored by an automated system (HP-1000 computer) that detects and stores the events for future analysis. In this test, the ASP was operating on the same data that were being monitored simultaneously by another automated system (the study at The Geysers involved two different arrays). During the first 3 weeks of the 5-week study, 347 events were detected on 3 or more stations. During the last 2 weeks of operation, 52 events were detected by 4 or more stations. Only 5 of these events were located with good results, primarily because the events were occurring outside of the array and/or they were being detected by only 3 or 4 stations. The ILNL systern detected 20 events that were subsequently located with high qualities within the array. The ASP detected the same 20 events and located 12 , but only 3 were located with results that can be rated as good. This experiment illustrated again the limitations in using a half-space velocity model in a large 
network. In addition, because this experiment was left operating for long periods without being attended, several subtle software problems were revealed. Their subsequent correction resulted in the gradual loss of stations through WORKER lock-up.

Another ASP application, with somewhat different hardware and at a much smaller scale, has been in the monitoring of thermally generated acoustic emissions asssociated with underground storage of nuclear wastes (Majer et al., 1981). The array dimensions are on the order of meters for this experiment in the climax facility at the Nevada Test site. A transient waveform analyzer is used to detect the high-frequency signals in the 1 to $20 \mathrm{kHz}$ band and to play them back at a reduced rate so that the ASP can process the data. This experiment has demonstrated the flexibility of the ASP in applying earthquake processing techniques to a variety of different scales of interest. Results to date from the Climax study have demonstrated the validity in scaling of the rock-fracturing process from earthquake size faults down to fractures of the acoustic emissions scale, probably centimeters in length.

\section{EVALUATION AND FUTURE WORR}

Overall, the ASP concept has proved to be well founded and has been applied in a variety of situations. Furthermore, throughout the experiments described here, which followed a thorough burn-in program, only one hardware failure has occurred--a PROM chip in one of the WORKERS. The field system, mounted in a truck, has been used in a variety of weather and dust conditions and transported large distances with no adverse effects. The low-power dc operation (1 W/channe1), coupled with hardware reliability, allows remote field operation for extended periods of time.

An attractive feature not initially appreciated is the "plug-in" capability of the ASP, which makes it adaptable to existing arrays. The ASP in reality is little more than a device for parallel time-series analyses that is programmed specifically for the location and characteriza$t i o n$ of discrete seismic events. The architecture of the ASP system, with a single computer monitoring and preprocessing each channel of data and supplying results to a controlling computer for network processing, has broad potential in any signal acquisition and analysis application.

The microearthquake processing software developed for the ASP is relatively simple, requiring accurate data for effective usage. Our attention to accuracy in timing, amplitude, and spectral algorithms was absolutely necessary to the successful implementation of the ASP. With processing time now reduced to less than one minute per earthquake, the goals of cost-effectiveness and real-time results have been attained with no compromise in quality.

The next step in development is to improve the processing power of Boss. This will be achieved by adding a Digital Equipment Corporation (DEC) LSI $11 / 23$ to the ASP to augment the present BOSS processing. BOSS will then be responsible only for determining the validity of an event and feeding valid data to the ISI $11 / 23$ for all mode calculations. An improved location program using a gradient over a half-space will augment the present location program. Two additional numerical operations will also be added to increase system capabilities. A moment-tensor inversion will be used to determine the principal stress directions using as input data the longperiod spectral values for the $P$ - and $S-$ waves and the polarity of the P-wave at each station. The second new feature will be a Wadati analysis to determine $V_{P} / V_{S}$ from $P$ and $S-P$ times. The ISI $11 / 23$ will be switched on only for computations, thus adding negligibly to the ASP power consumption.

With the addition of the ISI $11 / 23$ computer, the ASP will provide faster complete on-line analyses than has been achieved so far using only lab-based minicomputer systems. It is clear that the "ASPtype" approach to in-field data handling and analysis has application at varied scales to a range of seismological and other geophysical problems.

\section{REFERENCES CITHED}

Allen, R. V., and Ellis, J. O., 1980. An automatic on-line monitor for micro-earthquake networks. EOS, v. 61, p. 1030 .

Bolt, B. A., McEvilly, T. V., and Uhrhamer, R. A., 1981. The Livermore Valley, California, sequence of January 1980. Bulletin of the Seismological society of America, v. 71, p. 451-463.

Majer, E. L., and McEvilly, T. V., 1979. Seismological investigations at The Geysers geothermal field. Geophysics, v. 44, p. 246-269.

Majer, E. L., McEvilly, T. V., Albores, A., and Diaz, S., 1980. Seismological studies at the Cerro Prieto geothermal field. Geothermics, v. 9, p. 79-89.

Majer, E. L., McEvilly, T. V., and King, M. S., 1981. Monitoring an underground repository with modern seismological methods. International Journal of Rock Mechanics and Mineral Science, v. 18, p. 517-527.

Marks, S. M., Ludwin, R. S., Louie, R. B., and Bufe, C. G., 1980. Seismic monitoring at The Geysers geothermal field, California. U. $\mathbf{S}$. Geological Survey Open-File Report 78-798. 


\title{
ADVANCES IN TRANSIENT WELL-TESTING METHODOLOGY
}

\author{
C. W. Miller, S. M. Benson, and G. S. Bodvarsson
}

A major problem in determining the transmissivity and storativity of a geothermal reservoir is that in most cases the flow in the reservoir is two-phase. Conventional well-test methods are primarily applicable to isothermal, single-phase reservoirs. One of the tasks in fiscal 1981 was to understand the effects of two-phase well-bore flow on pressure transient tests and to determine appropriate testing and analysis procedures. Analysis methods for infection test data in a fractured two-phase reservoir were also studied.

\section{WELL-BORE EFFECTS IN THE ANALYSIS OF TWO-PHASE WELL TESTS}

There have been a number of attempts to extend conventional well-testing and analysis techniques to two-phase geothermal reservoirs (Grant, 1978; Garg, 1980; Garg and Pritchett, 1980; Sorey et al., 1980). It has been shown that if the fluid saturation and temperature in the reservoir are initially uniform throughout the reservoir and nearly so for the direction of the test, then a plot of pressure vs. the $\log$ of time will produce a straight line. The slope of a line is inversely proportional to the total kinematic mobility $\left(\mathrm{k} / \mathrm{v}_{\mathrm{T}}\right)$. Although it is rarely possible to maintain uniform saturation and temperature distributions in the reservoir for an entire field test, the tests can be designed so that they remain nearly uniform throughout. Numerical simulation techniques were used to study the effect of nonuniform reservoir saturation and the effect of wel1-bore transients on pressure transient tests.

The transient well-bore model WELBORE, developed at Lawrence Berkeley Laboratory (Miller, 1980 a), was coupled to a modified version of the reservolr simulator GEOTHNZ (Zyvoloski et al., 1979). The well-bore reservolr model was used to simulate drawdown and buildup tests. Four different cases were studied (Miller et al., 1981): (1) a single-phase hot water reservoir connected to a partially two-phase well bore; (2) a hot water reservoir that becomes two-phase during the test, (3) a two-phase liquid-dominated reservoir, and (4) a two-phase vapor-dominated reservoir.

To apply conventional well-test analysis methods to two-phase reservoirs, uniform saturation conditions must develop around the well bore. ing the similarity variable, $n=r / \sqrt{t}$, it has Len shown that for a reservoir with uniform initial thermodynamic conditions, the flowing enthalpy will reach a steady-state value soon after the start of production (O'Sullivan, 1980, Sorey et al., 1980), so that

$\lim \mathrm{dH}_{\mathrm{f}} / \mathrm{d} \eta=0$, $n \rightarrow 0$

where $H_{f}$ is the flowing enthalpy. The in-place saturation around the well bore also stabllizes, because the flowing enthalpy is primarily a function of saturation. Therefore, if a well test is designed so that this constant-saturation condition is applicable, state-of-the-art well-test methods can be used. It remains to be shown that a constant-saturation condition will still develop when conditions are not uniform initially.

Well-bore storage phenomena in two-phase geothermal well/reservoir systems can last several hours. Wel1-test methods assume a constant mass flow rate at the well/reservoir boundary. In a field test, an attempt is made to keep the mass flow rate at wellhead constant. until transient changes in the well bore are negligible, the mass flow rate at the reservoir will not be constant. Well-bore storage will persist until pressure and energy changes die out. The duration of the pressure changes has been estimated using conventional methods reported in the petroleum 1iterature, except that the average compressibility, $\mathrm{C}_{\mathrm{E}}$, In the well has been defined as

$\frac{1}{2} \int_{0}^{L}\left(\frac{\partial \rho}{\partial P}\right)_{E} d x$

where $L$ is the depth of the well and $(\partial \rho / \partial P)_{E}$ is the change in density with respect to pressure at constant energy.

Well-bore storage due to energy changes will persist until the flowing enthalpy from the reservoir is constant. Once $H_{f}$ is approximately constant at the well/reservoir boundary, there is additional time for the energy changes in the well to stabilize, which is approximately the time for a fluid particle to travel through the well bore. The calculation of the duration of well-bore storage depends on the reservoir conditions. Therefore, it is necessary to estimate well-bore storage, calculate the reservoir conditions, and then recheck using the reservoir value of $k / v_{t}$ and Hf $_{f}$ to determine whether well-bore storage was actually over when the pressure transient data were analyzed.

The following method of analysis was developed. First calculate the average value of the 
compressibility density term, $\rho C_{E}$, from the flowing conditions in the well before the flow rate is changed. After the rate is changed and well-bore storage is over (as estimated with $\rho C_{\mathfrak{E}}$ ), use the slope of the straight line segment on the plot of the downhole pressure vs. $\log$ of time to calculate $k / v_{T}$. Then, using the measured slope and the transmissivity $\left(\mathrm{Kh} / \mu_{\mathrm{T}}\right)$, recalculate the duration of well-bore storage. The duration of well-bore storage attributable to energy changes is best determined by monitoring the flowing enthalpy at wellhead. A rough estimate can be made by calculating the time for a fluid particle to reach wellhead, but it is still very important to know whether the flowing enthalpy from the reservolr is constant. If the straight line segment on the pressure-time plot was chosen while wellbore storage was important, a new line segment at later times must be chosen and the calculation redone.

As was mentioned earlier, four different cases were considered. The results of two of them are included here. For the case of a single-phase reservoir that flashes during the well test. Figure 1 shows two examples of the drawdown pressure curve. (The oscillations in the curves are due to discretization effects). Open circles show the effect of keeping the mass flow rate constant downhole (at the sandface), closed circles show the effect of keeping it constant at the wellhead. The latter curve more closely represents what occurs in the field. The former shows a break that corresponds to the start of flashing in the reservoir; this is completely masked by well-bore flow in the other curve. Wellbore storage is important up to $10^{3} \mathrm{~s}$, although a straight line can be seen from $100 \mathrm{~s}$ on. Nevertheless, because the wellhead enthalpy changes up to $10^{3} \mathrm{~s}$, the data should not be analyzed until that point.

Figure 2 shows a semilog plot of pressure vs. time for a two-phase liquid-dominated reservoir. The plateau in the drawdown pressure curve is due entirely to the interaction of the well-bore flow

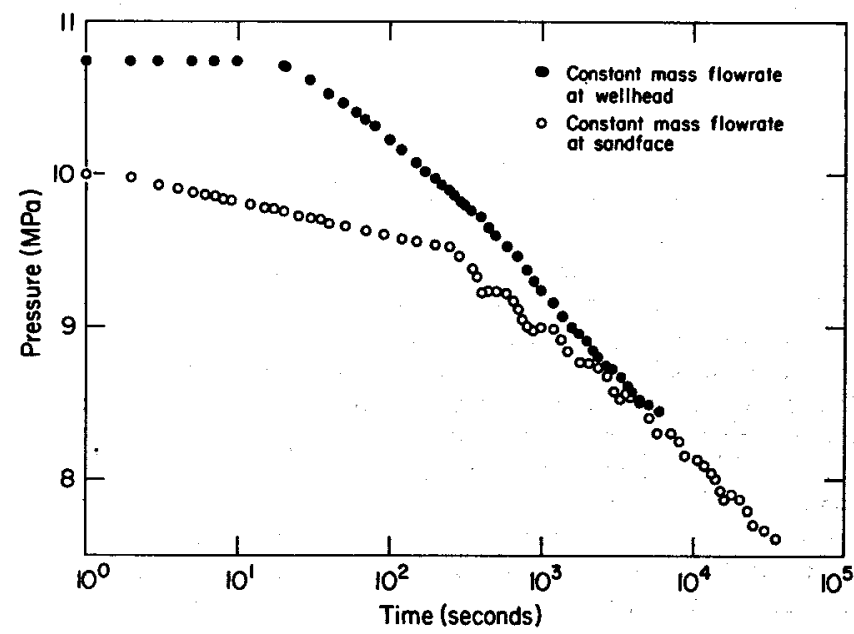

Figure 1. Two examples of pressure drawdown for a liquid reservoir which flashes during well test. [XBL 811-2118]

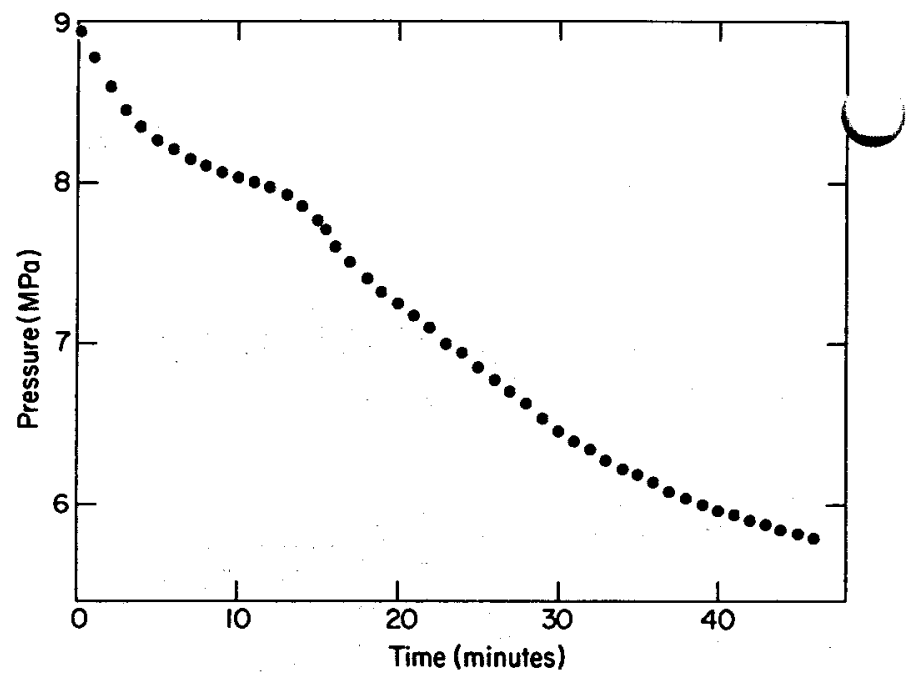

Figure 2. Linear plot of pressure drawdown curve for a liquid-dominated two-phase reservoir.

[XBL 811-2117]

with that of the reservoir when the flowing enthalpy from the reservoir changes (Miller et al., 1981).

It is often impossible to obtain constant flow rates with uniform conditions in the reservoir. An alternative is to use the transient well-bore model to solve for the sandface flow rate (Miller, 1980b). If the reservoir is single phase, the program ANALYzE (McEdwards and Benson, 1981) can be used to obtain the reservoir parameters from a best fit of the pressure curve. Figure 3 shows such a fit of the pressure data after the sandface flow rate was calculated using program WELBORE. If the flow in the reservoir is two phase, the fit must be done by modeling a two-phase reservoir with different guesses for saturation, transmissivity, and storativity.

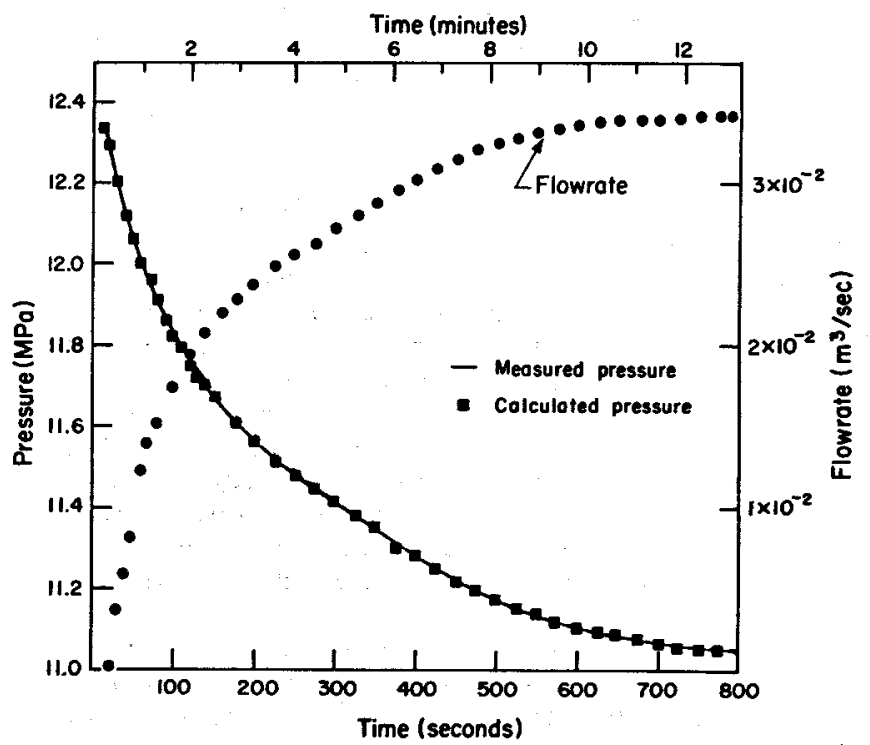

Figure 3. Sandface flow rate and drawdown pressure for a liquid reservoir. Also plotted in the pressure match calculated from ANALYZE.

[XBL 811-2124] 


\section{INJECTION TEST ANALYSIS}

To avold the problems encountered in drawdown lests, injection tests are commonly used in hightemperature geothermal reservolrs to obtain an estimate of the reservoir parameters. However, even in this case, analysis of the pressure data is not straightforward. Nonisothermal behavior in both well and reservolr must be considered. In addition, in wells with a free liguid level, well-bore storage phenomena can last up to several hours. In the Krafla geothermal field in Iceland, injection tests are routinely conducted immediately after the wells have been completed. There is some evidence to suggest that cold water injection increases the near-well-bore permeability. Thus injection tests have a twofold objective: to enhance the near-well-bore permeability, and to obtain pressure transient data. Tests usually last approximately $12 \mathrm{hr}$ and consist of several step-rate flow sequences (Fig. 4). Data analysis is complicated by variable flow rates, fracture flow, nonisothermal well and reservoir behavior, and prolonged well-bore storage.

Data were analyzed using the computer-codes ANALYZE and PT. To account for the flow-rate changes induced by well-bore storage, the sandface flow rate was calculated from the slope of the pressure data. In all subsequent pressure transient calculations, the real sandface flowrate data were used. For a preliminary analysis, the first pressure drop (Fig. 4) was analyzed with the computer code ANALYZE. The analysis gave a transmissivity of $1.5 \times 10^{-8} \mathrm{~m}^{3} / \mathrm{Pa}-\mathrm{s}$ and a storativity of $1 \times 10^{-7} \mathrm{~m} / \mathrm{Pa}$. The rest of the data was then analyzed in a similar manner. The match of the calculated and measured pressure for the entire test is shown in Figure 4.

A sensitivity study was conducted to assess the uniqueness of the reservoir parameters. The study indicates that the transmissivity, $\mathrm{kh} / \mu_{\text {r }}$ is correct to \pm 208 . The storativity, $\Phi \mathrm{ch}$, can be determined only roughly by this type of analysis. A variation of an order of magnitude in the storativity causes very little change in both the value of the transmissivity and the match of calculated and measured pressure data. Therefore, as is commonly understood, production tests (injection tests) are not a rellable method of obtaining the reservoir storativity.

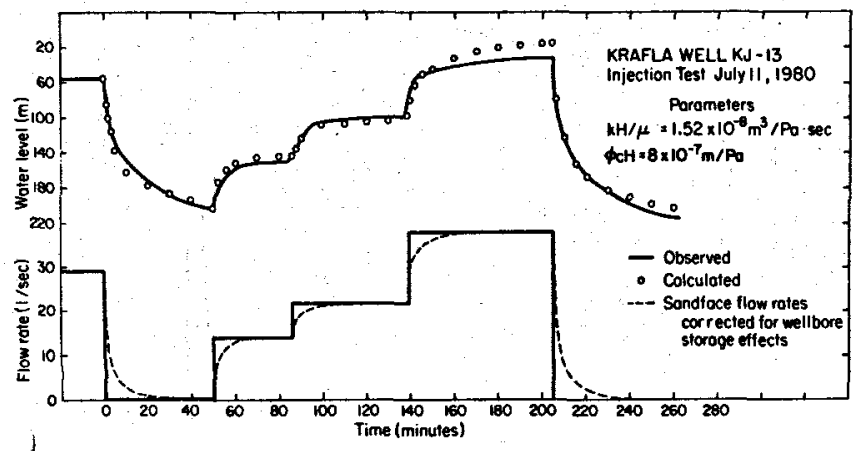

Figure 4. Match of observed and calculated welltest data from well $\mathrm{kJ}-15$, Krafla geothermal fleld, Iceland.
The numerical code PT is a three-dimensional, nonisothermal reservoir simulator (Bodvarsson, 1981). Liquid water reservoirs can be modeled to determine the pressure transient behavior of cold water injection into a hot water reservoir. Theoretical studies show that after a very short time (during injection), the pressure transient behavior appears to be isothermal (Bodvarsson et al., 1980). Therefore, it is satisfactory to use a relatively simple reservoir model to calculate the reservoir transmissivity. The results of the final analysis are shown in Figure 4. The match between the observed and calculated values is good, lending confidence to the reservoir parameters obtained. It should be noted, however, that injection characteristics may differ from production characteristics. Because of the high induced head differential during injection tests, the injected fluid does not necessarily enter only the zones from. which fluid production occurs.

\section{REFERENCES CITED}

Bodvarsson, G. S., 1982. Numerical modeling of the behavior of geothermal systems under exploltation (Ph.D. dissertation). Dept. Materials Sclence and Mineral Engineering, Oniversity of Callfornia, Berkeley.

Bodvarsson, G. S., and Tsang, C. F., 1980. Thermal effects in well tests of fractured reservoirs. In Proceedings, Third Invitational Well Testing Symposium, Berkeley, California, March 26-28, 1980. Lawrence Berkeley Laboratory Report IBL-12076, p. 110-119.

Garg, S. R., 1980. Pressure transient analysis for two-phase (water/steam) geothermal reservoirs. Society of Petroleum Engineers Journal, v. 20 , no. 3 , p. 206-214.

Garg, S. K., and Pritchett, J. W., 1980. Pressure transient analysis for hot water and two-phase geothermal wells: Some numerical results. Systems, Science and Software Report SSS-R-81-4708, La Jolla, California.

Grant, M. A., 1978. Two-phase linear geothermal pressure transients: A comparison with single-phase transients. New zealand Journal of Sclence, v. 21, p. 355-364.

MoEdwards, D. G., and Benson, S. M., 1981. User's guide for ANALYZE-A variable-rate, multiple-well, least squares matching routine for well-test analysis. Lawrence Berkeley Laboratory Report LBL-10907, $70 \mathrm{p}$.

Miller, c. W., 1980a. WELBORE user's manual. Lawrence Berkeley Laboratory Report LBL-10910, $48 \mathrm{p}$.

Miller, C. w., 1980b. El iminating the wellbore response in transient well test analysis. Presented at the 6 th workshop on Geothermal Reservoir Engineering, Stanford, California, December 16-18, 1980. Lawrence Berkeley Laboratory Report LBL-12037, $10 \mathrm{p}$.

Miller, C. W., Benson, S. M., O'sullivan, M. J.. and Pruess, K., 2981. Wellbore effects in the analysis of two-phase geothermal well tests. Presented at society of Petroleum Eng ineer' $s$ Meeting, Baker sfield, Callfornia, March 25-27, 1981. Lawrence Berkeley Laboratory Report LBL-12220, 15 p.

O'sullivan, M. J., 1980. A similarity method for geothermal well test analysis. Water Re- 
sources Research, v. 17, no. 2, p. 390-398. Lawrence Berkeley Laboratory Report LBL-10968. Sorey, M. L., Grant, M. A., and Bradford, E., 1980. Nonlinear effects in two-phase flow to wells in geothermal reservoirs. Water Resources Research, v. 16, no. 4, p. 767-777.
Zyvoloski, G. A., O'Sullivan, J. J., and Krol, D. E., 1979. Finite difference techniques for modeling geothermal reservoirs. Numerical and Analytical Methods in Geomechanics, v. 3 , p. 355-366.

\title{
LOW- TO MODERATE-TEMPERATURE HYDROTHERMAL RESERVOIR ENGINEERING RESEARCH
}

\author{
S. M. Benson, R. Solbau, and G. S. Bodvarsson
}

In 1981 a new program was established at Lawrence Berkeley Laboratory to develop reservoir engineering methodology and reservoir assessment techniques specific to low- and moderate-temperature hydrothermal systems. Until that time, little effort had been devoted to the understanding of these reservoirs and of problems related to them. The new program focused on developing a computational model for thin fault-charged hydrothermal reservoirs, development of well-testing instrumentation, compiling and publishing case studies of low- to moderate-temperature reservoirs, and writing a handbook with reservoir engineering guidelines for potential developers.

\section{MODELING OF FAULT-CHARGED RESERWOIRS}

Many of the low- to moderate-temperature hydrothermal systems being developed in the Cascade Range and the Basin and Range Province occur in highly permeable near-surface aquifers. Nearsurface temperature gradients are typically high $\left(3^{\circ} \mathrm{C} / \mathrm{m}\right)$, whereas temperature gradients at depth may be close to normal or have a reversal. The very high near-surface temperature gradients can be attributed to hydrothermal circulation. Meteoric waters circulate deeply, become heated, and return to the surface along faults and fractures. Where a fault is intersected by a permeable aquifer, the heated fluid enters the aquifer and forms a near-surface thermal anomaly. Figure 1 shows a schematic of this type of hydrothermal system. The schematic also shows the model used for computational purposes. Above the aquifer is a confining layer with a rock density of $\rho_{1}$, a heat capacity of $c_{1}$, and a thermal conductivity of $\lambda_{1}$. The basement rock has a rock density of $\lambda_{2}$, a heat capacity of $c_{2}$, and a thermal conductivity of $P_{2}$. It is assumed that both the cap rock and the basement rock are impermeable. Because no vertical temperature variations are considered in the aquifer, the model is applicable only to thin, permeable aquifers. The model has been applied to two types of problem: theoretical studies of the evolution of a fault-charged system and a site-specific study designed to predict the rate of hot water recharge into the hydrothermal anomaly at susanville, California.

\section{EVOLUTION OF A FAULT-CHARGED SYSTEM}

Because the mathematical solution developed for fault-charged systems is fully transient, the evolution of these systems can be studied.

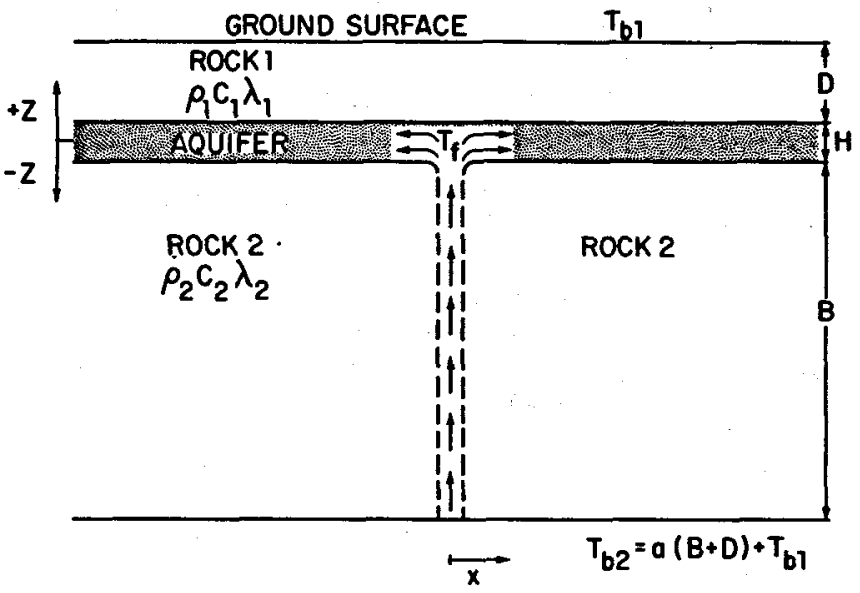

Figure 1. Computational model for a fault-charged aquifer.

[XBL 816-3178]

Figure 2 shows the evolution of one such system. Before the incidence of hydrothermal circulation, the temperature gradient is linear, with a temperature of $\mathrm{T}_{\mathrm{bl}}$ at the surface and a temperature of $\mathrm{T}_{\mathrm{b} 2}$ at the base of the thickness under consideration. When water begins to flow up the

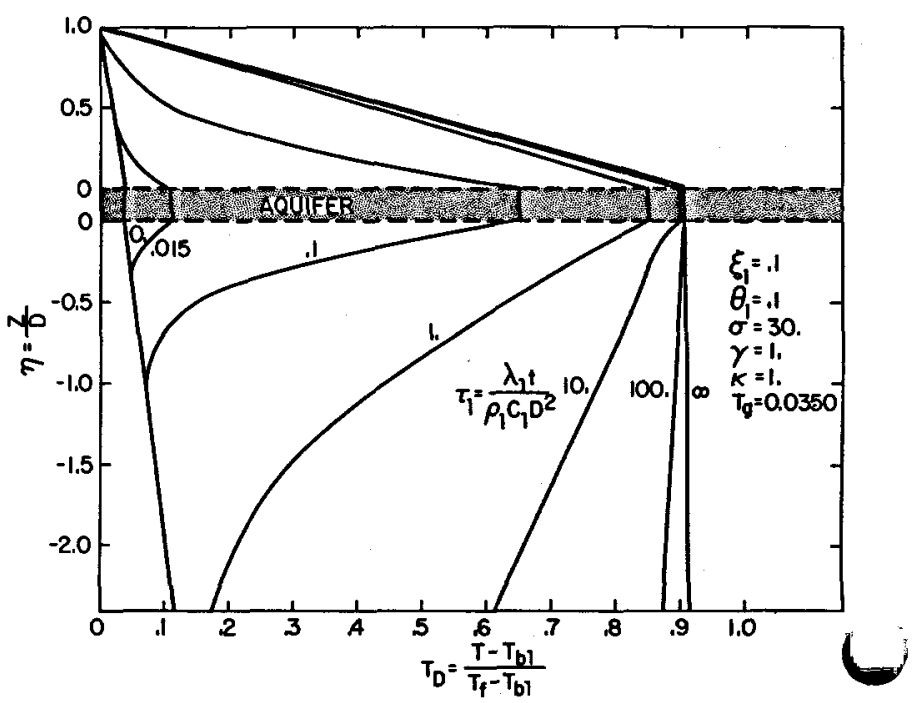

Figure 2. Evolution of a thin fault-charged hydrothermal system. 
fault and into the aquifer, the aquifer begins to heat up. The hot water flows laterally into the dquifer, and the loss of heat by conduction to both the cap rock and the basement produces the distinctive temperature reversal below the aquifer. With time, conductive heat losses to the cap rock stabilize and a typical linear gradient is established. At very large times, the temperature below the aquifer stabilizes and, for the case considered, becomes nearly isothermal.

Studies such as these are useful both for fundamental understanding of hydrothermal systems and for correlation with geologic phenomena, thus allowing quantitative conceptualization of the reservoir behavior. Without quantitative studies of reservoir systems, it is impossible to estimate reservoir potential and develop appropriate reservoir engineering methodology.

\section{RESERVOIR RECHARGE CALCULATIONS}

The Susanville geothermal anomaly is located in northeastern California at the intersection of the Basin and Range, the Sierra-Nevada, and the Modoc Plateau. Well testing and the drilling of twenty temperature-gradient holes located a shallow $K 150 \mathrm{~m}$ ) fault-related hydrothermal resource. Because the resource is of very limited vertical and areal extent, it is important to have an estimate of the hot water recharge in order to obtain a realistic estimate of reservoir potential.

Temperature profiles were measured in each of the temperature-gradient holes. In most cases, the temperature increased linearly to a depth of $125 \mathrm{~m}$ and then became isothermal or had a reversal. The highest temperatures recorded were 60 to $80^{\circ} \mathrm{C}$. By contouring the temperature data at several subsurface elevations, a clearly defined elongation of the thermal anomaly around a northwest-trending axis was identified. It is postulated that the shape of the thermal anomaly and the temperature profiles can be attributed to a recharging fault. Geologic data show that the area is highly faulted, lending credence to the assumption.

A simplifled model of the susanville system was formulated and calculations carried out in an attempt to match the temperature distribution in the observed thermal anomaly. Temperature profiles and contours were both considered in choosing the most likely recharge rate. Figures 3 and 4 show the match of the measured and calculated data. The calculated recharge rate is $9 \times 10^{-6}$ $\mathrm{m}^{3} / \mathrm{s}$ per meter of fault. Over a distance of $2500 \mathrm{~m}$, this is a total of $2.25 \times 10^{-2} \mathrm{~m}^{3} / \mathrm{s}$. Inclusion of this recharge in the longevity calculations (at a proposed extraction of $3.15 \times 10^{-2}$ $\mathrm{m}^{3} / \mathrm{s}$ ) gives a reservoir life of 25 to $75 \mathrm{yr}$ instead of the originally estimated 9 to $27 \mathrm{yr}$ (Bodvarsson et al., 1981).

LOW- TO MODERATE-TEMPERATURE WELL-TEST INSTRUMENTATION

Engineering drawings have been prepared and published for four well-test instruments. Included are a high-resolution ( $0.01 \mathrm{psi)}$ downhole temperature instrument; a multiconductor cable-
SUZY 2 SUZY 4 SUZY 8 SUZY 9 NAEF

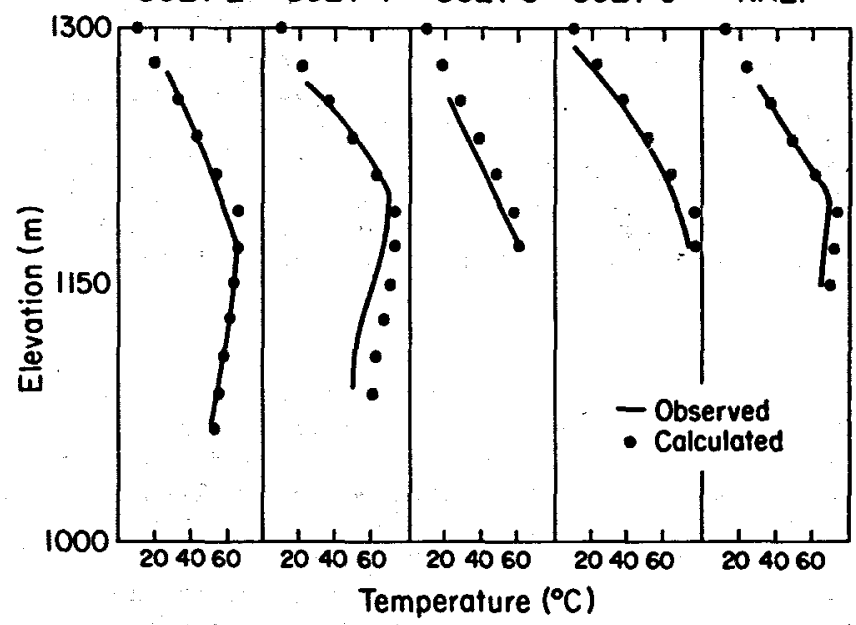

Figure 3. Match of temperature profiles at Susanville, California, using a fault recharge rate of $9 \times 10^{-6} \mathrm{~m}^{3} / \mathrm{s} / \mathrm{m}$.

[XBL 816-3181]

head; a line driver for a comercially manufactured pressure transducer, and a fluid-level indicator (Solbau et al., 1981). These have all performed satisfactorily when field tested under

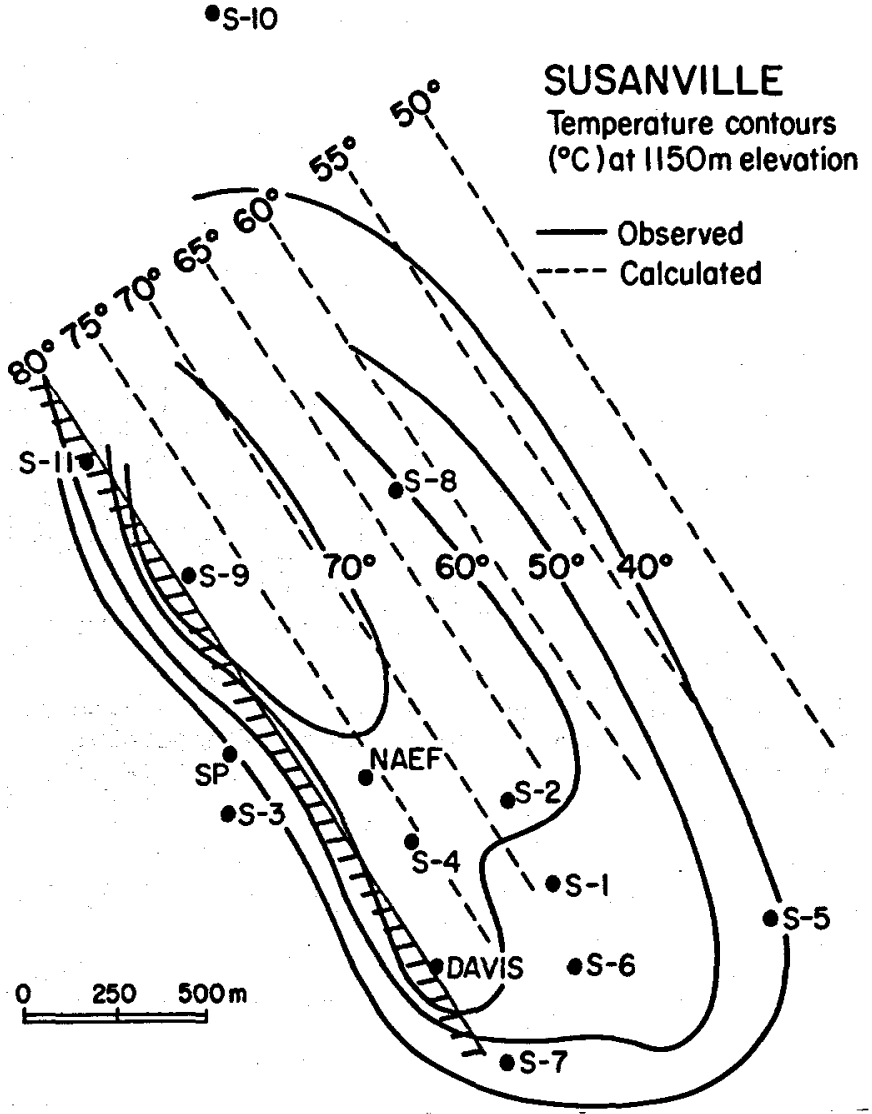

Figure 4. Match of temperature contours at Susanville, Callfornia, using a fault recharge rate of $9 \times 10^{-6} \mathrm{~m}^{3} / \mathrm{s} / \mathrm{m}$. 
harsh operating conditions. Figure 5 shows a plot of interference test data obtained using a combination of these components: the downhole probe, the multiconductor cablehead, and the line driver. A schematic of the setup is shown in Figure 6. This arrangement is suitable for use in the wells at temperatures up to $107^{\circ} \mathrm{C}$ and pressures up to 900 psi. A 3000-psi gauge will be incorporated into the instrument in 1982.

\section{CASE STUDIES}

As a joint effort of Lawrence Berkeley Laboratory and EG\&G Idaho, six case studies of the development of hydrothermal resources for directheat applications were compiled and published (IDO, 1981). The sites include the St. Mary's Hospital in Pierre, South Dakota; the First National Bank in White Sulfur Springs, Montana; Pagosa Springs, Colorado; Utah Roses in Sandy, Utah; Susanville, California; and Monroe, Utah. In five of the six projects, the hot fluid will be used for space heating; in the sixth, it will be used to warm a greenhouse.

Each study includes geologic, hydrologic, thermal, and exploratory data. Drilling techniques, well completion hardware, and drilling problems are discussed. Well-test data, results, and interpretation are also included. The case studies were intended to summarize all of the reservoir-related information for each site. The final section of the report compares the development of each site, the factors which led to the

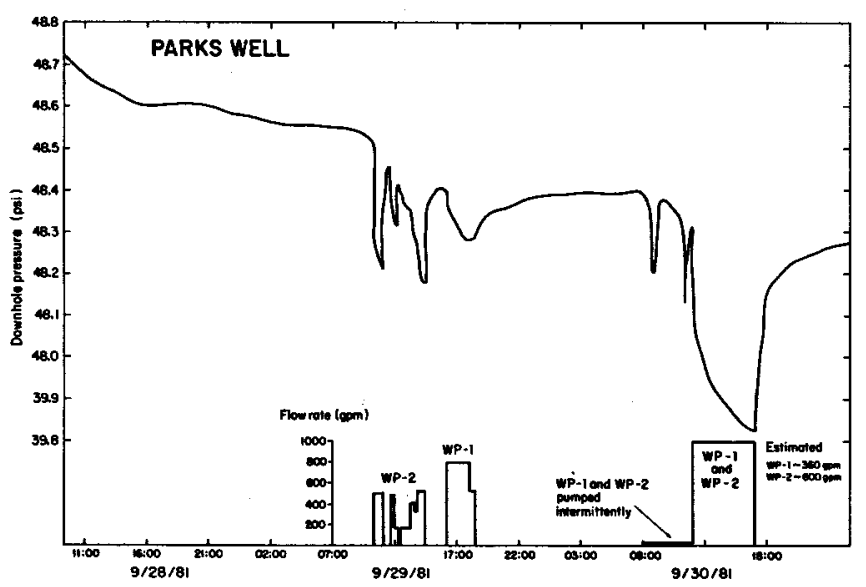

Figure 5. Interference test data obtained with the LBL-fabricated downhole pressure/temperature instrument.

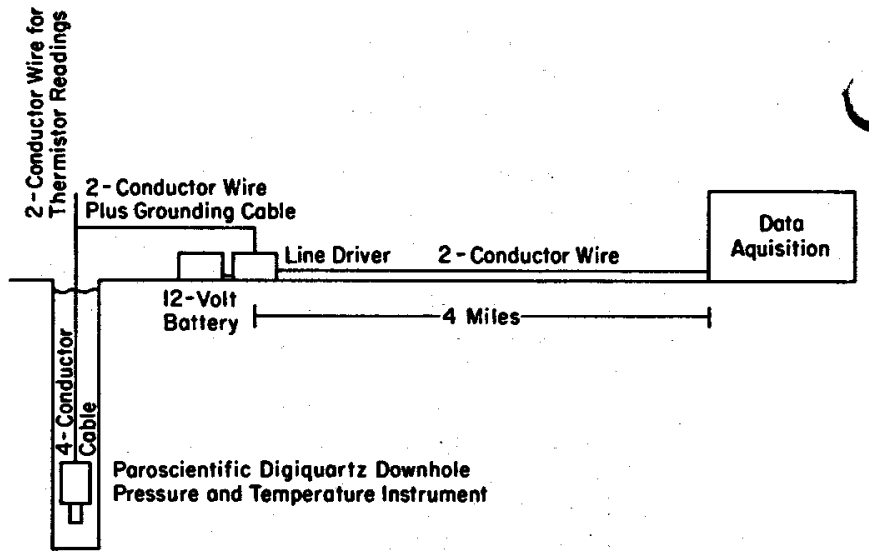

Figure 6. Schematic of a data-acquisition system using the line driver, cablehead, and pressure/temperature probe. project's success or failure, and makes recommendations on the most successful drilling, exploration, and development techniques.

\section{CONCLUSTONS}

A long-overlooked area of geothermal reservoir engineering is now being studied. Because low- to moderate-temperature thermal anomalies often cover high-temperature anomalies, we can expect that this program will also enhance our understanding of geothermal systems in general. without the benefit of sound reservoir engineering and reservoir assessment techniques we cannot look forward to replacing our existing energy sources with new and innovative resources such as hydrothermal energy.

\section{REFERENCES CITED}

Bodvarsson, G. S., Miller, C. W., and Benson, S. M., 1981. A simple model for fault-charged hydrothermal systems. Lawrence Berkeley Laboratory Report LBL-9459. (Presented at the Annual GRC Meeting, Houston, Texas, 1981.)

IDO, 1981. Case studies of low-to-moderate temperature hydrothermal energy development. Idaho Operations Office Report IDO-10098.

Solbau, R., Goranson, C. B., and Benson, S. M., 1981. Recently developed well test instrumentation for low-to-moderate temperature hydrothermal reservoirs. Lawrence Berkeley Laboratory Report LBL-13260, 36 p. 


\title{
EVALUATION OF THE HYDROTHERMAL POTENTIAL OF THE ASHDOD AREA, ISRAEL
}

\author{
M. Benson
}

The Earth Sciences Division has recently become involved in a project to evaluate the hydrothermal potential in and around Ashdod, Israel. Ashdod is located approximately $30 \mathrm{~km}$ south of Tel Aviv on Israel's southern coastal plain (Fig. 1). The U. S. Agency for International Development (AID) is evaluating the hydrothermal potential of this area because a seawater desalination plant being constructed in Ashdod will have large requirements for a low-grade heat source. The plant is being constructed under a cooperative program of the Israeli government and $v$. S. AID. It will desalinate sea water by the Zeresh Process--a process which subatmospherically flashes the brine to produce pure steam. The plant will use the waste heat from a power plant fired by fossil fuel. The temperature of the heating fluid at the inlet to the desalination plant will be approximately $62^{\circ} \mathrm{C}$ and the outlet temperature approximately $56^{\circ} \mathrm{C}$. The objective of this evaluation is to determine if the hydrothermal resource at Ashdod is of suitable temperature, brine chemistry, size, and productivity to economically replace the existing heat source for the plant. It is estimated that approximately $2100 \mathrm{~m}^{3} / \mathrm{hr}$ of $95^{\circ} \mathrm{C}$ brine will be required to replace the existing heat source.

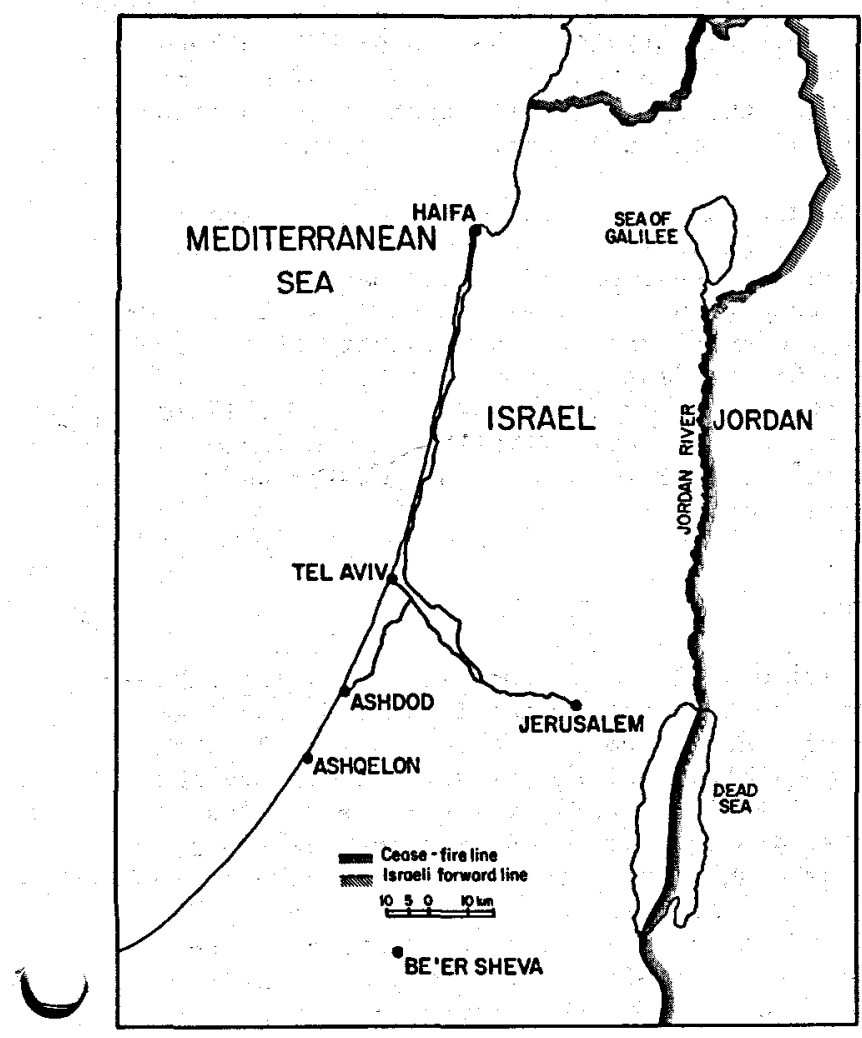

Figure 1. Map of Is rael showing location of Ashdod.

\section{RESERVOIR DATA}

Six deep wells have been drilled to the southeast of the desalination plant site (Fig. 2). These wells were drilled by the Israell oil Exploration (Investment) Ltd. in search of hydrocarbon deposits. Two of the six wells are producing a combined total of approximately $50 \mathrm{bbl} /$ day of crude oll (Koifman, 2980). The other four wells were "dry holes" and have been abandoned. Two of the abandoned wells (Ashdod 3 and Ashdod 4) have been recompleted to obtain data for a preliminary reservoir evaluation.

Ashdod 3 and Ashdod 4 were originally drilled to depths of $2731 \mathrm{~m}$ and $2685 \mathrm{~m}$, respectively. The wells penetrate sedimentary formations composed of dolomite, ilmestone, and shale. The potential geothermal aquifers were deposited in the Jurassic Era and begin at a depth of approximately $2600 \mathrm{~m}$ below sea level. There are three formations of potential interest; the zohar Formation, the Karmon shales, and the shderot Dolomite (Koifman, 1979).

The zohar Formation is a porous, vuggy, fractured dolomite. Many fractures are partially

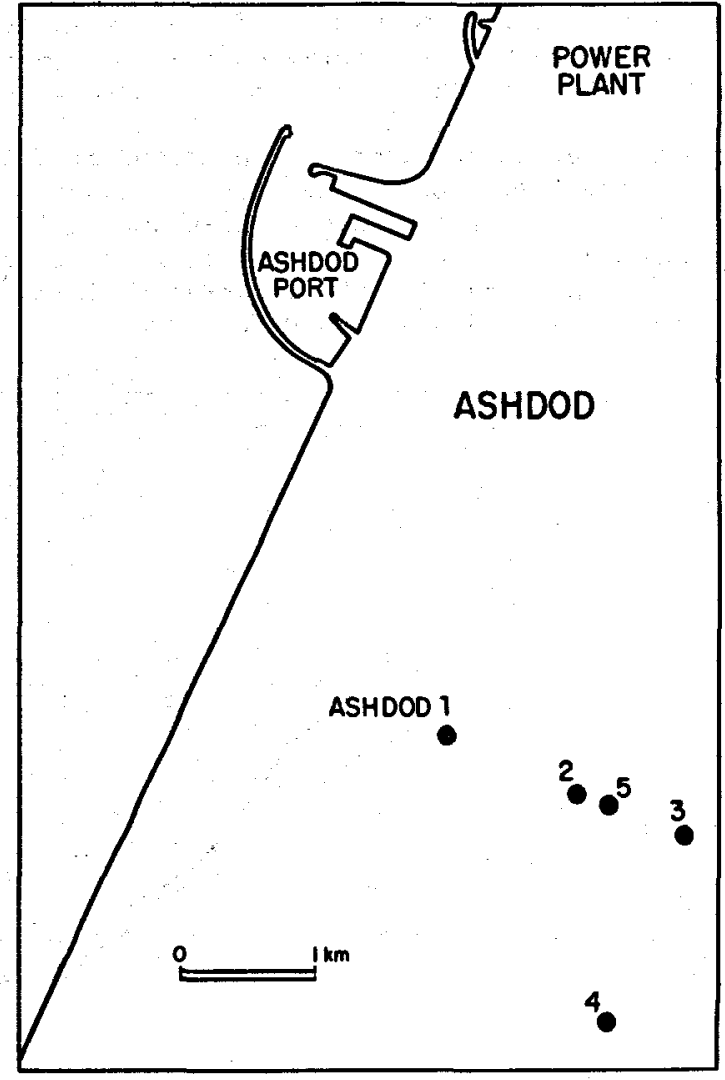

Figure 2. Location map of the well sites, the power plant, and the city of Ashdod.

[XBI 817-3358] 
filled with calcite and quartz deposits. The top of the zohar is belleved to have paleokarst dissolution channels. This may explain the large losses of drilling mud, which are typically noted when this formation is penetrated by the ari11 bit. A small amount of crude oil is presently being pumped from this formation. In the Ashdod area, the zohar has a thickness of approximately 50 to $100 \mathrm{~m}$.

The Karmon Shales, which underlie the zohar Formation, have a thickness of approximately $\mathbf{5 0}$ $m$. The top of the Shderot Dolomite, which underlies the Karmon Shales, is also porous, vuggy, and fractured, though less porous and less fractured than the Zohar Formation. Appreciable amounts of drilling fluid were also lost in the Shderot. Its total thickness is unknown. Because the Karmon Shales are marly and fissured, they probably do not act as an impermeable layer between the two dolomitic formations.

Both of the dolomitic formations have been tested, to some extent, for permeability and porosity. Drill stem tests were conducted on several isolated intervals during drilling. Analysis of these tests indicates for both formations an average permeability of 1 to $20 \mathrm{md}$. Cores were also obtained from these wells. Permeability and porosity measurements were made. Low matrix permeability measurements indicate that the formation is fractured. Porosities of 5 to 158 were measured. There have not been any tests to date from which the effective permeability and porosity of the combined fracture/matrix system can be calculated. The results of these will depend on the amount of fractures and vugs, as well as on the extent to which they are connected.

The geothermal gradient in the Ashdod area is close to normal $\left(\sim 30^{\circ} \mathrm{C} / \mathrm{km}\right)$. Figure 3 shows a nearly stabilized temperature profile obtained from Ashdod 3. At $2600 \mathrm{~m}$ depth, a temperature of $92{ }^{\circ} \mathrm{C} \pm 2{ }^{\circ} \mathrm{C}$ was measured. The temperature in Ashdod 4 , at the same depth, was $86^{\circ} \mathrm{C} \pm 2^{\circ} \mathrm{C}$.

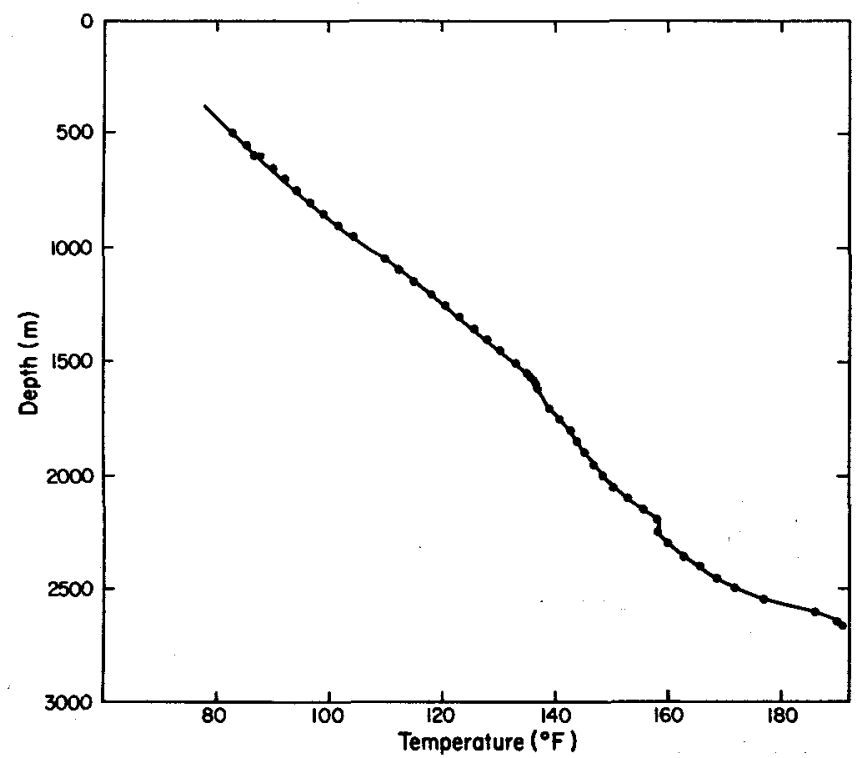

Figure 3. Temperature profile of Ashdod 3. [XBL 817-3357]
No truly representative sample of the brine has been obtained from these wells for chemical analysis. Analyses of samples obtained from the drill stem tests indicate that the fluid is a sodium chloride brine with a total dissolved solids content of approximately $100,000 \mathrm{ppm}$. No analyses were made for the amount of dissolved silica, hydrocarbons, or gases in the brine.

Little information is available from which the boundaries and size of the reservoir can be determined. To the west, along the coastline, there is a major lithologic change. It is not known if this is a structural change or merely a facies change. Nevertheless, it probably limits the extent of the resource to the west. Seismic studies Indicate that the subsurface is highly faulted, with faults trending both north-south and east-west. At the present time it is not known whether those features will act as barriers or conduits for fluid movement.

\section{PROGRAM PLAN}

The first phase of the program is to review all of the existing data pertinent to the evalua$t$ ion of the hydrothermal potential of the Ashdod area. These data have been identified and collected and are now being reviewed. Table 1 summarizes the available information.

The second phase is to design and implement a well-testing program in order to obtain a more complete understanding of the geohydrology and geochemistry of the system. The data obtained from these tests will be incorporated into a complete model of the system. Calculations will be made using analytical and numerical methods to evaluate the potential of the reservoir and determine the optimal well location (production and reinjection) and development scheme.

Concurrent with this work, the Desalination Project will assess the viability of using the hydrothermal resource. Key parameters include brine temperature, brine chemistry, well productivity, pumping costs, and proximity of the resource to the desalination plant. Estimates indicate a cost of $\$ 4$ to $\$ 9 / 10^{6} \mathrm{kcal}$ (J. Finke, personal communication, 1981). Approximately $75 \times 10^{6} \mathrm{kcal} / \mathrm{hr}$ is needed to operate the desalination plant.

\section{STATuS}

During well completion, workover, and subsequent injection tests, the fractures near the well bore have become clogged with drilling mud and, possibly, swelling clays. Laboratory studies will be undertaken to evaluate the most promising method of recovering the near-wellbore permeability. Most likely, a large-scale acid treatment will be required. After the acid treatment, a six-week production/interference test is planned from which the hydro$\log$ ic properties of the formations can be determined. Fluid and gas chemistry will also be analyzed to evaluate potential scaling and corrosion problems. 
Table 1. Summary of available data on the Ashdod area.

GEOLOGIC

Drill cutting analysis

Core analysis

Correlation of geologic data between wells

Electric and nuclear logs

WELL DESCRIPTION

Drilling records (Hebrew)

Completion records

Workover description of Ashdod 3 and 4

TEMPERATURE

Temperature surveys on Ashdod 3 and 4

Temperature data from drill stem tests on Ashdod 1, 2, 3, 4, 5, 6

GEOPHYS ICAL

Interpretation of geophysical surveys

HYDROLOGIC

Interpretation of drill stem test data on Ashdod 1, 2, 3, 4, 5, 6

Injection tests on Ashdod 3, 4, 5

Airlift test on Ashdod 3

Permeability and porosity measured from cores in Ashdod 1, 2, 3, 4, 5, 6

CHEMICAL

Analysis of brine from drill stem tests on Ashdod 1, 2, 3, 4, 5

\section{ACKNOWLEDGMENTS}

This project provides a unique opportunity in several ways. First, one of the intentions of this project is to demonstrate that low- to moderate-temperature hydrothermal resources may be practical for large direct-heat applications. It is a special case for which the application (sea-water desalination) may fit the resource. Clearly, the economics of the project will depend heavily on the specific low-grade heat requirements of the desalination plant. Second, it is a pleasure to share in and benefit from the knowledge gained by the international scientific community.

Thanks are due to L. Kolfman, A. Peled, and J. Finke of the U. S.-Israel Desalination Project for their insight and help in gathering Informa- tion for this evaluation, and to A. Nercado of Tahal Consulting Engineers, Ltd., with whom many hours were spent discussing the project. Finally, thanks to $S$. Reed of Oak Ridge National Laboratory, who recognized that the Earth Sciences Division of the Lawrence Berkeley Laboratory could play a helpful role in the evaluation of the geothermal potential of the Ashdod area.

\section{REFERENCES CITED}

Kolfman, L., 1979. Geothermal potential of the southern coastal plain. The Israel Institute of Petroleum and Energy, Tel Aviv, Israel.

Rolfman, L., 1980. Possible utilization of the geothermal energy in the Ashdod area. The Israel Institute of Petroleum and Energy, Tel Aviv, Is rael. 


\section{THE BACA DEMONSTRATION PROJECT}

\section{G. S. Bodvarsson, M. Wilt, J. Delany, and C. F. Tsang}

The Baca geothermal field is located in the Valles Caldera, New Mexico, approximately 55 miles north of Albuquerque (Fig. 1). The field is being developed for 50 me power production by the Union 011 company of California (Union) and the Public Service Company of New Mexico (PNM) in cooperation with the Department of Energy (DOE). To date, 24 wells have been drilled in the Redondo Creek area in the western part of the caldera; the locations of the wells are shown in Figure 2. The wells have encountered a high-temperature liquid-dominated reservoir (Union, 1978) with an overlying two-phase zone in one part of the reservoir (Grant and Garg, 1981). Only five of the wells in Redondo Creek are commercial producers, with a combined steam production capability of 15 to 20 MWe.

The role of Lawrence Berkeley Laboratory in the Baca project is to analyze the data made public by Union and to act as an advisor to DOE during the course of the project. This report summarizes this year's activities and describes the present status of the Baca project.

\section{GEOLOGICAL AND GEOPEYSICAL STUDY}

Stratigraphically the reservoir region can be described as a five-layer sequence (Fig. 3) which includes (1) caldera fill and the upper units of the Bandelier ash flow tuff; (2) the lower members of this tuff, which comprise the main reservoir rock at Baca; (3) the Pliocene Paliza Canyon volcanics; (4) Tertiary sands and Paleozoic sedimentary rocks; and (5) Precambrian granitic basement. Production is mainly controlled by fractures and faults which are ultimately related to activity in the Rio Grande Rift system. Geophysically, the caldera is characterized by a gravity minimum and a resistivity low. A 40-mgal gravity

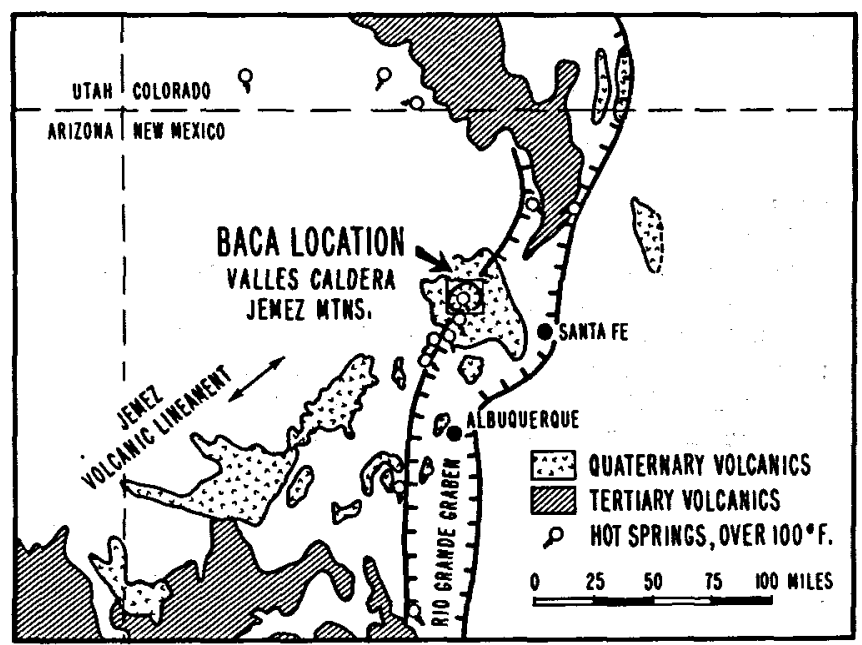

Figure 1. Regional location map for the Baca geothermal field, Jemez Mountains, New Mexico. [XBL 807-7259]

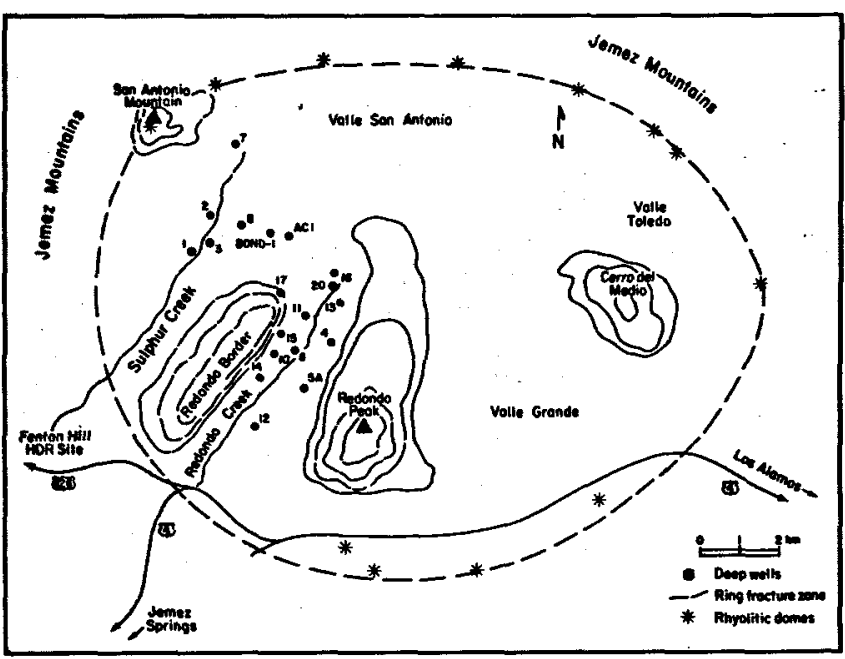

Figure 2. Site location map for the Baca geological and geophysical study.

[XBL 812-2618]

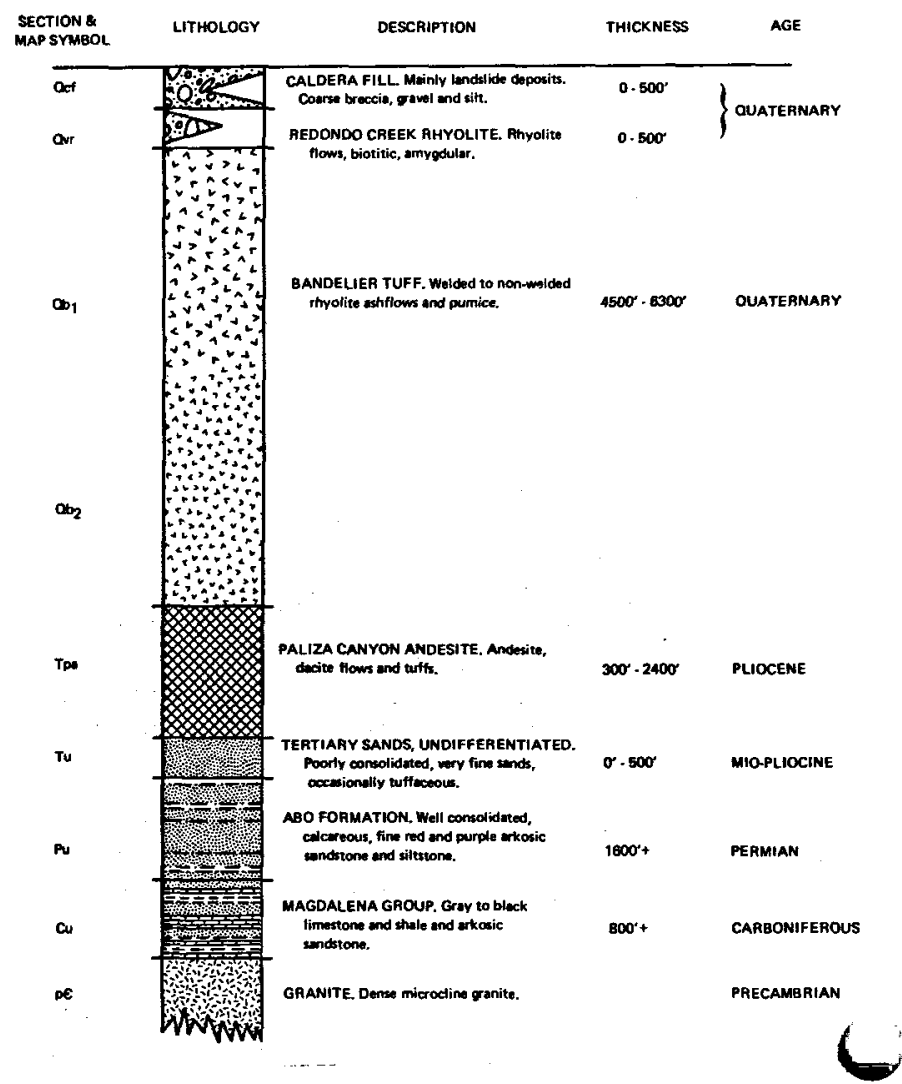

Figure 3. Ceneralized lithologic $\log$ as defined from deep geothermal wells at Baca.

[XBL 799-2904] 
minimum over the caldera is mostly due to the relatively low-density volcanics and sediments that fill the caldera and is probably not related to deep-seated magmatic sources. Two-dimensional gravity modeling indicates that the depth of Precambrian basement in Redondo Canyon is probably at least $3 \mathrm{~km}$ and may exceed $5 \mathrm{~km}$ in eastern parts of the caldera. Telluric and magnetotelluric surveys have shown that the reservolr region is associated with low resistivity and that a deep low-resistivity zone correlates well with the depth of the primary reservoir inferred from well data.

Telluric and magnetotelluric data have also identified possible fault zones in the eastern and western sections of the production region that may form boundaries to the Redondo Creek reservoir. These data also suggest that the reservolr region is located at the intersection of lineaments that trend north-south and northeast-southwest. Magnetotelluric results have indicated deep low resistivity at the western edge of the caldera which may be associated with deep hot fluids. On the basis of geophysical and well data, we make three estimates of reservoir dimensions depending on assumed reservoir parameters. The estimates of the aerial extent of the reservoir range from 10 to $30 \mathrm{~km}^{2}$, depending on whether the Sulphur Creek or the Valle Seco area is considered as containing deep geothermal resources (Fig. 4).

\section{GEOCHEMICAL STUDIES}

A preliminary study has been made of geochemical data released by Union for the Baca geothermal project. Partial fluid chemistry and dissolved gas analyses are avallable for only six producing wells. Chemical geothermometry calculations and salinity variations were used to determine probable fluid entry points and mixing relationships. These are summarized by the following conclusions:

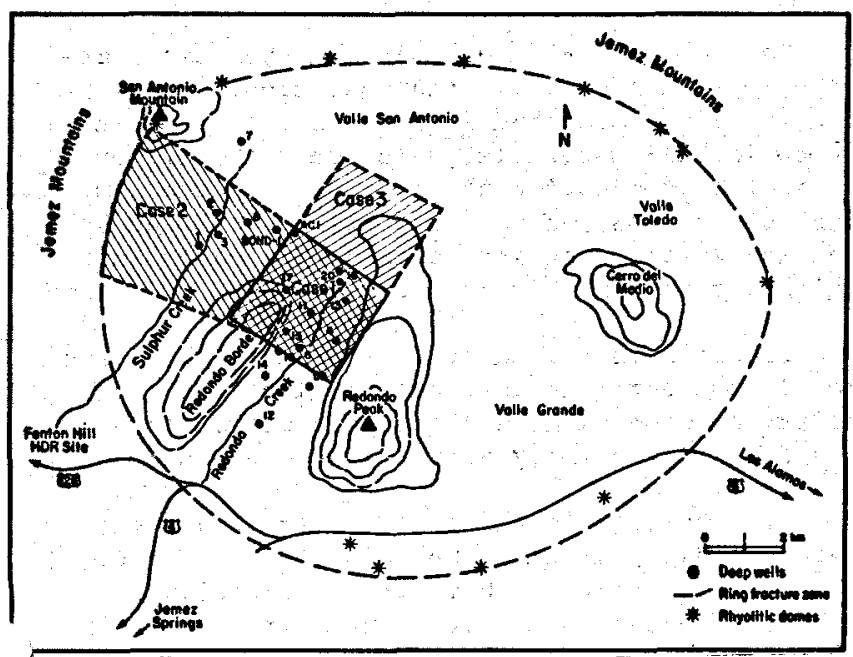

Figure 4. Map of the Baca field showing three possible cases for aerial boundaries of the deep geothermal field.
1. Fluid chemistry is in agreement with previous studies by Grant and Garg (1981) and Behrman and Knapp (1980), indicating that producing permeable horizons lie within the Bandeller Tuff and the Paliza Canyon Andesite.

2. Downhole temperatures estimated using the Na-K-Ca geothermometer (Fournier and Truesdell, 1973) can be directly correlated with temperatures at feed points located by Grant and Garg (1981) from downhole $P / T$ data.

3. Chemical geothermometer temperatures computed in this study are about 80 degrees lower than those reported by Union using the same data (Hartz, 1976).

4. Trends of decreasing $\mathrm{Cl}^{-}$content with increasing temperature suggest mixing of deep thermal waters with the more saline waters of a shallow aquifer.

5. Baca well 22 has distinctly different chemistry, indicating that it may not be in chemical communication with other producing wells.

\section{Modeling Studies}

The first simulation studies of the Baca reservolr were completed in early 1980 (Bodvarsson et al., 1980). The results indicated that the low transmissivity $(k H=6000 \mathrm{md}-\mathrm{ft}$ ) of the reservoir made it questionable whether 50 Mwe could be produced from the field for a period of $30 \mathrm{yr}$. A second simulation study of the Baca reservoir is underway. Thls study focuses on the nature of the fractures in the reservoir, using the MINC method, recently developed at IBL (Pruess and Narasimhan, 1981). Problems addressed are longterm deliverabilities of the wells and overall fluid and heat flow in the reservolr during exploitation. Recent work by Grant and Garg (1981) and Behrman and Knapp (1980) on the fracture/ fault system at Baca will be used in these simulations.

\section{REFERENCES CITED}

Behrman, P. G., and Knapp, R. B., 1980. Structure of the Redondo Creek area, Baca project: Implications concerning the nature of permeability and control on production. Internal Report No. NJSO-023, Union o1l Company of callfornia.

Bodvarsson, G. S., Vonder Haar, S., Wilt, M., and Tsang, C. F., 1980. Preliminary estimation of the reservoir capacity and the longevity of the Baca geothermal field, New Mexico. Paper SPE-9273, SPE-AIME Conference, Dallas, September 21-24, 1980.

Fournier, R. O., and Truesdell, A. H., 1973. An empirical $\mathrm{Na}-\mathrm{K}-\mathrm{Ca}$ geothermometer for natural waters. Geochimica et Cosmochimica Acta, v. 37. p. 1255-1275.

Grant, M. A., and Garg, S. K., 1981. Interpretation of downhole data from the Baca geothermal field, DOE/ET/27163-12, May 1981.

Hartz, J. D., 1976. Geothermal reservoir evaluation of the Redondo Creek area, Sandoval County, New Mexico. Union 011 Company Internal Report. 
Pruess, R., and Narasimhan, T. N., 1981. On fluid reservoirs and the production of superheated steam from fractured, vapor dominated geothermal reservoirs. (Submitted to Journal of Geophysical Research, 1981).
Union Oil Company of California and Public Service $C$. of New Mexico, 1978. Geothermal demonstration plant. Technical and management proposal to DOE, Open File Report VII.

\title{
INJECTION OF COLD WATER INTO GEOTHERMAL RESERVOIRS
}

\author{
G. S. Bodvarsson, C. F. Tsang, K. Pruess, and M. J. O'Sullivan
}

Reinjection of geothermal wastewater is gradually becoming a preferred means of waste disposal. At present, continuous reinjection is practiced at The Geysers, California; Ahuachapan, El Salvador; Mak Ban, Philippines; and five Japanese geothermal fields (Otake, Onuma, Onikobe, Hatchobaru, and Kakkonda). Small-scale reinjection tests have been reported at a number of geothermal fields, e.g.. Baca, New Mexico; East Mesa, California; Larderello, Italy; Cerro Prieto, Mexico; Broadlands, New Zealand; and Tongonan, Philippines. The increasing interest in reinjection undoubtedly results from growing environmental concerns regarding toxic minerals (e.g., boron, arsenic) present in geothermal wastewater.

The danger in employing reinjection is the possibility that the colder water will prematurely break through from its zone around the injection well into the production region and thus drastically reduce the efficiency of the operation. The movement of the cold water (thermal front) in porous media type reservoirs is fairly well known from theoretical studies by various investigators. However, fluid movement in most geothermal reservoirs (except those in the Imperial valley) is controlled by fractures, a more complicated situation. It is generally belleved that the cold water will advance very rapidly through the fractures and break through prematurely at the production wells.

Our objective has been to investigate the advancement of the thermal front during injection into a fractured reservoir system. The system under consideration consists of equally spaced horizontal fractures intersecting an injection well. Analytical and numerical studies are designed to address the important question of how fractures affect the movement of the thermal front during injection. Fundamental studies related to this problem have been reported by various researchers (Romm, 1966; Bodvarsson, 1969; Gringarten et al., 1975; Rasameyer and Schroeder, 1975; and Bodvarsson and Tsang, 1980).

\section{BASIC MODEL}

The physical model consists of an injection well that fully penetrates a reservoir with $n$ equally spaced horizontal fractures (Fig. 1). The fractures are all identical, have a constant aperture $b$, and extend to infinity. The injection rate, $q_{t}$, is assumed to be constant, and the same fluid mass flow rate, $q$, enters each fracture $\left(q_{t}=n \cdot q\right)$. Gravity effects are neg-

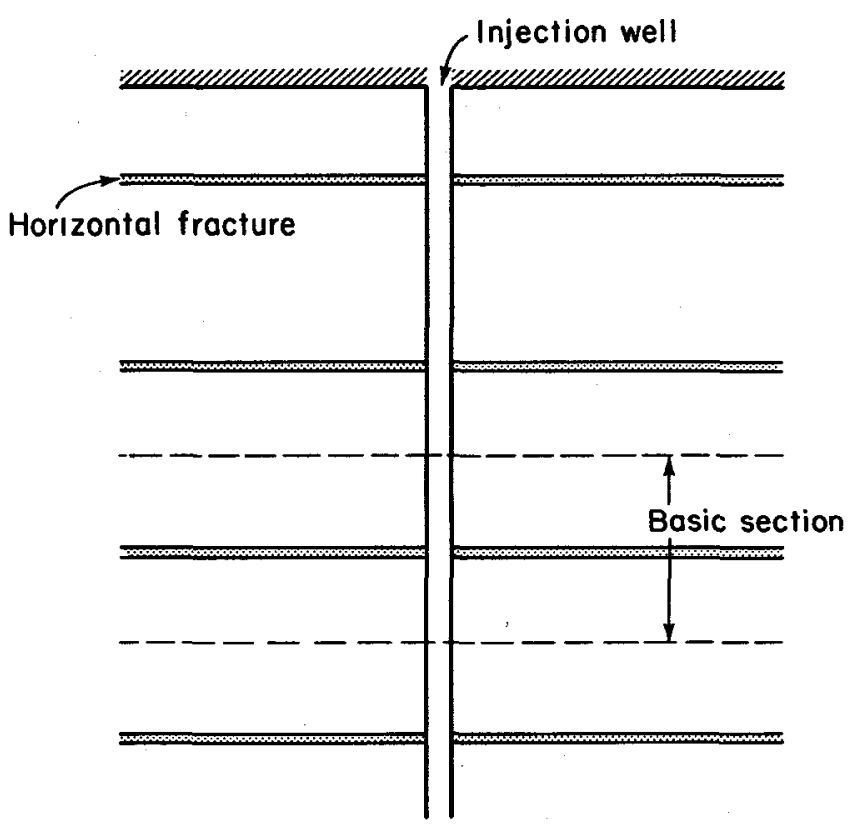

Figure 1. Basic model of an injection well penetrating a reservoir with equally spaced horizontal fractures.

[XBL 805-7081]

lected, and, because of symmetry, only the basic section specified in Figure 1 need be considered.

Both analytical and numerical techniques are used in this study. In the analytical work, the rock matrix associated with the fracture is assumed to be impermeable, hence only the effects of thermal conduction are present. In the numerical study, most of the assumptions employed in the analytical work are relaxed, and cases in which the rock matrix is permeable are considered.

Figure 2 is a schematic diagram of the basic model considered in the analytical study. Besides the general assumptions discussed above, the following primary assumptions are made:

1. The flow in the fracture is steady and purely radial, with the well located at $r=0$. The fracture aperture $b$ is at an elevation of $z=0$, with the rock matrix extending verticaliy to $z= \pm D$.

2. Thermal equilibrium between the fluid and the solids in the fracture is instantaneous. 


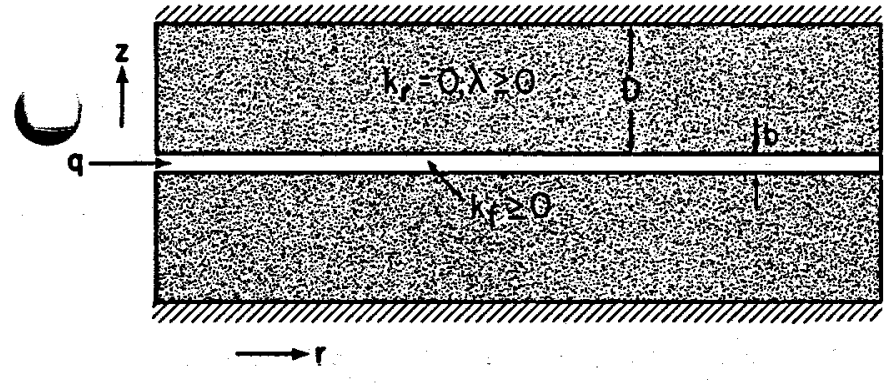

Figure 2. Schematic of analytical model.

[XBL 815-2968A]

Furthermore, horizontal conduction in the fracture is neglected, and temperature in the vertical direction is uniform (Infinite vertical thermal conductivity).

3. The rock matrix above and below the fracture is impermeable. Horizontal conduction is neglected, and the vertical thermal conductivity is finite. Heat flow boundaries at $z= \pm D$ are assumed to be no flow.

The differential equation governing the fluid temperature in the fracture can be derived by performing an energy balance on a control volume in the fracture. The derivation is similar to those reported by Lauwerier (1955), Bodvarsson (1969). and Gringarten et al. (1975), and will not be discussed here.

\section{ANALYTICAL STUDIES}

A solution for the temperature field can be obtained in the Laplace domain. However, because analytical inversion from the Laplace domain to real space is not possible, a numerical inverter was used. The inverter was developed by stehfest (1970), and for this problem it gave results accurate within 0.78 .

Figures 3 and 4 show the thermal diffusion from the fracture to the rock matrix for $\theta \leqslant 10^{-2}$ and $\theta \geqslant 100$, respectively. The dimensionless parameter $\theta$ represents the ratio of the energy potential of the fracture to that of the rock. Low values of $\theta$ indicate negligible energy content in the fracture, and large values correspond to negligible energy content in the rock. For the problem at hand, $\theta$ will most likely be less than $10^{-2}$ for all practical purposes.

In Figures 3 and 4 , each plotted line indicates the location of the thermal front at the specified dimensionless time. The figures show that during cold water injection into the fractured rock, the thermal front will advance very rapidly along the fracture at early times, as only a small amount of heat is obtained from the rock. Later on, however, as the available surface area for heat transfer from the rock to the fracture increases, the rate of advancement of the thermal front along the fracture decreases, a the cold front starts to penetrate the rock watrix. Eventually, the thermal front in the rock matrix catches up with the thermal front in the fracture at a time corresponding to $\tau \simeq 1.0$,

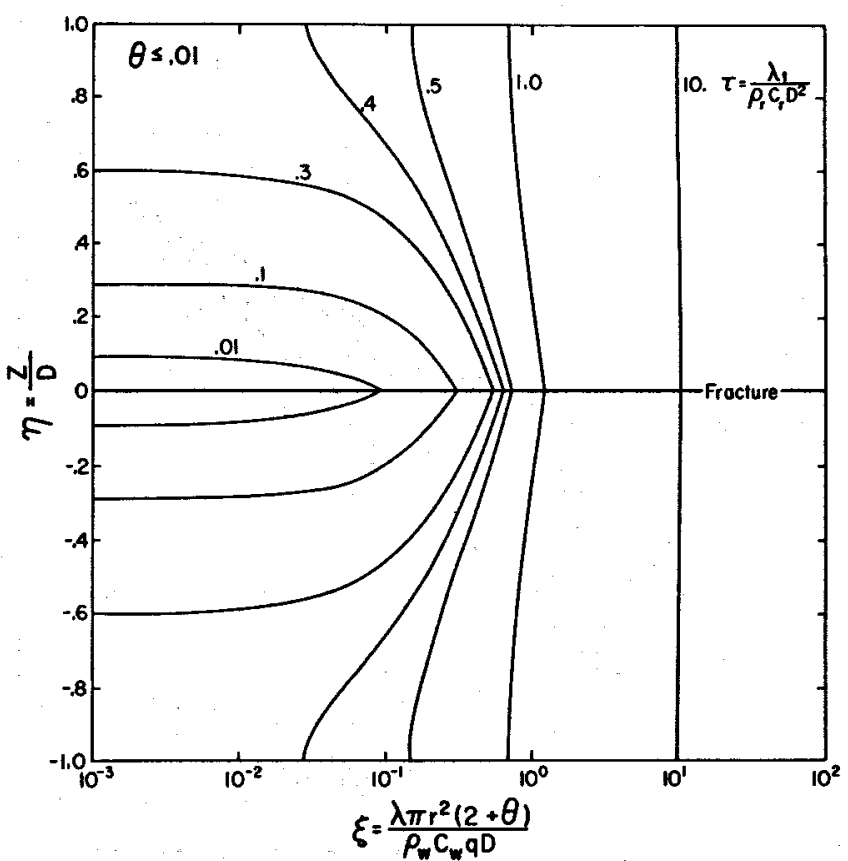

Figure 3. Plots of thermal fronts at various dimensionless times $\tau$ for $\theta<0.01, \eta$ is dimensionless vertical distance, and $\xi$ is dimensionless advancement along the fracture. [XBL 815-2951]

and after that a uniform energy-sweeping mechanism will prevail.

The rate of cold water advancement along the fracture is of course one of the major concerns in the present problem. In Figure 5, type curves representing the movement of the thermal front in

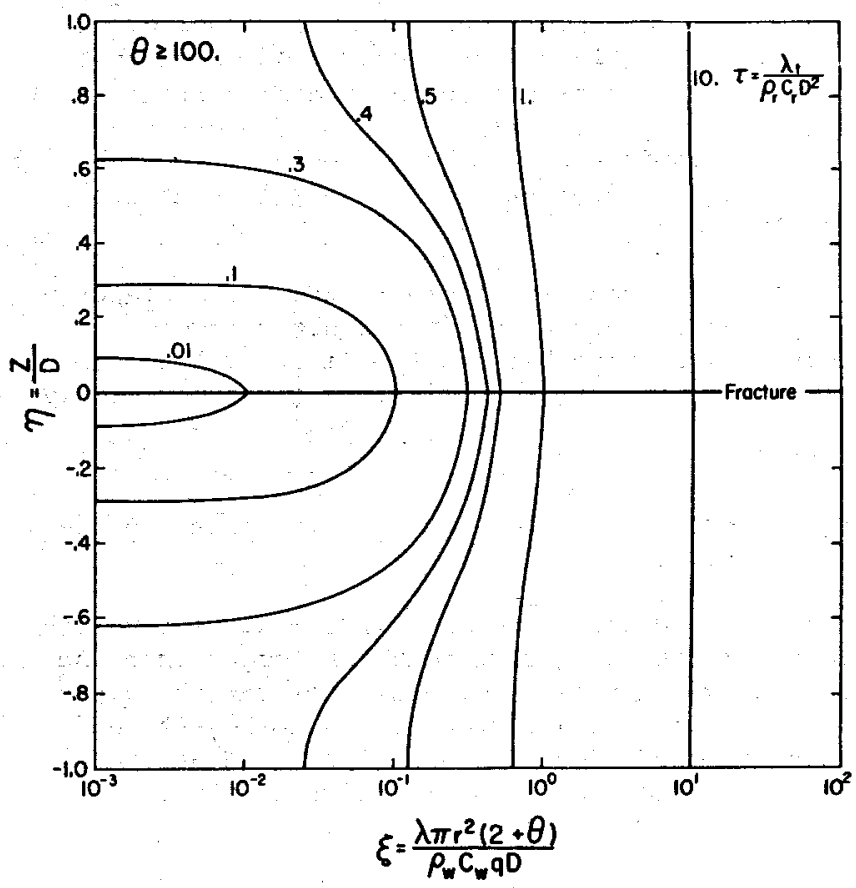

Figure 4. Plots of thermal fronts at various dimensionless times $\tau$ for $\theta>100$. [XBL 815-2952] 


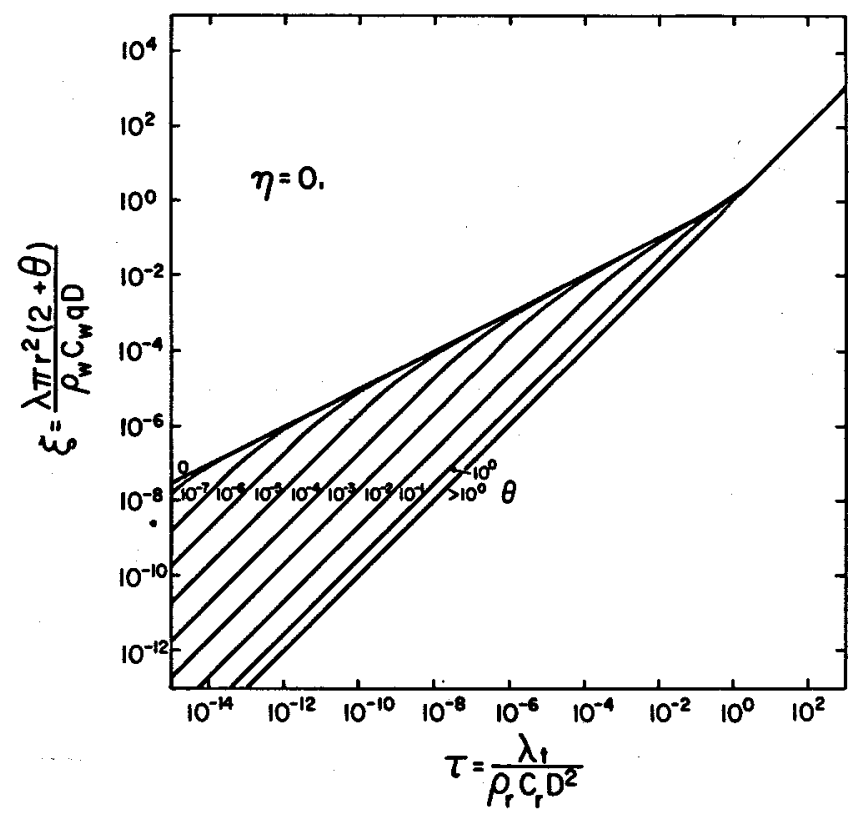

Figure 5. Type curves for the movement of the thermal front in the fracture for various values of $\theta$. [XBL 815-2950A]

the fracture $(\eta=0)$ are given for various values of $\theta$. At early times, the effects of heat conduction to cap rock and bedrock are negligibles consequently, a piston-like displacement occurs in the fracture. In this case the advancement of the thermal front along the fracture is controlled by $t / r^{2}$.

At intermediate times, the rock will start to conduct heat to the fracture and consequently slow the advancement of the cold water front along the fracture. This is evident in Figure 5 by the convergence of each $\theta$ curve to the mother curve $(\theta=0)$. The slope of the curve indicates that time $t$ is proportional to the radial distance to the fourth power. This indicates the power of the heat conduction and how it effectively retards the advancement of the thermal front along the fracture.

As is evident in Figure 5 , the $\theta$ dependence no longer exists at large dimensionless times, so that the relation between the dimensionless time $\tau$ and the dimensionless distance $\xi$ becomes simply

$\tau=\xi$

Equation (1) holds for both the fracture and the rock matrix.

The transition from the intermediate-time solution to the long-time solution occurs when the conductive heat flow from the rock matrix to the fracture becomes affected by the no-heat-flow boundary condition at $n=1$ (insulated at $z=D$ ). The transition occurs at the time and location given by the following equation:

$\tau=\xi=\frac{(2+\theta)^{2}}{4.396}$

NUMERICAL STUDIES

In addition to the analytical work discussed above, parallel numerical studies were carried out. The objective of the numerical studies is twofold:

1. To study the importance of the assumptions made in the analytical work.

2. To extend the analytical work to cases where the rock matrix is permeable.

Only a brief summary of the results is given here (for details, see Bodvarsson and Tsang, 1981).

The numerical simulation studied shows that the only critical assumption made in the analytical work is that of neglecting horizontal conduction in the cap rock and bedrock. Horizontal conduction, however, is important only after uniform sweep conditions are reached. A method of including horizontal conduction in calculations of the thermal field is suggested in Bodvarsson and Tsang (1981).

Additional LBL simulation studies have been carried out for porous-media reservoirs (0'Sul1Ivan and Pruess, 1980; Schroeder et al., 1980). Schroeder and his co-workers studied injection into vapor-dominated reservoirs with emphasis on well-test analysis, the five-spot problem, and gravity segregation. O'sullivan and Pruess studied the five-spot problem for both vapordominated and 1iquid-dominated reservoirs. The general conclusions of these studies are that injection can significantly increase the energy recovery from geothermal reservoirs, and can be an effective means for maintaining the reservoir pressures.

\section{NOMENCLATURE}

b: Fracture aperture (m)

D: Thickness of rock matrix per fracture (equivalent to half the fracture spacing) (m)

ก:

$\lambda:$

$\phi:$

q:

$q_{t}:$

$\mathbf{r}$ :

pc:

T:
Dimensionless vertical distance, $\eta=z / D$

Thermal conductivity of rock matrix (J/m-s- ${ }^{\circ} \mathrm{C}$ )

Porosity (-)

The injection rate into each fracture $\left(\mathrm{m}^{3} / \mathrm{s}\right)$

Total injection rate $\left(\mathrm{m}^{3} / \mathrm{s}\right)$

Radial coordinate (m)

Volumetric heat capacity $\left(\mathrm{J} / \mathrm{m}^{3}-{ }^{\circ} \mathrm{C}\right)$ (Note that $\rho_{f} c_{f}=\phi \rho_{w} c_{w}+(1-\phi) \rho_{r} c_{r}$.

Time (s)

Temperature $\left({ }^{\circ} \mathrm{C}\right)$ 
$T_{T F}$ : The isotherm defined as the "thermal front," generally $T_{T F}=\left(T_{i}+T_{0}\right) / 2$

$\tau$ : Dimensionless time, $\tau=\frac{\lambda t}{\rho_{r} c_{r} D^{2}}$

$\theta$ : Dimensionless energy potential, $\theta=\frac{\rho_{f} c_{f} b}{\rho_{f} c_{r} D}$

$\xi$ : Dimensionless distance, $\xi=\frac{\lambda \pi r^{2}(2+\theta)}{\rho_{w} c_{w} q \cdot D}$

z: Vertical cooräinate (m)

Subscripts

f: Fracture
I: Rock matrix
w: Liquid water

REFERENCES CITED

Bodvarsson, G., 1969. On the temperature of water flowing through fractures. Journal of Geophysical Re search, v. 74, no. 8, p. 1987-1992.

Bodvarsson, G. S., and Tsang, C. F., 1980. Injection into a fractured geothermal reservoir. Transactions, Geothermal Resources Council, v. 4, p. 393-396.

Bodvarsson, G. S., and Tsang, C. F., 1981. Injection and thermal breakthrough in fractured geothermal reservoirs. Jour- nal of Geophysical Research, v. 82, no. B2, p. 1031-1048.

Gringarten, A. C., Wither spoon, P. A., and Onishi, Y., 1975. Theory of heat extraction from fractured hot dry rock. Journal of Geophysical Re search, v. 80, no. 8, p. 1120-1124.

Kasameyer, P., and Schroeder, R., 1975. Thermal depletion of liquid-dominated geothermal reservoirs with fracture and pore permeability. Lawrence Livermore National Laboratory Report UCRL-77323.

Lauwerier, H. A., 1955. The transport of heat in an oil layer caused by the injection of hot fluid. Applied Scientific Re search, Sect. A., v. 5, p. 145 .

O'Sullivan, M. J., and Pruess, K., 1980. Numerical stuales of the energy sweep in five-spot geothermal production/injection systems. In proceedings, sixth Workshop on Geothermal Re servoir Eng ineering, Stanford University, Stanford, California, December 16-18, 1980. Lawrence Berkeley Laboratory Report LBL-12166.

Romm, E. S., 1966. On one case of heat transfer in fractured rock. All-Union Institute for Scientific Research and Gological Exploration of Petroleum, U.S.S.R., preprint.

Schroeder, R. C., O'Sullivan, M. J., Pruess, R., Celati, R., and Ruffilli, C., 1980. Reinjection studies of vapor-dominated systems. Lawrence Berkeley Laboratory Report LBL-12175. (Presented at the Italian-American Workshop, Berkeley, California, October 20-24, 1980.)

Stehfest, H., 1970. Numerical inversion of Laplace transforms. Communications of AO, v. 13, p. 44-49.

\title{
MODELING OF FRACTURE RESERVOIRS
}

\author{
K. Pruess, T. N. Narasimhan, and G. S. Bodvarsson
}

Most geothermal reservolrs are highly fractured systems. The fractures provide conduits through which fluid (and heat) can flow at rates which are sufficiently large to be of commercial interest. The rock matrix usually has a low flow capacity, but it stores most of the heat and fluid reserves. The rate at which heat and fluid can be transferred from the matrix to the fractures is therefore of cruclal importance for an assessment of reservoir longevity and energy recovery. Yet traditional approaches to geothermal reservolr evaluation and analysis have employed a "porous medium" approximation, which amounts to assuming instantaneous (thermal and hydrologic) equilibrium between fractures and matrix.

We have developed a new numerical modeling technique, termed the Multiple Interacting Con-inua" Method (MINC), which treats transient juid and heat flow within the matrix and fracZures. The MINC approach is considerably more general and broader in scope than any previous models discussed in the literature. Conceptu-

ally, it is a generalization of the double-porosity" method, as developed by Barenblatt et al. (1960), Warren and Root (1963), and others. In contrast to the double-porosity method, we do not Invoke quasisteady or analytical approximations for interporosity flow, and we allow for nonisothermal processes, including phase transitions.

For simplicity we considered an ldealized fractured reservoir with three perpendicular sets of infinite, plane, parallel fractures (Fig. 1). The MINC method is applicable to systems with irregular fracture distributions, but a simplified geometry is better suited for a discussion of the basic concepts. Modeling of fluid and heat flow in a fractured reservoir like that shown in Figure 1 requires that the flow region be part 1 tioned into a number of "suitably" chosen volume elements. The partitioning must be made in such a way that the fluid and heat fluxes between volume elements can be expressed in terms of average values of thermodynamic variables in the elements. This principle leads us to require approximate 


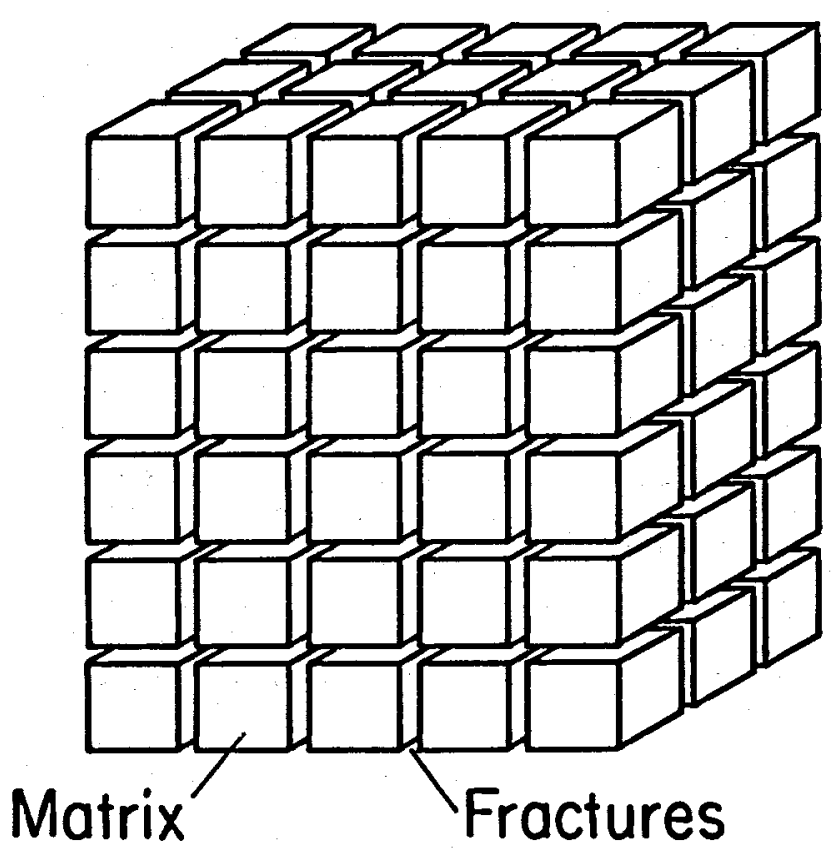

Figure 1. Idealized model of a fractured porous medium.

[XBL 813-2725]

thermodynamic equilibrium within each element at all times. Assuming further that thermodynamic conditions in the rock matrix depend primarily upon the distance from the nearest fracture, we arrive at a partitioning with nested elements, as shown in Figure 2 for the two-dimensional case.

Modeling of heat and fluid flow in such a system of nested volume elements, or interacting continua, is straightforward within the framework of the integral finite-difference method (IFD; Narasimhan and witherspoon, 1976). We have developed a pre-processor program which generates all geometric parameters needed as input to the simulator. The partitioning scheme outlined above can be further generalized to volume elements of arbitrary shape and size; this is discussed in Pruess and Narasimhan (1982), which also gives complete formulas for element volumes, interface areas, and nodal distances.

The MINC method can be immediately implemented with any simulator whose formulation is based on the IFD method. All that is needed is preprocessing of the geometrical information, and no changes are necessary in the simulator itself. We have used the MINC method in conjunction with our two-phase geothermal reservoir simulator SHAFT79 (Pruess and Schroeder, 1980). and with the geothermal version of our new compositional simulator MULROM. The method was validated by comparison with the analytical double-porosity solution of Warren and Root. Subsequently, several applications were made to fractured geothermal reservoirs.

On the basis of this method, interesting new effects are predicted for fractured reservoirs with boiling. Under two-phase conditions, there is a one-to-one correspondence between pressure

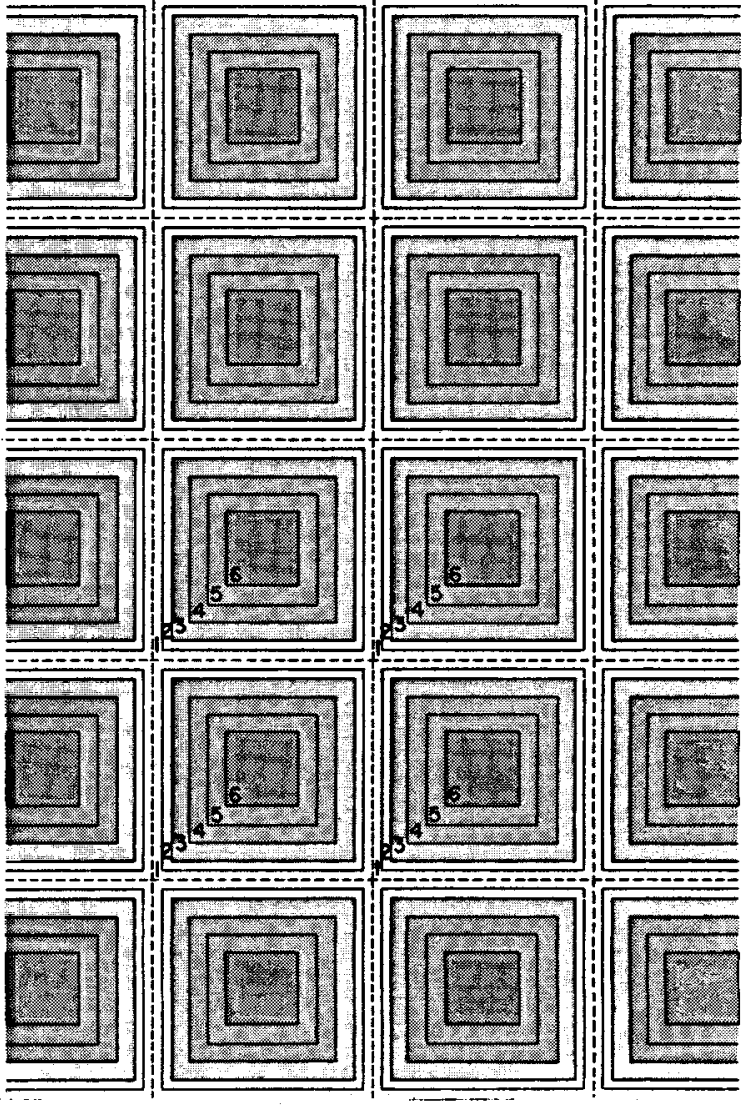

Figure 2. Basic computational mesh for fractured porous media (two-dimensional case).

[XBL 813-2753]

gradients (which drive fluid flow) and temperature gradients (which drive conductive heat flow). If matrix permeability is low, conductive heat transfer into the fracture system can become very significant in comparison with convective heat transfer. This can cause a substantial increase in the flowing enthalpy in the fractures. Our calculations show that it is possible that superheated steam is discharged into the fractures, even though liquid water is mobile and flowing in the matrix. Figure 3 shows our predicted enthalpies for a typical well at The Geysers for different values of matrix permeability, assuming a rather large mobile water saturation of 708 in the matrix (Pruess and Narasimhan, 1981). Thus heat conduction can have a crucial effect on fractured reservoir behavior even on a short time scale (minutes or hours). Conventional wisdom has held that heat conduction is too slow a process to be significant during the productive life of a geothermal reservoir. The study presented in Pruess and Narasimhan (1981) concludes that vapor-dominated reservoirs may be essentially completely water-saturated in the matrix in their natural state. This implies that fluid reserves may be considerably greater (by a factor of 2 to 3) than has been generally believed for such systems.

Further applications of the MINC method have explored the depletion behavior of boiling fractured geothermal reservoirs for different values 


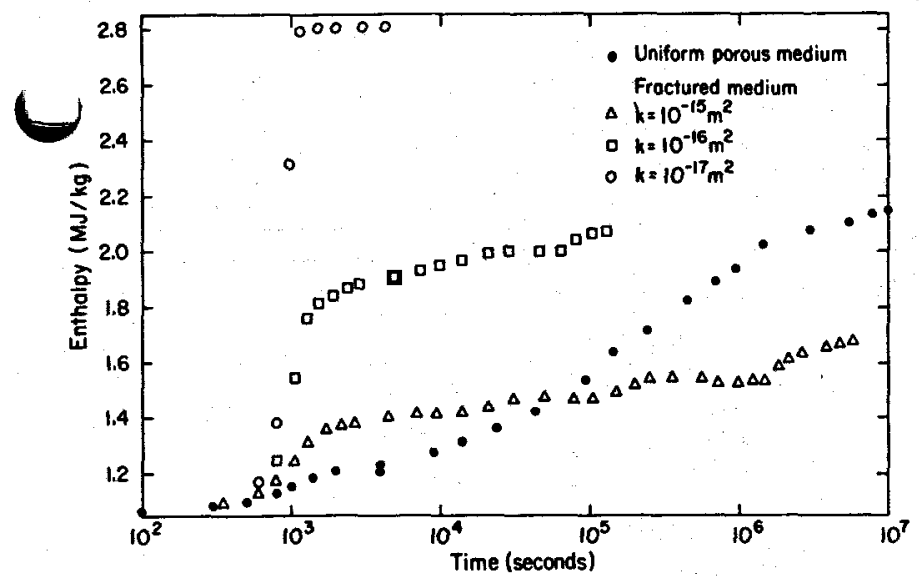

Figure 3. Enthalpy transients for a well in a fractured vapor-dominated reservoir.

[XBL 816-3276]

of fracture spacing and matrix permeability. It was found in these studies (Pruess, 1981; Pruess and Narasimhan, 1982) that reservoic longevity and energy recovery depend much more strongly upon matrix permeability than upon fracture spacing. Full reinjection was shown to be essentlal for pressure maintenance in fractured liquid-dominated reservoirs with low permeability; and excellent thermal sweeps appear possible.

We have also performed numerical simulation studies of constant pressure production from fractured single-phase reservoirs. The results show that after a short initial period dominated by well-bore and fracture storage, a plot of dimensionless flow rate versus dimensionless time exhibits a characteristic half-slope (1/2). The half-slope occurs when flow from the rock matrix into the fracture is linear; this half-slope is similar to that observed during a constant-flowrate testing of fractured reservoirs. The linear flow data can be used to determine hydraulic parameters of the rock matrix, whereas the early data are useful in determining fracture aperture and length.

\section{REFERENCES CITED}

Barenblatt, G. E., Zheltov, I. P., and Kochina, I. N., 1960. Basic components in the theory of homogeneous liquids in fissured rocks. Journal of Applied Mathematics (USSR), v. 24, no. 5, p. 1286-1303.

Narasimhan, T. N., and Witherspoon, P. A., 1976. An integrated finite difference method for analyzing fluid flow in porous media. Water Resources Research, v. 12, no. 1, p. 57-64.

Pruess, K., 1981. Heat transfer in fractured geothermal reservoirs with boiling. Presented at the Seventh Workshop on Geothermal Reservoir Engineering, Stanford, Californla, December 1981.

Pruess, K., and Narasimhan, T. N., 1981. On fluid reserves and the production of superheated steam from fractured, vapor-dominated geothermal reservoirs. Lawrence Berkeley Laboratory Report LBL-12921. (Submitted to Journal of Geophysical Research.)

Pruess, K., and Narasimhan, T. N., 1982. A practical method for modeling heat and fluid flow in fractured porous media. Presented at the Sixth SPE Symposium on Reservoir Simulation, New Orleans, Louisiania, SPE-10509.

Pruess, K., and Schroeder, R. C., 1980. SHAFT79 user's manual. Lawrence Berkeley Laboratory Report IBL-10861.

Warren, J. E., and Root, P. J., 1963. The behavior of naturally fractured reservoirs. Society of Petroleum Engineers Journal, v. 3, no. 3 , p. 245-255.

\section{GENERIC STUDIES OF GEOTHERMAL RESERVOIR BEHAVIOR}

\section{K. Pruess, G. S. Bodvarsson, M. J. Lippmann, and A. H. Truesdell*}

The characteristics and behavior of geothermal reservoirs are often strongly influenced by geologic and hydrologic conditions that are peculiar to a given site. Site-specific detail can render a reservoir description and analysis so complex that it becomes difficult to Identify the important physical mechanisms and parameters which govern reservoir behavior. Some important insight into the evolution of geothermal reservoirs under natural or man-made conditions can be gained from a study of schematic, 1dealized representations of such reservoirs. Hypothetical reservoir models can be designed to incorporate the more significant features of certain types of geothermal reservoirs while maintaining a simlicity which facilitates their quantitative debription and analysis. Generic studies are particularly useful for two-phase geothermal reservoirs with coexisting water and steam. The presence of two phases with different densities and heat contents can give rise to peculiar and sometimes surprising phenomena, which can be conveniently explored by means of computer simulation. In what follows, we shall summarize two such simulation studies. One addresses the problem of natural evolution of geothermal reservoirs over geologic time; the other examines energy recovery and reservoir longevity for different completion depths of production wells.

NATURAL EVOLUTION OF VAPOR-DOMINATED AYDROTHERMAL SYSTEMS

The natural state and the evolution of vapordominated hydrothermal systems have been the subject of considerable research and controversy (e.g., see the sumnary by Truesdell and white, 1973). We have used numerical simulation techniques to study the evolution of a simplified hypothetical model of a hydrothermal system over 
geologic time. Our model is not intended to be a representation of any particular geothermal system, but it was designed to incorporate the main features believed to be important in all geothermal systems (Fig. 1). The main permeable reservoir is overlain by a cap rock of lower permeability, through which it can communicate (by discharge, recharge, and heat conduction) with surface waters at ambient conditions. Initially, pressures are in hydrostatic equilibrium, and temperatures follow a typical "natural" gradient of $40^{\circ} \mathrm{c} / \mathrm{km}$ with depth. At time zero a powerful heat source at the bottom is switched on to initiate thermal convection. The system goes through a series of quite different and distinct flow patterns before reaching steady state after about 90,000 yr. The evolutionary phases are summarized in Table 1 ; a more detailed discussion is given in pruess and Truesdell (1980). One of the more interesting effects observed in the simulation is a lateral spreading of boiling, which had previously been hypothesized on the basis of geochemical evidence (D'Amore and Truesdel1, 1979).

Although our calculations were made for a simplified schematic model of a hydrothermal system, they do demonstrate many of the features inferred from the study of natural systems, including: (1) vertical counterflow of steam and water, with steam rising and condensate falling; (2) lateral movement of steam from the center toward the edges of the system; (3) condensation of steam due to upward conductive heat loss, with condensate draining downward to a liquiddominated zone where it flows toward a central zone of boiling; (4) an interface between a

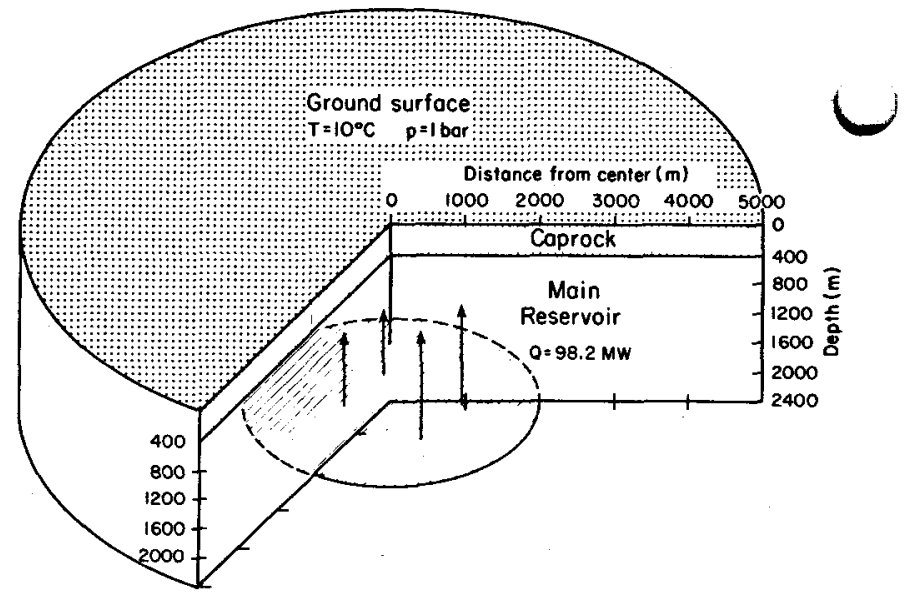

Figure 1. Model of a natural hydrothermal convection system (NHCS).

[XBL 803-6876A]

Table 1. Evolution of a vapor-dominated hydrothermal system.

shallow, liquid-saturated zone and a vapordominated zone that is at a temperature near the enthalpy maximum of saturated steam $\left(236^{\circ} \mathrm{C}\right)$; (5) boiling in the central part of the underlying liquid-dominated zone, with boiling rates increasing with depth to a maximum close to the bottom of the two-phase zone. The calculations also suggest that vapor-dominated reservoirs must have strong manifestations (zones of discharge or recharge), which observation is relevant for geothermal exploration.

Table 1. Evolution of a vapor-dominated hydrothermal system.

\begin{tabular}{|c|c|c|}
\hline Phase & Heat effects & Fluid flow \\
\hline Initial state & "Natural" heat flow & $\begin{array}{l}\text { No mass flow } \\
\text { (gravitational equilibrium } \\
\text { with surface waters) }\end{array}$ \\
\hline $\begin{array}{l}\text { "Dormant" state } \\
(0-300 \mathrm{yr})\end{array}$ & $\begin{array}{l}\text { Temperature rises above } \\
\text { heat source }\end{array}$ & $\begin{array}{l}\text { slow mass flow away } \\
\text { from heat source } \\
\text { (thermal expansion) }\end{array}$ \\
\hline $\begin{array}{l}\text { Evolution of } \\
\text { intense convection } \\
\text { above heat source } \\
(300-1000 \mathrm{yr})\end{array}$ & $\begin{array}{l}\text { Rapid increase in } \\
\text { temperatures upward } \\
\text { from heat source }\end{array}$ & $\begin{array}{l}\text { Rapid increase in mass flow } \\
\text { (positive feedbacks from } \\
\text { temperature-dependence } \\
\text { of viscosity) }\end{array}$ \\
\hline $\begin{array}{l}\text { Evolution of reservoir- } \\
\text { wide convection } \\
(1000-39,000 \mathrm{Yr})\end{array}$ & $\begin{array}{l}\text { Spreading of elevated } \\
\text { temperatures throughout } \\
\text { system }\end{array}$ & $\begin{array}{l}\text { slowly rearranging } \\
\text { "toroldal" flow pattern }\end{array}$ \\
\hline $\begin{array}{l}\text { Evolution of boiling } \\
(39,000-90,000 \mathrm{yr})\end{array}$ & $\begin{array}{l}\text { Stabilization of temperatures } \\
\text { (hence pressures) in } \\
\text { two-phase zones }\end{array}$ & $\begin{array}{l}\text { "Funnel-like" displacement } \\
\text { of convective upflow away } \\
\text { from two-phase zones, with } \\
\text { lateral spreading of boiling }\end{array}$ \\
\hline $\begin{array}{l}\text { Steady state } \\
\text { (after } 90,000 \text { yr) }\end{array}$ & $\begin{array}{l}\text { Surface heat loss equals } \\
\text { base heat inflow }\end{array}$ & Recharge equals discharge \\
\hline
\end{tabular}


ENERGY RECOVERY FROM GEOTHERMAL RESERVOIRS

Geothermal reservoirs are commonly several ilometers in thickness. When a thick reservoir is developed for production, one of the many decisions that have to be made is to what depth the production wells should be drilled. There are several benefits that can be derived from shallow completions, the most obvious being that the wells are cheaper. Also, shallow production may yield higher-enthalpy fluids. There appears to be a strong tendency among field developers to drill only as deep as necessary, and to complete a well as soon as good permeability and hot fluid entries are encountered. However, the benefits of shallow completions may be short-lived, and in the long run it may be more advantageous to produce from greater depth.

We have applied numerical simulation to study the relation between longevity of geothermal reservoirs and depth of the producing interval. The specific parameters used in our study were chosen to represent the olkaria reservoir in Kenya, East Africa (Bodvarsson et al., 1981). Olkaria is a thick, 1iquid-dominated reservoic of a rather common type, so that our results should be appl 1cable in other cases. Figure 2 shows the basic reservoir model and indicates the different producing intervals investigated in our study. We find that production from the vapor zone (case 1) gives rise to a rather localized depletion pattern. Fluid and heat reserves are tapped only

OLKARIA - basic model

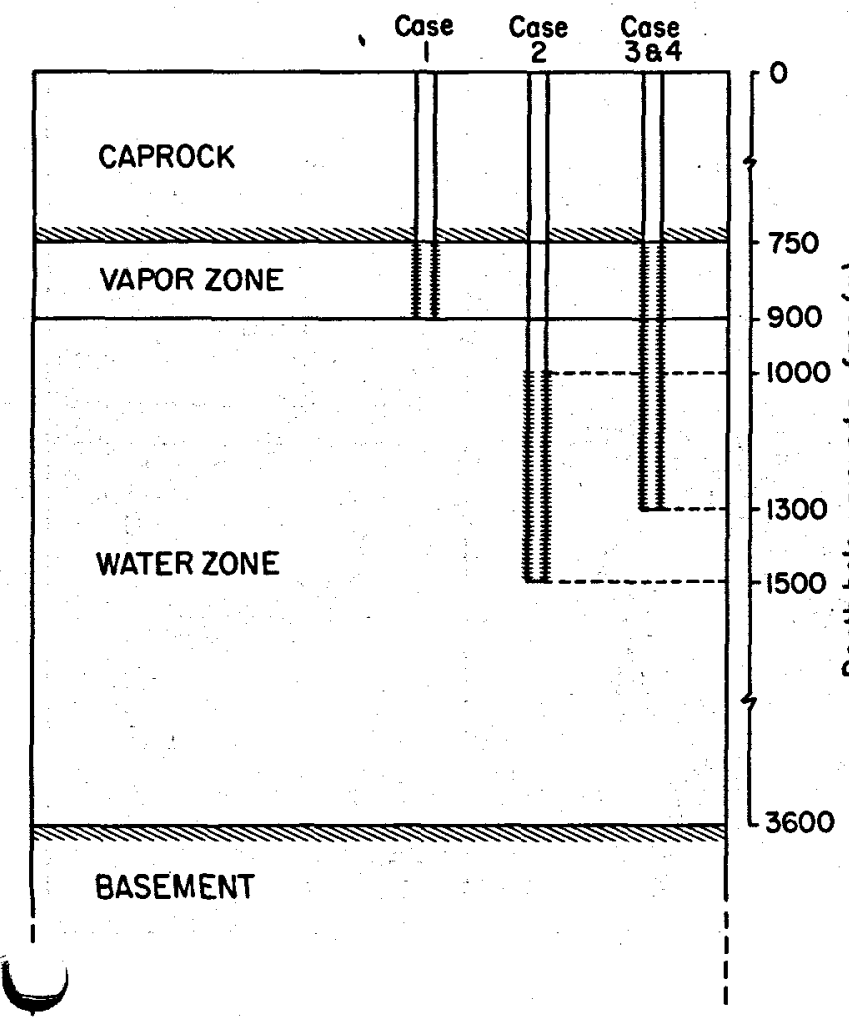

Figure 2. A schematic reservoir model of the olkaria geothermal field.

[XBL 814-2914] from the shallower portions of the reservoir, and pressures in the production zone decline rapidly. The steam requirements for a 45-MWe power plant $(120 \mathrm{~kg} / \mathrm{s})$ can be satisfied for about $20 \mathrm{yr}$. A completely different picture emerges in case 2 , where production is from the deeper, liquid-dominated zone. This gives rise to vigorous boiling, which rapidly spreads downward into zones of higher temperature and pressure. Subsequent$1 y$, large amounts of hot steam are driven upward by the large (approximately hydrostatic) vertical pressure gradients. This causes pressures and temperatures to decline at depth but to increase in shallower zones (Fig. 3). Such effects have actually been observed in New Zealand (Allis, 1979, Henley, 1979). In this case we are mining fluid and heat reserves from great depth, the driving force being the buoyancy of steam in a system with nearly hydrostatic pressure distribution. This process gives rise to a remarkably uniform reservoir depletion with maximum energy recovery and a predicted longevity of several hundred years. Similar behavior 1 s observed in case 3, where production is made from both vapor and liquid zones. The mechanism depends upon a sufficiently large vertical permeability. In case 4, vertical permeability was reduced by a factor of 10 (from the field-estimated value of $20 \mathrm{md}$ down to $2 \mathrm{md}$ ) in order to obtain a more conservative outlook on reservoir performance. Downward movement of the bolling front and upward buoyancy flow of steam are now substantially reduced. The reservoir is found to sustain 45 MWe

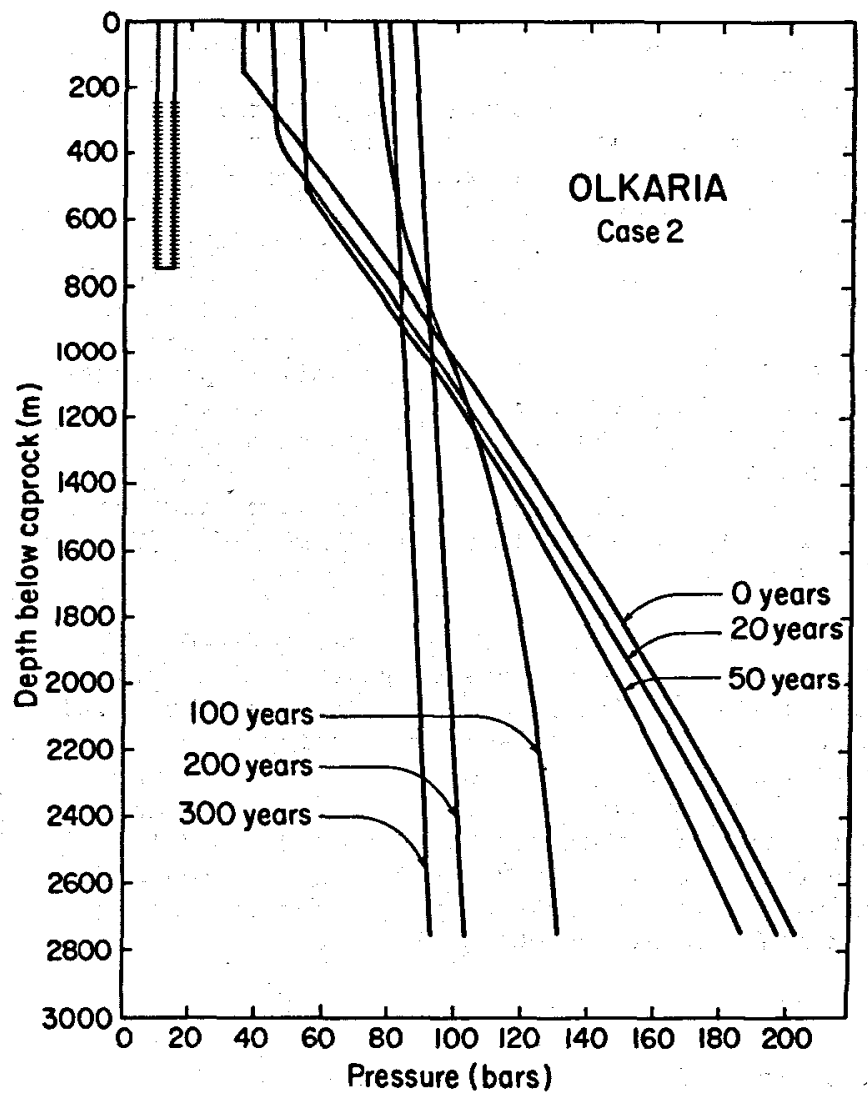

Figure 3. Pressure changes due to production from liquid zone (case 2).

[XBL 814-2919] 
for some $70 \mathrm{yr}$ in this case, which still is far better than could be achieved in the large permeability case with production from the steam zone only. This study clearly shows the great importance of vertical flow in bolling, liquid-dominated reservoirs. Production from deeper horizons can greatly improve the energy recovery from a geothermal reservoir, but the potential benefits depend strongly upon vertical permeabllity. Therefore, it is recommended that tests for vertical permeability should be made in geothermal reservoirs being developed for production.

*u. S. Geological Survey, Menlo Park, CA 94025.

REFERENCES CITED

Allis, R. G. , 1979. Changes in heat flow associated with exploration of the Wairakei geothermal field. In Proceedings, New Zealand Geothermal Workshop, University of Auckland, New Zealand, v. 1, p. 11-13.
Bodvarsson, G. S., Pruess, K., Lippman, M. J., and Björnsson, S., 1981. Improved energy recovery from geothermal reservoirs. Presented at the 56th Annual Fall Technical Conference and Exhibltion of the SPE; San Antonio, Texas, SPE-10312.

D'Amore, F., and Truesdell, A. H., 1979. Models for steam chemistry at Larderello and The Geysers. In Proceedings, Fifth Workshop on Geothermal Reservoir Engineering, Stanford, California, p. 283-297.

Henley, R. W.. 1979. Evolution of the Tauhara geothermal system. In Proceedings, New Zealand Geothermal Workshop, University of Auck1and, New Zealand, 1, p. 7-9.

Pruess, K., and Truesdell, A. H., 1980. A numerical simulation of the natural evolution of vapor-dominated hydrothermal systems. In Proceedings, Sixth Workshop on Geothermal Reservoir Engineering, Stanford, California, p. 194-203.

Truesdell, A. H., and White, D. E., 1973. Production of superheated steam from vapordominated geothermal reservoirs. Geothermics, v. 2, no. 3-4, P. 154-173.

\title{
SUBSIDENCE MODELING OF THE PLEASANT BAYOU GEOTHERMAL GEOPRESSURED REGION
}

\author{
.K. P. Goyal, T. N. Narasimhan, and S. P. Vonder Haar
}

The Pleasant Bayou prospect, a geothermal geopressured area, is located in Brazoria county, Texas. Deltaic sandstones of the Frio Formation, at a depth of about $14,000 \mathrm{ft}(4.27 \mathrm{~km})$, are found to have potential for a geothermal geopressured reservoir (Bebout et al., 1979). Two exploratory wells have been drilled by the $U$. $S$. Department of Energy (DOE), with a separation of $500 \mathrm{ft}$ (Fig. 1). The first well was drilled to a depth of $15,675 \mathrm{ft}(4.78 \mathrm{~km})$ and plugged at 8581 ft $(2.6 \mathrm{~km})$ because of hole instability problems. This well is now being used for shallow reinjection (Rodgers, 1981). The second test well (GCO-DOE PB 2) is drilled to a depth of 16,500 ft $(5.03 \mathrm{~km})$ with a $60-\mathrm{ft}$ perforated production interval between $14,644 \mathrm{ft}(4.46 \mathrm{~km})$ and 14,704 ft $(4.48 \mathrm{~km})$.

The Pleasant Bayou area is part of a deep sedimentary basin traversed by growth faults. The northwest side of Brazoria fairway is bounded by an extensive fault system trending northeastsouthwest at a distance of about 4 to $8 \mathrm{~km}$ from the wells (Bebout et al., 1979). Faults trending northeast-southwest are also found southeast of the test wells. For purposes of subsidence modeling, a circular area with a radius of 5 miles and centered at the DOE wells is considered.

Five geologic cross sections, shown as A-A', $B-B^{\prime}, C-C^{\prime}, D^{\prime} D^{\prime}$, and $E-E^{\prime}$, were prepared from well logs of about 45 petroleum wells. As an example, Figure 2 shows a section along line A-A'. The upper unit, consisting of mixed shales and

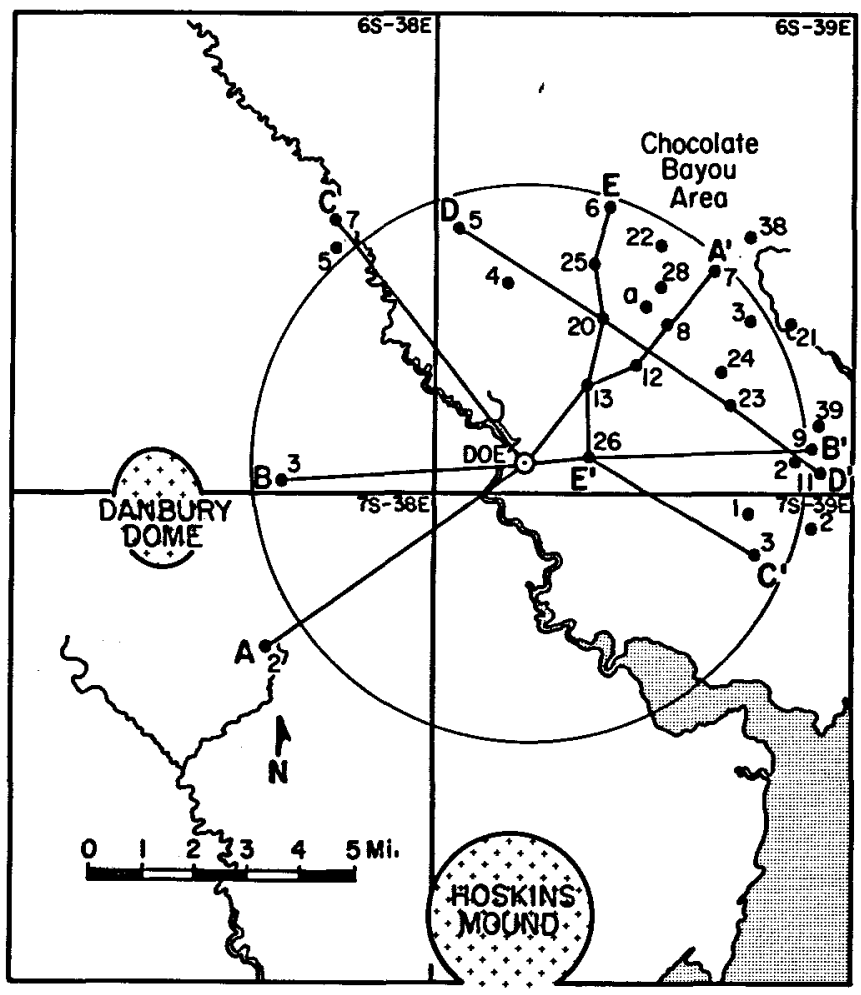

Figure 1. Site of GCO/DOE Pleasant Bayou wells. [XBL 815-3002] 


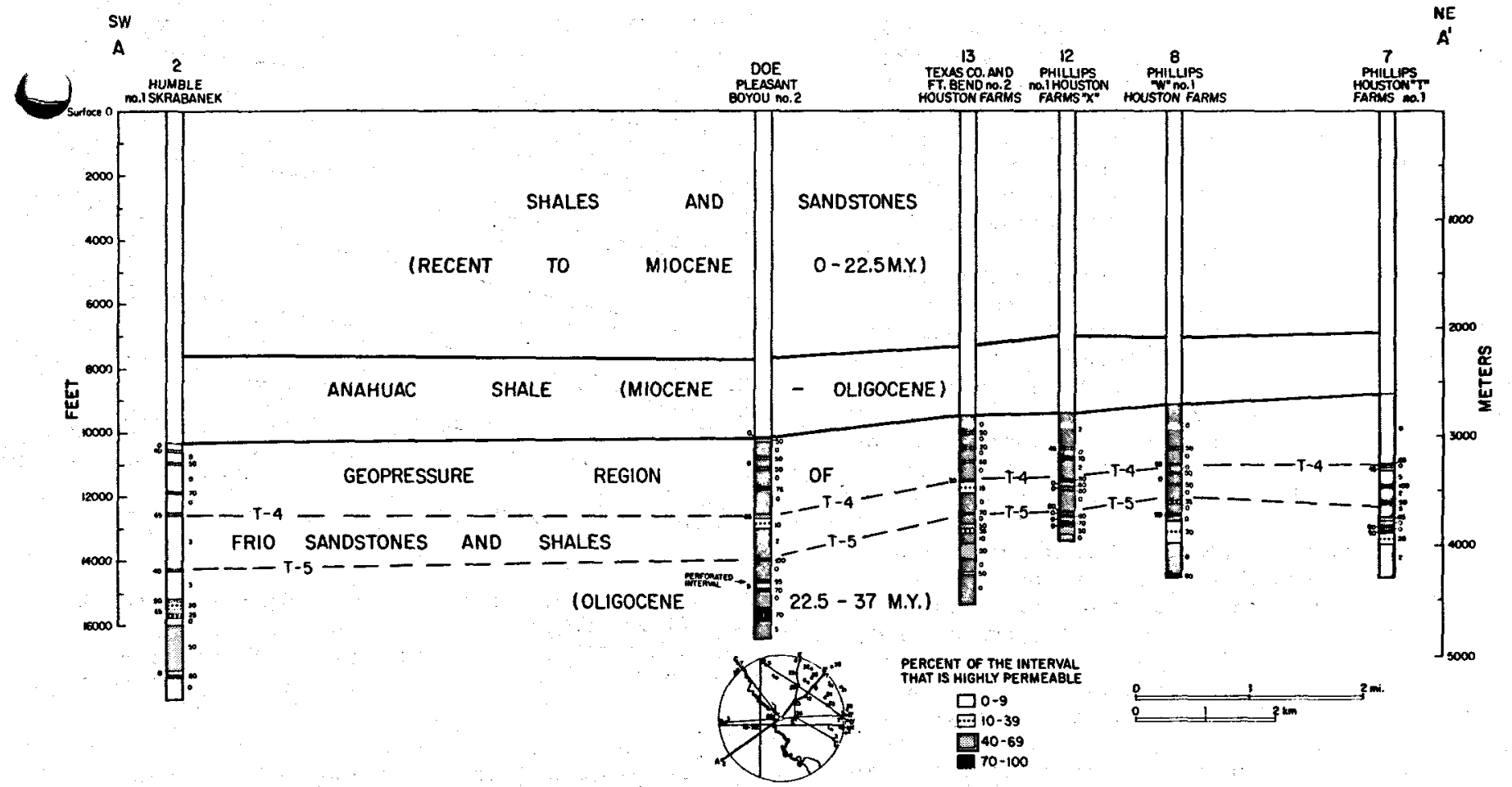

Figure 2. Simplified stratigraphic cross section A-A' (leveled in Fig. 1).

[XBL 817-3321]

sandstones of Miocene to Holocene age, is about 7000 ft $(2.13 \mathrm{~km})$ thick. Underlying it is the massive Miocene-Oligocene Anahuac Shale, which exceeds $2000 \mathrm{ft}$ in thickness. The geopressured region of Frio Sandstones and Shales lies below the Anahuac shale, which supposedly acts as a reservoir cap. The reservoir section is divisible Into zones on the basis of its permeability. Five highly permeable zones separated by shales can be recognized within the geopressured region. The permeable zones just above and below the perforated section may be expected to respond under production, whereas those farther away may not be disturbed, because of the poor permeability of the intervening shale layers. This perspective has guided the formulation of the mathematical model. The strata in the test wells dip 7 degrees to the southwest as determined by a dipmeter logging survey (Bebout et al., 1979). For the preliminary simulations, this gentle dip has been neglected.

Gregory and Backus (1979) discuss the evaluation of formation parameter 5 for $P B$ wells 1 and 12 on the basis of core analysis, arill stem tests, conventional well logs, and digitized logspaced sonic logs. Formation parameters for PB well $\$ 2$, as calculated from well-test analysis, are discussed in Garg et al. (1980), McDonald and Dorfman (1980), Garg et al. (1981), and Rodgers (1981). These results indicate a formation permeability of about $200 \mathrm{md}$, presence of a lineI barrier at about $3000 \mathrm{ft}$ from the well, and a gas-water ratio of 29 to $39 \mathrm{sCF} / \mathrm{s}$ H in the reservoir. Material properties obtained from laboratory tests are discussed in Gray et al. (1979), Gregory and Backus (1979), and Loucks et al.
(1979). In general, porosities are found to vary between 10 and 208 and horizontal permeabilities between 0.1 and 729 md in the geopressured region of $\mathrm{PB}$ well 12 . Oniaxial formation compressibility was found to be of the same order of magnitude as that of the water and varied between $0.3 \times 10^{-6}$ to $2.1 \times 10^{-6} \mathrm{psi}^{-1}$ in $\mathrm{PB}$ well 2 . Gas and brine analysis of the PB 12 fluid is given in Rharaka (1979) and Rodgers (1981). Results show that salinity of formation waters varies from 110,000 to 130,000 ppm in the geopressured zone of $\mathrm{BB}$ well \$2, and the formation waters are expected to be saturated with methane. Salinities calculated on the basis of formation pressure gradient and temperatures varied from 96,000 to 120,000 ppm (Bebout et al., 1979) in the geopressured zone of PB \$2. However, the apparent salinity of the formation waters, on the basis of the SP 109 , varied from 30,000 to 90,000 ppm (Gregory and Backus, 1979). The highest salinity value so far reported is $175,435 \mathrm{ppm}$, as measured by Southern petroleum Laboratory Inc. (Garg et al., 1980).

Inasmuch as the formation fluid is rich in dissolved methane, an adequate equation of state for the fluid, correlating methane saturation with pressure, temperature, density, and viscosity, is a necessary adjunct for the mathematical model: The equation of state for liquid water as a function of temperature and pressure is derived from analytical fits of data in the ASME Steam Tables (1967), as given in Garg et al. (1977). This equation is valid up to 1000 bars and $300^{\circ} \mathrm{C}$. The specific volume of methane gas is obtained from the ideal gas equation, which incorporates the gas compressibility factor. This dimensionless factor, as compiled by Sage and Lacey (1950), 
is expressed in analytical form, as discussed in Garg et al. (1977). Finally, a relation between the specific volume of liquid (water-methane solution) and that of water is given in Garg et al. (1977). Several researchers (O'Sullivan and Smith, 1970; Isokrari, 1976; Haas, 1978; Blount et al., 1979; Hanor, 1980; and Iglesias, 1980) have shown that the solubility of methane in brine decreases with increasing salinity. Using the data and analytical fits, as described in o'Sullivan and Smith (1970), Potter and Brown (1975), and Pritchett et al. (1979), we calculated methane solubility as a function of temperature and pressure for water-methane and brine-methane systems (Fig. 3). As can be seen, the solubility of methane increases with increasing pressure for both systems. An increase in the salinity of brine decreases the solubility of the methane.

As a first step toward modeling subsidence of the Pleasant Bayou area, the computer program TERzAGI is being used. This program, which is restricted to isothermal conditions, solves the three-dimensional fluid flow equation in conjunction with one-dimensional consolldation. The program is designed to account for heterogeneity and anisotropy. In order to realistically handle the brine-methane fluid of variable density, compressibility, and viscosity, the code TERzAGI has been suitably modified to simulate the brinemethane equation of state. Figure 4 shows a plot of total fluid density vs. pressure at various temperatures for a brine-methane system with a salinity of $150,000 \mathrm{ppm}$ and a methane mass fraction of 0.004 . As expected, the density of the fluid increases with increasing pressure and decreases with increasing temperature. The density of the fluid is higher than that of water because sodium chloride is present. This plot can also be used to determine the compressibility of the fluid at various temperatures and pressures.

The effects of temperature and pressure on the viscosity of brine and liquid water are shown in Figure 5. The viscosity of brine is higher than that of water under similar thermodynamic conditions. For all practical purposes, the effect of pressure on viscosity of brine and water seems to be small.

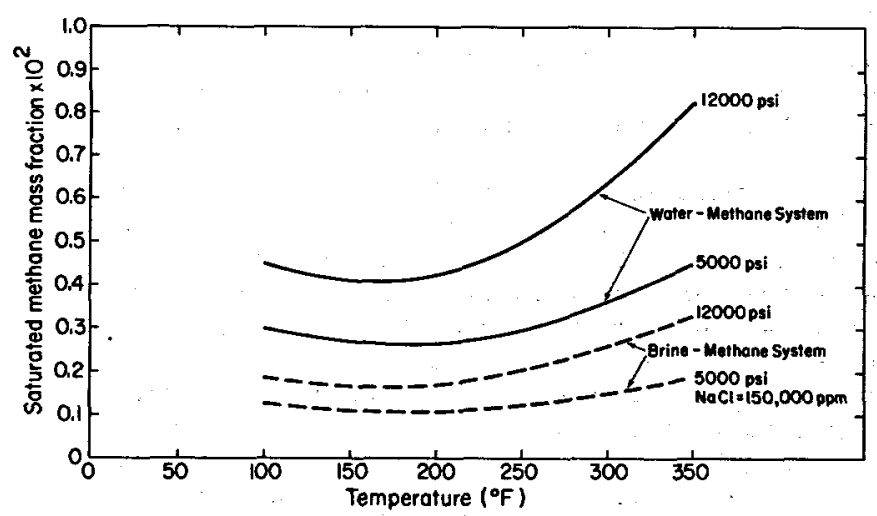

Figure 3. Solubility of methane in brine-methane and water-methane systems at various temperatures and pressures.

[XBL 8110-11697]

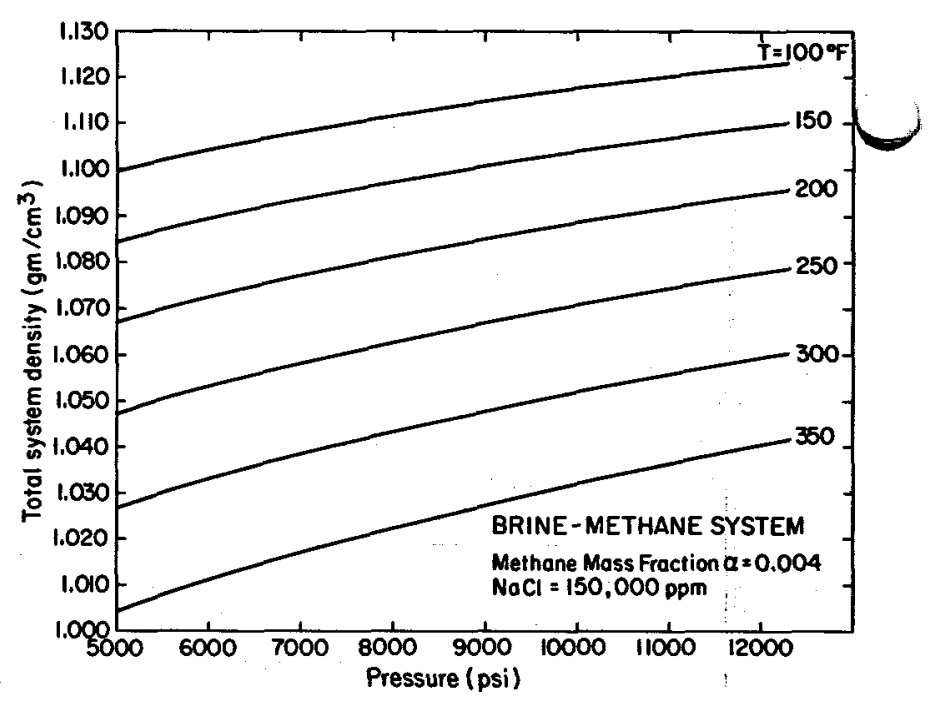

Figure 4. Total density of brine-methane mixture at various temperatures and pressures for a salinity of $150,000 \mathrm{ppm}$ and methane mass fraction of 0.004 .

[XBL 8110-11696]

The model is currently being applied to an idealized three-layer aquifer system so that it can be verified against known analytic solutions. The next step is to check the model against some of the solutions already generated by Garg and others from $\mathrm{s}^{3}$. The final phase is to carry out parametric studies using up-to-date pumping test results.

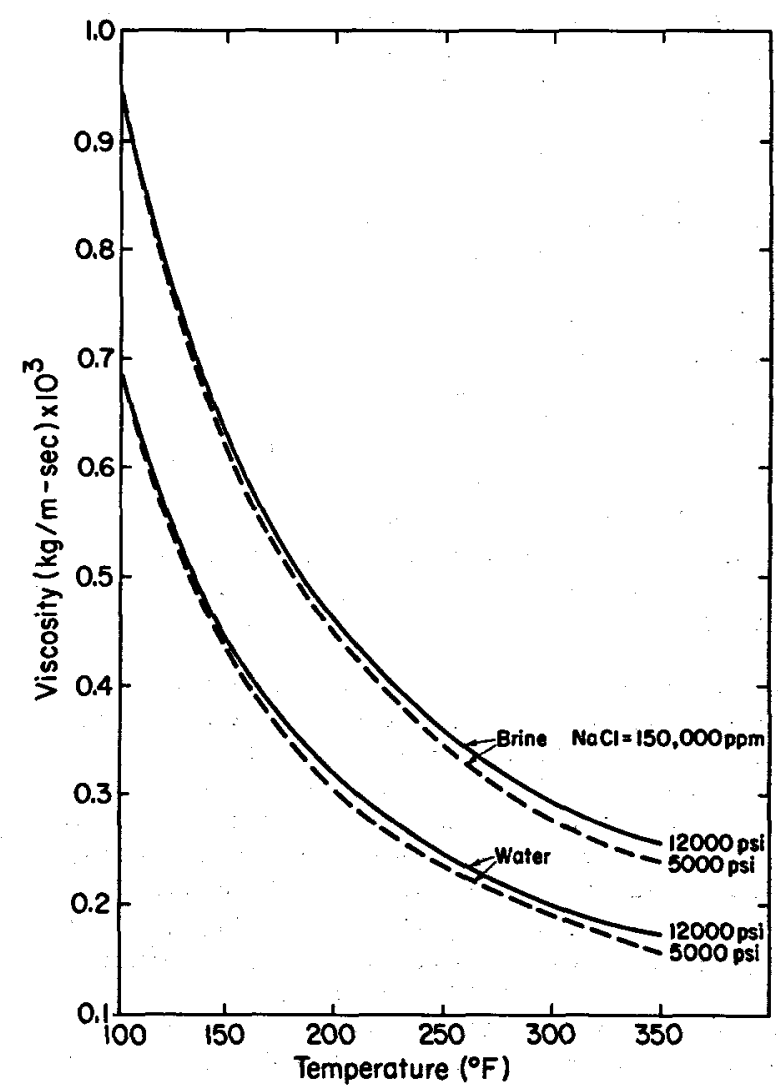

Figure 5. Viscosity of water and brine at various temperatures and pressures. 


\section{REF ERENCES CITED}

SME, 1967. ASME Steam Tables (2nd ed.). New York, The American Society of Mechanical Eng ineers.

Bebout, D. G., Loucks, R. G. , and Gregory; A. R., 1979. Ceologlcal aspects of Pleasant Bayou geopressured geothermal test we11, Austin Bayou Prospect, Brazorla County, Texas. In M. H. Dorfman and $T$. L. Fisher (eds.), Proceedings, Fourth United States Gulf coast Ceopressured Ceothermal Energy Conference. Center of Energy studies, University of Texas at Austin, $p \cdot 11-45$.

Blount, C. W., Price, L. C., Wenger, L. M., and Taru110, M., 1979. Methane solub111ty in aqueous $\mathrm{NaCl}$ solutions at elevated temperatures and pressures. In $M . H$. Dorfman and $W$. L. Fisher (eds.). Proceedings, Fourth United States Gulf coast Geopressured Geothermal Energy Conference. Center for Bnergy studies, University of Texas at Austin. p. 1225-1260.

Garg, S. K., Pritchett, J. W., Rice, L. F., and Riney, T. D., 1980. Nell test analysis and reservoir predictions for geopressured geothermal systems. La Jolla, California, Systems, science and software. Final report * DOE/ET/27202-3.

Garg, S. K., Pritchett, J. W., Rice, M. H., and Riney, T. D., 1977. U. S. Gulf Coast geopressured geothermal reservoir simulation. La Jolla, California, Systems, Sclence and software, SSS-R-77-3147, P. 112.

Garg, S. R., Riney, T. D., and Fwu, J, K., 1981 Analysis of phase I flow data from pleasant Bayou no. 2 geopressured well. La Jolla, California, Systems, Science and Software, Topical Report DOE/AV/10150-1.

Gray, K. E., Jogi, P. N., Morita, N., and Thompson, T. W., 1979. The deformation behavior of rocks from the Pleasant Bayou wells. In M. H. Dorfman and W. I. Fisher (eds.). Proceedings, Fourth United states Gulf Coast Ceopressured Ceothermal Energy Conference. Center for Bnergy studies, University of Texas at Austin, p. 1131-1059.

Gregory, A. R., and Backus, M. M., 1979. Geopressured formation parameters, geothermal we11, Brazoria County, Texas. In M. H. Dorfman and $w$. L. Fisher (eds.), Proceedings, Fourth United States Gulf Coast Ceopressured Ceothermal Energy conference. Center for Energy Studies, University of Texas at Austin, p. 235-311.

Haas, J. L. Jr. 1978. An empirical equation with tables of smoothed solubilities of methane in water and aqueous sodium chloride solutions up to 25 weight percent, $360 \mathrm{C}$ and 138 MPa. U. S. Geological Survey, Open-file Report 78-1004.

Hanor, J. S., 1980. Dissolved methane in sedimentary brines--Potential effect on the
PVT properties of fluid inclusions. Scientific Communications, Economic Geology, v. 75 , p. 603-617.

Iglesias, E. R., 1980. Sampling geopressured fluids: some contributions from the properties of the $\mathrm{H}_{2} \mathrm{O}-\mathrm{CH}_{4}$ systems. In $\mathrm{H}$. J. Ramey, Jr., and P. Rruger (eds.), Proceedings, Sixth Workshop Geothermal Reservoir Englineering. Stanford Untversity, SGP-TR-50, p. 84-97.

Isokrari, O. F., 1976. Numerical simulation of United States Gulf Coast geothermal geopressured reservoirs (Ph.D. dissertation), UnIversity of Texas at Austin.

Kharaka, Y. K., Lico, M. S., Wright, V. A., and Carothers, W. W., 1979. Geochemistry of formation waters from Pleasant Bayou no. 2 well and adjacent areas in coastal rexas. In $M$. H. Dorfman and W. L. Fisher (eds.), Proceedings, Fourth United States Gulf coast Geopressured Geothermal Energy Conference. Center for Energy Studies, University of Texas at Austin, p. 168-199.

Loucks, R. G., RIchmann, D. L., and Milliken, K. I. . 1979. Factors controlling porosity and permeability in geopressured Frio Sandstone reservoirs, General Crude 0i1/Department of Energy Pleasant Bayou test wells, Brazoria County, Texas. In M. B. Dorfman and W. L. Fisher (eds.), Proceedings, Fourth United States Gulf coast ceopressured Geothermal Energy Conference. Center for Energy Studies, University of Texas at Austin, P. 46-84.

McDonald, R. C., and Dorfman, M. H., 1980. Preliminary test results of the first geopressured-geothermal design well, Brazoria County, Texas. In H. J. Ramey, Jr.. and P. Kruger (eds.), Proceedings, sixth Workshop, Geothermal Reservolr Engineering. Stanford University, SGP-TR-50, p. 105-114.

O'Sullivan, T. D., and Smith, N. O., 1970. The solubility and partial molar volume of nitrogen and methane in water and in aqueous sodium chloride from 50 to $125 \mathrm{C}$ and 100 to 600 atm. Journal of Physical Chemistry, v. 74, p. 1460 .

Potter, R. W., II, and Brown, D. K., 1975. The volumetric properties of aqueous sodium chloride solutions from $0^{\circ}$ to $500^{\circ} \mathrm{C}$ at pressures up to 2000 bars based on a regression of the avallable literature data. U. S. Geological Survey, Open-file Report 75-636.

Pritchett, J. W., Garg, S. K., Rice, M. H., and Riney, T. D., 1979. Geopressured reservoir simulation. La Jolla, California, Systems, Sclence and Software, SSS-R-79-4022, p. 127.

Rodgers, J. A., 1981. Testing of Pleasant Bayou no. 2. Houston, Gruy Federal Inc., p. 55 .

Sage, B. H., and Lacey, W. N., 1950. Thermodynamic properties of the lighter paraffin hydrocarbons and nitrogen. New York, American petroleum Institute. 


\title{
FLUID SAMPLING AND ANALYSIS OF GEOPRESSURED BRINE
}

\author{
L. Hansen, R. M. Galbraith, O. Weres, M. Michel, and D. Sverjensky
}

Economic assessment of the low-temperature geopressured brines found in certain Gulf coast formations requires knowledge of their methane content and a clear understanding of the ir geochemistry. In support of the Gas Research Institute (GRI) and the Department of Energy (DOE), the Lawrence Berkeley Laboratory (LBL) has fabricated and tested a downhole fluid sampler designed to operate under the pressures, temperatures, and chemical conditions that prevail in geopressured zones. Additionally, through the use of brine modeling codes, LBL has studied the chemical problems associated with production and disposal of geopressured fluids.

\section{FLOW-THROUGH SAMPLER}

A flow-through sampler designed to operate in a temperature-pressure regime of $20,000 \mathrm{psi}$ and $400^{\circ} \mathrm{F}$ has been fabricated and partially tested. The sampler components are shown in Figure 1, and the specifications of the sampler are listed in Table 1. The sampler is made of MP35N alloy for corrosion resistance. The operating principle is as follows. Before the sampler is lowered into the hole on a single-conductor cable, springloaded valves at top and bottom are opened mechanically. The valves are kept open during the descent into the hole by a current-induced magnetic field. When the sampler has reached the desired sampling depth, the operator interrupts the current, which causes both valves to close.

Several laboratory and field tests have been completed. First, the magnet assembly was 1aboratory tested in December 1980 to ensure that it would operate at high temperatures in air. The assembly operated successfully up to $388^{\circ} \mathrm{F}$, the maximum temperature of the oven that was used. Next, the complete sampler was laboratory tested to verify satisfactory mechanical and electrical operation when totally immersed in tap water. An autoclave test was subsequently performed at Dresser-Atlas in Houston: the sampler operated perfectly in brine at 21,000 psi and $400^{\circ} \mathrm{F}$. Finally, the sampler was field tested in a geothermal well made available by Aminoil USA. The well is located near the southeastern extension of The Geysers geothermal field, where conditions are transitional to a liquid-dominated system.

A sample was taken at a depth of $7400 \mathrm{ft}$, approximately $200 \mathrm{ft}$ below the water level. Conditions at the sampling depth were estimated to be about $500^{\circ} \mathrm{F}$ and $680 \mathrm{psi}$, somewhat higher in temperature but much lower in pressure than geopressured conditions. The sample was successfully brought to the surface for analysis. Inspection of the sampler on the following day revealed that all eleven seals worked properly and that the Rrytox oil exhibited no deterioration from the high temperature.

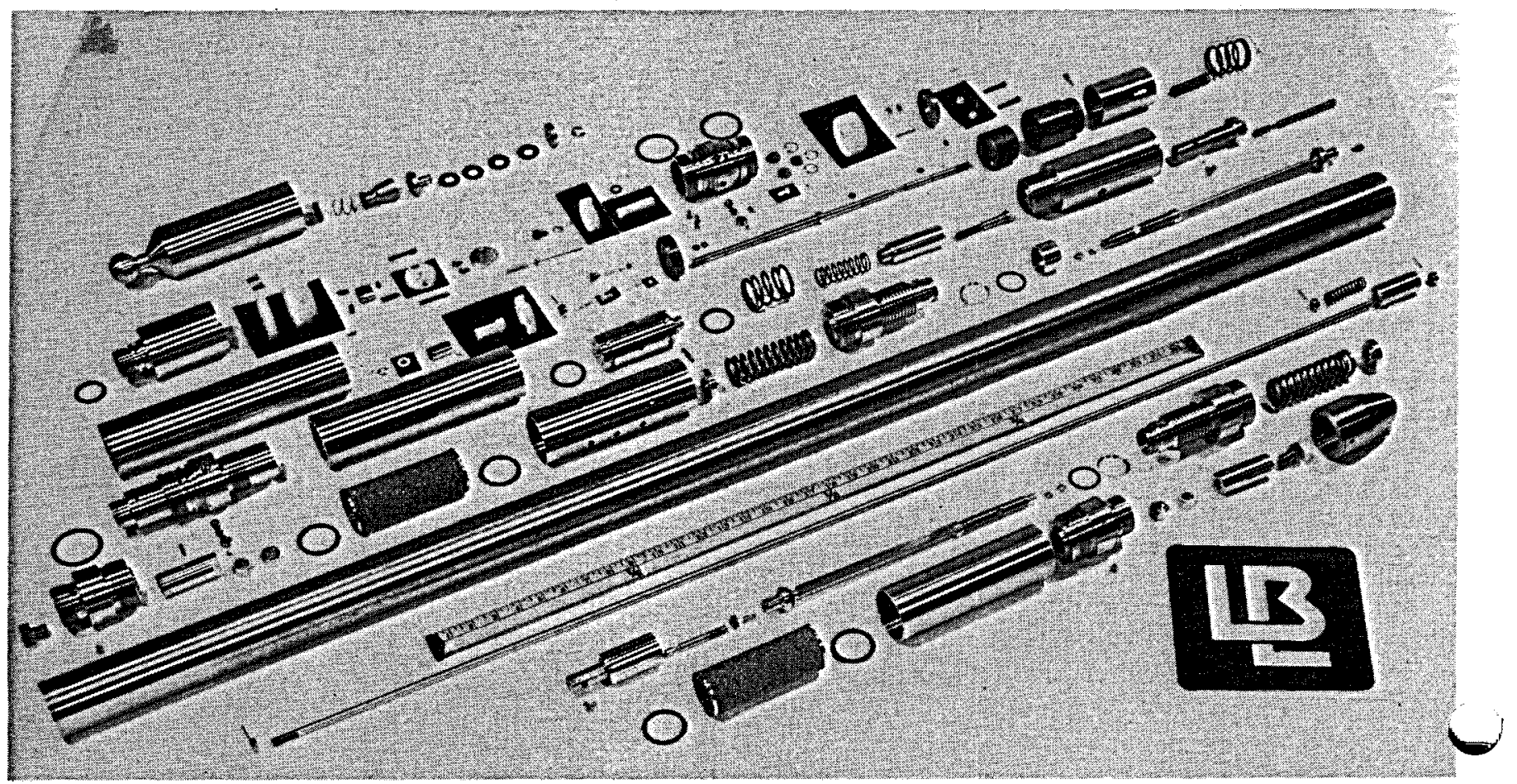

Figure 1. Components of the IBL flow-through sampler. 
Table 1. Specifications of the LBL flow-through sampler.

Overall length

Diameter

Dry weight

Sample volume

Recommended cable

Maximum bottomhole pressure:

Maximum outward differential

Maximum inward differential pressure

Maximum downhole temperature
120.25 in. (not including sinker bars)

2.25 in.

112 lb (not including sinker bars)

$980 \mathrm{ml}$ (approximate, pending volumetric test)

MP35N monoconductor cable

No upper limit

25,000 psi at $450^{\circ} \mathrm{F}$ (pending hydrostatic pressure proof test)

$350 \mathrm{ps} 1$ at $450^{\circ} \mathrm{F}$

$450^{\circ} \mathrm{F}\left(500^{\circ} \mathrm{F}+\right.$ may be feasible $)$

\section{GEOPRESSURED BRINES}

A review has been completed of the literature on the chemistry of geopressured brines at reservolr and well-bore conditions. We have concluded that about 908 of the geopressured brines that have been analyzed are chemically well represented by the system $\mathrm{NaCl}-\mathrm{CaCl}-\mathrm{H}_{2} \mathrm{O}$, in which the Na:Ca mole ratio is greater than about 9 and the molality of chloride is less than about 2.8 , In order to understand and predict brine-rock interactions in the reservolr, it is essential to know the chemistry of the brine and the mineralogy and geochemistry of the host rock. Therefore, a review has also been done of the literature on the mineralogy and geochemistry of the appropriate shales and sandstones. This information strongly suggests that the high secondary porosities of the economically attractive sandstone units are controlled by brine-rock interactions that occur during diagenesis of shales and sandstones.

The review also included a critical survey of the thermodynamic data bases for the minerals. aqueous species, and gases used in the various codes. Regardiess of the code, prediction of whether a given brine will precipitate minerals depends heavily on the thermodynamic data base. However, since the thermodynamic data base is poorly known, it becomes the largest source of uncertainty. Data bases were reviewed for the codes HITEQ (E. Iglesias, personal communication), EQ3/EQ6 (Wolery, 1979), SOLMNEQ (Kharaka and Barnes, 1973), and WATEQ2 and its relatives (Ball et al , 1980), and the Jaycor code (Levine et al., 1980). The maln results of this review sllow.

The only adequate thermodynamic data base for modeling geopressured brine chemistry at reservolr and well-bore conditions as well brine-rock
Interactions in the reservoir is that developed by Helgeson and co-workers (University of Callfornia, Berkeley) and embodied in the program SUPCRT. The only brine modeling code containing a thermodynamic data base generated by SUPCRT (and earller work) is EQ3. EQ3 contains thermodynamic data for computations at low (steam-saturated) and high (500 bars) pressures, but data for other high pressures could be very simply generated using SUPCRT and added to EQ3.

No single published code is suitable for modeling the chemistry of geopressured brines under all possible conditions from reservoir to surface. However, major code development is not considered necessary. Modeling the chemistry of geopressured brines under reservoir conditions (without a gas phase present) is feasible using the codes EQ3 and EQ6, which contain the best available thermodynamic data base. For modeling the chemistry of geopressured brines in surface equipment, where gas and liquid phases coexist, an expanded version of HITEQ is recommended. This would incorporate Pitzer's model of the electrolyte solutions (Pitzer, 1973, 1975, 1979, Pitzer and Kim, 1974; Pitzer and Mayorga, 1973, 1974) and thermodynamic data for gas/liquid partitioning in the system $\mathrm{NaCl}-\mathrm{CH}_{4}-\mathrm{H}_{2} \mathrm{O}$, presently beling measured by Prausnitz and co-workers at the University of California, Berkeley.

\section{REFERENCES CITED}

Ball, J. W., Nordstrom, D. K., and Everett, A. J. 1980. Additional and revised thermochemical data and computer code for WATEQ2: A computerized chemical model for trace and major element specification and mineral equilibria of natural waters. $u$. $s$. Geological Survey, Water Resources Investigations 78-116, $109 \mathrm{p}$. 
Kharaka, Y. K., and Barnes, M. I., 1973. SOIMNEQ: Solution:mineral equilibria computations. U. S. Geological Survey, PB 215 889, $81 \mathrm{p}$.

Levine, H. B., Dion, D. R., Laird, D. H., and Tatum, T. J., 1980. Calculation of chemical changes in brine samples recovered under insitu conditions from formation waters of geopressured zones in coastal Texas and Louisiana. Interim Report No. 1, JAYCOR project 5183, Institute of Gas Technology and Gas Research Institute, J510-80-010/5183.

Pitzer, K. S., 1973. Thermodynamics of electrolytes. I. Theoretical basis and general equations. Journal of Physical Chemistry, v. 77, p. 268-277.

Pitzer, R. S., 1975. Thermodynamics of electrolytes. V. Effects of higher order electrostatic terms. Journal of Solution Chemistry. v. 4, p. 249-265.

Pitzer, K. S., 1979. Characteristics of very concentrated aqueous solutions. Lawrence
Berkeley Laboratory Report LBL-9660.

Pitzer, K. S., and Kim J. J., I974. Thermodynamics of electrolytes. IV. Activity and osmotic coefficients for mixed electrolytes. Journal of the American Chemical society, v. 96, p. 5701-5707.

Pitzer, K. S., and Mayorga, G., 1973. Thermodynamics of electrolytes. II. Activity and osmotic coefficients for strong electrolytes with one or both ions univalent. Journal of Physical Chemistry, v. 77, p. 2300-2308.

Pitzer, K. S., and Mayorga, G., 1974. Thermodynamics of electrolytes. III. Activity and osmotic coefficients for 2-2 electrolytes. Journal of Solution Chemistry, v. 3 , p. 539-546.

wolery, T. J., 1979. Calculation of chemical equilibrium between aqueous solution and minerals: The $E Q 3 / 6$ software package. Lawrence Livermore National Laboratory Report UCRL-52658.

\title{
SIMULATION OF THERMAL ENERGY STORAGE IN A DOUBLET WELL SYSTEM
}

\author{
T. A. Buscheck, C. Doughty, and C. F. Tsang
}

While the first cycle of the 1981 series of experiments was being carried out by Auburn University at Mobile, Alabama, Lawrence Berkeley Laboratory (IBL) was performing a numerical simulation based on the field operating conditions to predict the outcome of the experiment before its conclusion. The goal was to test our understanding of the aquifer storage problem and to validate our numerical model $\mathrm{CCC}$.

In the Mobile experiment, $25,000 \mathrm{~m}^{3}$ of water at approximately 55 to $60^{\circ} \mathrm{C}$ was injected over a period of one month into an aquifer that is approximately $21 \mathrm{~m}$ thick, has a permeability of about $63 \mathrm{~d}$ and was initially at $20^{\circ} \mathrm{C}$. It was then stored for one month and subsequently produced. The injected water was obtained from a supply well perforated in the same aquifer $240 \mathrm{~m}$ away from the injection/production well and then heated in an oil-fired boiler. IBL was provided with the basic geological, well test, injection flow rate, and injection temperature data.

The simulation method was similar to that used by IBL to model the 1979-1980 Auburn experiment, which used another region of the same aquifer (Tsang et al.. 1981). The well-test data and geological information were studied and analyzed to obtain reservoir parameters and their ranges of uncertainty. Our results generally confirmed the analyses done by Auburn University. The parameters used in our numerical simulation are listed in Table 1 . Since the supply well is 240 m from the injection/storage well and the thermal radius is only about $25 \mathrm{~m}$, it was decided that a radial calculation mesh would be adequate. Using the injection flow rates and temperatures provided, we employed the numerical model CCC to calculate production temperature and energy re- covery factor for a given production flow-rate schedule. The results are presented as curve $A$ in Figure 1, where the experimental results are also plotted. The experimental results were made known to us after we completed and presented our results. The predicted energy recovery factor is 0.62 compared to the experimental value of 0.56 . We find this agreement to be satisfactory.

After comparing our predictions with the experimental results, we made a series of parameter sensitivity studies. Several sets of calculations were made, including:

1. Mesh variation. Results are found to be nearly independent of the mesh used.

2. Arbitrary increase of aquifer permeability from $63 \mathrm{~d}$ to $94 \mathrm{~d}$. The calculated recovery factor is reduced from 0.62 to 0.55 . The production temperature is shown as curve $B$ in Figure 1.

3. Two-layered-permeability aquifer, in which the upper layer is twice as permeable as the lower but with an average of $63 \mathrm{~d}$ corresponding to the field value. The recovery factor is calculated to be 0.60 .

4. Three-layered-permeability aquifer, in which the middle layer is twice as permeable as the upper and lower layers while keeping the average at the field value of $63 \mathrm{~d}$. The recovery factor is calculated to be 0.62 ; the production temperature is displayed as curve $c$ in Figure 1.

5. Simulation of a large thermal dispersion effect. We followed Sauty et al. (1978), who approximated this effect by using an effec- 
Table 1. Parameters used in numerical simulation.

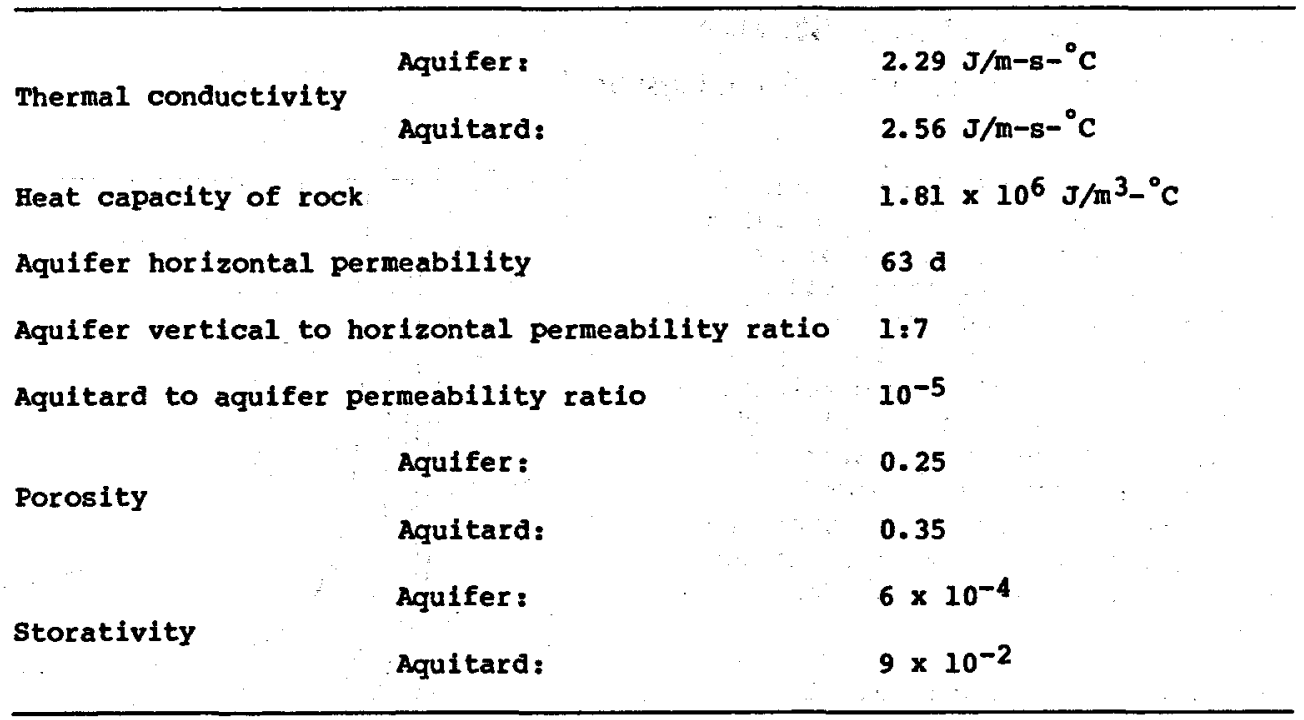

tive thermal conductivity value. A value 10 times the normal value was used. On the basis of an approximate relationship developed by Doughty et al. (1982), this corresponds to a dispersion length of $3 \mathrm{~m}$. The energy recovery factor is

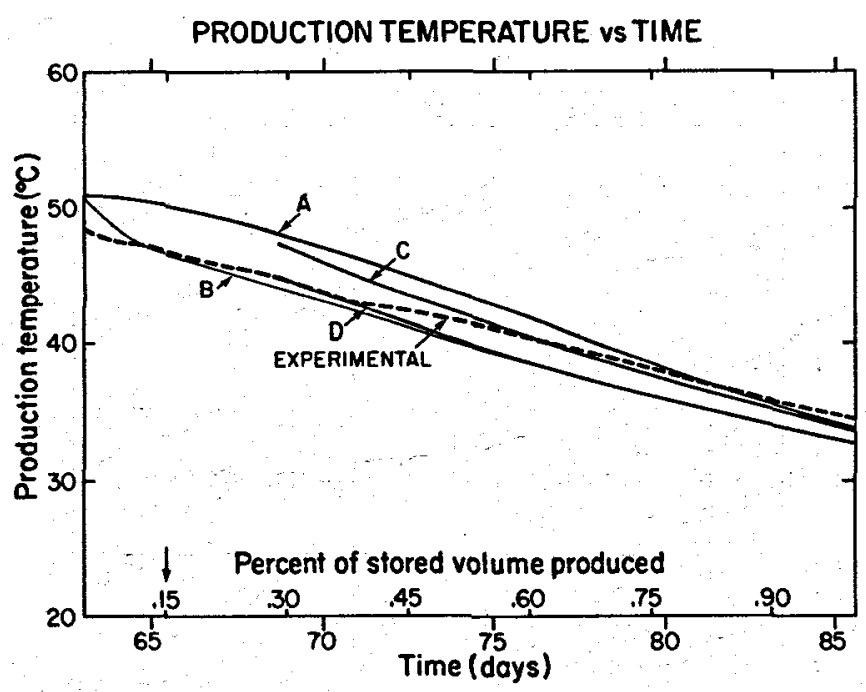

Figure 1. Production temperature during first cycle of the 1981 Mobile experiment as a function of time. Curve $A$ shows the basic numerical simulation results; curves $B, C$, and $D$ show results of the parameter studies described in the text.

[XBL 817-3266] calculated to be 0.57 ; the production temperature is shown as curve $D$ in Figure 1.

Several additional parameter-sensitivity calculations were made. It was found that although the recovery factor can be made to reproduce the experimental data, the time rate of decrease of calculated production temperature for many alternative cases is always faster than the experimental value. These studies led us to hypothesize that this production-temperature discrepancy may be due to either thermal dispersion or aquifer heterogeneity. Ef forts have been initiated to study both processes.

\section{REFERENCES CITED}

Doughty, C., Hellstrom, G., Tsang, C. F., and Claesson, J., 1982. A dimensionless parameter approach to the thermal behavior of an aquifer thermal energy storage system. Water Resources Research, in press. (A preliminary version is available as Lawrence Berkeley Laboratory Report IBL-11029.)

Sauty, J. P., Gringarten, A. C., and Landel, P. A. 1978. The effect of thermal dispersion on injection of hot water in aquifers. In Proceedings, Second Invitational Well Testing Symposium, October 25-27, 1978, Berkeley, California.

Tsang, C. F., Buscheck, T., and Doughty, C., 1981. Aquifer thermal energy storage--A numerical simulation of Auburn University fleld experiments, Water Resources Research, v. 17, no. 3, p. 647-658. 


\title{
A DIMENSIONLESS PARAMETER APPROACH TO THE THERMAL BEHAVIOR OF AN AQUIFER THERMAL ENERGY STORAGE SYSTEM
}

\author{
C. Doughty, G. Hellstrom*, C. F. Tsang, and J. Claesson*
}

The purpose of aquifer thermal energy storage (ATES) site-characterization studies is to develop a general procedure whereby the energy recovery factor for a given site may be predicted readily for a wide range of operating conditions without doing detailed numerical simulations. These predicted recovery factors provide the basic results needed for technical or economic optimization of the ATES system. The energy recovery factor is defined here as the energy recovered divided by the energy stored for the same amount of water injected into and produced from the aquifer. Energy is measured with reference to ambient aquifer temperature energy.

The study sumnarized here (Doughty et al., 1982) considers the thermal behavior of an ATES system with steady radial fluid flow around a single injection/production well. Buoyancy flow is neglected, and the aquifer is conf ined above and below by impermeable confining layers. Neglecting buoyancy flow may be a reasonable assumption for cases with low aquifer permeability, a vertically stratified aquifer, short storage cycle length, or small temperature difference between injected and original water. A criterion exists (Hellstrom et al., 1979) that may be used to determine if buoyancy flow is negligible for a given case. However, conclusions from this study may still be applicable in a qualitative sense for cases in which buoyancy flow is significant.

With the above assumptions, the thermal behavior of the system can be described in terms of the following four dimensionless parameter groups:

$P e=\frac{Q C_{w}}{2 \pi \lambda_{a} H}=\frac{C_{a} R^{2}}{2 \lambda_{a} t_{i}}, \Lambda=\frac{C_{a}^{2}{ }^{2}}{C_{c} \lambda_{c} t_{i}}$

$B i=\frac{\lambda_{a} c_{a}}{\lambda_{c} D_{c}}, \frac{c_{a}}{c_{c}}$,

where $Q$ is the flow rate; $B$ is the aquifer thickness; $\lambda_{a}$ and $\lambda_{c}$ are the aquifer and confining layer thermal conductivities; $c_{w}, c_{a}$, and $c_{c}$ are the water, aquifer, and confining layer volumetric heat capacities; and $t_{i}$ is the injection time period. Pe may also be written in terms of the thermal radius, $R$, as shown.

A simple, numerical steady-flow model has been used to calculate recovery factors and temperatures as a function of $\mathrm{Pe}, \Lambda$, and $\lambda_{\mathrm{a}} / \lambda_{\mathrm{c}}$. For typical fleld values, $C_{a} / C_{c}$ does not vary much. This numerical model uses a fully explicit, finite-difference scheme to calculate conductive heat transfer. Convection is simulated by translating the temperature field in the aquifer in accordance with a steady radial fluid flow. Some of the results are shown in Figures 1 and 2 .

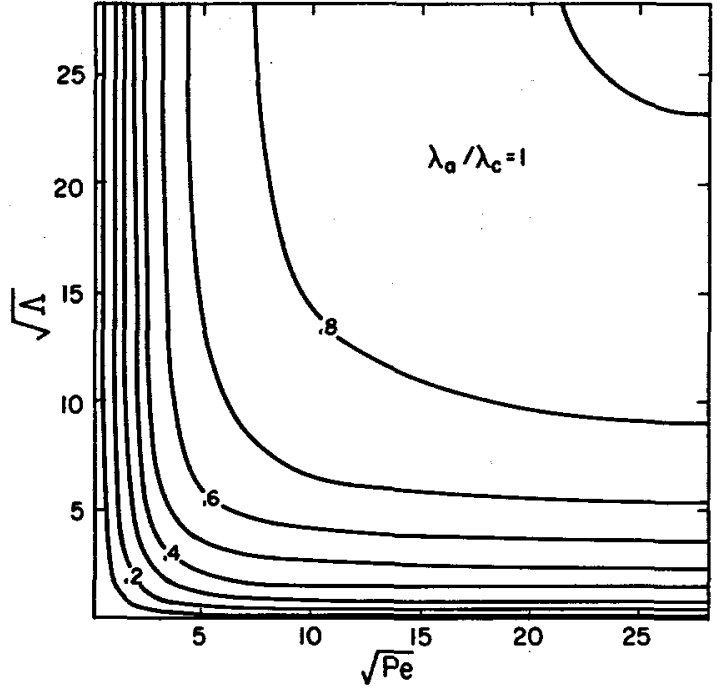

Figure 1. Recovery factor as a function of $\sqrt{\mathrm{Pe}}$ and $\sqrt{\Lambda}$ for the first cycle.

[XBL 8012-6516]

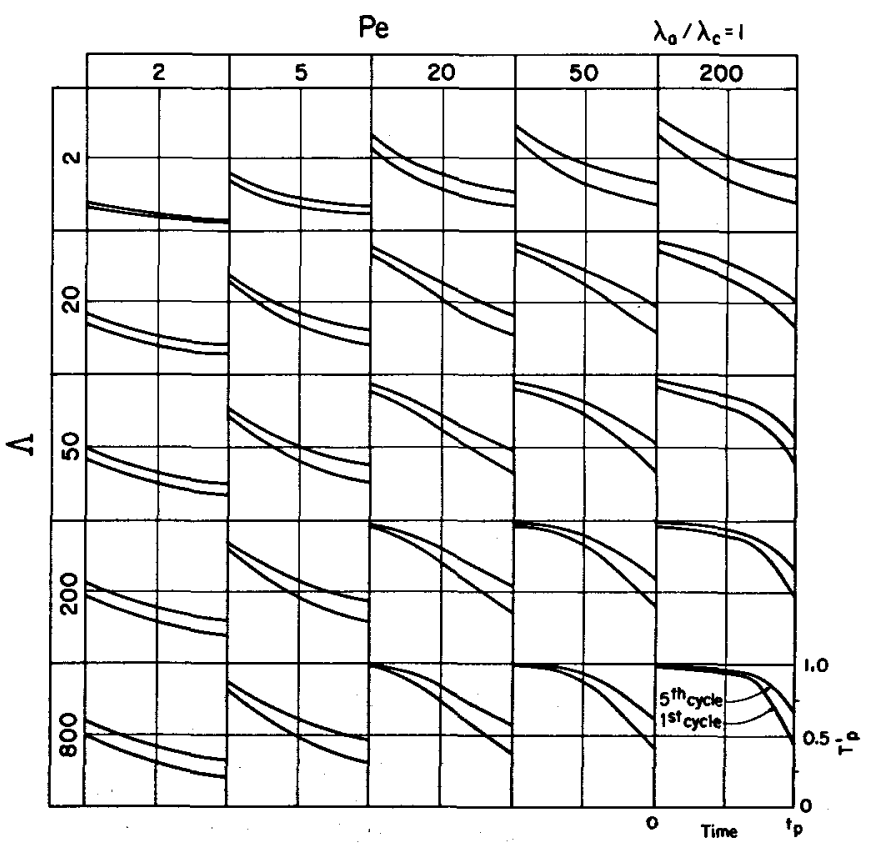

PRODUCTION TEMPERATURE

Figure 2. First and $f$ ifth cycle production teinperatures versus time for the range of $P e$ and $\Lambda$. [XBL 8012-6582C] 
Figure 1 shows the calculated energy recovery factor as a function of $P e$ and $\Lambda$ for the first jycle when $\lambda_{a} / \lambda_{c}=1$. Results for subsequent cycles and larger values of $\lambda_{a} / \lambda_{c}$ have also been calculated. Note that the large initial increase in recovery factor is followed by a more gradual increase as $P e$ and $\Lambda$ are increased.

Figure 2 displays the temperature of water extracted during the production period of the first and fifth cycles for different values of $\mathrm{Pe}$ and $\Lambda$ when $\lambda_{a} / \lambda_{c}=1$. For values of Pe larger than 200 , production temperature shows little dependence on $\mathrm{Pe}$.

Other factors have also been considered through the introduction of several parameters. Thermal dispersion has been modeled by creating an effective aquifer thermal conductivity $\tilde{\lambda}_{a}$. which adds a dispersion term to the usual aquifer thermal conductivity. This additional term may be constant, proportional to fluid velocity, or proportional to fluid velocity squared. Periods of unequal length within a cycle are dealt with by introducing a parameter $\tau$, defined as the average time a fluld particle spends in the aquifer. Both $\tilde{\lambda}_{a}$ and $\tau$ can be incorporated into the basic four parameter groups. A finite-thickness cap rock, overlain by a constant temperature boundary representing the ground surface or another aquifer, can be included in the analysis by introducing a parameter $d$, the ratio of the cap rock thickness to the aquifer thickness. Figure 3 shows the effect of the cap rock thickness on the recovery factor as a function of $\lambda$ for a range of values of $d$ when $\lambda_{a} / \lambda_{c}=1$. This variation is independent of Pe.

Table 1 displays the application of this approach to the Mobile (Molz et al., 1979, 1981) and Bonnaud (Menjox and Sauty, 1980) ATES fleld experiments. In this table, $\varepsilon$ is the calculated energy recovery factor and $\varepsilon_{\text {exp }}$ is the experimentally observed value. For the Auburn case, two calculations were made: calculation (a) assumes that the well penetrates the full thickness of the aquifer, calculation (b) corrects for the fact that, experimentally, the well was open to only $9 \mathrm{~m}$ of the aquifer's $21 \mathrm{~m}$ thickness. The comparisons are very encouraging and indicate that this dimensionless parameter approach can
FINITE THICKNESS CAPROCK EFFECT ON RECOVERY FACTOR

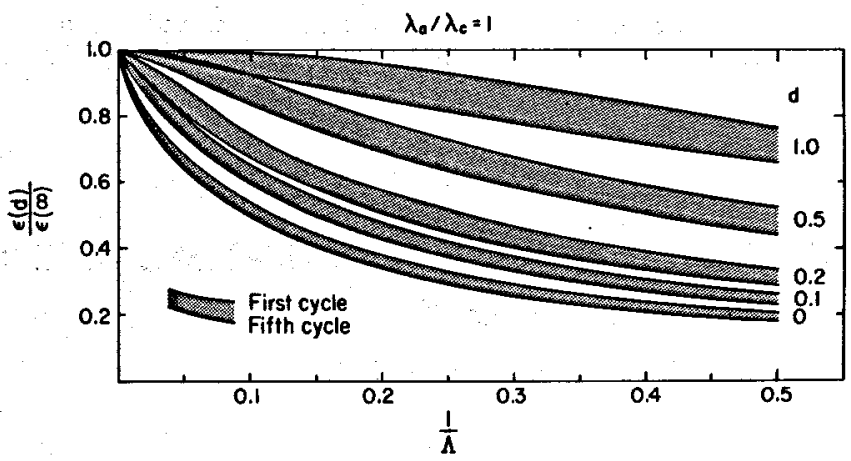

Figure 3. Finite-thickness cap rock effect for the first and fifth cycle recovery factors as a function of $\Lambda$.

[XBL 8012-6591]

give good results for quite different situations, as long as buoyancy flow is small.

*Department of Mathematical Physics, Lund Institute of Technology, Lund, Sweden.

\section{REFERENCES CITED}

Doughty, C., Hellstrom, G., Tsang, C. F., and Claesson, J., 1982. A dimensionless parameter approach to the thermal behavior of an aquifer thermal energy storage system. Water Resources Research, in press. (A preliminary version is avallable as Lawrence Berkeley Laboratory Report IBL-11029.1

Hellstrom, G. ; Tsang, C. F., and Claesson, J., 1979. Heat storage in aquifers: Buoyancy flow and thermal stratification problems. Lund Institute of Technology, Lund, Sweden. (Lawrence Berkeley Laboratory Report [BL-14246.)

Molz, F. J., Parr, A. D., and Andersen, F. P., 1981. Thermal energy storage in a confined aquifer--Second cycle. Water Resources Research, v. 17, no. 3, p. 647-658.

Molz, F. J., Parr, A. P., Andersen, P. F., Lucido, v. D., and Warman, J. C., 1979. Thermal energy storage in a confined aquifer: Experimental results. Water Resources Research, v. 15, no. 6, p. 1509-1514.

Table 1. Comparison of recovery factors from our dimensionless parameter approach and field experiments.

\begin{tabular}{lcccccc}
\hline & $\sqrt{P e}$ & $\pi$ & $\lambda_{a} / \lambda_{c}$ & $d$ & $\varepsilon$ & $\varepsilon_{\text {exp }}$ \\
\hline Mobile (first cycle) & & & & & & \\
Calculation (a) & 8.8 & 9.0 & 2 & 0.4 & 0.71 & \\
Calculation (b) & 10.1 & 6.8 & 2 & 0.6 & 0.68 & \\
\hline Bonnaud (fourth cycle) & 3.9 & 5.0 & 10 & 1.6 & 0.63 & 0.677 \\
\hline
\end{tabular}


Menjoz, A., and Sauty, J. P., 1980. Stockage de calories en aquifere par convection forcee a partir d'un puits unique. Presented at $7^{\text {eme }}$
Symposium International sur les Transferts de Chaleur et de Mass en Milieu Poreux, Toulouse, France, August 26-28, 1980.

\title{
THE CHARACTERIZATION OF HEAT STORAGE IN CONFINED AQUIFERS WITH BUOYANCY FLOW
}

\author{
T. A. Buscheck and C. F. Tsang
}

In order to develop a graphical means of estimating the energy recovery performance of a proposed storage aquifer, including buoyancy effects, numerical simulations have been conducted over a wide range of aquifer permeabilities and injection temperatures using the numerical model $\mathrm{CCC}$, which takes into account temperature-dependent parameters and the buoyancy flow process (Buscheck and Tsang, 1981). In each case, an energy balance was kept for various times, separating radial diffusive losses in the aquifer and the vertical losses to the confining layers. A study of these results shows that over a wide range of conditions, the radial and vertical heat losses can be decoupled. Thus the energy recovery factor $\varepsilon$ may be expressed as the product of two factors, $\varepsilon=\left(1-\Delta \mathrm{E}_{\mathrm{a}}\right)\left(1-\Delta \mathrm{E}_{\mathrm{C}}\right)$, where $\Delta \mathrm{E}_{\mathrm{a}}$ is the normalized energy lost radially when the aquifer is insulated from the confining layers above and below, and $\Delta \mathrm{E}_{\mathrm{c}}$ is the normalized energy loss due to vertical conduction into the upper and lower conf ining layers. The energy losses $\Delta \mathrm{E}_{\mathrm{a}}$ and $\Delta \mathrm{E}_{\mathrm{c}}$ are shown schematically in Figure 1.

A recent characterization study (Doughty et a1. , 1982), summarized in the previous article,

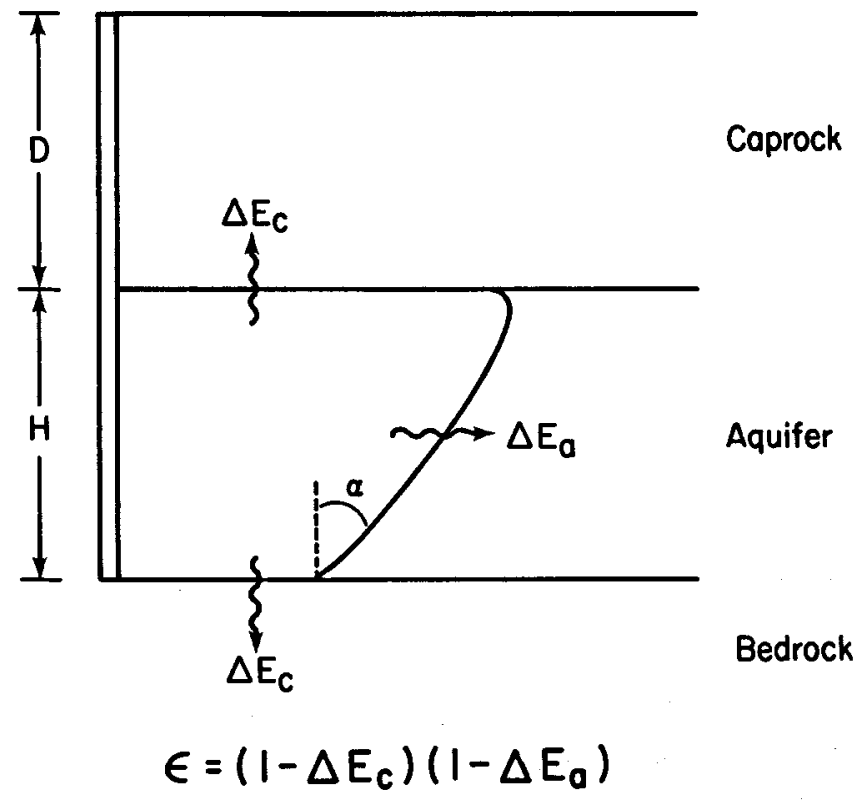

Figure 1. A schematic drawing of the energy losses associated with the characterization scheme, including buoyancy flow.

[XBL 818-3395] does not include buoyancy flow and uses four parameters derived from a nondimensionalization of the basic equation: $\mathrm{Pe}, \Lambda, \mathrm{Bi}$, and $\mathrm{C}_{\mathrm{a}} / \mathrm{C}_{\mathrm{C}}$. The decoupling of radial and vertical heat losses introduced here reduces the number of parameter groups required to describe the system to three: $\mathrm{Pe}, \Lambda$, and $\mathrm{Bi}$. However, the tilting of the thermal front influences both the radial and the vertical losses, since the tilting modifies the area over which heat conduction occurs. An empirical shape factor based on the angle of tilt of the thermal front, $\alpha$, is introduced to modify the parameter groups. Thus $\Delta E_{a}$ depends on the modified Peclet number, $\mathrm{Pe}^{*}$, whereas $\mathrm{E}_{c}$ depends on $\hbar$ and $\mathrm{Bi}^{*}$.

The closed form solution for $\alpha$ used in this study is based on several simplifying assumptions derived by Hellstrom et al. (1979). Figure 2 shows $\Delta E_{c}$ as a function of $\Lambda^{*}$ and $\mathrm{Bi}^{*}$ calculated from a one-dimensional heat conduction problem in which heat diffuses from aquifer to aquitard. Also included is the effect of a constant temperature boundary overlying a finite-thickness cap rock. Figure 3 shows $\Delta \mathrm{E}_{\mathrm{a}}$ as a function of $\mathrm{Pe}^{*}$ calculated from vertically insulated cases of ATES cycles. Hence, using values of $\mathrm{Pe}^{\star}, \Lambda^{\star}$, and $B{ }^{*}$ obtained from field input data, $\Delta A_{a}$ may be determined and combined to form $\varepsilon$. Although not mathematically rigorous, the method has been shown to yield accurate predictions for a wide range of conditions when compared with CCC-simulated results, as shown in Table 1 .

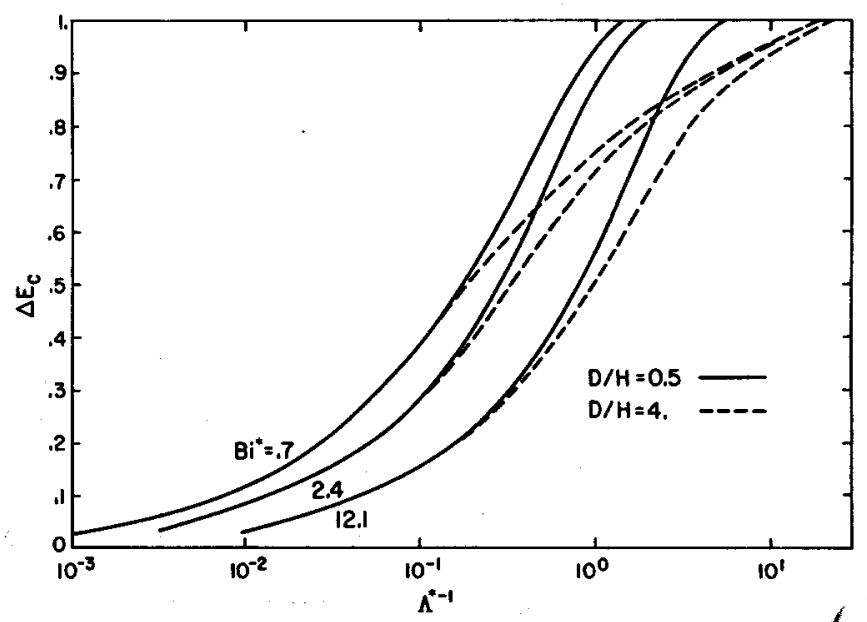

Figure 2. Vertical heat 1oss, $\Delta \mathrm{E}_{C}$, as a function of $\Lambda^{-1 *}, B i^{*}$, and $D / H$ (the ratio of cap rock to aquifer thickness). For $D / H \geqslant 4$, the system behaves as though $\mathrm{D} / \mathrm{H}=\infty$. [XBL 813-2757A] 


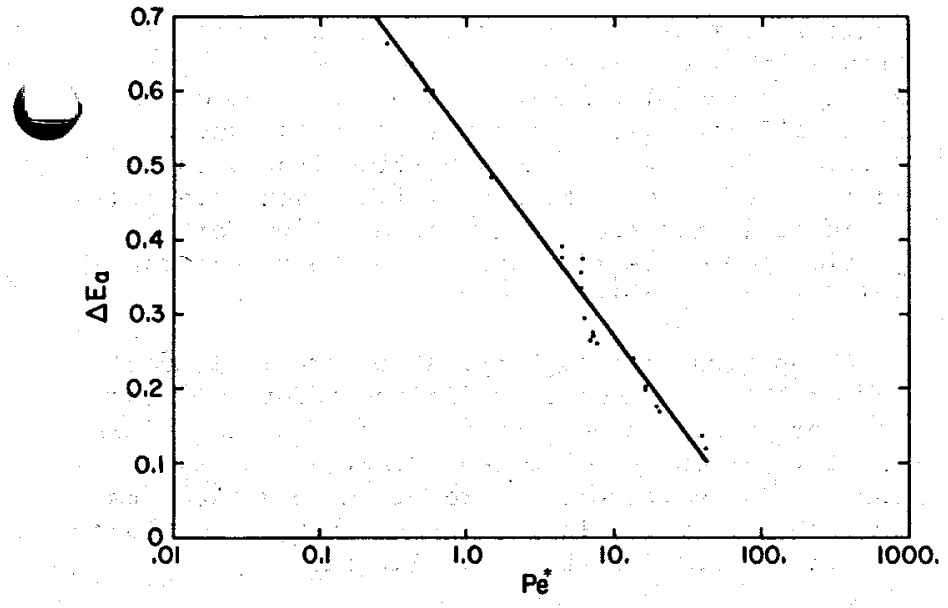

Figure 3. Radial heat loss, $\Delta \mathrm{E}_{\mathrm{a}}$, as a function of $\mathrm{Pe}^{\star}$. [XBL 813-2756]

REFERENCES CITED

Bu scheck, T. A., and Tsang, C. F., 1981. Characterization of heat storage in confined aquifers and its application to the Auburn field experiments. In proceedings, second wor 1d Congress of Chemical Eng ineering, October 4-9, 1981, Montreal, Canada.

Doughty, C. Hellstrom, G., Tsang, C. F., and Claesson, J., 1982. A dimensionless parameter approach to the thermal behavior of an aquifer thermal energy storage system. Water Resources Research, In press. (A preliminary version is avallable as Lawrence Berkeley Laboratory Report (BL-11029.)
Table 1. Comparisons of calculated and observed energy recovery ratio values. Calculated values obtained using the characterization scheme; observed values obtained from CCC simulations.

\begin{tabular}{lllll}
$T_{1}(\mathrm{c})$ & $k_{a}$ (d) & (deg) & (calc) & (obs) \\
\hline 36 & 15 & 12 & 0.66 & 0.69 \\
36 & 52 & 35 & 0.64 & 0.67 \\
55 & 52 & 64 & 0.54 & 0.57 \\
$55^{\star}$ & 52 & 54 & 0.64 & 0.65 \\
70 & 52 & 73 & 0.46 & 0.46 \\
90 & 52 & 79 & 0.34 & 0.34 \\
\hline
\end{tabular}

Notes:

$T_{1}$ - Injection temperature. Ambient temperature $1520 \mathrm{C}$.

$k_{a}=$ horlzontal aquifer permeablilty. vertical permeability is $1 / 10$ th horizontal permeabillty.

$\alpha$ - thermal front angle of tilt at the end of the storage period.

Aquifer thickness $1 \mathrm{~s} 21.2 \mathrm{~m}$.

volume of injected water is $55,000 \mathrm{~m}^{3}$.

Injection-Storage-Production cycle is 90-90-90days except case 55*, which 18 60-60-60 days.

Hellstrom, G., Tsang, C. F., and Claesson, J., 1979. Heat storage in aquifers: Buoyancy flow and thermal stratification problems. Lund Institute of Technology, Iund, Sweden. (Lawrence Berkeley Laboratory Report LBL-14246.)

\section{A COMPARATIVE STUDY OF FOUR MAJOR APPROACHES TO PREDICTING ATES PERFORMANCE

\author{
C. Doughty, T. A. Buscheck, G. S. Bodvarsson, and C. F. Tsang
}

The International Energy Agency test problem, briefly described below, has been solved using four approaches: the numerical model PT (formerIy $\mathrm{CCC}$. the simpler numertcal model SFM, and two graphical charactrization schemes (Doughty et al., 1982a). Each of the four techniques has its advantages and disadvantages, as discussed below.

The test problem considers an 80 -day ATES cycle for a doublet well system in a 10-m-thick aquifer confined above the below by $20-\mathrm{m}$ thick aquitards. The well spacing is $50 \mathrm{~m}$, the water flow rate is $10 \mathrm{~m}^{3} / \mathrm{hr}$, the injection temperature is $45^{\circ} \mathrm{C}$, and the ambient aquifer temperature is $11^{\circ} \mathrm{C}$. Horizontal permeability in the aquifer is $10^{-11} \mathrm{~m}^{2}(10 \mathrm{~d})$; values for cap rock and edrock are 10 and 100 times less, respectiveiy. For each layer, vertical permeability is 1/10th horizontal permeability.
NUMERICAL MODELS AND GRAPHICAL METHODS

PT (Pressure-Temperature)

PT (pressure-temperature), previously named ccc (conduction-convection-consolidation), is an integrated finite-difference code that solves simultaneously the coupled heat and mass transport equations for slightly compiessible fluid flow in a porous or fractured medium. Material properties may be temperature dependent and may vary throughout the system. Complex geometry systems with multiple wells may be modeled. The code CCC has been used extensively since 1975 for a multitude of aquifer thermal energy storage (ATES) and geothermal problems and has been validated against a variety of analytical solutions and several field experiments. Incorporation of improved mathematical and numerical formulations 
over the last few years has led to the recent name change to PT. Most of the ATES studies at Lawrence Berkeley Laboratory have been carried out using the new version. Details of this numerical model may be found in Tsang et al. (1976, 1978, 1981) and Bodvarsson (1982).

\section{SFM (Steady Flow Model)}

The SFM uses a fully explicit finite-difference scheme to calculate conductive heat transfer around a single well in a radially symmetric system. Convection is simulated by translating the temperature field in accordance with a steady radial fluid flow. The mesh is specifically designed to minimize the numerical dispersion that arises in convection-conduction problems. All material properties are temperature-independent. The aquifer is considered to be homogeneous and horizontal, the cap and bedrock impermeable. Note that the constraint of radial fluid flow requires that for this problem the supply-well (doublet) effects, buoyancy flow, and cap and bedrock permeabilities be negligible. Details of this numerical model may be found in Doughty et al. (1982b).

\section{Graphical Methods}

The purpose of our graphical characterization schemes is to develop some general parameters or procedures whereby the energy recovery factor may be predicted readily for a given problem without doing a detailed numerical simulation. Two graphical characterization schemes have been developed; the first neglects buoyancy flow (Doughty et al.. $1982 \mathrm{~b}$ ), and the second includes it (Buscheck and Tsang, 1981). The previous two articles in this report describe these characterization schemes.

\section{RESULTS}

\section{Areal Temperature Distribution}

In order to examine the areal temperature distribution in the aquifer, the program PT (CCC) was used to simulate an injection-storage-production cycle using a doublet mesh (Fig. 1), in which both the injection/production and supply

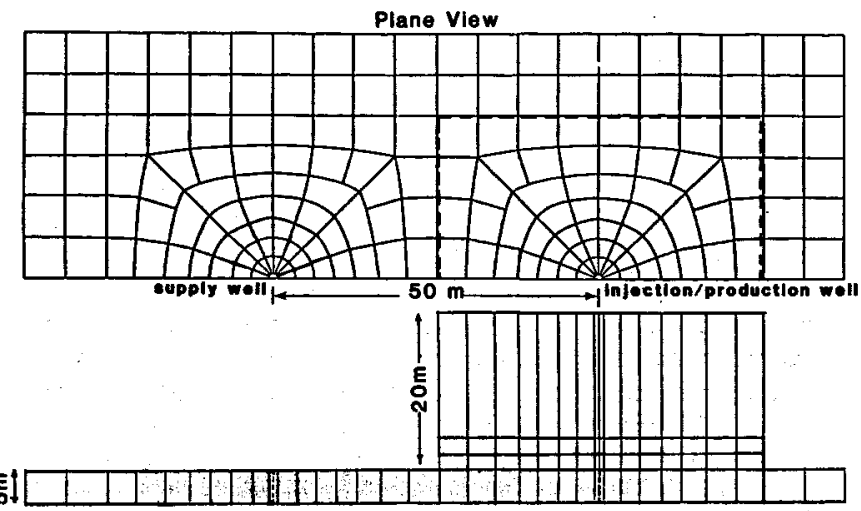

Vertical View

Figure 1. PT (CCC) doublet mesh. The broken lines in the plane view show the extent of the cap rock layers. wells were modeled. The temperature distribution at the end of injection is shown in Figure 2. A single-well, radially symmetric approximation will give circular temperature contours. Figure 2 illustrates the deviation from such an ideal case. The deviation will be even more significant if the flow rate, permeability, or injection period is increased from the values specified in the problem.

When running a sophisticated numerical model such as PT, the number of finite-difference mesh elements that can be used is limited by the availability of computer time and funding. Because the doublet configuration requires many elements in each horizontal layer, several simplifications had to be made for this calculation.

1. The mesh spacing is rather coarse. Hence numerical dispersion acts to artificially increase the horizontal diffusion of the thermal front; the contour line that is probably least affected by the dispersion is the one for $\left(T_{1}+T_{0}\right) / 2=28^{\circ} \mathrm{C}$. Vertical heat transfer is only slightly affected by the mesh coarseness.

2. The aquifer is modeled as a single layer of elements. This is possible because buoyancy flow is small and the aquifer is rather thin.

3. Only the top half of the system is modeled, with the midplane of the aquifer acting as a plane of symmetry. This is possible because buoyancy flow is negligible and the cap and bedrock have similar thermal and hydraulic properties.

The validity of these assumptions is discussed in Doughty et al. (1982b). The coarse mesh increases radial numerical dispersion, leading to a low energy recovery factor.

\section{Production Temperature and Energy Recovery Factor}

In order to calculate the energy recovery factor, production temperature as a function of time, energy balances, and detailed vertical temperature distributions, the codes PT (CCC) and SFM were run with radially symmetric meshes centered on the injection/production well. It turns out that since the production temperature and recovery factor are "integrated" quantities, and since doublet effects tend to cancel out over the course of the cycle, the radially symmetric and doublet meshes give similar results.

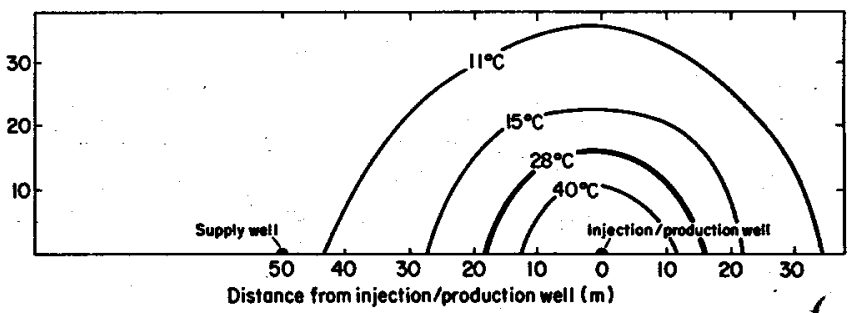

Figure 2. PT (CCC) doublet mesh. Areal temperature distribution at end of injection.

[XBL 8111-4805] 
1. The computer code PT (CCC) calculated an energy recovery factor of 0,704. Production temperature is shown in Figure 3 , and a vertical secjion temperature contour plot for the end of injection is shown in Figure 4.

2. The computer code SFM calculated an energy recovery factor of 0.749 . Production temperature is shown in Figure 3 , and a vertical section temperature contour plot for the end of injection is shown in Figure 5. The difference between the production temperature curves calculated by PT and SFM is due to the difference in diffuseness of the radial thermal front shown in Figures 4 and 5. The larger diffuseness calculated by PT is due to numerical dispersion.

\section{Graphical Characterization Schemes}

In order to get a quick estimate of energy recovery factor without the use of detailed numerical modeling, the graphical characterization schemes are used.

1. For the first scheme, which does not include buoyancy flow, the parameter groups are formed as:

$\mathrm{Pe}=98.2, \Lambda=89.2, \frac{\tilde{\lambda}_{\mathrm{a}}}{\lambda_{c}}=1.67, \mathrm{~d}=2$.

Then Figures 1 to 3 on pages 126 and 127 are read to determine the energy recovery factor and the shape of the production temperature curve. Note that for $d=2$, finite cap rock effects are negligible; that the energy recovery factor is 0.74 to 0.75 ; and that the shape of the production temperature curve will be similar to that shown for $\mathrm{Pe}=50 ; \Lambda=50$.

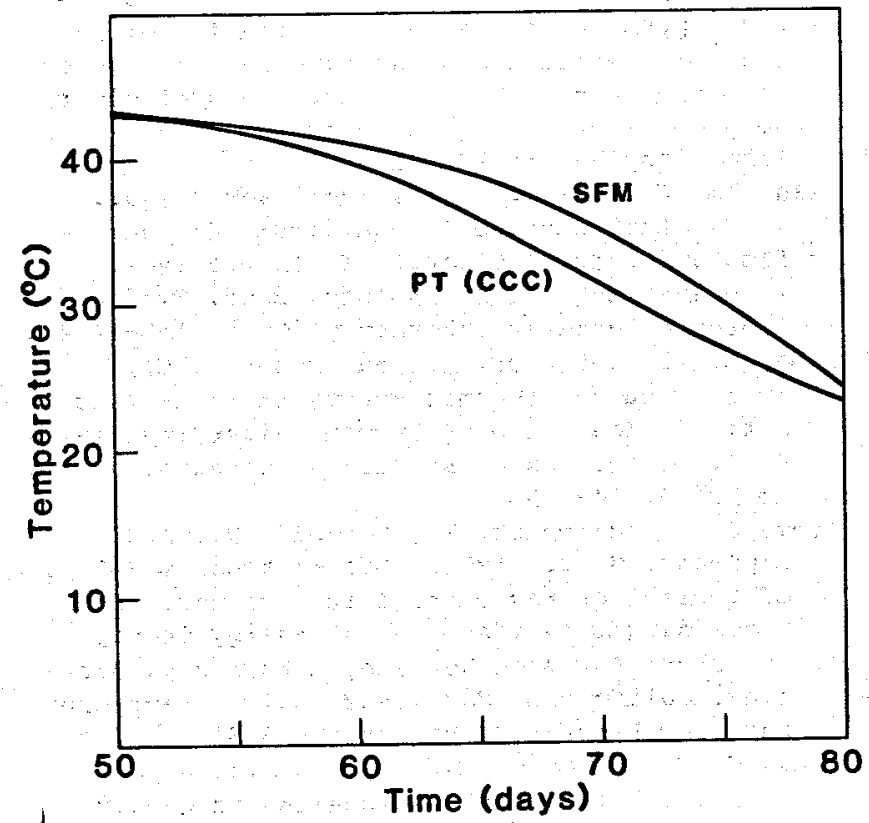

Figure 3. Production temperature vs. time.

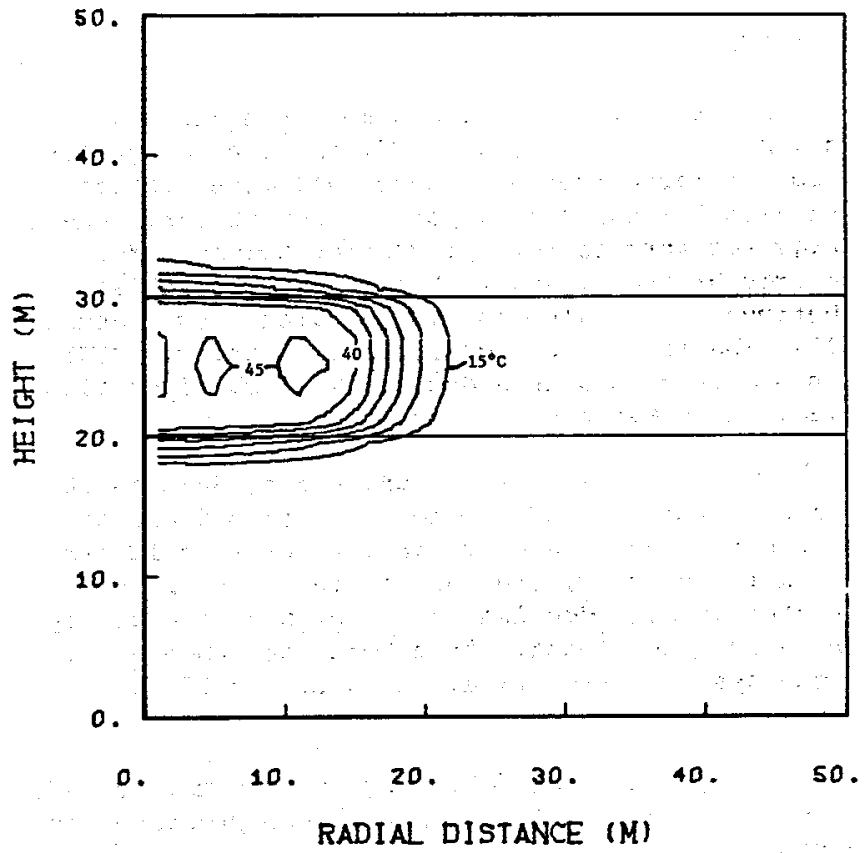

Figure 4. PT (CCC) radial mesh. Vertical temperature distribution at end of injection.

[XBL $8111-4807]$

2. The second scheme does include buoyancy flow, but since it is negligible for this problem, the parameters simplify to:

$P e^{*}=36.3, \Lambda^{*-1}=0.0157, B^{*}=0.731$.

From Figures 2 and 3 on pages 128 and 129, $\Delta \mathrm{E}_{\mathrm{c}}=0.145$ and $\Delta \mathrm{E}_{\mathrm{a}}=0.117$, so that $\varepsilon=0.753$.

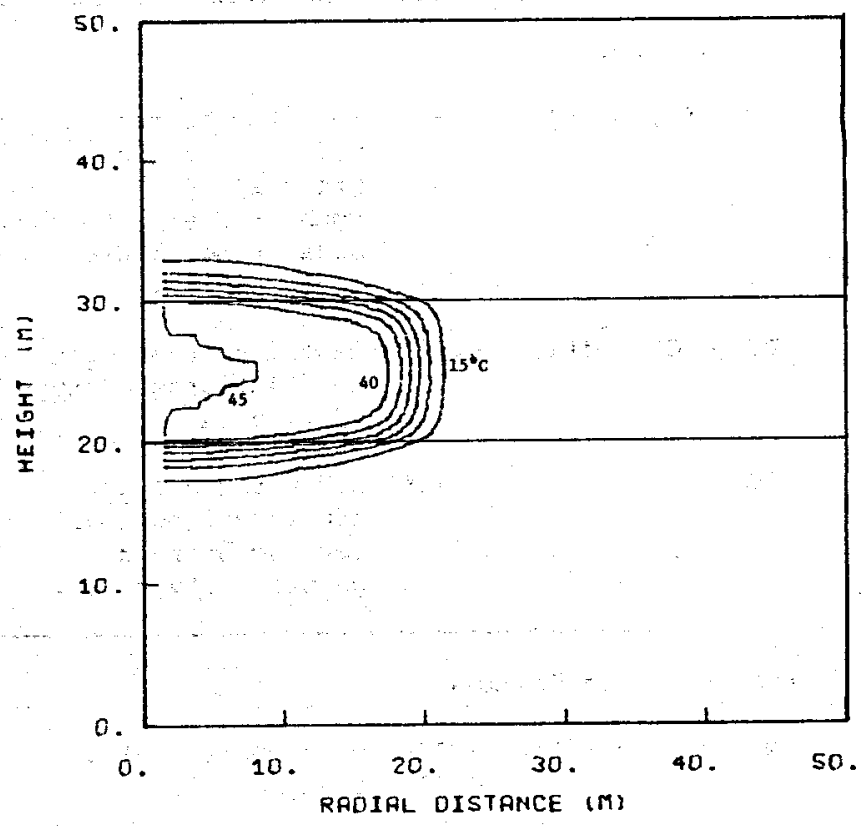

Figure 5. SFM mesh. Vertical temperature distribution at end of injection.

[XBL 8111-4809] 


\section{CONCLUSTONS AND REMARKS}

For this particular problem, the two numerical models, PT (CCC) and SFM, and the two graphical characterization schemes all give similar results for the most important quantities: energy recovery factor, production temperature, energy balances, and vertical temperature distributions. The exception is the areal temperature distribution in the aquifer; for this, PT (CCC) should be used with a doublet well configuration. Table 1 sumarizes the results.

This conclusion is strongly dependent on the problem solved. If the temperature difference between injected and original water were larger by a factor of 2 , and the permeability of the system is also doubled, the buoyancy effects may be very significant. Then both the SEM and the nonbuoyant characterization scheme would not be applicable.

In general, the following remarks may be made concerning the different approaches presented in this paper:

1. The nonbuoyant characterization scheme Ignores buoyancy effects and assumes simplified anisotropic properties of the system. On the other hand, the buoyant characterization scheme,

Table 1. Summary of results.

Method $\varepsilon \quad$ Comments

Numerical Models

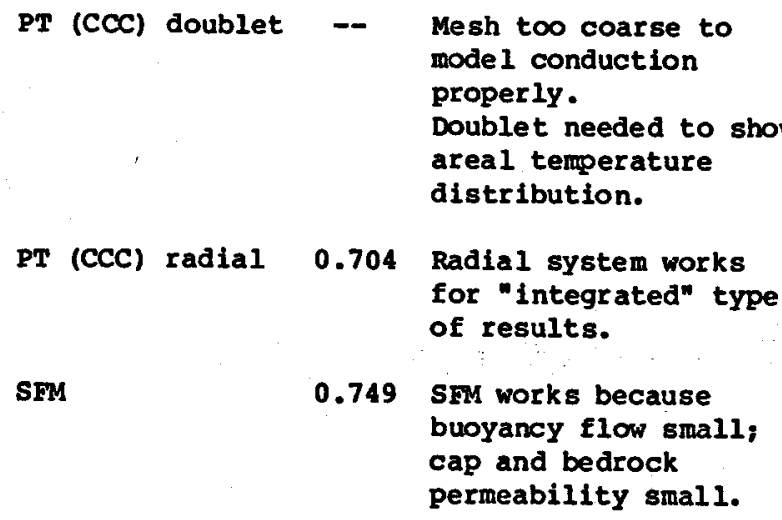

Characterization Schemes
No buoyancy flow
0.74- No computer calcula-
0.75 tion needed.
Buoyancy flow
0.753 No computer calcula- tion needed.

though it includes buoyancy flow, is a semiempirical approach. Nevertheless, both schemes are graphical and require no computer simulations. They should be used to give a first-order estimate of results.

2. Although the SFM ignores buoyancy flow and fluid flow in the confining layers, it does properly account for aquifer conduction and convection, aquitard conduction, effects of cap rock thickness, and different injection-storage-production periods. This model is applicable to cases in which buoyancy effects are small and the cap rock and bedrock are much less permeable than the aquifer.

3. The model PT (CCC) is the most general model, taking into account transient fluid flow behavior, complex properties and geometry, and temperature-dependent effects. It should be used to establish the applicability of SEM or other simpler models, or, where necessary, to solve the problem directly.

\section{REFERENCES CITED}

Bodvarsson, G. S., 1982. PT user's guide. Lawrence Berkeley Laboratory Report, in preparation.

Buscheck, T. A., and Tsang, C. F. 1981. Characterization of heat storage in confined aquifers and its application to the Auburn field experiments. In Proceedings, Second World Congress of Chemical Engineering, October 4-9, 1981, Montreal Canada.

Doughty, C., Buscheck, T. A., Bodvarsson, G. S., and Tsang, C. F., 1982a. A comparative study of two numerical and two graphical approaches to predicting aquifer thermal energy storage performance. Lawrence Berkeley Laboratory Report IBL-14302, in preparation.

Doughty, C., Hellstrom, G., Tsang, C. F., and Claesson, J., 1982b. A dimensionless parameter approach to the thermal behavior of an aquifer thermal energy storage system. Water Resources Research, in press. (A preliminary version is available as Lawrence Berkeley Laboratory Report IBL-11029.)

Hellstrom, G., Tsang, C. F., and Claesson, J., 1979. Heat storage in aquifers: Buoyancy flow and thermal stratification problems. Lund Institute of Technology, Lund, Sweden. Lawrence Berkeley Laboratory Report LBL-14246.

Tsang, C. F., Buscheck, T., and Doughty, C., 1981. Aquifer thermal energy storage-A numerical simulation of Auburn University field experiments. Water Resources Research, v. 17, no. 3, p. 647-658.

Tsang, C. F., Buscheck, T., Mangold, D., and Lippmann, M. J., 1978. Mathematical modeling of thermal energy storage in aquifers. In Proceedings, Aquifer Thermal Energy Storage Workshop, Lawrence Berkeley Laboratory, Berkeley, California, May 10-12, 1978. Lawrence Berkeley Laboratory Report LBL-8431.

Tsang, C. F., Lippmann, M. J., and Wither spoon, P. A., 1976. Numerical modeling of cyclic storage of hot water in aquifers. Symposium on use of aquifer systems for cyclic storage of water. Fall Annual Meeting of the Anerican Geophysical Union, San Francisco, 1976. 


\title{
CERRO PRIETO PROGRAM
}

\section{OVERVIEW OF THE MEXICAN-AMERICAN COOPERATIVE PROGRAM AT THE CERRO PRIETO GEOTHERMAL FIELD}

\author{
M. J. Lippmann and R. Zelwer
}

The Lawrence Berkeley Laboratory (IBL) is coordinating the $\mathrm{U}$. S. technical activities being carried out at Cerro Prieto under a five-year agreement between the U. S. Department of Energy (DOE) and the Comisiof Federal de Electricldad de Mexico (CFE) (Witherspoon et al., 1978). This agreement, signed in July 1977, is expected to expire in July 1982. Ef forts are being made to continue some of the research beyond the formal termination of the agreement.

The Cerro Prleto geothermal fleld is located in the Mexicall Valley, Baja California, Mexico, about $35 \mathrm{~km}$ southeast of the clty of Mexicali (Figs. 1 and 2). The installed electrical power generating capacity at the field is $180 \mathrm{MWe}$.

The development of the resource continues at a fast pace. In July 1981 four rigs were drilling in the field. About 90 deep wells have been completed (Fig. 3), and construction of two 220wwe power plants is underway (one of these plants is scheduled to go into operation in 1983 , the other, in 1984).

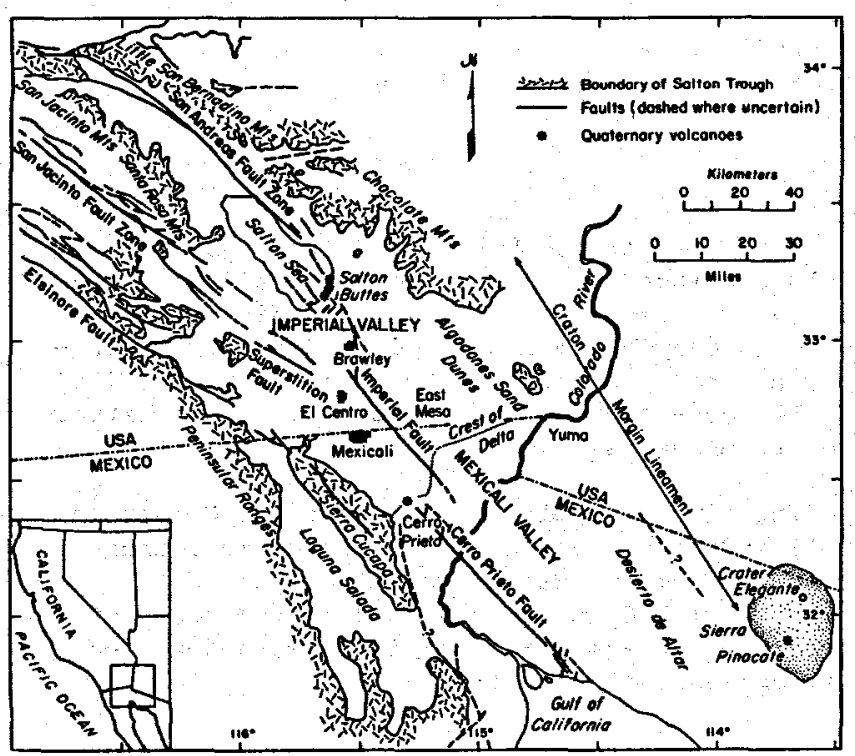

Sure 1. Regional geological map of the Salton Trough, showing the location of the Cerro Prieto field, southeast of the city of Mexicali.

[XBL 801-6718]

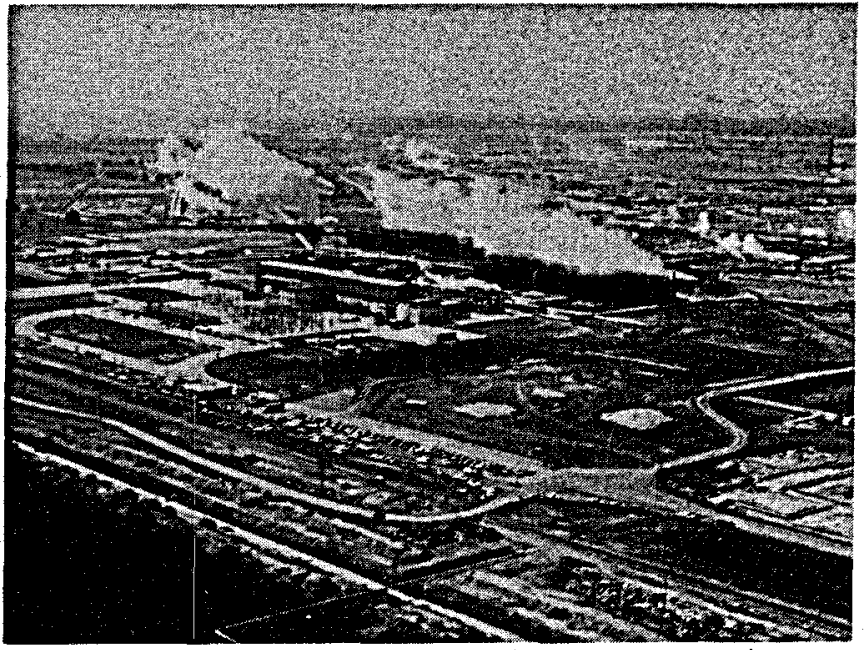

Figure 2. Cerro Prleto power plant and part of the well fleld. View is toward the south.

[CBB 803-3124]
Step-out wells have tentatively established the north and northeastern boundaries of the resource in the western part of the fleld (Cerro Prieto I). The producing reservoir is at a depth of $1250 \mathrm{~m}$ and has an average temperature of $280^{\circ} \mathrm{C}$ Deep wells recently drilled there have confirmed the existence of another aquifer that is not only deeper but hotter (about $350^{\circ} \mathrm{C}$ ).

During this past year, significant advances were made toward reaching the main objectives of the program, which are to develop a hydrogeologic model of the cerro prieto system and to study the system's response to large-scale fluid production. The analysis of recent geological, geophysical, geochemical, and reservoir engineering data are confirming the hypotheses that the reservoir is being recharged by hot waters coming mainly from the east and northeast, and that colder waters are moving into the reservolr from shallower aquifers and possibly from the western edges of the field.

The analysis of the performance of the wells from the Cerro Prieto I area, under exploitation since 1973, has shown changes in the output rate, quality, enthalpy, and chenistry of the produced fluids. These changes are attributed to continued fluid extraction. 


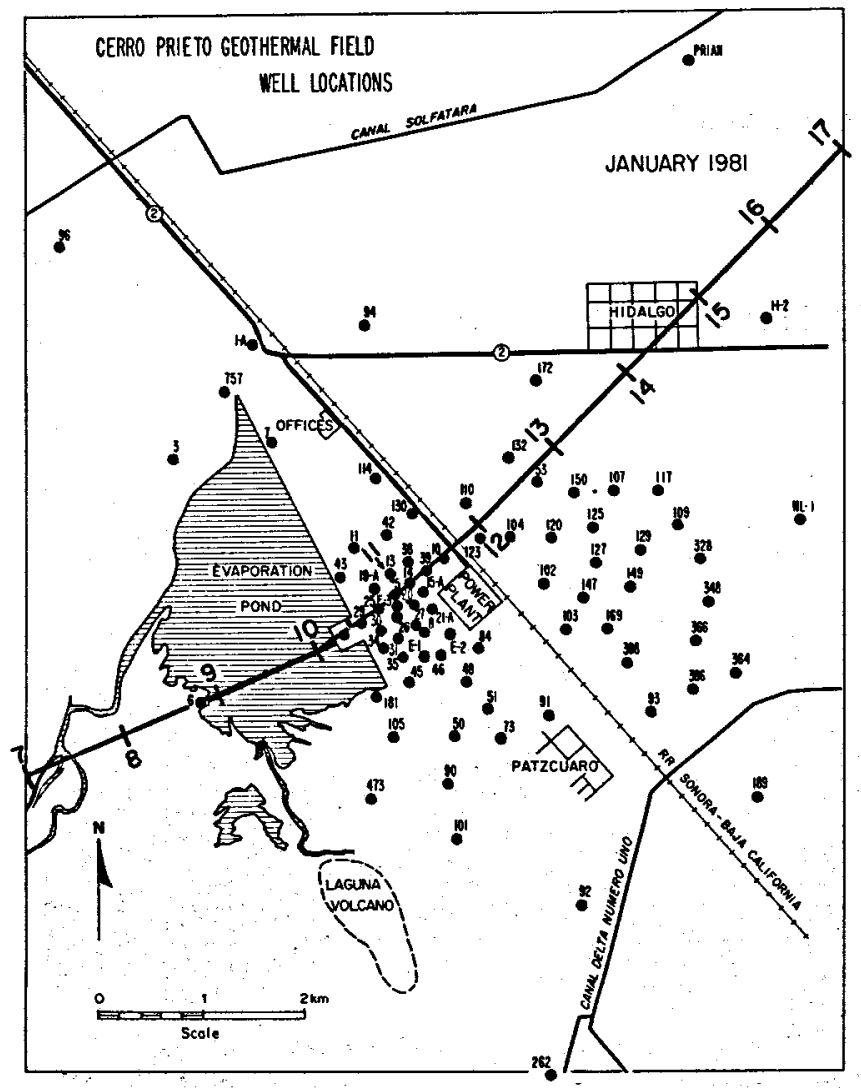

Figure 3. Location of deep wells at the Cerro Prieto field (as of July 1981).

[XBL 811-2532C]

\section{ACTIVITIES DURING FISCAL 1981}

Some of the activities and results discussed below are described in further detail elsewhere in this volume. Most of the results obtained previously are reported in the proceedings of the Cerro Prieto symposia (Lawrence Berkeley Laboratory, 1978, 1981; Comisión Federal de Electricidad, 1979).

\section{Geology}

The analysis of wireline logs from Cerro Prieto wells continued. The calculation of density, porosity, salinity, and permeability, and their distribution throughout the field were carried out using two computer programs (PETROS and ROMEO). The location of a volume of low-density rock extending from the Laguna Volcano toward the northeast is belleved to correspond to the site of current upwelling of geothermal hot water into the field. A relatively high-density rock volume found at shallow depth in the Cerro Prieto $I$ area is considered to be related to zones of increased mineralization resulting from the cooling of a rising plume of geothermal brine (Howard et al.. 1981).

Mainly on the basis of mineralogic and isotopic studies of well cuttings and cores, Elders et al. (1981) proposed a flow regime for the geothermal field before it was developed (Fig. 4).

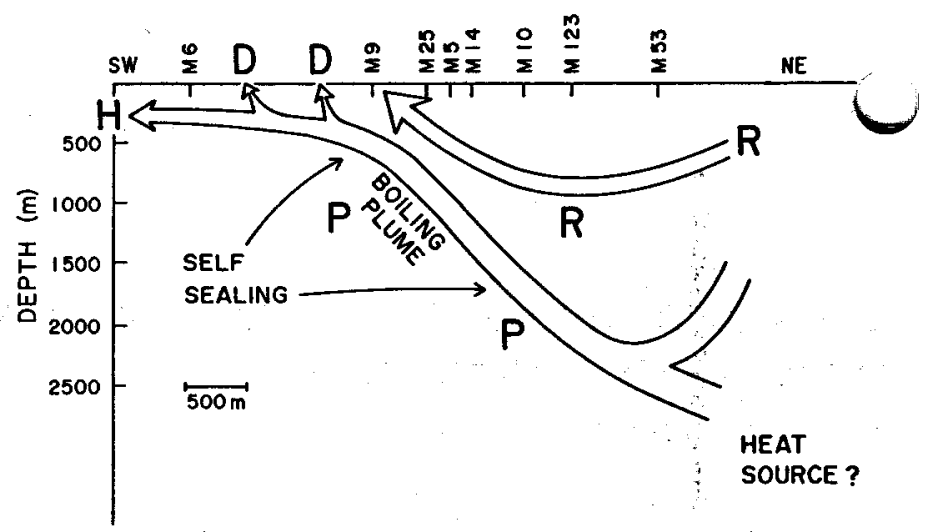

Figure 4. Southwest-northeast section across the field, showing the proposed flow regime. $R=$ recharge zone; $P=$ thermal plume zone; $D=\mathrm{d}$ ischarge zone; $H=$ horizontal flow zone (from Elders et al., 1981).

[XBL 8111-4843]

They suggested that the heat source of the hydrothermal system lies to the northeast of the field. A plume of hot saline water rises from this source, discharging upward and horizontally to the southwest, forming hot springs and fumaroles at the surface. The same authors, using data from isotope and fission-track annealing studies, computed an average fluid velocity of about $6 \mathrm{~m} / \mathrm{yr}$ for this plume.

A micropaleontological analysis of some 30 core samples was completed by Ingle (1982). The foraminiferal evidence indicates that $a$ sand and shale unit commonly present at depths between $\mathbf{7 0 0}$ and $1100 \mathrm{~m}$ represents a significant mid-Pleistocene marine incursion. Tentative correlations suggest that the Pliocene/Pleistocene boundary occurs at a depth of about $2000 \mathrm{~m}$ in the southeastern part of the field. The presence of reworked specimens of Cretaceous foraminifera and pelecypoda (Fig. 5) further substantiate the Colorado Plateau provenance of a significant portion of the deltaic sediments in the cerro Prieto area.

\section{Geophysics}

A program of geophysical monitoring of the field continued. A new set of dipole-dipole resistivity, precision gravity, and seismic monitoring surveys were completed to determine whether subsurface changes in the physical properties of the rocks occurred in response to fluid extraction from the reservoir.

The dipole-dipole survey (wilt and coldstein, 1981) indicated apparent resistivity increases over the Cerro Prieto I area at depths of $1 \mathrm{~km}$ and greater. On the other hand, large zones of decreasing apparent resistivities were detected west and east of that area.

For the third year in succession, precision gravity data were collected over the fleld (Fig. 6) (Grannell et al.. 1981). For the most part, the year-to-year gravity differences do not show significant variations. Gravity increases were observed between the third and fourth years of measurements. These increases appear to be 


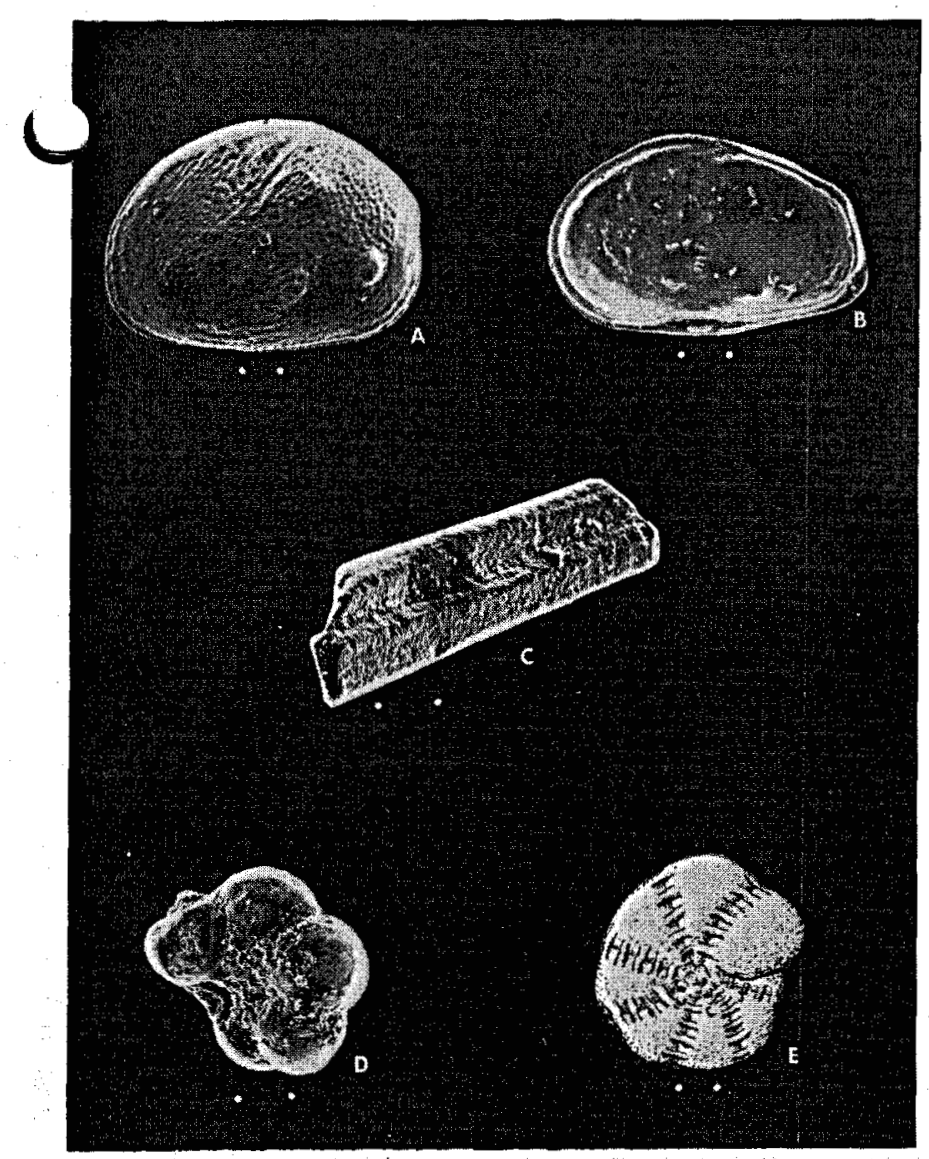

Figure 5. Representative microfossils recovered from Plio-pleistocene sediments of the Cerro Prieto geothermal field, Baja California, Mexico. (A) Scanning electron micrograph (SEM) exterlor view of ostracode shell from $706 \mathrm{~m}$ in well M-5. (B) SEM view of interior of ostracode shell from $706 \mathrm{~m}$ in well $M-5$. (C) SEM view of reworked Cretaceous Inoceramus prism from a depth of 818 to $824 \mathrm{~m}$ in well M-9. (D) SEM view of reworked partial internal mold of the Cretaceous planktic foraminifer Hedbergella. (E) Line drawing of a replaced specimen of the benthic foraminifer Elphdium gunteri cole from a depth of 1944 to $2952 \mathrm{~m}$ in well $\mathrm{M}-93$. Note that the distance between the two dots beneath each view represents 100 microns (from Ingle, 1981).

[XBB 821-493]

associated with the June 8,1980 , Victoria earthquake, which was centered nearby and caused conslderable ground subsidence.

The second IBL detailed microearthquake suxvey was carried out over Cerro prieto (Majer and MoEvilly, 1981). There appears to be an increase in seismic activity within the production zone since the first survey was completed in 1978, perhaps reflecting reservoir dynamics associated ith mass and heat withdrawal. It is believed that the small reinjection program started in August 1979 is not responsible for the increased seismic activity.

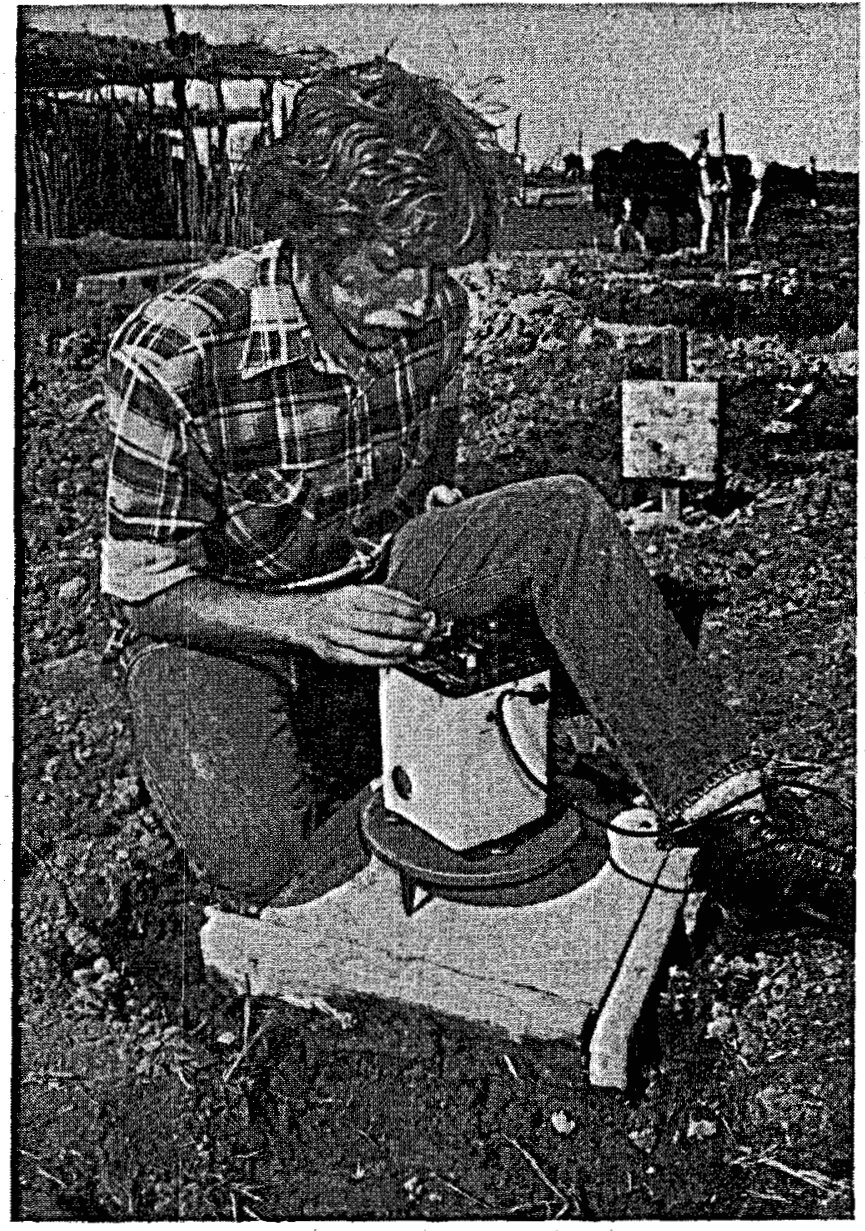

Figure 6. Precision gravity measurement being made at a permanent station of the Cerro Prieto net.

[CBB 782-2264]

\section{Geochemistry}

Mazor and Truesdell (1981) used noble gases as tracers to establish the dynamics of fluids of the Cerro prieto field. The positive correlations between concentrations of radiogenic (He, $40_{A r}$ ) and atmospheric ( $\mathrm{Ne}, \mathrm{Ar}$, and $\mathrm{Kr}$ ) noble gases suggested the following dynamic model: the geothermal fluids originate from meteoric water that penetrated to more than $2500 \mathrm{~m}$ depth and mixed with radiogenic hellum and argon-40 formed in the aqu 1fer rocks. Later, small amounts of $s$ team 10 to 38) were lost by a Ralelgh process (continuous steam removal as it was formed) and mixing with shallow cold water occurred (0 to 308 ).

Nehring and D'Amore (1981) analyzed the composition of the gases collected at the geothermal wells on the assumption that these gases were either derived from high-temperature reactions within the reservoir or introduced with the recharge waters. These authors found evidence of meteoric water flowing toward the reservoir from the west and northwest and of reservoir fluid degassing in the central part of the field due to the existence of a small two-phase fluid zone. 
Radon and ammonia transects were made by Semprint and kruger (1981) to study flow and thermodynamic characteristics of the reservir. It appears that phase separation occurs well within the Cerro Prieto reservoir and that radon achieves radioactive equilibrium partitioning model in which enrichment of ammonia correlates with higher-enthalpy vapor.

valette-silver et al. $(1981 a, b)$ classified the surface hydrothermal manifestations (at Cer ro Prieto) into five categories (e.g., hot springs, mud pots, "geysers," fumaroles, and warm pools) and studied their mineralogy and chemical characteristics. They observed significantly less potassium, slightly less calclum and chloride, and significantly more magnesium and sulfate in the waters of the surface manifestations than in the waters from producing wells. They suggested that these differences result from dilution and reaction with carbonate, clay minerals, and other aluminosilicates as the waters ascend from the geothermal reservoir to the surface.

On the basis of chemical, production, and reservoir engineering data, Grant et al. (1981) concluded that the relatively shallow western part of the Cerro Prieto reservoir is bounded below by low-permeability rocks and above and to the sides by an interface with cooler water. There is no continuous permeability barrier around or immediately above the reservoir. Permeability within the reservoir is predominantly intergranular. In the natural state, reservoir cooling takes place mainly by mixing of cooler water with the hot water rather than by boiling. Production has caused displacement of hot water by cooler water rather than by vapor. Local boiling occurs near most wells in response to pressure decreases, but no extended vapor zone has formed (Fig. 7).

\section{Subsidence}

Cores from nine wells were tested in the laboratory under simulated in situ conditions to measure porosity reduction triggered by reservoir drawdown (Schatz, 1981). Results indicate that compaction is often time-dependent. Extrapolations to a reservoir life of 20 to $30 \mathrm{yr}$ have shown that reductions of several percent in porosity and several tens of percent in permeability are possible.

In 1981 the U. S. Geological Survey resurveyed for the second time their regional trilateration net in the Mexicali valley and their local net around the Cerro Prieto field. Horizontal ground surface movements in the regional net were small and did not exceed the noise level. The 1979 resurvey of the local net showed an apparent horizontal movement of 2 to $3 \mathrm{~cm}$ toward the center of the production area; movement was restricted to the limits of the field. The 1981 resurvey of the local network did not show increased movement attributable to fluid extraction from the field (Massey, 1981).

\section{Reservolr Engineering}

Heat and mass production data for the period 1973 to 1980 were analyzed by Goyal et al. (1981).

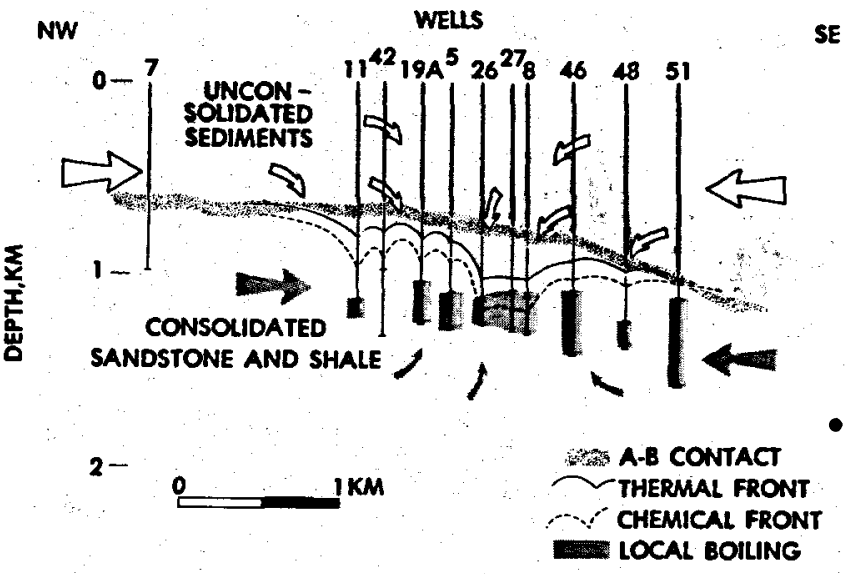

Figure 7. Schematic section across the western part of the Cerro Prieto field, showing movement of hot water (gray arrows) and cold water (white arrows) toward the producing wells, the chemical and thermal fronts, and zones of near-well boiling (from Grant et al., 1981).

[XBL 8111-4844]

It was found that the production of individual wells generally decreased with time due to relative permeability effects, a reduction of permeabillty, and/or a reduced pressure gradient in the reservoir. The average enthalpy of the produced fluids has varied over the years. The increases in enthalpy were, usually the result of bringing higher-enthalpy wells on line. The decrease in the average enthalpy is thought to be due to the mixing of relatively colder water with the geothermal reservoir fluids.

Using known wellhead data, Goyal et al. (1980, 1981) calculated downhole pressures, temperatures, and saturations in flowing wells. The data show that during the period 1973 to 1980, the pressures and temperatures decreased by about 15 bars and $20^{\circ} \mathrm{C}$, and the steam saturations had increased slightly in the near-well regions. The studies confirmed the fact that computed downhole pressures are very sensitive to measured wellhead conditions and to changes in the inside diameter of the well.

The response of the producing Cerro Prieto reservoir to fluid injection at different depths was analyzed by Tsang et al. (1981). A number of idealized models of the field were considered for both single-phase (liquid) and two-phase (steam and water) calculations.

\section{Conferences}

The Third Cerro Prieto symposium was held March 24-26, 1981, in San Francisco, California. It included a field trip to The Geysers geothermal field in Sonoma county. The meeting was organized by IBL with the assistance of $\mathrm{DOE}$ and CFE. Work on the proceedings of this symposium is underway; publication is expected for the first half of 1982 .

A meeting with CFE was held in preparation of the Fourth Symposium, scheduled for August 1982 in Guadalajara, Mexico. 


\section{REFERENCES CITED}

omisioń Federal de Electricidad, 1979. In Proceedings, Second Symposium on Cerro Prieto Geothermal Field, Mexicali, Baja California, Mexico, October 17-19, 1979. Mexicali, Comision Federal de Electricidad.

Elders, W. A., Williams, A. E., and Hoagland, J. R., 1981. An integrated model for the natural flow regime in the Cerro Prieto hydrothermal system, B.C., Mexico, based upon petrological and isotope geochemical criteria. In Proceedings. Third symposium on the Cerro Prieto Geothermal Field, Baja California, Mexico, March 24-26, 1981. Lawrence Berkeley Laboratory Report IBL-11967, in preparation.

Goyal, R. P., Miller, C. W., and Lipprann, M. J., 1980. Effects of measured wellhead parameters and well scalling on the computed downhole conditions in Cerro Prieto wells. In Proceedings, Sixth Workshop on Geothermal Reservoir Ingineering, December 16-18, 1980, Stanford, California, Stanford Geothermal Program Report SGP-TR-50, P. 130-138.

Goyal, K. P., Miller; C. W., Lippmann, M. J.. and Vonder Haar, S. P., 1981. Analysis of Cerro Prieto production data. In Proceedings, Third Symposium on the Cerro Prieto Ceothermal Field, Baja California, Mexico, March 24-26, 1981. Lawrence Berkeley Laboratory Report IBL-11967, in preparation.

Grannell, R. B., Kroll, R. C., Wyman, R. M., and Aronstam, P. S.. 1981. Precision gravity studies at Cerro Prieto--A progress report. In Proceedings, Third symposium on the Cerro Prieto Geothermal Field, Baja California, Mexico, March 24-26, 1981. Lawrence Berkeley Laboratory Report LBL-11967, In preparation.

Grant, M. A., Truesdell, A. H., and Mañón M., A., 1981. Production induced boiling and cold water entry in the Cerro Prieto geothermal reservoir indicated by chemical and physical measurements. In Proceedings, Third symposium on the Cerro Prieto Geothermal Field, Baja California, Mexico, March 24-26, 1981. Lawrence Berkeley Laboratory Report IBL-21967, in preparation.

Howard, J. H., Halfman, S. E., and Vonder Haar, S. P. 1981. Evaluation of Geological Characteristics at Cerro Prieto. In Proceedings, Third Symposium on the Cerro Prieto Geothermal Field, Baja California, Mexico, March 24-26, 1981. Lawrence Berkeley Laboratory Report LBL-11967, in preparation:

Ingle, T. C., Jr., 1982. Microfaunal evidence of age and depositional environments of the Cerro Prieto section (Plio-pleistocene), Baja CalIfornia, Mexico. Lawrence Berkeley Laboratory Report LBL-13897 in preparation.

Lawrence Berkeley Laboratory, 1978. Proceedings, First Symosium on the Cerro Prieto Geothermal Field, Baja Callfornia, Mexico, September 20-22, 1978. Lawrence Berkeley Laboratory Report LBL-7098.

Lawrence Berkeley Laboratory, 1981. Proceedings, Thira symposium on the Cerro Prieto Geothermal Fleld, Baja Callfornia, Mexico, March 24-26, 1981. Lawrence Berkeley Laboratory Report LBL-11967, in preparation.
Majer, E. L., and McEvilly, T. V., 1981. Detalled microearthquake studies at the Cerro prieto geothermal field. In Proceedings, Third Symposium on the Cer ro Prieto Geothermal Field, Baja California, Mexico, March 24-26, 1981. Lawrence Berkeley Laboratory Report LBL-11967, in preparation.

Massey, B. L., 1981. Measured ground-surface movements. Cerro prieto geothermal field, Baja Callfornia, Mexico. In Proceedings, Third Symposium on the Cer $\overline{r o}$ Prieto Geothermal Field, Baja California, Mexico, March 24-26, 1981. Lawrence Berkeley Laboratory Report LBL-11967, in preparation.

Mazor, E., and Truesdell, A. H., 1981. Dynamics of a geothermal field traced by noble gases? Cerro Prleto, Mexico. In Proceedings, Inird Symposium on the Cerro Prieto Geothermal Field, Baja California, Mexico, March 24-25, 1981. Lawrence Berkeley Laboratory Report LBL-11967, in preparation.

Wehring, N. L., and D'Amore, F., 1981. Gas chemistry and thermometry of the cerro Prieto geothermal field. In Proceedings, Third Symposium on the Cerro Prieto Geothermal Field, Baja Callfornia, Mexico, March 24-26, 1981. Lawrence Berkeley Labortory Report LBL-11967, in preparation.

Schatz, T. F., 1981. Properties of Cerro Prieto rock at simulated in-situ conditions.: In Proceedings, Third symposium on the Cer ro Prleto Geothermal Field, Baja California, Mexico, March 24-26, 1981. Lawrence Berkeley Laboratory Report LBL-11967, in preparation.

Semprint, L., and Kruger, P., 1981, Radon and ammonia transects across the cerro prleto geothermal field. In proceedings, Third symposium on the Cerro Prieto Geothermal Field, Baja California, Mexico, March 24-26, 1981 . Lawrence Berkeley Laboratory Report LBL-11967, in preparation.

Tsang, C. F.. Mangold, D. C., Doughty, C., and Lippmann, M. J., 1981. The Cerro Prieto reinjection tests: studies of a multilayer system. In Proceedings, Third Symposium on the Cerro Prieto Geothermal Field, Baja Californi a, Mexico, March 24-26, 1981. Lawrence Berkeley Laboratory Report LBL-11967, In preparation.

valette-silver, J. N., Esquer-Patiño, I. Elders, W. A., Collier, P. C., and Hoagland, J. R... 1981a. Hydrothermal alteration of sediments associated with surface emissions from the Cerro Prleto geothermal field, Baja Callforn1a. Mexico. In Proceedings, Third Symposium on the Cerro Prieto Geothermal Field, Baja California, Mexico, March 24-26, 1981. Lawrence Berkeley Laboratory Report IBL-11967 in preparation.

Valette-silver, J. N., Thompson, J. M., and Ball, J. W., 1981b. Relationship between water chemistry and mineralogy in the surficial part of the Cerro Prieto geothermal field. In Proceedings, Third symposium on the cerro Prieto Geothermal Field, Baja California, Mexico, March 24-26, 1981. Lawrence Berkeley Laboratory Report IBL-11967, In preparation.

Wilt, M. J.. and Goldstein, N. E., 1981. Results from two years of resistivity moni- 
toring at Cerro Prieto. In Proceedings, Third Symposium on the Cerro Prieto Geothermal Field, Baja California, Mexico, March 24-26, 1981. Lawrence Berkeley Laboratory Report IBL-11967, in preparation.
Witherspoon, P., A., Alonso E., H., Lippmann, M. J., Mañón M., A., and Wollenberg, H. A., 1978. Mexican-American Cooperative Program at the Cerro Prieto geothermal fleld. Lawrence Berkeley Laboratory Report IBL-7095.

\title{
GEOLOGIC MODEL OF THE CERRO PRIETO GEOTHERMAL FIELD
}

\author{
S. E. Halfman, J. H. Howard, and S. P. Vonder Haar
}

One of the tasks under the Mexican-American cooperative agreement is the comprehensive geologic study of the Cerro Prieto geothermal fleld. Using logs from over seventy deep wells as the basic source of information on the subsurface geology, a working model of the Cerro Prieto geothermal field is being developed.

\section{COMPUTER CODES USED}

Two computer codes are being used to handle the vast amounts of data involved in this study. The first code, PETROS (Petroleum Information Corporation, 1979), is a log analysis system consisting of several modules capable of handling a number of routine tasks, such as data imput and output, data maintenance, and programs for analyzing logs. The second code, ROMEO2 (Dynamic Graphics Incorporated, 1978; C. Doughty, personal communication, 1980) is a contouring program that uses a minimum-curvature interpolation scheme (Briggs, 1974). ROMEO2 is extremely useful in mapping field-wide variations of different parameters of interest. with the aid of PETros and ROMEO2, the data can be organized and analyzed quickly and efficiently to help define the characteristics of the geothermal field located in a predominantly clastic environment.

\section{WORKING MODEL OF. THE FIELD}

Cerro Prieto is a water-dominated geothermal field in a sedimentary-metasedimentary environment located on the Colorado River delta. In terms of the ideas expressed in Howard et al. (1981) on geothermal resources, the Cerro prieto field can be described as having:

1. a zone of normally compacted sediments, exhibiting primary porosity,

2. a cap rock,

3. a zone of chemistry altered primary porosity,

4. a zone in which temperatures and transmissivities are such that the resource is exploitable both technically and economically.

5. a zone of essentially no porosity,

6. a source of heat,

7. a set of fluid sources and sinks associated with the geothermal system.
These concepts are shown in an idealized way in Figure 1. The zone of normally compacted primary porosity consists of the shallowest mass of sediment and sedimentary rock in the resource. The rocks of the Cerro Prieto field are largely a collection of clastics deposited by the Colorado River, with a small contribution from the alluvial fans of mountain ranges to the west (Lyons and van de Kamp, 1980). As with all sediments, they have been compacted mechanically in the course of burial, and, as a consequence, rock density increases with depth.

The concept of a cap rock for a geothermal resource is an important one (Faca, 1973). A cap rock can be thought of as a surface or zone that acts as an insulator and as a barrier to fluid flow. Such a zone may result from mineralization and densification. However, it may also be the consequence of primary deposition (i.e., one or more closely spaced, areally significant aquitards). Within the Cerro Prieto field, the cap rock at least locally corresponds to the $A / B$ contact, which marks the boundary between unconsolidated (A) and consolidated (B) sediments. (Puente and de la Pena, 1978). However, other zones may act as the cap rock elsewhere in the field.

zones of chemically altered primary porosity are thought to be of major significance to the Cerro Prieto field. Fluids moving through the original material have the capacity to dissolve it as well as to precipitate new material in the physicochemical environment into which the fluid

IDEAUZED CERRO PAIETO GEOTHERMAL RESOURCE

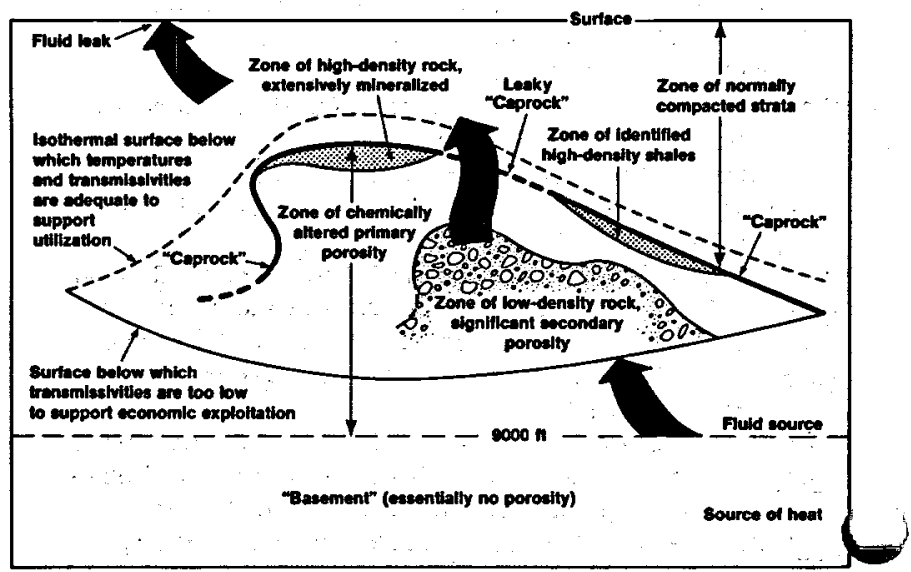

Figure 1. Idealized geothermal resource model for Cerro Prieto. 
is flowing (see Elders et al., 1978, Lyons and van de Kamp, 1980; Vonder Haar and Noble, 1980; Jonder Haar, 1981; Vonder Haar et al., 1981). Consequently, original bulk density within the resource may change. It would appear that where porosity is increased (i.e.., density decreased), the resource could be locally more permeable and have higher fluid storage capacity. On the other hand, densified rock can also be an effective reservolr, particularly if it has been fractured. Its capacity of storing fluid should be less inasmuch as its porosity is expected to be less.

At Cerro Prieto the zones of adequate temperature and transmissivity correspond to the zone of altered primary porosity. These are the heart of the exploitable geothermal resource-i.e., that volume of the resource that one would expect to drill and produce in a profitable way.

The zone of essentially no porosity corresponds to the basement underlying the exploitable geothermal resource. Its relation to the recharge of heat to the resource needs further study.

The concept of a heat source reguires no particular explanation. However, it should be noted that the nature and location of the heat source at Cerro Prieto is not precisely known. Recently, Elders et al. (1981) postulated the existence of a heat source east of the presentiy exploited reservoir. Heating may be due to a complex of dikes and $5111 \mathrm{~s}$ intruded within and beneath the reservoir (Lyons and van de Kamp, 1980; Elders et al., 1981).

The major source of fluid for the resource is thought to be the Colorado River system to the northeast (Truesdell et al., 1979). Iaguna volcano and an extensive set of springs, fumaroles, and mud pots to the north and northwest of the main geothermal fleld collectively represent the sink associated with the system. Mercado (1968). estimated the magnitude of discharge to these surface manifestations.

\section{FLUID FLON PATTERN}

Figure 2 greatly simplifies the lithology of the field. On the basis of wire-line log data, the sedimentary materials have been grouped into mostly shale and mostly sandstone units (labeled "mostly ss" in Fig. 2). Hereafter these are simply called shale and sand units. Figure 2 shows the simplified ilthology along a cross section between wells $M-6$ and NL-1, data from wells $M-$ 110 and $M-127$ have been projected into the section (modified after Lyons and van de Kamp, 1980). Superimposed on this cross section are temperature profiles for wells $M-29, M-110$, and $M-150$ given by Bermejo et al. (1979). Also shown are the $A / B$ contacts for wells $M-29$ and $M-150$. Not shown are the producing intervals, which are located within shale unit 3 (well M-29) and below shale unit 3 in the eastern portion of the field.

By comparing the temperature curves for $M-110$ and $M-150$ with the 1ithology, an increase in temperature gradient is noticeable around the boundary of shale unit 3 and the overlying sand unit.

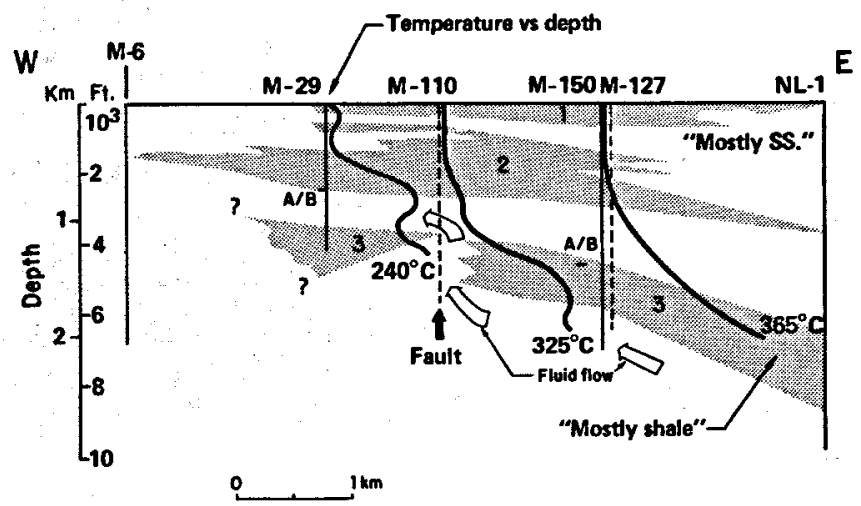

Figure 2. East-west cross section across the Cerro Prieto field, showing simplified lithologies and temperature profiles (approximate maximums are shown for each temperature profile) and $A / B$ contacts for some of the wells. Arrows indicate possible fluid flow paths.

[XBL 8111-4811]

For M-29, a similar increase in temperature gradient is noticeable, but in shale unit 2 instead of 3. Since the sudden changes in temperature gradients occur in these shale units (unit 3 in the eastern portion of the field and unit 2 in the western part), it is considered that they must be acting as barriers to upward heat flow, i.e., essentially acting as cap rocks.

On the basis of the distribution of sand units in the field, the location of the producing intervals in the wells, and the temperature profiles, a path of fluid flow has been postulated. The geothermal fluid is believed to enter the field from the east below shale unit 3 and then to flow westerly below that unit until it reaches a gap in the unit near well $M-110$. Here the geothermal fluid flows upward through the gap and westerly under shale unit 2 , which acts as a higher cap rock. This path of fluid flow is shown by arrows in Figure 2.

The postulated flow pattern is consistent with the concept of a geothermal resource set forth in Howard et al, (1981), since the model essentially includes a (leaky) cap rock, a geothermal reservolr of sufficiently high temperature and transmissivity, and fluid and heat source (to the east) and sinks (to the west).

\section{OTHER DATA BEING ANALYZED}

other information that is being analyzed but has not yet been incorporated into the above model is based on the resistivity logs. Cross sections of averaged resistivity values were mapped throughout cerro prieto.

A consistent pattern in the distribution of resistivity was observed in all the cross sections constructed, as can be seen in the example showing in Figure 3 . Extending from near the surface of the ground to depths of 4000 to 5000 $f t$ in the eastern portion of the field and to shallow depths in the western portion of the field, there exists a zone of high resistivities 

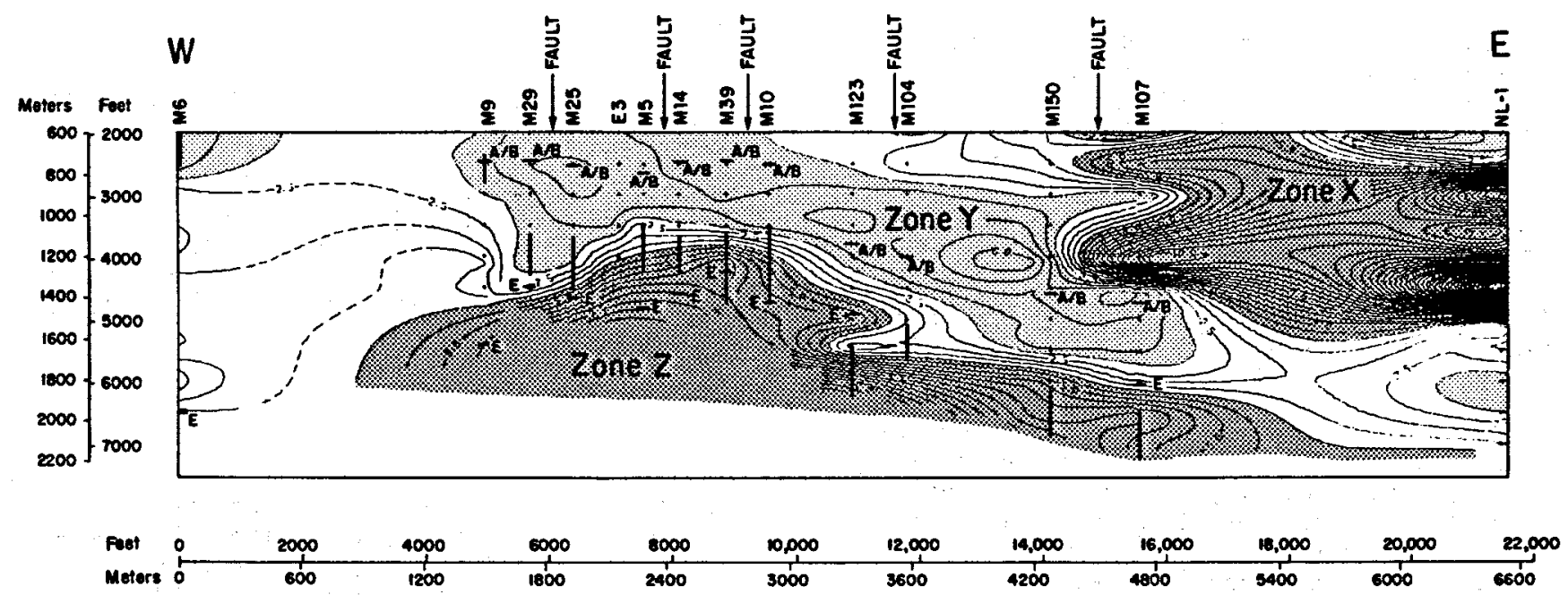

Figure 3. West-east resistivity cross section across the Cerro Prieto field, derived from wire-line $\log$ analysis. Producing intervals of wells are indicated by heavy vertical line segments. $A / B=A / B$ contact. Small crosses are data points. Resistivities in zones $X$ and $Z$ are $\geqslant 4$ ohm-m; in zone $Y, \geqslant 2$ ohm-m.

[XBL 821-1674]

(zone $x, \pm 4$ ohm-m) believed to be due to fresh water influx (Lyons and van de Kamp, 1980). Underlying this is a zone of lower resistivities (zone $Y_{\text {, }} \pm 2 \mathrm{ohm}-\mathrm{m}$ ), which is about 1000 feet thick. Below this low-resistivity zone lies another of high-resistivity (zone $\mathrm{z}, \pm 4 \mathrm{ohm}-\mathrm{m}$ ). The main production comes from this zone.

These resisitivity measurements show trends that are consistent with (1) the model derived from surface dipole-dipole resistivity measurements, (2) well completion depths, (3) temperature measurements, and (4) mineralogic characteristics (Bermejo et al., 1979; wilt and coldstein, 1980).

\section{REFERENCES CITED}

Bermejo M., F. J., Navarro O., F. X., Castillo B., F., Esquer P., C. A., and Cortez A., C., 1979. Pressure variation at the Cerro Prieto Reservoir during production. In Proceedings, Second Symposium on the Geothermal Field, Baja California, Mexico, October 17-19, 1979. Comisión Federal de Electricidad. p. 473-496.

Briggs, I. C., 1974. Machine contouring using minimum curvature. Geophysics, v. 39, p. 39-48.

Dynamic Graphics, Incorporated, 1978. User manual for the surface display library. Berkeley, Callfornia, Dynamic Graphics, Incorporated.

Elders, W. A. , Hoagland, J. R., and McDowell, S. D., 1978. Hyarothermal mineral zones in the geothermal reservoir of Cer ro Pireto. Proceedings, First Symposium on the Cerro prieto Geothermal Field, Baja California,
Mexico, September 20-22, 1978. Lawrence Berkeley Laboratory Report LBL-7098, p. 68-82.

Elders, พ. A., Williams, A. E., and Hoagland, J. E. 1981. An integrated model for the natural flow regime in the Cerro Prieto hydrothermal system, B. C., based upon petrological and isotope geochemical criteria. In Proceedings, Third Symposium on the Cerro Prieto Geothermal Field, Baja California, Mexico, March 24-26, 1981. Lawrence Berkeley Laboratory Report LBL-11967, in preparation.

Faca, Giancarlo, 1973. The structure and behavior of geothermal fields. In H. C. H. Armstead (ed.), Geothermal Energy, UNESCO, Paris, France. (LC No. 72-97138).

Howard, J. H., Halfman, S. E., and Vonder Haar, S. P., 1981. Computer assisted well $\mathrm{log}$ analysis at Cerro Prieto. In Proceedings, Third Symposium on the Cerro Prieto Geothermal Field, Baja California, Mexico, March 24-26, 1981. Lawrence Berkeley Laboratory Report IBL-11967, in preparation.

Lyons, D. J., and van de Ramp, P. C., 1980. Subsurface geological and geophysical study of the Cerro Prieto geothermal field. Iawrence Berkeley Laboratory Report LBL-10540.

Majer, E. L., and McEvilly, T. V., 1981. Detailed microearthquakes studies at the Cerro Prieto geothermal field. In Proceedings, Third Symposium on the Cerro Prieto Geothermal Field, Baja California, Mexico, March 24-26, 1981. Lawrence Berkeley Laboratory Report IBL-11967, in preparation.

Mercado, G., S., 1968. Localizacion de zonas de maxima actividad hidrotermal por medio de proporciones quifilcas, campo geoténico de Cerro Prieto, B. C. Presented at the III Congreso Mexicano de quifica Pura y Aplicada, March 21-23, 1968, Guadalajara, Mexico. sociedad Quifilca de México. 
Petroleum Information Corporation, 1979. Petros: Petrophysical evaluation system log and core analysis. Petroleum Information Company, Dallas, Texas.

puente C., I., and de la Peña L., A., 1978. Geology of the Cerro Prieto field. In Proceedings, First symposium on the Cerro Prieto Geothermal Field, Baja California, Mexico, September 20-22, 1978. Lawrence Berkeley Laboratory Report IBL-7098, p. 17-40.

Truesdell, A. H., Thompson, J. M., Coplen, T. B., Nehering, N. L., Janik, C. J., 1979. The origin of the Cerro Prieto geothermal brine. In Proceedings, Second Symposium on the Cerro Prieto Geothermal Field, Baja California, Mexico, October 17-19, 1979. Comisión Federal de Electricidad, p. 224-240.

Vonder Haar, S. P., 1981. A structural and sedimentological study of the Cerro Prleto geothermal field, Baja California, Mexico. Lawrence Berkeley Laboratory Report IBL-12796.

Vonder Haar, S. P., and Noble, J. E., 1980. Diagenetic processes in sandstone from the Cerro Prieto geothermal field, Baja Callfornie, Mexico. In Abstracts (Vol. 1). AAPG-SEPM-EMD annual Convention, Denver, Colorado, p. 99.

Vonder Haar, S. P., Schatz, J., and Wolgemuth, K.. 1981. Clay mineral fabric and chemistry in Salton Trough in geothermal fields: Lawrence Berkeley Laboratory Report IBL-12348.

wilt, M. J., and Goldstein, N. E., 1979. Resistivity monitoring at Cerro Prieto. In Proceedings, Second Symposium on the Cerro Prieto Geothermal Field, Baja Californiá, Mexico, October 17-19, 1979. Comisión Federal de Electricidad, p. 419-433.

\title{
GEOPHYSICAL MONITORING AT THE CERRO PRIETO GEOTHERMAL FIELD
}

\author{
M. Wilt, R. Zelwer, and E. L. Majer
}

In 1978 we began a program of reservoir monitoring at the Cerro Prieto geothermal field using surface geophysical methods with the objective of observing changes resulting from production. The three methods used in this study are dipole-dipole resistivity, precision gravity, and passive seismic monitoring.

\section{GRAVITY MONITORING AND SUBSIDENCE}

The measurement of gravity with high precision at Cerro Prieto had two principal objectives. The first was to compare repetitive gravity measurements with leveling surveys made over time to provide information about net mass changes in the reservolr and compaction of reservoir and overlying rocks. The second objective of the measurements was to produce an accurate Bouguer anomaly map of the field.

The gravity data were acquired and reduced by R. B. Grannell using a Lacoste and Romberg G-type gravity meter. Surveys began in 1978 and have been repeated at yearly intervals. Data-gathering procedures and the Bouguer gravity map are described by Chase et al. (1978) and Grannell et al. (1979, 1981).

Second-order leveling surveys in the inmediate vicinity of the field were carried out by the comistón Federal de Electricidad (CFE) in conjunction with the precision gravity surveys. They were also used to monitor local production-related surface elevation changes. CFE is well aware of the potential for subsidence, since nearly 180 million tonnes of fluid had been extracted from the geothermal reservoir as of December 1980 (de la Peña, 1981).

The first evidence for significant elevation and gravity changes emerged in 1981, following a magnitude 6.7 earthquake that took place in June
1980 and whose epicenter was located approximately $25 \mathrm{~km}$ southeast of the fleld. Figure 1 shows the differences between the winter 1981 (postearthquake) and winter 1980 (pre-earthquake) gravity measurements. Elevation changes determined from the second-order level surveys showed a very similar pattern over the same period, with subsidence of the order of $25 \mathrm{~cm}$ over relatively large areas. A calculation of the gravity changes that would result from the measured elevation changes shows good agreement with the observed gravity changes, both in magnitude and

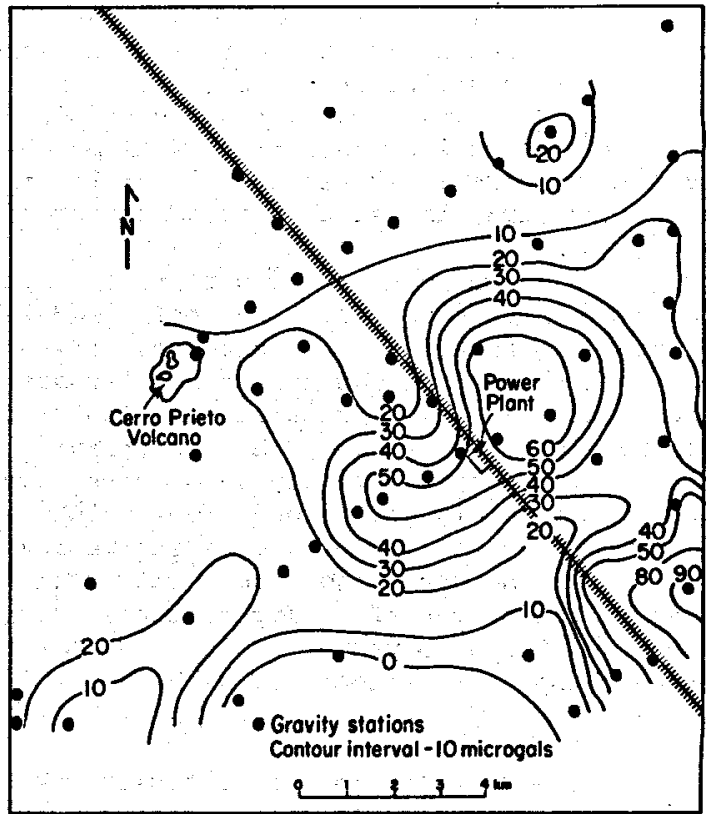

Figure 1. Contour map of gravity changes (1n gal) between winter 1981 and winter 1980.

[XBL 821-1774] 
location. Gravity and elevation changes over a three-year period preceding the June 1980 earthquake were relatively insignificant, even over the center of the production region.

We have concluded that subsidence over the field is earthquake induced; moreover, because the earthquake was accompanied by evidence of liquefaction near the surface (de la Peña, 1981)., we think that most of the subsidence is a result of compaction of the poorly consolidated nearsurface sediments.

Comparison of the gravity and elevation changes seems to indicate that the reservoir is experiencing a rapid recharge in response to mass extraction, without the formation of a steam cap as occurred, for example, at Wa irakei (Grimsrud et a1., 1978). The increase in gravity over time and its very close correspondence to elevation decreases also supports the notion of rapid recharge. If the reservoir were not being recharged, the values of gravity would have decreased, or increased less rapidly, because of a net loss of mass from the reservoir. This rapid recharge has also been confirmed by chemical and reservoir engineering considerations by Grant et al., (1981).

\section{RESISTIVITY MONITORING}

Dipole-dipole resistivity measurements for the combined purpose of reservoir delineation and resistivity monitoring have been made at cerro Prieto on an annual basis since 1978 (Wilt et al., 1981). For reservoir delineation, measurements were made along two lines $20 \mathrm{~km}$ long (Fig. 2). The results were interpreted by two-dimensional modeling (Wilt and Goldstein, 1979).

Resistivity measurements are taken using a 25-kW generator capable of $80 \mathrm{~A}$ output and a microprocessor-controlled, signal-a veraging receiver. This high-power, low-noise system is capable of precise measurements even at large transmitter-receiver separations ( 8 or $9 \mathrm{~km}$ ). Standard error calculations for collected data indicate errors of less than 58 for all points, but 958 confidence intervals show er ror 1 imits about 2 to 4 times larger than standard errors.

Figure 3 shows pseudosection plots of apparent resistivity differences from the spring and fall 1980 data sets relative to measurements taken in 1979. Both pseudosections show a similar pattern for transmitter-receiver separations greater than twice the electrode spacing. A significant increase in apparent resistivity is observed over the present zone of steam production, which is flanked by large regions of decreasing resistivity. Over the production zone, only small changes in the near-surface apparent resistivity are observed for both years, indicating that the observed changes are associated with reservoir depths.

The increase in apparent resistivity may be due to various related effects. Pressure decline and drawdown due to production could cause expansion of the two-phase zones close to the production wells. At the same time, shallow recharge

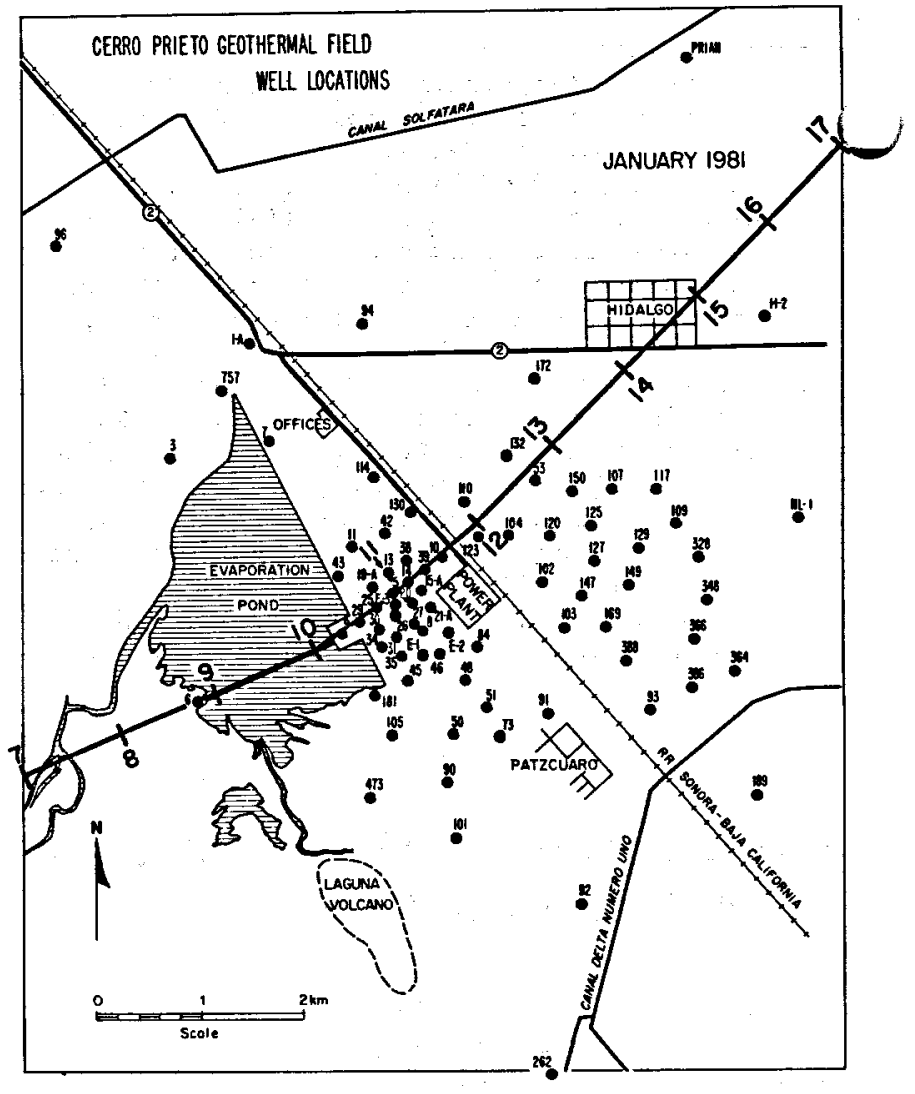

Figure 2. Station location map for dipole-dipole resistivity line $\mathrm{E}-\mathrm{E}^{\prime}$.

[XBL 811-2532C]

of cooler, less saline water would increase pore fluid resistivity while carbonate deposition caused by the introduction of cooler waters into hot rocks would decrease porosity.

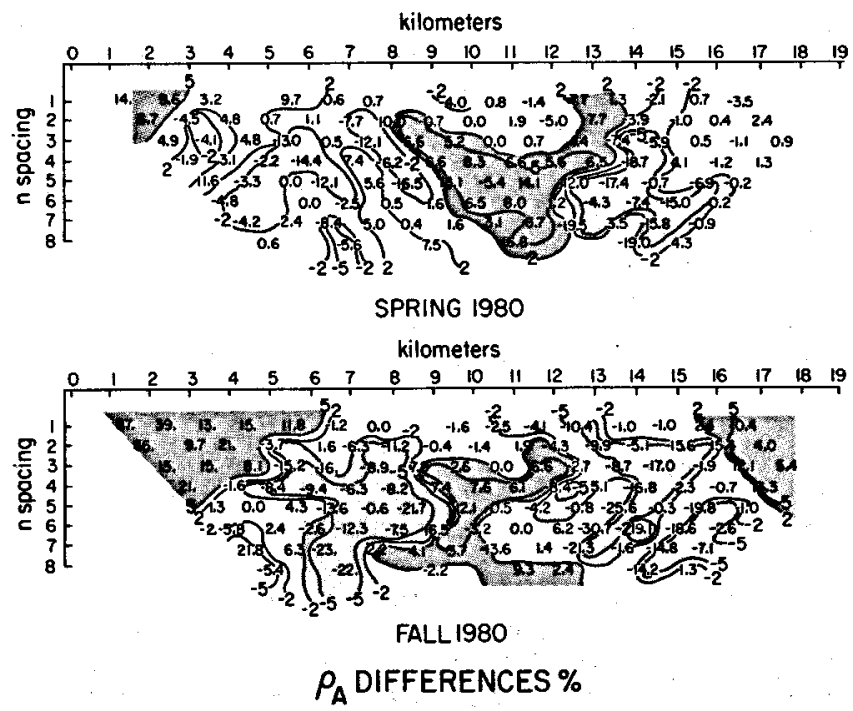

Figure 3. Pseudosection plot of apparent resistivity differences (in 8) for spring 1980 relative to spring 1979 data set (top) and fall 1980 relative to spring 1979 data set (bottom).

[XBL 813-2718A] 
More difficult to explain are the zones of declining resistivity flanking the main production area.: Perhaps production has stimulated a hatural fluid recharge from depth, causing a convective fluid flow that results in hotter waters moving laterally and upward toward the production zone.

\section{SEISMICITY}

A 17-day detailed microearthquake study (Nov. to Dec. 1980) was carried out over the production zone to Identify any earthquake activity within the production zone and, if possible, to relate it to mass and heat transfer. The survey was conducted using 4.5-Hz vertical geophones. The data were radiotelemetered to a central location where they were processed with an Automated Selsmic Processor (ASP).

Each of the 15 channels of ASP (WORKERS) automatically detects the arrival of $P$ and $S$ waves. Arrival times are recorded, and the data are sampled at 100 samples per second. Fast Fourier Transforms (FFT) are computed for both $P$ and $S$ waves. There data from each channel are then processed with a central microprocessor (BOSS), which computes hypocenter location, running b-values, source parameters, even count, and P-wave polarities. The system is capable of processing a 15-station detection in approximately $40 \mathrm{~s}$, excluding printout. The initial trials have demonstrated that in-field, real-time analysis of data maximizes the efficiency of microearthquake surveys, allowing flexibility in experimental procedures with a minimum of the traditional labor-intensive post-processing.

ASP has two mechanisms for discriminating against events outside of the array. In the first, an S-P input parameter, when exceeded, prevents location, and a message is printed out to that effect. The second mechanism is a time window in which a mintmum number of p-readings must be received before an event is judged valid for further processing.

Figure 4 shows the distribution of seismic stations relative to known fault zones and production activity. At the time of the survey, the main production was coming from an area defined by wells $M-114, M-9, M-101$, and $M-109$. In total, 26 wells were supplying steam/water for $150 \mathrm{MW}$ of power production. $M-9$ is the only infection well.

During 17 days of monitoring, 119 events were recorded on 4 or more of the 11 stations deployed. of these 119 events, 40 were located within the array area. Locations for twenty-nine of the 40 events were judged to be of good quality; these events are shown in Figure 4. Most of the hypocenters are located on a surface coinciding with the Hidalgo Fault zone (Fig. 4). Applying these methods, it was possible to conclude after only 17 days of monitoring that there has been a clear increase in seismic activity in the production zone pver previously measured levels (Majer et al.; 1980) and that there is an excellent colncidence of hypocenters with the mapped fault zones.

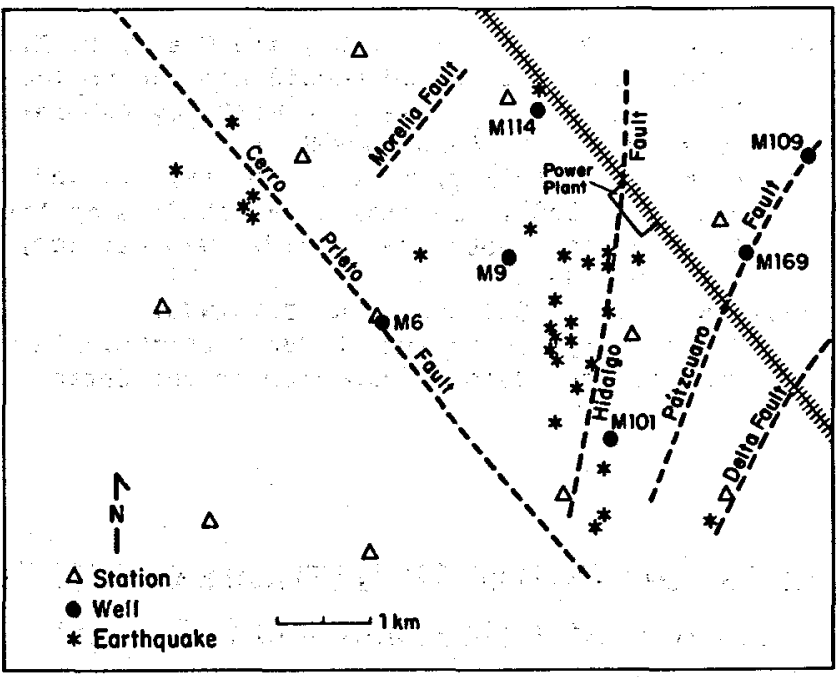

Figure 4. Map of Cerro Prieto geothermal field, Mexico, showing faults, temporary seismographic stations, wells, and epicenters of local microearthquakes determined by ASP in the period November 16 to December 10, 1980. [XBL 821-1773]

\section{REFERENCES CITED}

Chase, D. S., Clover, R. C., Grannell, R. B., Leggewle, R. M., Tarman, D. W., and coldstein N. E. 1978. precision gravity studies at Cerro Prleto. In Proceedings, First Symposium on the Cerro Prieto Geothermal Field, Baja Callfornia, Mexico, September 20-22, 1978. Lawrence Berkeley Laboratory Report LBL-7098, Pp. 249-256.

de la Peña L. . A., 1981. Results from the first order leveling surveys carried out in the Mexicali Valley and at the Cerro Prieto Field. In Proceedings, Third Symposium on the Cerro Prieto Geothermal Field, Baja California, Mexico, March 24-26, 1981. Lawrence Berkeley Laboratory Report LBL-11967, in preparation.

Grannel1, R. B., Rroll, R. C., Myma n, R. M:, and Aronstam, P. S., 1981. Precision gravity studies at Cerro Prieto - A progress report, 1981. In Proceedings, Third Symposium on the Cerro prieto Geothermal Field, Baja Californ1a, Mexico, March 24-26, 1981. Iawrence Berkeley Laboratory Report LBL-11967, in preparation.

Grannell, R. B.. Tarman, D. W., Clover, R. C.,

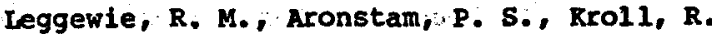
C., and Eppink, J., 1979. Precision gravity studies at Cerro Prieto geothermal field. In proceedings, second Symposium on the Cerro Prieto Geothermal Field, Baja California, Mexico, October 17-19, 1979.

Grant, M. A.., Truesdell, A. H., and Mañón M., A., 1981. Production induced boiling and cold water entry in the cerro Prieto geothermal reservolr indicated by chemical and physical measurements, 1981. In Proceedings, Third Symposium on the Cerro Prieto Geothermal Field, Baja Callfornia, Mexico, March 24-26, 1981. Lawrence Berkeley Laboratory Report LBL-11967, in preparation. 
Grimsrud, G. P., Turner, B. L., and Frame, P. A., 1978. Areas of ground subsidence due to geofluid withdrawal. Lawrence Berkeley Laboratory Report LBL-8618 (GRSMP-4).

Majer, E. L., MaEvilly, T. V., Albores, A., and Díaz, S., 1980. Seismological studies at the Cerro Prieto geothermal fleld. Geothermics, v. 9, p. 79-89.

Wilt, K. J., and Goldstein, N. E., 1979. Resistivity monitoring at Cerro Prieto. In proceedings, Second Symposium on the Cerro
Prieto Geothermal Field, Baja California, Mexico, October 17-19, 1979. Comisión Federal de Electricidad, Mexicali, Pp. 419-428. Wilt, M. J., Coldstein, N. E., and Razo M., A., 1979. IBL resistivity studies at Cerro Prieto. In Proceedings, First Symposium on the Cerro Prieto Geothermal Field, Baja Callfornia, Mexico, September 20-22, 1978. Lawrence Berkeley Laboratory Report IBL-7098, pp. 179-188.

\title{
RESERVOIR ENGINEERING STUDIES OF THE CERRO PRIETO GEOTHERMAL FIELD
}

\author{
K. P. Goyal, M. J. Lippmann, and C. F. Tsang
}

Reservoir engineering studies of the Cerro prieto geothermal fleld began in 1978 under a five-year cooperative agreement between the 0 . $s$. Department of Energy and the Comision Federal de Electricidad de Mexico (CFE), with the ultimate objective of simulating the reservolr to forecast its production capacity, energy longevity, and recharge capability under various production and injection scenarios. During the fiscal year 1981, attempts were made to collect information on the evolution history of the field since exploitation began; the information is to be used later to validate the reservoir model. To this end, wellhead production data were analyzed for heat and mass flow and also for changes in reservolr pressures, temperatures, and saturations for the perlod from March 1973 to November 1980. In twophase systems, the wellhead pressures cannot be used to simulate reservoir pressures because significant changes in pressures and temperatures take place in the well bore as a result of flashing. The effect on reservoir behavior of shallow reinjection in $M-9$ was studied numerically.

\section{HEAT AND MASS PRODUCTION DATA}

During the validation of the mathematical model of a geothermal field, the actual mass produced is used as input data. In general, one can choose either a monthly averaged or an annually averaged mass flow rate. ro obtain a monthly averaged mass production rate, we compiled the monthly production from each well in the field. The hourly production rate, as shown in Figure 1, was then obtained by dividing the total production from the entire field in a given month by the number of hours in that month.

It may be noted in this figure that the production rate increases sharply during 1973, from 1000 tonnes $/ \mathrm{hr}$ to about 2200 tonnes $/ \mathrm{hr}$. This increase is attributed to the fact that more vells were brought into production. The total number of wells increased almost threefold, from 4 wells in March 1973 to 11 wells in December 1973. The increase in the mass flow rate during 1976 to 1977 was also the result of an increase in the number of production wells. The average number of production wells during 1974 to 1975 was about 12 compared to 15 duxing 1976 to 1977.

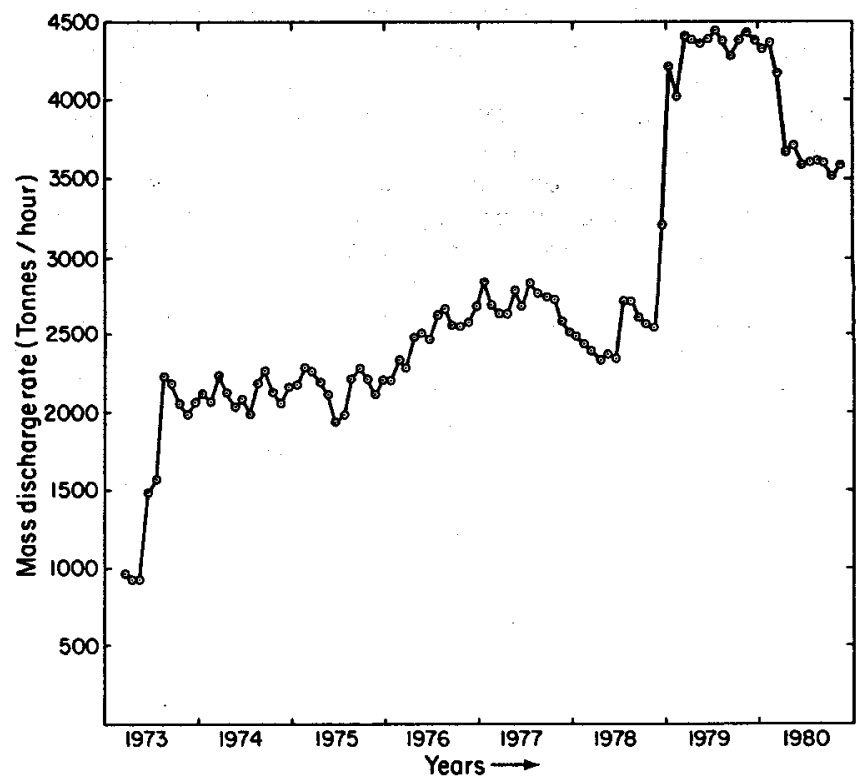

Figure 1. Monthly averaged total mass (steam-water mixture) production rate of the Cerro prieto field.

[XBL 808-7266A]

After a slight decline in the average production rate of the field during late 1977 and early 1978, another sharp increase may be observed durIng late 1978 and early 1979. A decline in the production rate is the result of behavior shown by the majority of wells in the field--i.e., a decrease in production with time. The increase in production rate of the field as a whole is again caused by an increase in the number of production wells from 17 in November 1978 to 26 in April 1979, when the original capacity of 75 MWe was doubled to 150 MWe. Although 4 additional wells were placed into operation between september 1979 and February 1980, the average mass production xate of about 4400 tonnes/hr remained almost unchanged, as compared to April 1979, wher only 26 wells were producing. Thus the addition 4 wells only helped compensate for the decreased production of the other 26 wells. Another decrease in the production rate in early 1980 was 


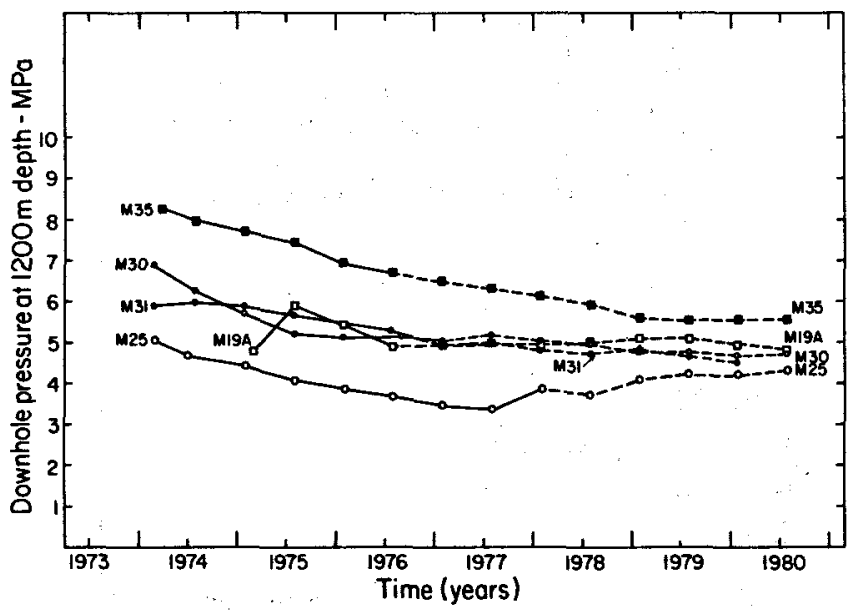

Figure 3. Computed downhole pressures at $1200 \mathrm{~m}$ depth in production wells $M-19 A, M-25, M-30, M-31$, and $M-35$ under flowing conditions. [XBL 813-2755]

Thereafter, the production and wellhead pressure in M-25 changed remarkably. The computed downhole temperatures showed a drop of about $20^{\circ} \mathrm{C}$ over a seven-year period. The steam saturation in the near-well region increased from 70-908 in 1974 to $80-908$ in 1980 (Goyal et al.. 1981).

\section{REINJECTION STUDIES}

Since August 1979, CPE has been carrying out reinjection of $165^{\circ} \mathrm{C}$ untreated brines into well M-9 at Cerro Prieto. The maximum injection rate was reported to have been approximately 80 tonnes/ hr. However, the monitoring of neighboring production wells, such as M-29, has not shown changes in wellhead temperature, pressure, or enthalpy caused by the injection operation. The shallow depth of injection (721 to 864 in in well M-9) could explain why the surrounding producing wells do not show any effects, since the depth of the producing zone in this area is more than $1100 \mathrm{~m}$.

In the studies carried out by Tsang et al. (1981), the pressure response of the producing Cerro prieto reservoirs to shallow and deep reinjection was analyzed using LBL computer codes PT and sHAFT79 to simulate single-phase and two-phase flow conditions, respectively. For this purpose. several idealized axisymetric and planar, twodimensional, multilayered models of the injection area of Cerro Prieto were employed.

In the axisymetric, single-phase calculation, it was found that pressures in the lower production interval were only slightly affected $(\sim 4$ psi) by brine reinjection of 80 tonnes $/ \mathrm{hr}$ in the upper reservolr even after one year if the shallow and deep reservoirs are separated by a 20m-thick low-permeability shale layer (Fig. 4). This is consistent with fleld observation. If the brine is reinjected at the same depth as the production interval of well $\mathrm{M-29}$, the pressure should increase noticeably in that well ( 13 psi) after one year. A two-dimensional, single-phase calculation, which included a more accurate model of the geology of this region, also confirmed these general results.

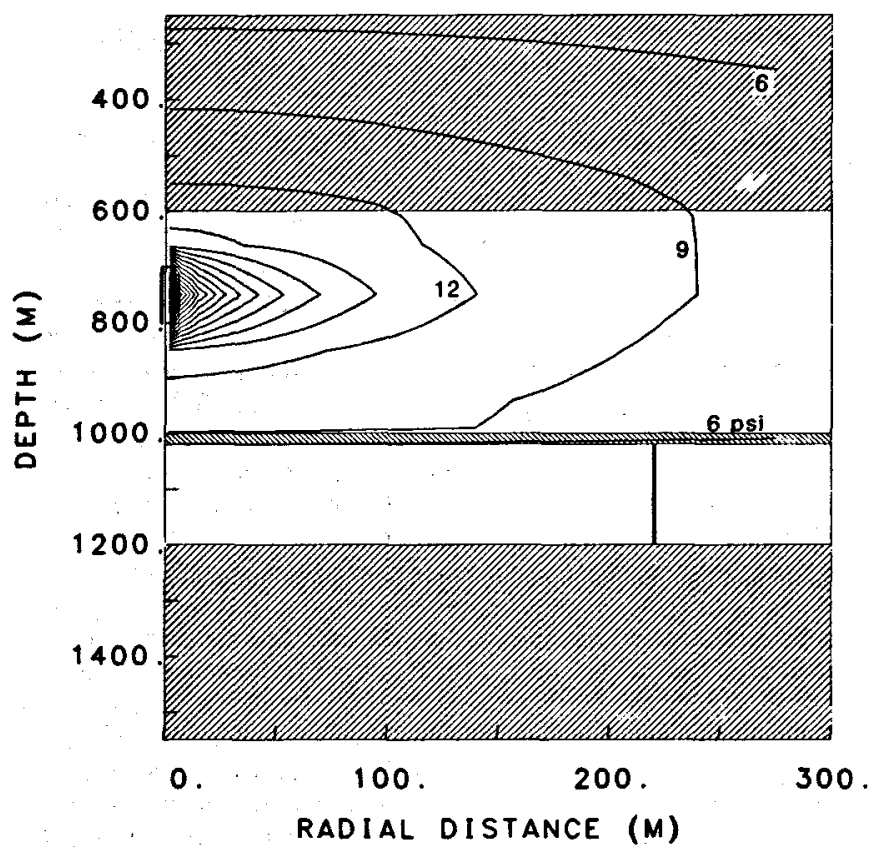

Figure 4. Reservolr pressure changes after one year due to shallow reinjection in $M-9$ for an isotropic, single-phase, axisymmetric model.

[XBL 824-2127]

The effect on the reservoir pressure response of anisotropy in the permeabilities of formations was also studied. The results indicate that an overall 10-to-l horizontal-to-vertical anisotropy and a thin, low-permeability layer in an isotropic system yield similar responses to infection into the upper reservoir at the production interval of well $\mathrm{M}-29$.

Further calculations were made for an axisymmetric two-layer model with a two-phase upper reservoir. These simulations showed that the pressures in M-29 would still be unaffected by brine reinjection in the shallow reservoir. Moreover, two-dimensional two-phase calculations were performed on a large model that included the whole production area of the cerro prieto field. The results confirmed the previous findings.

\section{REFERENCES CITED}

Goyal, K. P. Miller, c. W., Lippmann, M. J., 1980. Effect of measured wellhead parameters and well scaling on the computed downhole conditions in Cerro Prieto wells. In Proceedings, Sixth Workshop on Geothermal Reservoir Engineering, Stanford University, Stanford, SGP-TR-50, Pp. 130-138.

coyal, K. P., Miller, C. W., Lippmann, M. J., and Vonder Haar, S. P., 1981. Analysis of Cerro Prleto production data. In Proceedings, Third Symposium on the Cerro Prieto Geothermal Field, Baja California, Mexico, March 24-26, 1981. Lawrence Berkeley Laboratory Report LBL-11967, In preparation.

Grant, M. A., Truesdell, A. H., and Mañón K., A., 1981. Production Induced bolling and cold water entry in the Cerro Prieto geothermal reservoir indicated by chemical and physical 
caused by the reduction of the number of production wells from 30 to 26. Total mass produced from the Cerro Prieto field as of November 1980 was about 188 million tonnes, if we neglect the mass produced by standby wells and that blown off before March 1973, when power production began in the Cerro Prieto field.

In general, it was observed that the average mass produced by a well decreased with time. For example, the average production rate per well decreased from about 240 tonnes/hr in 1973 to about 140 tonnes $/ \mathrm{hr}$ in 1980 (Goyal et al., 1981). The reduction in mass flow rate is probably caused by silica precipitation in the reservolr pores, relative permeability effects in the two-phase region near and around the well (Grant et al., 1981), and/or reduced pressure gradients due to fluid exploitation. The total heat produced from the Cerro Prieto field as of November 1980 was about $60 \times 10^{12} \mathrm{kcal}$ or about 780 million wW-hr. For an ambient temperature of about $15^{\circ} \mathrm{C}$, this amounts to about 65 million MW-hr of available energy. This is equivalent to an average thermal electric power production of about $966 \mathrm{MW}$ for the period March 1973 to November 1980. The Cerro prieto field produced $75 \mathrm{kWe} u n t i l$ April 1979, when its production was doubled to $150 \mathrm{MWe}$. This amounts to an average production of about 90 MWe electric power from the field since 1973. It shows that a factor of about 9.58 exists between the generated electric power and the extracted heat.

DOWNHOLE PRESSURES, TEMPERATURES, AND SATURATIONS

As a first step toward calculating reservoir pressures, we computed downhole conditions in a flowing well from known wellhead data. These calculations require data on the inside diameter, depth, and open interval of the well, in addition to mass flow rate, enthalpy, and wellhead pressure. Quite a few wells in the Cerro Prieto field are found to have scale deposits, which reduce their inside well diameter. The changes in diameter have to be taken into consideration in order to compute correct downhole conditions. The theory and method of calculating downhole conditions in a flowing, two-phase, multiple-diameter well are discussed in Miller (1979) and coyal et al. (1980).

The computed pressures in wells $M-90, M-51$, and M-91 were compared with those actually measured in the field. It was found that the maximum error between calculated and measured pressures was within 6 or 78 for these wells. Excellent agreement between calculated and measured pressures was obtained for well $M-91$, as shown in Figure 2.

The sensitivity of the measured wellhead parameters, such as pressure, mass flow rate, and enthalpy, was studied on the calculated downhole conditions and discussed in Goyal et al. (1980). It was established that the calculated downhole pressures were quite sensitive to measured wellhead conditions and inside diameter of the well. It is suggested on the basis of this study that the parameters to be measured, In order of decreasing accuracy, are inside diameter of the

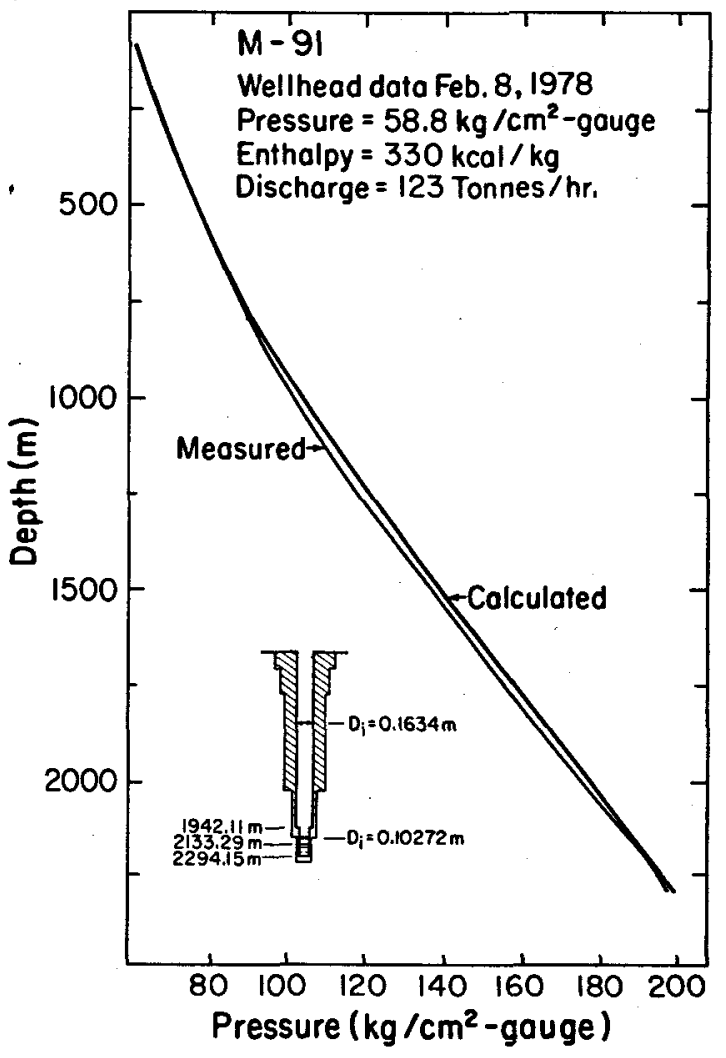

Figure 2. Computed and measured pressures in well $\mathrm{M}-91$.

[XBL $8012-6576$ ]

well, wellhead pressure, enthalpy, and mass flow rate.

We1ls $M-19 A, M-25, M-30, M-31$, and $M-35$ were selected to compute downhole pressures, temperatures, and saturations under flowing conditions. These wells were found to have much thinner scale deposits than the other wells in the field. Most deposits in these wells were confined to the open intervals. Thus we believe that these computed results are reasonable. Downhole pressures, computed at $1200 \mathrm{~m}$ depth in the well, are shown in Figure 3 for the period 1974 to 1980 . All the wells shown in this figure are open at this depth except for $M-30$, which is open below $1230 \mathrm{~m}$.

Solid lines indicate that scaling data are known; broken lines indicate that data are assumed. For example, scaling data for well $M-35$ are known up to July 1976; beyond that time, scaling in the well was assumed on the basis of data for 1974 to 1976. From Figure 3, it is clear that pressures in the old part of the field (Cerro Prieto I) are declining, although the rate of pressure decline decreases with time. On the other hand, the difference in downhole pressure between these wells decreases from about 35 bars in 1974 to 15 bars in 1980. Thus the pressures in the wells appear to stabilize and become more uniform over the years. After December 1977, the behavior of well $M-25$ is quite different from the other wells. This well started producing sand at this time, which was subsequently corrected by throttling it (R. Molinar, personal communication, 1980). 
measurements. In Proceedings, Third Symposium on the Cerro Prieto Geothermal Field, Baja California, Mexico, March 24-26, 1981. Lawrence Berkeley Laboratory Report LBL-11967, in preparation.

Miller, C. W.. 1979. Numerical model of translent two-phase flow in a wellbore. Lawrence Berkeley Laboratory Report LBL-9056 Rev., $31 \mathrm{p}$.
Tsang, C. F., Mangold, D. C., Doughty, C., and Lippmann, M. J.. 1981. The Cerro Prieto reinjection tests: studies of a multilayer system. In Proceedings, Third symposium on the Cerro Prieto Geothermal Field, Baja California, Mexico, March 24-26, 1981. Lawrence Berkeley Laboratory Report LBL-11967, in preparation. 
ن 


\section{GEOSCIENCES}

The work accomplished in fiscal 1981 and described in the short papers in this section encompasses a broad range of geosciences. Though applied and fundamental geochemistry are emphasized, three projects in applied geomechanics are also included.

Applied geomechanics is exemplified by studies of rock properties at elevated temperatures and pressures, a new method to measure in situ stresses in rock, and the application of a systems approach to planning the ventilation of coal mines.

Applied geochemistry is represented by investigations of the chemical properties of components of radioactive waste and materials used to contain the waste, the partitioning of hydrogen sulfide in geothermal energy conversion systems, a chemical process to improve the recovery of heavy oil, new techniques to discern the bonding of elements on surfaces of minerals (important in mineral beneficiation), and application of laser fluorescence techniques through the use of optical fibers to determine trace constituents of groundwater at depth in boreholes.

Fundamental geochemistry is represented by investigations of the thermodynamics of high-temperature brines, measurements of solubilities of rock-forming minerals in the aqueous phase at temperatures typical of those in hydrothermal systems, measurements of the thermodynamic properties of silicate materials at high temperatures over a wide range of compositions, and investigations of the transport of chemically reactive solutes by groundwater systems.

These investigations utilize computational, analytical, and experimental facilities at the Lawrence Berkeley Laboratory and on the University of California campus. The work is shared by LBL staff, campus faculty, and graduate students.

This work was supported under U. S. Department of Energy Contract No. DE-ACO3$765 F 00098$ by (1) The office of Energy Research, Office of Basic Energy Sciences, Division of Engineering, Mathematics and Geosciences; (2) the Assistant secretary for Conservation and Renewable Energy, office of Renewable Technology, Division of Geothermal and Hydropower Technologies; (3) the Assistant Secretary for Fossil Energy, office of Coal Technology, Division of Coal Mining; (4) the Assistant Secretary for Fossil Energy, Office of Oil, Gas, and Shale Technology, Division of Oil; and (5) the Assistant Secretary for Nuclear Energy, office of Nuclear Waste Isolation through Battelle Memorial Institute. 


\section{AND PRESSURES}

\section{N. H. Somerton}

With an increase in the number of underground processes being studied in environments that are either artificially heated or that are naturally subject to high temperatures and pressures, know1edge of the physical properties and behavior of rock-fluid systems under stress and at elevated temperatures has become important in designing, controlling, and analyzing such processes. The purpose of the present research project is to provide data on the following properties of rockfluid systems: deformation properties, including pore and bulk compressibilities and thermal expansions; $\mathrm{P}-$ and s-wave velocities; absolute permeability, electrical resistivity factor; and thermal properties, including conductivity, diffusivity, and specific heats. These data are being used to check theoretical models and correlations for use in reservoir simulation studies. We are also developing a new multiproperties apparatus (Somerton, 1980) that will increase the $r$ ange of temperature and pressure under which we can operate and will allow us to measure most of the above properties during the same test on the same test specimen. Data from these tests are needed to confirm our correlation and modeling work.

Work accomplished during the past year in two areas (modeling of pore and bulk compressibilities and thermal expansions, and measurements of electrical resistivity factors at elevated temperatures) is reviewed here.

\section{ROCR PROPERTIES RESEARCH}

\section{Compressibility}

Earlier work (Somerton, 1974) has shown that bulk compressibility of reservoir type rocks increases substantially with increased temperature. This has important implications in cases where pore fluid pressure declines in hot or heated reservoir formations. Surface subsidence can be expected to be of greater importance in such cases. Since the behavior of pore volume compressibility parallels that of bulk compressibility, substantial contraction of reservoir volume can also be expected upon decrease in pore pressure. This must be accounted for in material balance calculations.

Measurement of rock compressibility is a difficult and time-consuming procedure. Greenwald and Somerton $(1981)$ have recently proposed a model from which pore volume compressibility may be estimated knowing only some simple properties of the rock. These Include mineral composition and elastic moduli of the minerals, porosity, grain ize, and a parameter that is related to roundhess of the mineral grains. Rnowledge of the clay content of the porous rock is also needed to predict the effect of stress on pore volume compressibility.

Zimmerman (1981) has followed up on Greenwald's work, using a similar hollow sphere model to determine compressibilities and effective stress coefficients. The important findings of his work are that, although the effective stress coefficient ( $N$ in the equation $P_{\text {eff }}=P_{\text {comp }}$ N $X$ Pore) is always unity for changes in porosity, it is generally less than unity for both pore volume and bulk volume changes with stress. The effective stress coefficient w111 always increase as Poisson's ratio increases and as porosity increases. The numerical value of $\mathrm{N}$ will always be larger for pore volume changes than for bulk volume changes.

We are now in the process of testing the above findings by experimental measurements on highly uniform porous alundum cores. The effects of temperature are being investigated, and the model is being reworked for pores in the shape of prolate spheroids.

\section{Formation Resistivity Factor}

Rugama (19B1) completed a series of tests on three outcrop sandstones in which he measured the electrical resistivities at three frequencies $(0.5,1.0$, and $3.88 \mathrm{kBz})$ and temperatures to $200^{\circ} \mathrm{C}$. Dividing these resistivity values by the corresponding values of resistivity of the saturating fluid $(6000 \mathrm{ppm} \mathrm{NaCl}$ solution), formation resistivity factor values were obtained; these were shown to be constants in the temperature range of 30 to $160^{\circ} \mathrm{C}$ for all samples. At higher temperatures the formation resigtivity factor values increased somewhat ( 5 to 108 for the temperature range 160 to $200^{\circ} \mathrm{C}$. The sample with lowest porosity and highest clay content showed the greatest increase. The two lower-frequency runs gave nearly identical results, but the higher-frequency runs yielded substantially higher values of formation resistivity factor. This increase was the greatest $(+158)$ for the sample with highest clay content.

The above results tend to substantiate the findings of Dcok (1979) but are contrary to the earlier results of Sanyal et al. (1972). Since a reciprocal relationship exists between formation resistivity factor and absolute permeability (through the tortuosity factor), these results would then agree with the recent findings of Potter et al. (1981), which Indicate that the permeability of clean sandstones is independent of temperature. We have completely rebuilt our high-temperature permeability apparatus to test this observation. Tests will be run on the same core material that Rugama used for resistivity tests and that zimmerman is using to test his model results. 


\section{REFERENCES CITED}

Greenwald, R. F., and Somerton, W. H., 1981. A theoretical model for determination of pore volume compressibilities of consolidated sandstones. Society of Petroleum Engineers. preprint 10076 .

Potter, J. M., Dibble, W. E., and Nur, A., 1981. Effects of temperature and solution composition on the permeability of st. Peters sandstone-Role of iron III. Journal of Petroleum Technology, v. 33, no. 5, p. 905.

Rugama, C. R., 1981. The effects of temperature and frequency on formation resistivity factor of porous rocks (M.S. Research-Report). Dept. of Petroleum Engineering, University of California, Berkeley.

Sanyal, S. K., Marsden, S. S., and Ramey, H. J., 1972. The effects of temperature on electrical resistivity of porous media (Society of Professional Well Log Analysts). Annual logging Symposium, May 7-10, 1972.
Somerton, W. H., 1974. Deformation modull of water-bearing formations at elevated temperatures. California water Resources Center, Contrib. No. 146, University of California, Davis.

Somerton, W. H., 1980. The behavior of rock-fluid systems at elevated temperatures and pressures. In Earth Sciences Division Annual Report $1 \overline{980}$. Lawrence Berkeley Laboratory Report IBL-12100.

Ucok, H., 1979. Temperature dependence of electrical resistivity of aqueous salt solutions and solution saturated porous rocks (Ph. D. dissertation). Dept. of Petroleum Engineering, University of Southern California, Los Angeles.

zimmerman, R., 1981. Use of a hollow sphere model of porous rocks in determining compressibilities and effective stress coefficients. Petroleum Engineering Laboratory Report, University of California, Berkeley.

\title{
THERMODYNAMICS OF HIGH-TEMPERATURE BRINES
}

\author{
K. S. Pitzer, P. S. Z. Rogers, and J. C. Peiper
}

Current interest in a variety of geochemical phenomena, including geothermal and geopressurized brines, has focused attention on the importance of a model for aqueous solution properties at high temperatures and pressures. The number of different brines encountered is large, hence obtaining detailed measurements on each of them is impractical. A model was needed that would be capable of predicting the properties of complex brines yet be based on a minimum amount of experimental data on a few key systems. Thus a program was begun in 1975 to study the solution thermodynamics of brine systems, including both modeling and experimental work.

The usefulness of a model for aqueous solutions is not limited to geothermal or other natural brines. Research and engineering design in many fields depend on a knowledge of brine chemistry; examples are desalination, industrial waste treatment, hydrometallurgy, materials corrosion, solution mining, and hydrothermal ore deposition.

Initial modeling work involved testing a system of equations developed by Pitzer and coworkers (Pitzer, 1973, 1975, Pitzer and Mayorga, 1973, 1974; Pitzer and Kim, 1974) for its ability to reproduce experimental data for strong electrolytes at room temperature. Existing data were reproduced to within experimental error, up to concentrations of 6 molal, in terms of parameters having physical significance. The model equation also has been used to reproduce the various thermodynamic properties of sodium chloride and sodium sulfate solutions at temperatures up to $300^{\circ} \mathrm{C}$ (Silvester and Pitzer, 1977; Rogers and Pitzer, $1981 a, b)$.
The equation yields unambiguous values for mixtures of unlimited complexity but requires some knowledge of the properties of each of the pure electrolytes that make up the solution. Thus a major part of the effort to build a model for natural brines has been to obtain basic thermodynamic data at high temperatures and pressures. Both a calorimeter and a densimeter, designed to obtain data at high temperatures and at pressures along and above the liquid-vapor saturation curve, have been constructed. The measurements for $\mathrm{Na}_{2} \mathrm{SO}_{4}$, discussed in last year's report, were completed and published (Rogers and Pitzer, 1981b). Although the experimental program continues, this report emphasizes the two important advances in modeling discussed below.

MODELING EQUATIONS FOR BRINES OONTAINING CARBONATES

A significant advance was made in the accuracy of modeling the thermodynamics of the aqueous carbonate system in the important temperature range 273 to $323 \mathrm{~K}$. In particular, aqueous mixtures of $\mathrm{CO}_{3}{ }^{2-}$ and $\mathrm{BCO}_{3}^{-}$, with $\mathrm{Cl}^{-}$and $\mathrm{Na}^{+}$, $\mathrm{K}^{+}, \mathrm{Mg}^{2+}$ or $\mathrm{Ca}^{2+}$ are important in geologic and biologic chemistry. Despite this importance, the accumulation of accurate thermodynamic information about these systems has been frustrated by hydrolysis of $\mathrm{C}_{3}{ }^{2-}$ and disproportionation of $\mathrm{HCO}_{3}{ }^{-}$, which results in a significant $\mathrm{\omega}_{2}$ vapor pressure. Aqueous solutions of carbonates and bicarbonates are therefore complex mixtures. The effectiveness of the equations of Pitzer and $\mathrm{Kim}$ (1974) for other mixed electrolyte systems pro- 
Table 1. Example showing the types of data obtained for $\mathrm{Na}_{2} \mathrm{CO}_{3}$ solutions. $T=298 \mathrm{~K} ; \phi^{\text {st }}$ and $\gamma^{\text {st }}$ are stoichiometric quantities calculated as if hydrolysis did not occur.

\begin{tabular}{llcccccc}
\hline $\begin{array}{l}\text { Nominal } \\
\text { molality }\end{array}$ & \multicolumn{2}{c}{$\begin{array}{c}\text { Equilibrium } \\
\text { molalities }\end{array}$} & & & & & \\
& $0_{3}^{2-}$ & $\mathrm{HCL}_{3}-$ & $\mathrm{OH}^{-}$ & $\phi$ & $\phi^{\text {st }}$ & $\gamma$ & $\gamma^{\text {st }}$ \\
\hline 0.001 & 0.0007 & 0.0003 & 0.0003 & 0.971 & 1.083 & 0.893 & 0.775 \\
0.01 & 0.0088 & 0.0012 & 0.0012 & 0.910 & 0.945 & 0.724 & 0.695 \\
0.00 & 0.0968 & 0.0032 & 0.0032 & 0.817 & 0.826 & 0.478 & 0.473 \\
0.2 & 0.1958 & 0.0042 & 0.0042 & 0.784 & 0.790 & 0.402 & 0.399 \\
0.6 & 0.5939 & 0.0061 & 0.0061 & 0.715 & 0.717 & 0.285 & 0.284 \\
1.0 & 0.9932 & 0.0068 & 0.0068 & 0.683 & 0.684 & 0.236 & 0.235 \\
2.0 & 1.993 & 0.007 & 0.007 & 0.681 & 0.682 & 0.188 & 0.188 \\
\hline
\end{tabular}

vided the justification for treating a variety of published measurements on these solutions. A comprehensive treatment of solutions involving $\mathrm{CO}_{2}(\mathrm{aq}), \mathrm{HCO}_{3}^{-}, \mathrm{C}_{3}^{2-}, \mathrm{Cl}^{-}$with $\mathrm{Na}^{+}$at the Gibbs energy, enthalphy, and heat capacity levels is complete (Peiper and Pitzer, 1981). A sample of activity information at $298 \mathrm{~K}$, obtained on the basis of this treatment, is presented in Table 1 . Also complete, although limited only to activity information, is a similar treatment for solutions with $\mathrm{K}^{+}$in place of $\mathrm{Na}^{+}$(Roy et al., 1981). Work is in progress for solutions of $\mathrm{Mg}^{2+}$ and $\mathrm{Ca}^{2+}$.

\section{SOLUBILITY OF GYPSUM IN BRINES}

A major advance in the prediction of mineral solubility in seawater-related brines was made by Harvie and Weare (1980), whose calculations were based on the modeling equations of this project. Their work explained several anomalies in the seawater evaporate sequence (Eugster et al., 1980; Harvie et al., 1980). The change from earller modeling calculations was most striking for gypsum solubility in both $\mathrm{NaCl}$ and $\mathrm{NaCl}-\mathrm{Na}_{2} \mathrm{SO}_{4}$ mixtures. We have received more extensive solubility data for gypsum in various brine components (Briggs, 1978) and have carried out new calculations that yield very accurate agreement with these and other related data (Rogers, 1981). Most important in attaining this agreement is the inclusion of the higher-order electrostatic terms for the unsymmetrical mixing of ions of different charges of the same sign, i.e.. $\mathrm{Na}^{+}$with $\mathrm{Ca}^{2+}$ and $\mathrm{Cl}^{-}$with $\mathrm{SO}_{4}{ }^{2-}$. (Pitzer, 1975). This is 11lustrated in igure 1, which shows the activity coefficient of
$\mathrm{CaSO}_{4}$ in mixtures with $\mathrm{NaCl}$ calculated with and without these higher-order terms in comparison with values derived from Briggs' solubility measurements. Figure 2 shows a comparison of predicted (with higher-order terms) and observed solubilities of gypsum in seawater. The excellence of agreement is evident.

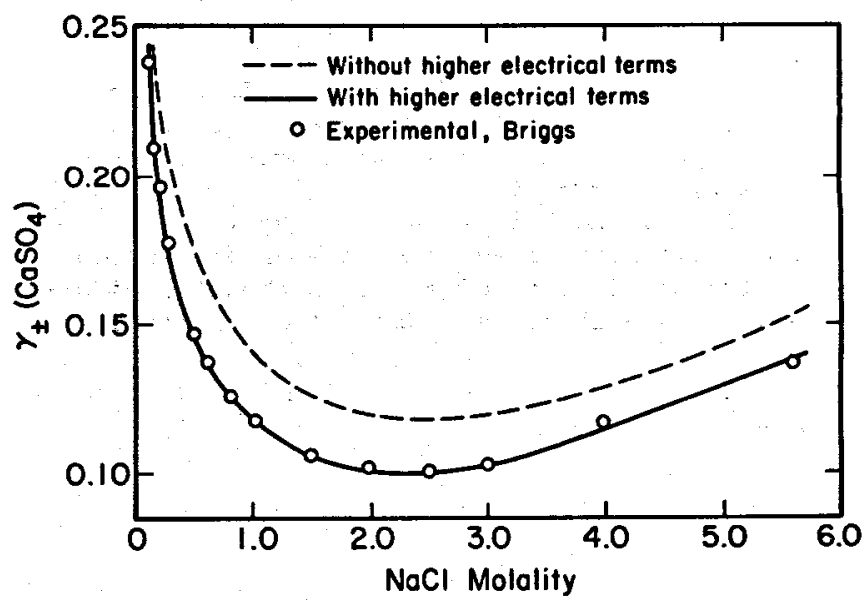

Figure 1. Mean activity coefficients of $\mathrm{CaSO}_{4}$ in solutions of $\mathrm{NaCl}$ saturated with gypsum. Points are calculated from solubllity measurements of Briggs (1978). The broken curve was calculated without higher-order electrostatic terms; the solid curve with those terms.

[XBL B21-7729] 


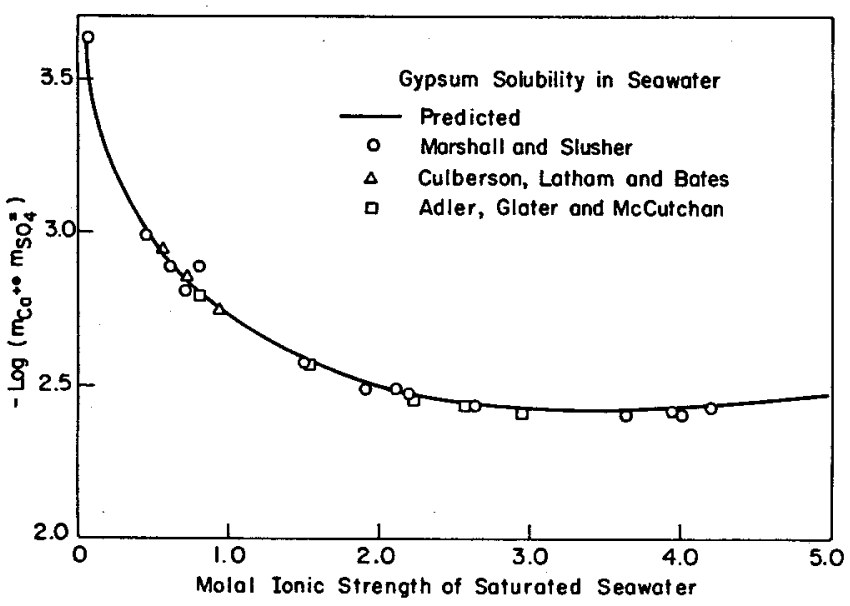

Figure 2. Gypsum solubility in seawater. The solid line represents solubilities predicted using Pitzer's equations and the $\mathrm{CaSO}_{4}$ parameters determined in this study. Sources of data points are given in Rogers (1981).

[XBL 812-5188]

\section{REFERENCES CITED}

Briggs, C. C., 1978. (Ph. D. Dissertation), Dept. of Chemistry, University of Sheffield, Sheffield, England.

Eugster, H. P., Harvie, C. E., and Weare, J. H., 1980. Mineral equilibria in a six-component seawater system, $\mathrm{Na}-\mathrm{K}-\mathrm{Hg}-\mathrm{Ca}-\mathrm{SO}_{4}-\mathrm{Cl}-\mathrm{H}_{2}$, at $25^{\circ} \mathrm{C}$. Geochimica et Cosmochimica Acta, v. 44, p. 1335-1347.

Harvie, C. E., and Weare, J. H. , 1980 . The prediction of mineral solubilities in natural waters: The $\mathrm{Na}-\mathrm{K}-\mathrm{Mg}-\mathrm{Ca}-\mathrm{Cl}-\mathrm{SO}_{4}-\mathrm{H}_{2} \mathrm{O}$ system from zero to high concentration at $25^{\circ} \mathrm{C}$. Geochimica et Cosmochimica Acta, v. 44, p. 981-997.

Harvie, C. E., Weare, J. H., Hardie, L. A., and Bugster, H. P., 1980. Evaporation of seawater: Calculated mineral sequences. Science, v. 208, p. 498-500.

Peiper, J. C., and Pitzer, R. S., 1981. Thermodynamics of aqueous carbonate solutions including mixtures of sodium carbonate, bicarbonate, and chloride. Journal of Chemical

Thermodynamics, in press. (Lawrence Berkeley Laboratory Report IBL-12725).

Pitzer, K. S., 1973. Thermodynamics of electrolytes. I. Theoretical basis and general equations. Journal of Physical Chemistry, v. 77, p. 268-277.

Pitzer, R. S., 1975. Thermodynamics of electrolytes. V. Effects of higher-order electrostatic terms. Journal of Solution Chemistry v. 4, p. 249.

Pitzer, K. S., and Kim, J. J., 1974. Thermodynamics of electrolytes. IV. Activity and osmotic coefficients for mixed electrolytes. Journal of the American Chemical Society, v. 96, p. 5701-5707.

Pitzer, K. S., and Nayorga, G., 1973. Thermodynamics of electrolytes. II. Activity and osmotic coefficients for strong electrolytes with one or both lons univalent. Journal of Physical Chemistry, v. 77, p. 2300-2308.

Pitzer, K. S., and Mayorga, G., 1974. Thermodynamics of electrolytes. III. Activity and osmotic coefficients for 2-2 electrolytes. Journal of Solution Chemistry, v. 3, p. 539546.

Rogers, P. S. Z., 1981. Thermodynamics of geothermal brines. Lawrence Berkeley Laboratory Report IBL-12356.

Rogers, P. S. Z., and Pitzer, K. S., 1981a. volumetric properties of aqueous sodium chloride. Journal of Physical and Chemical Reference Data, in press. (Lawrence Berkeley Laboratory Report LBL-12414.)

Rogers, P. S. Z., and Pitzer, R. S., 1981b. High temperature thermodynamic properties of aqueous sodium sulfate solutions. Journal of Physical Chemistry, v. 85, p. 2886-2895.

Roy, R. N., Gibbons, J. J., Wood, M. D., williams, R. W., Peiper, J. C., and Pitzer, R. S., 1981. The first ionization constant of carbonic acid in aqueous solutions of potassium chloride including the activity coefficients of potassium bicarbonate. Lawrence Berkeley Laboratory Report LBL-13482. (Submitted to the Journal of Chemical Thermodynamics.)

Silvester, L. F., and Pitzer, R. S., 1977. Thermodynamics of electrolytes. VIrI. Hightemperature properties, including enthalpy and heat capacity, with application to sodium chloride. Journal of Physical Chemistry. v. 81, p. $1822-1828$. 


\section{Neil and J. A. Apps}

One of the benefits to be gained from measuring the solubilities of major rock-forming minerals in the aqueous phase at elevated temperatures is the opportunity of testing thermochemical models describing aqueous interactions. The refinement of such models is an important step in interpreting geochemical reactions taking place during diagensis, metasomatism, and metamorphism.

The logic behind the experimental program is shown schematically in Figure 1. The mineral under study is characterized in terms of its composition, crystallographic state, and physical and thermochemical properties. The thermochemical data of the mineral can be used as input to a computer code developed from the aqueous solution model of Helgeson and Kirkham (1976), which calculates the solubility product of the mineral as a function of temperature and pressure. Comparison between measured solubilities and the solubilities projected from calorimetric data serves to identify either data base or model errors, which become the departure point for further research.

As noted previously (Ne11 and Apps, 1981), one such source of error is the uncertainty about the species of aluminum in solution at elevated temperatures. The effect of these errors is shown in Figure 2; the experimental data for the solubility of low albite (Nell and Apps, 1979, 1980, 1981) were calculated using aluminum species dissolution constants completed by Helgeson (1969) and plotted as solubility products. The solubility product is based on the dissolution reaction

$\mathrm{NaAlSi} 3_{8} \mathrm{O}_{8} \mathrm{H}^{+}+4 \mathrm{H}_{2} \mathrm{O}=\mathrm{Na}^{+}+\mathrm{Al}^{3+}+3 \mathrm{~S}_{1}(\mathrm{OH})_{4}^{\circ}$,

where

$K_{S P}(T)=\frac{\left[\mathrm{Na}^{+}\right]\left[\mathrm{Al}^{3+}\right]\left[\mathrm{Si}(\mathrm{OH})_{4}\right]^{3}}{\left[\mathrm{NaAlSi}_{3} \mathrm{O}_{8}\right]\left[\mathrm{H}^{+}\right]^{4}\left[\mathrm{H}_{2} \mathrm{O}^{4}\right.}$

The scatter in these experimentally derived solubility products is primarily due to difficulties in measuring the quenched $\mathrm{pH}$. The experimentally determined solubility products are compared with the solubility product calculated using a solu$t$ Ion model developed by Helgeson and Kirkham (1976) that incorporates thermochemical data for albite compiled by Helgeson et al. (1978). The large change in the solubility product of albite above $275^{\circ} \mathrm{C}$ is the result of the decrease of the dielectric constant of water as $1 \mathrm{t}$ approaches its critical point.

The stability constants of aluminum species have been computed by several investigators, priarily for the purpose of utilizing them in comQutations of rock-water interaction at elevated temperatures. Figure 3 graphically shows the

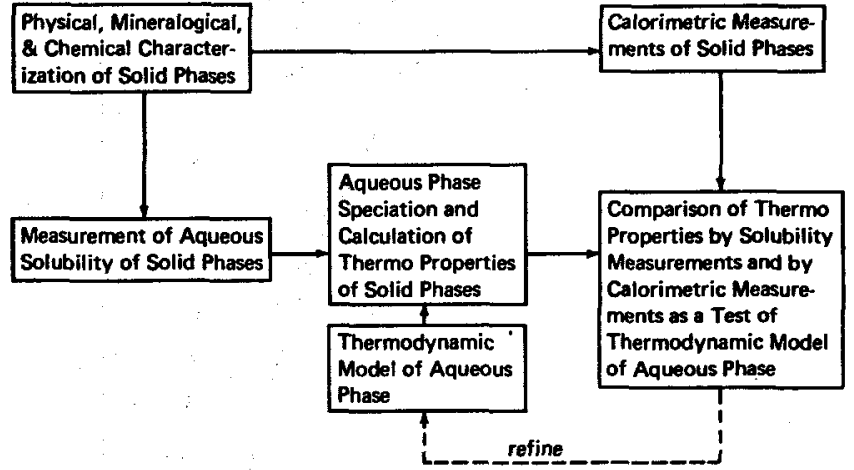

Figure 1. Schematic outline of the experimental philosophy. A well-characterized mineral phase is used to generate thermodynamic and solubility data. The comparison of the two sets of data is used to test and refine the computer model of mineral dissolution.

[XBL 8112-4892]

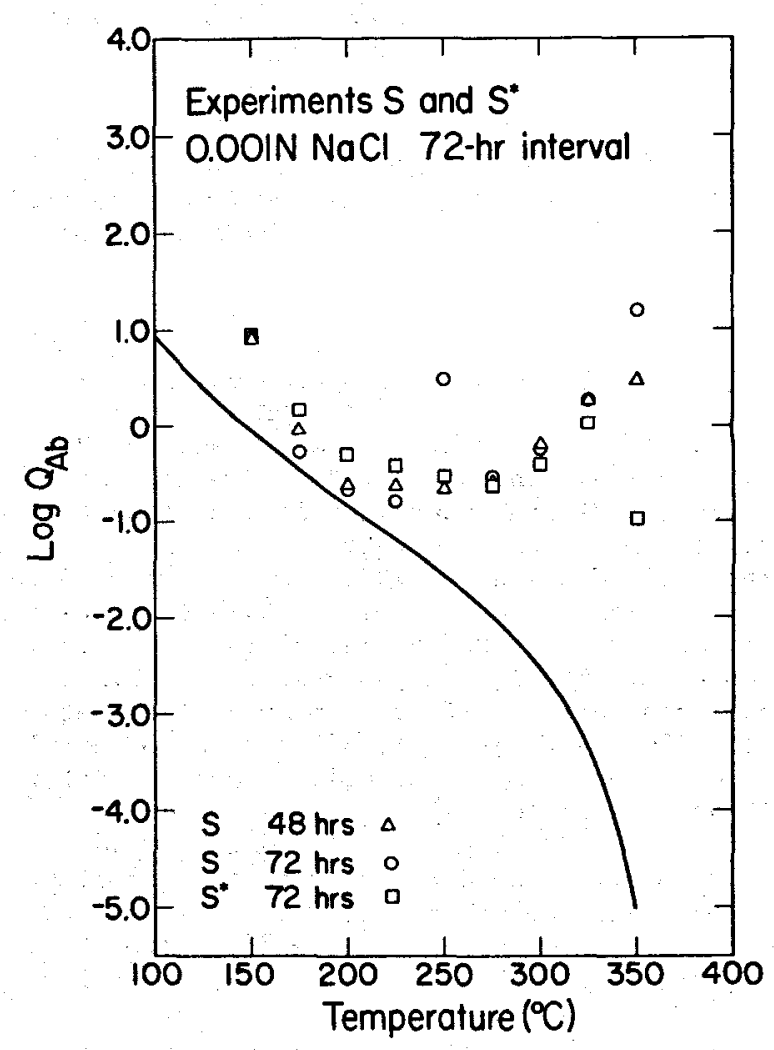

Figure 2. Comparison of thermodynamic and solubility data for albite in $0.001 \mathrm{~N} \mathrm{NaCl}$ solutions as a function of temperature.

[XBL 818-1133] 


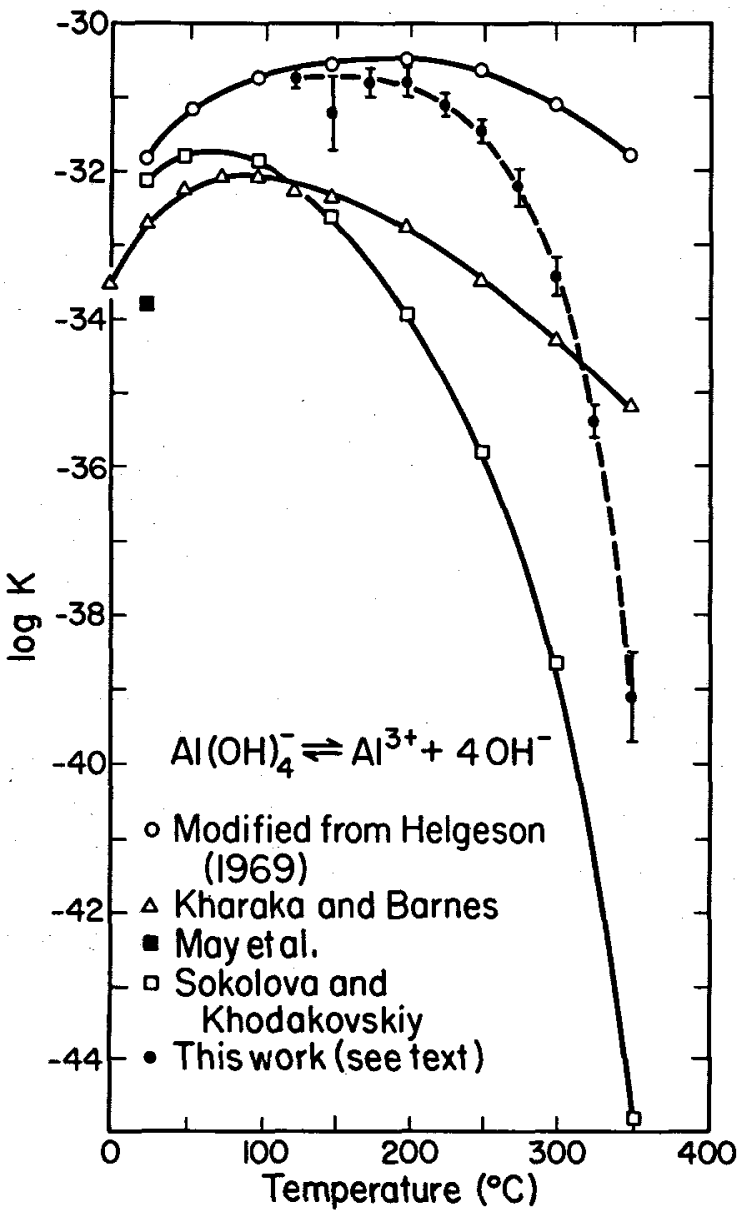

Figure 3. Comparison of $\log \mathrm{KB}_{4}$ for $\mathrm{Al}(\mathrm{OH})_{4}^{-}$ from different sources with the $\log _{\mathrm{K}_{4}}$ calculated from albite solubility data. [XBL 818-1131]

poor agreement between the computed values for $\log \mathrm{K}_{B 4}\left(=\log \left[\mathrm{Al}^{3+}\right]\left[\mathrm{OH}^{-}\right]^{4} /\left[\mathrm{Al}(\mathrm{OH})_{4}^{-}\right]\right)$ of various investigators. The $25^{\circ} \mathrm{C}$ value of May et al. (1979) and the data of Sokolova and Khodakovskiy (1977) are determined from aluminum mineral solubilities. Kharaka and Barnes (1973) use the revised Helgeson (1971) values, which were derived from the feldspar solubility data of Lagache (1965): all of their $K_{B 4}$ values above $200^{\circ} \mathrm{C}$ are extrapolated. The $\mathrm{K}_{\beta_{4}}$ values used in calculations in this paper were modified from an earlier data base compiled by Helgeson (1969) for the original PATH code. The gibbsite solubility data of Kittrick (1966) and the aqueous species free energy of formation $(\triangle G Q, 298.15)$ of $\mathrm{Al}^{3+}$ and $\mathrm{OH}^{-}$(Wagman et al., 1968) were used to generate the stability constants. The published stability constants for the other aluminum species (Al(OH) ${ }^{2+}, \mathrm{Al}_{(\mathrm{OH})}{ }^{+}$, and $\mathrm{Al}(\mathrm{OH}) 3^{\circ}$ ) also show a lack of consistency.

Because of the large discrepancies between the $\mathrm{K}_{\beta}$ values of various investigators, it was elected to reverse the approach by computing the $\mathrm{K}_{\mathrm{B}_{4}}$ as a function of temperature using the relation $\mathrm{NaAlSi}_{3} \mathrm{O}_{8}+8 \mathrm{H}_{2} \mathrm{O}=\mathrm{Na}^{+}+\mathrm{Al}(\mathrm{OH})_{4}-3 \mathrm{Si}(\mathrm{OH})_{4}^{\circ}$, where

$$
K_{\mathrm{SP}}^{\prime}(\mathrm{T})=\frac{\left[\mathrm{Na}^{+}\right][\mathrm{AL}(\mathrm{OH})]_{4}^{-}\left[\mathrm{Si}(\mathrm{OH})_{4}{ }^{\circ}\right]^{3}}{\left[\mathrm{NaAl}_{3} \mathrm{Si}_{3} \mathrm{O}_{8}\right]\left[\mathrm{H}_{2} \mathrm{O}^{8}\right.}
$$

Use of this relationship involves the approximation that the aluminum is present predominantly as $\mathrm{Al}(\mathrm{OH})_{4}-$. which is a reasonable assumption, as most albite solubility measurements were conducted where $\mathrm{pH} \geqslant$ 8.5. One advantage to this form of the solubility product equation is that the hydrogen ion activity does not appear. Thus errors resulting from the experimental difficulty of measuring pH are avoided. Furthermore, the activity coefficient of $\mathrm{Al}(\mathrm{OH})_{4}^{-}$can be assumed to be equivalent to that of $\mathrm{Cl}^{2}, \mathrm{~K}_{\mathrm{B}_{4}}$ can be obtained using the relation

$\log \mathrm{K}_{\beta_{4}}=\log \mathrm{K}_{\mathrm{sp}}-\log \mathrm{K}_{\mathrm{sp}} \cdot-4 \log \mathrm{K}_{w}$.

Figure 3 shows the average $\log \mathrm{K}_{B}$ derived by this procedure with albite solubility data from experiments $R, S$, and $s^{*}$. The values for $k_{B_{4}}$ from the other investigators are shown for comparison.

The computed $\log \mathrm{K}_{\beta_{4}}$ values differ markedly from the extrapolations by other investigators. This is clear evidence that independent measurements must be made to determine the accurate values of dissociation constants of aluminum species in solution as a function of temperature. To this end a large $(800-g)$ gem-quality single crystal of Turkish diaspore $(\alpha-\mathrm{AlO}(\mathrm{OH}))$, purchased from Ward's Scientific Establishment, has been crushed and sized for dissolution experiments at elevated temperatures.

The autoclave to be used for these studies has been modified by the addition of a precisionvolume, high-pressure injector. This will permit the $\mathrm{pH}$ in the autoclave to be changed in small steps by injections of sodium hydroxide or hydrochloric acid solutions. Experiments will be done at five different temperatures $\left(25^{\circ}, 100^{\circ}, 175^{\circ}\right.$, $250^{\circ}$, and $\left.325^{\circ}\right)$. From the curve of total aluminum as a function of $\mathrm{pH}$, the stability constants for the aqueous aluminum hydroxide species can be derived using a curve-fitting routine similar to that used by May et al. (1979). Once the nature of aluminum speciation in solution is clarified, the albite solubility data can be re-examined.

\section{REFERENCES CITED}

Helgeson, H. C., 1969. Thermodynamics of hydrothermal systems. American Journal of Science, v. 267, p. 729-804.

Helgeson, H. C., 1971. Rinetics of mass transfer among silicates and aqueous solutions. Geochimica et Cosmochimica Acta, v. 35, p. 421-469.

Helgeson, H. C., and Kirkham, D. H., 1976. Theoretical prediction of the thermodynamic properties of aqueous electrolytes at high pressures and temperatures: III. Equation of state for aqueous species at infinite dilution. American Journal of Science, v. 276, p. 97-240. 
Eelgeson, H. C., Delany, J. M., Nesbitt, H. W., and Bird, D. K., 1978. Summary and critique of the thermodynamic properties of rock-forming minerals. American Journal of Science, v. 278-A, 229 p.

Kharaka, Y. K., and Barnes, I., 1973, SOLMNEQ: Solution-mineral equilibrium computations. National Technical Information Service Report PB-215-899, 82 p.

Kittrick, J. A., 1966. The free energy of formation of gibbsite and $\mathrm{Al}(\mathrm{OH})_{4}^{-}$from solubility measurements. Soil Science Society of America Proceedings, v. 30 , p. 595-598.

Lagache, M.. 1965, Contribution á l'étude de 1 'altération des feldspaths, dans 1 'eau, entre 100 et $200^{\circ} \mathrm{C}$, sous diverses pressions de $\mathrm{O}_{2}$, et applications á la synthése des minéraux angileaux. Bulletin de la Societe Francalse de Mineralogie et de Cristallographie, v. 88, p. 223-253.

May, H. M., Helmke, P. A., and Jackson, M. L., 1979. Gibbsite solubility and thermodynamic properties of hydroxy-aluminum ions in aqueous solution at $25^{\circ} \mathrm{C}$. Geochimica et Cosmochimica Acta, v. 43, p. $861-868$.
Neil, J. M., and Apps, J. A., 1979. Solubility of albite in the aqueous phase at elevated temperatures. Lawrence Berkeley Laboratory Report IBL-10349, p. 16-21.

Neil, J. M., and Apps, J. A., 1980. Solubility of low albite in NaCl solutions at $250^{\circ} \mathrm{C}$. Lawrence Berkeley Laboratory Report IBL-10686, P. 159-165.

Ne 11, J. M., and Apps, J. A., 1981. Results of albite solubility measurements as a function of temperature $\left(125-350^{\circ} \mathrm{C}\right)$. In Earth Sciences Division Annual Report 1980. Lawrence Berkeley Laboratory Report IBL-12100, p. 41-43.

Sokolova, N. J., and Khodakovskiy, I. L., 1977. The mobility of aluminum in hydrothermal systems. Geochemistry International, v. 1977, p. 105-112.

Wagman, D. D., Evans, W. H., Halow, I., Parker, V. B., Bailey, S. M., and Schumm, R. H., 1968. Selected values of chemical thermodynamic properties, Part 3. National Bureau of Standards Technological Note $270-3$, p. 208.

\title{
THERMODYNAMIC PROPERTIES OF SILICATE MATERIALS
}

\author{
I. S. E. Carmichael, L. K. Moret, M. L. Rivers, J. F. Stebbins, and X. Mo
}

Measurements of the thermodynamic properties of silicate liquids and glasses are generally few in number, and yet essential if the generation of magmas at depth in the earth, their ascent toward the surface, and their cooling on or near the surface are to be quantifled. General geologic investigations have provided almost unlimited data on the range of compositions of natural silicate liquids, but comparatively little on the correspondence between their composition and such properties as volume, thermal expansion, compressibility, heat content, and heat capacity. It is the intent of this experimental program to remedy this situation by combining measurements of thermodynamic properties over a wide range of silicate compositions to obtain the compositional dependence of the measured property.

\section{COMPRESSIBILITY OF SILICATE LIQUIDS}

Understanding the behavior of magmas at high pressures requires a knowledge of the molar volumes of silicate liquids as a function of temperature, pressure, and composition. This project is a imed at determining how the molar volume w111 change as a function of pressure by measuring the ulk modulus of silicate liquids over a range of Lemperature and composition.

We have determined the adiabatic bulk modulus, $k_{5}$, by measuring the velocity with which ultra- sonic waves travel through the sample. The two quantities are related by $K_{s}=v^{2} \rho$, where $v$ is the ultrasonic velocity and $\rho$ is the density. The change in volume with pressure is usually expressed in terms of

$\beta_{T}=\frac{1}{V}\left(\frac{\partial v}{\partial P}\right)_{T}$

the isothermal compressibility. This is related to the adiabatic compressibility $\beta_{S}$ by $\beta_{T}=B_{S}$ $+T_{a p} / \rho C_{p}$, where $\alpha_{p}$ and $C_{p}$ are the isobaric thermal expansion and heat capacity, respectively. $B_{T}$ for silicate liquids differs by at most a few percent from $B_{8}$, and $B_{s}$ is $s i m p l y ~ 1 / K_{s}$.

We have constructed the apparatus required to measure ultrasonic velocities to an accuracy of \pm 0.18 up to $1560^{\circ} \mathrm{C}$. Since the ultrasonic transducers used to generate and receive the signals are Iimited to low-temperature operation, a buffer rod is used to transmit the signals to and from the high-temperature liquid samples. We have found that a polycrystalline molybdenum rod knurled along its entire length provides both low signal loss and a dramatic reduction in unwanted signals reflected from the sides of the rod. The sample is contained in a molybdenum crucible, the bottom of which is a reflecting surface. The time required for the signals to travel through the liquid is measured by determining the time between the echo 
that is reflected from the end of the rod and the one that travels through the liquid, bounces off the bottom of the crucible, and returns up the rod. The time is about $1-10 \times 10^{-6} \mathrm{~s}$, and can be measured to $\pm 10^{-10} \mathrm{~s}$. The velocity in the liquid is determined by measuring the change in time as the path length through the liquid is changed by moving the rod up and down.

We have completed measurements on three silicate liquids. $\mathrm{Na}_{2} \mathrm{SiO}_{3}$ was determined to have a sonic velocity of $2752 \mathrm{~m} / \mathrm{s}$ at $1193^{\circ} \mathrm{C}$ and $2663 \mathrm{~m} / \mathrm{s}$ at $1300^{\circ} \mathrm{C}$. These values agree to within 0.18 and \pm 0.58 , respectively, with the values measured by Bockris et al. (1960). Liquid diopside $\left(\mathrm{CaMgSi}_{2} \mathrm{O}_{6}\right)$ has an almost constant velocity of $3043 \mathrm{~m} / \mathrm{s}$ between 1410 and $1520^{\circ} \mathrm{C}$. This leads to a compressibility that, together with enthalpy and volume data for the solid, reproduces well the fusion curve as a function of pressure and temperature. Finally, anorthite liquid $\left(\mathrm{CaAl}_{2} \mathrm{Si}_{2} \mathrm{O}_{8}\right)$ has a velocity of $2844 \mathrm{~m} / \mathrm{s}$ at $1550^{\circ} \mathrm{C}$. Uitimately, these data will form part of a data set to recover partial molar compressibilities.

\section{Bigh-Temperature Drop Calorimetry}

Our program of drop calorimetry has produced data on both the standard state properties of silicate liquids of stoichiometric composition and on their mixing properties.

Measurements on 1 lquid diopside $\left(\mathrm{CaMgsi}_{2} \mathrm{O}_{6}\right)$ and glass have been combined with data in the literature to yield the following equation for the heat of fusion of diopside:

$$
\begin{aligned}
\Delta \mathrm{H}_{\mathrm{f}}= & 0.03148 \mathrm{~T}-3.93 \times 10^{-6} \mathrm{~T}^{2} \\
& -1.574 \times 10^{3} \mathrm{~T}^{-1}-7.713 \mathrm{kcal} / \mathrm{mole} .
\end{aligned}
$$

The liquid heat capacity $\left(c_{\mathrm{p}}\right)$ is $84.4 \mathrm{cal} / \mathrm{mole}-\mathrm{K}$.

For the first time, data on sanidine (KAlsi ${ }_{3} 0_{8}$ ) liquid allow an expression of the heat of fusion of sanidine that includes the measured liquid $C_{p}$ of $89.5 \mathrm{cal} /$ mole $-\mathrm{R}$ :

$$
\begin{aligned}
\Delta \mathrm{H}_{\mathrm{f}}= & 0.02779 \mathrm{~T}-6.95 \times 10^{-6} \mathrm{~T}^{2} \\
& -1.501 \times 10^{3} \mathrm{~T}^{-1}-11.73 \mathrm{kcal} / \mathrm{mole} .
\end{aligned}
$$

The fusion curves of sanidine, diopside, albite, and anorthite have been calculated at high pressure by combining our heat of fusion determinations with data in the literature on the properties of the solids. The results for diopside are consistent with $s$ imple elastic compression of the liquid and a relatively small change in compressibility with pressure. For albite and anorthite, however, the volumes of the liquids must decrease very rapldly between 1 bar and 10 kilobars, suggesting some kind of structural rearrangement. Above 10 kilobars, the compressibility of albite liquid must be almost constant.

In the albite (NaAlsi ${ }_{3} \mathrm{O}_{8}$ )-anorthite ( $\mathrm{CaAlSi} \mathrm{O}_{2} \mathrm{O}_{8}$ )-diopside $\left(\mathrm{CaMgS} \mathrm{i}_{2} \mathrm{O}_{6}\right.$ ) system, enthalpy and heat capacity measurements have been completed for thirteen liquid compositions. Data on the ternary compositions do not show the simple line- ar relation to composition found in the albiteanorthite binary. This unexpected result led to a careful assessment of the assumptions involved in the interpretation of drop calorimetric data on glass-forming liquids. In the laboratory of A. Navrotsky at Arizona state Onfversity, we carried out a series of inverse drop and drop-solution calorimetric measurements on glasses in this system. The results show that glass annealing affects the enthalpy by as much as $1200 \mathrm{cal} / \mathrm{mole}$ and can cause significant errors in calculated heats of mixing in the liquids. On the other hand, glasses prepared by quenching a given 1iquid from various temperatures have no measurable differences in their calorimetric properties, confirming that drop calorimetric determinations of heat capacity are reliable.

\section{Heat Capacities of Glasses}

The heat capacity $\left(C_{p}\right)$ of eighteen glasses in the system $\mathrm{NaAlSi}_{3} \mathrm{O}_{8}(\mathrm{Ab})-\mathrm{CaAl}_{2} \mathrm{Si}_{2} \mathrm{O}_{8}$ (An) -CaMgSi ${ }_{2} \mathrm{O}_{6}(\mathrm{Di})$ have been measured over the range 400 to $940 \mathrm{~K}$ using a differential scarining calorimeter. The measured glasses are the three end members and nine binary and six ternary compositions. Approximately $\mathbf{4 0 0}$ points were recorded for each composition from 400 to $940 \mathrm{~K}$, and the typical fit equation for each has a standard error of 0.58 . The heat capacity for all eighteen compositions at 10 -degree intervals was regressed to yield the following equation (cal/mole-K) :

$$
\begin{aligned}
C_{p}= & 69.189 X_{A b}+63.912 X_{A n}+46.415 X_{D i} \\
& +T\left(1.1146 \times 10^{-2} X_{A b}+1.6041 \times 10^{-2} X_{A n}\right. \\
& \left.+1.6975 \times 10^{-2} X_{D i}\right)-T^{-2}\left(2.5455 \times 10^{6} X_{A b}\right. \\
& \left.+1.8573 \times 10^{6} X_{A n}+1.0141 \times 10^{6} X_{D i}\right)
\end{aligned}
$$

which also has an average error of 0.58 , with a maximum of 1.48. Thus within the glass stability region, the heat capacity of any composition within this ternary system may be estimated from a linear combination of the three end members to give an estimate within 0.58 on average of those measured.

\section{Density measurements of silicate liquids}

Density measurements of a variety of silicate liquids were used by Bottinga and Weill (1970) to derive partial molar volumes of oxide components and their temperature dependence. Since then ternary and multicomponent silicate liquids contailing $\mathrm{TiO}_{2}$ have been measured, and estimates of the partial molar volumes of the components $\mathrm{SiO}_{2}, \mathrm{TiO}_{2}, \mathrm{Al}_{2} \mathrm{O}_{3}, \mathrm{FeO}, \mathrm{MgO}, \mathrm{CaO}, \mathrm{Na} 2 \mathrm{O}$, and $\mathrm{K}_{2} \mathrm{O}$ have been given by Nelson and Carmichael (1979). Al though many of the density measurements of FeOcontaining systems have indicated small amounts of $\mathrm{Fe}_{2} \mathrm{O}_{3}$. (e.g.. Henderson, 1964; Shiraishi et al.., 1978), the concentrations of that component were so small that Bottinga and Weill constrained its volume in silicate liquids by analogy to that of crystalline $\mathrm{Fe}_{2} \mathrm{O}_{3}$ (hematite).

We have measured the density of eight $\mathrm{Fe}_{2} \mathrm{O}_{3}-$ containing silicate liquids (Fig. 1) in air as a function of temperature. The ratio $\mathrm{Fe}_{2} \mathrm{O}_{3}-\mathrm{FeO}$ in 


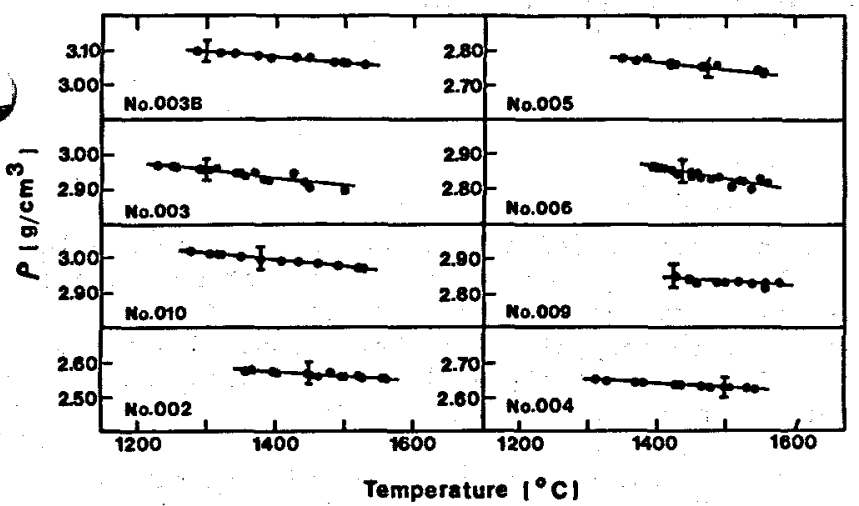

Figure 1. Density determinations of eight silicate IIquids as a function of temperature. Error brackets represent \pm 18 .

Table 1. Partial molar volumes of oxide components in silicate liquids $\left(\mathrm{cm}^{3} /\right.$ mole $)$.

\begin{tabular}{lcccccc}
\hline & $1523 \mathrm{~K}$ & $1573 \mathrm{~K}$ & $1673 \mathrm{~K}$ & $1773 \mathrm{~K}$ & $1873 \mathrm{~K}$ \\
\hline $\mathrm{SiO}_{2}$ & $27.07(0.14)$ & $27.04(0.14)$ & $27.01(0.14)$ & $26.99(0.18)$ & $27.01(0.23)$ \\
$\mathrm{TiO}_{2}$ & $21.67(0.83)$ & $22.00(0.79)$ & $22.64(0.83)$ & $23.23(1.02)$ & $23.79(1.29)$ \\
$\mathrm{Al}_{2} \mathrm{O}_{3}$ & $35.81(0.35)$ & $6.09(0.33)$ & $36.64(0.35)$ & $37.18(0.43)$ & $37.70(0.55)$ \\
$\mathrm{Fe}_{2} \mathrm{O}_{3}$ & $42.86(1.07)$ & $43.16(1.06)$ & $43.89(1.23)$ & $44.37(1.70)$ & $44.68(2.52)$ \\
$\mathrm{FeO}$ & $13.28(0.20)$ & $13.44(0.19)$ & $13.73(0.20)$ & $14.27(0.27)$ & $14.81(0.36)$ \\
$\mathrm{MgO}$ & $11.25(0.33)$ & $11.32(0.31)$ & $11.46(0.32)$ & $11.57(0.40)$ & $11.62(0.51)$ \\
$\mathrm{CaO}$ & $15.38(0.21)$ & $15.70(0.20)$ & $16.32(0.21)$ & $16.96(0.27)$ & $17.57(0.34)$ \\
$\mathrm{Na}_{2} \mathrm{O}$ & $27.74(0.24)$ & $28.10(0.23)$ & $28.80(0.24)$ & $29.48(0.29)$ & $30.10(0.37)$ \\
$\mathrm{K}_{2} \mathrm{O}$ & $44.28(0.52)$ & $44.79(0.50)$ & $45.97(0.52)$ & $47.12(0.64)$ & $48.18(0.82)$ \\
\hline
\end{tabular}

Note: Numbers in parentheses represent one standard error.

a silicate liguld decreases with temperature at constant oxygen fugacity. The temperature dependence of this ratio was taken from Sack et al. (1980), and was combined with the analyzed value of $\mathrm{Fe}_{2} \mathrm{O}_{3}-\mathrm{FeO}$ in each Ilquid quenched from a known temperature to calculate the liquid compositions.

Using density measurements converted to volume/gram formula weight for 129 silicate liquids, values of the partial molar volumes of the most abundant nine oxides in natural sllicate liquids have been calculated. These are shown in Table 1 together with one standard error of the estimate.

\section{REFERENCES CITED}

pckris, J., and Kojonen, E., 1960. The compressibilities of certain molten albite silicates and borates. Journal of the American Chemical Society, v. 82, p. 4493-4497.
Bottinga, Y., and Well1, D. F., 1970. Densities of liquid silicate systems calculated from partial molar volumes of oxide components. American Journal of Science, v. 269, p. 169-182.

Henderson, J., 1964. Density of IIme-iron oxide-silicate melts. Transactions of the American Institute of Mining, Metallurgical and Petroleum Engineers, v. 20, p. 501-504.

Nelson, S. A., and Carmichael, I.S.E., 1979. Partial molar volumes of oxide components in silicate liquids. Contributions to Mineralogy and Petrology, v. 71, p. 117-124.

Sack, R. O., Carmichael, I.S.E., Rivers, M.. and Ghiorso, M. S., 1980. Ferric-ferrous equilibria in natural sillcate liquids at 1 bar. Contributions to Mineralogy and Petrology, v. 75, p. 369-376.

Shiraishi, Y., Ikeda, X., Tamura, A., and Salto, T., 1978. On the viscosity and density of the molten $\mathrm{FeO}-\mathrm{SHO}_{2}$ system. Transactions of the Japan Institute of Metals, v. 19, p. 264-274. 


\title{
NONEQUILIBRIUM, INTERPHASE MASS TRANSFER IN CHEMICAL TRANSPORT BY GROUNDWATER
}

\author{
C. L. Carnahan and J. S. Remer
}

The study of transport of chemically reactive solutes by flowing groundwater systems has many applications to current investigations in the fields of hydrology and geochemistry. Processes of mass transport and interphase mass transfer play important roles in natural systems such as ore deposits and geothermal reservoirs. Disturbances of natural systems by human activities also may require evaluation and prediction of rates and extents of mass transport. These disturbances include, for example, subsurface disposal of radioactive or toxic chemical wastes, acidic drainage from mines, and leaching of landfills, tailings dams, and spoil heaps.

The research described here is a part of a larger study of nonequilibrium processes in mass transport by flowing groundwater. In this phase of the work, we have developed analytical solutions for convective-dispersive transport of a radioactive solute that undergoes time-dependent sorption on surfaces of the matrix supporting the flow. The rate of sorption is represented by a linear kinetic rate law, corresponding to the approximation of very low sorbate activity in the fluid phase. These solutions were derived, along with solutions for the case of equilibrium sorption, to serve as references for comparison with numerical results for transport problems using nonlinear kinetic rate laws of sorption and with more complex treatments, including effects of thermodynamic coupling of transport processes; these investigations are now in progress.

Our solutions are geometrically symetric about an axis parallel to the direction of fluid flow, and include different values of the coefficients of hydrodynamic dispersion in longitudinal and transverse directions. The medium supporting fluid flow is assumed homogeneous and infinite in extent. Three conditions governing release of solute are considered: (1) an instantaneous release of a finite quantity of solute, (2) a continuous. time-dependent release, and (3) a time-dependent release terminated at a finite time.

Our approach has been to derive analytical solutions to the problem of release of solute at a hypothetical, single point in space. The analytical solutions to this problem are useful in two ways. First, the point-source solutions by themselves are useful approximations to solute concentration histories at distances sufficiently far from source regions that the dimensions of the latter can be considered relatively negligible. Second, the point-source solutions can be used as the kernels of integrals over finite volumes of space to provide analytical solutions for source regions having finite spatial extents and a variety of geometrical shapes. This extension allows evaluation of solute concentration histories at source-to-observer distances that are not large relative to source dimensions.

The solutions for nonequilibrium sorption are expressed in closed form as definite integrals in which time is the variable of integration. These integrals appear to be irreducible, and must be evaluated numerically. We have composed a computer code that numerically evaluates the point-source solutions.

Detailed derivations of our results have been reported elsewhere (Carnahan and Remer, 1981).

\section{STATEMENT OF THE PROBLEM}

The transport problem is stated by two simultaneous partial differential equations:

$$
\begin{aligned}
\frac{\partial C}{\partial t} & =D_{T}\left(\frac{\partial^{2} c}{\partial x^{2}}+\frac{\partial^{2} c}{\partial y^{2}}\right) \\
& +D_{L} \frac{\partial^{2} c}{\partial x^{2}}-v \frac{\partial C^{2}}{\partial z}-\lambda c-\alpha_{\left(k_{1} c-k_{2} Q\right),} \\
\frac{\partial Q}{\partial t} & =-\lambda Q+k_{1} c-k_{2} Q,
\end{aligned}
$$

in which $C$ is concentration of solute in the fluid phase, $Q$ is concentration of solute in the solid phase $D_{T}$ and $D_{L}$ are transverse and longitudinal dispersion coefficients, $v$ is average velocity of the fluid phase, $\lambda$ is the radioactive decay constant of the solute, $\alpha$ is the ratio of solid volume to fluid volume, $k_{1}$ and $k_{2}$ are forward and backward rate constants for the sorption reaction, and $x, y, z$, and $t$ have their usual meanings. We require solutions to (1) and (2) subject to the initial conditions:

$C=0, Q=0$ for $\rho>0, t=0$,

where $\rho^{2}=x^{2}+y^{2}+z^{2}$

and the boundary condition is given by

$\lim c=0, t>0$

$\rho \rightarrow \infty$

We require also that the amount of solute present in all space at any time, $t$, be equal to the total amount of solute released at the source with correction for radioactive decay of the solute. Bence, if $M(t)$ is total mass of solute present at $t$ ime $t$, it follows that

$\int_{\substack{\text { all } \\ \text { space }}}[\varepsilon C+(1-\varepsilon) Q] d V=M(t)$.

Laplace transform methods were used to derive solutions of ( 1 ) and (2), subject to (3), (4), and (5), using appropriate forms for $M(t)$. 
SOLUT IONS FOR INSTANTANEOUS RELEASE OF SOLUTE

A quantity of radioactive solute, $\mathrm{N}_{0}$, is eleased instantaneously at time zero at the oriin of coordinates. The quantity of solute present at time $t, M(t)$, is

$M(t)=M_{0} e^{-\lambda t}$

$C$ and $Q$ are then given by

$C=\frac{M_{0} e^{-\lambda t}}{8 \pi^{3 / 2} D_{T} D_{L}^{1 / 2} \varepsilon}\left\{\frac{e^{-\frac{r^{2}}{4 D_{T} t}-\frac{(z-v t)^{2}}{4 D_{L} t}-\alpha k_{1} t}}{t^{3 / 2}}\right.$

$+\left(\alpha k_{1} k_{2}\right)^{1 / 2} e^{-k_{2} t} \int_{0}^{t} e^{-\frac{r^{2}}{4 D_{T} \tau}-\frac{(z-v \tau)^{2}}{4 D_{L}}-\left(\alpha k_{1}-k_{2}\right) \tau}$

- $\left.I_{1}\left[2 \sqrt{a k_{1} k_{2} \tau(t-\tau)}\right] \frac{d \tau}{\tau(t-\tau)^{1 / 2}}\right\}$.

$Q=\frac{k_{1} M_{0} e^{-\left(\lambda+k_{2}\right) t}}{8 \pi^{3 / 2} D_{T} D_{L}^{1 / 2} \varepsilon} \int_{0}^{t} e^{-\frac{r^{2}}{4 D_{T} \tau}-\frac{\left(z-\sigma^{2}\right)}{4 D_{L} \tau}-\left(\alpha k_{1}-k_{2}\right) \tau}$

$$
\text { - } I_{0}\left[2 \sqrt{a k_{1} k_{2} \tau(t-\tau)}\right] \frac{d \tau}{\tau^{3 / 2}} \text {. }
$$

SOLUTIONS FOR CONTINUOUS RELEASE OF SOLUTE

Radioactive solute is released continuously at the origin beginning at time zero. The release rate is $m_{0}$ mass units per unit time at time zero, and decreases exponentially in time with a time constant $\gamma$. Then $M(t)$ is obtained from

$\frac{d M(t)}{d t}=M_{0} e^{-(\tau+\lambda) t}-\lambda M(t)$

with the initial condition

$M(0)=0$.

In this case $c$ and $Q$ are given by:

$c=\frac{m_{0} e^{-\left(\lambda+k_{2}\right) t}}{B_{\pi}^{3 / 2} D_{T} D_{L}^{1 / 2} \varepsilon} \int_{0}^{-\frac{r^{2}}{4 D_{T} \tau}-\frac{\left(z-v \tau^{2}\right)}{4 D_{L} \tau}+\left(\frac{\alpha k_{1}}{k_{2}-\gamma}+1\right) \gamma \tau}$

$$
\text { - } J\left[\frac{\alpha k_{1} k_{2} \tau}{k_{2}-\gamma},\left(k_{2}-\gamma\right)(t-\tau) \frac{d \tau}{3 / 2}\right]
$$

$Q=\frac{k_{1}}{k_{2}-\gamma} \int-\frac{m_{0} e^{-\left(\lambda+k_{2}\right) t}}{8 \pi^{-3 / 2} D_{T} D_{L}^{1 / 2}} \int_{\varepsilon}^{t} e^{-\frac{r^{2}}{4 D_{T} \tau}-\frac{\left(z-v \tau^{2}\right)}{4 D_{L}{ }^{2}}-\left(\alpha k_{1}-k_{2}\right) \tau}$

$$
\text { - } \left.I_{0}\left[2 \sqrt{a k_{1} k_{2} \tau(t-\tau)}\right] \frac{d \tau}{\tau^{3 / 2}}\right\}
$$

where the function $J(\eta, \xi)$ is defined according to Goldstein (1953) as:

$$
\begin{aligned}
J(N, \xi) & =1-e^{-\xi} \int_{0}^{\eta_{1}} e^{-\sigma} I_{0}(2 \sqrt[j]{\xi \sigma}) d \sigma . \\
& =e^{-\xi} \int_{n}^{\infty} e^{-\sigma} I_{0}(2 \sqrt{\xi \sigma}) d \sigma .
\end{aligned}
$$

\section{SOLUTIONS FOR A PULSED RELEASE OF SOLUTE}

Radioactive solute is released at the origin beginning at time zero. The release rate is $\mathrm{m}_{0}$ mass units per unit time at time zero, and decreases exponentially in time with a time constant $\gamma$; simultaneously, solute disappears by radioactive decay with a decay constant $\lambda$. The release continues until time $T$, when it stops; transport of previously released solute continues after time $T$. At any $t$ ime, $t$, the net rate of change of solute mass, $M(t)$, In all space is obtalned from:

$\frac{d M(t)}{d t}=m_{0} e^{-(\gamma+\lambda) t}[U(t)-U(t-T)]-\lambda M(t)$,

with the initial condition

$H(0)=0$

$v(t)$ is the unit step function, defined by:

$U(t)=\left\{\begin{array}{l}0 \text { for } t<0 \\ 1 \text { for } t>0\end{array}\right.$

The fluid concentration at time $t, t>T$, is

$c=c_{c}-c_{p}$

where $c_{c}$ is given by (11) and $c_{p}$ is given by:

$c_{p}(t)=e^{-(\lambda+\gamma) T} C_{C}(t-T) ;$ 
thus

$$
\begin{aligned}
C_{p}=\frac{m_{0} e^{-(\gamma+\lambda) t}}{8 \pi^{3 / 2} D_{T} D_{L}^{1 / 2} \varepsilon} \int_{0}^{t-T} e^{-\frac{r^{2}}{4 D_{T} \tau}-\frac{\left(z-\nabla \tau^{2}\right)}{4 D_{L} \tau}+\left(\frac{\alpha k_{1}}{k_{2}-\gamma}+1\right) \gamma \tau} \\
x \quad J\left[\frac{\alpha k_{1} k_{2} \tau}{k_{2}-\gamma},\left(k_{2}-\gamma\right)(t-T-\tau)\right] \frac{d \tau}{\tau^{3 / 2}} \cdot
\end{aligned}
$$

The solid concentration at time $t, t>T$, is

$Q=Q_{c}-Q_{p}$

where $Q_{c}$ is given by (12) and $Q_{p}$ is given by:

$Q_{p}(t)=e^{-(\lambda+\gamma) T} Q(t-T) ;$

thus

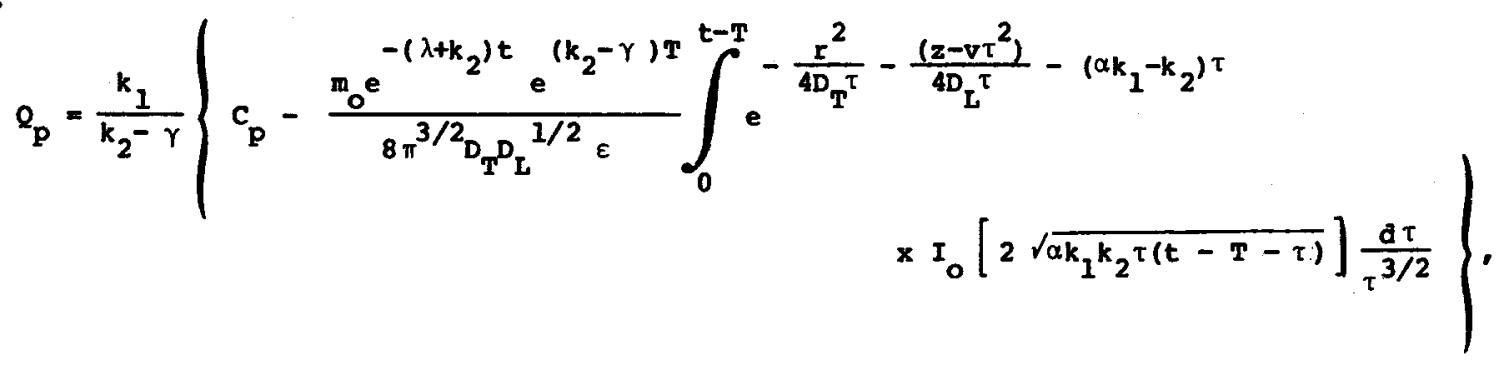

where $c_{p}$ is given by (17).

\section{EXTENSION OF SOLUTIONS TO FINITE SOURCES}

The point-source solutions developed in earlier sections can be used to construct solutions resulting from nonpoint sources. The term "nonpoint source" is used to denote one-, two-, or three-dimensional regions that contain a uniform distribution of point sources. The concentration at a point outside the source region is the sum of the contributions from each point source in the source region. This method has been widely used to solve heat conduction problems (e.g.., Carslaw and Jaeger, 1959, Chapter 10) in which temperature is analogous to concentration and the quantity of heat released is analogous to the mass of solute released.

In the development of the point-source solutions earlier in this work, the point source was assumed to be located at $(0,0,0)$ and the concentration was calculated at a point $(x, y, z)$. If the point source is instead located at $\left(x^{\prime}, y^{\prime}, z^{\prime}\right)$, the variables $x, y$, and $z$ in the point-source solutions must be replaced by $x-x^{\prime}, y-y^{\prime}$, and $z-z^{\prime}$. The spatial integrations are then with respect to $x^{\prime}, y^{\prime}$, and $z^{\prime}$. For example, if point sources are distributed along the $x$ axis from $x_{1}$ to $x_{2}$, then the integration is with respect to $x$ ' with lower and upper limits of integration $x_{1}$ and $x_{2}$. If the source region is a circular disk of radius $R$ in the $x-y$ plane, then one integration is first performed with respect to $x^{\prime}$ with limits of integration from $-\sqrt{R^{2}-Y^{12}}$ to $+\sqrt{R^{2}-Y^{12}}$ followed by an integration with respect to $Y^{\prime}$ from $-R$ to R. If a radial coordinate system is used instead of a Cartesian coordinate system and the appro- priate change of variables is made in the integrand, then the integration is from 0 to $R$ with respect to $r^{\prime}$ and from 0 to $2 \pi$ with respect to $\theta^{\prime}$. The last example shows how a change of coordinate system may simplify the integration. The integration may also be simplified by aligning the source region with the coordinate axes and by making use of a plane or axis of symmetry if one exists.

\section{SUMMARY}

We have derived analytical solutions to the transport equation under the assumption that the number of sites available on surfaces of the solid phase for either ion exchange or the Iangmuir type of sorption is very large relative to the number of sites occupied by sorbate ions or molecules. For the rate of mass transfer between fluid and solid phases, this assumption leads to a kinetic law that is linear in concentrations of sorbate in both phases. Thus our analysis is strictly applicable only to sorption upon a solid phase in which the concentration of sorbate is small relative to the saturation concentration or, equivalently, to sorptive systems characterized by a linear isotherm for sorption.

Our point-source solutions will serve as standards for checking of, and comparison with, numerical models of nonlinear, sorptive systems now under development. Additionally, the pointand line-source solutions are useful approximations, in the far field, to solutions of linear transport problems involving source functions for which a total rate of release of sorbate can be specified. Finally, the point-source solutions are directly applicable to the development of analytical solutions of problems involving source 
functions occupying finite regions of the space in which transport takes place. This application is possible because the transport equation and, In the cases of nonequilibrium sorption, the associated mass transfer equation, are linear equations, and the principle of superposition can be used to construct the analytical expressions for finite sources.

It should be noted that solutions for finite source regions, derived from our point-source solutions, describe transport away from source regions that have physical and chemical properties identical to those of the surrounding medium, except that mass is introduced within the source regions. In particular, the source regions do not perturb the fluid flow fleld. Thus, for example, these solutions do not describe transport of a solute introduced at the surface of a region of space that is impervious to fluid flow.

\section{REFERENCES CITED}

Carnahan, C. L.,. and Remer, J. S., 1981. Non-equilibrium and equilibrium sorption with a linear sorption isotherm during mass transport through an infinite, porous medium: some analytical solutions. Lawrence Berkeley Iaboratory Report LBL-13005.

Carslaw, H. S., and Jaeger, J. C., 1959. Conduction of Eeat in Solids (Second Edition). London, Oxford University Press, $510 \mathrm{p}$.

coldstein, S., 1953. On the mathematics of exchange processes in fixed columns. I. Mathematical solutions and asymptotic expansions. Proceedings of the Royal Society (London), v. A219, p. 151-171.

\title{
CHEMISTRY OF NUCLEAR WASTE SUBSTANCES IN AQUEOUS SOLUTIONS
}

\author{
S. L. Phillips and A. Igbene
}

Underground storage of nuclear wastes requires prediction of the likelihood of leaching from containers and subsequent migration of waste nuclides into natural waters. Although a great deal of information is needed, this work is $11 \mathrm{~m}-$ ited to thermodynamic and kinetic data on metalion species in aqueous media. Such data are used in computer codes, Eh-ph diagrams, and other calculations of metal species at high temperatures (Phillips, 1980).

Initial work centered on critically surveying existing experimental and calculated data for the following four categories of data:

1. Eydrolysis, formation, and ionization constants.

2. solubility.

3. Standard potential.

4. Eomogeneous and heterogeneous reaction rates.

Table 1 is a partial listing of a result of the survey; hydrolysis and formation constants are given for species of aluminum, americium, ceslum, and two values for copper. The complete listing (Phillips, 1982) consists of similar constants for about twenty elements.

Temperature dependence of interest to waste zolation generally covers the range 5 to $200^{\circ} \mathrm{C}$. have tabulated over this range the dissociation constants for water, using the correlation developed by Olofsson and olofsson (1980), and the ionization constants for carbonate, calcu- lated with the correlation published by Maurer $(1980)$; see Table 2 (parts a and c) for sample listings.

Besides $\mathrm{F}, \mathrm{OH}, \mathrm{Cl}, \infty_{3}, \mathrm{SO}_{4}$, and $\mathrm{PO}_{4}$, sitespecific complexing ligands such as humic and fulvic acids are of importance. Table 2 (part b) lists binding constants for Th $4+$ with humic acid; these were calculated from the experimental data published by Nash and Choppin (1980). Their values were obtained by careful measurements with purified humic and fulvic acid samples from soils, lake bottom sediments, and a laboratory supply house. Experimental measurements were obtained at 0.1 ionic strength, pH 3.95 to 5.03 , and 5.0 to $50.0^{\circ} \mathrm{C}$, the stated uncertaintles were better than \pm 18 of the $\log K$ values. We have fit their data for the lake bottom sediment of humic acid to the following equation:

$$
\begin{aligned}
\log x & =16.818-\frac{1701.729}{(273.15+T)} \\
& -5.462 \times 10^{-5}(273.15+T) \\
& +6.713 \times 10^{-3} \log (273.15+T)
\end{aligned}
$$

where $\mathrm{T}=$ temperature $\left({ }^{\circ} \mathrm{C}\right)$. Th1s equation reproduces their values to better than \pm 0.28 at 5.0 , 25.0 , and $50.0^{\circ} \mathrm{C}$. Extrapolation to higher temperatures increases the uncertainty to an estimated \pm 58 at $200^{\circ} \mathrm{C}$.

During this year, our work on basic properties of aqueous solutions such as sodium chloride resulted in four reports and publications 
Table 1. Typical hydrolysis and formation constants of nuclear waste species; $25^{\circ} \mathrm{C}, \mathrm{I}=0$.

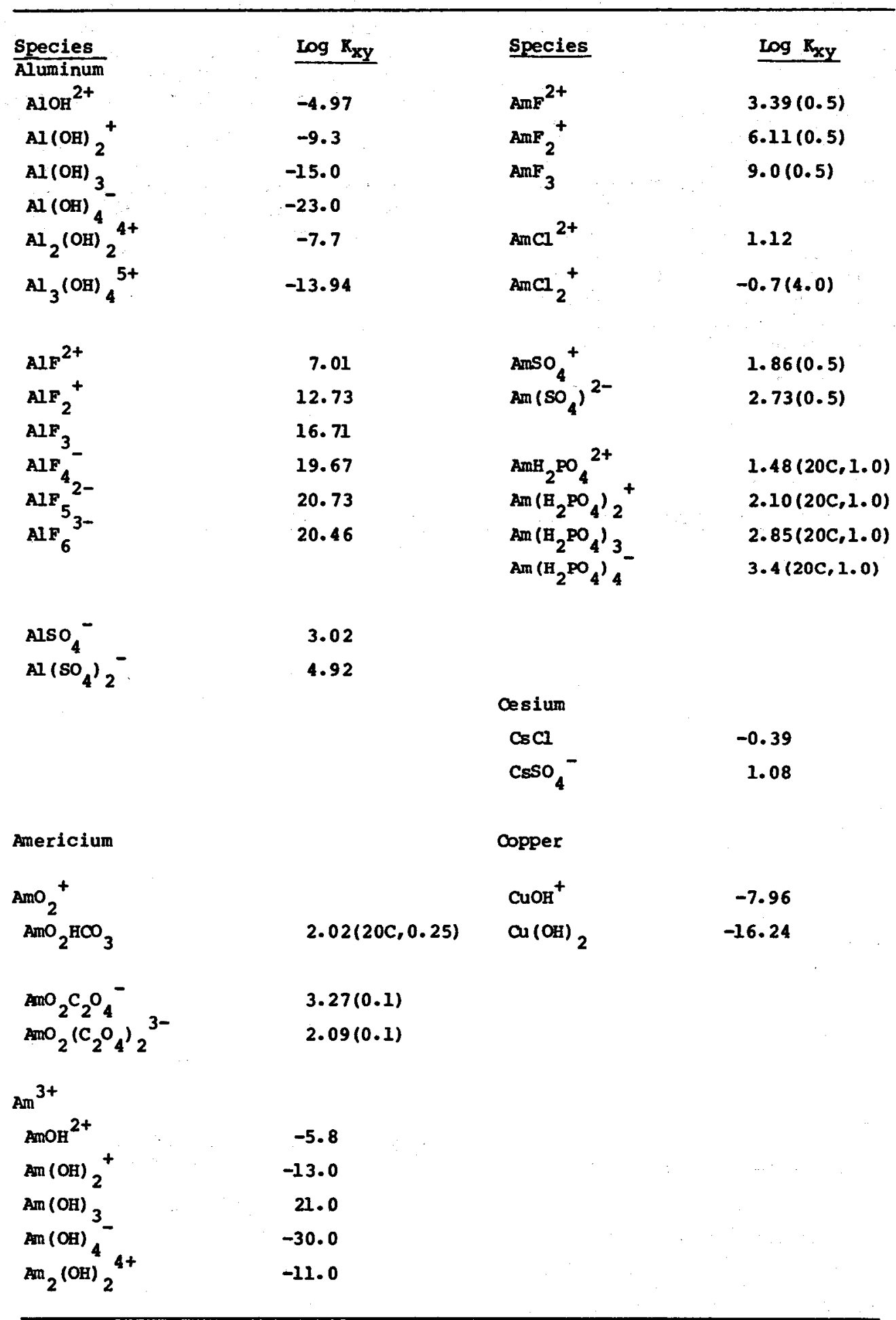

Numbers in parenthesis following a value for $\log \mathrm{K}_{\mathrm{xy}}$ denote temperature and ionic strength when either or both differs from $25^{\circ} \mathrm{C}$ and zero, respectively:

$2.20(20 \mathrm{C}, 0.25)$ is $\log \mathrm{K}_{X Y}$ at $20^{\circ} \mathrm{C}, \mathrm{I}=0.25$;

$3.27(0.1)$ is $\log \mathrm{K}_{x y}$ at $\mathrm{I}=0.1$ with $25^{\circ} \mathrm{C}$ implied. 
Table 2. Typical data to high temperatures.

(a) Ionization constants for carbonate

$$
\begin{aligned}
& K 1: \infty_{2}+H_{2} O=H \infty_{3}^{-}+H^{+}, K 1=\frac{\left({ }_{H} \infty_{3}{ }^{-}\right)\left(a_{H}+\right)}{\left(a_{H_{2} \infty_{3}}\right)} \\
& \text { K2: } H \infty_{3}^{-}=\infty_{3}^{2-}+\mathrm{H}^{+} ; \mathrm{K2}=\frac{\left(\mathrm{a}_{\infty_{3}}{ }^{2-}\right)\left(\mathrm{a}_{\mathrm{H}}{ }^{+}\right)}{\left(\mathrm{a}_{\mathrm{H} \infty_{3}}{ }^{-}\right)}
\end{aligned}
$$

(b)

$\underline{T / C}$

$\begin{array}{rl}5 & 10.70 \\ 25 & 11.11 \\ 50 & 11.55 \\ 75 & 11.93 \\ 100 & 12.25 \\ 125 & 12.5 \\ 150 & 12.7 \\ 175 & 13.0 \\ 200 & 13.2\end{array}$

(c) Dissociation constant of water

\begin{tabular}{rr}
$T / C$ & $\log K_{w}$ \\
\hline 25 & -14.004 \\
50 & -13.280 \\
75 & -12.713 \\
100 & -12.267 \\
125 & -11.917 \\
150 & -11.647 \\
175 & -11.445 \\
200 & -11.300
\end{tabular}

(Phillips et al., 1981a, 1981b, 1981c, 1981d): This research was more or less specific to geothermal energy, and is expected to constitute a low level of activity compared with nuclear waste disposal.

REFERENCES CITED

Maurer, G., 1980. On the solubility of weak electrolytes in aqueous solutions. In S. A. Newman (ed.), Thermodynamics of Aqueous Systems with Industrial Applications. ACS Symposium Series 133, Washington, D.C.. p. 139-172.

Nash, R. L., and Choppin, G. R., 1980. Interaction of humic and fulvic acids with Th(IV). Journal of Inorganic and Nuclear Chemistry, v. 42, p. 1045-1050.

Olofsson, G. , and Olofsson, I., 1981. Empirical equations for some thermodynamic quantities for the ionization of water as a function of temperature. Journal of Chemical Thermodynamics, v. 13, p. 437-440.

Phillips, S. L., 1980. A database of chemical properties of nuclear waste elements in aqueous solutions. Lawrence Berkeley Laboratory Report LBID-162.

Phillips, S. L., 1982. Hyarolysis and formation constants at $25^{\circ} \mathrm{C}$. Lawrence Berkeley Laboratory Report IBL-14313.

Phillips, S. L., Igbene, A., Fair, J. A., Ozbek, H., and Tavana, M., 1981a. A technical databook for geothermal energy utilization.: Lawrence Berkeley Laboratory Report LBL-12810.

Phillips, S. L., Mathur, A. K., and Garrison, W.. 1981b. Treatment methods for geothermal brines. In L. A. Casper and T. R. Pinchback (eds.), Ceothermal scaling and corrosion. ASTM Special Publication 717, p. 207-224.

Phillips, S. L., Otto, R. J., Ozbek, H., and Tavana, M., 1981c. Aqueous solutions database to high temperatures and pressures. In Proceedings, Workshop on Techniques for Measurement of Thermodynamic Properties, Bureau of Mines Information Circ. IC-8853, Albany, Oregon.

Phillips, S. L., Igbene, A., Fair, J. A., Ozbek, H.. Tavana, M., 1981d. A technical databook for geothermal energy utilization. Presented at Eighth Symposium on Thermophysical Properties, National Bureau of Standards, Gaitersburg, Maryland. (Accepted for publication in conference proceedings.) 
Many oils, especially those classed as heavy oils, contain natural acids, such as alkyl and aryl carboxylics and porphyrins. In contact with aqueous alkalis, these acidic components can produce surface-active molecules that aid in oil displacement. The objective of this project is to study the fundamental mechanisms of alkalienhanced oil recovery to permit better process design.

\section{OIL DISPLACEMENT}

Using the simple idea that acid hydrolysis will generate surfactants (e.g., HA oil + $\mathrm{NaOH} \approx \mathrm{NaA}_{\text {water }}+\mathrm{H}_{2} \mathrm{O}$ ), we have devised a chromatographic equilibrium displacement mod$e 1$ to predict oil recovery history (de Zabala et al., 1980). The calculations rely on coherence theory, and are complicated because the problem is trivariant.

An important prediction of the displacement model is that oil recovery effectiveness is significantly improved by increasing the water-phase viscosity. To verify this prediction we have completed a suite of oil displacement experiments using different concentrations of polyacrylamide polymers. The experiments confirm earlier oil production in a bank fashion as the alkaline water viscosity is increased by the addition of polymer. For heavy viscous oils it is critical that the recovery effectiveness be improved by some form of mobility control, such as that provided by polymer thickening.

Polymers play a second role aside from increasing oil recovery effectiveness. They also increase the total amount of oil recovery or the efficiency of oil displacement. Figure 1 shows

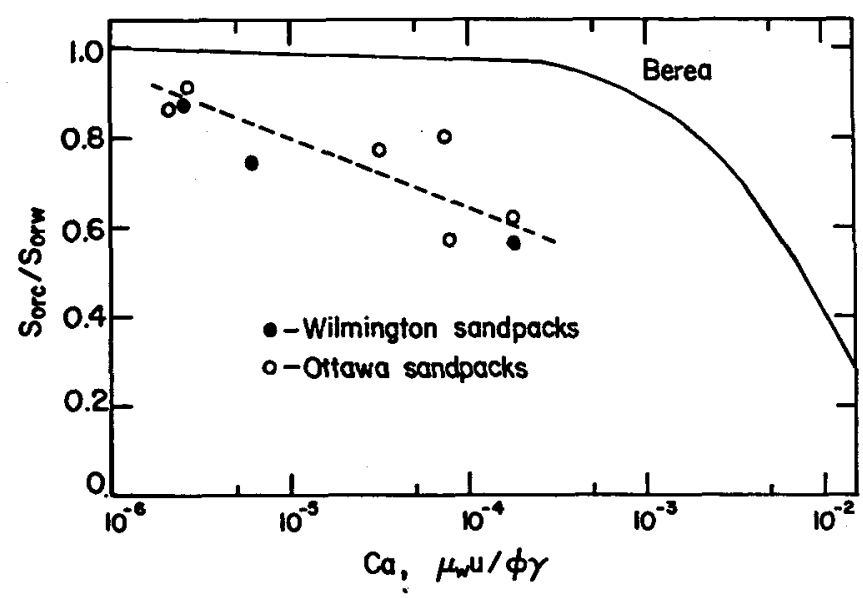

Figure 1. Residual oil saturation after chemical flooding compared to the residual oll saturation after water flooding as a function of capillary number. The solid line corresponds to literature dạta for Berea Sandstone. the final oil saturation after alkaline flooding. Sorc as compared to that remaining after standard water flooding, $S_{\text {orw }}$. Note that the ratio $s_{\text {orc }} / S_{\text {orw }}$ is less than unity, indicating more oil recovery with the alkaline floods. From the theory of. blob mechanics, it is known that oil recovery efficiency is primarily a function of the dimensionless capillary number, $C a=\mu_{w} \mathrm{U} / \phi \gamma$, where $\mu_{w}$ is the viscosity of the displacing alkaline water phase, $U$ is the superficial velocity, $\phi$ is the porosity, and $\lambda$ is the oil-water interfacial tension. Hence the capillary number is plotted as the abscissa in Figure 1. How polymers increase oil recovery is explained by the larger capillary number due to polymer augmenting the water-phase viscosity.

Figure 1 reveals a discrepancy between published results for Berea Sandstone cores (solid line) and our results for Wilmington reservoir and Ottawa sandpacks (broken line). The physical reason is that the residual oil blobs in the sandpacks have a larger size distribution than those in the Berea Sandstone. This implies a larger pore-size distribution in the sandpacks than in the sandstone. Experimental water drainage curves determined by the centrifugal technique provide the confirming evidence for the larger pore-size distribution in the sandpacks.

Polymers serve two roles in the alkaline displacement of heavy viscous oils. First, as predicted by the mathematical chromatographic displacement model, they increase the effectiveness of oil recovery. Second, by increasing the capillary number, they permit additional residual oil recovery. Both aspects are important in the application of the alkaline flooding technique.

\section{CHEMICAL ONSUMPTION}

In order to maximize oil production, the alkali must propagate through the reservoir and continuously generate surfactants. Little or no chemical loss can be tolerated. We have demonstrated that alkali reacts with reservoir minerals to produce water-soluble silicate and aluminate. The reaction is dominated by silica minerals, is approximately first order in hydroxide concentration, and takes place very slowly, at least on laboratory time scales (Bunge and Radke, 1981). Reaction speed or hydroxide loss rate must, of course, be judged in relation to the residence time in the reactor (i.e., the reservoir). The appropriate dimensionless number for scaling from laboratory experiments to reservoir conditions is the Damkohler number, $\mathrm{Da}=\hat{\mathrm{k}} \phi \mathrm{L} / \mathrm{v}$, where $\hat{k}$ is the intrinsic rate constant and $L$ is the length of the system (i.e., the laboratory column length or the reservoir well spacing). Even though the rate constant for alkali-mineral reaction is very small, the extent of alkali consumption can be large when the Damkohler number is large. 
To establish quantitatively the importance of alkali-rock reaction under field conditions, we solve the nondimensional continuity equation for Jydroxide with an irreversible loss reaction, a reversible Langmuirian $\mathrm{Na}-\mathrm{H}$ ion exchange, and a pulse injection. The mathematical solutions employ the method of characteristics (Bunge and Radke, 1982).

Figure 2 demonstrates what happens to a pulse of alkall as it migrates from an injection well (i.e., $\tilde{z}=0$ ) to an injection well (i.e., $\tilde{z}=1$ ). In this figure, $\theta_{1}$ is the ratio of the local hydroxide concentration to its injection value, and $\tilde{z}=\mathrm{z} / \mathrm{L}$, where $\mathrm{z}$ is the linear distance from the injection well. Figure 1 shows two cases: no rock dissolution, $\mathrm{Da}=0$, and a finite reaction rate, $\mathrm{Da}=1$. The concentration decrease near the front of the reacting pulse is due to the first-order dissolution reaction (1.e., $\mathrm{m}=1$ ), and the spreading at the back of the pulse is due mainly to Ion exchange. For a 0.4 pore volume reacting pulse at initially 0.1 normal hydroxide, the concentration at the pulse front is less than 108 of its initial value after covering 828 of the interwell spacing.

On the basis of the mathematics presented in Figure 1, it is possible to estimate the distance that an alkaline pulse travels before its highest concentration diminishes to a level below which surfactant generation is no longer favored. This effective distance can then be investigated as a function of the Damkohler number, pulse size, and ion-exchange isotherm parameters (Bunge and

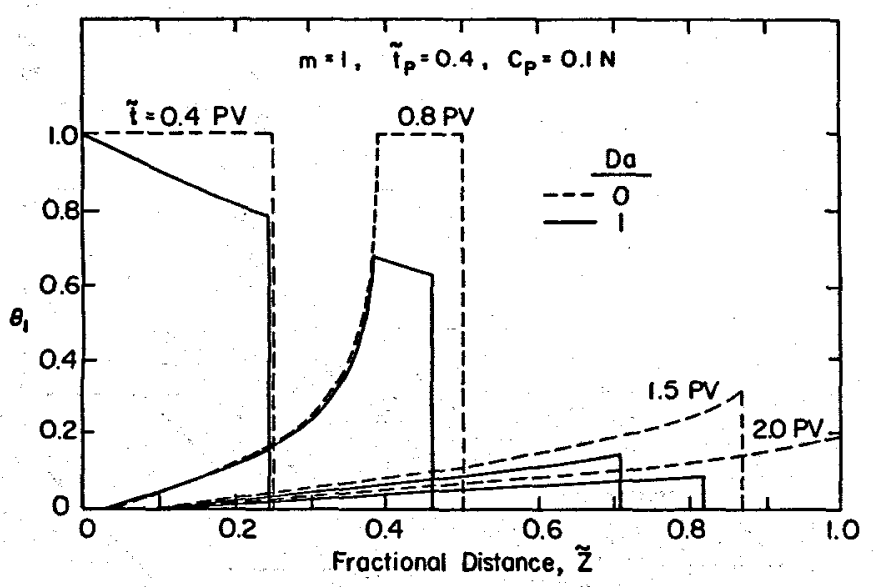

Figure 2. Fractional hydroxide concentration profile for an alkaline pulse with dissolution $(\mathrm{Da}=1)$ and without dissolution $(\mathrm{Da}=0)$.

[XBL 821-1691]
Radke, 1981): Thus, for the first time, it is possible to obtain a design estimate for the effective life-time that alkali exhibits under reservoir time scales using only data obtained from laboratory experiments (Bunge and Radke, $1981)$.

The calculations presented above, when adjusted to reservoir time scales, indicate the need to reduce the already small dissolution rate constant, $k$. We find that addition of aluminum to the aqueous solution drastically reduces the rate at which pure silica (amorphous or crystalline) dissolves in alkali. The explanation is that aluminum can substitute for silicon atoms at the silica-water interface, creating kinetically an aluminosilicate interface. We have established from batch kinetic studies that aluminosilicates, such as kaolinite, lllite, montmorillonite, chlorite, plagioclase, and albite all dissolve much more slowly than pure sllica, when compared on a unit surface area basis. This result is consistent with addition of aqueous aluminum slowing down the alkaline silica dissolution. Thus, one technique for improving alkali lifetimes in a reservoir is to lace the aqueous alkaline solution with aluminate.

\section{CONCLUSIONS}

Alkaline displacement of heavy viscous oil requires mobility control. If polymers are used to achieve this mobility control, they serve to increase both the effectiveness and the efficiency of the oil displacement. To maintain the alkaline process, it is necessary that little or no consumption occur. A calculational scheme utilizing only laboratory kinetic data has been developed to determine how long an alkaline pulse, will remain effective under reservoir conditions.

\section{REFERENCES CITED}

Bunge, A. L., and Radke, C. J., 1981. Migration of alkaline pulses in reservoir sands. Presented at the 56th Annual conference of SPE, San Antonio, Texas, October, 1981. SPE-10288.

Bunge, A. L., and Radke, C. J., 1982. Pulse chromatography of adsorbing and reacting chemicals. Presented at the 1982 National Meeting of AIChE, Orlando, Florida, March 1982.

dezabala, E. F., Vislocky, J., Rubin, E., and Radke, C. J.. 1980. A chemical theory for linear alkaline flooding. Presented at the 5th SPE International Symposium on Oilfield and Geothermal chemistry, Stanford, California, May 1980. SPE-8997. 


\section{THE PARTITIONING OF HYDROGEN SULFIDE IN THE CONDENSERS OF GEYSERS UNIT 15}

\section{O. Weres}

Geysers Unit 15 was the first of the geothermal units equipped with surface condensers to go on line at The Geysers power plant of the Pacific Gas and Electric Company. Units 1 through 12 have contact condensers. The switch to surface condensers was motivated by considerations of hydrogen sulfide emission abatement. In the contact condensers, there is a large liquid-to-vapor ratio, and about 758 of the hydrogen sulfide that is present in the geothermal steam supply ends up dissolved in the cooling water. Once in the cooling water, it is emitted to the atmosphere from the cooling towers unless further, "tertiary" abatement is employed.

It was reasoned that, because the liquidto-vapor ratio in a surface condenser would be smaller by a factor of about twenty-five than in a contact condenser, most of the hydrogen sulfide would remain in the vapor phase and leave with the gas vented from the condenser rather than by dissolving in the condensate. Unit 15 is equipped with a Stretford Unit, which removes the hydrogen sulfide from the vent gas and converts it to elemental sulfur by reaction with air. Therefore, the fraction of the hydrogen sulfide that leaves the condenser with the vent gas is not emitted to the atmosphere. The fraction that dissolves in the condensate must be destroyed by reaction with costly hydrogen peroxide to prevent its emission to the atmosphere.

The Geysers steam also contains ammonia (Table 1). Ammonia increases the concentration of hydrogen sulfide in the condensate by increasing its $\mathrm{pH}$ and thereby increasing the solubility of hydrogen sulfide in it (see below). This effect limits the effectiveness of surface condensers in shifting the hydrogen sulfide to the vent gas stream. The $\mathrm{pH}$ of the surface condenser condensate is practically determined mostly by the ammonia and hydrogen sulfide in it; the carbon dioxide and boric acid have only secondary effects.

\section{THE CONDENSER MODELING CODE CNDSR}

CNDSR is a computer program used to model the steady-state partitioning and transport of gases in the condensers and cooling water loop of a steam-cycle geothermal power plant. CNDSR models gas partitioning and transport in terms of a number of "boxes" that represent the different parts of the system being modeled. For each box, the partition of the gases between the liquid and vapor phases is calculated assuming a thermal and chemical steady state within the box. The actual mass fluxes within the condenser are calculated using the steady-state results for the individual boxes and the patterns of liquid and vapor flow between the boxes that were specified in the input. The whole procedure is repeated until a global steady-state solution is attained.

\section{THE DESIGN AND FUNCTION OF UNIT 15}

Unit $15^{\prime} \mathrm{s}$ main condenser has two essentially identical tubing bundles, only one of which need be modeled. Figure 1 is a schematized depiction of one of these tubing bundles. The cooling water tubes run down the length of the bundle. The cooling water passes through the tubes twice. The cooling water flow is countercurrent to the depicted "design vapor flow." There are a number of tube sheets, and these are perpendicular to the cooling water tubes, which run through them and are supported by them. The "vapor channels" on either side of the condenser are defined by rectangular orifices cut in the tube sheets.

The two vapor channels are separated by a metal plate that also serves to provide some structural support to the bundle. This support plate is connected to two other plates of $\mathrm{D}$ shaped cross section, one above and one below the vapor channels. The two "U's" are open upward and downward, respectively, and are empty. The design vapor flow is shown in Figure 1 . The actual vapor flow pattern turned out to be different. Instead of drawing vapor out evenly from throughout the bundle, the ejectors vent only the cold-pass side. Meanwhile, relatively cool, gasrich vapor stagnates on the essentially unvented

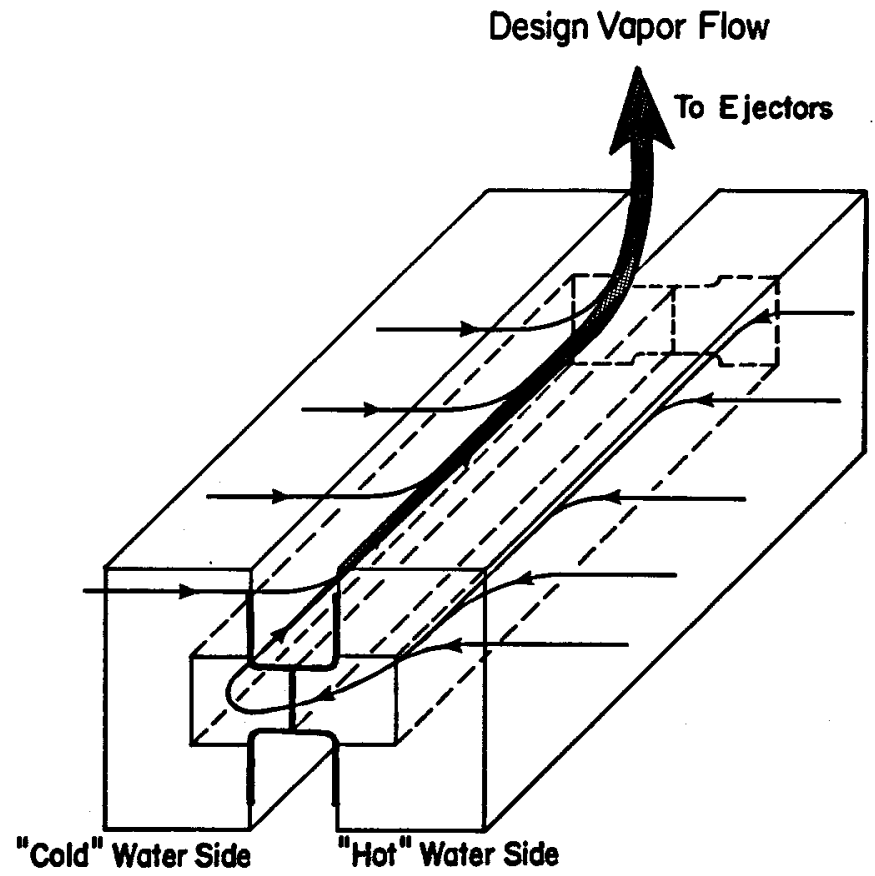

Figure 1. The vapor flow pattern that the main condenser of Geysers Unit 15 had been designed for. Only one tubing bundle in the main condenser is depicted. 
Table 1. Comparison of modeling results with field data.

\begin{tabular}{lccccc}
\hline & \multicolumn{2}{c}{ Premodification } & Postmodification \\
& $\frac{\text { Field }}{1.65}$ & $\frac{\text { Colculated }}{1.87}$ & $\frac{\text { Field }}{1.47}$ & $\frac{\text { Calculated }}{1.56}$ \\
$\mathrm{H}_{2} \mathrm{~S}$ in condensate (mmolal) & 5.29 & 5.19 & - & 7.36 \\
$\mathrm{NH}_{3}$ in condensate (mmolal) & 0.97 & 0.82 & - & 0.74 \\
$\mathrm{CO}_{2}$ in condensate (mmolal) & 33 & 39 & 19 & 21 \\
Percent total $\mathrm{H}_{2} \mathrm{~S}$ in condensate & 33 & 8.34 & 8.5 & 8.64 \\
Condensate pH & 8.5 & & & \\
\hline
\end{tabular}

hot-pass side of the bundle. This combination of unbalanced venting and gas blockage increases the fraction of the hydrogen sulfide that dissolves in the condensate.

The empirical chemical data are summarized in the first column of Table 1. The interpretation of the vapor flow pattern that was ultimately arrived at on the basis of field data and modelIng studies is depicted in Figure 2. The vapor flow on either side of the bundle is in the same direction: toward the vapor exhaust hood. Because the vapor exhaust hood vents only (one end of) the cold pass, the vapor from the hot-pass side must somehow be vented to the cold-pass side. The only possible path is to cross underneath the bundle and then go up into the vapor channel on the cold-pass side.

The modeling studies established what proved to be the key to successfully retrofitting the

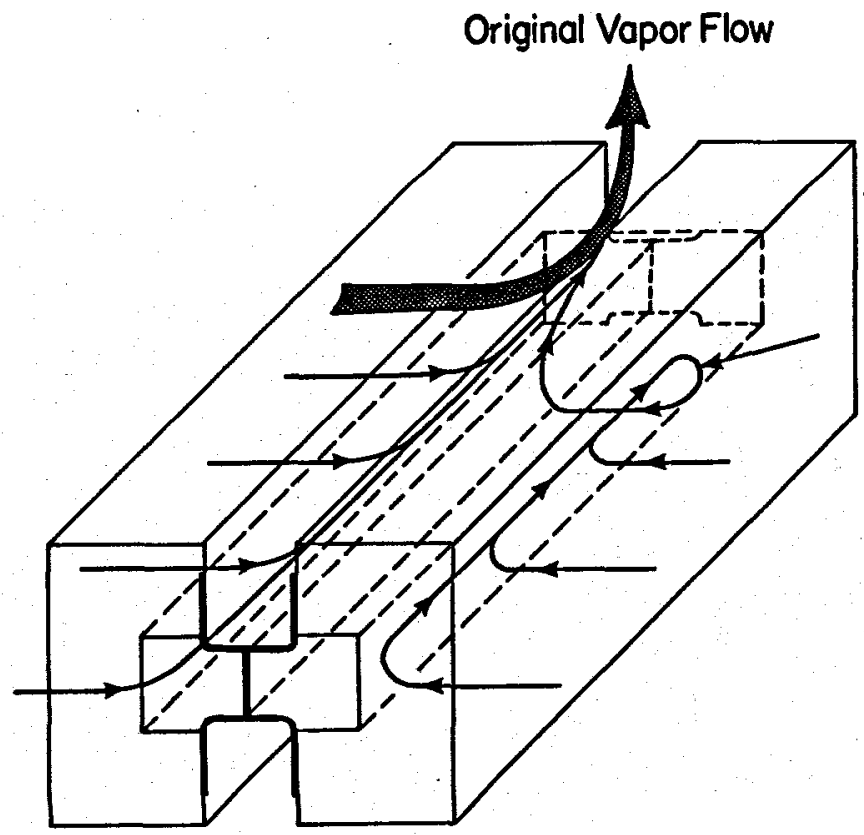

Figure 2. The actual vapor flow pattern in a tublng bundle before the condenser was modified, as inferred from field data and modeling studies.

[XBL 815-865] condenser and substantially improving its hydrogen sulfide performance. Apparently, very little vapor is actually vented from most of the bundle; perforce, this small amount of vapor is very gas $r$ ich because it carries with it most of the noncondensible gases that accumulate in the bundle as the steam condenses. Thus, not only the hotpass side of the bundle is vapor blocked, but most of the cold-pass side appears to be as well. Nost of the ejector capacity is satiated by drawing vapor with a much lower gas content out of just that small part of the bundle that is immedlately adjacent to the vapor exhaust hood. The poorly vented part of the bundle has poor heat transfer, and the condensate falling out of it contains a substantial concentration of hydrogen sulfide. The vapor flow pattern depicted in Figure 2 was the only one that enabled the model to predict partitioning as poor as was actually observed in the field.

\section{RESULTS AND PRACTICAC RECOMMENDATIONS}

The first column in Table 1 presents the essential data about the chemical performance of Geysers Unit 15, as determied soon after it went on Iine in mid-1979. At that time, its steam supply contained about $4.8 \mathrm{mg}-\mathrm{mole} / \mathrm{kg} \mathrm{H} \mathrm{H}_{2}$ and $5.2 \mathrm{mg}-\mathrm{mole} / \mathrm{kg} \mathrm{NH_{3 }}$. The second column in Table 1 presents the same quantities as calculated using the computer model of Onit 15 which we developed.

It turned out that the condenser could be physically modified to correct the problem of poor venting. The essence of this modification is shown in Figure 3 ; the U-shaped channel on the top of the bundle was covered with a welded metal plate to make it an enclosed vapor removal duct. Venting of each section of the tube bundle into the duct is provided by properly sized holes drilled through the floor of the duct into each section on either side of the bundle. The newly formed duct is vented to the vapor exhaust hood at one end, and the original vapor flow channel is blocked off from the hood.

The Idea of this modification is to force properly balanced venting of all sections of the tube bundle. Ideally, the amount of vapor vented from each section in the bundle should be proportional to the amount of steam that condenses with in that section. In this case, the partial pressure of noncondensibles in the vapor, the temperature, and the vapor-to-liquid ratio would be the 


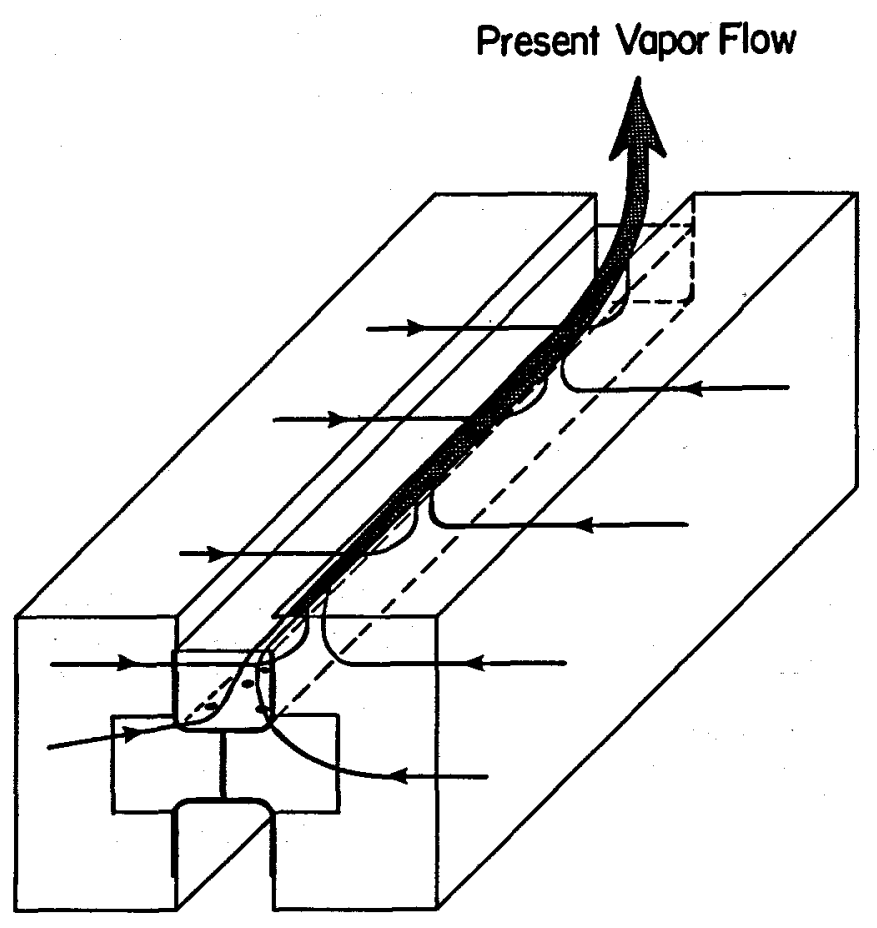

Figure 3. The vapor flow pattern in a tubing bundle after the condenser had been modified as discussed in the text.

[XBL 815-864]

same in each section of the bundle. This modification was originally proposed by G. W. Allen, who was then with PGE's Department of Engineering Research. It was evaluated by LBL using the numerical model of Unit 15 described above, correspondingly modified for this purpose.

These calculations indicated that modifying the condenser in this way would improve its hydrogen sulfide partitioning performance. On the basis of these calculations, the decision was made by PGE to proceed with the modifications.

After the shutdown, the composition of its steam supply was different: the concentrations of $\mathrm{H}_{2} \mathrm{~S}$ and $\mathrm{NH}_{3}$ had each increased to about $7.5 \mathrm{mg}-\mathrm{mole} / \mathrm{kg}$. Therefore, the predictions of the postmodification model were recalculated using the new steam composition; the results of this calculation are presented in the last column of Table 1. Comparing these figures with those in the preceding column indicates that after having been modified, the condenser functioned as had been predicted by the modeling work.

Although the steam concentrations of hydrogen sulfide and ammonia had both increased by about half, the concentration of hydrogen sulfide in the condensate had actually decreased by a small amount (compare columns 1 and 3 of Table 1). However, there had been a substantial decrease in the fraction of the hydrogen sulfide in the condensate. This significantly reduced the cost of tertiary abatement, compared to what they would have been had the condenser not been modified.

\section{ACKNOWLEDGMEN'IS}

This work was supported by the Division of Geothermal and Bydropower Technologies of the v. S. Department of Energy and by the Department of Engineering Research of the Pacific Gas and Electric Company. 
In the last several years, a number of new instrumental surface techniques have been developed that are quite effective in detecting changes in the surfaces of minerals that have undergone chemically induced reactions or natural geologic alteration. These techniques are quite sensitive, and they make it possible to monitor very small amounts (fractional percentages of the monolayers of heavy metals in many cases) of elements that may be present on the mineral surfaces. Thus, any change in the surface due to chemical composition or bonding may be readily measured qualitatively and, in some cases, quantitatively.

Surface measurements as part of a mineral geochemical study have several advantages. First, the technigues are sensitive to all elements in the periodic table. Second, several of the techniques, such as $x-r$ ay photoelectron spectroscopy. give important information about the chemical bonding environment of the element being studied. Third, surface studies involve only the first several layers of the mineral. where rock -water interactions have their greatest effect. Finally, many surface methods can be coupled with depth profiling to actually measure changes in elemental concentration as a function of depth below the surface layer of rocks and minerals. Several of the more widely used techniques are discussed below.

\section{X-RAY PEOTOELECTRON SPECTROSCOPY (XPS)}

X-ray photoelectron spectroscopy (also called electron spectroscopy for chemical analysis, or ESCA, is a surface technique that can be used to detect qualitatively (and quantitatively, in several cases) elements on mineral surfaces as well as the chemical state of the elements. The basic experimental apparatus for performing XPS studies includes an $x$-ray source (most comonly $M g K_{\alpha}$ or Al $K_{\alpha}$ radiation), an electron energy analyzer, and a specimen holder. As the $x$-rays impinge on the solid samples, electrons are emitted from the surface. The electron energy analyzer then measures the kinetic energy of the emitted electrons, which can be directly related to the binding energy of the electron in that particular atom. The binding energies of the individual atoms yield information about their chemical states.

X-ray photoelectron spectroscopy can be performed on any sample that is vacuum compatible-1.e. does not decompose under vacuum in the range $10^{-7}$ to $10^{-10}$ torr. In most cases, the technique does little or no damage to the sample surface, although $x-r$ ay-induced chemical reactions (such as metal ion reduction) may occur. As a surface technique, it gives a signal that mirrors pproximately the top 10 to $50 \AA$ of the surface.

In terms of limits, most elements $(z \geqslant 3)$ can be detected at a level of less than $10^{-2}$ monolayer. Semiquantitative data can be obtained with an accuracy of a few percent with proper standards, and concentration differences between quite sinilar samples can be measured to an accuracy of \pm 58 .

\section{AUGER ELECTRON SPECTROSCOPY (AES)}

Auger electron spectroscopy is a type of electron spectroscopy that is used for determining solId surface elemental composition. An experiment is conducted by bombarding a solid surface with an electron beam of energy ranging from $1 \mathrm{keV}$ to 10 keV. The Auger electrons, emitted from an atom by means of a radiationless transition, are detected by an energy analyzer. The sensitivity of this technique is a function of the probability of the Auger transition peculiar to a particular element, the current and energy of the impinging electron beam, and the efficlency of the electron analyzer.

The Auger effect is based upon results from the following processes. Opon lonization of a core atomic level in a solid sample, the atom may undergo a decay to a lower energy level. This leaves the atom in a doubly ionized state, and the energy difference between the two states is transmitted to the ejected Auger electron. Those Auger transitions that occur near the surface of the solid result in ejected Auger electrons that do not undergo electron energy 10ss. The shape and energy of the resulting Auger peaks are thus useful in identifying the chemical composition of the sample surface.

Auger electron spectroscopy monitors only the first few layers of the solid surface. This technique can detect all elements of $z \geqslant 3$ at a level of about $10^{-3}$ monolayer. Quantitative analytical data involving absolute concentrations for different type samples are generally accurate to within \pm 58 with standards.

\section{SECONDARY ION MASS SPECTROMETRY (SIMS)}

Secondary ion mass spectrometry is a surface technique that is a variation of classical mass spectrometry. An incident ion beam of $5 \mathrm{keV}$ or less is directed onto the solid surface of a sample, thus sputtering atoms and molecules from the surface. As they are sputtered, some of the atoms and molecules are ionized (the secondary ions) and then directed into an energy filter and mass analyzer. The lons that are generated may be either positive or negative. The negative ion spectrum is more sensitive to lighter elemental ion species (oxygen, sulfur, carbon, etc.) and hydrocarbons, the positive spectrum shows greater sensitivity to heavier mass species such as metals. The ejected secondary ions typically come from a depth of $5 \AA$, the technique being capable of detecting all elements of the perlodic table. Its detection sensitivity is approximately $10^{-6}$ monolayer for a spectfic element. 
USES OF THE TECENIQUES

The techniques have a wide array of applications, including those that are analytical and physicochemical (such as bonding studies) in nature. Typical examples of research studies by this author include the chemical analysis and bonding of oxidized hornblende surfaces (Perry and White, 1981), surface chemistry of synthetic ferrite minerals (Percy et al.. 1977), and the analysis of Mt. St. Belens ash (Perry et al.. 1981). Detailed bonding studies have been conducted on uranium chelate compounds (Perry, 1981) that can be used as models for uranium compounds adsorbed on geologic substances.

Several workers have addressed other geochemical systems using these techniques. Nakai et al. (1978) have studied the valence states of copper in a wide array of minerals. Yin et al. (1971) have attempted to distinguish the difference between bridging and nonbridging oxygen atoms in silicates using $x$-ray photoelectron spectroscopy. Nakai et al. (1976) have studied the oxidation state of vanadium in vanadium-bearing aegirines using $x$-ray photoelectron spectroscopy.

\section{OTHER APPLICATIONS}

There are many other applications of these techniques to the study of geologic materials. $x-r$ ay photoelectron spectroscopy can be used to study minute changes in electronic charge densities of elements in minerals, adsorption of metal ions on geologic substrates, interfaces involving minerals and surface coatings, and migration of metal ions from mineral surfaces into the bulk at high temperatures and pressures (using depth-profiling techniques). Secondary ion mass spectrometry is quite useful in studying isotopes and mineral impurities. Auger spectroscopy (and scanning Auger microscopy, or SAM) is effective for giving elemental concentrations along mineral grain boundaries and for element segregation on mineral surfaces.

Several areas of geologic research can be addressed using various combinations of these high vacuum surface techniques or combinations of these techniques and other instrumental approaches. The chemisorption of organic compounds from solution onto mineral substrates can be studied using $x$-ray photoelectron and Auger spectroscopy in conjunction with Fourier transform infrared spectroscopy (which is useful for monitoring changes in organic functional groups that are present on the surface). Metal ions such as uranyl $\left(\mathrm{UO}_{2}{ }^{2+}\right)$, erbium, and europium can be adsorbed on geologic substrates as site probes and then experimentally observed using fluorescence spectroscopy in addition to the abovementioned vacuum techniques.

Other areas of geologic research that can be explored using a combined instrumentation approach are many. Surface reactions involving solid-liquid systems could be studied, this would have applications in mineral processing research. The analysis of precious and strategic metal ores could be conducted using these techniques. In summary, any solid surface that is involved in a geologic process (either natural or laboratory induced) can be studied in order to monitor its inherent material properties and its surface characteristics before and after reaction.

\section{REFERENCES CITED}

Nakai, I., Ogawa, H., Sugitani, Y., Niwa, Y., and Nagashima, K., 1976. X-ray photoelectron spectroscopic study of vanadium-bearing aegirines. Mineralogical Journal, v. 8, p. 129-134.

Naka1, I., Sugitani, Y., Nagasimi, $K_{+}$, and Niwa, Y., 1978. X-ray photoelectron spectroscopic study of copper minerals. Journal of Inorganic and Nuclear Chemistry, v. 40, p. 789-791.

Perry, D. L., 1981. Synthesis and properties of uranyl monothlocarbamate alkoxides, an airstable class of uranyl alkoxides. Inorganica Chimica Acta, v. 48, p. 117-124.

Perry, D. L., and White, A. F., 1981. Surface and bulk studies of hornblende using secondary ion mass spectrometry (SIMS), Auger electron spectroscopy (AES), and $x$-ray photoelectron spectroscopy (XPS). In Proceedings of the 18 2nd National Meeting of the American Chemical Society, New York, 1981.

Per ry, D. L., Bonnell, D. W., Parks, G. D., and Margrave, J. L., 1977. Spectroscopic studies of high temperature materials. I. The use of $x$-ray photoelectron spectroscopy (XPS) to study the surface chemistry of copper, cobalt, and nickel ferrites. High Temperature Science, v. 9, P. 85-98.

Perry, D. L., White, A. F., and Benson, L. V., 1981. X-ray photoelectron studies of volcanic ash from Mt. St. Helens. In Proceedings of the 181st National Meeting of the American Chemical Society, Atlanta, 1981.

Yin, L. I., Gose, S., and Adler, I., 1971. core binding energy difference between bridging and non-bridging oxygen atoms in a silicate chain. Science, v. 173, p. 633-635. 


\section{MINE VENTILATION PLANNING: A CASE STUDY}

\section{J. McPherson and M. Hood}

The need for a systems approach to planning ventilation in underground coal mines generally has not been recognized in the United States. The reasons for this are varied, but one explanation is that the direct costs associated with providing afrflows to the working areas usually are small when compared with the overall mining costs. However, poor mine ventilation design commonly results in considerable indirect costs, such as additional shafts and extra underground personnel to maintain door 8 , stoppings, etc. In Europe, where most of the underground coal mines are deeper by a factor of at least two than most U. S. mines, operators have been forced to adopt a more rigorous approach to ventilation planning.

One of the main objectives of this work program was to investigate the benefits of employing a systems approach to ventilation design in an existing U. S. mine. Sunnyside Mine 3 in Utah has been operating continuously for more than $80 \mathrm{yr}$. It was selected for the study because its ventilation system was incapable of supplying adequate quantities of air to the working faces.

\section{STATEMENT OF THE PROBLEM}

Figure 1 shows schematically the layout of the existing ventilation network and the air quantities flowing in the various roadway branches. The future life of this mine lies in an extension in the downdip direction. Col production will come from one longwall face and two development ends. Minimum afrflow requirements are $30,000 \mathrm{cfm}$ along the longwall face and $45,000 \mathrm{cfm}$ supplied to each development. The first longwall will be in position A (Fig. 1), the next two longwalls will be in positions $B$ and $C$, respectively, in this figure. Development will be carried out at any time in two of the three positions marked $x, y$, and $z$ in this figure. Inspection of Figure 1 shows that the current airflows are $10,000 \mathrm{cfm}$ across the face of the long wall in panel $A$ and $28,000 \mathrm{cfm}, 27,000 \mathrm{cfm}$, and $33,000 \mathrm{cfm}$ across the development ends. Thus all of these flows need to be increased. The method proposed by the mine to achieve these required increases in airflow was to sink a new shaft at the location marked $s$ (Fig. 1). This site was selected not as a result of prior determination that it would

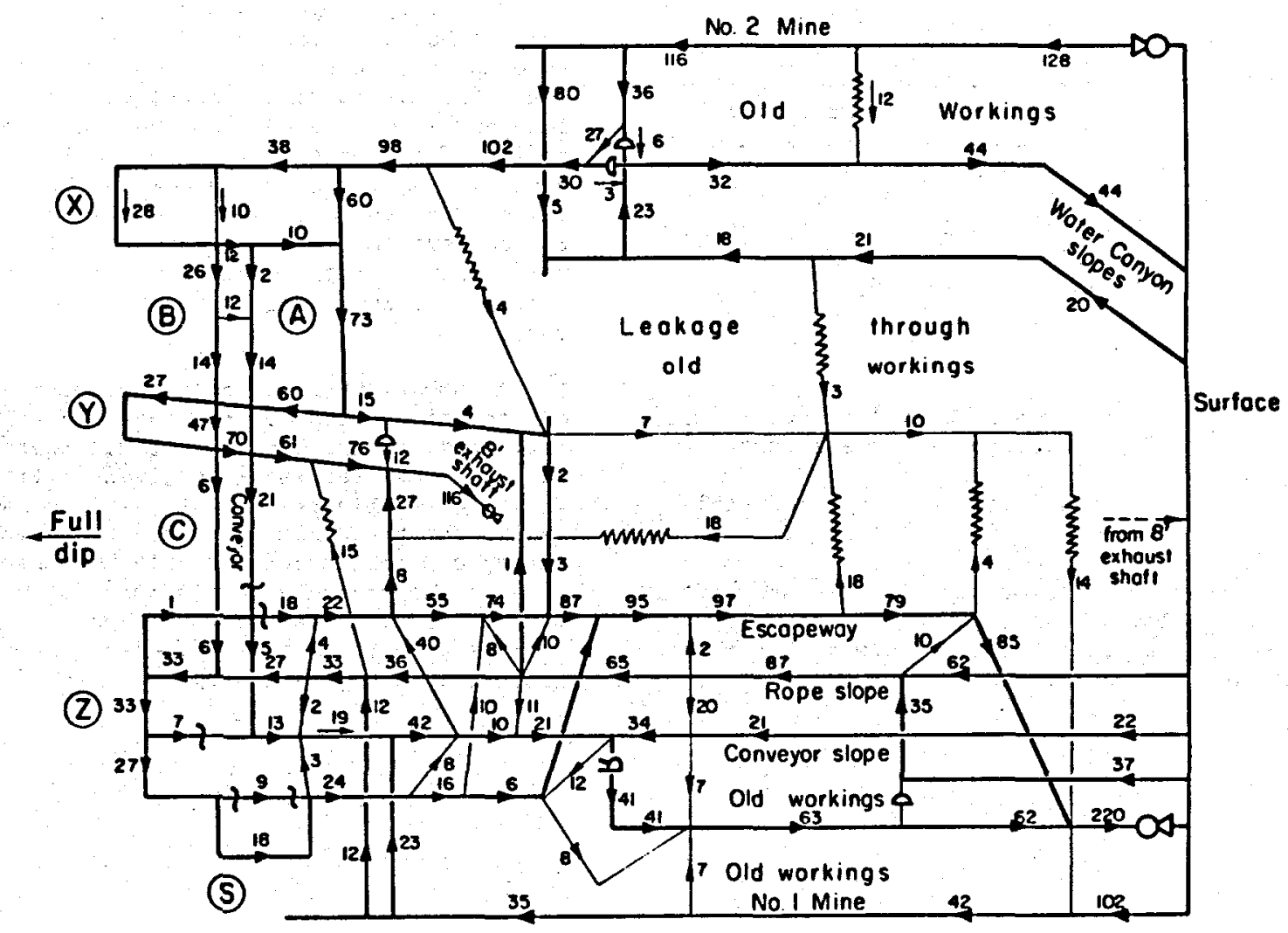

Figure 1. Schematic of the existing ventilation system in Sunnyside Mine \#3. Airflows are given in thousands of cubic feet per minute. 
be optimal for ventilation, but rather because placing the surface connection in a canyon would minimize shaft depth and thereby capital costs. The estimated cost of this new shaft was $\$ 4,000,000$.

\section{APPROACE USED TO SOLVE THE PROBLEM}

During the past $15 \mathrm{yr}$, a number of computer programs have been written to model airflows in mine ventilation circuits. These programs all use an iterative approach to estimate the flow distribution, making use of a modified form of a technique originated in 1934 by Professor Hardy Cross of the University of Illinois. One of these programs was used for the majority of the modeling exercises that were conducted for this case study. At a later stage of the investigation, five existing programs were compared to determine (1) how well they solved the problem, (2) what size computer was necessary to run the program, (3) ease of data input, and (4) ease of interpreting the data output.

The first stage in conducting a modeling exercise of this type is to collect reliable input data. These data, comprising airflow quantities and pressure drops around the existing mine, were obtained by carrying out an intensive two-week survey in the mine using two three-person teams.

\section{VENTILATION SURVEY}

Considerable care was taken to ensure accuracy in the measured survey data. This included fabrication of a special low-turbulence, uniformvelocity-profile wind tunnel to calibrate the instruments both before and after the survey and to obtain detailed measurements of the airflows and pressure drops around the mine circuit. This attention to detail was rewarded when at the start of the modeling exercise a correlation between the computer model and the measured data, specifled in terms of the overall percentage error, where

percentage error $=\frac{\text { sum of actual errors }}{\text { sum of measured airflows }} \times 100$

was found to be 3.668 , a low and very acceptable value.

The survey results for the airflows are given in Figure 1. Immediately apparent in this figure is the fact that, of the $380,000 \mathrm{cfm}$ of air that is drawn into the mine, only $73,000 \mathrm{cfm}$ reaches the working faces. This gives an overall volumetric efficiency of 198 , a very low value.

\section{MODELING EXERCISES}

More than 500 exercises were examined using the computer model. These exercises were split into four phases, the first phase representing the present mining situation; the second phase representing the mining geometry after $3 \mathrm{yr}$; the third phase, $8 \mathrm{yr}$; and the fourth phase, $16 \mathrm{yr}$. In order to ensure the long-term viability of the ventilation system design, the initial planning effort was concentrated on phase 3 . The subsequent exercises on the other phases were chosen to be commensurate with the phase 3 design.

The first significant result to emerge from phase 3 was that if a new shaft were sunk in the planned location (site $S$ in Fig. 1), then very little benefit would be derived in terms of improved airflows at the faces. Thus, if this plan were to be implemented, the mine would expend $\$ 4,000,000$ for minimal return. Another major result was that the present system of using the parallel slopes marked Escapeway and Rope slope in Figure 1 as adjacent intake and return airways was highly ineffective. Instead, two preferred ventilation systems were demonstrated. Both of these systems required a new shaft, but this shaft is located considerably downdip of the position originally selected for this airway.

One of these proposed systems, termed the Utube method and illustrated in Figure 2, employs forcing fans at the two slopes named water canyon. The air is drawn around through the workIngs and is exhausted from the mine through the series of slopes that include the Rope slope and the Escapeway, and up the new shaft. The alternative, and the more desirable system, termed the through system and illustrated in Figure 3, employs only a single exhausting fan on the new shaft. The remainder of the mine serves as intake.

A summary of the findings--expressed in terms of operating costs for the fans and volumetric efficiency of the systems for all four phases of the modeling exercises--is given in Figure 4. This figure illustrates that with no new shaft needed for the first $3 \mathrm{yr}$, the operating efficiency can be increased simply by a reconfiguration of the present ventilation system from the present 198 up to about 608 . When the new shaft is sunk, the volumetric efficiency increases to about 758 at $8 \mathrm{yr}$ and drops back to 628 at $16 \mathrm{yr}$. 


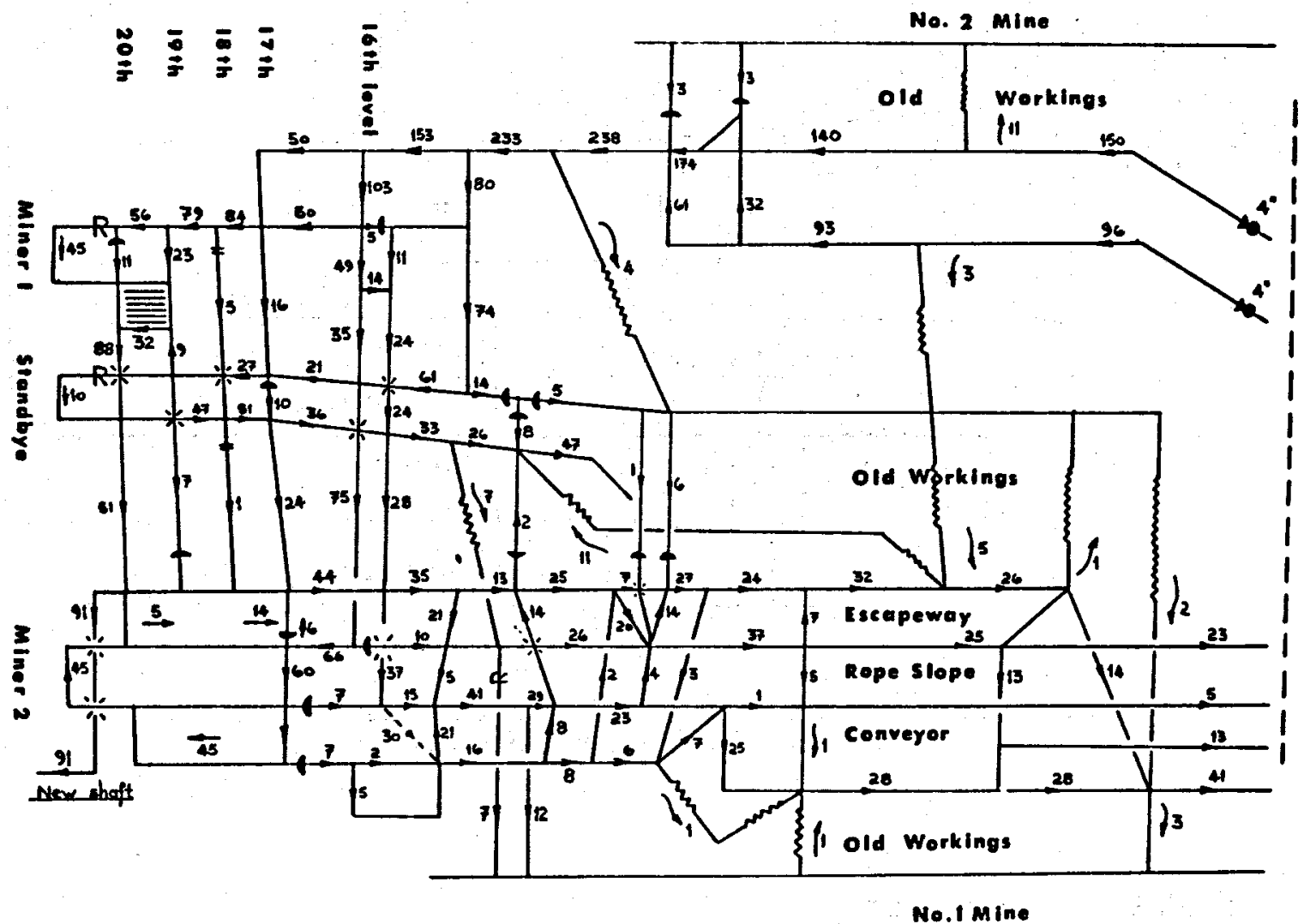

Figure 2. Phase 3. 4" w.g. fans at water Canyon. Shaft on site 2

with no fan. Op. cost $=\$ 57,925 / \mathrm{yr}$; vol. eff. $=52$. $\quad[\mathrm{XBL} 821-1779]$ 


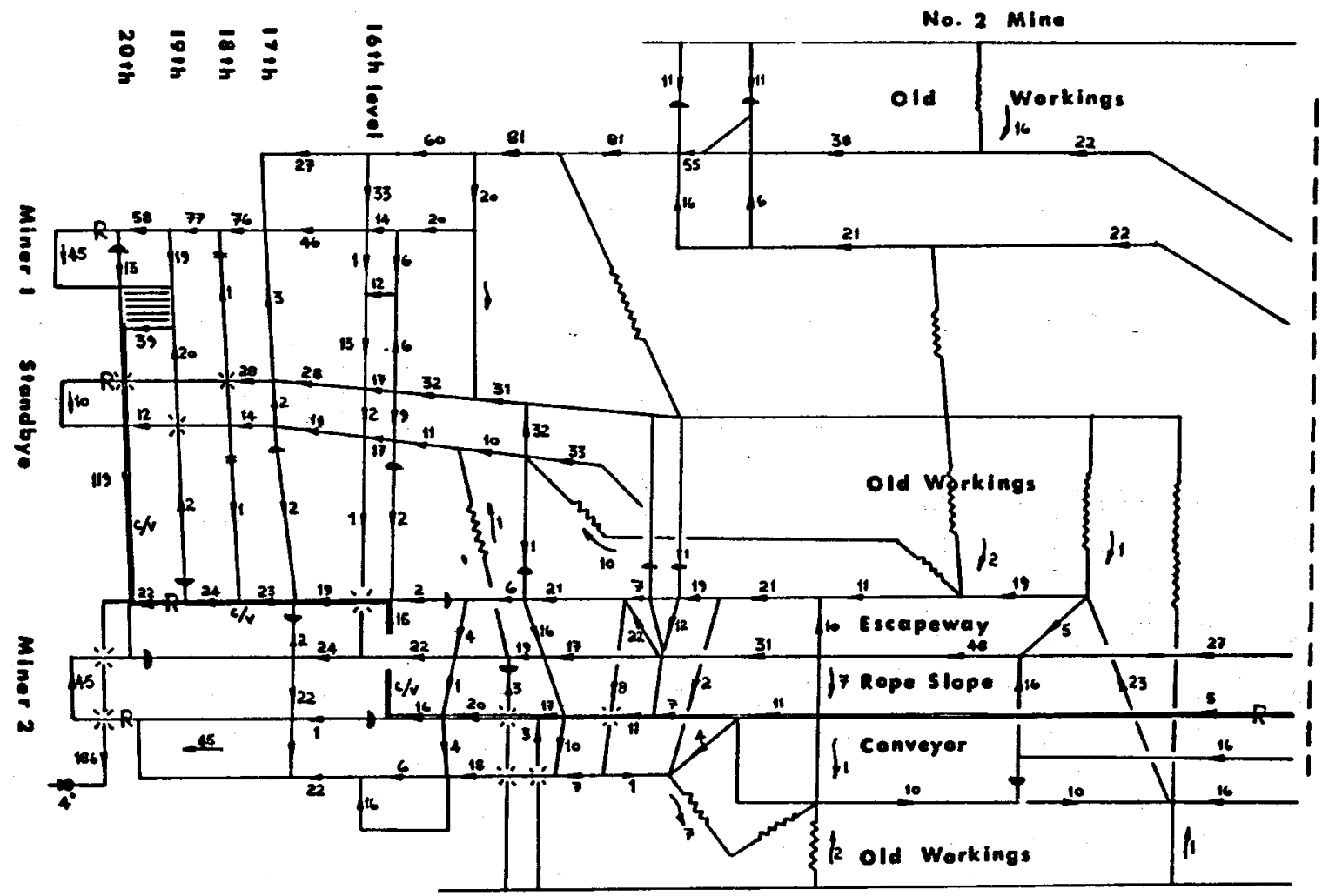

No.I Mine

Figure 3. Phase 3. System D. Through ventilation. New shaft on Site 2 with 4" exhausting fan. Op. cost $=\$ 43,797 / \mathrm{Yr}$; vol. eff. $=75$ \%

[XBL 821-1778]

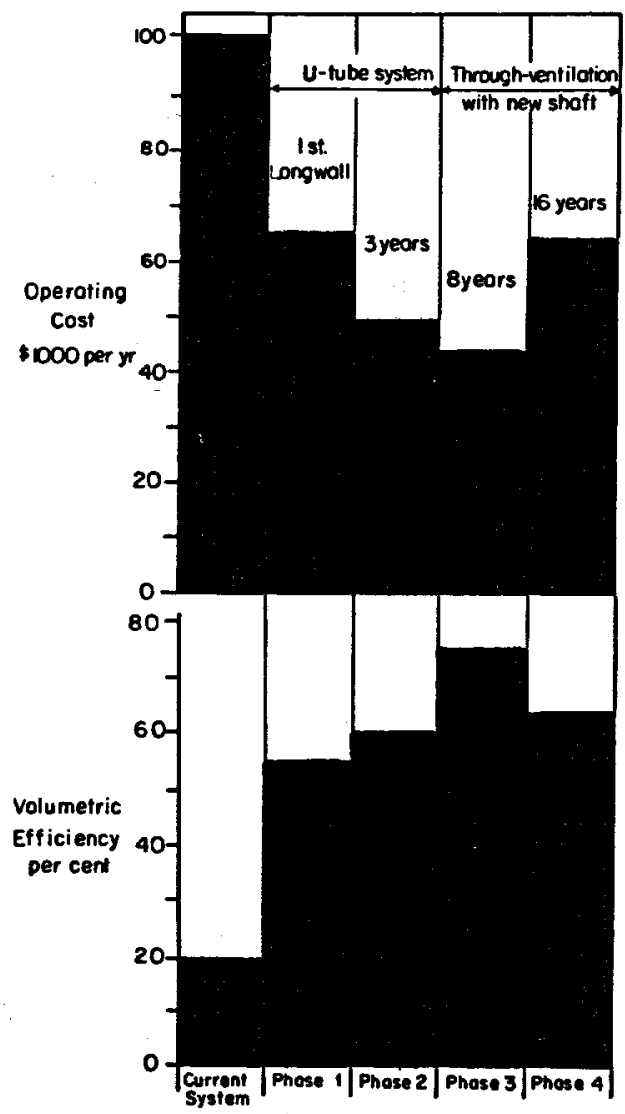

\section{CONCLUSIONS}

The value of mine ventilation planning in the U. S. context has been highlighted by this case study. Although it is shown that the annual operating costs for the ventilation system can be reduced by as much as a factor of 2 , even though the mine is developing and becoming more extensive, this probably is not the most important result. The model demonstrates that a major capital expenditure in the form of a new shaft can be ineffective from the viewpoint of improving the air quantities in the working areas unless a detailed study of the type described here is undertaken.

Figure 4. Comparison of operating costs and volumetric efficiency over $16 \mathrm{yr}$.

[XBL 821-1777] 


\author{
E. Schempp, J. B. Murdoch, and S. M. Klainer
}

The measurement of stress in rocks underground is a difficult but very important problem in mining engineering and in the design of underground waste repositories. The structural stability of any excavation is critically dependent on the stress distribution in the surrounding rock and its capability to bear the stress, which can build up to hundreds of atmospheres in deep mines. Because existing methods for the determination of stress have Iimitations, Lawrence Berkeley Laboratory (LBL) has been investigating the use of spectroscopic techniques--nuclear quadrupole resonance (NQR) and nuclear magnetic resonance (NMR)--for rapid in situ measurement of three-dimensional stress in both salt and hard rock. Efforts in the past year have been directed toward computer simulation of borehole stress patterns and NQR lineshapes, laboratory measurements on salt and aluminosilicates, and construction of a state-of-the-art pulsed NQR spectrometer.

\section{BACKGROUND}

NMR and NQR are two forms of radiofrequency spectroscopy in which a nucleus with nonzero spin is used as a probe of 1 ts molecular or lonic environment. In particular, nuclei with spin $>1$ are censitive to local electric field gradients. The magnitude of this interaction depends on both the intrinsic nuclear charge distribution (described by the nuclear quadrupole moment $Q$ ) and the arrangement and spacing of nearby atoms. When stress 18 applied to a solid containing such nuclel, the resulting strain affects bond distances and directions. A change in bond distance of 0.018 can in turn change the nuclear quadrupole interaction by thousands of hertz. This frequency shift can be detected in either the NMR spectrum (taken with the sample in a strong magnetic field) or the NQR spectrum (for which no static magnetic field is necessary).

In the case of salt, all three major isotopes, $\mathrm{Na}^{23}, \mathrm{Cl}^{35}$, and $\mathrm{Cl}^{37}$, have spin $3 / 2$ and thus are accessible by NQR. However, the cubic site symmetry of the unstressed crystal requires that nuclel experience no net electric field gradient. When the crystal is strained anisotropically, the symetry is lowered and a small quadrupole interaction appears.

Direct NQR detection of the resulting lowfrequency $(2$ to $10 \mathrm{kBz})$ transitions suffers from poor sensitivity. Instead, one can employ a varlety of magnetic-field-cycling nuclear double resonance techniques (RoO, 1970; Hahn et al., 1972; Edmonds, 1977, Edmonds and Mailer, 1977) to detect, for example, the weak quadrupolar signal of $\mathrm{Cl}^{35}$ by its effect on the strong MR signal of $\mathrm{Na}^{23}$.

A much more detailed analysis of the applicaion of resonance techniques to the measurement of stress can be found in earlier reports (Schempp et al., $1980 \mathrm{a}, \mathrm{b}$; 1982).
COMPUTER SIMULATIONS

The eventual goal is to use a pattern of NQR or NMR Iineshapes to measure stress in polycrystalline salt or rock around a borehole. To this end it must be possible to do the following:

1. By means of movable coils and variable magnetic fields, measure transition frequencies of nuclei in the surrounding medium in various directions and at varying distances from the borehole.

2. Calculate the stresses that produce a given Iineshape.

3. Relate the stress distribution around a borehole to the initial unperturbed stresses in the region.

The last two points have been addressed by computer analysis.

\section{Borehole Stress Patterns}

In the absence of a borehole, the stress tensor in a given region can be described in terms of three principal values and the orientation of 1ts three principal axes. If the of ten reasonable assumption is made that one axis is perpendicular to the surface, then oniy one azimuthal angle is necessary to specify the orientation of the principal axis system. A borehole introduces perturbations in the stress distribution, but these can be calculated analytically (Jaeger and Cook, 1976). A given set of unperturbed principal stresses gives rise to a characteristic borehole stress pattern which can be mapped using NQR or NMR.

In the case of salt, no hydrostatic (isotropic) stress component can affect the quadrupole interaction, again because of the cubic symmetry. Furthermore, since the salt is expected to be polycrystaline, no information about principal stress axis orientation is obtainable from any one spectrum. The two quantities which are of importance in determining the NQR or NMR lineshape are the stress anisotropy $\delta(\sigma)$ and, to a lesser extent, the stress asymmetry parameter $\eta(\sigma)$. These are defined as follows: if $\sigma_{i 1}$, $\sigma_{j j}$, and $\sigma_{k k}$ are the principal stress values at a particular location with $\langle\sigma\rangle=\left(\sigma_{11}+\sigma_{j j}+\sigma_{k k}\right) / 3$ and if

$\left|\sigma_{11}-\langle\sigma\rangle\right| \geqslant\left|\sigma_{j j}-\langle\sigma\rangle\right| \geqslant\left|\sigma_{k k}-\langle\sigma\rangle\right|$.

then

$\delta(\sigma) \equiv\left|\sigma_{11}-\langle\sigma\rangle\right|$.

and

$n(\sigma) \equiv\left|\sigma_{j j}-\sigma_{k k}\right| / \delta(\sigma) \quad(0<n(\sigma)<1.0)$.

Computer programs have been developed to cal- 
Unperturbed principal stresses:

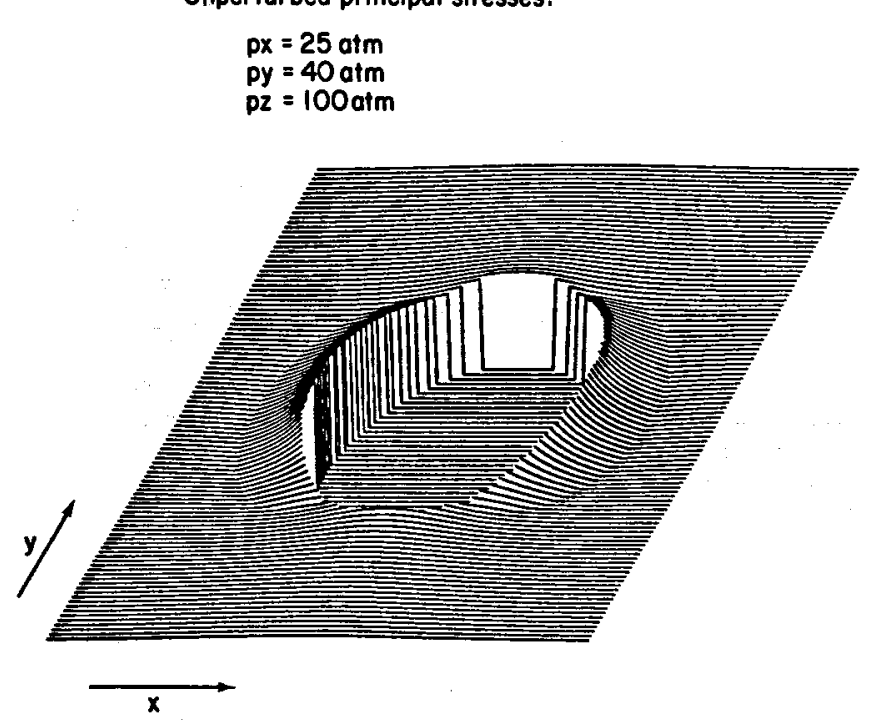

Figure 1. Stress anisotropy $\delta(\sigma)$ around a borehole. The maximum value of $\delta(\sigma)$ on this plot is $65 \mathrm{~atm}$; its unperturbed value far from the borehole is $45 \mathrm{~atm}$.

[XBL 8111-12163]

culate and display $\delta(\sigma)$ and $\eta(\sigma)$ in the vicinity of a borehole. For example, Figure 1 depicts $\delta(\sigma)$ in a plane perpendicular to the borehole when the unperturbed stresses are $\sigma_{x}=25$ atm, $\sigma_{y}=40 \mathrm{~atm}$, and $\sigma_{z}=100 \mathrm{~atm}$. Note that the direction of maximum horizontal stress is clearly visible. An NQR or NMR mapping of such a pattern is expected to provide enough information to calculate the unperturbed stresses and the orientation of the horizontal axes.

\section{NQR Lineshapes}

The electric field gradient tensor $v_{i j}$ experienced by a given nucleus is related to the stress tensor $\sigma_{i j}$ by

$v_{i j}=\sum_{k, l} c_{i j k l \sigma_{k l}}$

where $C$ is the fourth-rank gradient stress tensor. Values for the elements of $C$ can be measured in the laboratory and are different for each crystalline substance. For salt, the gradient stress tensor takes on a particularly simple form, and values can be found in the literature (Kanert and Mehring, 1971).

In a single crystal, each type of spin-3/2 nucleus gives rise to a single NQR transition whose frequency depends on the orientation of the applied stress relative to the crystal axes and whose intensity depends on the direction of the rf exciting field. In contrast, a stressed polycrystalline sample gives $r$ ise to distinct powder pattern lineshapes. We have written a number of computer programs to calculate these powder lineshapes. As an example, Figure 2 is a simulation of the $\mathrm{Cl}^{35} \mathrm{NQR}$ spectrum in salt under 100 atm uniaxial stress $(\delta(\sigma)=66.7 \mathrm{~atm}$,

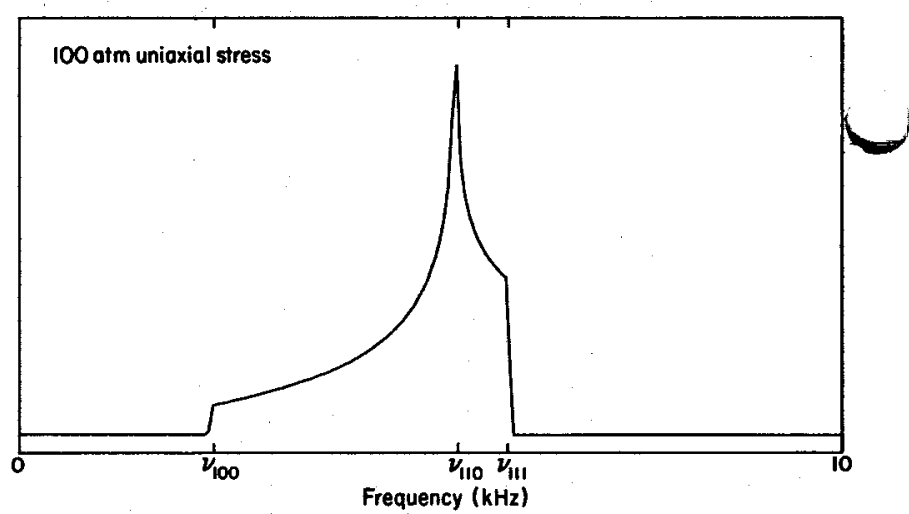

Figure 2. Stress-broadened $N Q R$ lineshape of $\mathrm{Cl}^{35}$ in polycrystalline salt.

[XBL 8111-12164]

$\eta(\sigma)=0)$. There are three discontinuities in the spectrum corresponding to the application of stress along the [100], (110], and [111] crystal directions. For these special directions, the relationship of $N Q R$ frequency to applied stress is particularly simple (Schempp et al., 1980a,b; 1982).

In the more general case of triaxial stress $(\eta(\sigma)>0)$, the lineshape in Figure 2 broadens and distorts in a characteristic fashion. Analysis of an experimental spectrum with good resolution should therefore yield values for both $\delta(\sigma)$ and $\eta(\sigma)$.

As a final word on lineshapes, it should be pointed out that the calculation of Figure 2 ignores two sources of distortion, namely the dependence of $\mathrm{NQR}$ intensity on the orientation of the irradiating rf field with respect to the stress tensor and the broadening effects of magnetic dipole-dipole coupling between neighboring nuclei. Preliminary computer analysis is underway to address these problems, as well as to simulate the corresponding WR spectra (Schempp et al. . 1982).

\section{EXPER IMEN TS}

Work was begun in conjunction with J. Ragle and associates at the University of Massachusetts on nuclear double resonance experiments in stressed and unstressed salt. [111] and [110] single crystals as well as polycrystalline salt were used in a pressure cell capable of applying uniaxial stress up to $200 \mathrm{~atm}$. The pressure cell was first placed between the poles of an electromagnet to polarize the sodium nuclear magnetization, then quickly shuttled by use of compressed air to a zero-magnetic-field environment for variable-frequency rf irradiation of the chlorine nuclei, and then returned rapidly to the magnet for detection of the sodium NMR signal. A number of interesting low-frequency spectral phenomena were observed, including $\Delta \mathrm{m}=2$ dipolar transitions, but these preliminary spectra did not appear to show any stress-dependent features. Direct sodium dipolar absorption is apparently 


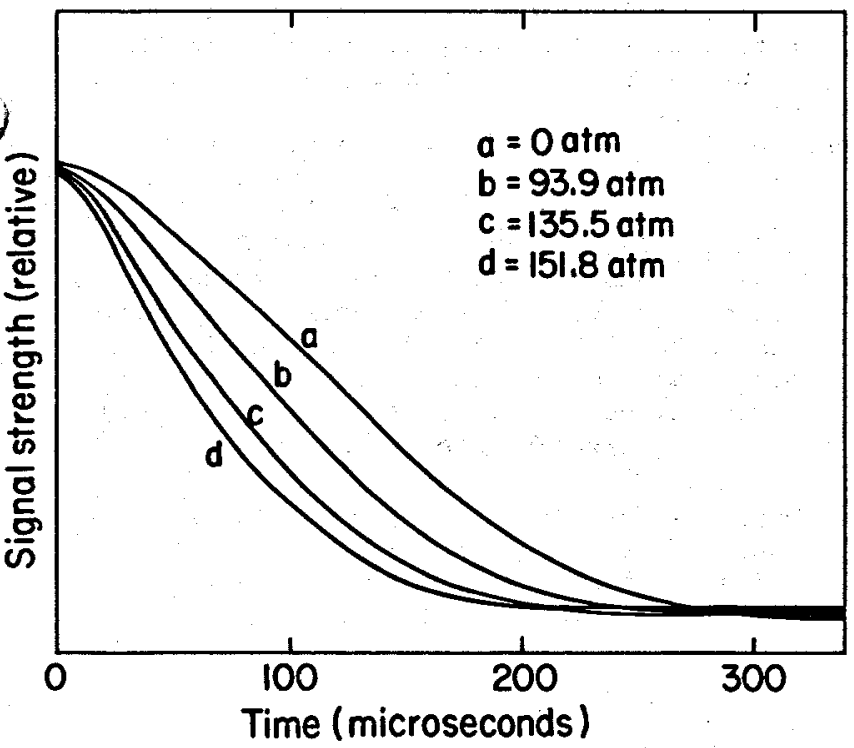

Figure 3. Sodium WMR signals from a single crystal rod of $\mathrm{NaCl}$, with uniaxial stress applied along the crystallographic [11i] direction.

[XBL 8111-12165]

sufficiently intense below $10 \mathrm{kHz}$ to mask any quadrupolar effects.

The sodium MMR signal, on the other hand, was clearly dependent on applied stress (Fig. 3). Increasing stress broadens the MMR spectrum, which is reflected in the time domain by a faster rate of decay. These results suggest that NMR may prove more effective than NQR in the measurement of stress in the particular case of salt.

A second set of fleld-cycling experiments, also supported by IBL, was carrled out by $R$. Marino and S. Sengupta at Hunter college in New York. They successfully detected the three NQR transitions of aluminum-27 (spin 5/2) in muscovite (mica) by monitoring the MMR signal of $\mathbf{H}^{1}$ nuclei (Fig. 4). (Unlike salt, mica has a noncubic crystal structure, NQR transitions are therefore observable in an unstressed sample.) Resonant frequencles lie between 0.5 and 2.0 MHz, far from any direct dipolar absorption. This result bodes well for the eventual investigation of stress using $\mathrm{Al}^{27}$ resonance in aluminosilicates.

\section{INSTRUMENTAT ION}

C. C. Lo and B. Leskovar of the Electronics Research and Development Group at IBL have continued work on the design and construction of a pulsed NQR spectrometer capable of operating over a wide range of frequencies for a variety of applications in the geosciences. One major problem hat has largely been solved is how to rapidly bwer the $Q$ of the tuned probe circuit after rf pulses. Such Q-switching is necessary to minimize probe "ringing," which could overload the receiver preamplifier and completely mask NQR
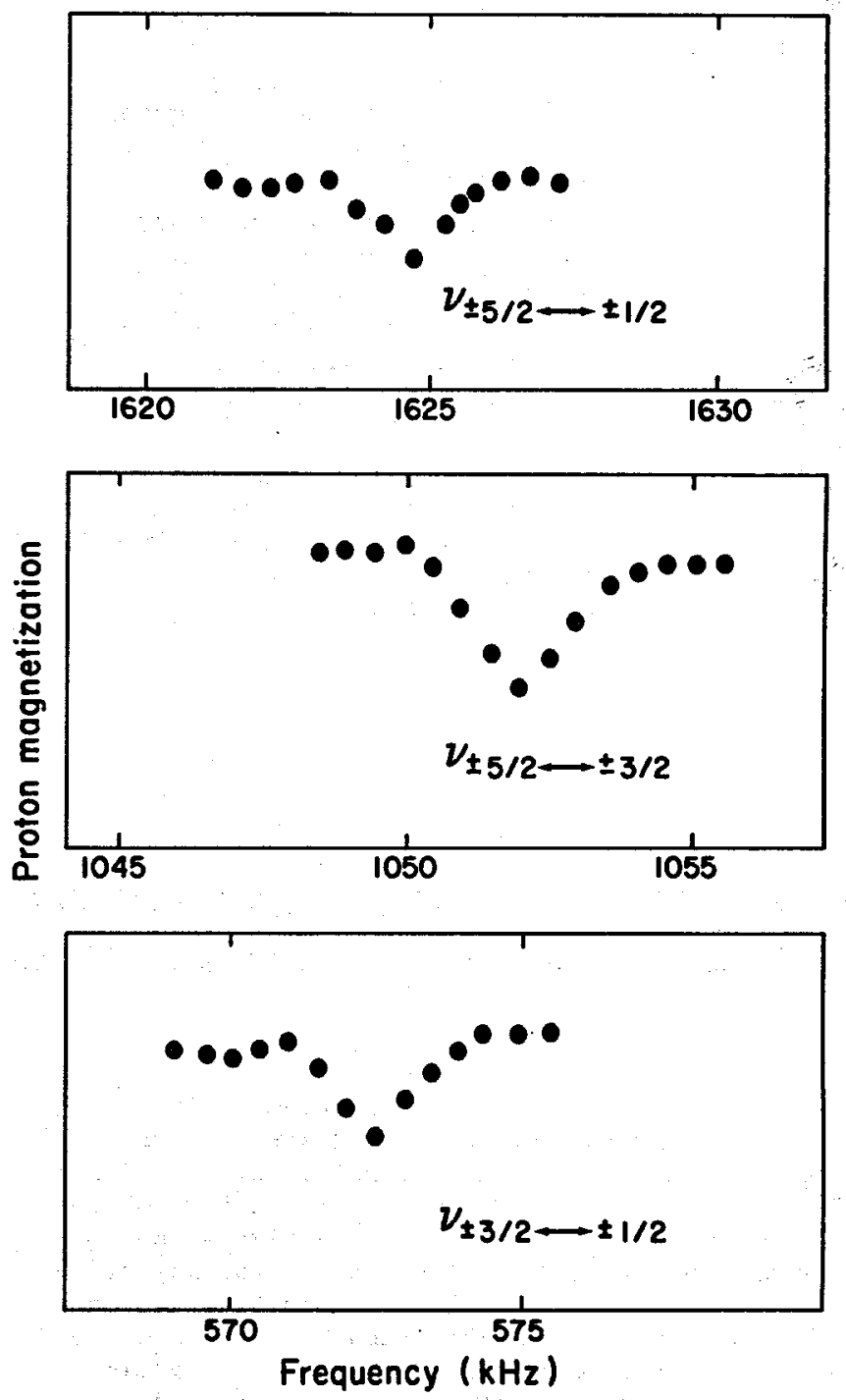

Figure 4. The three NQR transitions of octahedrally bound aluminum in muscovite, detected using $\mathrm{H}^{1}-\mathrm{Al}^{27}$ double resonance. The quadrupole coupling constant $e^{2} \mathrm{qQ} / \mathrm{h}$ and the asymmetry parameter $n$ of the electric field gradient were determined to be $3554.8 \mathrm{kHz}$ and 0.2646 , respectively.

[XBL 81 10-11683]

signals from the sample. After much thought and experimentation, an Eimac 8877 triode in grounded cathode configuration was found to work best for that application. The same type of triode was also selected for use in the final amplifier stage of the transmitter. Recovery times of $<15 \mu s$, and preferably $<5$ js, are essential for detecting the NQR lines expected in Al 27 compounds. Prior to the IBL work, ringdown times of $100 \mathrm{\mu s}$ at these low frequencies were considered quite good. The overall ringdown time at $6 \mathrm{MHz}$ was found to be less than 14 us.

\section{REFERENCES CITED}

Edmonds, D. T., 1977. Nuclear quadrupole dou- 
ble resonance. Physics Reports, v. C29, p. 233-290.

Edmonds, D. T., and Mailer, J. P. G., 1977. The sensitive detection of deuterium quadrupole resonance. Journal of Magnetic Resonance, v. 26, p. 93-99.

Hahn, E. L., Koo, J. C., and Hsieh, Y., 1972. Pure nuclear quadrupole resonance of naturally abundant $0^{17}$ in organic solids. Chemical Physics Letters, v. 13, p. 563-566.

Jaeger, J. C., and Cook, N. G. W., 1976. Fundamentals of Rock Mechanics. Iondon, Chapman and Ball, Ltd.

Kanert, O., and Mehring, M., 1971. Static quadrupole effects in disordered cubic solids. In P. Diehl, E. Fluck, and R. Kosfeld (eds.), NMR Basic Principles and Progress (Volume 3). New York, Springer-Verlag.
Koo, J. C., 1970. Low field nuclear quadrupole resonance spectroscopy (Ph.D. dissertation). Dept. of Physics, University of California, Berkeley.

Schempp, E., Hirschfeld, T., and Klainer, S., 1980a. The measurement of in-situ stress in salt and rock using $\mathrm{NQR}$ techniques. Lawrence Berkeley Iaboratory Report IBL-11895.

Schempp, E. , Rlainer, S. M., and Hirschfeld, T., $1980 \mathrm{~b}$. An evaluation of nuclear quadrupole resonance (NQR) techniques for the in-situ measurement of stress/strain in salt. In Earth Sciences Division Annual Report 1980. Lawrence Berkeley Laboratory Report IBL-12100, p. 62-66.

Schempp, E., Murdoch, J. B... and Klainer, S. M.. 1982. Measurement of in-situ stress in rock using NQR techniques. Lawrence Berkeley Laboratory Report LBL-14411.

\title{
UNIQUE DEVELOPMENTS IN LASER-INDUCED FLUORESCENCE FLUORIMETRY (LIFF)
}

\author{
S. M. Klainer, H. R. Bowman, J. Conway, T. Hirschfeld,* and F. Milanovich*
}

A new analytical technique based on laser-induced fluorescence fluorimetry (LIFF) allows the detection and quantitative measurement of variety of species in groundwater samples through the use of fiber optics for in situ analysis and monitoring and coprecipitation methods for identification and quantification with sensitivities many orders of magnitude higher than presently achieved with other analytical methods. To date, actinides, lanthanides, fluorescent tracers, and some cations, anions, and organics have been analyzed using this method.

The new method provides for two modes of analysis: (1) an in situ system in which direct chemical and other measurements are made in natural water systems over long distances using lasers and fiber optics (RFF), and (2) a field laboratory system that is far more sensitive and involves (on-site) measurements on collected water samples $(<1 \mathrm{cc})$ after they have been coprecipi tated with inorganic materials such as calcium fluoride (CEF).

\section{REMOTE EIBER FLNORIMETRY (RFF)}

A laser is focused onto an optical fiber through a specially designed mirror with a small hole in it (Fig. 1). The laser light travels through the fiber, excites fluorescence in the sample, and the resulting fluorescent light travels back through the same fiber. The returning unfocused light impinges on the mirror rather than passing through the hole and is focused onto the slits of a double monochromator. The fluorescence spectra are processed and displayed using a minicomputer and graphic display. Using this method, in situ tracer measurements to $10^{-7} M$ can be made for groundwater constituents and contaminants with the present equipment. On the other hand, specifically chosen tracer materials are presently detected at $10^{-11} \mathrm{M}$.

The sensitivity of the remote fiber fluorimeter is dependent, to a great extent, on the size of the excited sample and the efficiency with which the generated fluorescent light can be 01 lected. This has a direct relationship to fiber size, the smaller the fiber, the smaller its field of view. Ideally, it is desirable to have a fiber

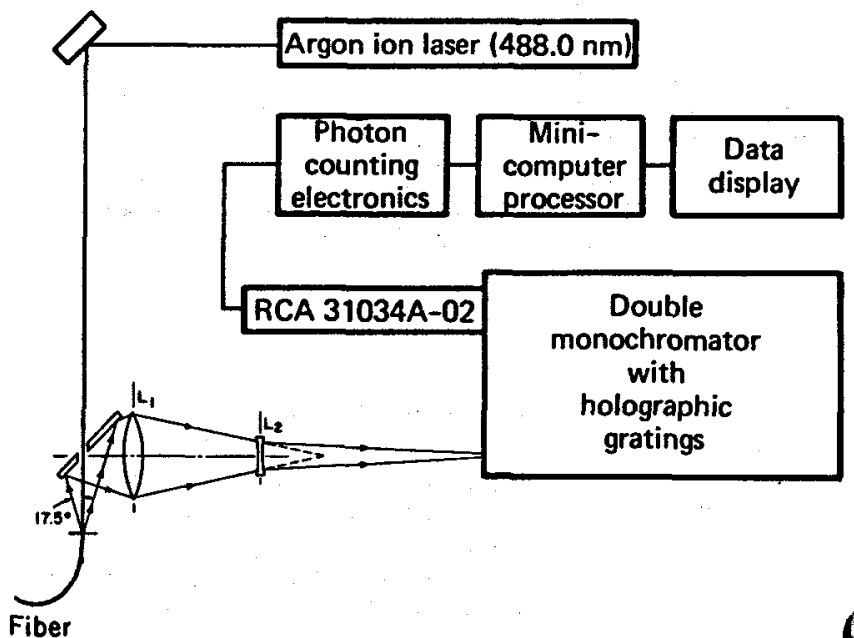

Figure 1.' Fiber optic fluorimeter.

[XBL, 821-1692] 


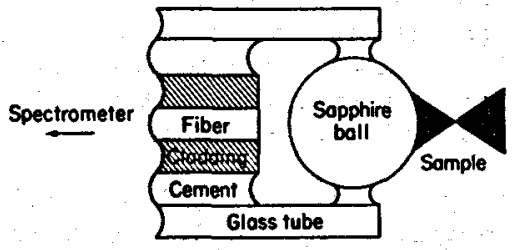

Figure 2. Sapphire ball used to give the fiber optic a large field of view.

[XBL 8111-4852]

of minimum diameter (weight, flexibility, bundle size, cost, etc.) with maximum optical efficiency. This goal has been attained by using a sapphire ball at the end of the fiber, as shown in Figure 2. Here the field of view is essentially that subtended by the ball, not the flber, and an Increase in sensitivity of $>100$ times is observed.

\section{Optrodes}

In place of the simple fiber end piece, one can use ion-specific optrodes (similar to ionspecific electrodes). The optrode is essentially a fiber optic with a small chemistry laboratory at its distal end. The objective is to use reagents to increase specificity and sensitivity and to extend the technique to species that fluoresce poorly or not at all.

A general optrode design 18 shown in Figure 3. Here the fiber 18 contained in an outer tube, and the far end of the tube is terminated so that the light focuses on a semiporous membrane. The reagent(s) In the reservoir wets the membrane and provides an active surface where it can chemically react $w i$ th the surrounding environment. These chemical reactions may result in fluorescence, shift in fluorescence, quenching of fluorescence, etc., depending on the speclfic appl1cation.

In the case of $\mathrm{UO}_{2}{ }^{2+}$, an 88 phosphoric acid solution is used in the capillary tube. This solution increases the decay time for excited uranyl ions from 5 to 90 is and thus allows this fluorescence to be separated from prompt light reactlons, such as Raman effects and other form $s$ of scattering, primarily in the fiber. When a specially designed test optrode is used, uranyl ion fluorescence is observed at the $10^{-7} \mathrm{M}$ level. Future work should make $10^{-10} \mathrm{M}$ accessible.

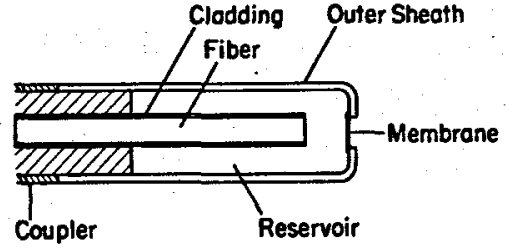

Figure 3. Optrode design for fluorescence using an active reagent in a reservoir.
A number of different optrode configurations have been examined. Research to date has been focused on increasing the specificity and sensitivity of normally fluorescent compounds. Organic chloride, lodine, organic phosphates, rare earths, and actinides are some of the species being researched. In addition, it has been demonstrated that physical measurements such as temperature, $\mathrm{pH}$, Eh, pressure, and flow rate can be made using the optrode concept. Figure 4 shows the performance of a test temperature optrode with a neodymium glass termination.

\section{COPRECIPITATION-ENHANCED FLUORIMETRY (CEF)}

This procedure consists of an initial coprecipitation of a solute ion (e.g., actínide, lanthanide) with a carrier material. The species of interest actually becomes incorporated into the lattice of the host compound. Thus selectivity is enhanced because the crystal structure of the carrier must accept the species to be analyzed. The coprecipitated sample is calcined and pressed Into a pellet whose size matches the laser irradlation spot. The coprecipitation-calcination procedures concentrate the sample by removing the water, purify the sample by removing volatile contaminants, increase the response of the sample by providing an environment for energy exchange, and maximize utilization of the sample by assuring it is completely excited by the laser beam.

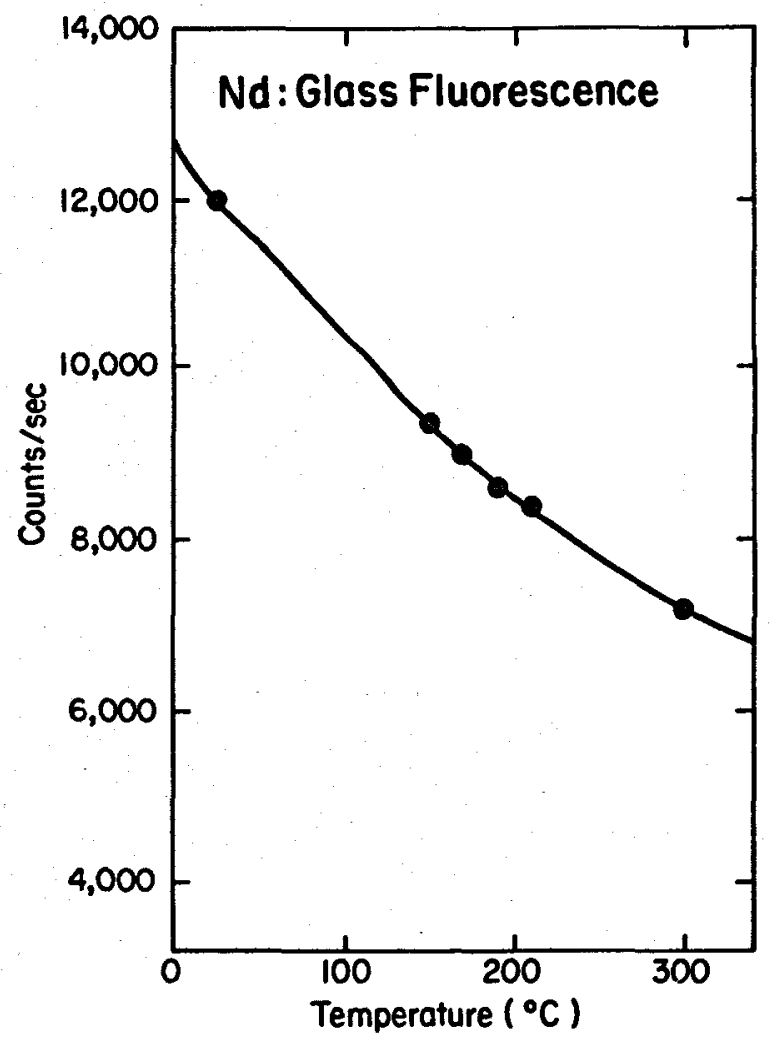

Figure 4, Performance of a temperature optrode. [XBL 8110-11688A] 
Uranium can be measured at the sub-ppt level ( $10^{-13}$ ) using $\mathrm{CaF}_{2}$ as the carrier-host. Natural reagent backgrounds are the factors determining the lower limits of detectability. The coprecipitated lathanides are also detected at the sub-ppt level with $\mathrm{CaF}_{2}$. Two broad spectral lines are observed at 625 and $741 \mathrm{~nm}$ when americium is coprecipitated with $\mathrm{CaF}_{2}$, providing a possible direct method of detection. Americium also causes a tenfold enhancement in the $\mathrm{BF}_{3}$ spectral lines when $\mathrm{TbF}_{3}$ is used as the host material, and thus may be indirectly measured by energy exchange. Pu(III) is detected with a $\mathrm{LaCl}_{3}$ host material. Projected sensitivity is in the $10^{-16} \underline{M}$ range.

\section{Field Studies of CEF}

About 20 groundwater samples were collected from a low-level radioactive waste storage area known to be leaking radioactive materials into the near-field groundwater system. In order to be in the linear analysis range, many of the samples had to be diluted by several orders of mag-. nitude with pure water prior to the coprecipitation. Uranium, for example, is difficult to measure at levels higher than 1 ppm.

The 20 samples were analyzed for uranium using the coprecipitation method. Analytical results were internally self-consistent to \pm 28 on uranium concentrations varying between 65 and $320 \mathrm{ppb}$. Results were favorably compared with the results of two independent analytical methods. There was no indication that the coprecipitation uranium analytical technique was interfered with by the more than 18 other species that were present in the groundwater.

\footnotetext{
* Lawrence Livermore National Laboratory, University of California, Livermore, CA 94550.
} 


\section{APPENDIXES}

\section{APPENDIX A: PUBLICATIONS}

\section{JOURNAL ARTICLES}

Benson, L. V., and Leach, D. L., 1980. Uranium transport in the Walker River Basin. Journal of Geochemical Exploration, v. 11, p. 227-248. (IBL-11441)

Bodvarsson, G. S., and Tsang, C. F., 1981. Injection and thermal breakthrough in fractured geothermal reservoirs. (Accepted for publication in the Journal of Geophysical Research.) (LBL-12698)

Bowman, H., Wollenberg, H. A., Asaro, F., and Bowen, R. G. , 1981. Iridium in spring waters and summit crater lake of Mt. Hood, Oregon. (Submitted to Science.) (IBL-12345)

Chambré, T. L. , Ting, D. K., and Pigford, T. H., 1981. Two-dimensional migration of long actinide chains through geologic media. (Accepted for publication in the Transactions of the American Nuclear Society.) (LBL-13096)

Choi, J., and Pigford, T. H., 1981. Water dilution volumes for high-level wastes. (AC-) cepted for publication in the Transactions of the American Nuclear Society.) (LBL-13097)

Doughty, C., Hellstrom, G., Tsang, C. F., and Claesson, J., 1981. A study of ATES thermal behavior using a steady flow model. (Accepted for publication in Water Resources Research.) (LBL-11029)

Franklin, M. I., and Morse, J. W., 1981. The interaction of copper with the surface of calcite. (Submitted to Colloid and Interface Sciences.) (LBL-12959)

Golabi, K., Scherer, C. R., Tsang, C. F., and Mozumder, S.. 1981. Optimal energy extraction from a hot water geothermal reservoir. Water Resources Research, v. 17, no. 1, p. 1-10. (LBL-12470)

Goldstein, N. E., Mozley, E., and wilt, M., 1981. Interpretation of shallow electrical features from electromagnetic and magnetotelluric surveys at Mt. Hood, Oregon. (ACcepted for publication in the Journal of Geophysical Research.) (LBL-11212)

Hoversten, G. N., Dey, A., and horrison, E. F., 1981. Comparison of five least-squares inversion techniques in resistivity sounding. (Accepted for publication in Geophysical Prospecting.) (IBL-12203)

versten, G. N., Lee, R. H., and Morrison, B. F., 1980. Electromagnetic profiling of conductive overburden. (Submitted to Geophysics.) (IBL-12374)
Iwamoto, F.. Ranki, T... Harada, M., Chambre, P. L., Leung, D., and Pigford, T. H., 1981. Solubility limited migration of a radionuclide chain through a geological medium. Transactions of the American Nuclear society, v. 38, p. 161-163.

Kanki, T., Chambre, P. L., and Pigford, T. H., 1981. Eydrogeologic transport of decay chains with nonequilibrium chemical species. (AC-) cepted for publication in the Transactions of the American Nuclear Society.) (LBL-13095)

Kanki, T.. Iwamoto, F.. Chambre, P. I., and pigford, T. H.. 1981. Bydrogeologic transport with equilibrium chemical species of radionuclldes. Transactions of the American Nuclear Society, v. 38, p. 264-166. (LBL-13002)

Majer, E. L., McEvilly, T. V., and King, M. S., 1981. Monitoring an underground repository with modern seismological methods. (Accepted for publication in the International Journal of Rock Mechanics and Mining Engineers.) (LBL-11764)

McEvilly, T. V., and Majer, E. L., 1981. ASP: An automated seismic processor for microearthquake networks. (Accepted for publication in the Bulletin of the Selsmological Society of America.). (LBL-13165)

Narasimhan, T. N., 1981. Source terms in the transient seepage equation. (Submitted to the Journal of the Geotechnical Engineering Division of the American Society of Civil Engineer 5.) (LBL-12284)

Narasimhan, T. N., and Palen, W. A., 1981. Interpretation of a hydraulic fracturing experiment, Monticello, South Carolina. Geophysical Research Letter 5, v. 8, no. 5, P. 481-484. (LBL-12091)

Noortshad, J., and Doe, T. W., 1981. Numerical simulation of fluid injection into deformable fractures. (Submitted to the Journal of Geophysical Research.) (IBL-12833)

Peiper, J. C., and Pitzer, K. S., 1981. Thermodynamics of aqueous carbonate solutions including mixtures of sodium carbonate, bicarbonate and chloride. (Subnitted to the Journal of Chemical Thermodynamics.) (LBL-12725)

Perry, D. L., Klainer, S. M., Bowman, H. R., Milanovich, F. R., Hirschfeld, T., and Miller, S., 1981. Detection of ultra-trace levels of uranium in aqueous samples by laser induced fluorescence spectrometry. Analytical Chemistry, v. 53, p. 1048-1050. (LBL-12583) 
Pigford, T. H., 1981. Migration of brine inclusions in salt. (Accepted for publication in Nuclear Technology.) (LBL-13093)

Pruess, K., and Narasimhan, T. N., 1981. On fluid reserves and the production of superheated steam from fractured, vapor-dominated geothermal reservoirs. (Submitted to the Journal of Economic Geology•) (LBL-12921)

Rogers, P. S. Z., and Pitzer, K. S., 1981. Eigh temperature thermodynamic properties of aqueous sodium sulfate solutions. (Accepted for publication in the Journal of Physical Chemistry,) (IBL-12415)

Rogers, P. S. Z., and Pitzer, K. S., 1981. volumetric properties of aqueous sodium chloride solutions. (Accepted for publication in the Journal of Chemical and Physical Reference Data.) (LBL-12414)

Sack, R. O., Carmichael, I. S. E., Rivers, M., and Ghiorso, M. S., 1980. Ferric-ferrous equilibria in natural silicate liquids at 1 bar. Contributions to Mineralogy and Petrology, v. 75, p. 369-376. (LBL-11595)

Snoke, A. W., Quick J. E., and Bowman, H. R., 1981. Bear Mountain igneous complex, Klamath Mountains, California-An ultrabasic to silicic calc-alkaline suite. Journal of Petrology, v. 22, no. 4, p. 501-552. (LBID-369)

Sundaram, P. N., 1981. Underground large scale test facility for rocks. Geophysical Research Letters, v. 8, no. 7, p. 709-710. (LBL-13036)

Tsang, Y. W., and witherspoon, P. A., 1981. Hydromechanical behavior of a deformable rock fracture subject to normal stress. (Accepted for publication in the Journal of Geophysical Research.) (LBL-12297)

Van Valin, R., and Morse, J. W., 1981. An investigation of methods for the selective removal and characterization of transition metals associated with solids in the marine environment. (Submitted to Marine Chemistry.) (LBL-12675)

Vonder Haar, S., 1981. Surface ruptures east of Mexicali from the Imperial valley earthquake of 15 October 1979. (Submitted to the Bulletin of the Seismological Society of America, Letters to the Editor.) (IBL-12373)

Watkins, D. J., 1981. Acquisition and preparation of specimens of rock for large scale testing. Geophysical Research Letters, v. 8 , no. 7, p. 679-682. (LBL-12059)

Wilt, M. J., and Stark, M., 1981. A simple method for calculating apparent resistivity from electromagnetic sounding data. (Submitted to Geophysics.) (LBL-12160)

Witherspoon, P. A., 1981. Effect of size on fluid movement in rock fractures. Geophysical Research Letters, v. 8, no. 7, p. 659-661. (LBL-13316)

\section{IBL REPORTS}

Carnahan, C. L., and Remer, J. S., 1981. Non-equilibrium and equilibrium sorption with a linear sorption isotherm during mass transport through an infinite porous medium: some analytical solutions. (IBL-13005)

Earth Sclences Division, 1980. Earth Sciences Division Newletter. v. 3, no. 3. (PUB-343)

Earth Sciences Division, 1980. News from Geothermal Reservoir Engineering Management Program (GREMP) Newsletter. v. III, no. 2. (PUB -332)

Earth Sciences Division, 1980. Proceedings of the Third Invitational Well-Testing Symposium: Well Testing in Low Permeability Environments (T. Doe and W. J. Schwarz, editors), Lawrence Berkeley Laboratory, Berkeley, California, March 26-28, 1980. (LBL-12076)

Earth Sciences Division, 1980. Proceedings of the Workshop on Numerical Modeling of Thermohydrological Flow in Fractured Rock Masses, Lawrence Berkeley Laboratory. Berkeley, California, February 19-20, 1980 (LBL-11566; ONW I-240)

Earth Sciences Division, 1981. Earth Sciences Division Annual Report 1980. (LBL-12100)

Earth Sciences Division, 1981. Earth Sciences Division Newletter. v. 4, nos. 1-2. (PUB-396)

Earth Sciences Division, 1981. News of Geothermal Energy Conversion Technology (GECT) Newsletter. v. III, no. 1. (PUB-399)

Earth Sciences Division, 1981. Proceedings of the Second DOE-ENEL Workshop for Cooperative Research in Geothermal Energy, Lawrence Berkeley Laboratory, . Berkeley, California, October 20-23, 2980. (LBL-11555; CONF-801098)

Earth Sciences Division, 1981. Seasonal Thermal Energy Storage (STES) Newsletter. v. III, nos. 2-4. (PUB-393)

EDAW, Inc., and Earth Science Associates, 1980. A problem definition study of subsidence caused by geopressured geothermal resource deve lopment. (LBL-12392; GSRMP-10)

Eldredge, L. G., and Kropp, 1981. Selected bibliography of the physical, chemicial and blological oceanographic ilterature for the waters surrounding Guam. (LBL-13443)

Flock, M. E., and Hopkins, T. L., 1981. An analysis of six groups of zooplankton in samples taken in $1978 / 79$ at the proposed OTEC site in the eastern Gulf of Mexico off Tampa Bay (Volumes 1 and 2). (LBL-12674)

Forster, C. B., and Gale, J. E., 1980. A laboratory assessment of the use of borehole pressure transients to measure the permeability of fractured rock masses. (LBL-8674; SAC-28) 
Goldstein, N. E., Noble, J, E., and Simkin, T. L., 1980. Geothermal subsidence research program plan and review. (LBL-11271)

Granne11, R. B.. Whitcomb, J. H. Aronstam, P. S., and Clover, R. C., 1981. An assessment of precise surface gravity measurements for monitoring the response of a geothermal reservoir to exploitation. (LBL-12910, GSRMP-11)

Howard, J. H., 1981. Price estimates of hot water geothermal energy. (LBL-11133)

Howard, J. H., 1981. Estimates of the cost of hot water geothermal energy. (LBID-325)

Jones, A. T., 1981. List of fish at a proposed OTEC site off Rahe Point, Hawail, derived from commerclal fish records, 1959-1978. (IBL-12947)

Jones, A. T., Hartwig, E. O., and Qu inby-Hunt, M. S., 1981. Adenosine triphosphate (ATP) in the marine environment - A bibliography. (LBL-12431)

Klainer, S. M., Hirschfeld, T., Bowman, H., Milanovich, F., Perry, D., and Johnson, D., 1980. A monitor for detecting nuclear waste leakage in a subsurface repository. (LBL-11981)

Marine Sciences Group, 1981. List of fish at a proposed OTEC site off Reahole Point, Hawa1i, derived from commercial fish records, 1959-1978. (LBL-12666)

Mehran, M., Narasimhan, T. N., and Eox, J. P., 1980. An investigation of dewatering for the modifled in-situ retorting process, piceance Creek Basin, colorado. (LBL-11819)

Michels, D. E., 1981. Carbon dioxide and carbonate chemistry applied to geothermal engineering. Republic Geothermal, Inc. (IBL-11509; GREMP-15)

Nelson, P. H., Rachiele, R., and Smith, A., 1980. The effect of radon transport in groundwater upon gamma-ray borehole logs. (IBL-11180, SAC-30)

Noda, E. K., Bienfang, P. K., Kimmerer, J., and Walsh, T. W., 1981. Plum survey, OTEC-1, mixed water discharge, April 11-12, 1981. (LBL-12951)

Noorishad, J., and Ayatollah1, M. S., 1980. Program ROCMAS: Introduction and user's guide. (IBL-12987)

Palen, W. A., and Narasimhan, T. N., 1981. The roles of pore pressure and fluid flow in the hydraulic fracture processes (Ph.D. dissertation of w. A. Palen).' (LBL-13049)

Paulsson, B. N. P., King, M. S., and Rachiele, R., 1980. U1trasonic and acoustic emission results from the Stripa heater experiments. part I: A crosshole investigation of a rock mass subjected to heating. Part II: Acoustic emission monitoring during cool down of the stripa heater experiment. (IBL-10975; SAC-32)

Payne, S. F.. 1981. The marine mammals of Puerto Rico: A bibliography. (LBL-13193)

Payne, S. F., 1981. The marine mammals of Hawa11: A bibliography. (LBL-13192)

Payne, S. F., 1981. A bibliography of marine turtles in Hawai1. (LBL-12902)

Payne, S. F., 1981. A bibliography of marine turtles in the Gulf of Mexico. (LBL-12901)

Pigford, T. H., Chambre, P. L., Albert, M., Foglia, M.. Harada, M., Iwamoto, F., Kanki, T., Leung, D., Masuda, S., Muraoka, S., and Ting, D., 1980. Migration of radionuclides through sorbing media, analytical solutions II (Volumes I and II). (LBL-11616)

Schempp, E., Hirschfeld, T., and Klainer, S., 1980. The measurement of in-situ stress in salt and rock using NQR techniques. (LBI-11895)

Shuert, P. G., and Hopkins, T. L., 1980. Aspects of feeding in marine zooplankton. (LBL-12513)

S1lvester, L. F., Beaulaurier, L. O., Mirk, R. F., and Fulton, R. L., 1981. Supercritical heat exchanger fleld test (SHEFT). Is Field performance data on shell and tube heat exchangers in geothermal service.' (LBL-12850)

Solbau, R., Goranson, C. B., and Benson, S. M., 1981. Recently developed well-test instrumentation for low-to-moderate temperature hydrothermal reservoir8. (LBL-13260)

Su, H-J., 1981. Heat transfer in porous media with fluid phase changes (Ph.D. dissertation). (LBL-13187)

Thorpe, R., Watkins, D. J., Ralph, W. E., Hsu, R. and Flexser, S., 1980. Strength and permeability tests on ultra large stripa granite core. (LBL-11203, sAC-31)

Vetter, O. J., and zinnow, K. P., 1981. Evaluation of well-to-well tracers for geothermal reservolrs. Part 1: Literature survey, Part 2: Laboratory work. (LBL-1.1500, GREMP-14)

\section{CONFERENCES AND PROCEEDINGS}

Apps, J. A., and cook, N. G. W., 1981. Backfill barriers: The use of engineered barriers based on geologic materials to assure isolation of radioactive wastes in a repository. (Presented at the Third International symposIum on the Scientific Basis for Nuclear Waste Management, Boston, Massachusetts, November 17-20, 1980, and published in the Proceedings, Scientific Basis for Nuclear Waste Management, volume 3, John G. Noore, editor, Plenum Pub1lshing Co., New York, p. 291-298.) (LBL-11143) 
Bodvarsson, G. S., Miller, C. W., and Benson, S. M., 1981. A simple model for faultcharged hydrothermal systems. (Presented at the Annual Neeting of the Geothermal Resources Council, Houston, Texas, October 25-29, 1981.) (LBL-12869, revised)

Bodvarsson, G. S., Kruess, K., Lipprann, M. J., and Bjornsson, S., 1981. Improved energy recovery from geothermal reservolrs. (Presented at the 56th Annual Fall Technical Conference and Exhibition of the Society of Petroleum Engineers of AIME, San Antonio, Texas, October 5.7, 1981.) (LBL-12341; SPE-10312)

Chan, T., and Jeffrey, J. A., 1981. The absence of -size effect in the thermal conductivity and diffusivity of Stripa granite. (Presented at the Geological Special Session on Heat Transfer in Geological Materials, at the 20th ASME/AIChE National Heat Transfer Conference, Milwaukee, Wisconsin, August 2-5, 1981.) (LBL-12001, abstract)

Doe, T., Ingevald, K., Strindell, L., Haimson, B., and Carlsson, H., 1981. Hydraulic fracturing and overcoring stress measurements in a deep borehole at the Stripa test mine, Sweden. (Presented at the 22nd U. S. Symposium on Rock Mechanics, MIT, Cambridge, Massachusetts, June 29-July 2, 1981.) (LBL-12478)

Guvanasen, V., 1980. Numerical study of fluid heat interaction in a jointed rock mass. (Presented at the Special Session on Heat Transfer in Geologic Materials, at the 20th ASME/AIChE National Beat Transfer Conference, Milwaukee, Wisconsin, August 2-5, 1981.) (LBL-12035, abstract)

Harms, v. W., 1981. Current measurements off Reahole Point, Hawaii - Application to OTEC-1 ocean test platform. (Presented at the $U$. $S$. Department of Energy/Marine Technology Society Eighth Ocean Energy Conference 1981, Washington, D. C., June 7-11, 1981.) (LBL-13208)

Hartwig, E. O., 1981. OTEC environmental biological oceanographic program. (Presented at the v. S. Department of Energy/Marine Technology Society Eighth Ocean Energy Conference 1981, Washington, D. C., June 7-11, 1981.)

Hartwig, E. O., and Reitzel, J., 1981. Suspended particles and the downward attentuation of light in coastal waters. (Presented at Ocean Sciences: AGU/ASLO Joint Meeting, San Antonio, Texas, February 16-19, 1981.) (LBL-13565, abstract)

Howard, J. H., 1980. Identification of geothermal reserves and estimation of their value. (Presented at the Sixth Annual Workshop on Geothermal Reservoir Engineering, Stanford Geothermal Program, Stanford, California, December 16-18, 1980.) (LBL-11940)

McEdwards, D. G., and Benson, S. M., 1981. User's manual for ANALYZE - A variable-rate, multiple-well, least-squares matching routine for well-test analysis. (Presented at the
Geothermal Computer Program Workshop, Lawrence Berkeley Laboratory, Berkeley, California, June 17-19, 1980.) (LBL-10907)

Mehran, M., Narasimhan, T. N., and Fox, J. P., 1981. Hydrogeologic consequences of the modified in-situ retorting process, Piceance Creek Basin, Colorado. (Presented at the 14th Oil Shale Symposium, Golden, Colorado, April 22-24, 1981.) (LBL-12063)

Mozley, E. C., and Goldstein, N. E., 1981. An infer red conductivity distribution in the vicinity of a Cascade volcano. (Presented at the 1981 Annual Meeting of the Society of Exploration Geophysicists, Los Angeles, California, October 11-16, 1981.) (IBL-12831, abstract)

Palen, W. A., and Narasimhan, T. N., 1980. Interpretation of a hydraulic fracturing experiment, Monticello, South Carolina. (Presented at the American Geophysical Union Fall Meeting on Earthquake Prediction - Hydrological and Geochemical Studies, San Francisco, California, December 8-12, 1980.) (LBL-11438, abstract)

Perry, D. L., and White, A. F., 1981. Surface and bulk studies of hornblende using secondary ion mass spectrometry (SIMS), auger electron spectroscopy (AES), and $x$-ray photoelectron spectroscopy (SPS). (Presented at the 18 2nd Annual Meeting of the American Chemical Society, New York, New York, August 23-28, 1981.) (LBL-13282, abstract)

Pruess, $K_{.}$, and Narasimhan, T. N., 1981. On fluid reserves in fractured, vapor dominated geothermal reservoirs. (Presented at the Fall Meeting of the American Geophysical Union, San Francisco, California, December 7-11, 1981.)

Pruess, K., and Tsang, C. F., 1981. Applications of numerical simulation to geothermal field problems. (Submitted to the International Conference on Geothermal Energy, Florence, Italy, May 11-14, 1982.) (IBL-13092, abstract)

Pruess, K., Weres, O., Schroeder, R., Marconcini, R., and Neri, G., 1980. Performance matching and prediction for Serrazzano geothermal reservoir by means of numerical simulation. 'Presented at the second DOE-ENEL Workshop for Cooperative Research in Geothermal Energy, Lawrence Berkeley Laboratory, October 20-23, 1980.) (IBL-12174)

Quinby-Funt, M. S., Fanning, K., Ziemann, D., Walsh, T. W., and Knauer, G. A., 1981. Nutrient and dissolved oxygen studies at OTEC sites. (Presented at the U. S. Department of Energy/Marine Technology Society Eighth Ocean Energy Conference 1981, Washington, D. C.. June 7-11, 1981.) (LBL-13209)

Quinby-Hunt, M. S., Wilde, P., Corrigan, D., Asaro, F., and Michel, H. V., 1981. The elemental composition of sediments from Ioin1 Seamount, Hawail. (Presented as an invited 
paper at the American Geophysical Union Fall Neeting, San Francisco, California, December 7-11, 1981.)

(LBL-13182, abstract)

Rachiele, R., and Nelson, P. H., 1980. Acoustic emission activity from underground heating experiments in granite. (Presented at the 1980 Fall Meeting of the American Geophysical Union, San Francisco, California, December 8-12, 1980.) (LBL-11574, abstract)

Rapier, P. M., 1981. Design features and equilibrium flash modeling of direct binary fluid heat exchangers for use with geothermal brines. (Presented at the 20th ASME/AIChE National Heat Transfer Conference, Knoxville, Tennessee, August 2-5, 1981.) (IBL-12115)

Ryan, C. J., and Jones, A. T., 1981. Commercial fishery data from three proposed OTEC sites. (Presented at the U. S. Department of Energy/ Marine Technology Society Eighth Ocean. Energy Conference 1981, Washington, D. C., June 7-11, 1981.) (LBL-12956)

Sands, M. D.. 1980. Ocean thermal energy conversion programmatic environmental assessment. (Presented at the 7th Ocean mergy Conference, Washington, D. C., June 2-5, 1980.) (LBL-11832)

Schroeder, R. C., O'Sullivan, M. J., Pruess, K., Celati, R., and Ruffilli, C., 1980. Reinjection studies of vapor dominated systems. (Presented at the Second DOE-ENEL Workshop for Cooperative Research in Geothermal Energy, Lawrence Berkeley Laboratory, Berkeley, Cal1fornia, October 20-23, 1980.) (IBL-12175)

Sullivan, S. M., and Sands, M. D., 1980. A preliminary evaluation of impingement and entrainment by ocean thermal energy conversion (OTEC) plants. (Presented at the 7th Ocean Energy Conference, Washington, D. C., June $2-5,1980).($ IBL-11833)

Thorpe, R. R., 1981, An example of fracture characterization in granitic rock. (Presented at the 2 2nd U. S. Symposium on Rock Mechanics: Rock Mechanics from Research to Application, MIT, Cambridge, Massachusetts, June 29-July 2, 1981.) (LBL-11953)

Tsang, C. F. . 1981. A survey of recent international activities in aguifer thermal energy storage. (Presented at the Solar Energy Soc- lety of Canada, Inc., National Conference on Solar Energy, Montreal, Canada, August 4-7. 1981.) (LBL-13212)

Watkins, D. J., and Thorpe, R. K., 1981. Large volume tests in rock mechanics. (Presented at the Institute of Geophysics and Planetary Physics of the Oniversity of California, Los Alamos Conference on Properties of Materials Under Extreme Conditions, Los Alamos Scientific Laboratory, Los Alamos, New Mexico, May 18-19, 1981.) (LBL-12467)

White, A. F., 1981. Controls on 1sotopic compositions of groundwater systems in southern Nevada. (Presented at the 1981 Spring Meeting of the American Geophysical Union, Baltimore, Maryland, April 28, 1981.) (LBL-12601, abstract)

wilde, P., 1981. Environmental programs for ocean thermal energy conversion (ONEC). (Presented at the Marine Technology society Conference, Oceans ' 81, Boston, Massachusetts, September 16-18, 1981.) (LBL-12977)

Wilde, P., Quinby-Hunt, M. S., Hartwig, E., Noda, E. K., Ziemann, D., Frye, D., and Leavitt, $R_{\text {., }}$ 1981. OTEC-1 environmental monitoring program. (Presented at the $U$. S. Department of Energy/Marine Technology Society Eighth Ocean Energy Conference 1981, Washington, D. C.. June 7-11, 1981.) (LBL-13211)

Wilt, M. J., Eaught, J. R., Goldstein, N. E., and Morrison, H. F., 1981. Experience with the EM-60 electromagnetic system for geothermal exploration in Nevada. (Presented at the 5lst Annual International Meeting and Exposition of the society of Exploration Geophysicists, Los Angeles, California, October 11-15, 1981.) (LBL-12618)

Wi therspoon, P. A., 1981, Geotechnical aspects of investigations at stripa on radioactive waste isolation. (Presented at the 34th Canadian Geotechnical Conference, Fredericton, New Brunswick, Canada, September 30-October 2. 1981.) (LBL-13334)

Wt therspoon, P. A., Tsang, Y. W., Long, J. C. S., and Noorishad, J., 1981. New approaches to problems of fluid flow in fractured rock masses. (Fresented at the 2 2nd $U$. S. SymposIum on Rock Mechanics, MIT, Cambridge, Massachusetts, June 29-July 2, 1981.) (LBL-12511) 
PAUL A. WITHERSPOON*

Associated Director, Lawrence Berkeley Laboratory

Division Head, Earth Sciences Division

DIVISION ADMINISTRATION

Karl Olson, Deputy Division Eead

Milford N. Bookman, Division Administrator

Monique Adam, Division Office Administration

STAFF OF FISCAL YEAR 1981

Mark Abashian

Lennart Andersson

John Apps

Michele Arcidiacono

Lois Armetta

Lawrence Beaulaurier

Robert Bellman

Larry Benson

Sally Benson

Eugene Binnall

Gudmundur Bodvarsson

Mary Bodvarsson

Barry Bowman

Michael Boyle

- Daniel Bradley

Susan Brady

Anders Bro

Douglas Brookins

Jeffrey Brown

Daniel Brunner

Annette Bunge

Thomas Buscheck

Timothy Buscheck

Patricia Butler

Hans Carlsson

Ian Carmichael*

coen Carmiggelt

Chalon Carnahan

Jim Caroompas

Jade Carroll

Paul Chambre*

Joseph Chan

Iap-Yen Chan

Tin Chan

Mitchell che

Sheng-po Chen

Clement Chou

John Clarke*

Cara coad

Lewis Cohen*

Marcie Commins

Mary Connell

Neville Cook*

Donald Corrigan

James Davey

Robert Davis

Joan Delany
Edward de Zabala

Ellen Diamond $t$

Laurie Di Fraia

Thomas Doe

Christine Doughty

Padraic Doyle

Allan Dubin

Andrew DuBois

Peter Duncan

Richard Eckman

Laurel Egenberger

Paul Elias

Janice Elliot

Howard Endo

Eugene Eno

Geraldine Erickson

Daniel Estrella

James Evans

James Ferguson

Steve Flexser

George Flowers

Mauro Foglia

Douglas Frink

Conny Frisch

Jonathan Frisch

Philip Fong

Ted Fugita

Robert Fulton

Ellen Gailing

Robert Galbraith

Thomas Gamble

Anoushiravan Ghaffari

Susan Gillett

Beverly Gimeno

Orah Goldman

Norman Goldstein

Richard Goodman*

Wolfgang Goubau

Reshav Coyal

Alexander Graf

Roy Greenwald

Varuttama Guvanasen :

Susan Halfman

Leif Hansen

Jeri Hara

Volker Harms
Satya Harpalani Rosemary Hart Eric Hartwig Niamh Harty Ramsey Haught Harold Helgeson* Runio Higashi Mark Hoit Michael Hood* Deborah Hopkins Alex Borne* John Boward

Eduardo Iglesias Jeffrey Irvine

Frank Jahnke Dennis Jamison Barbara Jansen Abdul Rahim Jaouni Iraj Javandel Julie Jeffrey Peter Johnson Richard Johnsont Anthony Jones Barbara Jones Randall Jones L. C. Jordon

Brian Kanehiro Kenzi Rarasaki Jacqueline Rent William Keyes Tjiep Kho Michael King Ellen Klahn Stanley Rlainer Steven Kramer Pavel Kurfurst

Cheng-Hsien Lai

$\mathrm{Ki}$ Ha Lee Raymond Lee Wayne Lee David Leung Peter Iichtner Donald Lippert Marcelo Lippmann Nicholas Littlestone Jane Long

Steve Lundgren 
Peggy Maclean Ernest Majer Donald Mangold Donald McCarthy Thomas McEvilly* Maurice McEvoy Malcolm McPherson* Maynard Michel Constance Miller Coral Miller James Mitchell Milton Moebus Francis Moffitt David Moncada Alison Monroe Leuren Moret H. Frank Morrison* James Murdoch Larry Myer

T. N. Narasimhan Ravi Narasimhan John Ne1l Gary Nelson $t$ Philip Nelson Sher-Ran Niou Jahandar Noorishad Duane Norgren

Maura O'Brien John Oldson Michael O'Sullivan Irmgard Orzech

Walter Palen Bjorn Paulsson Susan Payne Christopher pelper Dale Perry scott Peterson Ronald PhIlipe Ramesh phutela Thomas Pigford* Renneth Pitzer* Cheri Plumlee
Nancy Pope

William pope

Karsten Pruess

Richard Rachiele

Clayton Radke*

William Ralph

Michaele Ramirez

Pascal Rapier

Joe Ratigan

Ruthie Redic

Janet Remer

Richard Remillard

Carlos Riveros

Marc Rivers

Morris Roach

Gene Rochlin

Pamela Rogers

Donald Rondeau

Karl Saar1

Ellory Schempp

David Schmidt

Deanna Schmidt

Eeidl schmidt

Werner Schwarz

Michael Shea

Eugene Shen

Robert Silva

Lenard Silvester

Terrance Simkin

John simonson

Ray Solbau

wilbur somerton*

Hwaill soo

Robin Spencer

Jonathan Stebbins

Rebecca sterbentz

Robert Sterrett

Robert Stolzman

Beverly Strisower

Andrew Stromdahl

Dimitri Sverjensky

Ho-Jeen Su

P. Sundaram
Jerome Thomas

Ne11 Thomsen

Daniel Ting

David Ting

Harry Todd

Chin Fu Trang

Yvonne Tsang

Leon Tsao

Williarn Thur

Badawi Tleimat

Kent vdell

Richard Valentine

Ashok Verma

Aylette villemain

william villet

Jer 1 Edgar-Vogt

Stephen Vonder Haar

OlIver Wan

Joseph Wang

David Watkins

Christopher Weaver

virginia Weaver

Eugene Wedge

Hans Wenk*

Oleh Weres

Jerry West

Arthur White

Richard Whiteman

Pat wilde

Linda Williams

Charles wilson

Michael Wilt

Harold Wollenberg, Jr. William Wong

James Wright*

Cynthia Yang

Andrew Yee

Ruben zelwer

Robert zimmerman 


\section{APPENDIX C: PRINCIPAL MEETINGS OF 1981}

During fiscal 1981 the Earth Sciences Division organized three major meetings, including two international symposia.

The Second DOE-ENEL Workshop for Cooperative Research in Geothermal Energy was held in Berkeley, California, October 20-23, 1980. A cooperative agreement signed June 1975 in Rome by the v. S. Energy Research and Development Administration (ERDA), now the U. S. Department of Energy (DOE), and the Ente Nazionale per 1 'Energia Elettrica (BNEL) authorized the following joint research projects:

Project 1. Stimulation of hot dry rocks and hydrothermal reservoirs.

Project 2. Utilization of hot brine resources.

Project 3. Reservoir physics, engineering, and resource assessment.

Project 4. Deep drilling.

Project 5. Environmental control technologies.

The first meeting, held september 12-16, 1977, at Larderello, Italy, was exclusively devoted to Project 3, which continued to occupy "center stage " in subsequent years, with most of the research activities focused on geothermal reservoir engineering. The second meeting, attended by nearly 100 participants from Belgium, Iceland, Italy, Mexico, and the United States, was held to discuss future plans for additional cooperative projects and to disseminate the achievements of research on geothermal reservoir engineering to the geothermal community at large. The proceedings of the workshop have been published by Lawrence Berkeley Laboratory as LBL-11555 (March 1981 ).
The Third Symposium on the Cerro Prieto Geothermal Field, Baja California, Mexico, was held in San Francisco, California, March 24-26, 1981. Hosted by the U. S. Department of Energy and Lawrence Berkeley Laboratory, the meeting concentrated on results obtained since the signing of the U. S.-Mexican cooperative Agreement in 1977. During this period, much has been learned about the subsurface of the field and its response to exploitation. Nost of the findings to date were summarized in the papers presented at this meeting. About 250 scientists, engineers, and government officials from Belgium, Canada, Israel, Japan, Mexico, and the United states attended the symposium. Subjects covered were geology, hydrology, geochemistry, subsidence, geophysics, well drilling, reservoir engineering, and reinjection. The proceedings of the symposium have been published by Lawrence Berkeley Laboratory as LBL-11967 (March 1981).

An invitational workshop on Bydrological Issues Associated with Oil-Shale Development was held at Berkeley, California, Septembver 15-17, 1981. Coordinated with Dr. Arthur Hartstein, Office of Oil, Gas and Oil Shale, U. S. Department of Energy, this workshop was intended to identify and discuss the key hydrological issues associated with the overall development of the western oil shales. Among the issues covered were site dewatering and mine drainage, hydrology of spent shale piles, surface-water/groundwater interactions, and leaching and solute transport. The workshop brought together about 75 experts from mining engineering, chemical engineering, geology/hydrogeology, soil physics, chemistry/geochemistry, mathematical modeling, and geotechnical engineering. No proceedings will be issued for the workshop. 


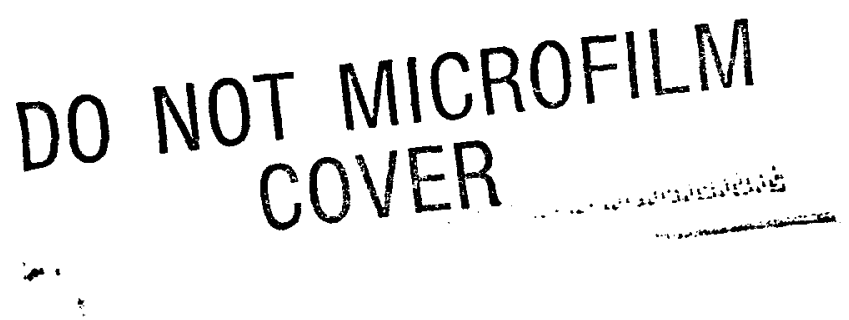

This report was done with support from the Department of Energy. Any conclusions or opinions expressed in this report represent solely those of the author(s) and not necessarily those of The Regents of the University of California, the Lawrence Berkeley Laboratory or the Department of Energy.

Reference to a company or product name does not imply approval or recommendation of the product by the University of California or the U.S. Department of Energy to the exclusion of others that may be suitable. 